\title{
Rheological and Geological Constraints on the Earthquake Distribution in the Charlevoix Seismic Zone, Québec, Canada
}

\author{
by \\ Maurice Lamontagne, B.A.Sc., M.Sc.
}

A thesis submitted to the faculty of Graduate Studies and Research in partial fulfilment of the requirements for the degree of Doctor of Philosophy

Department of Earth Sciences

Carleton University

Ottawa, Ontario, Canada

January, 1999

(C) Copyright

1999, Natural Resources Canada 
National Library

of Canada

Acquisitions and

Bibliographic Services

395 Wellington Street Ottawa ON K1A ON4

Canada
Bibliothèque nationale

du Canada

Acquisitions et

services bibliographiques

395, rue Wellington

Ottawa ON K1A ON4

Canada
The author has granted a nonexclusive licence allowing the National Library of Canada to reproduce, loan, distribute or sell copies of this thesis in microform, paper or electronic formats.
L'auteur a accordé une licence non exclusive permettant à la Bibliothèque nationale du Canada de reproduire, prêter, distribuer ou vendre des copies de cette thèse sous la forme de microfiche/film, de reproduction sur papier ou sur format électronique.

L'auteur conserve la propriété du droit d'auteur qui protège cette thèse. $\mathrm{Ni}$ la thèse ni des extraits substantiels de celle-ci ne doivent être imprimés ou autrement reproduits sans son autorisation. 


\section{Abstract}

Located on the St. Lawrence River some $100 \mathrm{~km}$ downstream from Quebec City, the Charlevoix Seismic Zone (CSZ) is the most active seismic zone of eastern Canada with 5 historical earthquakes in the magnitude 6 to 7 range and continuous microearthquake activity. Between October 1977 and December 1997, some 1500 earthquakes with magnitudes between -1.0 and 5.0 were recorded by a local seismograph network. Epicentres define a 30 by $85 \mathrm{~km}$ ellipse with the long axis parallel to the river, with $99 \%$ of hypocentres shallower than $25 \mathrm{~km}$ depth $\left(\mathrm{D}_{99 \%}\right)$. Earthquakes are not distributed uniformly across the seismic zone, but concentrate in groups separated by less active areas.

On the basis of the heat conduction equation and Grenvillian surface heat flow, the temperature at $\mathrm{D}_{99 \%}$ has been estimated to be between 215 and $355^{\circ} \mathrm{C}$. These temperatures and the inferred quartz-depleted mid- and lower-crustal compositions imply a brittle-ductile transition deeper than $25 \mathrm{~km}$. The quartz-depleted mid- to lower crust is supported by the high P-velocities revealed by seismic refraction surveys. This depth may represent the passage from velocity weakening to velocity strengthening if the onset of flow in hydrated feldspars occurs at temperatures in the $300-350^{\circ} \mathrm{C}$ range. With an assumed maximum crustal stress difference of about $200 \mathrm{MPa}$, fault reactivation at midcrustal depth can occur with a low friction coefficient and/or with a high pore fluid pressure. 
Remote sensing, magnetic, gravimetric and seismic reflection data are used to define the positions of geological faults. Most regional normal faults correspond to lineaments or geophysical trends generally parallel to the St. Lawrence River. Most regional faults bound active volumes while one correlates with earthquake hypocentres, including some magnitude $>4$ events. Inside the impact crater, earthquakes are generally of smaller magnitude, possibly due to the high fracturing associated with the Charlevoix impact structure.

The orientations of the local stress and of the reactivated faults vary across the CSZ. The comparison of some 20 focal mechanisms (mostly reverse to reverse-oblique faulting) with earthquake groups and multiplets (found to represent less than $15 \%$ of the events between 1988 and 1997) suggest reactivated faults with various orientations, not necessarily parallel to the regional paleo-rift faults. Most microearthquakes appear to occur in highly fractured volumes, partly related to the impact structure. No surface rupture is found on the seismic reflection lines acquired on the St. Lawrence River.

Using local earthquake data, a pseudo-2D layered velocity model is proposed. The main upper crustal velocity perturbations are imaged, i.e. the $6 \mathrm{~km}$ thick Appalachian sequence (5.6 to $5.8 \mathrm{~km} / \mathrm{s} \mathrm{P-velocity)} \mathrm{and} \mathrm{the} \mathrm{Precambrian} \mathrm{basement} \mathrm{(6.2} \mathrm{to} 6.6 \mathrm{~km} / \mathrm{s} \mathrm{P}$ velocity). From $\mathrm{Vp} / \mathrm{Vs}$ ratio information, the CSZ velocity structure differs from that of the neighbouring Laurentides Park region, where upper crustal basic rocks are found. 
Even with the addition of all local stress contributors, the CSZ is not subject to substantially higher stress difference levels than the rest of Eastern Canada. Consequently, the anomalous CSZ earthquake activity must be due to inherent crustal weakness and/or high pore fluid pressure. Although the presence of a gouge may weaken some faults, the existence of pervasive high pore-fluid pressure coupled with a high degree of fracturing is the favoured explanation for the weak crust that gives rise to earthquake activity. A qualitative model is proposed where some rift faults act as conduits to crustal fluids under pressure, triggering earthquakes on these faults and in neighbouring fractured volumes. 


\section{Résumé}

Située le long du fleuve Saint-Laurent à quelque $100 \mathrm{~km}$ en aval de Québec, la Zone sismique de Charlevoix (ZSC) est la plus active de l'est du Canada avec ses 5 séismes historiques de magnitude entre 6 et 7 et son activité micro-séismique continue. Entre octobre 1977 et décembre 1997, quelque 1500 tremblements de terre de magnitude variant entre -1.0 et 5.0 furent enregistrés par un réseau sismographique local. Les épicentres définissent une ellipse de $30 \mathrm{~km}$ par $85 \mathrm{~km}$ allongée parallèlement au fleuve, avec $99 \%$ des foyers moins profonds que $25 \mathrm{~km}\left(\mathrm{D}_{99 \%}\right)$. Les séismes ne sont pas distribués uniformément sur toute la superficie de la zone sismique, mais se concentrent en groupes séparés par des régions moins actives.

D'après l'équation de conduction de chaleur et d'un flux de chaleur à la surface typique du Grenville, la température à $\mathrm{D}_{99 \%}$ fut estimée entre 215 and $355^{\circ} \mathrm{C}$. Ces températures et les compositions déficientes en quartz présumées de la croûte moyenne et profonde impliquent un passage fragile-ductile plus profond que $25 \mathrm{~km}$. La composition de la croûte moyenne à inférieure est appuyée par les hautes vitesses sismiques révélées par les levés de sismique réfraction. Cette profondeur peut correspondre au passage de l'affaiblissement par vitesse (velocity weakening) au renforcement par vitesse (velocity strengthening) si le début du fluage des feldspaths hydratés se produit autour de 300 $350^{\circ} \mathrm{C}$. En présumant une différence maximale de contrainte d'environ $200 \mathrm{MPa}$ pour la 
croûte, la réactivation des failles dans la croûte moyenne peut se produire avec un bas coefficient de friction et/ou avec des pressions de fluide élevées.

Les données de télédétection, magnétiques, gravimétriques et de sismique-réflexion sont utilisées pour définir les positions des failles géologiques. La plupart des failles régionales correspondent à des linéaments ou à des orientations géophysiques généralement parallèles au fleuve Saint-Laurent. La plupart des failles régionales bordent des volumes actifs alors qu'une d'entre elles corrèle avec des foyers de séismes, incluant quelques événements de magnitude > 4. À l'intérieur du cratère météoritique, les séismes sont généralement plus petits, possiblement reliés au haut niveau de fracturation associé à la structure météoritique de Charlevoix.

Les orientations des contraintes locales et des failles réactivées varient dans la ZSC. La comparaison de quelque 20 mécanismes au foyer (la plupart de faille inverse ou inverse-oblique) avec les groupes de séismes et multiplets (moins de 15\% des séismes entre 1988 et 1997) suggère que des failles réactivées à orientations variées, pas toujours parallèles aux failles de paléo-rift régionales. La plupart des micro-séismes semblent se produire dans des volumes très fracturés, liés en partie à la structure météoritique. Aucune rupture en surface n'est évidente sur les profils de sismique-réflection sur le fleuve SaintLaurent.

À partir des données séismiques locales, un modèle multi-couches pseudo-2D est 
proposé. Des perturbations de vitesse dans la croûte supérieure sont révélées, c'est-à-dire une séquence Appalachienne de $6 \mathrm{~km}$ d'épaisseur (vitesse de P entre 6.2 et $6.6 \mathrm{~km} / \mathrm{s}$ ) et le socle Précambrien (vitesse de P entre 6.2 et $6.6 \mathrm{~km} / \mathrm{s}$ ). À partir des rapports Vp/Vs, la structure de vitesse de la ZSC diffère de celle de la région voisine du Parc des Laurentides, où des roches basiques existent près de la surface.

Même en ajoutant les sources de contraintes locales, la ZSC n'est pas sujette à un niveau de contraintes différentielles tellement plus élevé que le reste de l'est du Canada. Par conséquent, l'activité séismique anomale de la ZSC doit être reliée à une faiblesse crustale particulière et/ou à des pressions de fluide élevées. Quoique la présence d'argile de faille pourrait affaiblir quelques failles, l'effet combiné des pressions de fluide élevées et d'un haut niveau de fracturation est l'explication avancée pour expliquer l'activité séismique dans la croûte fragile. Un modèle qualitatif est proposé dans lequel quelques failles de rift agissent comme conduits à des fluides crustaux sous pression, causant des séismes sur ces failles et dans les volumes fracturés adjacents. 


\section{Acknowledgments}

The completion of this thesis was made possible by the help and cooperation of numerous people. My gratitude goes to my supervisor, Professor Giorgio Ranalli, for his continuous support in our attempt to unveil part of the "Enigma of the Charlevoix earthquakes". His knowledge, advice and enthusiasm have been a continuous source of inspiration throughout the course of this study.

The author thanks the Seismology Program of the Geological Survey of Canada (Natural Resources Canada), and in particular the author's supervisor R.J. Wetmiller, for their support that included a one-year educational leave at Carleton University and time for research during working hours.

My research benefitted from discussions and contributions of other scientists. I particularly thank Pierre Keating, Gervais Perron (both GSC Ottawa) and Bernard Long (UQAR Rimouski) for their work on Charlevoix data sets. I also thank, for their collaboration in various aspects of this work, Bob Wetmiller, Philip Munro, Stephen Halchuk, and Mike Andrew (GSC Seismology Section); Thierry Toutin (Canadian Centre

for Remote Sensing); Roy Cooper and John Halpenny (NRCan Gravity Section); Dave Graham, formerly with the GSC); and Dave Forsyth (GSC Continental Geoscience). 
I also thank the Société Québécoise d'initiatives pétrolières (SOQUIP) for providing the seismic profiles and digital data of Line 13 . The gravity profiles were modelled with the program IGAO of the École Polytechnique de Montréal, while epicentral maps were prepared with the public domain GIS software Xmap8 written by J.M. Lees.

Last, but not least, I thank my spouse Sylvie for her love, patience and encouragement throughout the course of my studies, and my son Félix for cheerfully bringing me back to life's reality between long days of work. 


\section{Original Contribution}

This thesis contains only the results of the research conducted by the candidate, under the guidance of his supervisor. Most of the material presented in Chapter 2 has been published in Lamontagne and Ranalli (1996); similarly, most of the description of the earthquake activity near La Malbaie (Section 4.6.1.1) has been published in Lamontagne and Ranalli (1997). In both papers, the candidate is the senior author, and the supervisor's (second author) contribution has consisted of advice and cooperation in the writing of the paper. Due to an error in the computation of the stress difference, Figure 8B of Lamontagne and Ranalli (1996) should be replaced by Figure 2.9B.

A few sections of Chapter 3 result from collaborative work with scientists of the Geological Survey of Canada. The gravity and magnetic maps, and the Euler deconvolution solutions (Section 3.2.2.1), were produced by Dr. Pierre Keating. Reprocessing of the SOQUIP seismic line 13 was done by Gervais Perron (Section 3.2.2.3). Finally, the chromo-stereoscopic image of the Charlevoix region was produced by Thierry Toutin of the Canada Centre for Remote Sensing.

In Chapter 4, the focal mechanisms of Section 4.3 are described in Lamontagne (1998) and the 1996 Summer field work in Lamontagne et al. (1997). 


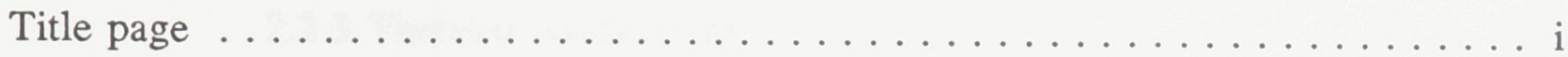

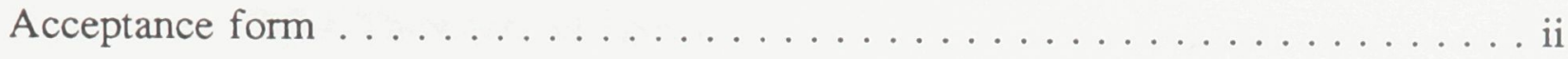

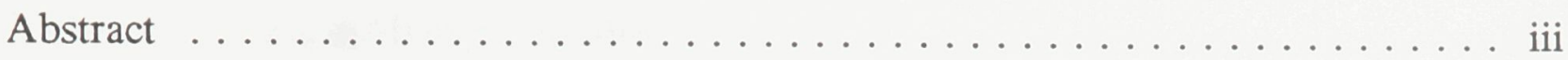

Résumé $\ldots \ldots \ldots \ldots \ldots \ldots \ldots \ldots \ldots \ldots \ldots \ldots \ldots \ldots \ldots \ldots \ldots \ldots \ldots$

Acknowledgments ...................... ix

Original Contribution $\ldots \ldots \ldots \ldots \ldots \ldots \ldots \ldots \ldots \ldots \ldots \ldots \ldots \ldots \ldots \ldots \ldots$

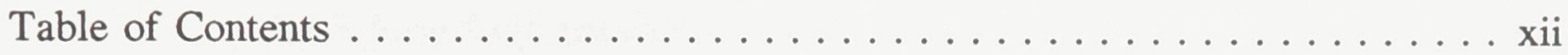

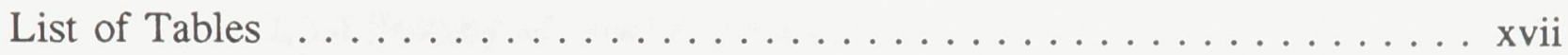

List of Figures $\ldots \ldots \ldots \ldots \ldots \ldots \ldots \ldots \ldots \ldots \ldots \ldots \ldots \ldots \ldots \ldots \ldots \ldots$ xviii

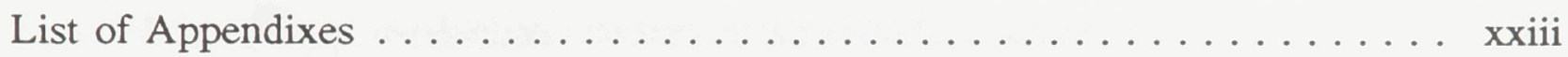

\section{Chapter 1}

The Charlevoix Seismic Zone: overview of the earthquake activity and the geological environment $\ldots \ldots \ldots \ldots \ldots \ldots \ldots$

1.1 Introduction $\ldots \ldots \ldots \ldots \ldots \ldots \ldots \ldots \ldots \ldots \ldots \ldots \ldots \ldots \ldots$

1.2 Objectives and outline of the dissertation $\ldots \ldots \ldots \ldots \ldots$

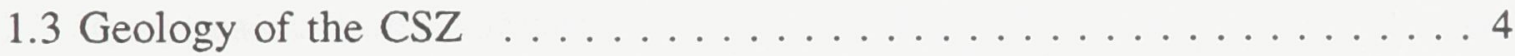

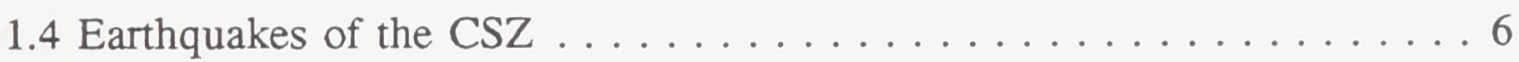

1.4.1 Earthquake monitoring $\ldots \ldots \ldots \ldots \ldots \ldots \ldots$

1.4.2 Hypocentre Locations $\ldots \ldots \ldots \ldots \ldots \ldots$

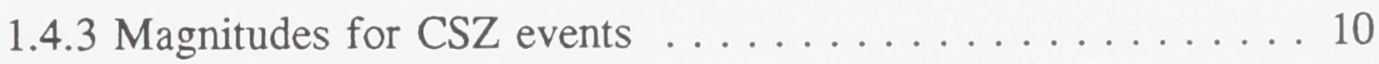

1.4.4 Frequency of occurrence of CSZ earthquakes . . . . . . 14

1.4.5 Spatial distribution and focal mechanisms of CSZ earthquakes

\section{Chapter 2}

Thermal and rheological constraints on the spatial distribution of CSZ

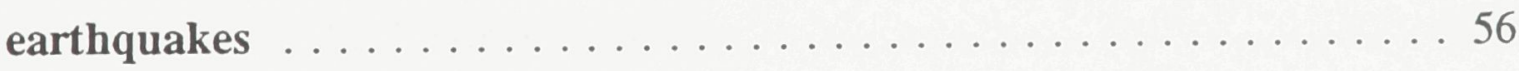

2.1 Introduction $\ldots \ldots \ldots \ldots \ldots \ldots \ldots \ldots \ldots \ldots \ldots \ldots \ldots \ldots \ldots \ldots \ldots \ldots$

2.2 Temperature . . . . . . . . . . . . . . 57

2.2.1 Surface heat flow ................. 59 
2.2.2 Heat production $\ldots \ldots \ldots \ldots \ldots \ldots \ldots \ldots \ldots \ldots \ldots \ldots$

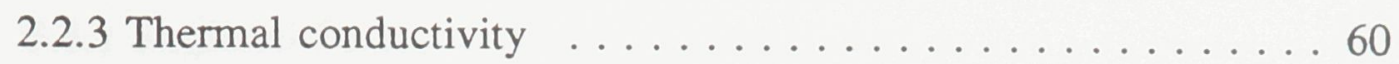

2.2.4 Thickness of layers . . . . . . . . . . . . 61

2.2.5 Mantle heat flow . . . . . . . . . . . . . . . . 61

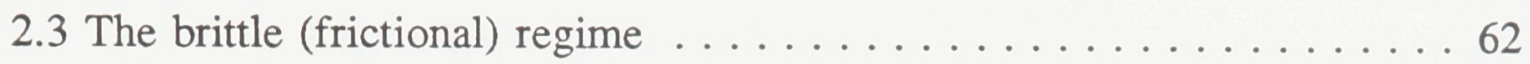

2.3.1 Crustal stress magnitude and orientation $\ldots \ldots \ldots \ldots 64$

2.3.2 Coefficient of friction and cohesion . . . . . . . . . 65

2.3.3 Pore fluid pressure $\ldots \ldots \ldots \ldots \ldots \ldots 6$

2.3.4 Density of overlying rocks . . . . . . . . . . 67

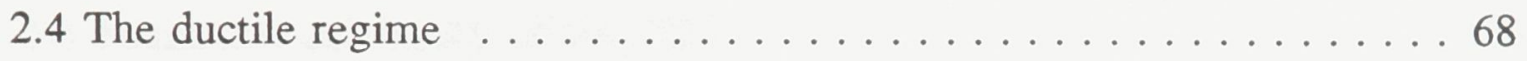

2.5 Velocity weakening-velocity strengthening transition . . . . . . . . 69

2.6 Thermal and rheological controls on CSZ earthquakes . . . . . . 71

2.6.1 Calculation of geotherms . . . . . . . . . . . 73

2.6.2 Ductile regime . . . . . . . . . . . . . . . 77

2.6.3 Change from velocity weakening to velocity strengthening $\ldots 78$

2.6.4 Maximum plausible stress difference . . . . . . . . 78

2.7 Discussion and conclusions $\ldots \ldots \ldots \ldots \ldots \ldots$

\section{Chapter 3}

Geological faults in the CSZ and their correlation with earthquakes

3.1 Introduction

3.2 Data sets and methodology

3.2.1 Remote sensing imagery $\ldots \ldots \ldots \ldots \ldots \ldots \ldots$

3.2.2 Geophysical data sets $\ldots \ldots \ldots \ldots \ldots \ldots \ldots \ldots \ldots 111$

3.2.2.1 Magnetics . . . . . . . . . . . 111

3.2.2.2 Gravity and rock densities ............ 114

3.2.2.3 Seismic profiles . . . . . . . . . . 115

3.2.3 Testing the methodology on the magnitude $\mathrm{m}_{\mathrm{N}} 5.1$ Cap-Rouge earthquake . . . . . . . . . . . . 120

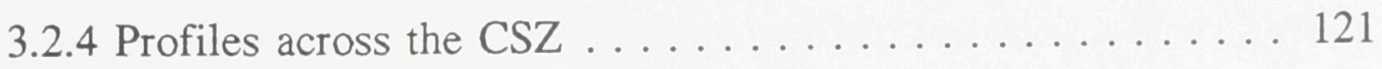




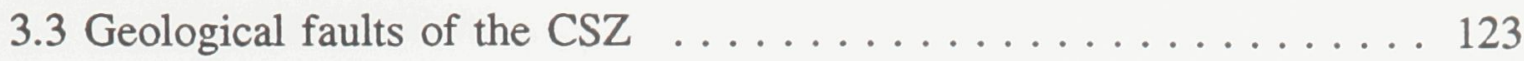

3.3.1 Regional Faults . . . . . . . . . . . . . . . 124

3.3.1.1 The St-Laurent fault . . . . . . . . . . . . . 124

3.3.1.2 The Gouffre NW fault ........... 126

3.3.1.3 The Charlevoix fault (new feature) . . . . . . 126

3.2.1.4 The South Shore fault (new feature) . . . . . . 127

3.3.2 Northeast zone . . . . . . . . . . . . . . . . . . 127

3.3.3 The impact structure faults . . . . . . . . . 128

3.3.4 The SW section . . . . . . . . . . . . . . 129

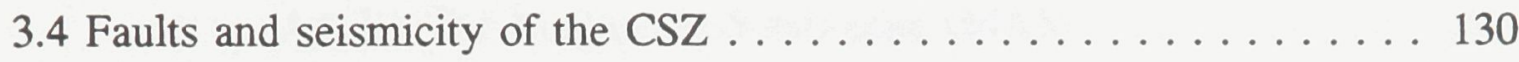

3.4.1 Faults of regional extent . . . . . . . . . . . . 130

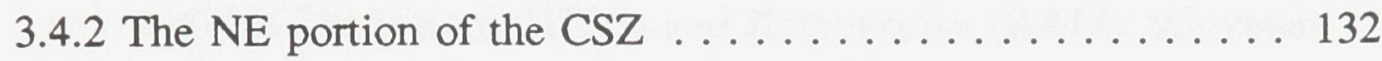

3.4.3 The impact structure . . . . . . . . . . 132

3.4.4 The $\mathrm{SW}$ section $\ldots \ldots \ldots \ldots \ldots \ldots \ldots \ldots \ldots$

3.5 Discussion . . . . . . . . . . . . . . . . . . . . 134

\section{Chapter 4}

Seismicity patterns from focal mechanisms, earthquake clusters, multiplet analysis, and the search for surface fault ruptures $\ldots \ldots 186$

4.1 Introduction . . . . . . . . . . . . . . . . 186

4.2 The search for surface fault ruptures $\ldots \ldots \ldots \ldots \ldots \ldots$

4.3 Focal mechanisms of CSZ earthquakes . . . . . . . . . . 192

4.3.1 Introduction . . . . . . . . . . . . . . . . . . 192

4.3.2 Input data and methodology . . . . . . . . . 193

4.3.3 Results . . . . . . . . . . . . . . . . . . 196

4.3.4 Discussion of the focal mechanisms . . . . . . . 202

4.4 Hypocentre groups and alignments . . . . . . . . . 203

4.4.1 Hypocentre groups . . . . . . . . . . . . . 203

4.4.2 Discussion . . . . . . . . . . . . . . . 204

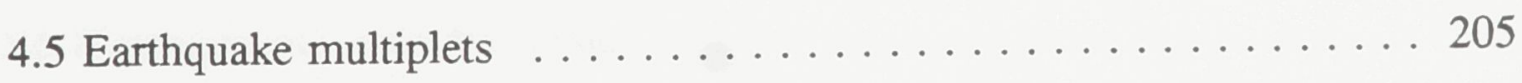


4.5.1 Introduction . . . . . . . . . . . . . . . . 205

4.5.2 Results . . . . . . . . . . . . . . . . . . . . 207

4.6 Integration of focal mechanisms, earthquake groups and multiplets

4.6.1 Sub-zones with shallow activity . . . . . . . . . . 209

4.6.1.1 Earthquakes of the A61 sub-zone . . . . . . . . . . 209

4.6.1.2 Ile-aux-Coudres sub-zone (COU) . . . . . . . . 216

4.6.1.3 Les Eboulements sub-zone (EBO) . . . . . . . 216

4.6 .2 Intermediate depth sub-zones . . . . . . . . . . . . 217

4.6.2.1 The Magnitude 5 sub-zone (MA5) . . . . . . 217

4.6.2.2 The St-Irénée sub-zone (IRE) _. . . . . . . . . 220

4.6.2.3 The Central (CEN) and Kamouraska (KAM) sub-zones

220

4.6.2.4 The La Pocatière (POC) sub-zone . . . . . . . . 220

4.6.3 Deep activity sub-zones . . . . . . . . . . . . . 221

4.6.3.1 The Cap-aux-Oies sub-zone (OIE) . . . . . . . 221

4.6.3.2 The Deep Northeast sub-zone (DNE) . . . . . . 221

4.6.4 Weakly seismic sub-zones (SHI, SGA, CGA, AIG, NGA, UPS, DOW, SOS, LOU $\ldots \ldots \ldots \ldots \ldots \ldots \ldots \ldots \ldots \ldots$

4.7 Discussion ......................... 223

\section{Chapter 5}

Determination of the CSZ velocity structure from local earthquake data

5.1 Introduction

5.2 Previous studies of the regional velocity structure and routine analysis of the

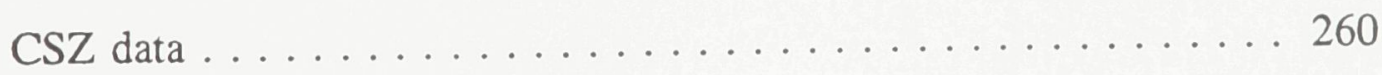

5.4 Selection of the earthquake data $\ldots \ldots \ldots \ldots \ldots \ldots \ldots \ldots$

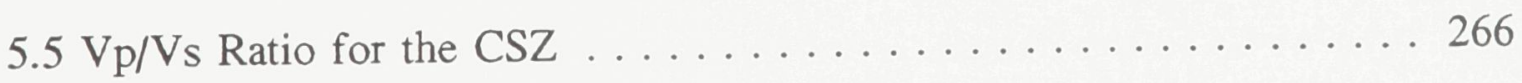

5.6 Homogeneous velocity model $\ldots \ldots \ldots \ldots \ldots \ldots \ldots \ldots$

5.7 Calculation of layered velocity models for the north and the south shores 
5.8 Impact on CSZ earthquake locations . . . . . . . . . . . . . 274

5.9 Velocity model between the CSZ and station DAQ . . . . . . . 274

5.10 Impact of the velocity models on the understanding of the CSZ . . . 277

\section{Chapter 6}

Summary and discussion $\ldots \ldots \ldots \ldots \ldots \ldots \ldots \ldots \ldots$

6.1 Summary of the findings of this thesis $\ldots \ldots \ldots \ldots \ldots \ldots 11$

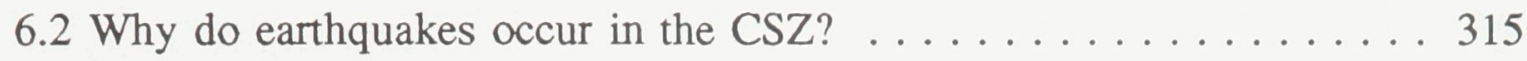

6.2.1 The stress system in the CSZ . . . . . . . . . 317

6.2.2 Physical conditions of the faults . . . . . . . . . 321

6.2.2.1 Coefficient of friction . . . . . . . . . . 321

6.2.2.2 Pore-fluid pressure . . . . . . . . . . . 323

6.3 Discussion . . . . . . . . . . . . . . . . 325

References . . . . . . . . . . . . . . . . . . . . 332 


\section{List of Tables}

Table 1.1 Estimated first year of complete reporting of magnitude levels in the CSZ

Table 1.2 Number and yearly rate of located CSZ events by magnitude range . . . 16

Table 2.1 Creep parameters of rocks used in this study . . . . . . . . . . 70

Table 2.2: Thickness and thermal parameters of crustal layers in the Charlevoix region

Table 3.1: Rock Densities . . . . . . . . . . . . . . . . . . . . 116

Table 3.2 Seismic profiles of the CSZ . . . . . . . . . . . . . . 117

Table 3.3 Fault dimensions for stable continental earthquakes . . . . . . . . . 130

Table 4.1 Factors defining the nature of the potential ruptures $\ldots . . \ldots 190$

Table 4.2 Rating scheme of the focal mechanism . . . . . . . . . . . . . . . 195

Table 4.3: Focal mechanisms of earthquakes of magnitude 3.0 and larger . . . . 197

Table 4.4: Focal mechanisms of earthquakes recorded during the 1996 summer field survey . . . . . . . . . . . . . . . . . . . . . . . . . 199

Table 4.5 Other mechanisms. $(1974 ; 1979+$ events near La Malbaie) . . . . . . 200

Table 4.6 Statistics of the various sub-zones . . . . . . . . . . . . . . . 210

Table 4.7 Aftershocks of the 19971028 event . . . . . . . . . . . . . . . . . 219

Table 5.1: Station corrections to be used with the standard velocity model . . . . 269

Table 5.2 Velocities used to model the north and the south shore . . . . . . . 270

Table 5.3 Range of $\mathrm{P}$-wave velocities used in the 2-D velocity analysis . . . . . 271

Table 5.4 Velocity model that minimizes the RMS . . . . . . . . . . . 273

Table 5.5 Velocity model for the Laurentides Park region . . . . . . . . . 276 


\section{List of Figures}

Figure 1.1 Earthquakes in eastern Canada. . . . . . . . . . . . . . . 18

Figure 1.2 Boundaries of the Charlevoix Seismic Zone (CSZ) . . . . . . . . . . . . 19

Figure 1.3 Elevation in meters and earthquake hypocentres of the CSZ . . . . . 20

Figure 1.4 CSZ hypocentres of the period October 1977 to May 1983 . . . . . . . 21

Figure 1.5 Topography of the CSZ with elevation in meters. . . . . . . . 22

Figure 1.6 Scenes of the Charlevoix Seismic Zone. . . . . . . . . . . . . . . 24

Figure 1.7 Main geological features of the CSZ . . . . . . . . . . . 27

Figure 1.8 Time-history of the Charlevoix network between 1970 and 1998 . . . 28

Figure 1.9 Location of the permanent seismograph stations in the CSZ . . . . . 29

Figure 1.10 Examples of how arrival times have been picked over the years . . . 30

Figure 1.11 Regional stations surrounding the CSZ . . . . . . . . . . . 34

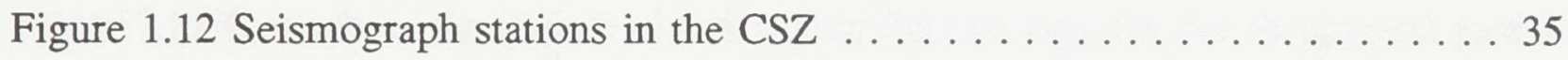

Figure 1.13 Correlation between $\mathrm{m}_{\mathrm{N}}$ and $\mathrm{M}_{\mathrm{L}}$ magnitudes $\ldots \ldots \ldots \ldots$

Figure 1.14 Distribution of located earthquakes for the period October 1977 - December 1997 . . . . . . . . . . . . . . . . . . . . . . . . . . . . . . . . 37

Figure 1.15 Number of events for various magnitude thresholds . . . . . . 38

Figure 1.16 Sub-zones around earthquake clusters with similar depth distribution

Figure 1.17 Time-history of the activity of the various sub-zones of Figure 1.16 . 40

Figure 1.18 A 30 day histogram of located earthquakes in the CSZ . . . . . . 42

Figure 1.19 Magnitude-recurrence curves for the CSZ . . . . . . . . . 43

Figure 1.20 Focal depth distribution of the Charlevoix earthquakes for the period October 1977 - December 1997 . . . . . . . . . . . . . . . . . . . . . 44

Figure $1.21 \mathrm{CSZ}$ hypocentres and stations $\ldots \ldots \ldots \ldots \ldots \ldots \ldots \ldots \ldots \ldots$

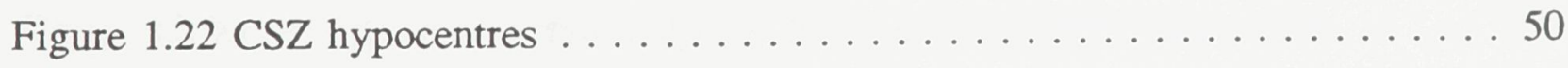

Figure 1.23 Hypocentres by magnitude ranges $\ldots \ldots \ldots \ldots \ldots \ldots \ldots \ldots \ldots$

Figure 1.24 Lower hemisphere focal mechanisms in the CSZ . . . . . . . 55

Figure 2.1 Focal depth distribution of the Charlevoix earthquakes for the period October 
Figure 2.2 Sketch representing the various factors intervening in fault reactivation

Figure 2.3 Distribution of inferred maximum stress differences $\ldots \ldots \ldots \ldots 8$

Figure 2.4 Distribution of heat flow measurements in the Grenville Province . . . 90

Figure 2.5 Computed geotherms for the Grenville region . . . . . . . . . . 91

Figure 2.6 Geotherms calculated with a surface heat flow of $60 \mathrm{~mW} / \mathrm{m} \ldots \ldots 95$

Figure 2.7 Crustal strength as a function of depth . . . . . . . . . 96

Figure 2.8 Crustal strength as a function of depth . . . . . . . . . . . 100

Figure 2.9 Stress difference (MPa) necessary to reactivate a fault located at a depth of 20

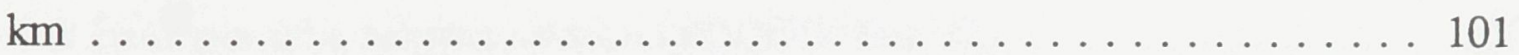

Figure 2.10 Map of the relation between pore-fluid pressure, coefficient of friction and reactivation angle . . . . . . . . . . . . . . . . . . . 104

Figure 2.11 Example of the impact of a change in fracture type for the rheological profile

Figure 2.12 Synoptic model of the factors controlling the earthquake occurrences in the

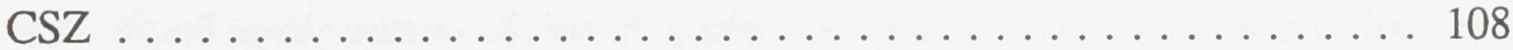

Figure 3.1 Location map of the CSZ surroundings and geographic entities mentioned in the text . . . . . . . . . . . . . . . . . . . . . 137

Figure 3.2 Principle of the side-looking radar system . . . . . . . . 138

Figure 3.3 Remote sensing radar images of the CSZ . . . . . . . . . . . 139

Figure $3.4 \mathrm{CSZ}$ total magnetic field . . . . . . . . . . . . . 147

Figure 3.5 Solutions of the Euler deconvolution $(\mathrm{N}=0)$ of the magnetic field . . . 148

Figure 3.6 Photos taken during the August 1994 gravity survey . . . . . . . 154

Figure 3.7 Gravity and density data . . . . . . . . . . . 155

Figure 3.8 Location map of the SOQUIP seismic reflection lines in the CSZ . 158

Figure 3.9 Euler solutions of the magnetic field in the Quebec City region . . . . 159

Figure 3.10 Location of the four geophysical profiles discussed in text . . . . 160

Figure 3.11 Geophysical profile near Ile-aux-Coudres . . . . . . . . . . 161

Figure 3.12 Crater profile . . . . . . . . . . . . . . . 167 
Figure 3.13 Line 13 profile . . . . . . . . . . . . . . . . . . . 170

Figure 3.14 Ile-aux-Lièvres profile . . . . . . . . . . . . . . . . 176

Figure 3.15 The three main sub-regions discussed in text $\ldots \ldots \ldots . \ldots 179$

Figure 3.16 Interpreted structures of the CSZ . . . . . . . . . . . . 180

Figure 3.17 Major faults of the CSZ . . . . . . . . . . . . . . 181

Figure 3.18 SOQUIP seismic line $22 \ldots \ldots \ldots \ldots \ldots$. . . . . . . . . 182

Figure 3.19 SOQUIP seismic line A . . . . . . . . . . . . . 183

Figure 3.20 Geological faults and CSZ hypocentres . . . . . . . . . . . . 184

Figure 3.21 Cross-section across the 1979 M5 earthquake zone . . . . . . . . . 185

Figure 4.1 Schematic cross-section of the type of rupture expected in the CSZ . 226

Figure 4.2 Example of a seismic section (SOQUIP line 22) . . . . . . . . . 227

Figure 4.3 Location map of the seismic lines acquired by SOQUIP and by their partners

Figure 4.4 Seismic profiles that show the Quaternary sequence . . . . . . . . 229

Figure 4.5 Lower hemisphere focal mechanisms of the 12 quality $\mathrm{A}$ and $\mathrm{B}$ focal mechanisms for events of magnitude $\mathrm{m}_{\mathrm{N}} \geq 3.0 \ldots \ldots \ldots \ldots 231$

Figure 4.6. Focal mechanisms of the 8 quality $\mathrm{A}$ and $\mathrm{B}$ focal mechanisms for 1996

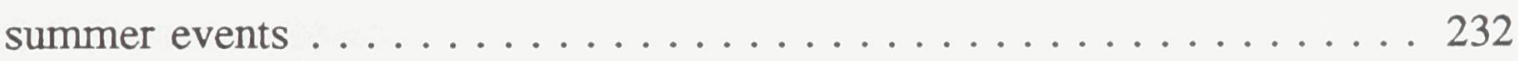

Figure 4.7 The two well-constrained focal mechanisms for the 1974 field survey

Figure 4.8 Focal mechanisms of the $1979 \mathrm{mN} 5.0$ earthquake . . . . . . . . 234

Figure 4.9 Revised focal mechanisms of Figure $1.26 \ldots \ldots \ldots \ldots 235$

Figure 4.10 Focal mechanisms of quality " $\mathrm{A}$ " and "B" . . . . . . . 236

Figure 4.11 Results from the quality " $A$ " and " $B$ " of Figure $4.8 \ldots \ldots 237$

Figure 4.12 Method of defining earthquake groups $\ldots \ldots \ldots \ldots \ldots \ldots$

Figure 4.13 Hypocentre groups with 10 events or more . . . . . . . . 239

Figure 4.14 Cross-sections across the largest group of hypocentres . . . . . . . 240

Figure 4.15 Earthquake groups ( $1.5 \mathrm{~km}$ distance) with a focal mechanism . . . 241

Figure 4.16 Traces of a nine-tuplet (earthquake swarm) $\ldots \ldots \ldots . \ldots 242$

Figure 4.17 Characteristics of the events of multiplets $\ldots \ldots \ldots \ldots \ldots 245$ 
Figure 4.18 CSZ Multiplets of the period November 1988 to August 1997 . . . . 246

Figure 4.19 Earthquake hypocentres and sub-zones . . . . . . . . . . . . . . 247

Figure 4.20 Focal depth distribution for the various sub-zones . . . . . . . . . 248

Figure 4.21 Hypocentres of the A61 sub-zone . . . . . . . . . . . . 251

Figure 4.22 Compared depth distributions . . . . . . . . . . . . . 252

Figure 4.23 Vertical seismic traces of three quarry blasts . . . . . . . . . 253

Figure 4.24 Airborne Synthetic Aperture Radar (SAR) image of the A61 Sub-zone

Figure 4.25 The 19971028 aftershock sequence . . . . . . . . . . . . 256

Figure 4.26 Hypocentres of the DNE sub-zone . . . . . . . . . . . . 257

Figure 5.1 P-wave velocity models of the Charlevoix and the Saguenay regions . 281

Figure 5.2 Absolute time differences between the $\mathrm{Pg}$ and $\mathrm{Sg}$ arrivals . . . . . 282

Figure 5.3 Characteristics of the events selected for the velocity inversion . . . 283

Figure 5.4 Wadati plot for the events selected . . . . . . . . . . 286

Figure 5.5 RMS values for various combinations of $\mathrm{Vp}$ and $\mathrm{Vs} \ldots \ldots 287$

Figure 5.6 Residuals for the various CSZ stations . . . . . . . . . . . 288

Figure 5.7 RMS values, as in Figure 5.5 . . . . . . . . . . . . . . 290

Figure 5.8 P-wave residuals . . . . . . . . . . . . . . . . . . . . . 292

Figure 5.9 Best RMS obtained as a function of P-wave velocity . . . . . . . 293

Figure 5.10 Number of residuals grouped in $0.05 \mathrm{~s}$ classes for the CSZ stations

Figure 5.11 Shifts between original event locations $(X=Y=0)$ and locations computed with the best layered model . . . . . . . . . . . . . . . . 297

Figure 5.12 Epicentral map showing shift between original (yellow) and the relocated (red) epicentres . . . . . . . . . . . . . . . . . 298

Figure $5.13 \mathrm{CSZ}$ events recorded at station DAQ . . . . . . . . . 299

Figure 5.14 Wadati plot for the CSZ events recorded on DAQ . . . . . . 301

Figure $5.15 \mathrm{Vp}$-Vs tests for the DAQ data with RMS values in seconds . . . . 302

Figure 5.16 Best RMS for DAQ data obtained for given P-wave velocities and depth of layers . . . . . . . . . . . . . . . . . 303 
Figure 5.17 Number of DAQ residuals for $\mathrm{P}$ and $\mathrm{S}$ waves grouped by $0.05 \mathrm{~s}$ classes

Figure 5.18 Distribution of the $\mathrm{P}$ and $\mathrm{S}$ residuals . . . . . . . . . 305

Figure 5.19 Wadati plot for CSZ events recorded on DAQ . . . . . . . . . . 306

Figure 5.20 RMS calculated for crustal $\mathrm{P}$ and $\mathrm{S}$ velocities with CSZ events . . . 307

Figure 5.21 Best RMS values at given depth and P velocities . . . . . . . . . 308

Figure 5.22 $\mathrm{P}$ and $\mathrm{S}$ residuals computed with the best layered velocity model

Figure 5.23 Comparison of the computed 1-D velocity models with other models of the

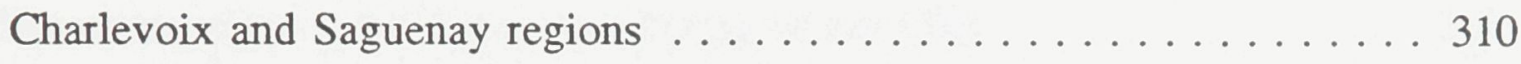

Figure 6.1 Mohr diagram representing relationship between stresses and failure parameters

Figure 6.2 Factors that can lead to earthquakes in the CSZ . . . . . . . 330

Figure 6.3 Schematic model of the CSZ earthquakes . . . . . . . . . . 331 


\section{List of Appendixes}

Appendix 1

Example of a focal mechanism calculation and plots . . . . . . . 348

Appendix 2

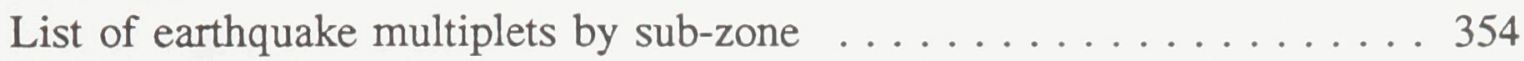

\section{Appendix 3}

Recommendations for future monitoring of the CSZ . . . . . . 360 


\section{Chapter 1}

The Charlevoix Seismic Zone: overview of the earthquake activity and the geological environment

\subsection{Introduction}

Located some $100 \mathrm{~km}$ downstream from Quebec City, the Charlevoix Seismic Zone $(\mathrm{CSZ})^{1}$ is the most seismically active region of eastern Canada (Figure 1.1). Historically, the zone has been subject to five earthquakes of magnitude 6 or larger: in 1663 (magnitude 7.0); 1791 (magnitude 6.0); 1860 (magnitude 6.0); 1870 (magnitude 6.5); and $1925\left(\mathbf{M}^{2}\right.$ 6.2) (magnitudes as listed in Anglin et al., 1990; Bent, 1992). The earthquake potential of the CSZ led the Earth Physics Branch (EPB; now part of the Geological Survey of Canada: GSC) to conduct two field surveys, in 1970 and 1974 respectively (Leblanc et al., 1973; Leblanc and Buchbinder, 1977). The 63 hypocentres located during these two surveys clearly defined the boundaries of the CSZ, i.e. an active zone about 30 by $85 \mathrm{~km}$, elongated along the St. Lawrence River, enclosing the towns of Baie-St-Paul, La Malbaie and La Pocatière (Figure 1.2). In 1977, the EPB deployed a seven-station local seismograph network centred on the active zone defined

1 The name Charlevoix associated with the seismic zone is somewhat misleading: most of the earthquakes occur under the St. Lawrence River, between Charlevoix County on the north shore and Kamouraska County on the south shore. To consider this aspect, the CSZ is sometimes referred to as the Charlevoix-Kamouraska Seismic Zone. In this dissertation, we will use the traditional name CSZ of Basham et al. (1982).

${ }^{2} \mathbf{M}$ is the moment magnitude, formerly listed as $\mathbf{M}_{w}$ in some publications. 
by the field surveys. Between 1978 and 1997 inclusively, the network detected nearly 2200 local earthquakes, of which 54 exceeded Nuttli Magnitude $\left(m_{N}\right) 3.0$ (Figure 1.3). The current CSZ network detects more than 200 earthquakes per year. Based on historical and current earthquake rates, the CSZ is the highest seismic hazard zone in continental eastern Canada.

The hypocentres located ${ }^{3}$ over the years have provided an insight into the CSZ seismotectonics. Most earthquakes cluster along or between the mapped Iapetan faults (also called St. Lawrence paleo-rift faults; Anglin, 1984; Adams et al., 1995). Under the north shore of the St. Lawrence River, for example, hypocentres define a SE steeply dipping plane. When projected to the surface along the trend and dip of that steeply dipping plane, the hypocentres are bounded by two Iapetan faults (the St-Laurent and the Gouffre NW faults; Figure 1.4). Based on this evidence, Anglin (1984) concluded that "almost all the activity in this section of the St. Lawrence River valley is related to preexisting steeply dipping faults that strike along the direction of the valley" (p. 602). Outside the CSZ, the Iapetan fault system extends along the St. Lawrence, Saguenay and Ottawa rivers. Therefore, in these areas, the earthquake hazard may be higher than suggested by the low level of historical seismicity. This geological control of earthquake occurrences has been included in the recent national seismic hazard maps of Canada

2 In this dissertation, the term "located" refers to an event for which an epicentre (and often an hypocentre) can be determined. It differs from the terms "recorded" and "detected" earthquake, which represents an event recorded on one station or more, but not necessarily located. Since only located earthquakes are kept in the GSC database, the discussion will only refer to "located" earthquakes. 
(Adams et al., 1996).

\subsection{Objectives and outline of the dissertation}

This dissertation uses newly available information to examine the factors that control the occurrence and spatial distribution of CSZ earthquakes. The current knowledge of CSZ seismotectonics is mainly based on the findings of Anglin (1984). Since then, the scientific database has increased considerably in quantity as well as quality. While Anglin (1984) relied on some 250 hypocentres recorded between October 1977 and May 1983, 1300 additional earthquakes were located between June 1983 and December 1997, using mostly three-component digital data. These high quality records can be used to study focal mechanisms, earthquake clusters, and crustal velocities. In addition, since the work by Anglin (1984), advances have occurred in several related fields: crustal processes leading to fault instabilities; earthquake clustering; and temperature distribution controlling rock rheology. Finally, faults, especially those under the St. Lawrence River, can now be inferred by improved techniques to analyze the gravity and magnetic fields, together with radar images and seismic profiles.

The dissertation is divided into six chapters. In Chapter 1 , introductory information on the CSZ geology and earthquakes is presented. The section on seismicity covers the earthquake monitoring, locations, magnitude, frequency and distribution of events. In Chapter 2, factors that control earthquake occurrences (temperature distribution, rheology, 
stress differences) are presented and applied to the CSZ. In Chapter 3, an update to structural geology of the CSZ is presented and compared with the seismicity. The section includes the description of new faults, mainly under the St. Lawrence River, as revealed with new data sets and techniques. In Chapter 4 , focal mechanisms, earthquake groups and multiplets are integrated into a seismotectonic analysis of the CSZ. In Chapter 5, local earthquake data are used to invert local and regional velocity models. Finally, in Chapter 6 , the factors leading to seismicity in the CSZ are discussed based on the results of the previous chapters.

\subsection{Geology of the CSZ}

Geomorphologically, the CSZ is an area of contrasting topography, with elevations varying between sea level and 1171 meters (Figure 1.5A). While the south shore is a gently rolling landscape, the north shore is a mixture of rugged highlands, plateaus and valleys, separated by dramatic changes in elevation (Figure 1.6). To the west and northwest of the CSZ, the Laurentian Plateau is an area of high elevation (up to $1171 \mathrm{~m}$ above sea level), cut by numerous steep valleys (Figure $1.5 \mathrm{~B}$ ). To the north and east, tectonic events and glacial erosion created a gentler relief. To the north of the CSZ, the plateau is cut by a series of EW normal faults related to the creation of the Saguenay Graben in late Precambrian to Ordovician ( 700-500Ma). Along the St. Lawrence River, low relief generally corresponds to the hanging wall of normal faults of similar age. In addition, a Devonian meteorite impact $(\sim 350 \mathrm{Ma})$ has shattered the plateau, creating a 
semi-circular depression $56 \mathrm{~km}$ in diameter. The centre of the crater is a $768 \mathrm{~m}$ high central peak, Mont des Eboulements, which is surrounded by an interior plateau of up to $15 \mathrm{~km}$ radius, and by a peripheral depression of up to $27.5 \mathrm{~km}$ radius (Rondot, 1989). In the Quaternary, the multiple passages of the glaciers have preferentially eroded the shattered impact structure and the regional fault zones to the north and west of the CSZ. The St. Lawrence River covers about $25 \%$ of the surface of the CSZ. The deepest areas can be $150 \mathrm{~m}$ deep near the north shore. Southeast of Ile-aux-Coudres and Ile-auxLièvres, the river is generally shallow and the underwater relief very gentle.

Four main geological assemblages make up the geology of the CSZ: the Precambrian Shield of Grenvillian age, the Ordovician St. Lawrence platform, the Appalachian nappes and the Quaternary deposits (Rondot, 1979; Figure 1.7). The main lithologies of the Precambrian Shield are the charnockite-mangerite assemblages, metasediments, anorthosite intrusives and local gabbro dykes within fault zones. The charnockite-mangerite assemblages of the Laurentides Park Charnockite Complex cover most of the western part of the region. Locally, the complex is intruded by magmatic bodies, such as the St-Urbain Anorthosite. The Ordovician sedimentary rocks, mainly limestones, rest unconformably on the Precambrian basement, as thin erosion remnants on the north shore, and as thick sedimentary sequences under the St. Lawrence River. The Appalachian sequences are made up of Cambrian sedimentary rocks (sandstones, mudstones) thrust over the Precambrian and Ordovician rocks. The surface expression of this thrust plane is often referred to as Logan's Line. Finally, Quaternary deposits cover 
the previous assemblages. On land, these Quaternary deposits are generally thin but pervasive sequences of glacial till and marine clays. Offshore, deposits hundreds of meters thick are found in elongated valleys filled with multi-episodic interglacial sedimentary sequences, covering more than 250,000 years of the St. Lawrence River's history (Occhietti et al., 1997).

All CSZ earthquakes occur within the Precambrian basement (Leblanc and Buchbinder, 1977). The seismogenic basement is cut by faults created during four major tectonic events: the Grenvillian collision $(\approx 1100$ to $\approx 900 \mathrm{Ma})$; the rifting episode related to the opening of the Iapetus Ocean $(\approx 700 \mathrm{Ma})$; the Taconian reactivation of these faults at the closing of that ocean $(\approx 450 \mathrm{Ma})$; and finally, a Devonian meteor impact $(\approx 350$ Ma; Rondot, 1979). In addition to being mapped in the field, most major faults correspond to strong lineaments in remote sensing imagery. Under the St. Lawrence River, geological structures in the seismogenic Precambrian basement are hidden by several kilometres of Appalachian nappes (Lyons et al., 1980) and hundreds of meters of Quaternary sediments. Chapter 3 describes how some fault positions can be determined with gravity, magnetics, remote sensing and seismic profiles.

\subsection{Earthquakes of the CSZ}

\subsubsection{Earthquake monitoring}

Between 1977 and 1998, the Charlevoix region has been the only eastern Canadian 
seismic zone with a seismograph network sufficiently dense for routine hypocentre determinations. Since October 1977, the area has been monitored by a microseismic network of between 6 to 8 stations located on both shores of the St. Lawrence River (Figures 1.8 and 1.9). Between 1977 and 1988, the Charlevoix seismograph network consisted of a six to seven component vertical short-period analogue network. The signals from the stations were radio-transmitted to a central node where they were archived on a magnetic tape together with a time signal from a local clock. Weekly, the tapes were sent to the head office in Ottawa. Based on events seen on the LMQ analogue records, an analyst (generally F. Anglin of the EPB) would digitize the analogue data at 60 samples/s and print a selected time window of the data with a time scale of $1.5 \mathrm{~cm} / \mathrm{s}$ (Anglin and Buchbinder, 1981; Figure 1.10). The Y-scale of the traces (gain) was adjusted to ease the phase picking on paper play-outs. Two stations completed the Charlevoix network, one analogue station on the north shore (LMQ) and one station on the south shore (at first, a low gain analogue station, POC, then, an Eastern Canadian Telemetered Network (ECTN) station, LPQ).

In November 1988, the Charlevoix local network became the Charlevoix Local Telemetered Network (CLTN), a digital three-component short-period array. The data, sampled at $80 \mathrm{~Hz}$, were radio transmitted to a central node where timing was added. There, a detection algorithm analyzed each vertical component for seismic events, and, for each trigger, stored a time slice of the whole CLTN data. Daily, the data were transferred to Ottawa and analyzed with an interactive analysis package (Figure 1.10C). 
Later, in January 1994, the station LMQ became a digital broadband Canadian National Seismograph Network (CNSN) station, with GPS timing and continuous archival of the data in Ottawa. Finally, in August 1994, each CLTN station was upgraded to a high gain short-period digital instrument with $100 \mathrm{~Hz}$ sampling rate and GPS timing. As with any CNSN station, an automatic trigger algorithm continuously scans the CLTN data for events of interest. To detect very small events, LMQ analogue seismograms are also examined. To complete the CSZ network, regional stations provide first motion data and peak amplitudes for magnitude calculations (Figure 1.11).

Between June and November 1996, additional stations were deployed to help define focal mechanisms of micro-earthquakes and to provide additional constraints on the simultaneous velocity inversion for this Ph.D. dissertation. Up to 8 additional sites were occupied by portable seismographs (Lamontagne et al., 1997; Figure 1.12). Six stations were digital three-component short-period instruments sampling at $200 \mathrm{~Hz}$ and two were analogue MEQ-800 instruments, used for picking first motions. The network detected some 120 events during the survey.

\subsubsection{Hypocentre Locations}

CSZ hypocentres are routinely located with direct $\mathrm{P}(\mathrm{Pg})$ and $\mathrm{S}(\mathrm{Sg})$ phases recorded by the local Charlevoix network. Phases from stations outside the CSZ are not used due to the poorly constrained regional velocity model. The GSC program "GRL", 
based on a grid search algorithm, locates hypocentres with a homogeneous half-space velocity model $(6.2 \mathrm{~km} / \mathrm{s}$ for $\mathrm{Pg} ; 3.57 \mathrm{~km} / \mathrm{s}$ for $\mathrm{Sg})$. This velocity model does not consider the lower velocity Appalachian rocks, on which three stations are located. With a wedge of lower velocity material, most hypocentres shift by 0.3 to $1.5 \mathrm{~km}$ towards the southeast (Lamontagne, 1987). In this thesis, most hypocentral maps show earthquake locations computed with the homogeneous velocity model. The seismic velocity aspects are examined in more details in Chapter 5.

Most CSZ events locate within the seismograph network, with epicentral distances varying between 0 and about $80 \mathrm{~km}$. The average Root Mean Square (RMS) for the solutions is about $0.08 \mathrm{~s}$, with $90 \%$ of the RMS less than $0.12 \mathrm{~s}$. These errors are due to the imprecision of phase picking and to the imperfect velocity model. The solutions have average formal errors of $\pm 0.6 \mathrm{~km}$ in epicentral location and $\pm 1 \mathrm{~km}$ in depth, for events within the network (Anglin, 1984). These errors can be larger for events outside the network.

The picking precision of $\mathrm{Pg}$ and $\mathrm{Sg}$ phases has changed over the years. In the location process, weights are assigned to the phases according to their quality (most Charlevoix stations are quality " $\mathrm{A}$ " $( \pm 0.25$ second; weight $=4)$, while some can be $\mathrm{B}( \pm$ 1 second; weight $=1)$ or $\mathrm{C}( \pm 4$ seconds; weight $=0.25)$. Since the original analogue Charlevoix array had only vertical seismometers, it is probable that $\mathrm{Sg}$ phases were not as precise as they have been since November 1988, when the CLTN stations became 
three-component. Since then, most Pg arrivals are picked on the vertical component, while most $\mathrm{Sg}$ phases are measured off the horizontal components.

\subsubsection{Magnitudes for CSZ events}

Since the beginning of operation of the Charlevoix local network, in October 1977, and December 1997, 2164 earthquakes were located in the CSZ. As for other eastern Canadian earthquakes, the magnitude scales $\mathrm{M}_{\mathrm{L}}$ (Richter or local magnitude) and $\mathrm{m}_{\mathrm{N}}$ (Nuttli) are used for CSZ earthquakes. Located CSZ earthquakes vary in size between magnitude $M_{L}-0.5$ and $m_{N} 5.0$. At the Geological Survey of Canada (GSC), the $m_{N}$ and the $\mathrm{M}_{\mathrm{L}}$ scales are used to measure eastern Canadian earthquakes. The following descriptions of the two scales are based on Drysdale et al. (1990).

Nuttli (1973) defines the $\mathrm{m}_{\mathrm{bLg}}$ scale for two distance ranges: 50 to $400 \mathrm{~km}$ and 400 to $800 \mathrm{~km}$. In eastern Canada, the first formula did not give acceptable results in its defined appropriate distance range. Thus, the $\mathrm{m}_{\mathrm{N}}$ scale used by the GSC is an extrapolation of the second formula to epicentral distances between 50 and $400 \mathrm{~km}$ (R.J. Wetmiller, pers. comm.). The formula applied by the GSC is as follows

$$
m_{N}=-0.1+1.66 \log _{10} D+\log _{10}\left(\frac{A}{|K T|}\right)
$$

where $\mathrm{D}$ is the epicentral distance in $\mathrm{km}$; $\mathrm{A}$ is the half peak-to-peak trace amplitude of 
the $S$ phase in millimetres; $T$ is the period of the trace at the maximum; $K$ is the trace magnification in thousands for that period.

The $\mathrm{m}_{\mathrm{N}}$ scale is used for events recorded by stations beyond $50 \mathrm{~km}$. On a given seismic trace, the peak-to-peak trace amplitude of the $\mathrm{Lg}$ wave is measured if not over attenuated. If recorded only within $50 \mathrm{~km}$ epicentral distance, the event is rated on the $\mathrm{M}_{\mathrm{L}}$ scale. The $M_{L}$ scale is defined as (Gutenberg and Richter, 1956)

$$
M_{L}=\log _{10}\left(\frac{A K_{W}}{K}\right)-\log _{10} A_{0}(D)
$$

where $K$ is the trace magnification in thousands at period $T, K_{W}$ is the magnification of the Wood-Anderson seismograph for that period, and $\log _{10} A_{0}(D)$ is the calibration function specified by Richter (1958). This scale was defined for California earthquakes, where the attenuation is higher than in the Canadian Shield. According to Leblanc et al. (1973), the $M_{L}$ scale can be deficient at distances of less than $50 \mathrm{~km}$, especially in respect to the attenuation of high frequency waves in the near-field, and the local variations of site amplification, radiation pattern and rock properties. Consequently, the $M_{L}$ scale is used only as a relative measure of the size of CSZ earthquakes.

For the CSZ, the two magnitude scales are approximately related as (Figure 1.13)

$$
\mathrm{m}_{\mathrm{N}}=0.63 \mathrm{M}_{\mathrm{L}}+1.41
$$


This relation was obtained by applying with robust statistics (Huber, 1981) to the data set described in the figure caption of Figure 1.13. This empirical relation remains approximate due to the large data scatter. Ideally, a uniform magnitude scale for the CSZ earthquakes could be defined with a spectral level analysis (moment magnitude), which we did not attempt in this study. Until then, predictions based on variations of b-values for micro-earthquakes cannot be properly evaluated.

For the time period 1970-1997, the number of located earthquakes is closely related to the number and sensitivity of the local stations (Figure 1.14). Prior to the deployment of the Charlevoix local network in October 1977, only a few tens of earthquakes could be located with the regional stations. The 1970 and 1974 field surveys revealed a high level of earthquake activity, undetected by the regional stations. With the local network, the annual number of located earthquakes increased to nearly 100 in 1978 . At the same time, the magnitude threshold decreased from $\mathrm{m}_{\mathrm{N}} 3.0-3.5$ to $\mathrm{m}_{\mathrm{N}} 2.0$ (Figure 1.14).

As described above, two magnitude scales are used for CSZ events. Between 1977 and 1997, a gradual increase in the number of $\mathrm{m}_{\mathrm{N}}$ magnitude events has occurred (Figure 1.15). This increase is closely related to changes in the number and the type of stations at regional distances. In the early 1980 's, the $\mathrm{m}_{\mathrm{N}}$ scale, extrapolated down to $50 \mathrm{~km}$ epicentral distance, started to be used routinely in eastern Canada. At the same time, 
additional stations of the ECTN were installed within $200 \mathrm{~km}$ of the CSZ. These factors explain the increase in $\mathrm{m}_{\mathrm{N}} \geq 2.0$ events and the corresponding decrease in $\mathrm{M}_{\mathrm{L}} \geq 1.0$ events at around year 1980 (Figure 1.15). Starting in December 1988, the magnitude of smaller $\mathrm{m}_{\mathrm{N}}$ events started to be calculated with the installation of the ECTN station Lac Daran (DAQ), located some $90 \mathrm{~km}$ west of the CSZ. In August 1994, the CLTN and station DAQ became part of the CNSN network. The continuous archiving of the data allowed the location of small events, previously undetectable, and the calculation of $m_{N}$ magnitudes with DAQ data (Figure 1.15). These two factors led to an increase in the number of located events (ALL) and $m_{N} \geq 1.0(M 1+)$ events. Finally, the 1996 June to November field survey caused a peak in the number of located events, largely due to location of many $\mathrm{M}_{\mathrm{L}}<0$ events.

The initial year of complete reporting of different magnitude levels can be estimated. According to Basham et al. (1982), all $\mathrm{m}_{\mathrm{N}} \geq 2.8$ earthquakes have been located since 1968 (Table 1.1). In the period 1970-1976, however, a rather small number of earthquakes with $m_{N} \geq 3.0$ was recorded (three years out of six with no earthquakes; Figure 1.14). Two possibilities exist: a quiescent period, or a period with a detection threshold $>m_{N}$ 3.0. The apparent increase in the number of $m_{N} \geq 3.0$ events after LMQ and the local network became operational (in November 1976) is more in line with the second interpretation. The location threshold for events in the 1968-1977 period is therefore conservatively taken to be $\mathrm{m}_{\mathrm{N}} 3.5$. 
Table 1.1 Estimated first year of complete reporting of magnitude levels in the CSZ (Basham et al., 1982). The magnitudes are defined to one-tenth unit; each category includes earthquakes in a half-magnitude range; ex: magnitude 5.5 includes mag. 5.3- 5.7.

\begin{tabular}{|c|c|c|c|c|c|c|c|c|}
\hline 3.0 & 3.5 & 4.0 & 4.5 & 5.0 & 5.5 & 6.0 & 6.5 & 7.0 \\
\hline 1968 & 1963 & 1937 & 1928 & 1920 & 1900 & 1800 & 1660 & 1660 \\
\hline
\end{tabular}

For the period from October 1977 to December 1997, the magnitude of complete reporting is closely related to the early stages of the Charlevoix local network, between October 1977 and November 1988. During that period, the analogue records of station LMQ served as a visual detector of CSZ earthquakes, all located within $70 \mathrm{~km}$ epicentral distance. The detection of an event on the LMQ records occurred for an amplitude of about $2 \mathrm{~mm}$ (zero-to-peak). For comparison, on 19970217 at 19:47, an $\mathrm{m}_{\mathrm{N}} 1.7$ event, located $55 \mathrm{~km}$ from LMQ, gave a peak-to-peak amplitude of $6.7 \mathrm{~mm}$ on LMQ. From this, we can estimate that a $2-\mathrm{mm}$ amplitude translates into a $\mathrm{m}_{\mathrm{N}} 1.2\left(\mathrm{M}_{\mathrm{L}} \approx-0.3\right)$. For the period 1977-1997, the location completeness is therefore conservatively taken to be $m_{N}$ 1.5 (or $\mathrm{M}_{\mathrm{L}} 0.2$ based on Equation 1.3). After the conversion to the CNSN in August 1994, the location threshold is probably lower: during the 1996 field survey, most events missed by routine analysis, but detected by the temporary stations, were smaller than $M_{L}<0.0$ (Lamontagne et al., 1997).

\subsubsection{Frequency of occurrence of CSZ earthquakes}

For the period 1977-1997, nearly 2000 earthquakes have been located in the CSZ 
with magnitudes varying between $\mathrm{M}_{\mathrm{L}}-0.5$ and $\mathrm{m}_{\mathrm{N}} 5.0$ (Table 1.2). The distribution of earthquakes in time and space was examined interactively without finding any conclusive pattern. To illustrate this, the epicentre map was divided into sub-zones within which hypocentres showed similar characteristics (closely grouped hypocentres with similar depth distribution; Figure 1.16). While some zones show almost continuous activity (zone 10 for example), others have sporadic activity followed by quiescence (zones 3 and 15 for example; Figure 1.17). Magnitude $m_{N} \geq 4.0$ events do not seem to follow a definite pattern with other events in their surroundings; they can start, continue or end a period of increased activity.

An earthquake occurrence rate larger than 30 events per 30 days was thought to provide a warning for an imminent magnitude $>5.5$ earthquake (Buchbinder et al., 1988). The activity plot by these authors was based on events detected on LMQ (and not necessarily located by the network). Since their data are lost and the exercise ended in the late 80 's, I decided to produce a similar plot with the located events, keeping in mind that the local network capability controls the total numbers (Figure 1.18). During the time period 1977 to 1997 , the number of located earthquakes varies between 0 and about 30 per 30-day period, similar to what was reported for the period 1977-1985. No rate increase is noticed prior to an event of magnitude $m_{N} \geq 4.0$.

Using the magnitude completeness and the $\mathrm{M}_{\mathrm{L}}-\mathrm{m}_{\mathrm{N}}$ relation, the magnituderecurrence curve was determined (Figure 1.19). For the period October 1977 to December 1997, the $\log$ (cumulative rate) is a linear function of the magnitude, up to about 
magnitude 4. The best estimate of the slope $\beta$ is 2.14 . At about magnitude $>4$, the slope changes, implying a higher rate for larger events than suggested by the low magnitude earthquakes. This may suggest that the magnitude $>4$ events have overestimated magnitudes, or that there is a real change in occurrence rates at higher magnitudes.

Table 1.2 Number and yearly rate of located CSZ events by magnitude range for the period October 1977 to December 1997. Due to the $\mathrm{M}_{\mathrm{L}}-\mathrm{m}_{\mathrm{N}}$ magnitude overlap, the numbers are the total number of earthquakes of both magnitude types. Consequently, some annual rate statistics were not computed where they are considered not representative (N.R.).

\begin{tabular}{|l|c|c|c|c|c|c|c|}
\hline & $\begin{array}{c}\text { All } \\
\text { located } \\
\text { events }\end{array}$ & $\begin{array}{c}\mathrm{M} \geq 0.0 \\
\left(\mathrm{M}_{\mathrm{L}} \text { and }\right. \\
\left.\mathrm{m}_{\mathrm{N}}\right)\end{array}$ & $\begin{array}{c}\mathrm{M} \geq 1.0 \\
\left(\mathrm{M}_{\mathrm{L}} \text { and }\right. \\
\left.\mathrm{m}_{\mathrm{N}}\right)\end{array}$ & $\begin{array}{c}\mathrm{M} \geq 2.0 \\
(\mathrm{mostly} \\
\left.\mathrm{m}_{\mathrm{N}}\right)\end{array}$ & $\begin{array}{c}\mathrm{M} \geq 3.0 \\
\left(\mathrm{~m}_{\mathrm{N}}\right)\end{array}$ & $\begin{array}{c}\mathrm{M} \geq 4.0 \\
\left(\mathrm{~m}_{\mathrm{N}}\right)\end{array}$ & $\begin{array}{c}\mathrm{M} \geq 5.0 \\
\left(\mathrm{~m}_{\mathrm{N}}\right)\end{array}$ \\
\hline Number & 2164 & 1766 & 838 & 318 & 54 & 8 & 1 \\
\hline $\begin{array}{l}\text { Average } \\
\text { Yearly } \\
\text { Rate }\end{array}$ & N.R. & N.R. & N.R. & N.R. & 2.7 & 0.4 & N.R. \\
\hline
\end{tabular}

\subsubsection{Spatial distribution and focal mechanisms of CSZ earthquakes}

To define the characteristics of the earthquake activity of the CSZ, a hypocentre data set must be defined. From the 2164 earthquakes located between October 1977 and December 1997, some 1450 hypocentres were selected based on at least 5 local stations 
with a minimum of $8 \mathrm{Pg}$ and $\mathrm{Sg}$ phases (see Figure 1.3). This selection insures an acceptable precision to most hypocentre locations (same as in Anglin, 1984). Considering their distribution in respect to depth, two-thirds of Charlevoix earthquakes occur between 7 and $17 \mathrm{~km}$ (Figure 1.20), with more than $80 \%$ at less than $15 \mathrm{~km}$. Interestingly, this is also the depth range where two large events occurred $\left(1925 \mathrm{~m}_{\mathrm{b}} 6.5: 10 \pm 2 \mathrm{~km}\right.$; Bent, 1992; and $1979 \mathrm{~m}_{\mathrm{bLg}}$ 5.0: $10 \pm 2 \mathrm{~km}$; Hasegawa and Wetmiller, 1980). The concentration of large earthquakes at $10 \mathrm{~km}$ depth may correspond to the strongest part of the crust (Wetmiller and Adams, 1990).

Across the CSZ, the earthquake depth distribution varies; shallow $(<5 \mathrm{~km})$ and deep (> $20 \mathrm{~km}$ ) events, for example, concentrate in certain areas (Figure 1.21A-E). On a section perpendicular to the St. Lawrence River (Figure 1.22C), the hypocentres define two major groups, one that dips steeply to the southeast, and one located under the River without obvious alignment. The section parallel to the River shows the focal depth variations along that trend (Figure 1.21C). Events with magnitude $m_{N} \geq 4.0$ concentrate near the two zones of magnitude $\geq 4.0$ for the period 1924-1978 (Stevens, 1980; Figure 1.23A). Earthquakes of smaller magnitude $\left(\mathrm{m}_{\mathrm{N}} \geq 3.0\right.$ events; Figure $1.23 \mathrm{~B} ; \mathrm{m}_{\mathrm{N}} \geq 2.0$ events; Figure 1.23C) do not cluster in one particular subarea.

CSZ focal mechanisms are quite variable in orientation and, to a lesser extent, faulting style (Figure 1.24). It is generally assumed that, on the average, most Charlevoix earthquakes occur as thrust events on preexisting SE steeply $\left(\geq 60^{\circ}\right)$ dipping faults. These focal mechanisms, along with additional ones, are examined and discussed in Chapter 4. 

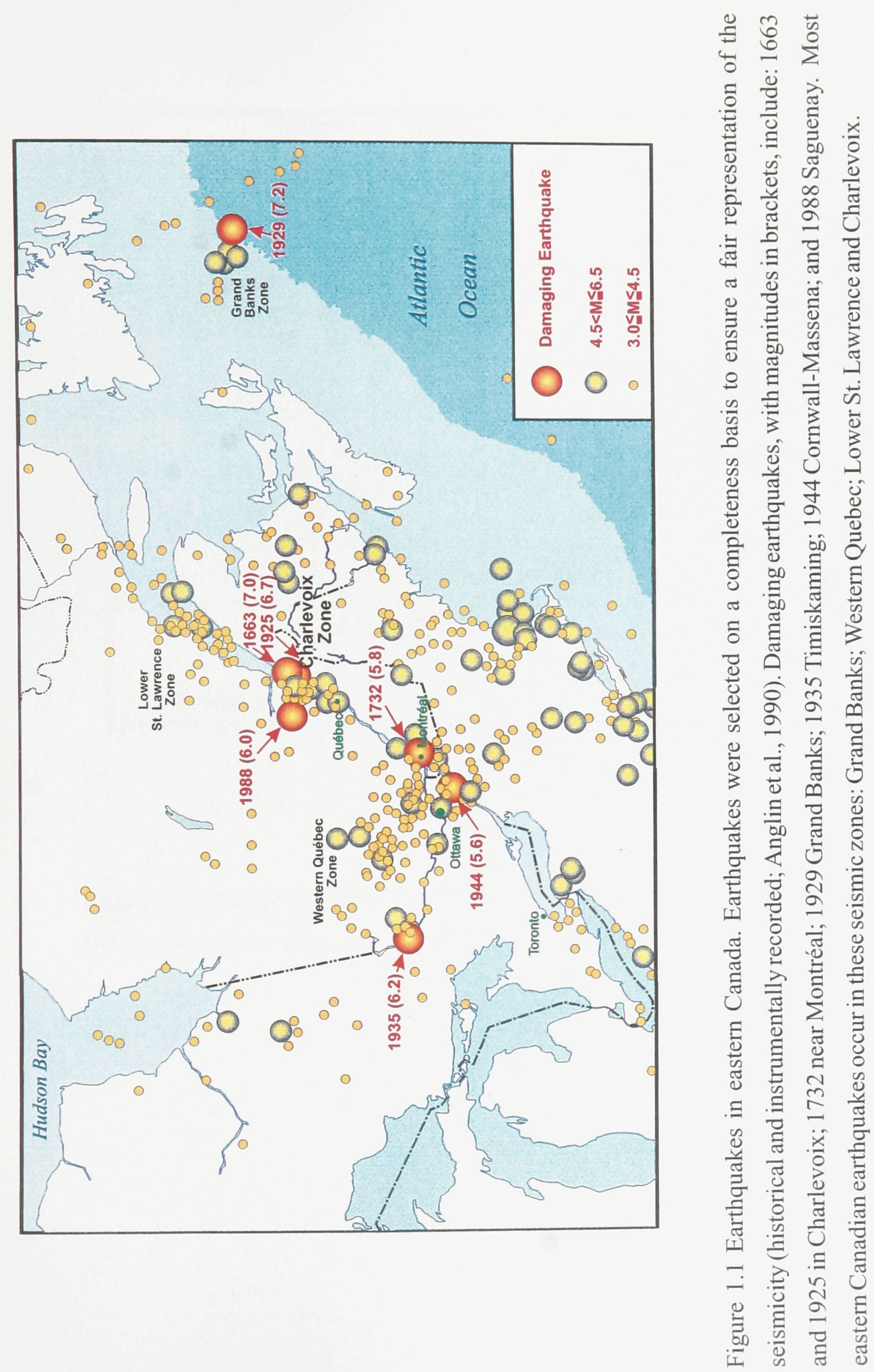


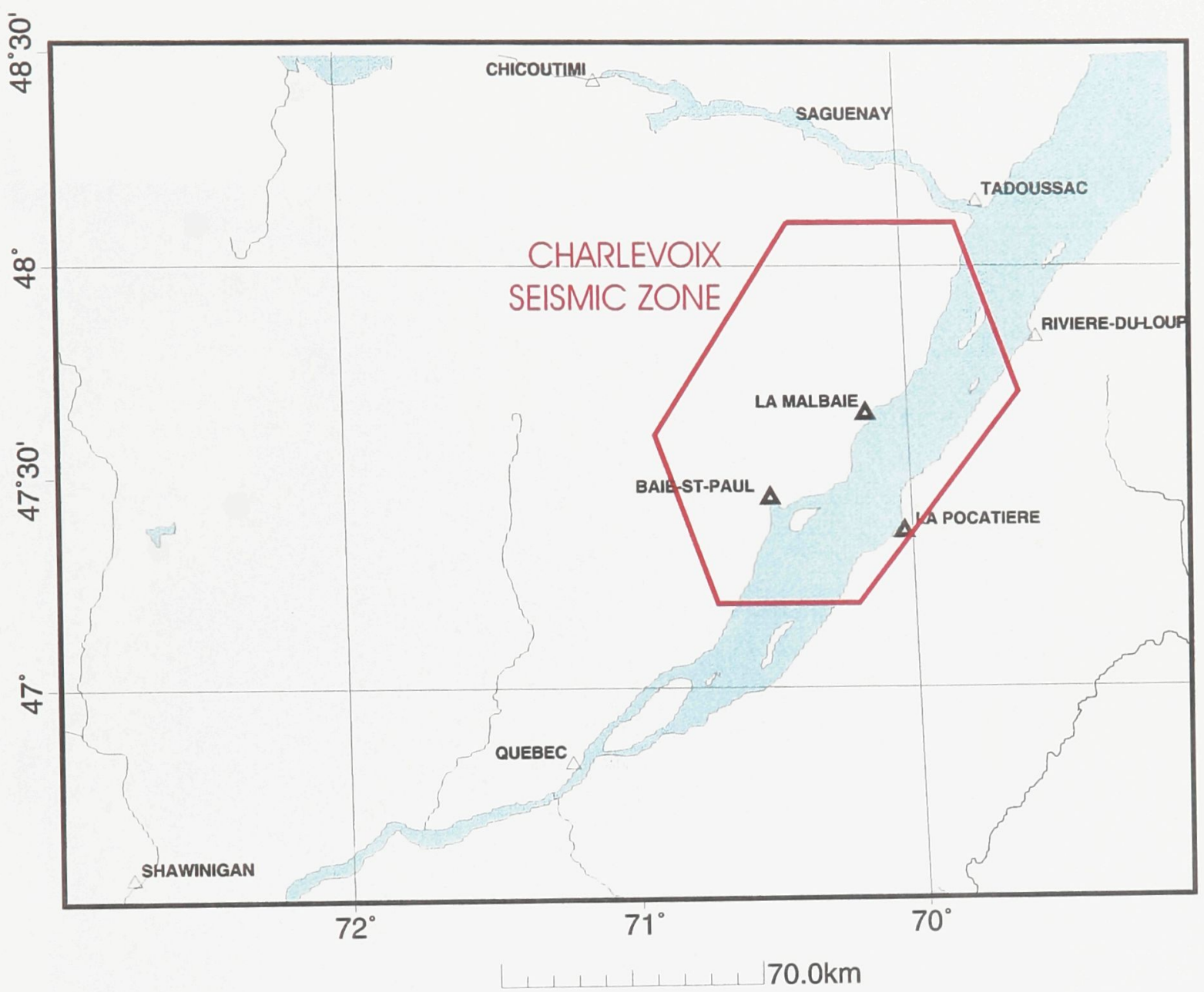

Figure 1.2 Boundaries of the Charlevoix Seismic Zone (CSZ) after Basham et al. (1982). Some place names referred to in the text are shown. 


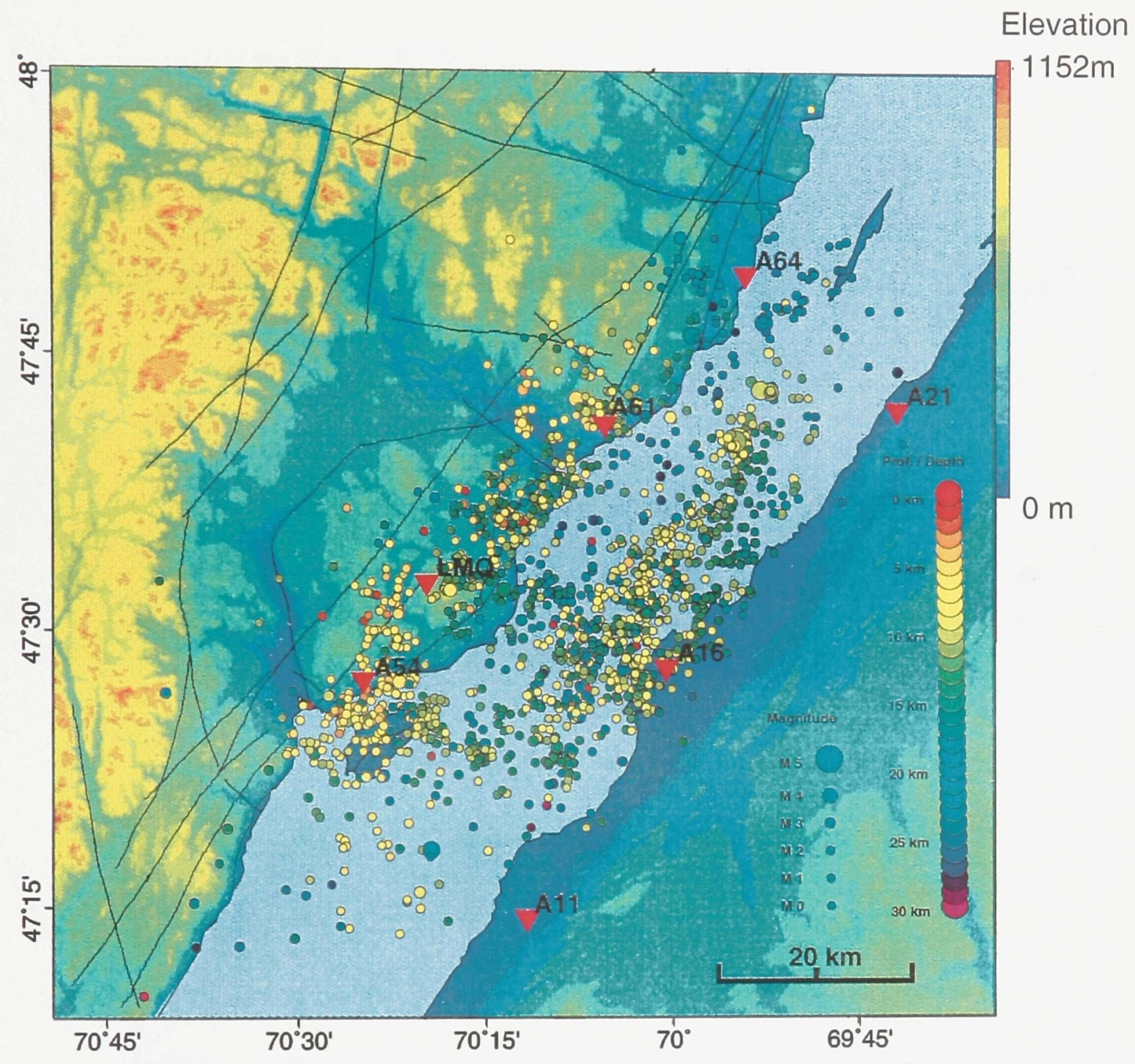

Figure 1.3 Earthquake hypocentres of the CSZ for the period October 1977-

December 1997. Only events with 8 phases from 5 stations are shown. Triangles are the stations of the Charlevoix network, Major faults (black lines) from Rondot (1979). 


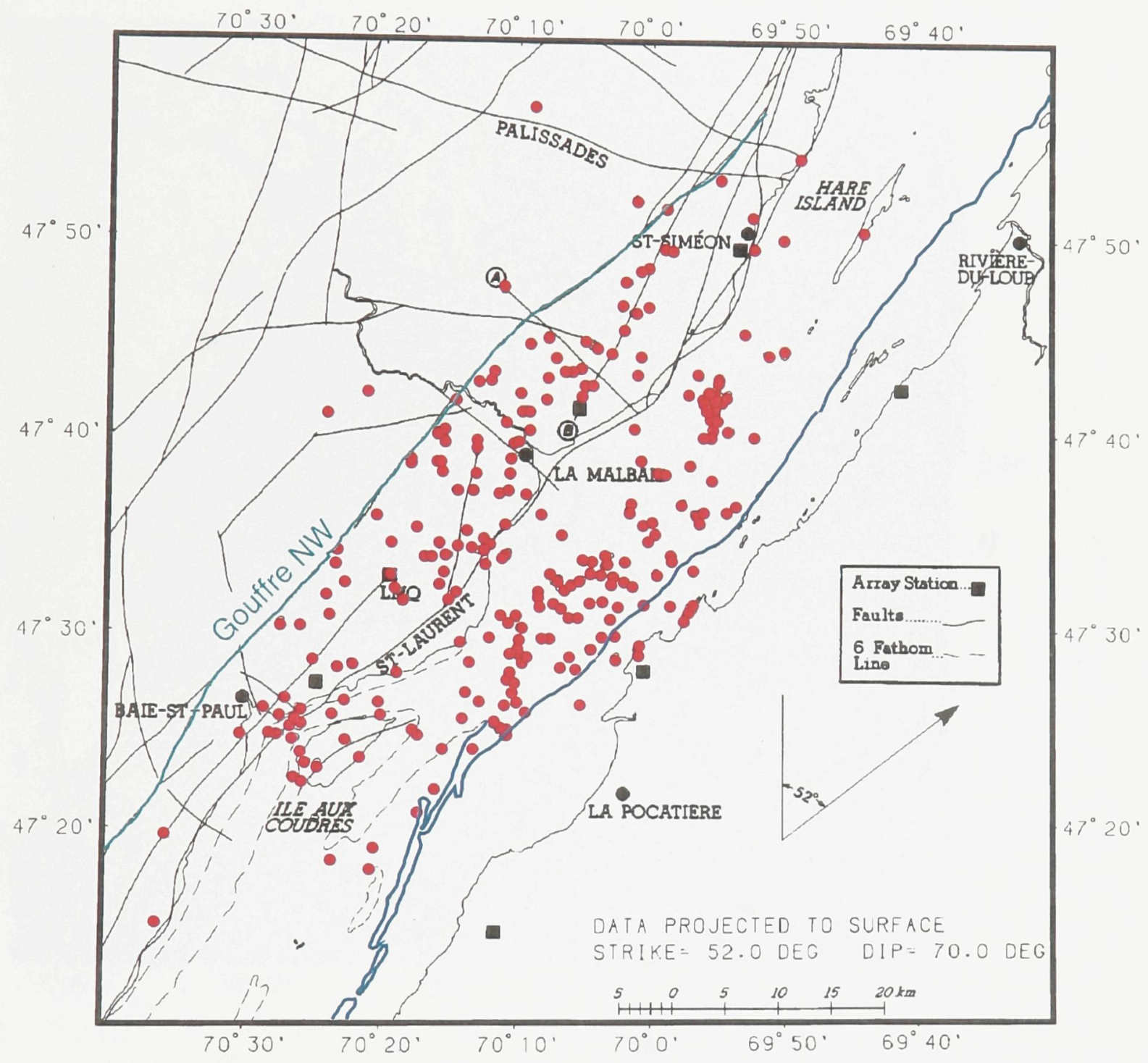

Figure 1.4 CSZ hypocentres (red circles) of the period October 1977 to May 1983 projected to the surface along a plane oriented $\mathrm{N} 52^{\circ} \mathrm{E}$ and dipping $70^{\circ} \mathrm{SE}$ (from Anglin, 1984). Major faults (black lines) from Rondot (1979). Annotations A and B refer to faults that appear to bound the seismic activity according to Anglin (1984). The six-fathom line (in blue) appears to bound the earthquakes to the SE, while the Gouffre NW fault (in green) appears limits earthquakes to the NW. (C)1987 Seismological Society of America. All rights reserved. 
Elevation

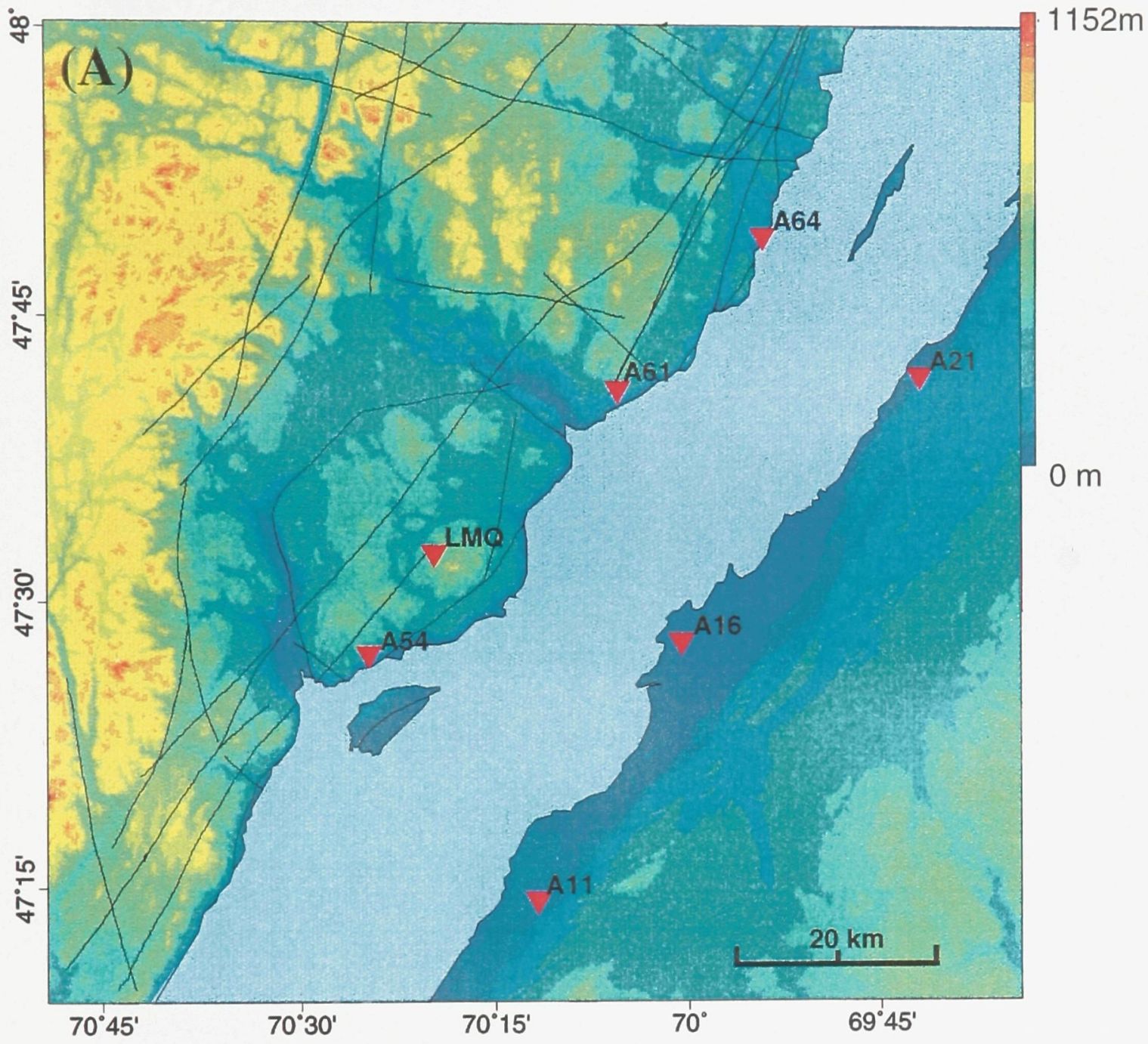

Figure 1.5 Topography of the CSZ with elevation in meters. (A) With major faults of Rondot (1979) and seismograph stations (triangles). (B) Chromo-stereoscopic image of the north shore of the CSZ integrating RADARSAT-SAR ortho-image with the digital elevation model. The colour range varies from $-50 \mathrm{~m}$ (in blue) to $1082 \mathrm{~m}$ (in red) The texture of the land surface comes from the Radar data (image courtesy of T. Toutin, Canada Centre for Remote Sensing; Toutin and Rivard, 1997). 


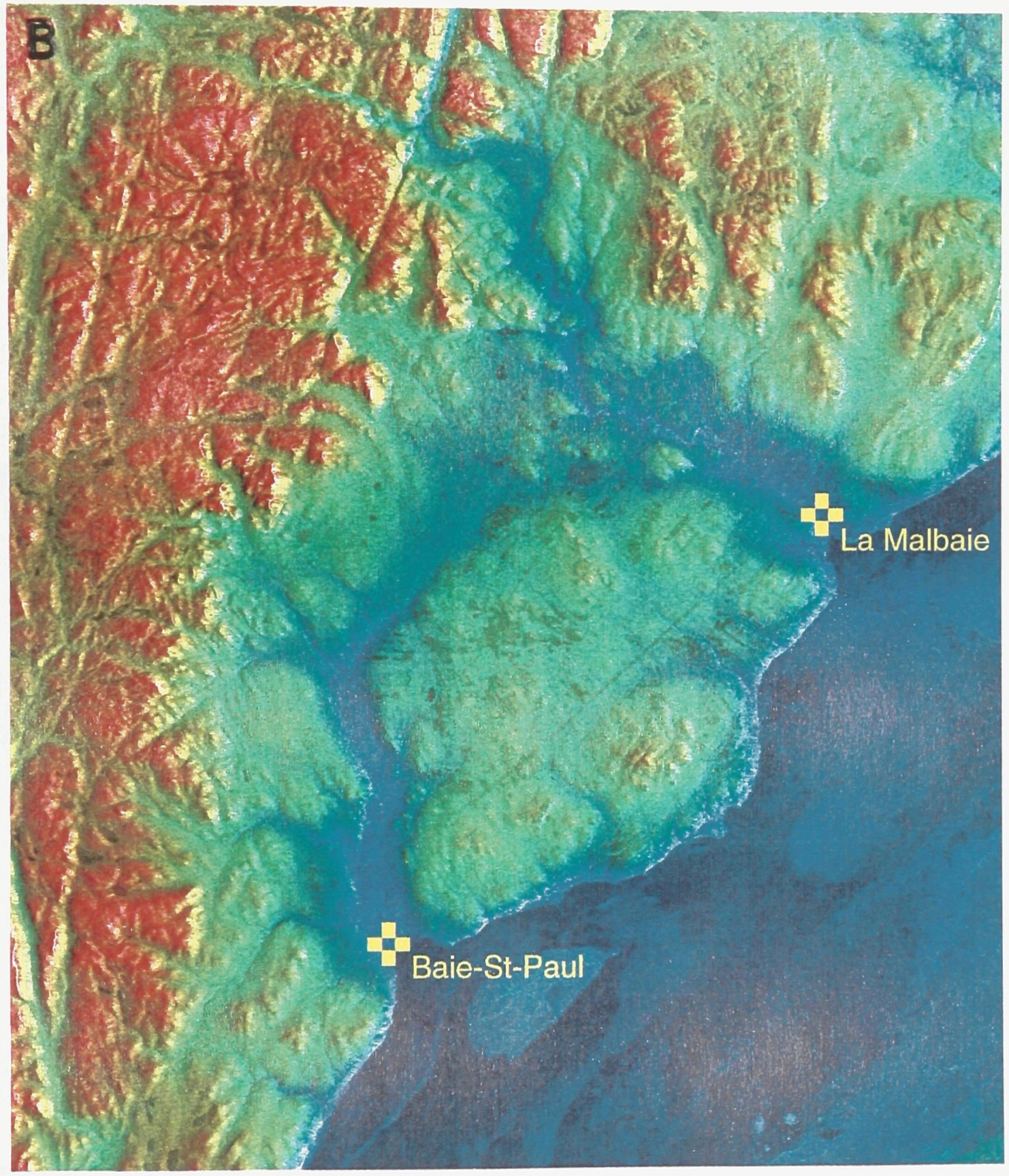




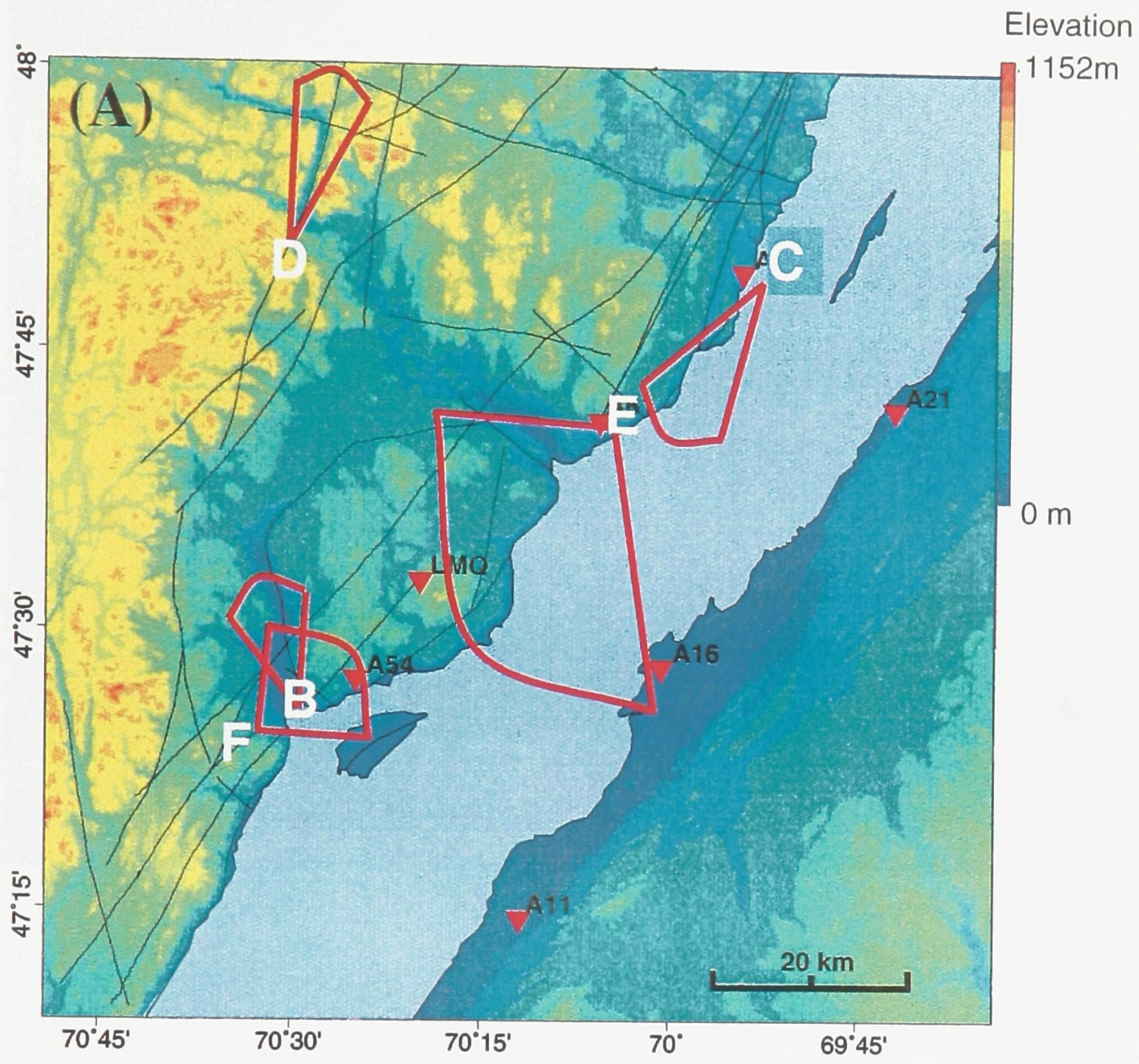

Figure 1.6 Scenery of the Charlevoix Seismic Zone. (A) Location map of the photos; (B) Gouffre River valley which represents a part of the peripheral graben of the impact structure; (C) Linear coastline of the north shore, created by normal faults; (D) The Malbaie River U-shaped valley, created by a fault and deeply eroded by glaciers; (E) View of the impact structure from La Malbaie and of its central peak, the Mont des Eboulements; (F) View of the impact structure from Baie-St-Paul. Ile-aux-Coudres to the left belongs to the Appalachian nappes. 


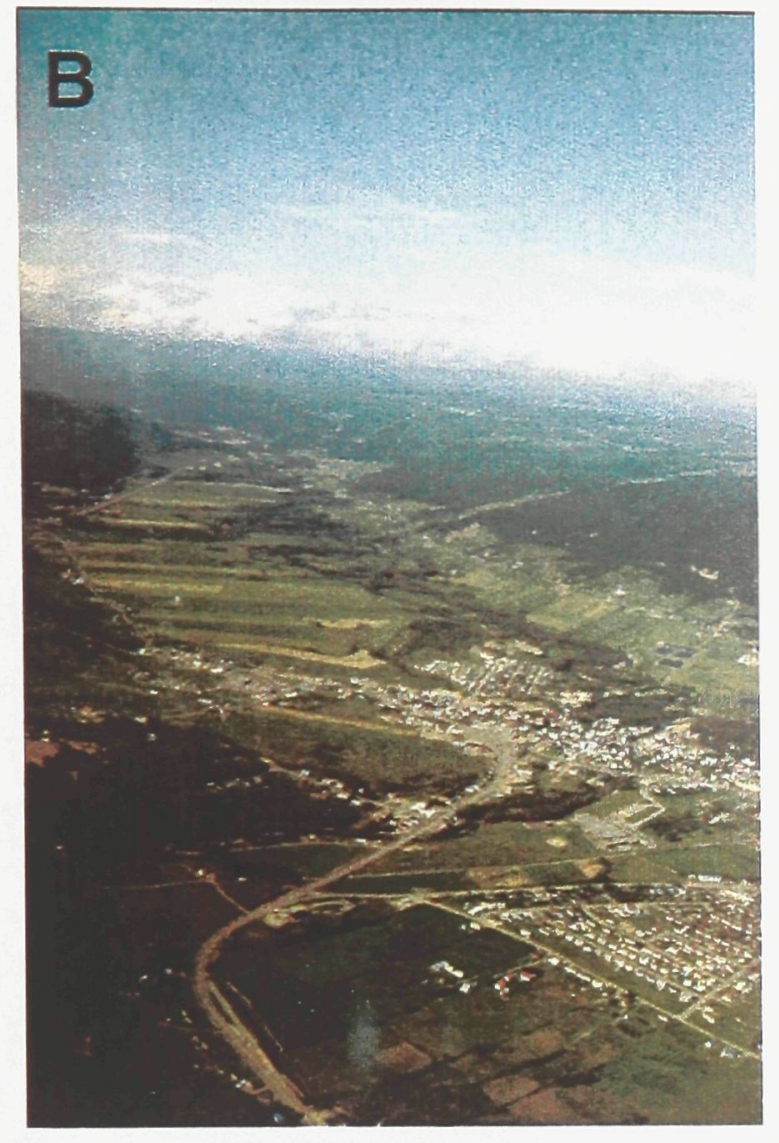

\section{C}

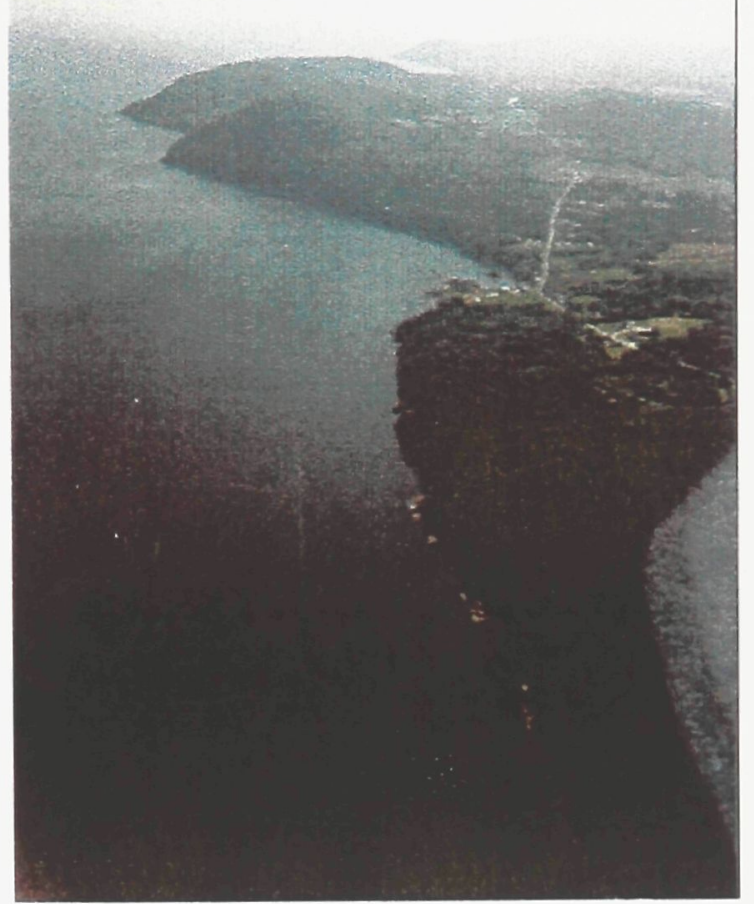

D

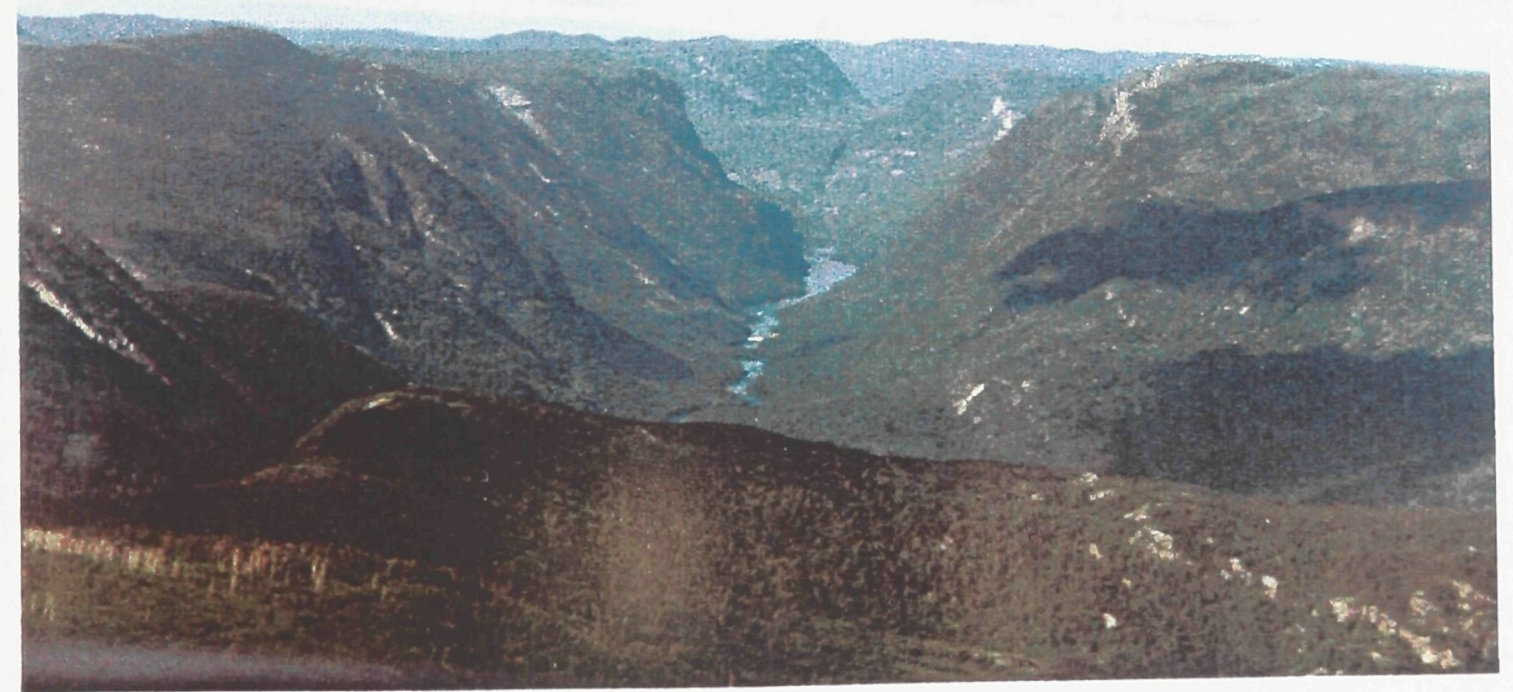



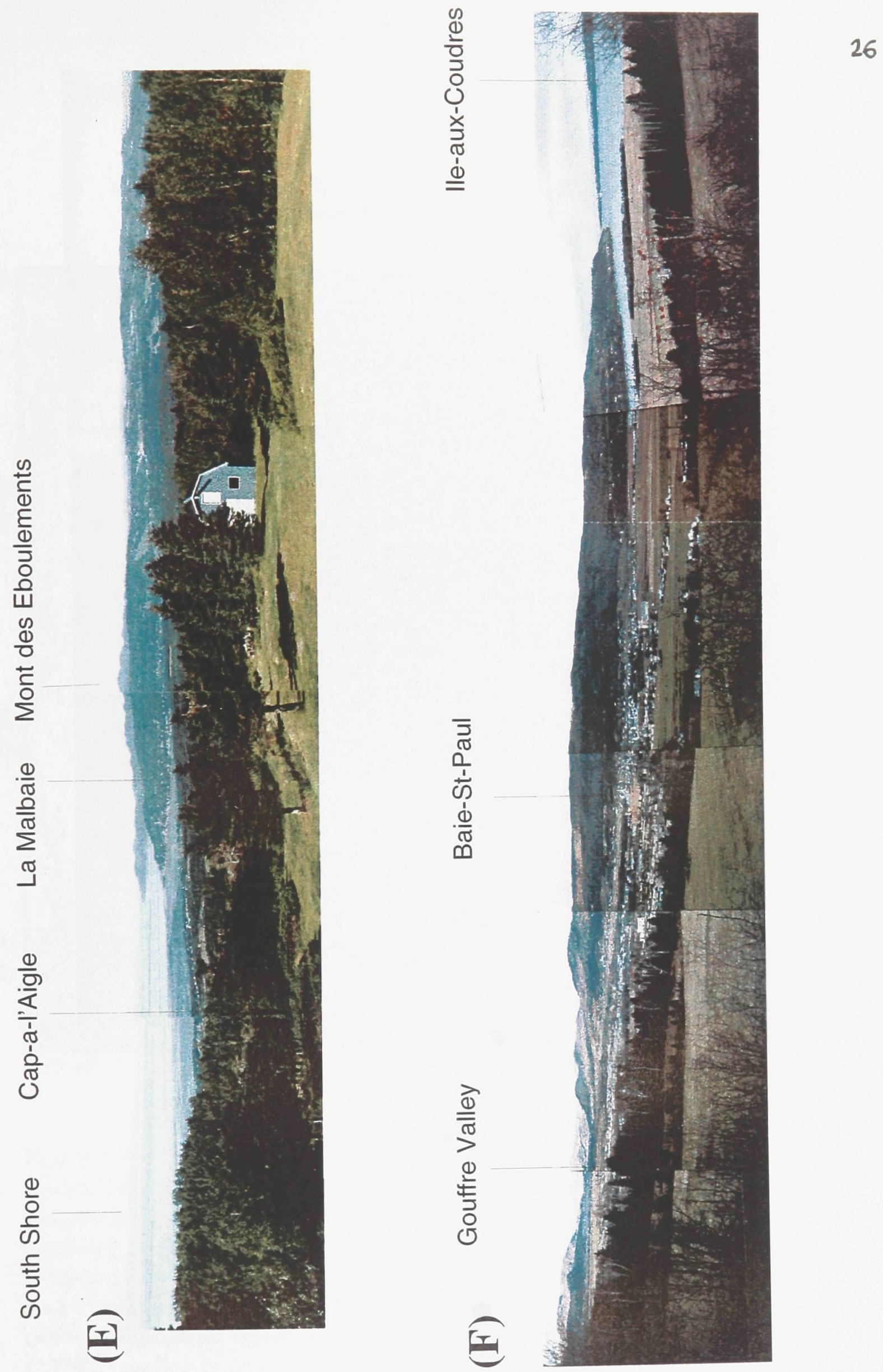


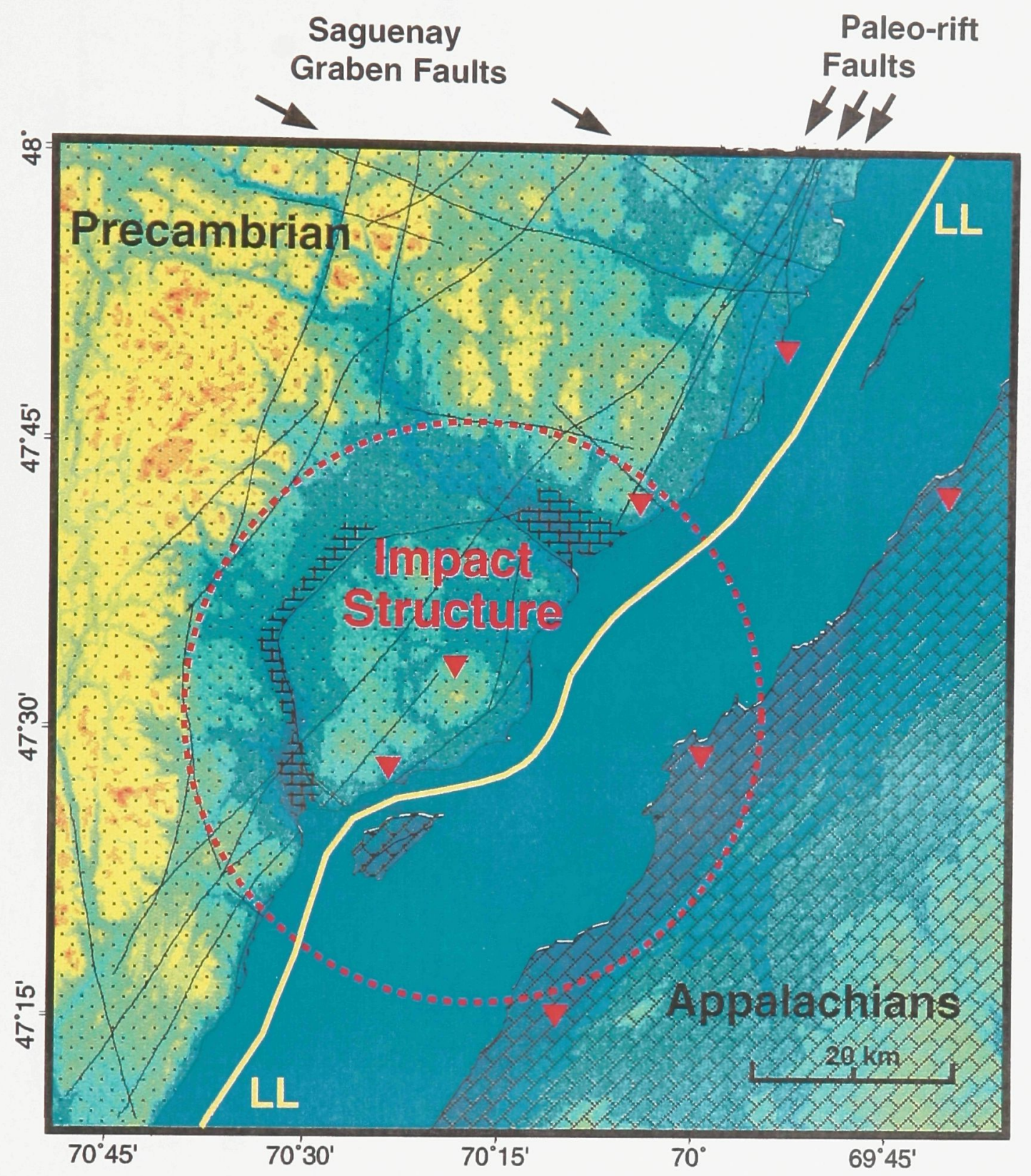

Figure 1.7 Main geological features of the CSZ overlaying the elevation model. Tectonostratigraphic units are grouped as Precambrian units (dotted), Ordovician sedimentary rocks (bricks) and Appalachian rocks (slanted bricks). Logan's Line (LL) represents a structural discontinuity between the complexly deformed rocks to the southeast (the Appalachian nappes) and the rocks to the northwest (the Canadian Shield with its Ordovician sedimentary cover). Major fault positions (black lines) of the north shore are from Rondot (1979). 


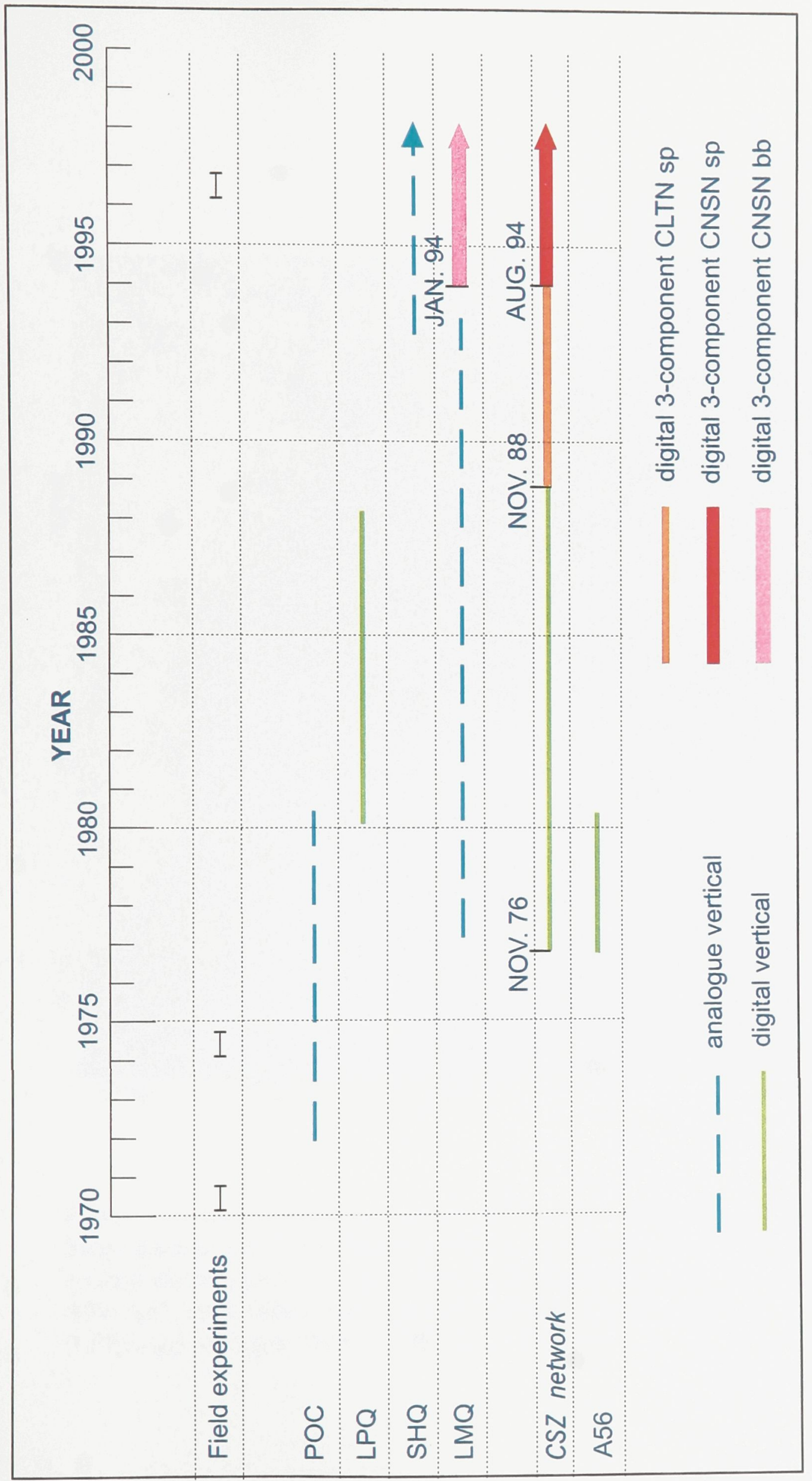

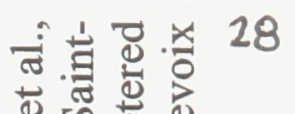
屯 첨 戛 踏正

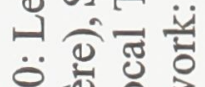

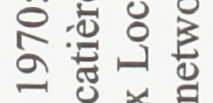

$\exists \circ$.

i

迅光

븡므뭄

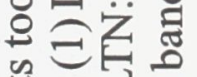

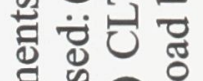

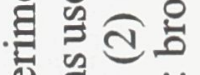

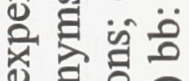

응 을

近导要

ษ $\dot{2}$ 을

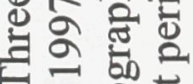

元最

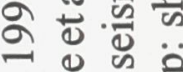

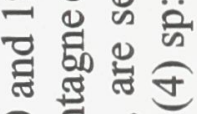

응혀월

ี.

过专乙

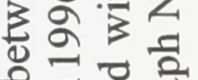

园 윰

牙䒕

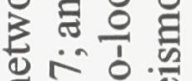

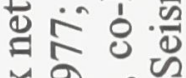

.

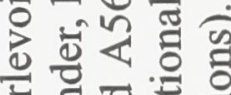
息可产

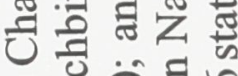
0

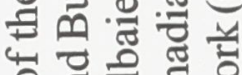
뜽 음 施记 우ㅇㅝㅡ 包已出

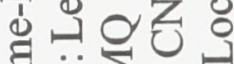
ヨ汸向 ศก็凹。 $\infty$ 을

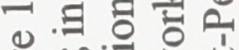
m 的合清艺 
Elevation

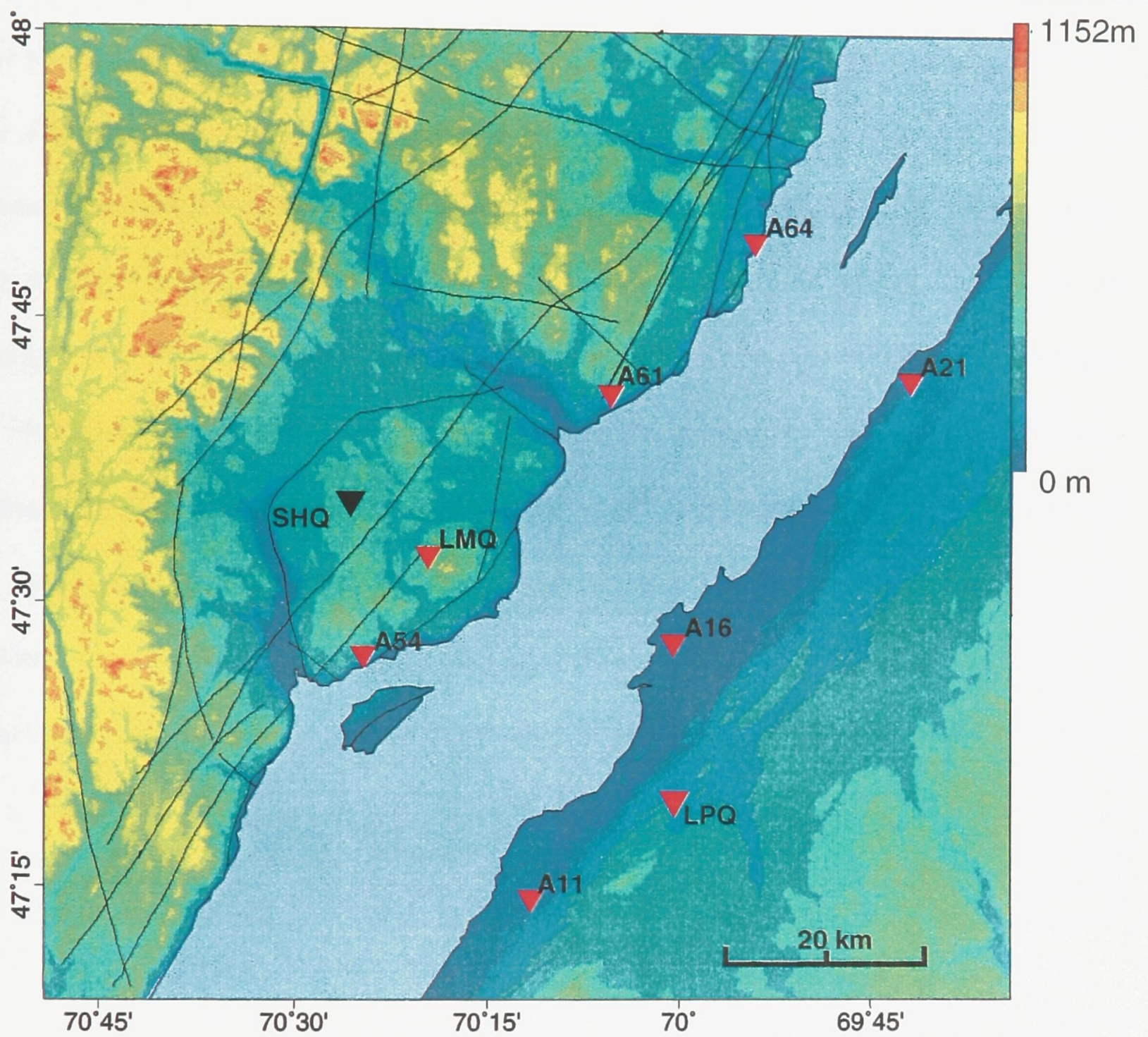

Figure 1.9 Location of the permanent seismograph stations in the CSZ. Some stations were relocated over the first few years, without changing the general distribution of stations. Since 1985, the stations are: A11, A16, A21, A54, A61, A64. Other stations are: broadband (LMQ); digital short-period (LPQ); and analogue (POC; LMQ until 1993, SHQ). 
Figure 1.10 Examples of how arrival times have been picked over the years. Traces of the 19840214 09:01 $\mathrm{m}_{\mathrm{N}} 2.5$ event from which $\mathrm{Pg}$ and $\mathrm{Sg}$ phases were picked during the period October 1977 to November 1988. (A) High gain display. The top and bottom X axes are second marks. The six traces correspond to stations A10; A16; A20; A64; A54 and A61. Arrival times were measured by interpolating between the two vertical 10 second lines. Since only the vertical traces existed, $\mathrm{Pg}$ phases were generally more evident than the Sg phases. (B) Low gain display. Some Sg phases were picked on this plot. C) Example of a computer display used to pick Pg and Sg phases after 1993 (software "dan" by Nanometrix Inc). The icons (top) represent the various options to get, display or analyse data. The lower three traces are the three components of station A54 (Z: vertical; $\mathrm{N}$ : north-south; E: east-west). The time scale for these three traces can be seen at the bottom ( 40 seconds total). The top trace represents an enlarged view of 2 seconds of the trace A54..EHZ. Phases are picked in the zoom window, with adjustable X and Y scaling. 


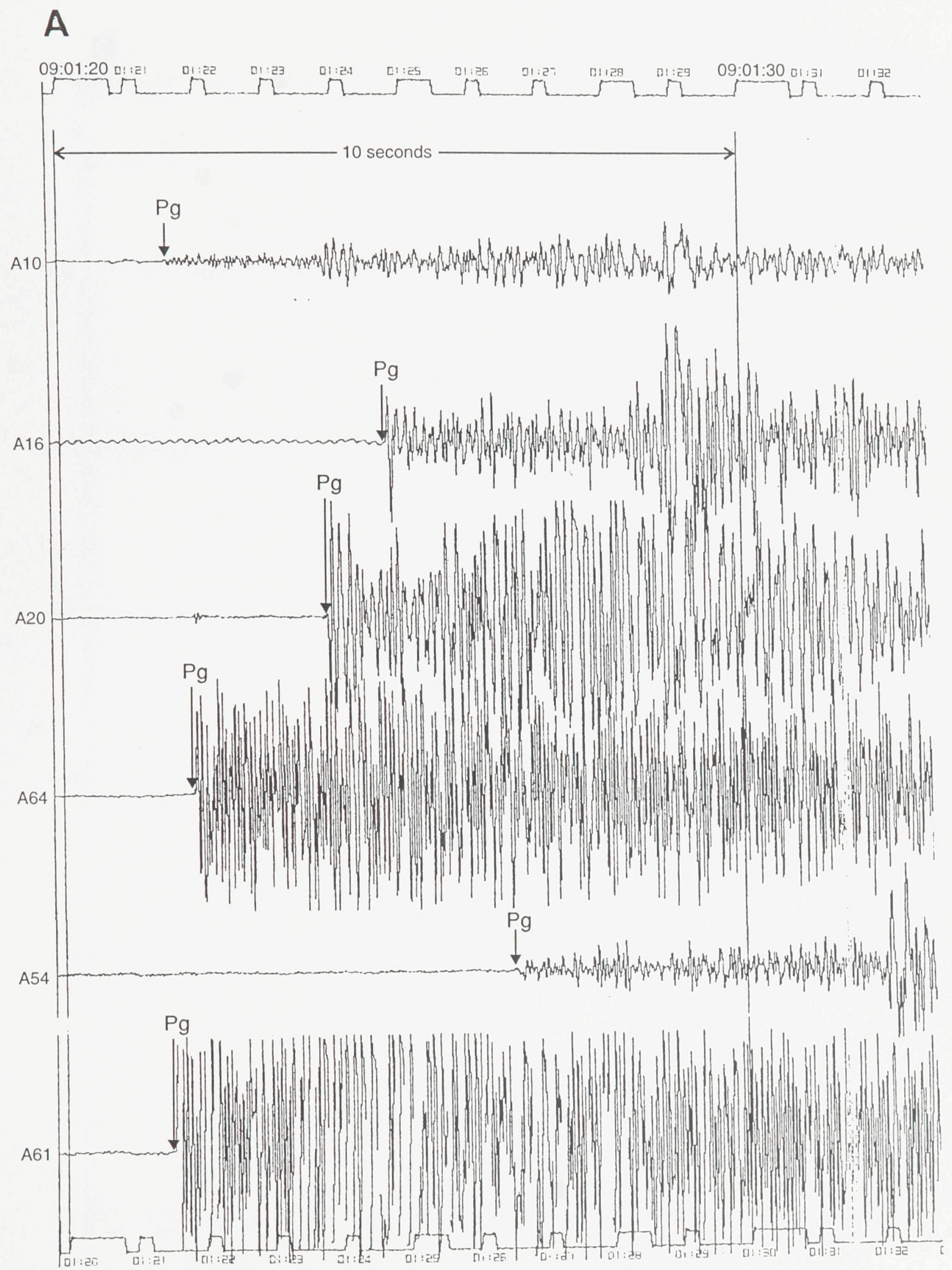




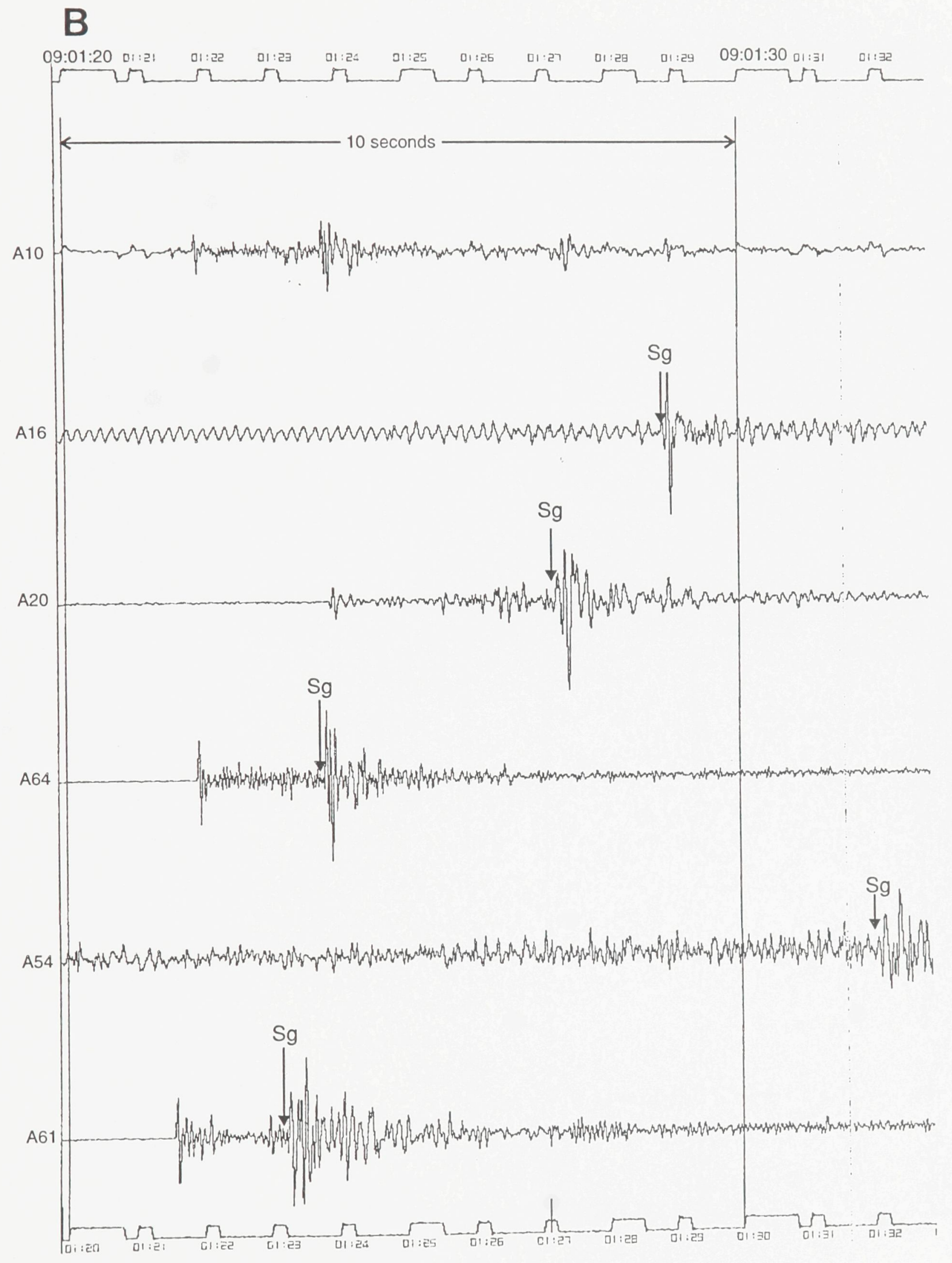




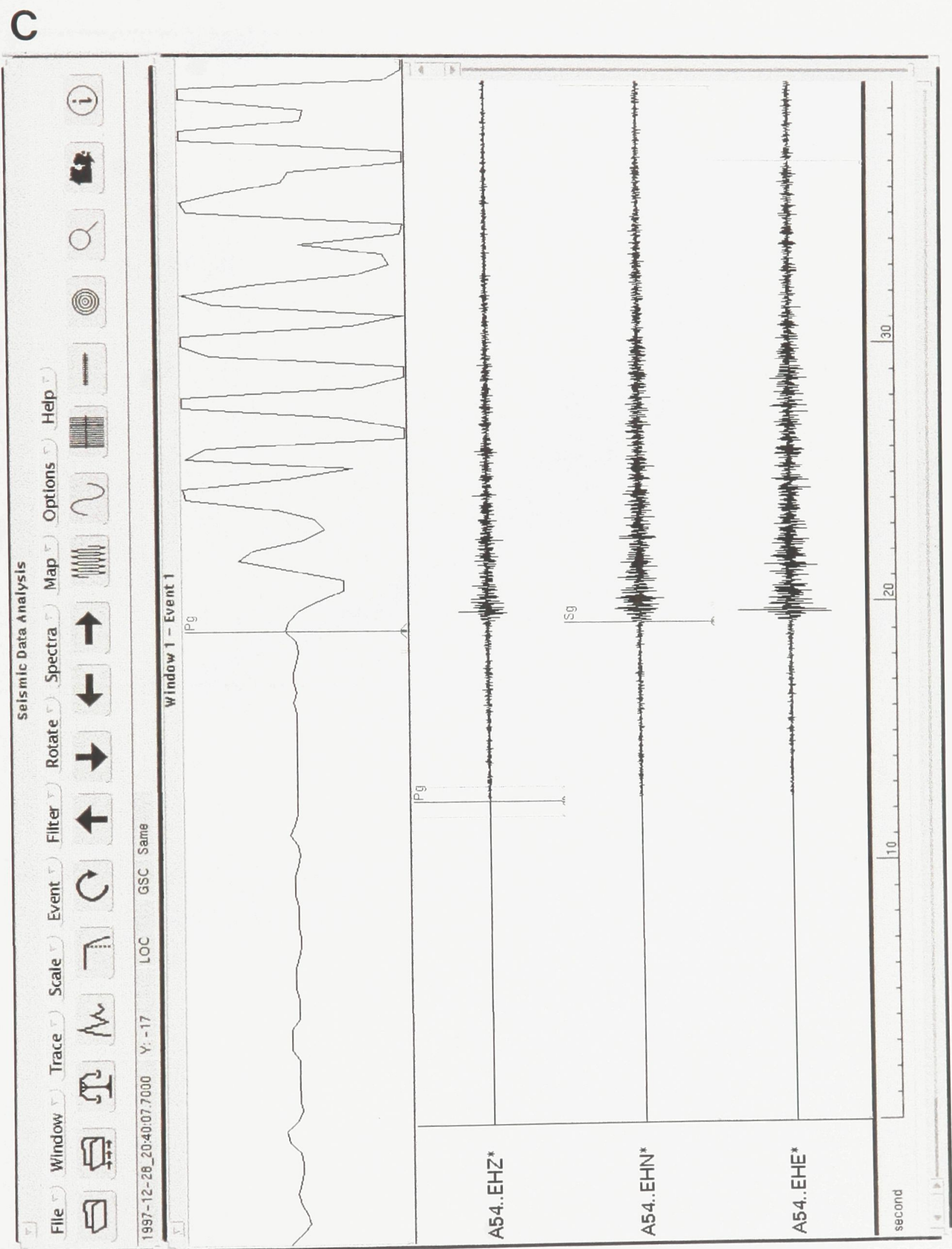




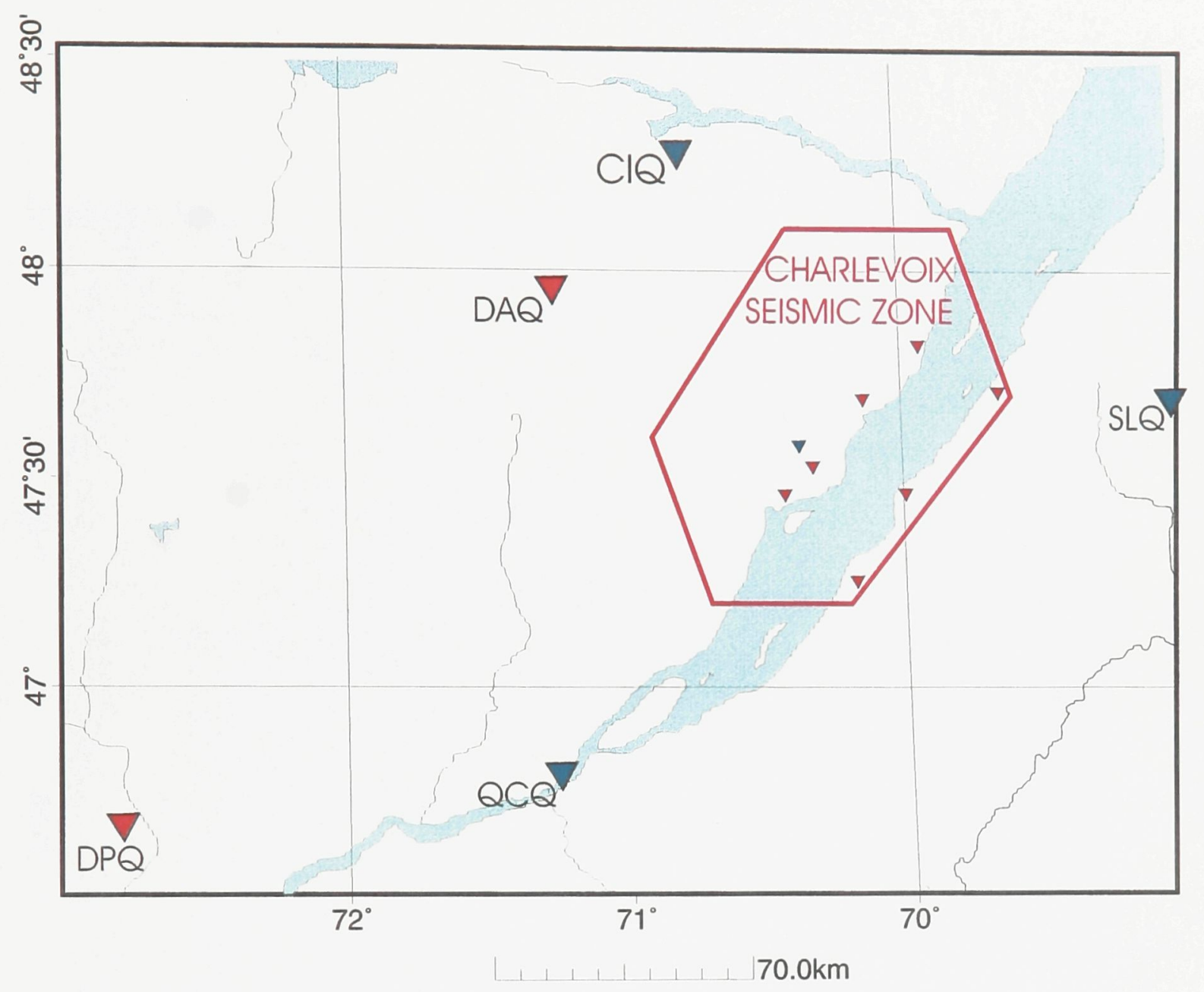

Figure 1.11 Regional stations surrounding the CSZ (triangles), digital (DPQ; DAQ) and analogue (CIQ; QCQ; SLQ). 
Elevation

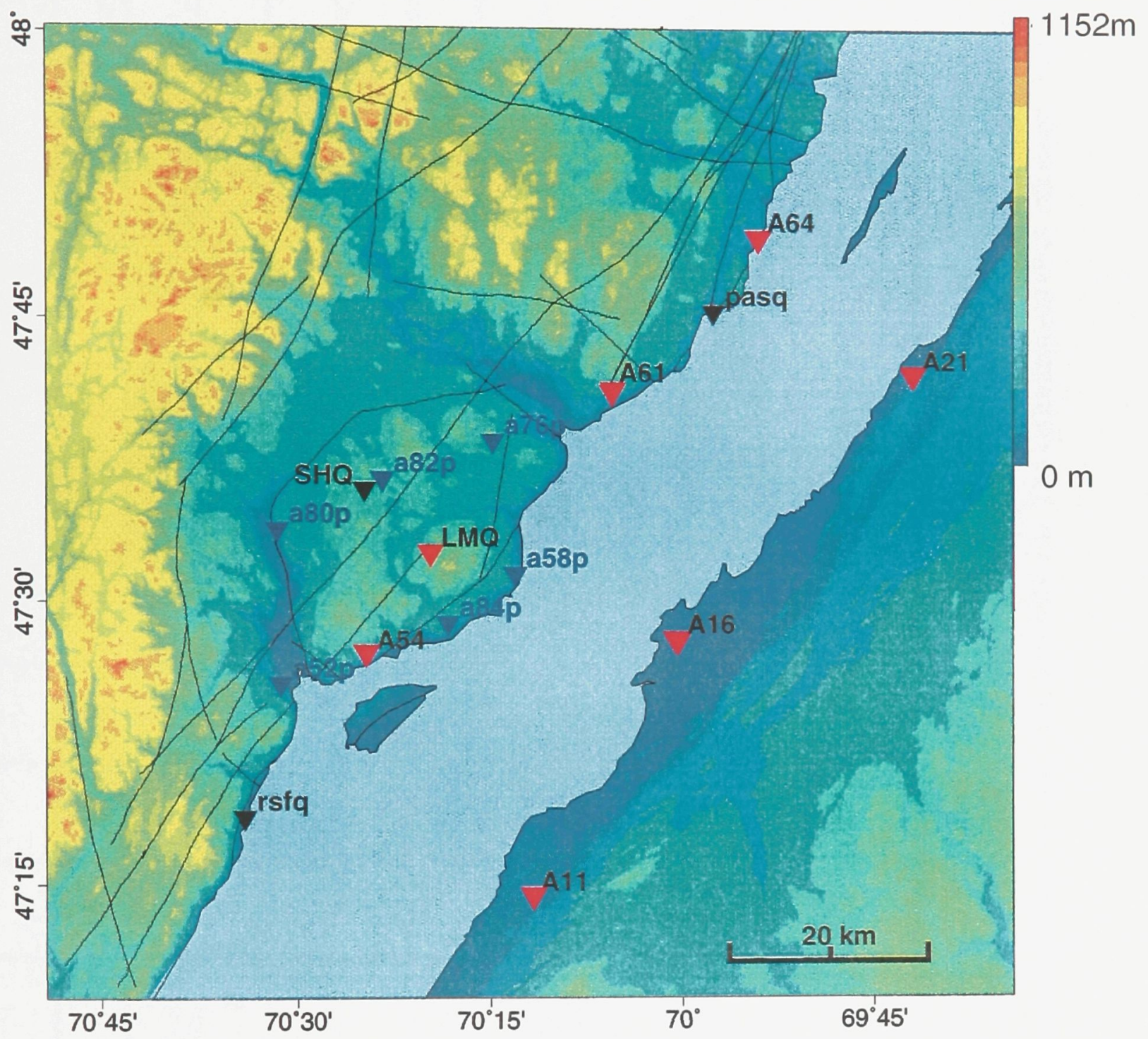

Figure 1.12 Seismograph stations in the CSZ (triangles) during the 1996 Summer field survey: permanent (red); digital portable (blue); analogue (black); Lamontagne et al., 1997). 


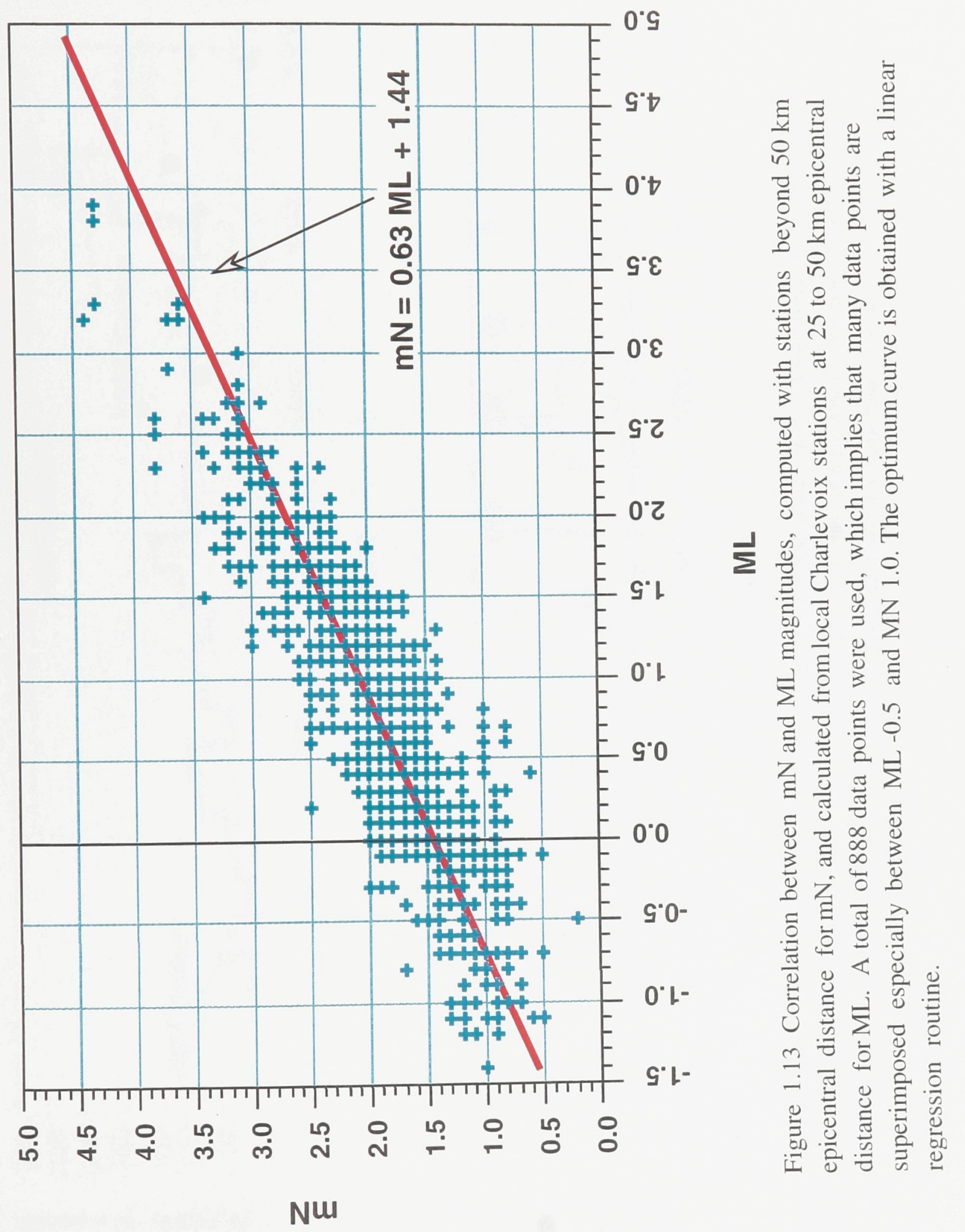




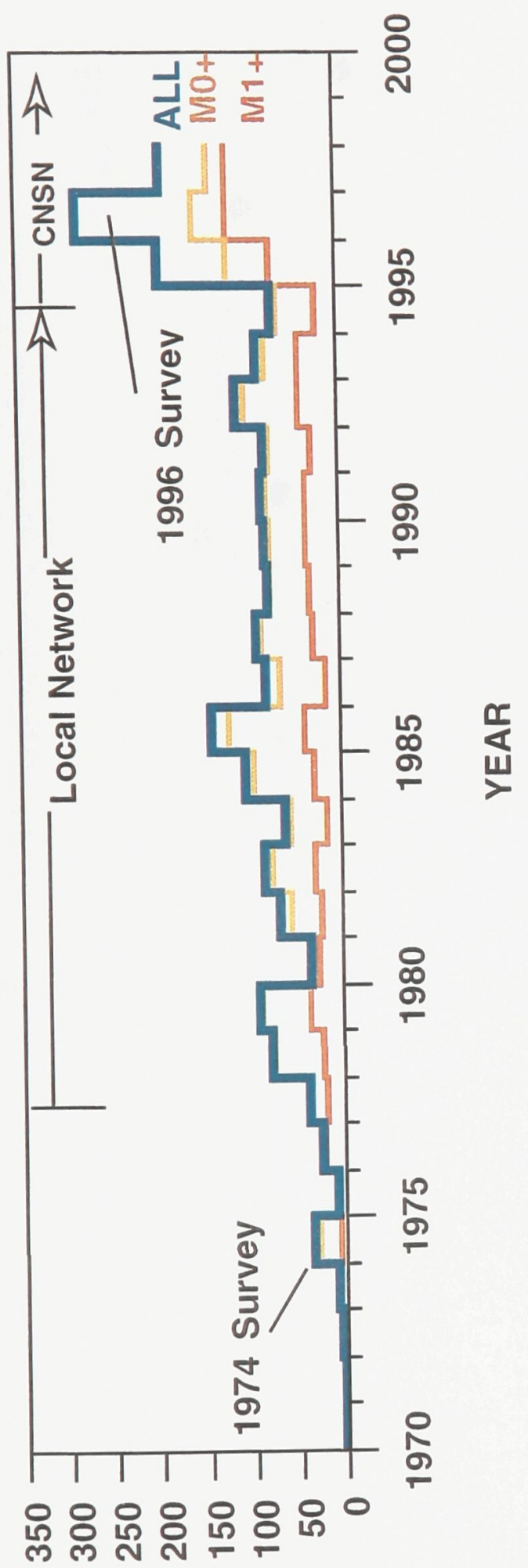

słuə^ə to ^əqunN

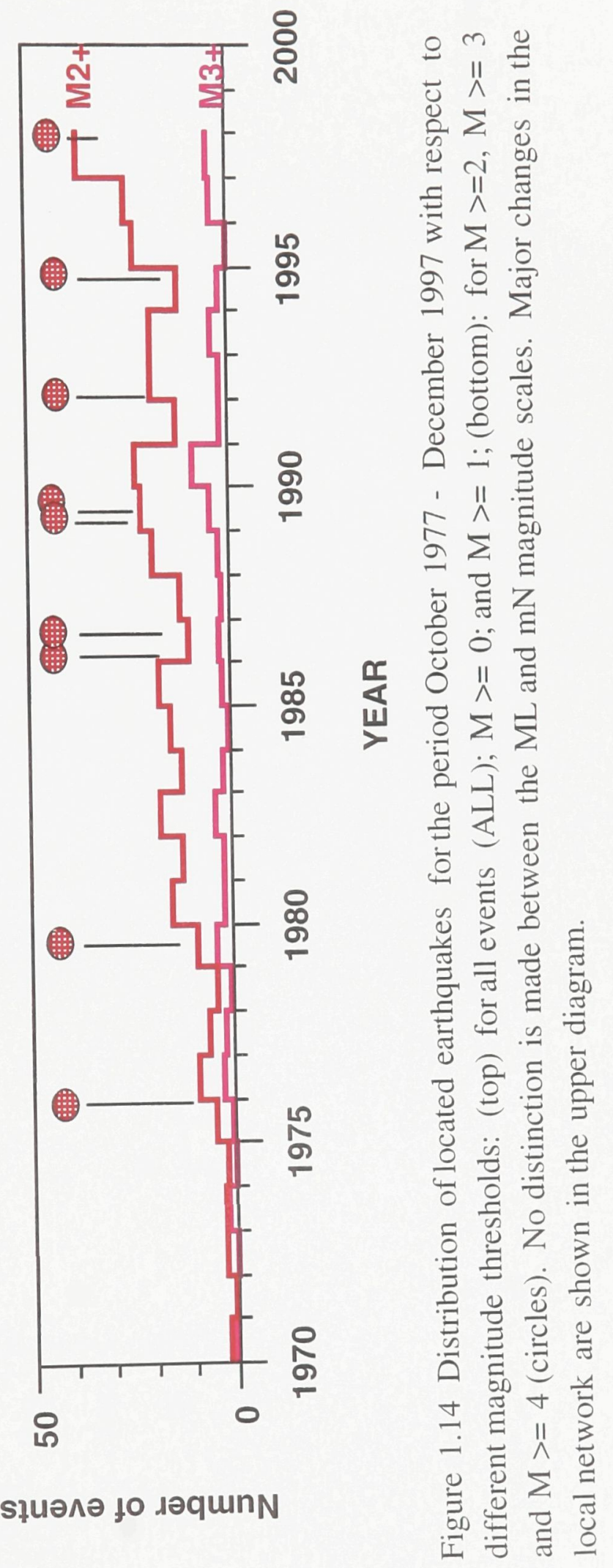




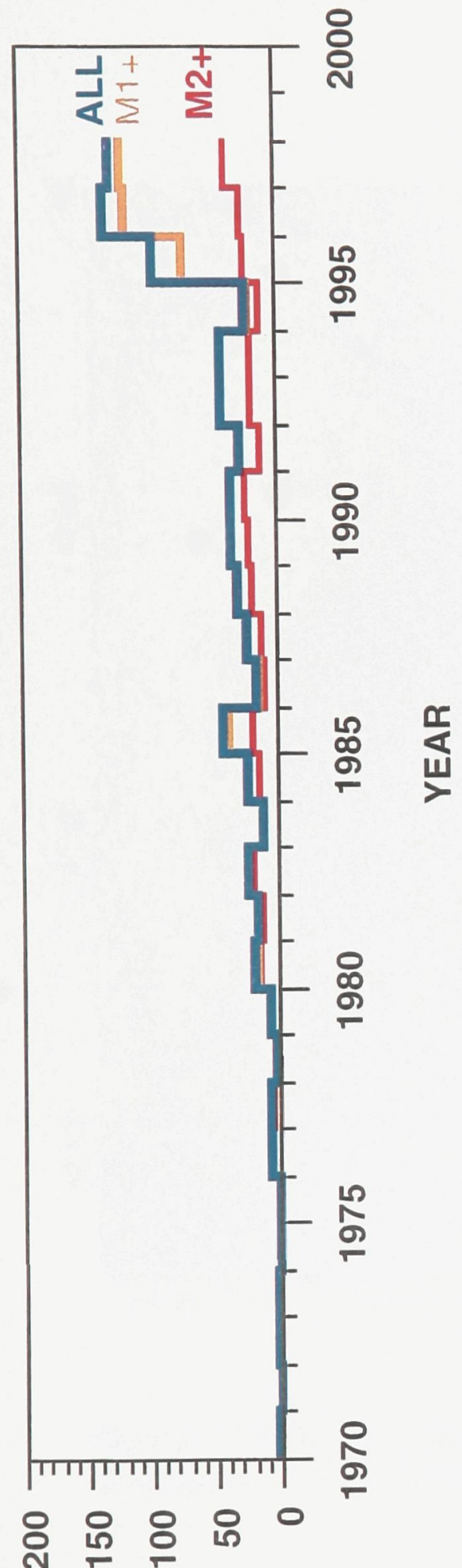

słuə^ə to ^əquinN

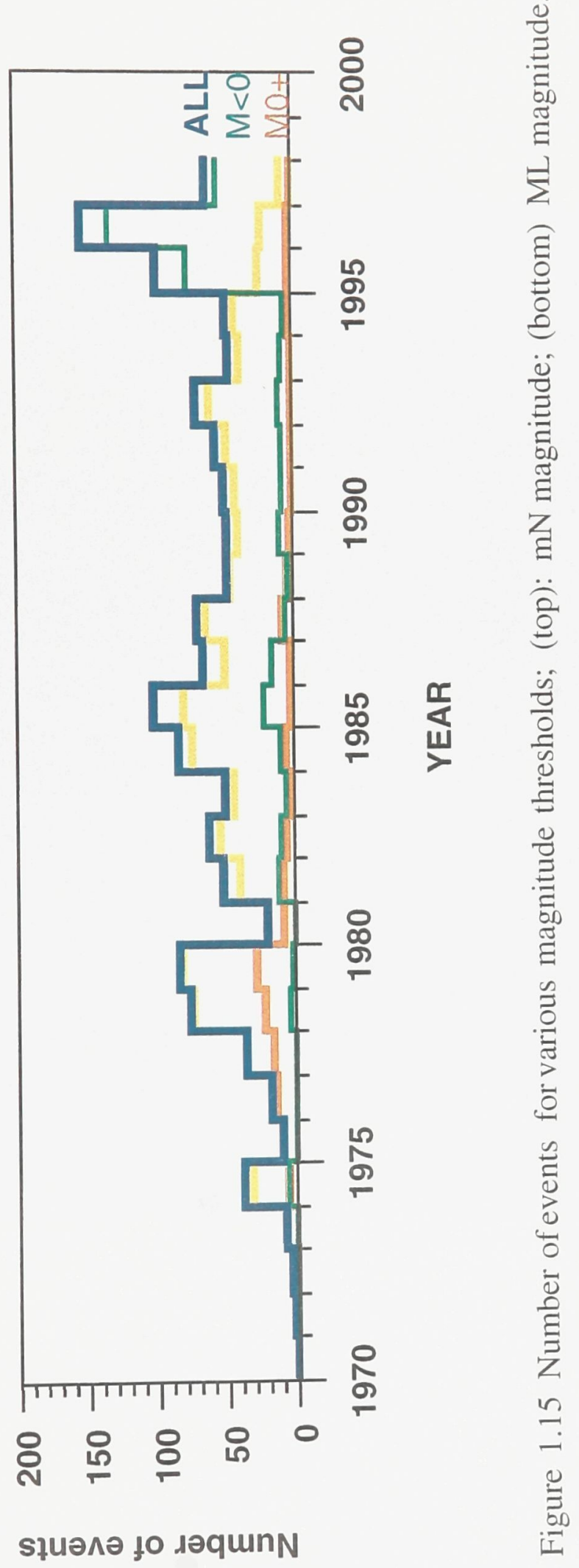




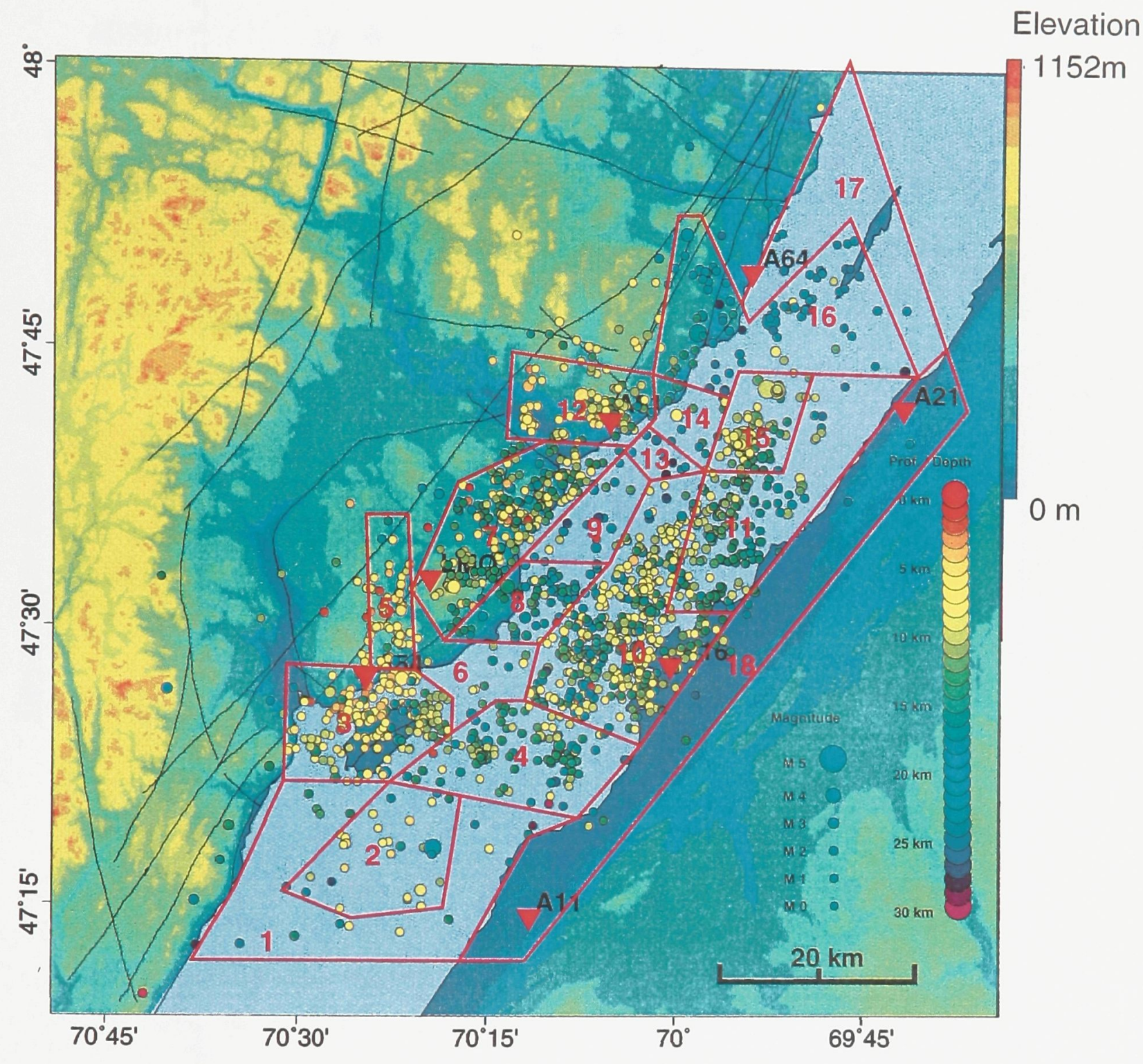

Figure 1.16 Sub-zones around earthquake clusters with similar depth distribution. These sub-zones are discussed in Chapter 4. 


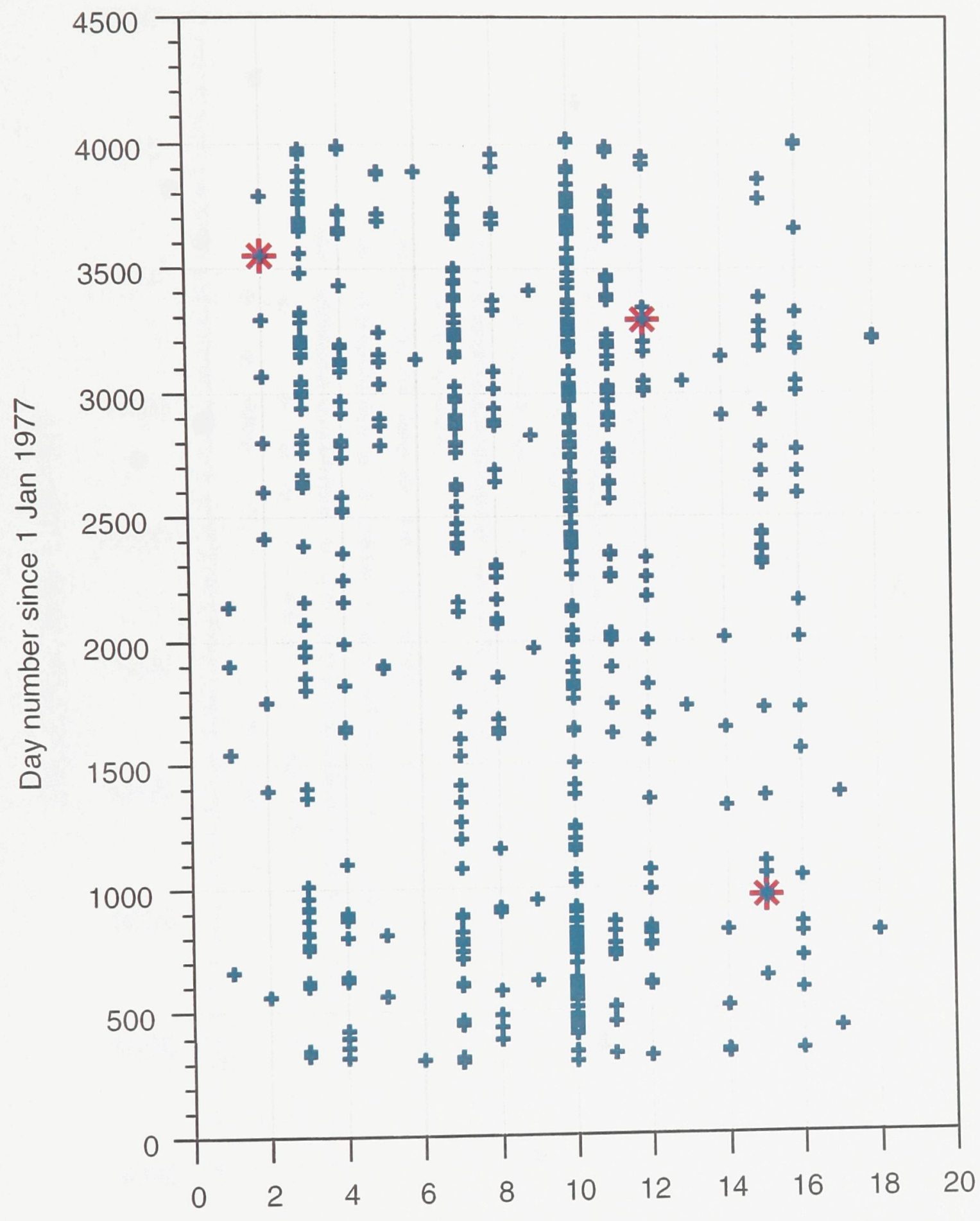

Subzone number

Figure 1.17 Time-history of the activity of the various sub-zones of Figure 1.16 fo (A) the period October 1977 - December 1987; (B) The period January 1988 December 1997. 


\section{B}

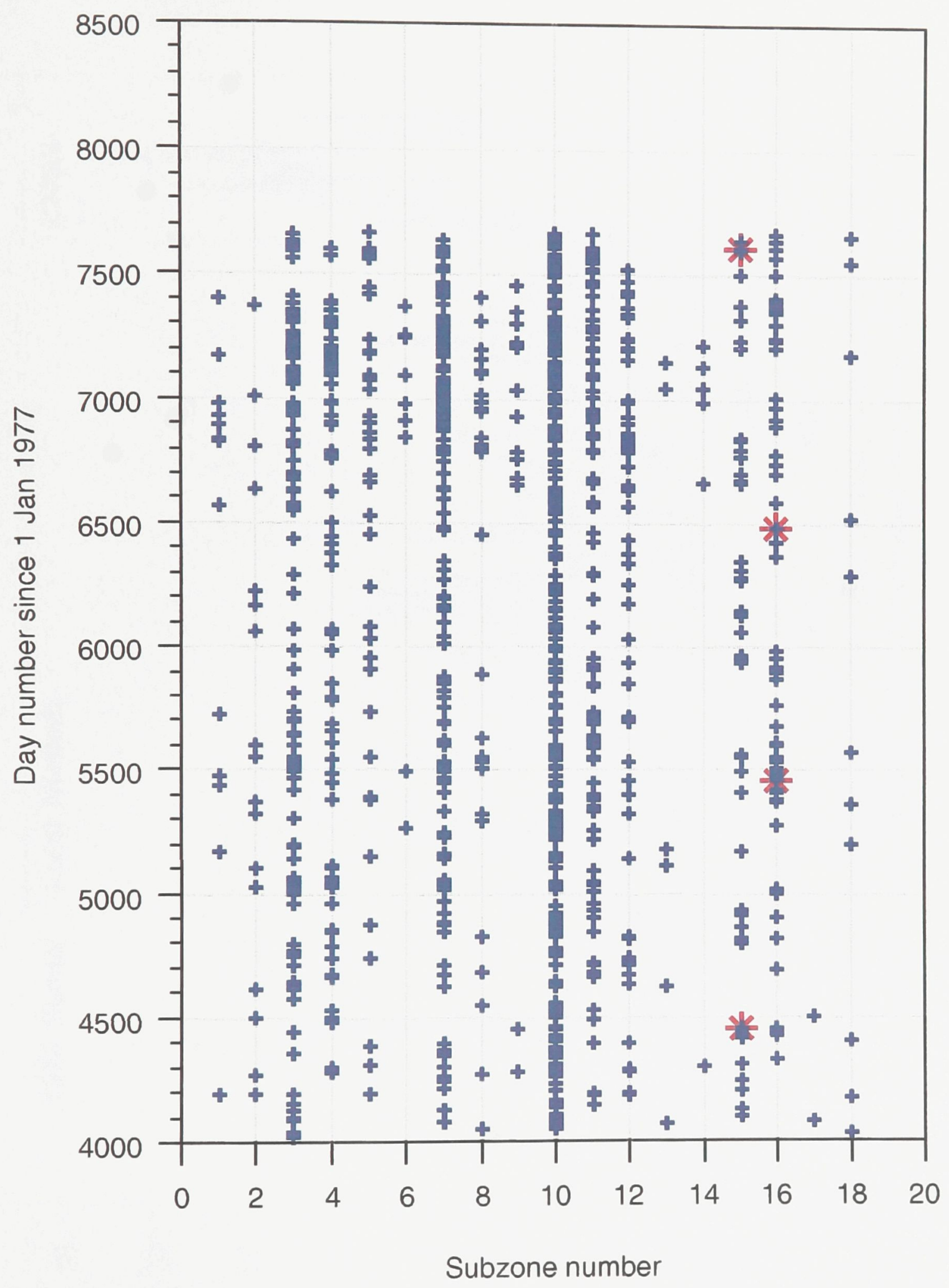

1988-1997 


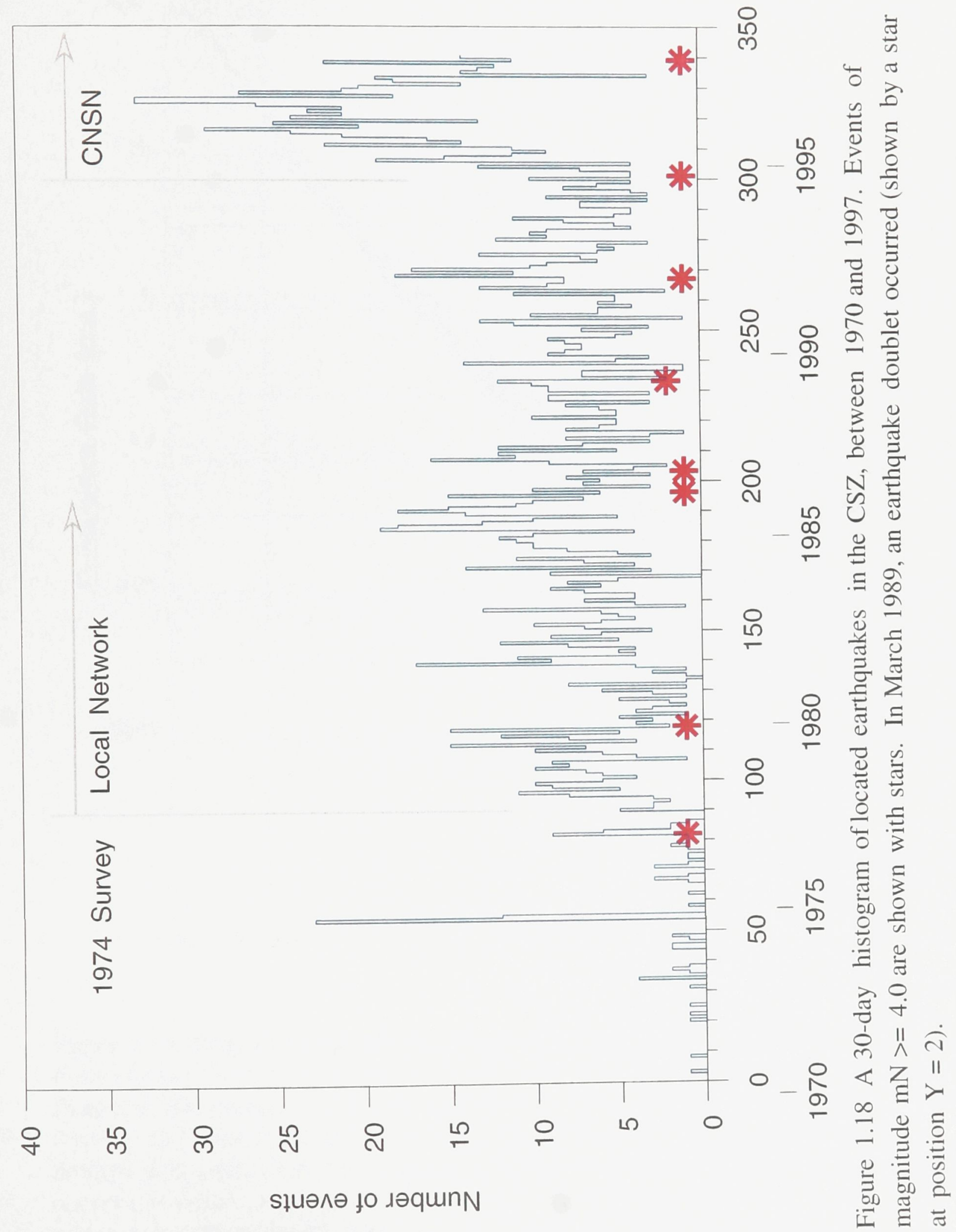




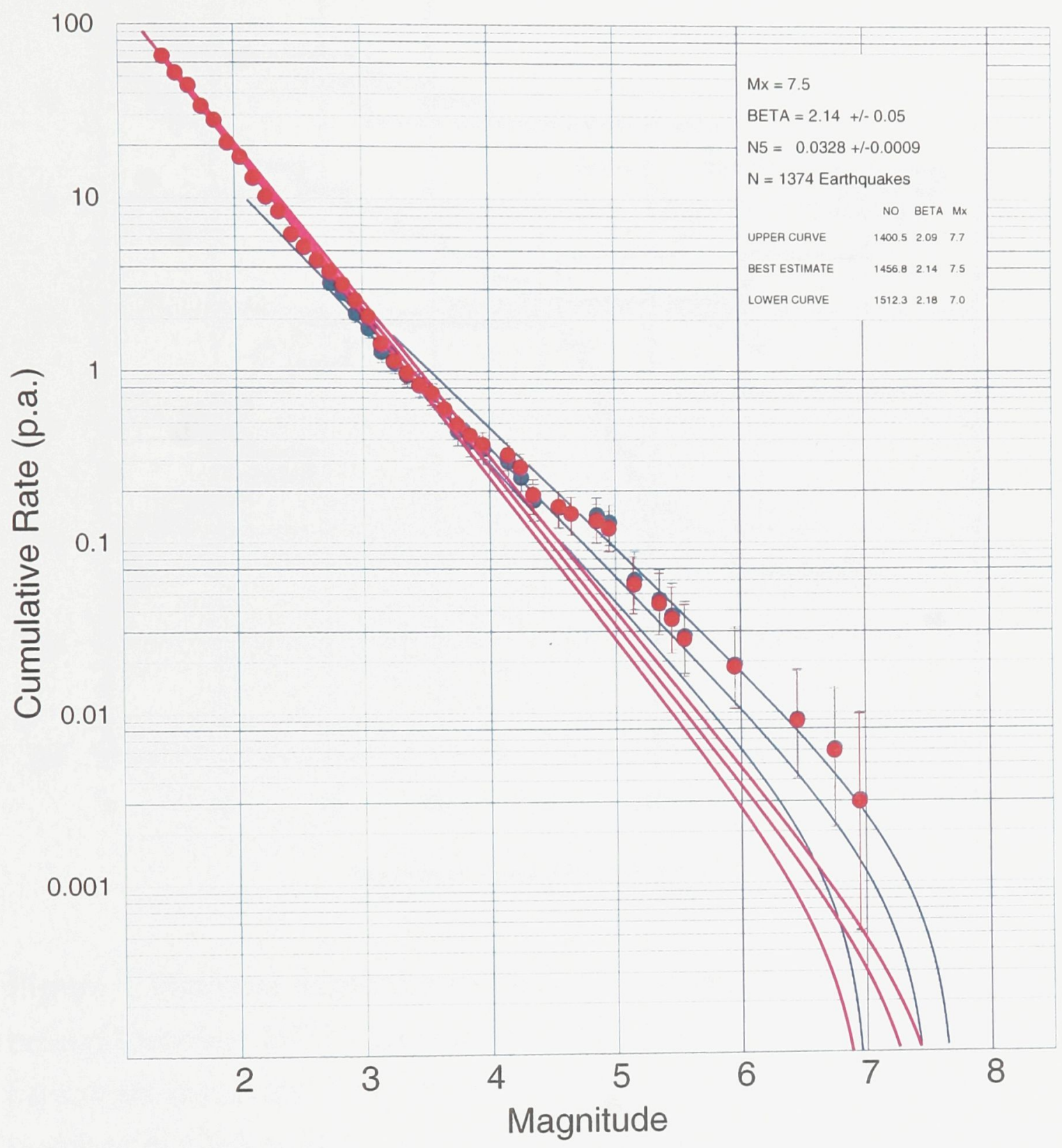

Figure 1.19 Magnitude-recurrence curves for the CSZ. Data points in blue are based on events before October 1977 that meet the magnitude completeness criteria of Table 1.1 (less than 300 points). Red dots represent the previous events, plus the events between October 1977 and December 1997 that meet the magnitude completeness criteria defined in Section 1.4.4. The blue and red curves represent the magnitude-recurrence curves (minimum, average and maximum) based on their respective data sets. In the upper right corner, the parameters of the recurrence curves in red are given: $\mathrm{Mx}$ : maximum magnitude; Beta: slope of the curve; N5: number of events at magnitude 5; $\mathrm{N}$ : total number of events; N0: number of events at magnitude 0 . 


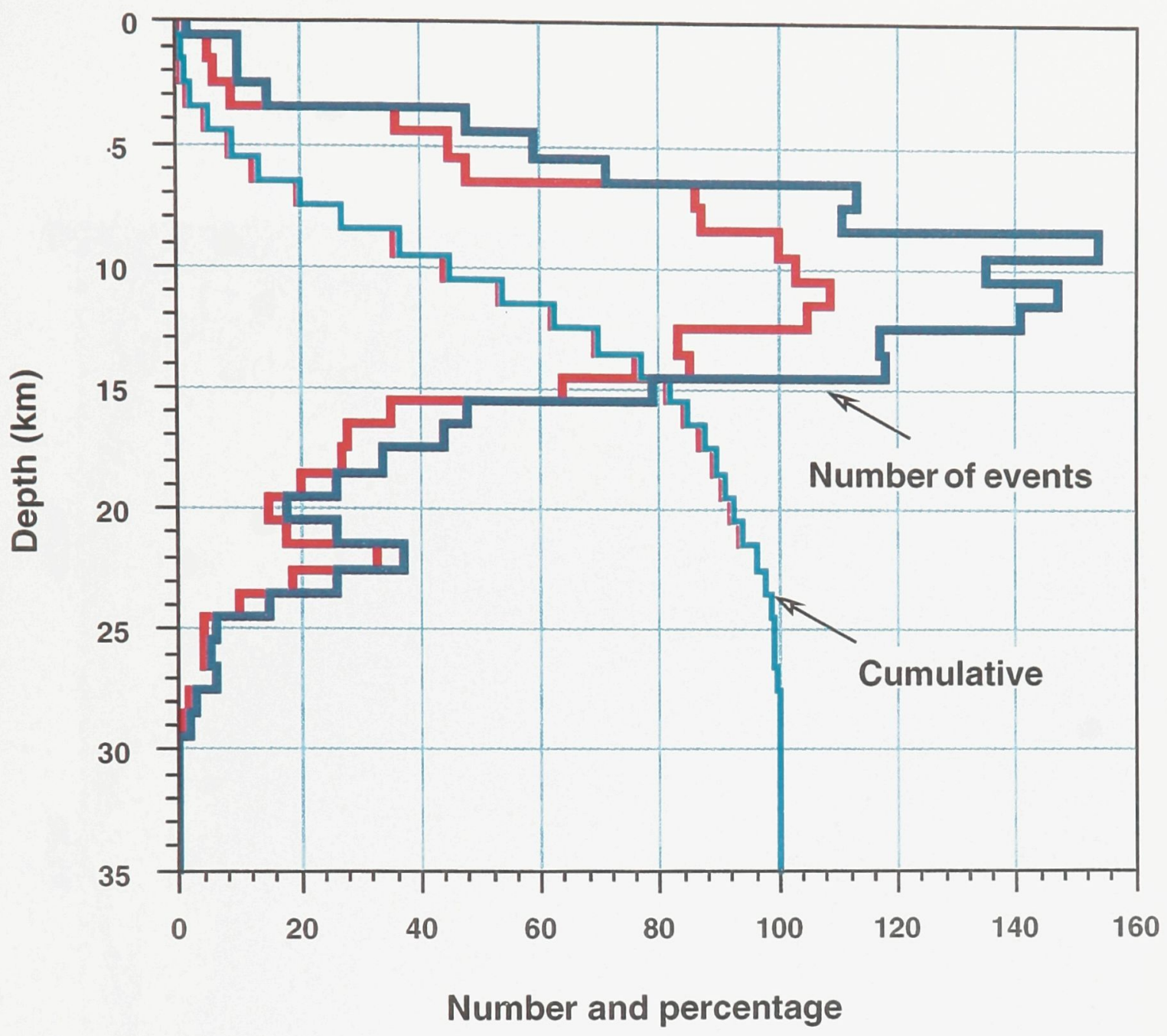

Figure 1.20 Focal depth distribution of the CSZ earthquakes for the period October 1977- December 1997. Events are grouped in one kilometre intervals. Two styles of curves are drawn:one for the number of earthquakes at a given depth and one for the cumulative percentage. Two data sets are plotted, allevents (blue) and events that met the magnitude completeness criteria (red). 
Elevation

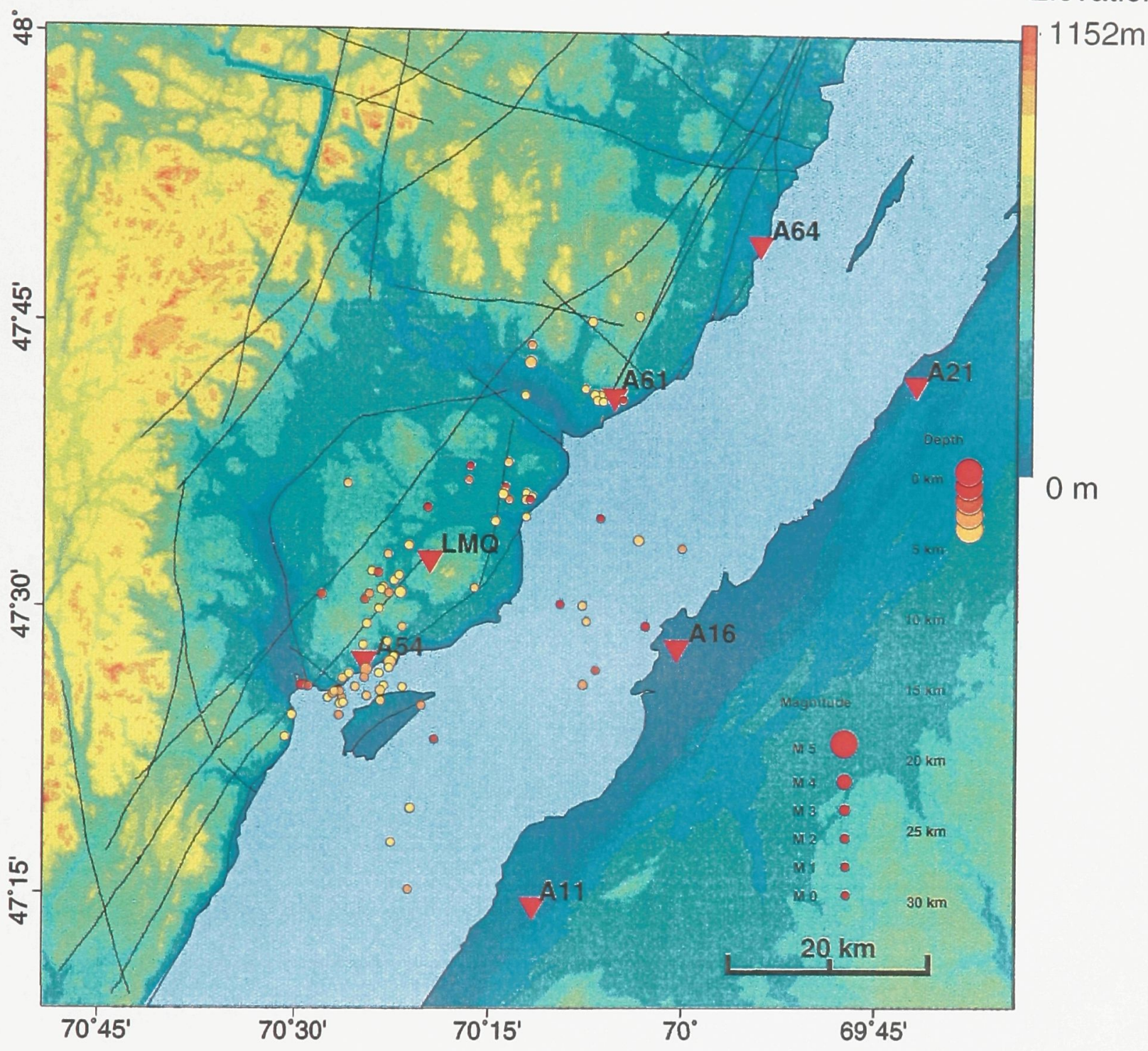

Figure 1.21 CSZ hypocentres and stations (circles and triangles respectively) plotted on an elevation map of the CSZ: (A) 0 to $5 \mathrm{~km}$ focal depth; (B) 5 to $10 \mathrm{~km}$ depth; (C) 10 to $15 \mathrm{~km}$ depth; (D) 15 to $20 \mathrm{~km}$ depth; (E) deeper than $20 \mathrm{~km}$. Circle colours represent the focal depth of the events. 


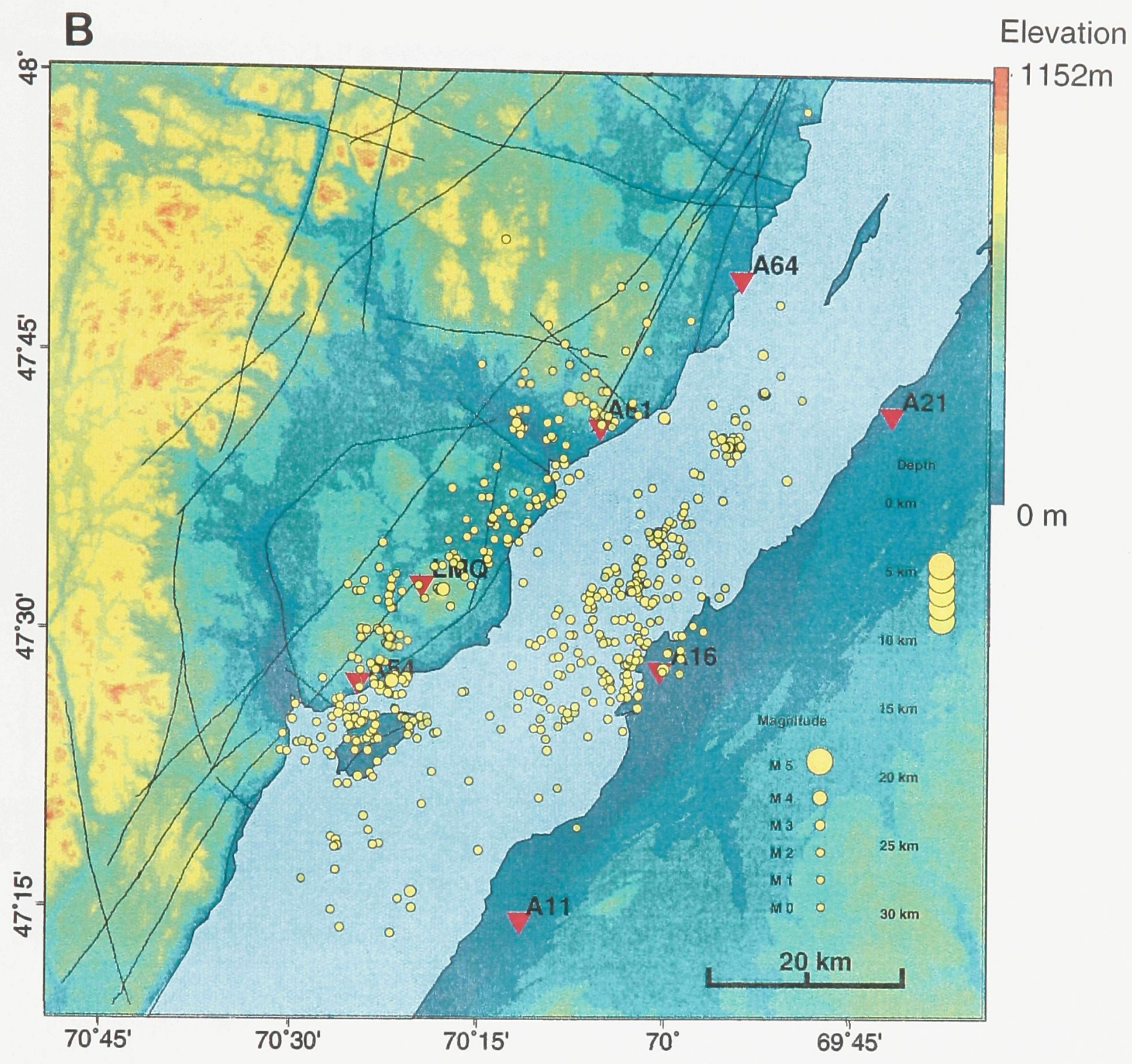




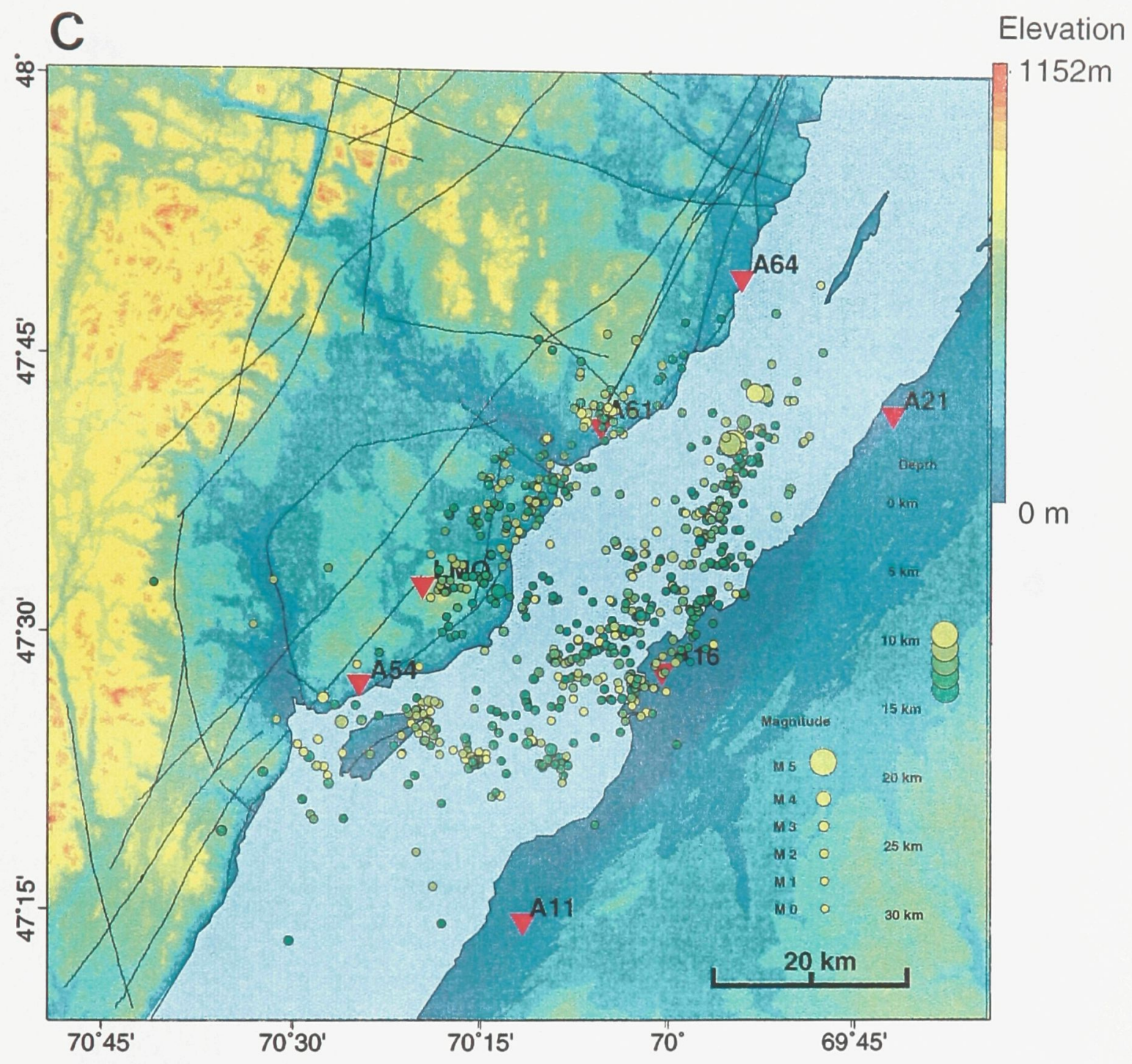




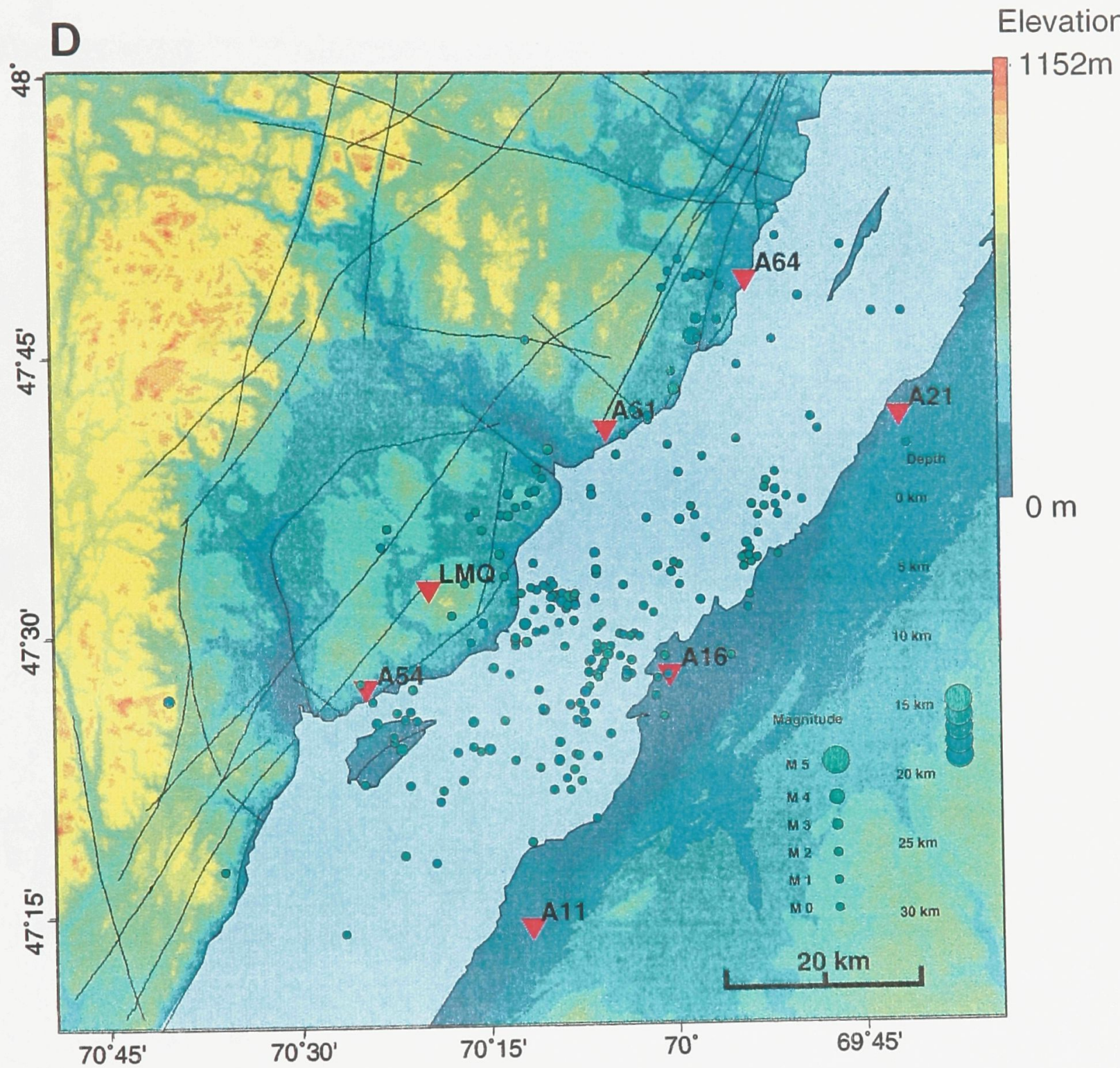




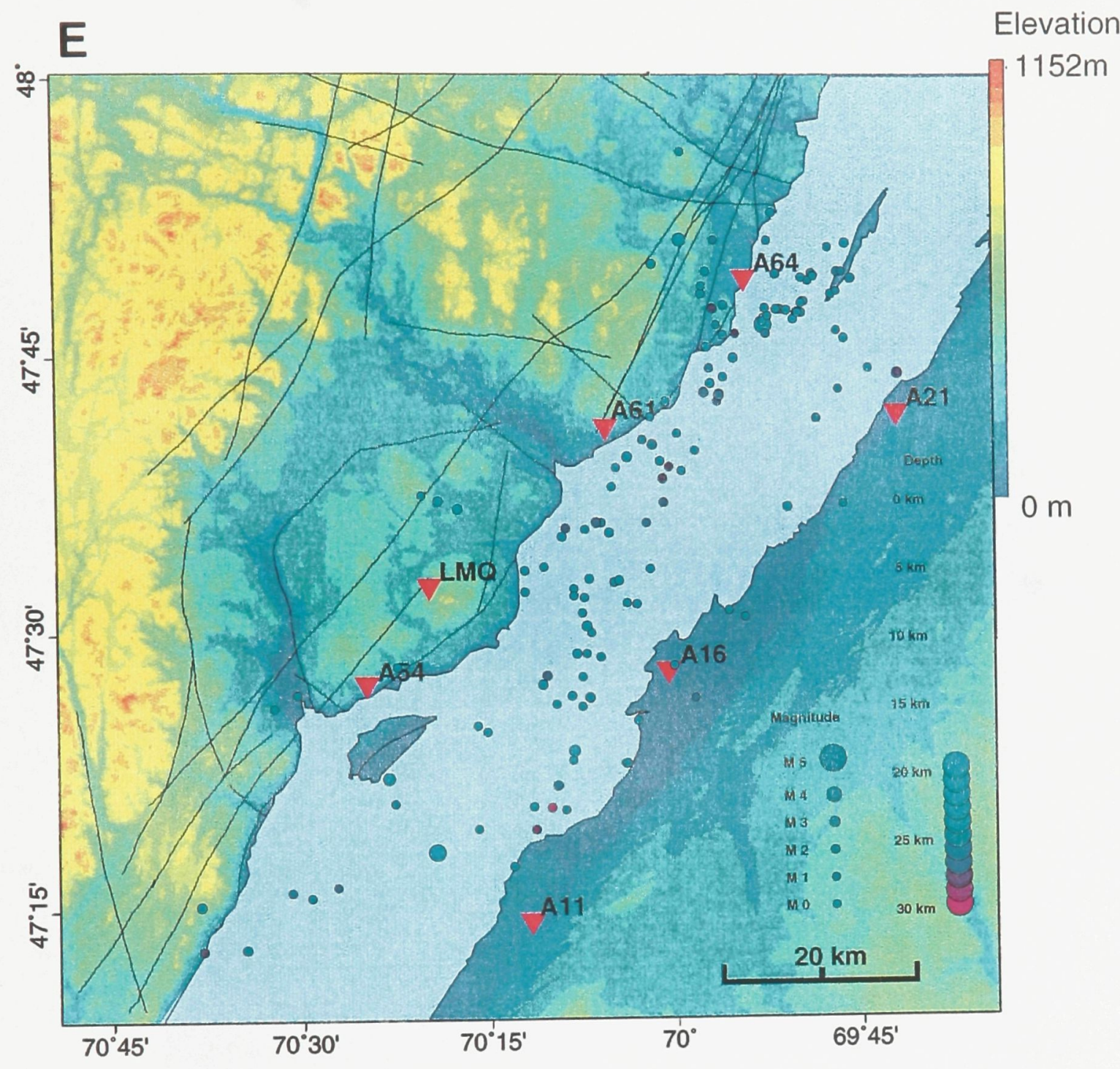




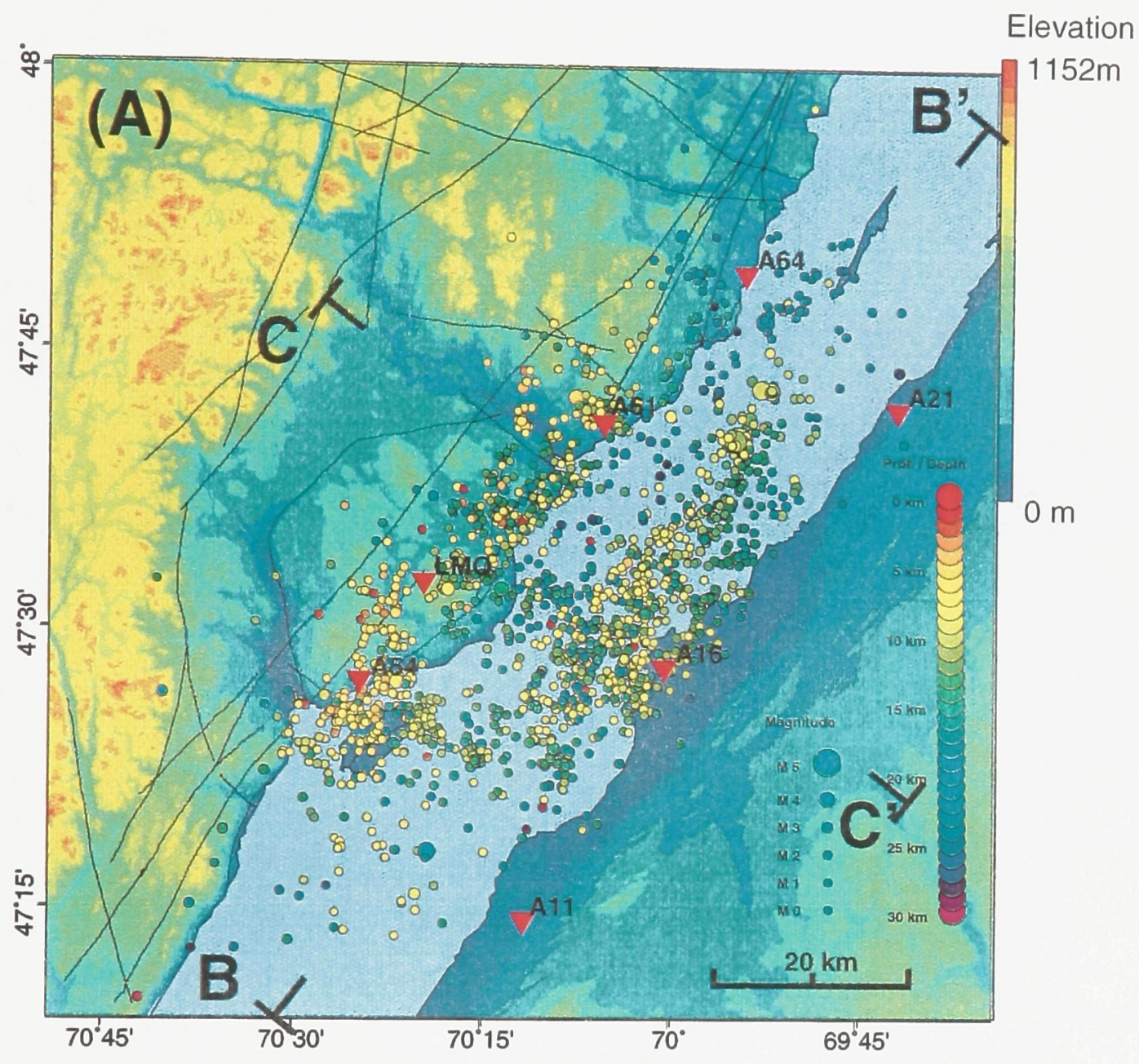

Figure 1.22 CSZ hypocentres: (A) Hypocentres (circles) and stations (triangles) with the end points of the two cross-sections B-B' and CC' plotted on an elevation map of the CSZ; (B) Projection of all hypocentres on a vertical cross-section perpendicular to the St. Lawrence River. The width of the active zones may represent the volume where fractures are reactivated as well as variations of fault trends. Red circles are the magnitude $\geq 4.0$ earthquakes; $(C)$ Projection of all hypocentres on a vertical plane parallel to the St. Lawrence River. Red circles are the magnitude $\geq 4.0$ earthquakes. 


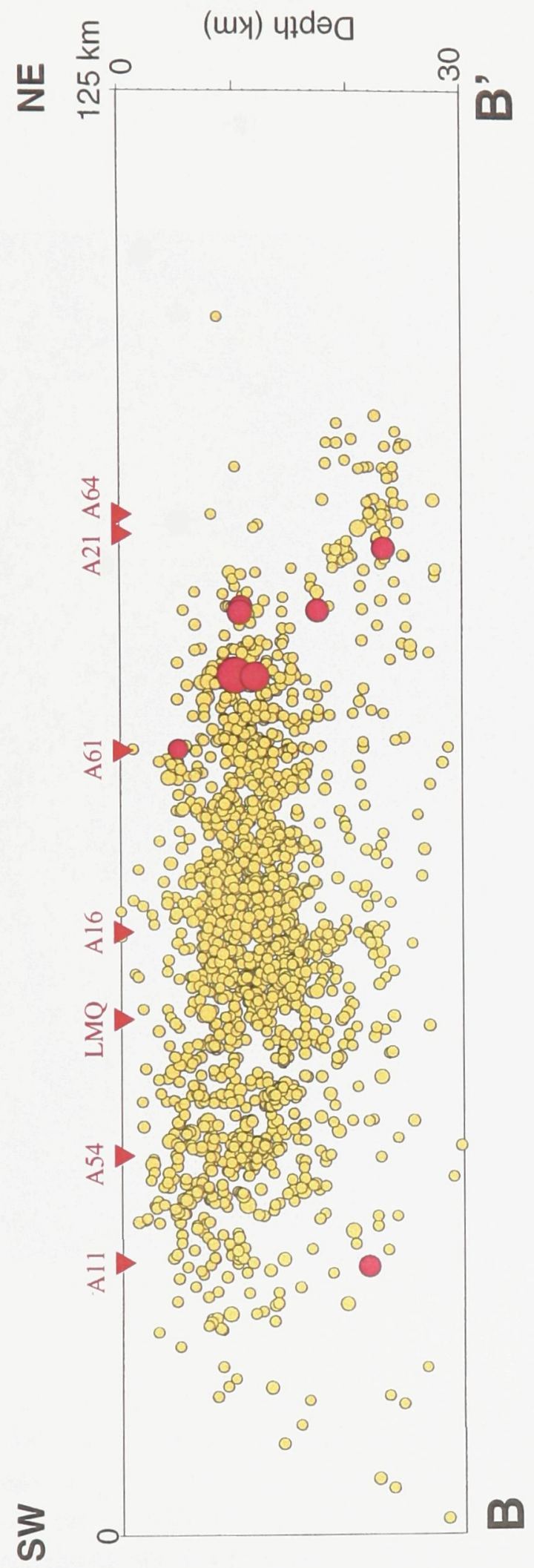

(uy) 41 dəa

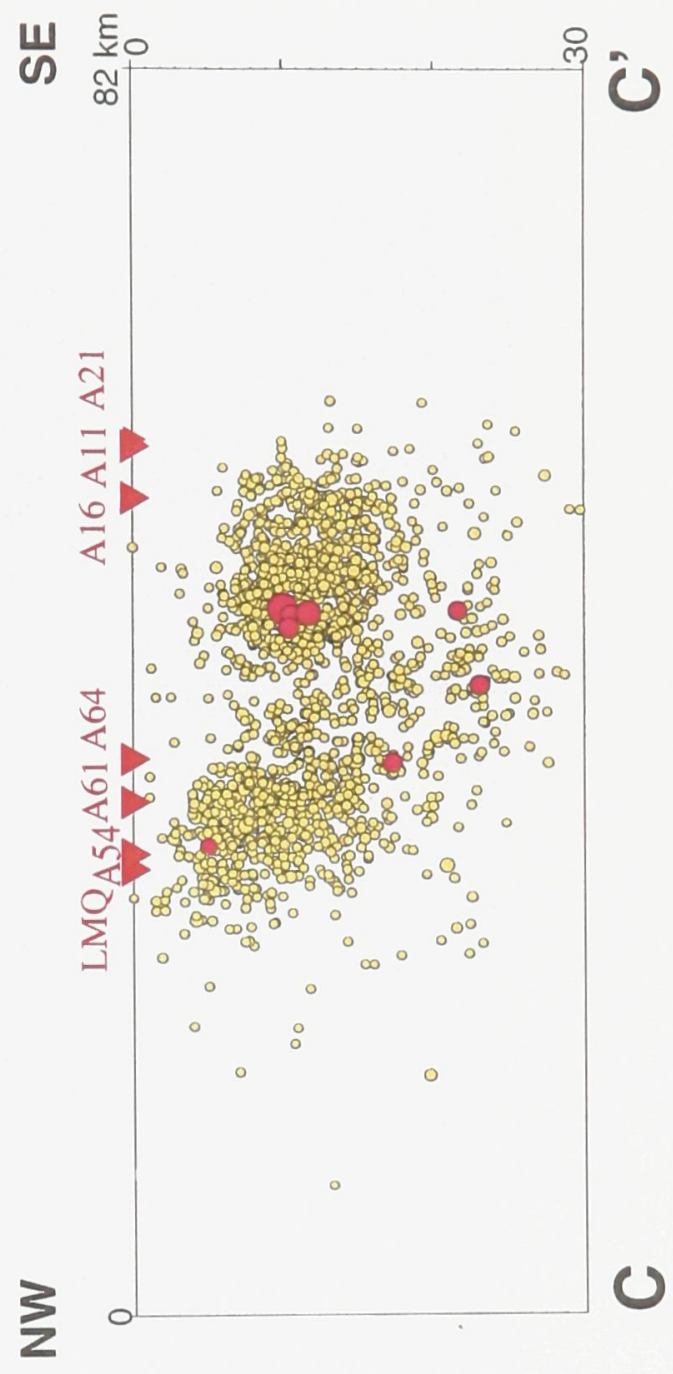

ก

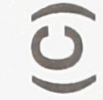


Elevation

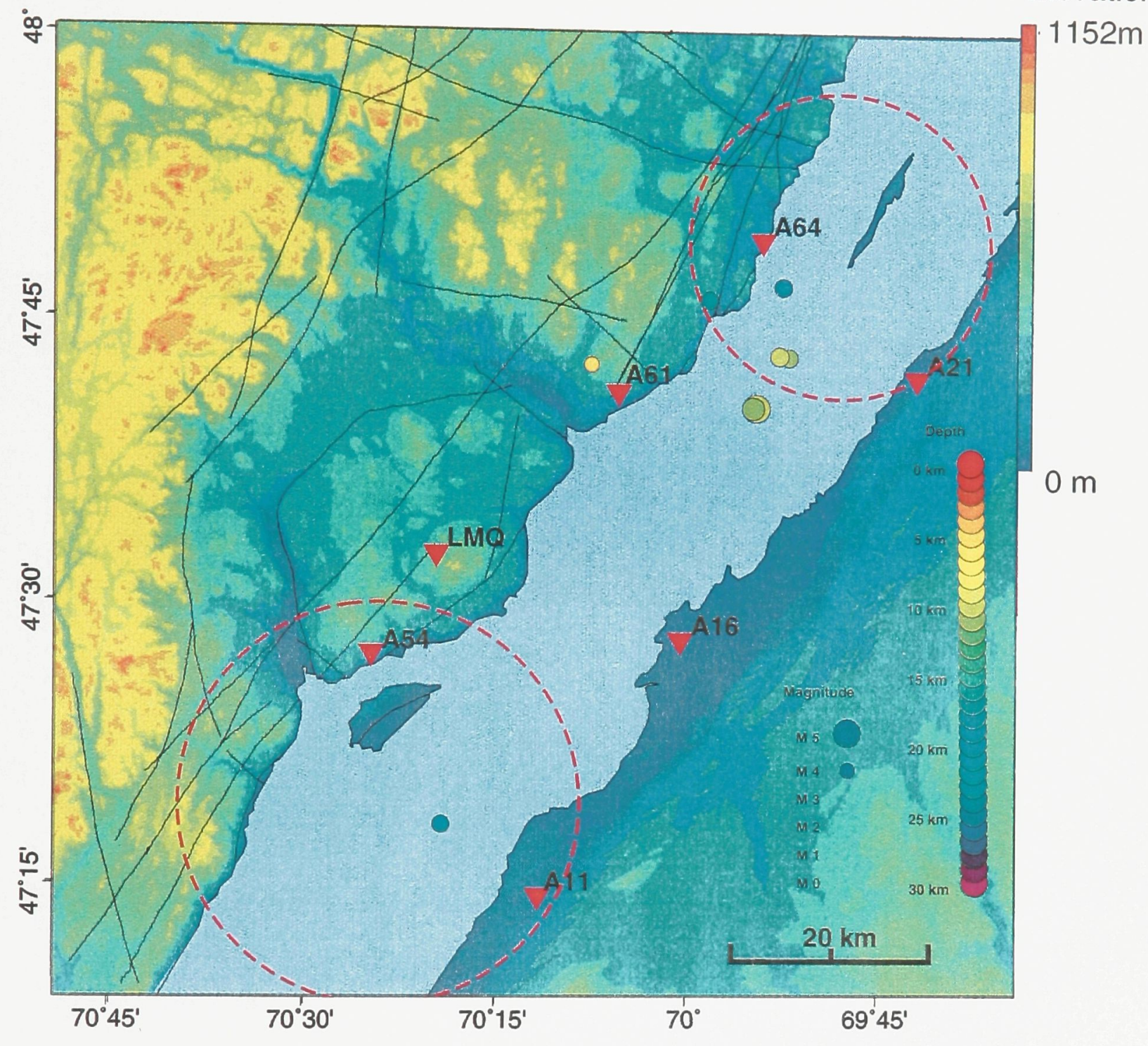

Figure 1.23 Hypocentres by magnitude ranges. Hypocentres (circles) and stations (triangles) plotted for various magnitude ranges: (A) $\mathrm{mN} \geq 4.0$ (the two large circles are the two areas of larger earthquakes of Stevens (1980); (B) $\mathrm{mN} \geq 3.0$; (C) Magnitudes ( $\mathrm{mN}$ and $\mathrm{ML}) \geq 2$.0. Circle colours represent the focal depth of the events. 


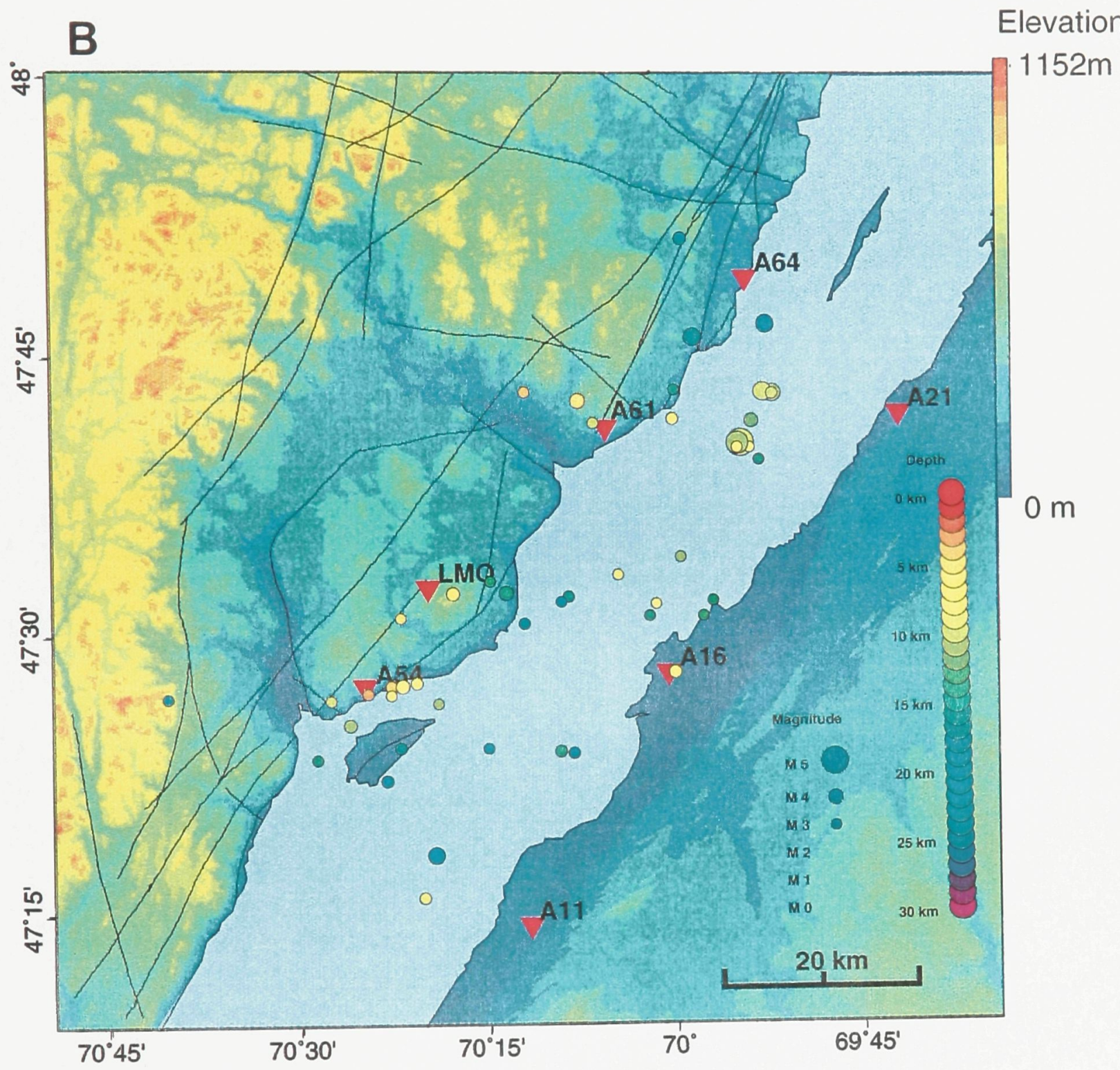




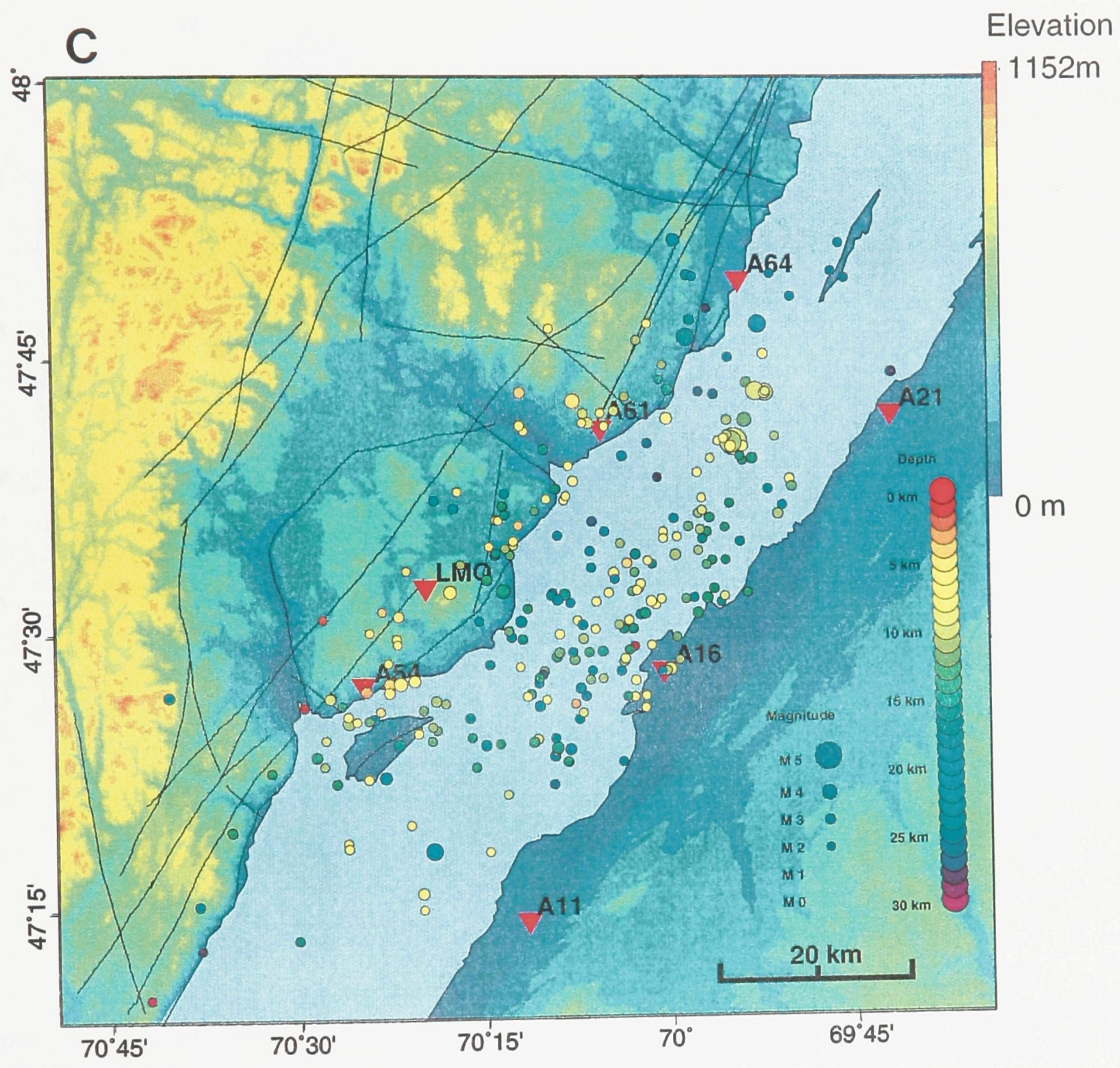




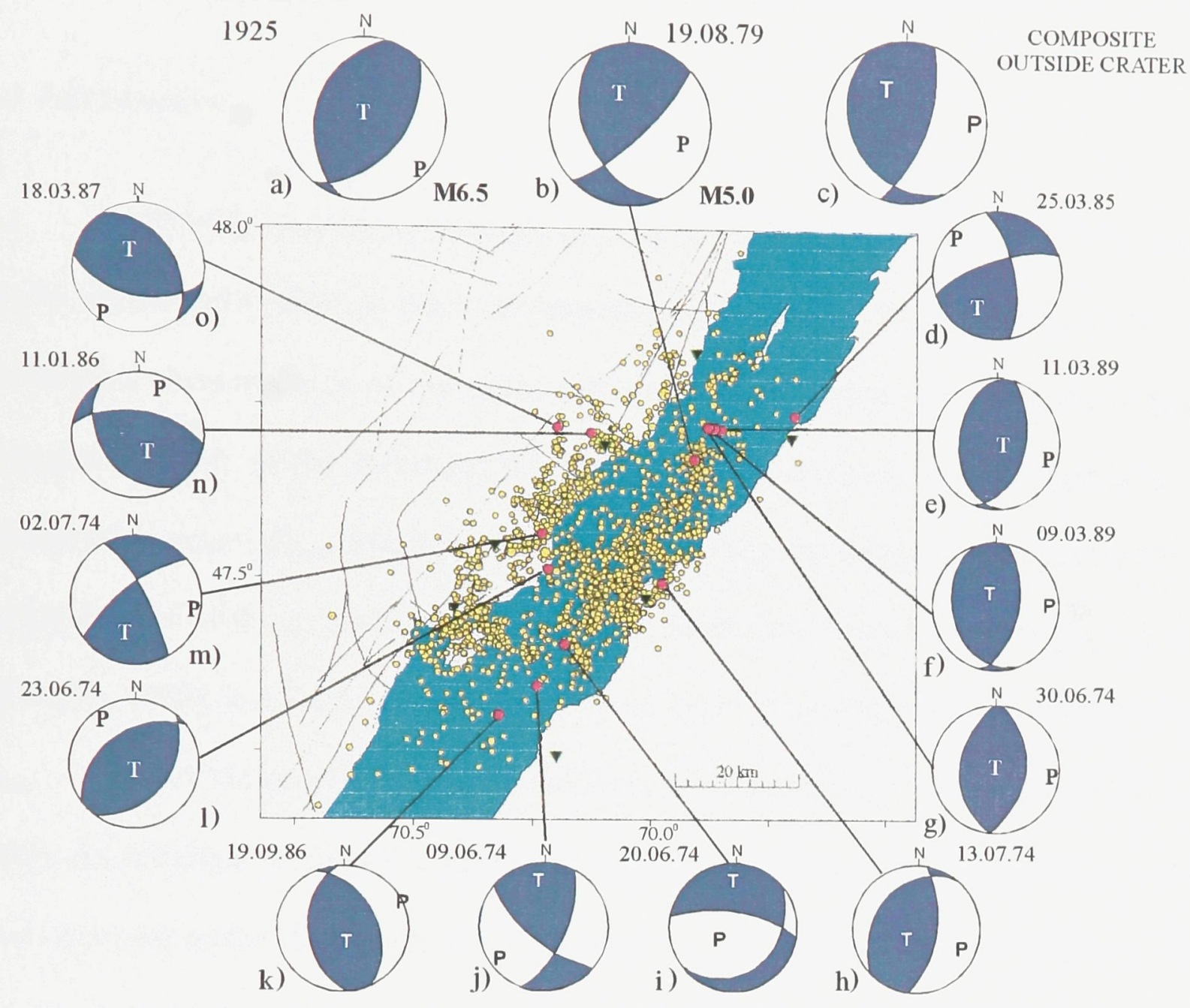

Figure 1.24 Lower hemisphere focal mechanisms in the CSZ. The zones of compressional readings are shaded. The maximum and minimum pressure axes are shown as $\mathrm{P}$ and $\mathrm{T}$, respectively. The dates of the events and the magnitudes (M) of the two largest events are shown: (a) from Bent, 1992; (b) from Hasegawa and Wetmiller, 1980; (c) from Lamontagne, 1987; (d, e) from Wetmiller and Adams, 1990; (f, h, i, j, 1, m) from Leblanc and Buchbinder, 1977; (k, n) from Adams et al, 1988; (g, o) from Adams et al., 1989. 


\section{Chapter 2}

\section{Thermal and rheological constraints on the spatial distribution of CSZ earthquakes}

\subsection{Introduction}

Worldwide, numerous attempts have been made at explaining why, in a given region, crustal earthquakes do not occur beneath a certain depth. To be compared with the rheological characteristics of the crust, earthquake focal depths are evaluated in three different fashions in the literature: the depth where a decrease in the distribution of earthquakes occurs ( $D_{\text {Dec }}$; Meissner and Strehlau, 1982); the depth above which $80 \%$ of earthquakes occur $\left(\mathrm{D}_{80 \%}\right.$; Smith and Bruhn, 1984; Doser and Kanamori, 1986; Banda and Cloetingh, 1992); and finally the maximum focal depth of earthquakes (named thereafter $\mathrm{D}_{\text {Max }}$; Chen and Molnar, 1983; Kusznir and Park, 1984; Ranalli and Murphy, 1987; Chen, 1988). As described in Chapter 1, CSZ earthquakes occur exclusively in the mid- to upper crust, from the surface to a depth of $30 \mathrm{~km}$, with $D_{\text {Dec }}$ at about $13 \mathrm{~km}$ and $D_{80 \%}$ at $15 \mathrm{~km}$ (Figure 2.1). In the CSZ, $D_{\operatorname{Max}}$ is at $29 \mathrm{~km}$; however, only $1 \%$ of earthquakes occur between 25 and $29 \mathrm{~km}$ depth. We therefore adopt the depth of $25 \mathrm{~km}\left(\mathrm{D}_{99 \%}\right)$ as a representative value for the lower limit of the seismic crust. This should not be interpreted as a sign that earthquakes between 25 and $30 \mathrm{~km}$ are negligible; as a reminder the 25 November $1988 \mathrm{~m}_{\text {bLg }} 6.5$ Saguenay earthquake occurred in the Grenville Province about $100 \mathrm{~km}$ west of the Charlevoix Seismic Zone, with an unusual focal depth of $29 \mathrm{~km}$ (North et al., 1989). The final discussion of this chapter will briefly examine the 
significance of this earthquake, and of others in the 25 to $30 \mathrm{~km}$ range, in light of the Charlevoix modelling.

Rheological modelling can provide constraints to the earthquake depth distribution, from the seismogenic brittle layers at upper to mid crustal depth to the plastic regime in the mid- to lower crust. To model the factors that favour or inhibit the occurrence of earthquakes, lithology, structure, temperature and pressure, pore fluid pressure, stress and strain rate have to be considered (Ranalli, 1991). In this chapter, some important factors in modeling the brittle and ductile parts of the crust are reviewed and applied to the CSZ. Based on these results, the factors controlling the CSZ depth distribution are discussed.

\subsection{Temperature}

Crustal temperatures can be estimated assuming that conductive heat transfer is predominant in continental intraplate environments such as Eastern Canada. Steady state 1-D heat transfer in a medium with heat production $A(z)$ is used and can be described by a Poisson equation (see e.g. Chapman, 1986)

$$
\frac{\delta^{2} T}{\delta z^{2}}=-\frac{A}{k}
$$

where $\mathrm{T}$ is temperature, $\mathrm{z}$ depth, $\mathrm{A}$ heat production rate, and $\mathrm{k}$ thermal conductivity. By double integration with respect to $z$, and by assuming $q_{T}$ is the heat flow at the surface, one obtains for a layer of constant heat generation and thermal conductivity

$$
T(z)=T_{T}+\frac{1}{k}\left(q_{T} z-\frac{A z^{2}}{2}\right)
$$


where $T_{T}$ is the temperature at the surface.

If a layer has thickness $\Delta z$, then, at the bottom of the layer, the temperature $T_{B}$ and the heat flow $\mathrm{q}_{\mathrm{B}}$ can be expressed in terms of the temperature and heat flow at the top of the layer $\left(T_{T}, q_{T}\right)$ and properties $(A, k)$ of the layer

$$
\begin{gathered}
T_{B}=T_{T}+\frac{1}{k}\left(q_{T} \Delta z-\frac{A \Delta z^{2}}{2}\right) \\
q_{B}=q_{T}-A \Delta z
\end{gathered}
$$

Equations (2.3) and (2.4) can be used to calculate $T(z)$, resetting $T_{T}$ and $q_{T}$ at the top of each new layer with the values $T_{B}$ and $q_{B}$ solved for the bottom of the previous layer. This formula can be used for one-dimensional modelling of the geotherms where heat production is assumed constant within layers. Although one-dimensional modelling represents an oversimplification (Ranalli, 1991), the uneven data distribution for the Grenville Province restricts studies to the one-dimensional case.

There has been considerable debate as to how heat generation is distributed with depth. Another possibility is an exponential decrease of heat generation with depth

$$
A(z)=A_{0} \exp \left(-\frac{z}{D}\right)
$$

where $\mathrm{DA}_{0}$ represents the contribution from radiogenic heat sources in the upper crust, with $\mathrm{D}$ being related to the characteristic thickness of the heat generating layer. This approach is based on the known enrictumient in $K$, Th and $U$ of upper crustal rocks. The 
exponential decrease model is not considered appropriate anymore; heat generation data from the $12 \mathrm{~km}$ deep Kola peninsula well support a step-like distribution rather than an exponential distribution (Drury, 1989). Thus, a step-like distribution is assumed in the following sections.

\subsubsection{Surface heat flow}

The most important factor in geotherm calculations is surface heat flow. At a given site, measurements are subject to experimental errors (generally considered small) and to near-surface perturbations of conductive heat transfer, such as ground water circulation. In continental environments, surface heat flow can be measured in different geological environments such as in deep wells in hard rock, in dry water wells and in lake bottom sediment columns. At a given site, the assigned heat flow value represents an average of values (temperature gradient and conductivity) from different depths. In general, the deeper measurements are the most reliable, being remote from near-surface perturbations caused by water circulation, topography variations or paleoclimatic disturbances. Due to these factors, it may be necessary to assume an uncertainty of at least $10 \%$ in heat flow measurements (Drury, 1987). In assigning a heat flow value to a given geological province, many assumptions have to be made: that quality of the data is high; that heat flow is relatively constant over the area (or that the mean and standard deviation of heat flow values provide a fair estimate of the real values); and that all geological settings of the province were properly sampled. In other words, a heat flow value can be considered typical of an area if heat flow measurements are reliable (i.e. the effects of near-surface perturbations are removed), numerous enough to be statistically 
significant and spatially distributed over most sub-areas.

\subsubsection{Heat production}

Although the uncertainty in heat generation for a given sample is relatively small, variability of heat generation can be very high for a given rock type (Drury, 1987). Heat production studies provide estimates of various "typical" rock types that can be related to crustal levels. In general, upper crustal rocks have higher heat production values than the lower crust (generally higher than $0.4 \mu \mathrm{W} / \mathrm{m}^{3}$, and up to more than $5.0 \mu \mathrm{W} / \mathrm{m}^{3}$ ). This range is related to the more felsic composition of the upper crust with its higher concentration in radioactive elements. In most studies, upper crustal heat production is determined from values of surface rocks and from geological and geophysical knowledge of the area. In general, lower crustal heat production values are assumed to be in the 0.4 $\pm 0.3 \mu \mathrm{W} / \mathrm{m}^{3}$ range, which corresponds to granulite facies rocks (Ashwal et al. 1987).

\subsubsection{Thermal conductivity}

Although thermal conductivity may vary from sample to sample, it is less variable that heat production and is generally assumed to be constant within a given crustal layer (generally between 2.5 and $3.0 \mathrm{~W} / \mathrm{m} \bullet \mathrm{K}$ ). As will be examined in more detail in other sections, small variations in thermal conductivity have little effect on geotherms. 


\subsubsection{Thickness of layers}

Geophysical information, such as seismic and gravity data, can be used to assess the thickness of the crustal layers. For geotherm calculations, typical values of heat generation and thermal conductivity can be associated with the assumed geological units. Major uncertainties arise when no geophysical profiles exist in a given area or when the depth extent of geological units cannot be adequately constrained. Due to spatial variations of tectonic history over any given geological province, extrapolations of thicknesses over the whole area is necessarily faced with large uncertainties. Generally, interpretations will rely on rather simple models with a few layers of different thermal characteristics. Fortunately, the few kilometres of uncertainty in layer positions do not have much of an impact on geotherm calculations (Chapman, 1986).

\subsubsection{Mantle heat flow}

Certain additional constraints govern the depth extrapolation of heat generation values. Surface heat flow represents the sum of the heat generated in the crust plus the contribution from the mantle. Although not directly measurable, mantle heat flow is generally assumed to represent between $1 / 3$ and $2 / 3$ of the surface heat flow. In addition, it is natural to assume that mantle heat flow is more or less constant beneath Precambrian shields. For the Superior Province for instance, Guillou et al. (1994), assume mantle heat flow to range between 10 and $14 \mathrm{~mW} / \mathrm{m}^{2}$. Jaupart et al., (1998) give a range of 7 to 15 $\mathrm{mW} / \mathrm{m}^{2}$ for the Canadian Shield as a whole. The crustal contribution represents the remaining part of the surface heat flow. With these constraints it is generally possible to 
build plausible models of crustal heat flow.

\subsection{The brittle (frictional) regime}

From a rock mechanics point of view, earthquakes are dynamic slip instabilities usually occurring on preexisting sliding surfaces (Scholz, 1992). In a highly fractured intraplate environment subject to deviatoric stresses, such as the CSZ, rocks cross-cut by pre-existing fractures can slide abruptly, generating earthquakes. The process leading to fault reactivation is controlled by pressure, but is independent of rock type and temperature as a first approximation. To cause slip on a fracture (i.e. a fault in the case of an earthquake), the shear stress, induced by the existence of a tectonic stress field, has to overcome friction. Amonton's law (Jaeger and Cook, 1979) is an empirical formulation of the problem

$$
|\tau|=\mu_{0} \sigma
$$

where $\tau$ and $\sigma$ are the shear and normal stress acting on the plane of fracture, and $\mu_{0}$ denotes the friction coefficient. The frictional law can also be written as the NavierCoulomb criterion:

$$
|\tau|=S_{o}+\mu_{o}\left(\sigma-P_{f}\right)
$$

where $S_{o}$ is the cohesion and $P_{f}$ is the pore fluid pressure, assuming compressive stresses are positive.

Assuming $S_{o}=0$ and $\mu_{o}=0.75$, Sibson (1974) derived expressions of the critical 
stress difference (strength) necessary to reactivate preexisting fracture planes favourably oriented with respect to the stress field, i.e. with an angle $\psi=(1 / 2) \tan ^{-1}\left(1 / \mu_{0}\right) \approx 26.5^{\circ}$ with the axis of maximum compression $\left(\sigma_{1}\right)$

$$
\sigma_{1}-\sigma_{3}=\beta \rho \mathrm{gz}(1-\lambda)
$$

where $\sigma_{3}$ is the minimum compressive stress, $\beta$ is a factor related to the type of faulting ( 3 for thrust, 1.2 for strike-slip and 0.75 for normal faults), $\rho$ the average density of the overlying rocks at depth $\mathrm{z}, \mathrm{g}$ the acceleration of gravity, and $\lambda$ the pore fluid factor ( $\lambda$ $\left.=P_{f} / \rho g z\right)$.

Expanding on Sibson's formulation, Yin (1993) derived more general expressions including variations in $\psi, S_{o}$, and $\mu_{o}$, as well as fracturing of isotropic rocks (with $S$ and $\mu$, the cohesion and friction coefficient for unfractured rocks). For thrust faulting on a preexisting fracture, the expression of the critical stress difference is

$$
\left(\sigma_{1}-\sigma_{3}\right)=\frac{2 \mu_{0} \rho g z(1-\lambda)+2 S_{0}}{\sin 2 \psi+\mu_{0}(\cos 2 \psi-1)}
$$

Yin (1993) also derived expressions for the limiting angles for reactivation of preexisting faults, with $\phi_{0}=\tan ^{-1}\left(\mu_{0}\right)$

$$
\begin{aligned}
& \Psi_{\min }=\frac{1}{2}\left\{\sin ^{-1}\left[\frac{\left(\mu^{2}+1\right)\left[\left(\mu_{0} \rho g z(1-\lambda)+S_{0}\right)+\left(S \mu_{0}-S_{0} \mu\right)\right]}{\left(\mu_{0}^{2}+1\right)(\mu \rho g z(1-\lambda)+S)}\right]-\phi_{0}\right\} \\
& \Psi_{\max }=\frac{1}{2}\left\{\pi-\sin ^{-1}\left[\frac{\left(\mu^{2}+1\right)\left[\left(\mu_{0} \rho g z(1-\lambda)+S_{0}\right)+\left(S \mu_{0}-S_{0} \mu\right)\right]}{\left(\mu_{0}^{2}+1\right)(\mu \rho g z(1-\lambda)+S)}\right]-\phi_{0}\right\}
\end{aligned}
$$


If the angle between the maximum compressive axis and the fracture is outside these boundary values, a new fracture is created (if sufficient stress differences exist). Before applying these expressions to a crustal model of the CSZ, we review the main factors contained in Equations 2.9 to 2.11. Figure 2.2 shows graphically the parameters intervening in fault reactivation.

\subsubsection{Crustal stress magnitude and orientation}

Fault reactivation occurs when the deviatoric stresses are sufficiently large to make the shear stress overcome friction. Fault strength can be computed from equation 2.9; however, assessing the level of deviatoric stress in the crust is more difficult. In an intraplate environment such as the CSZ, there are many potential sources of deviatoric stress, some existing from plate-boundary processes and some of local origin (Hasegawa et al., 1985). In the North American plate, ridge push appears to be the main contributor to tectonic stress (Zoback, 1992a) with some contribution from basal drag. Local sources can also add to the ambient stress field. These sources are flexural stresses (such as glacial loading/unloading), lateral density contrasts, and crustal inhomogeneities (intrusions, structural boundaries, intersecting lineaments, impact craters) that can reorient and concentrate stresses. Studies of the local sources of stress have shown that glacial rebound stress are of the order of less than $5 \mathrm{MPa}^{4}$ (Hasegawa et al., 1985). They could act as a trigger mechanism on optimally oriented pre-existing faults on the verge of failure (Wu and Hasegawa, 1996). Lateral density variations induce stresses that do not exceed

One $\mathrm{MPa}$ corresponds to 10 bars. 
$10 \mathrm{MPa}$ in the CSZ (Assameur and Mareschal, 1995). Worldwide, direct measurements and modelling of tectonic stresses suggest that the maximum crustal stress difference has an upper limit of about 100-200 MPa (see Figure 2.3 with references).

To be reactivated, faults have to be favourably oriented with respect to the stress field. With all other conditions constant, a fault with an optimum orientation will necessitate a lower critical stress difference to cause slip. In the CSZ case, small scale fractures exist at all scales due to the multiple tectonic episodes of the region. Large scale features, on the other hand, concentrate along certain trends (see section 1.3).

\subsubsection{Coefficient of friction and cohesion}

The coefficient of friction $\mu$ (either for intact rock $\mu$ or for fractured rock $\mu_{\mathrm{o}}$ ) is defined as (neglecting cohesion)

$$
\mu=\tau / \sigma
$$

where $\tau$ and $\sigma$ are the shear and normal stress acting on the surface during sliding (Byerlee, 1978). At low pressures (less than $5 \mathrm{MPa}$ ), experimental data show a wide scatter as friction relates mainly to surface roughness. At higher pressures, friction becomes independent of rock types and surface roughness. Byerlee (1978) obtained two expressions for the shear stress

$$
\tau=0.85 \sigma
$$

for $\sigma_{3}<114 \mathrm{MPa}$ (or $\mathrm{z}<7 \mathrm{~km}$ where $\sigma_{3}$ is vertical), and 


$$
\tau=50 \mathrm{MPa}+0.6 \sigma
$$

for $200 \mathrm{MPa}<\sigma_{3}<2000 \mathrm{MPa}$ (or $\mathrm{z}>7 \mathrm{~km}$ where $\sigma_{3}$ is vertical).

In most cases, $\mu$ varies between 0.5 and 0.8 , with a generally accepted value of 0.75. Notable exceptions are fault gouges consisting of clay minerals that can have $\mu$ as low as 0.2. Lower values for the coefficient of friction widen the range of fault orientations that can be reactivated (see Equations 2.10 and 2.11). Finally, the cohesion of the surface (or cementation strength; Sibson, 1992) is the shear stress necessary to cause slip even in the absence of normal stress. It is generally of the order of 1 to $20 \mathrm{MPa}$ for preexisting fractures (Etheridge, 1983).

Recent experiments have shown that a high pressure type of brittle fracture exists where the critical stress difference increases with pressure less steeply than in the frictional case (Shimada, 1993). At higher confining pressures, the high-pressure type of fracture occurs, since compressive strength becomes lower than the frictional strength. If confirmed by further experiments, these results may provide a mechanism by which the crust's strength may not reach values as high as those predicted by Byerlee's law at midcrustal depth. At a certain depth, the crustal strength would increase, at a lower rate than near the surface, until the ductile field is reached.

\subsubsection{Pore fluid pressure}

Pore fluids can favour fracturing by lowering the normal stress acting on the fracture plane and/or by chemically weakening the fault surface (Locker, 1995). The 
effective normal stress $\left(\sigma_{\text {eff }}\right)$ is

$$
\sigma_{e f f}=\sigma-P_{f}
$$

where $P_{f}$ is the pore pressure. The pore fluid factor $(\lambda)$ can be expressed as the ratio of pore fluid pressure to lithostatic pressure

$$
\lambda=P_{f} / \rho g z
$$

Absence of fluids implies $\lambda=0, \lambda \approx 0.4$ (hydrostatic) means that the pores are connected from the surface to the depth considered and the pore fluid pressure is $P_{f}=\rho_{w} g z$, where $\rho_{w}$ is the density of water; and a lithostatic pressure $(\lambda \approx 1.0)$ implies that fluid pressure is equal to the overburden pressure. Suprahydrostatic pressures can occur by consolidation of sediments (in sedimentary basins) and by dehydration reactions in metamorphism (Scholz, 1990). The mechanism to sustain such pore fluid pressures, especially in areas without tectonic or volcanic activity, is still debated. There is geologic evidence that zones of suprahydrostatic pore fluid pressures are fairly common (Carter and Tsenn, 1987). As will be discussed below, this has implications for the nature of deformation at depth and for the magnitude of stress necessary to reactivate faults.

\subsubsection{Density of overlying rocks}

The average density of the overlying rock is used to compute the lithostatic pressure which, in the case of thrust faulting, is the minimum compressive stress $\left(\sigma_{3}\right.$ vertical). We use an average density $\rho=2.8 \mathrm{~g} \cdot \mathrm{cm}^{-3}$ for crustal rocks. 


\subsection{The ductile regime}

The increase of temperature and pressure with depth affects the behaviour of rocks and fracture planes subject to deviatoric stress. When temperature and pressure are sufficiently high, minerals tend to flow instead of behaving in a brittle fashion. With increasing temperature, the whole rock can flow, leading to bulk flow (ductility or plasticity). Rock ductility can be modeled from extrapolations of experiments conducted at higher strain rates. The strength of the ductile part of the lithosphere is generally determined from the relation

$$
\sigma_{1}-\sigma_{3}=\left(\frac{\dot{\varepsilon}}{A}\right)^{\frac{1}{n}} \exp \left(\frac{Q}{n R T}\right)
$$

where $\sigma_{1}-\sigma_{3}$ is the creep strength (stress difference necessary to achieve a given steadystate strain rate $\dot{\varepsilon}, \mathrm{R}$ is the gas constant, $\mathrm{T}$ the absolute temperature and $\mathrm{A}, \mathrm{n}$ and $\mathrm{Q}$ are material parameters which are approximately stress- and temperature-independent in the range of interest (Kirby, 1983; Ranalli, 1995).

Although strain is generally localized in highly deformed areas such as shear zones of interplate regions, it is acceptable to use average strain rate in intraplate areas where deformation affects large areas. Whereas rates can be as high as $10^{-12} \mathrm{~s}^{-1}$ in regions such as the San Andreas fault, in an intraplate environment such as the CSZ, $\dot{\varepsilon}$ is assumed to be in the $10^{-15}$ to $10^{-16} \mathrm{~s}^{-1}$ range (Hasegawa, 1986). For comparison, $10^{-16} \mathrm{~s}^{-1}$ corresponds to a yearly change of $3 \mathrm{~mm}$ over a horizontal distance of $1000 \mathrm{~km}$. There are no direct strain rate measurements for the CSZ. 
The material parameters $\mathrm{A}, \mathrm{n}$ and $\mathrm{Q}$ are known for a selection of silicate materials (examples in Table 2.1; Carter and Tsenn, 1987; Kirby and Kronenberg, 1987). The experimental uncertainties of these creep materials correspond to a 10 to $20 \%$ uncertainty in the accuracy of the creep strength (Ranalli, 1991). The creep strength of silicate rocks is approximately inversely proportional to the silica content. In the lower crust, this translates into basic rocks being stronger than acidic to intermediate rocks. Water, even in trace amounts, can enhance rock ductility (Carter and Tsenn, 1987). Thus, a number of rocks have parameters measured as dry and wet. Because finer materials are generally weaker (since creep is effected by vacancy diffusion instead of dislocation motion), small grain sizes lower rock strength and can lead to linear rheology (Ranalli, 1991). If found in bands of regional extent, these finer materials can become shear zones by concentrating strain (Kirby and Kronenberg, 1987). Section 2.6 describes how the passage from the brittle to the ductile regime can be related to the earthquake activity.

\subsection{Velocity weakening-velocity strengthening transition}

When the crustal temperature reaches about $300^{\circ} \mathrm{C}$, the frictional properties of fault zones change and a temperature-controlled sliding stability transition occurs (see e.g. Scholz, 1990). Unlike bulk flow which is related to whole rock properties, this transition impacts on the sliding properties of the fault surface. It was found experimentally that rock volumes subjected to sliding along a fracture plane, will react differently to a change of sliding velocity, depending on the temperature. At temperatures below $300^{\circ} \mathrm{C}$, rocks 
욱

\begin{tabular}{|c|c|c|c|c|c|c|c|}
\hline 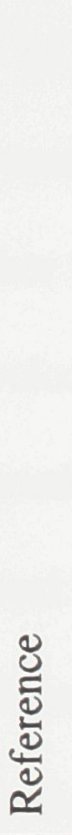 & 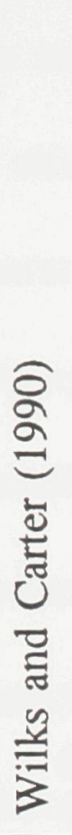 & 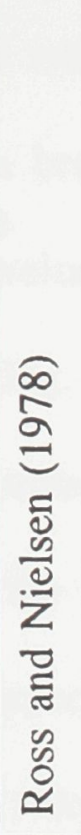 & 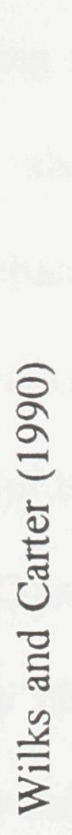 & 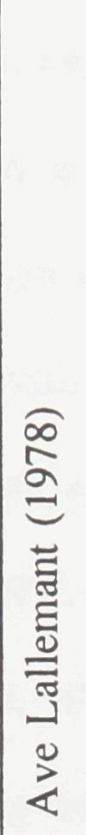 & 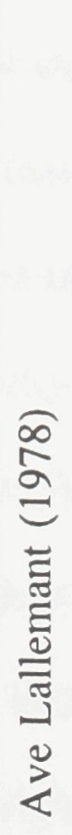 & 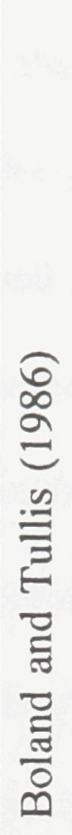 & 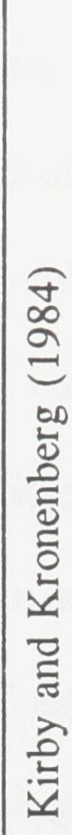 \\
\hline 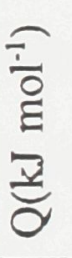 & $\stackrel{m}{\sim}$ & $\frac{\frac{\infty}{+1}}{\stackrel{N}{N}}$ & 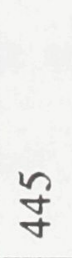 & $\begin{array}{l}a \\
\text { +1 } \\
\text { d. } \\
\text { m }\end{array}$ & $\begin{array}{c}\text { त् } \\
\text { N } \\
\infty \\
\infty\end{array}$ & 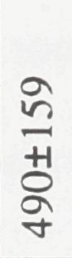 & $\begin{array}{l}0 \\
\tilde{T} \\
+ \\
\infty \\
\infty \\
\infty\end{array}$ \\
\hline$=$ & $\vec{m}$ & $\begin{array}{l}n \\
0 \\
+ \\
\infty \\
i \\
i\end{array}$ & $\stackrel{\sim}{\forall}$ & $\begin{array}{l}0 \\
\stackrel{0}{+} \\
\stackrel{+}{m} \\
\dot{r}\end{array}$ & $\begin{array}{l}+ \\
0 \\
+1 \\
\text { in } \\
n\end{array}$ & $\begin{array}{l}a \\
0 \\
+1 \\
m \\
m\end{array}$ & $\begin{array}{l}= \\
+1 \\
+1 \\
\text { in }\end{array}$ \\
\hline 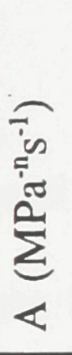 & $\begin{array}{l}\text { o. } \\
\dot{1} \\
8 \\
\infty \\
\infty\end{array}$ & 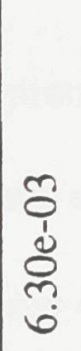 & \begin{tabular}{l} 
J \\
+ \\
+ \\
0 \\
\multirow{0}{*}{} \\
-
\end{tabular} & $\begin{array}{l}\text { o } \\
\dot{1} \\
\stackrel{0}{0} \\
\stackrel{+}{+}\end{array}$ & $\begin{array}{l}\mathscr{0} \\
0 \\
\dot{d} \\
8 \\
\text { i }\end{array}$ & 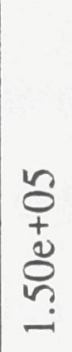 & $\begin{array}{l}n \\
0 \\
\delta \\
8 \\
8 \\
\end{array}$ \\
\hline 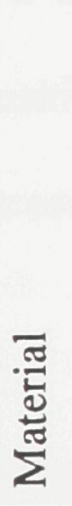 & 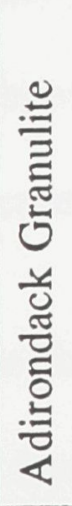 & 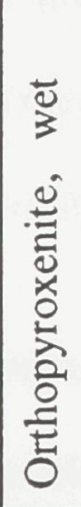 & 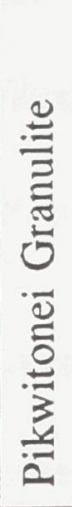 & 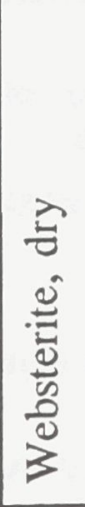 & 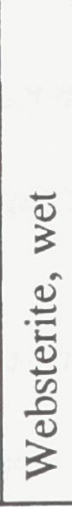 & 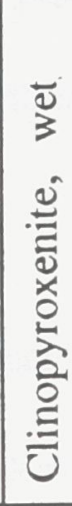 & 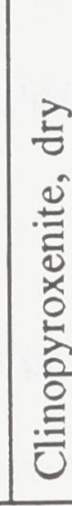 \\
\hline
\end{tabular}


will be in the velocity weakening mode, i.e., a change in the sliding velocity can lead to an unstable situation brought about by a decrease in the frictional shear strength. At higher temperature, velocity changes can lead to increased frictional shear strength, i.e. to velocity strengthening. The change from velocity weakening to velocity strengthening is possibly related to materials of the fault surface. For a quartzo-feldspatic crust, possible critical temperatures are $300^{\circ} \mathrm{C}$ and $450^{\circ} \mathrm{C}$ which correspond to the onsets of quartz and feldspar plasticity respectively (Scholz, 1988). Below the critical temperature, the fault is in the seismogenic velocity weakening field, while above it the fault is in the aseismic velocity strengthening field (Tse and Rice, 1986; Scholz, 1990). For granite, experiments with high fluid pressures show that the transition temperature is in the $350^{\circ} \mathrm{C}$ range (Blanpied et al., 1991).

\subsection{Thermal and rheological controls on CSZ earthquakes}

In most intraplate seismic areas of the world, the thickness of the seismogenic crustal layer correlates with surface heat flow (Sibson, 1982; Chen and Molnar, 1983; Chen, 1988). Geotherms control the maximum depth of crustal earthquakes $\left(D_{M a x}\right)$ either by a transition from brittleness to ductile flow (the brittle-ductile transition) or by a transition from velocity-weakening to velocity-strengthening fault behaviour. Both processes occur approximately at the same temperature.

In the first model, $D_{M a x}$ corresponds to the rheological change from a seismogenic brittle upper layer, modeled by the Navier-Coulomb criterion (Byerlee's law), to a ductile lower layer where strain is accommodated by aseismic creep (the brittle-ductile transition; 
see e.g. Meissner and Strehlau, 1982; Sibson, 1982; Fadaie and Ranalli, 1990). The strength of the ductile part is modelled by an extrapolation to low strain rates of steadystate creep equations (Equation 2.17). This approach has limitations (cf. Rutter and Brodie, 1992), chief among which (in addition to uncertainties in thermal and rheological parameters) is the assumption that strain is uniform, while observation shows that strain is highly localized in deep crustal exposures. However, it provides a first-order estimate of the rheology of the crust with a general rule that the critical temperature for bulk flow is about one-half of the melting temperature.

In the second model, the lower limit of seismicity is caused by a modification of slip behaviour. $\mathrm{D}_{\mathrm{Max}}$ corresponds to a temperature-controlled sliding stability transition rather than to a transition in bulk rheology (see e.g. Scholz, 1990). For a quartzofeldspatic crust, seismicity stops when a critical temperature of $300^{\circ} \mathrm{C}$ for quartz-rich rocks or $450^{\circ} \mathrm{C}$ for feldspar-rich rocks is reached (Scholz, 1988).

In most seismic regions, both the brittle-ductile and the velocity weakeningstrengthening models fit as a first approximation (which implies that the difference between the two critical temperatures is not large). However, in some areas, such as northern Switzerland (Deichmann and Rybach, 1989) deep crustal earthquakes occur, apparently in the ductile zone.

The following sections examine the rheological controls on the Charlevoix earthquake depth distribution. First, our one-dimensional geothermal modelling is described. The computed geotherms are used to infer the transition depth to bulk flow or 
to velocity strengthening. Finally, the frictional constraints imposed on seismicity in the mid- to lower crust are discussed.

\subsubsection{Calculation of geotherms}

Temperature is a critical factor in rheological models, but the uncertainties of geotherm calculations are often underestimated. Generally, these calculations use measured values of surface heat flow, and assumed values of thermal conductivity and heat production. This approach underestimates geotherm uncertainties. In the present analysis, a set of 22,000 geotherms is computed using wide ranges of values for all geothermal parameters. The calculation is based on one-dimensional heat conduction (equations 2.3 and 2.4). Fixed ranges of heat production and thermal conductivity within layers of known thicknesses are assumed.

The distribution of heat flow measurements is poor in the Grenville, with a mean value typical of Precambrian Shield regions of $41 \pm 10 \mathrm{~mW} / \mathrm{m}^{2}$ (mean value \pm 1 standard deviation; Pinet et al., 1991; see Figure 2.4). There are only three surface heat flow determinations for the CSZ, one in the Appalachians $\left(55 \mathrm{~mW} / \mathrm{m}^{2}\right.$ ) and two in the Precambrian basement: $65 \mathrm{~mW} / \mathrm{m}^{2}$ (La Malbaie) and $57 \mathrm{~mW} / \mathrm{m}^{2}$ (Les Eboulements; Guillou-Frottier et al., 1995). The higher than average values for the two CSZ sites are due to higher heat production rates (Guillou-Frottier et al., 1995). Two series of calculations are made in the following: one with the $41 \pm 10 \mathrm{~mW} / \mathrm{m}^{2}$ mean value for the surface heat flow in the Grenville, and one with a surface heat flow of $60 \mathrm{~mW} / \mathrm{m}^{2}$ to consider the higher values measured in the CSZ (to be discussed later). The crust in the 
Charlevoix region is $43 \mathrm{~km}$ thick with a discontinuity at $18 \mathrm{~km}$ depth (from seismic refraction; Lyons et al., 1980). On the basis of geological evidence (Emslie and Hunt, 1990), the upper layer is assumed to be more felsic than the lower one which is taken to be a basic residue of partial melting, rich in plagioclase and without quartz. This hypothesis is also supported by the rather high P-velocities $(\sim 6.7-6.8 \mathrm{~km} / \mathrm{s})$ measured below $18 \mathrm{~km}$ (Lyons et al., 1980; see Figure 5.23). In this two-layer crustal model, upper crustal heat production has been assumed to vary between 0.3 and $2.0 \mu \mathrm{W} / \mathrm{m}^{3}$ to include lateral heterogeneities such as granitic intrusives (high heat production) and large anorthositic bodies (low heat production). Lower crustal heat production has been taken to vary between 0.1 and $0.5 \mu \mathrm{W} / \mathrm{m}^{3}$ (granulite facies rocks; Ashwal et al., 1987). Thermal conductivity is assumed to vary between 2.3 and $2.7 \mathrm{~W} / \mathrm{m}{ }^{\circ} \mathrm{C}$, a range that covers most crustal rock types. Table 2.2 lists the ranges of values for thermal parameters. Three additional conditions are used: heat production in the upper crust has to be equal to or larger than that in the lower crust, as shown by measurements of representative rocks (Ashwal et al., 1987); mantle heat flow has to be in the $10-25 \mathrm{~mW} / \mathrm{m}^{2}$ range, which is plausible for the Precambrian Shield (it includes the 10 and $14 \mathrm{~mW} / \mathrm{m}^{2}$ assumed for the Superior Province by Guillou et al., 1994); and thermal conductivity in the upper crustal layer is higher than or equal to that of the lower crustal layer. Computations are performed assuming all possible combinations of surface heat flow values between 31 and $51 \mathrm{~mW} / \mathrm{m}^{2}$ (in $1 \mathrm{~mW} / \mathrm{m}^{2}$ increments), heat production (in $0.1 \mu \mathrm{W} / \mathrm{m}^{3}$ increments) and thermal conductivity (in $0.1 \mathrm{~W} / \mathrm{m}^{\circ} \mathrm{C}$ increments) for the ranges specified above.

The results of 22,000 geotherm calculations can be summarized by five geotherms; 
$\stackrel{n}{\sim}$

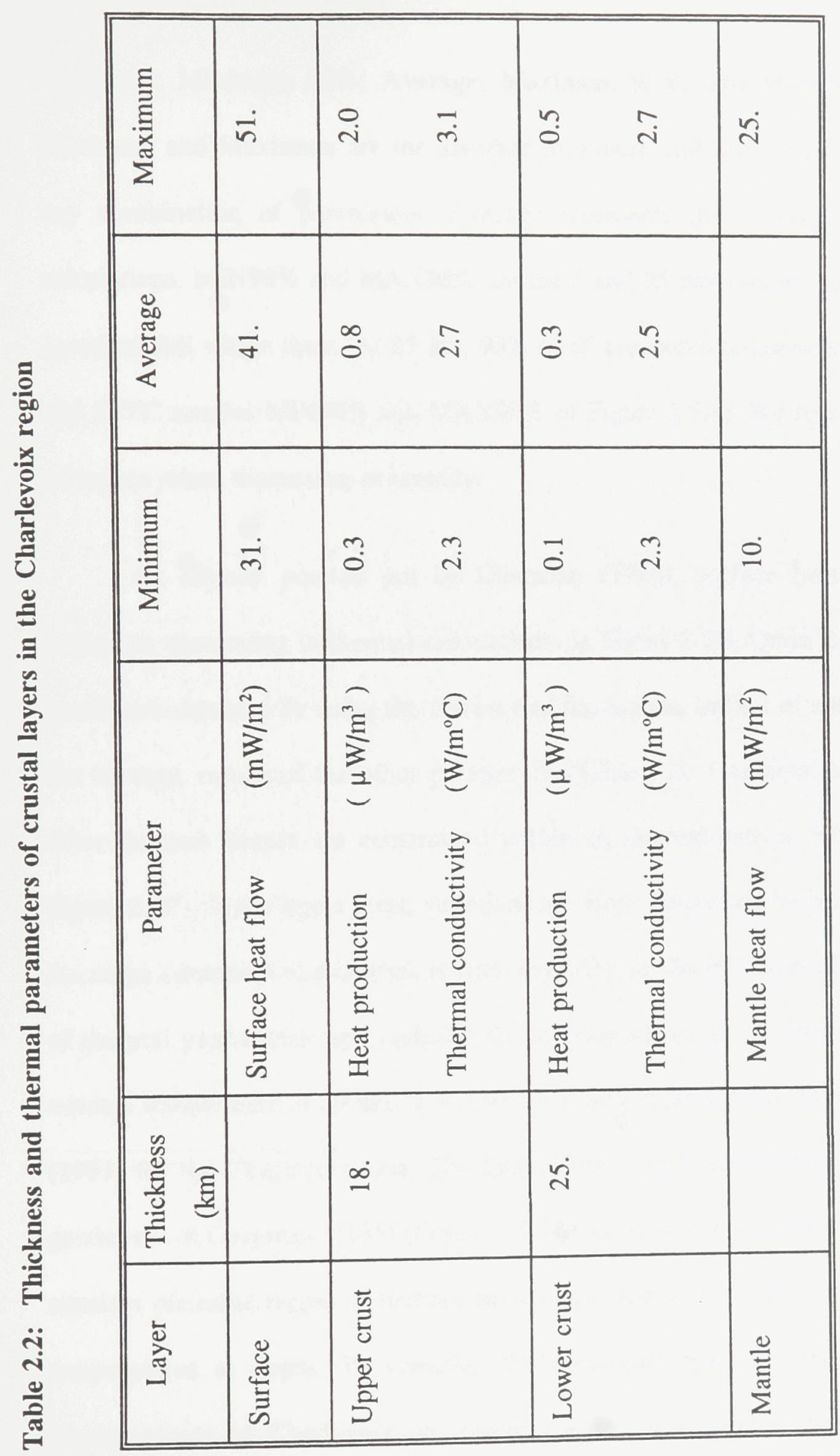


Minimum; Minimum 90\%; Average; Maximum 90\%; and Maximum (Figure 2.5A). Minimum and Maximum are the absolute minimum and maximum values obtained for any combination of parameters. Average represents the average of all temperature calculations. MIN90\% and MAX90\% are the 5 and 95 percentiles, such that $90 \%$ of the iterations fall within them. At $25 \mathrm{~km}, 90 \%$ of all computed temperatures fall between 215 and $355^{\circ} \mathrm{C}$ (curves MIN90\% and MAX90\% of Figure 2.5A). We refer to this $90 \%$ range of values when discussing seismicity.

As already pointed out by Chapman (1986), surface heat flow is the most important uncertainty in thermal calculations. In Figure 2.5B, Qmin and Qmax denote the geotherms obtained by using the lowest and the highest values of surface heat flow and the average values of the other parameters (Table 2.2). Temperature variations due to other thermal factors are constrained within an approximate $\pm 50^{\circ} \mathrm{C}$ band (arrows in Figure 2.5C). In the upper crust, variations are more influenced by heat production. While the range computed in this work is very wide (due to the inclusion of all plausible values of thermal parameters) and includes all previous values in the Precambrian Shield, the average temperature at $20 \mathrm{~km}\left(\mathrm{~T} \approx 280^{\circ} \mathrm{C}\right)$ is very close to that estimated by Mareschal (1991) for the Charlevoix area. The Qmin-Qmax range also includes the most relevant geotherms of Chapman (1986) (Figure 2.5C). One-dimensional geotherm calculations that consider plausible ranges of thermal parameters clearly show the uncertainties of crustal temperatures at depth. To consider the possibility that the two surface heat flow measurements of Charlevoix are representative of a locally higher thermal regime, geotherm calculations were made with a $60 \mathrm{~mW} / \mathrm{m}^{2}$ surface heat flow. As expected, 
higher crustal temperatures are obtained (Figure 2.6).

\subsubsection{Ductile regime}

Using equation 2.17 and the geotherms computed above, the creep strength can be calculated for given crustal material parameters. The lower crustal rocks used in this thesis are: Adirondack (felsic) and Pikwitonei (basic) granulites; dry and wet orthopyroxenites; dry and wet clinopyroxenites; and dry and wet websterites (rheological parametres given in Table 2.1). The Adirondack granulite has a much higher quartz content (21\%) than plausible for the Charlevoix mid to lower crust and is only used as an upper felsic (soft) limit.

Results for three different geotherms (Minimum 90\%; Average; Maximum 90\%) are shown in Figures 2.7A, B and C. Geotherms lower than or equal to the Average produce a brittle crust down to $30 \mathrm{~km}$ or more. The maximum depth of earthquakes cannot be controlled by the brittle-ductile transition if the average Grenville geotherm applies to the Charlevoix region and the lower crust is basic. With the Maximum 90\% geotherm, bulk flow may start at about $25 \mathrm{~km}$, but only for the quartz-rich Adirondack Granulite. Lower strain rates could also raise the transition but the change is only a few kilometres for a decrease of two orders of magnitude. Passage to ductility at $25 \mathrm{~km}$ depth requires geotherms very close to the upper limit, or felsic rock composition (Adirondack granulite facies types). Ductility would be more probable with a wet lower crust as proposed by Hyndman and Shearer (1989). If the lower crust is dry as indicated by some interpretations of lower crustal petrology (Frost and Bucher, 1994), the crust would be 
entirely within the brittle field.

Using the geotherm computed with a surface heat flow of $60 \mathrm{~mW} / \mathrm{m}^{2}$, bulk flow was calculated for the same materials (Figure 2.8). As expected, the brittle-ductile transition is shallower for this warmer geotherm.

\subsubsection{Change from velocity weakening to velocity strengthening}

In the frictional model, the transition from velocity weakening to velocity strengthening behaviour marks the lower boundary of the seismic layer. Scholz's (1988) seismo-rheological model assumes that $\mathrm{D}_{\operatorname{Max}}$ coincides with the onset of ductility of the most ductile rock component. Experimentally, $300^{\circ} \mathrm{C}$ marks the onset of quartz plasticity and $450^{\circ} \mathrm{C}$ corresponds to the onset of feldspar plasticity. Since the Charlevoix middle and lower crustal rocks are assumed not to contain quartz, the critical temperature should be the latter. The $450^{\circ} \mathrm{C}$ isotherm is found at about $33 \mathrm{~km}$ for the Maximum $90 \%$ and deeper for colder geotherms. A possible hydrolytic weakening of the feldspars could bring the critical transition temperature down to $350^{\circ} \mathrm{C}$ (Tullis and Yund, 1980). At $25 \mathrm{~km}$, this temperature is reached by geotherms close to Maximum90\% (Figure 2.4A). Consequently, seismogenic control by onset of hydrated feldspar plasticity is possible with our warmest geotherms.

\subsubsection{Maximum plausible stress difference}

Another problem arises with the predicted stress differences necessary to cause frictional failure. The Coulomb-Navier failure criterion (with low pore fluid pressures and 
a static coefficient of friction; Equation 2.8 and Figure 2.6) implies very high stress differences at mid- to lower crustal depths under dry conditions. At $25 \mathrm{~km}$, for example, a hydrostatic pore fluid pressure $(\lambda=0.4)$ and a coefficient of friction of 0.75 imply a critical stress difference for sliding of about $1200 \mathrm{MPa}$ in an ideally-oriented reactivated thrust fault. These high stress differences are about one order of magnitude larger than the upper limit of 100-200 MPa discussed in Section 2.3.1.

Stress differences causing thrust fault reactivation can be computed as a function of depth, material parameters and fault orientation (Ranalli and Yin, 1990; Yin and Ranalli, 1992). The two parameters that can maintain $\left(\sigma_{1}-\sigma_{3}\right)$ below $200 \mathrm{MPa}$ in the mid- to lower crust are a high pore fluid pressure and/or a low coefficient of friction. Figure 2.9A shows the critical stress difference necessary to cause thrust faulting at a depth of $20 \mathrm{~km}$, assuming a static friction coefficient of 0.75 , as a function of the angle $\theta$ that the fault makes with the maximum compression direction and the pore fluid/overburden pressure ratio $(\lambda)$. High pore-fluid pressures equal at least to $80 \%$ of overburden pressure must exist for $\left(\sigma_{1}-\sigma_{3}\right)$ to be less than $200 \mathrm{MPa}$. However, the steeply-dipping rift faults $\left(\approx 70^{\circ}\right)$ are not favourably oriented for thrust reactivation, assuming the sub-horizontal maximum stress direction that prevails in eastern North America (Zoback and Zoback, 1991), which may be slightly reoriented in the CSZ due to postglacial rebound (Wu, 1998). At a depth of $20 \mathrm{~km}$, the limiting angle between preexisting fault and maximum compression direction for reactivation as a thrust fault is $54^{\circ}$ for any pore-fluid pressure below or equal to the lithostatic. An additional possibility is a reduced coefficient of friction. Figure $2.9 \mathrm{~B}$ shows the maximum dip angle of a fault 
with respect to the maximum compression direction assuming that the coefficient of friction is 0.3 . Reactivation of faults dipping up to $72^{\circ}$ is now possible, and the required pore-fluid pressures are considerably less. Assuming a $200 \mathrm{MPa}$ maximum stress difference, it is possible to map the relationship between the pore-fluid pressure, the coefficient of friction and the angle between $\sigma_{1}$ and the fault surface (Figure 2.10). There is also the possibility that the paleo-rift faults become listric at depth. According to Figure $2.10 \mathrm{~B}$, fractures that make an angle of $40^{\circ}$ with the axis of maximum compression can be reactivated with coefficients of friction in the 0.6-0.75 range. Although high pore-fluid pressures are still required $(\lambda \sim 0.8)$, listric faults could be reactivated with standard values for the coefficient of friction. Finally, the high pressure type of fracture may also account for the maximum crustal strength at a level slightly above $200 \mathrm{MPa}$ (Shimada, 1993; Figure 2.11).

\subsection{Discussion and conclusions}

In Charlevoix, $\mathrm{D}_{99 \%}, \mathrm{D}_{80 \%}$ and $\mathrm{D}_{\mathrm{Dec}}$ do not appear to correspond to a transition to ductile bulk rock behaviour unless the geotherm is near the maximum possible value and/or the lower crust is quartz-rich. This conclusion is based on one-dimensional geothermal modelling of Grenville surface heat flow for a wide range of thermal parameters and on an examination of the rheology of materials likely to form the lower crust. None of the materials can be ductile within our $90 \%$ confidence limits for the geotherms. Only a high surface heat flow $\left(\geq 60 \mathrm{~mW} / \mathrm{m}^{2}\right)$ can lead to a passage to ductility at $\mathrm{D}_{99 \%}$, with a quartz-rich mid- to lower crustal composition. However, the high heat flow value (Q $65 \mathrm{~mW} / \mathrm{m}^{2}$; Guillou-Frottier et al., 1995) appears to be affected by the high 
thermal conductivity (J.-C. Mareschal, pers. comm.).

Therefore, although there is a global correlation between surface heat flow and maximum depth of crustal earthquakes (Sibson, 1982; Meissner and Strehlau, 1982; Chen and Molnar, 1983), a detailed analysis of the CSZ shows that ithe brittle-ductile transition is probably deeper than the $D_{99 \%}$ of earthquakes. It should be noted that the present model uses a basic lower crust while most models assume a uniform felsic crust with the rheology of quartzite or granite. The present choice, on the other hand, is based on inferences on the composition of the mid- to lower crust of the Charlevoix region. Another difference between this approach and models of other regions is the consideration of temperature uncertainties. Most geotherm models assume fixed values for thermal parameters.

The passage from velocity weakening to velocity strengthening frictional behaviour may explain $\mathrm{D}_{99 \%}$. Feldspar only starts flowing at about $450^{\circ} \mathrm{C}$, but this temperature can be lowered to $\approx 350-400^{\circ} \mathrm{C}$ by the presence of $\mathrm{H}_{2} \mathrm{O}$ (Tullis and Yund, 1980). Consequently, at $25 \mathrm{~km}$ depth, hydrated feldspar can possibly become ductile with the warmest geotherms (including the one with $60 \mathrm{~mW} / \mathrm{m}^{2}$ surface heat flow). Below $\mathrm{D}_{99 \%}$, the absence of three local instability factors may explain the quasi-complete absence of earthquakes. The available stress difference may not reach the frictional strength level. High pore-fluid pressures may exist only above $\mathrm{D}_{99 \%}$, possibly due to hydration reactions that eliminate any free water at temperatures over $250^{\circ} \mathrm{C}$ (Frost and Bucher, 1994). Finally, below $\mathrm{D}_{99 \%}$ fractures may be less numerous or more stable possibly due to healing. Figure 2.12 presents a synoptic model of seismogenic factors in this region. 
Unless the high-pressure type of fracturing is validated by further testing, high pore fluid pressure and/or low coefficient of friction must exist not to exceed the maximum crustal stress difference level. Earthquakes occur where these conditions exist. The presence of deep crustal fluids and of high pore fluid pressures has gained much support in recent years (Hyndman and Shearer, 1989; Meissner and Wever, 1992). Examples for eastern Canada are numerous: Zoback (1992b) used a high pore-fluid pressure to explain the apparent mismatch between the regional compressive stress direction and the focal mechanism of the $1979 \mathrm{~m}_{\mathrm{bLg}} 5.0$ Charlevoix earthquake; shear wave splitting observed for Charlevoix earthquakes can be explained by saturated cracks (Buchbinder, 1989); in the Miramichi earthquake area in New Brunswick, near-lithostatic pore-fluid pressures can explain reactivation of high angle faults (Sibson, 1989). One open question, however, is how such high pore fluid pressures are created and maintained. In the CSZ, no active geological process, such as tectonism, sediment compaction or metamorphic dehydration, are likely to give rise to suprahydrostatic fluid pressures. In addition, it has been argued that at temperatures higher than $250^{\circ} \mathrm{C}$, free water cannot exist due to a rapid consumption by hydration reactions (Frost and Bucher, 1994). Although the debate about the presence or absence of mid- to lower-crustal fluids is open, high pore-fluid pressures appear to solve the seismological problem of maximum possible stress difference at mid- and lower-crustal depth.

The alternative is a low friction coefficient. In a dry thrust environment with subhorizontal maximum compressive stress, a low friction coefficient is necessary to reactivate steeply-dipping faults. This possibility was also suggested by Zoback (1992b). 
Near the surface, low friction coefficients may correspond to thick fault gouges made up of clay minerals; at depth, however, these minerals lose their lubricating properties due to dehydration (Scholz, 1990). A low friction coefficient at mid-crustal depth may correspond to highly fractured zones. Variations in hypocentral depths along the trend of the St. Lawrence River, and variability in reactivated fault planes shown by focal mechanisms (Figure 1.26) indicate that Charlevoix earthquakes occur in zones of intense fracturing.

In terms of the seismic hazard estimate in the St. Lawrence valley, the presence of paleo-rift faults alone does not explain earthquake occurrence. Local fault conditions, such as transient enhanced pore-fluid pressures, leading to frictional instabilities should also be considered.

Worldwide, large intracontinental earthquakes tend to occur at the base of the seismogenic layer defined by micro-earthquakes, which represents the peak in the shear resistance of a rheological profile (Sibson, 1984). In contrast, the two largest CSZ earthquakes for which focal depths are known (1925 mb 6.2: Bent, 1992; and $1979 \mathrm{~m}_{\mathrm{bLB}}$ 5.0: Hasegawa and Wetmiller, 1980) occurred at about $10 \mathrm{~km}$ depth. In addition, the 5 to $15 \mathrm{~km}$ depth range also includes magnitude $\geq 3.0$ earthquakes for the period 1977 to 1997. Based on our rheological modelling, the concentration of larger earthquakes between 5 and $15 \mathrm{~km}$ depth cannot be associated with the much deeper brittle-ductile transition. Again, local factors, such as high pore fluid pressures, degree of fracturing, or lower coefficient of friction, may explain the enhanced activity of this crustal level. 
The $\mathrm{m}_{\mathrm{bLg}} 6.51988$ Saguenay earthquake occurred at $29 \mathrm{~km}$ depth, in the Grenville Province. Based on our rheological modelling, it probably occurred in the brittle crust, but much closer to the brittle-ductile transition, if a warm Grenville geotherm (Max90\%) is considered (a situation similar to Figure 2.8). In this case, the earthquake may have occurred in the strongest part of the crust, as proposed by Sibson (1984). This would be consistent with the unusually high stress drop of this event (Atkinson and Boore, 1998).

If the two higher than average CSZ surface heat flow measurements of GuillouFrottier et al. (1995) are representative of a regional anomaly in the Grenville, the $\mathrm{D}_{99 \%}$ may correspond to the brittle-ductile transition (assuming the warmest geotherm). In this case, many earthquake concentrations in the 20 to $30 \mathrm{~km}$ depth range could be seen as "sticking patches" in a surrounding ductile regime (e.g. Sibson, 1984). Interestingly, most earthquakes below $20 \mathrm{~km}$ depth occur in an elongated zone, that could be located between more ductile areas. It would be interesting to see if the next large CSZ earthquake nucleates at 20 to $30 \mathrm{~km}$ depth, near one of these locking points.

Although this study examines the case of the Charlevoix seismic zone, most questions raised in this analysis also apply to other seismically active areas of the continental crust. It appears that the onset of bulk flow is only one factor affecting the maximum depth of intraplate earthquakes. Charlevoix earthquakes are not controlled by the brittle-ductile transition. The probable composition of the mid- to lower crust and the surface heat flow show that rocks are still brittle at $\mathrm{D}_{99 \%}$. A passage from velocityweakening to velocity-strengthening at $300-350^{\circ} \mathrm{C}$ may correspond to $\mathrm{D}_{99 \%}$, but only if this transition temperature applies to hydrated basic rocks, where feldspar is the most ductile 
material. Some instability factors may explain the occurrence of earthquakes: high porefluid pressure and low friction coefficient, possibly related to unhealed zones of intense fracturing. Independently of the pore-fluid pressure, a low coefficient of friction may be another factor to account for the thrust reactivation of steeply-dipping faults. 


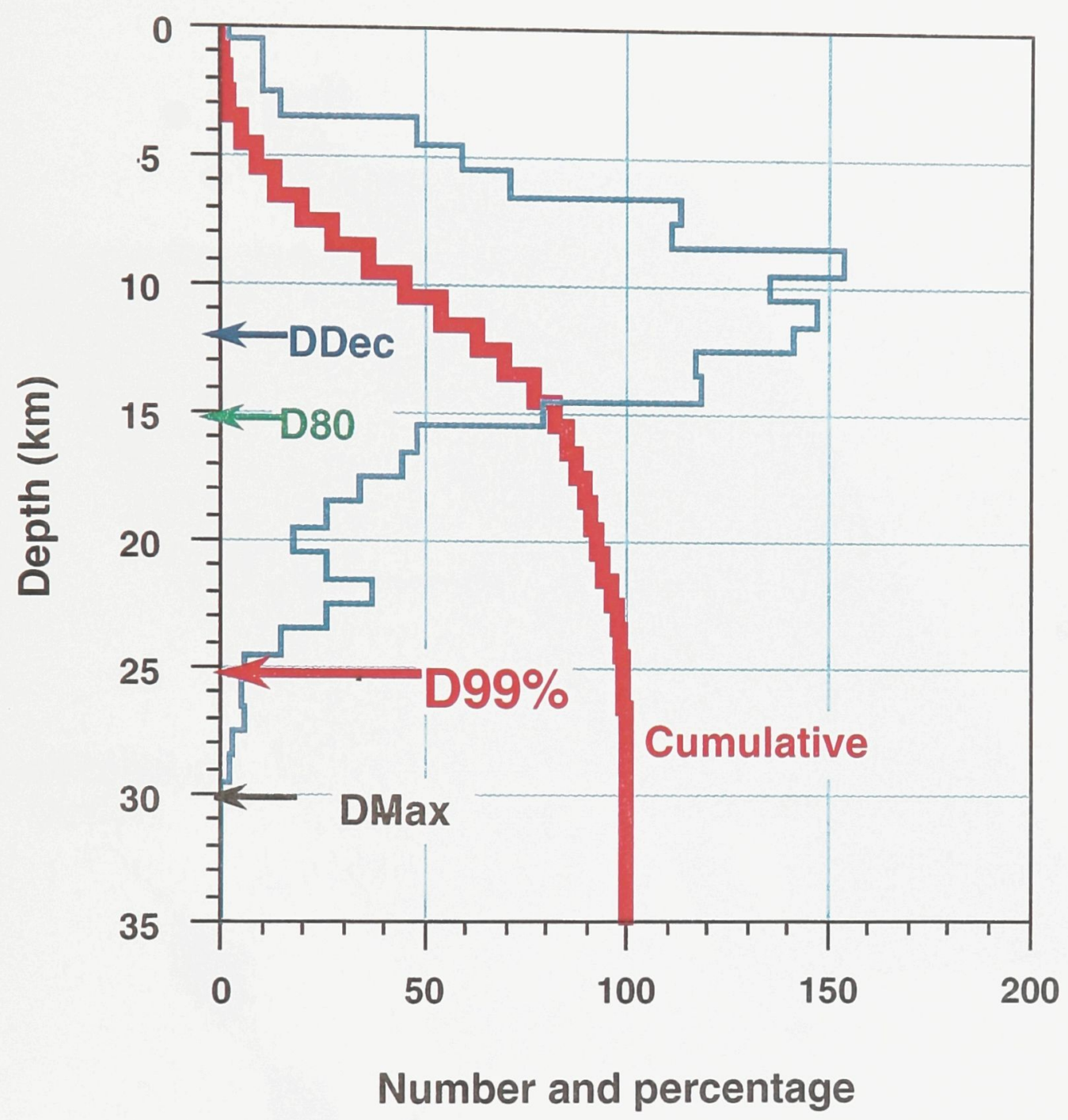

Figure 2.1 Focal depth distribution of the Charlevoix earthquakes for the period October 1977 to December 1997. Events are grouped in one kilometre intervals. Two curves are drawn: one for absolute numbers (blue) and one for the cumulative percentage (red). See text for descriptions of cut-off depths. 


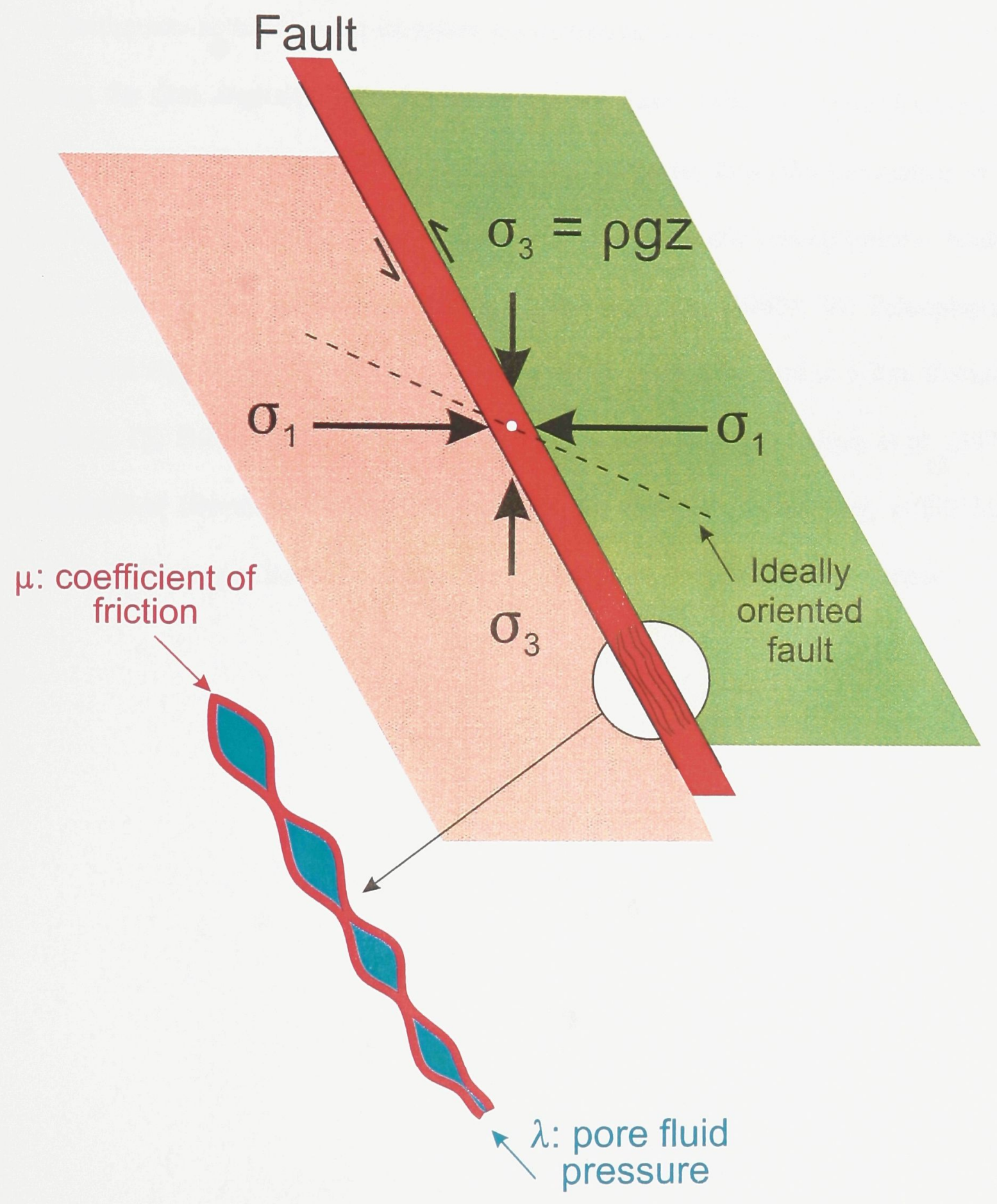

Figure 2.2. Sketch representing the various factors intervening in fault reactivation. 
Figure 2.3 Distribution of inferred maximum stress differences. The numbers refer to: 1 ) Ridge push: Zoback and Magee (1991); 2) Upper crustal amplification of ridge push: Kusznir and Bott (1977); Hasegawa et al. (1985); 3) Tensile fracturing : Etheridge (1983); 4) Earthquake stress drops in intraplate environments: Hasegawa et al. (1985); 5) Estimate along the San Andreas fault: Lachenbruch and Sass (1980); 6) Hydrofracturing-strain relief: McGarr and Gay (1978); 7) Composite estimates from the summation of eastern Canadian stress sources: Hasegawa et al. (1985); 8) Isostatic considerations: Molnar and Lyon-Caen (1988); 9) Mylonitization: Christie and Ord (1980); 10) Paleopiezometers: Kohlstedt and Weathers, 1980); 11) KTB borehole value measured at $6 \mathrm{~km}$ : Zoback et al. (1993); 12) Estimates along the Alpine fault of New Zealand: Scholz et al. (1979); 13) Mechanical twinning: Tullis (1980). Except for mechanical twinning, a $200 \mathrm{MPa}$ is a conservative upper bound estimate of the maximum crustal stress difference. 


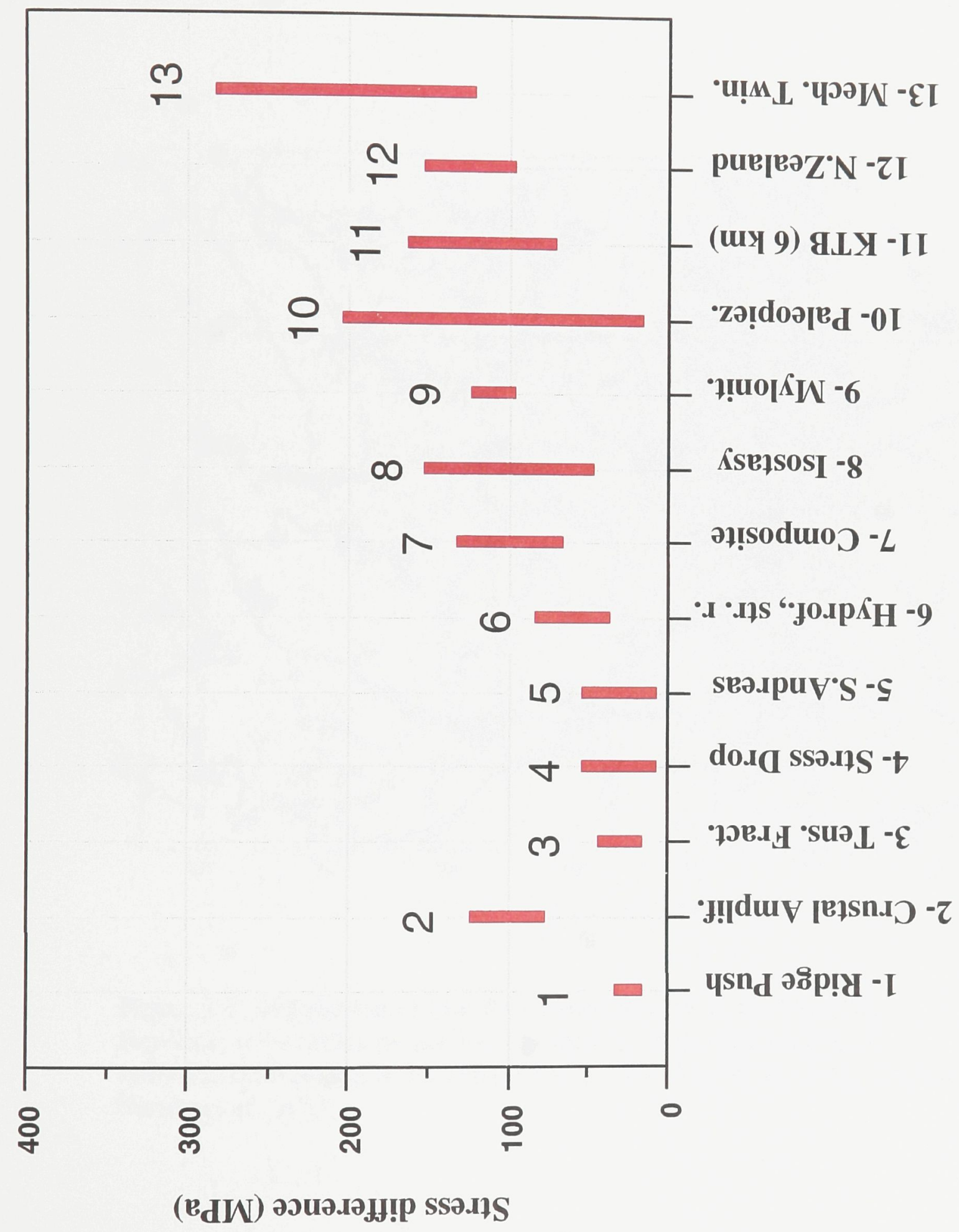




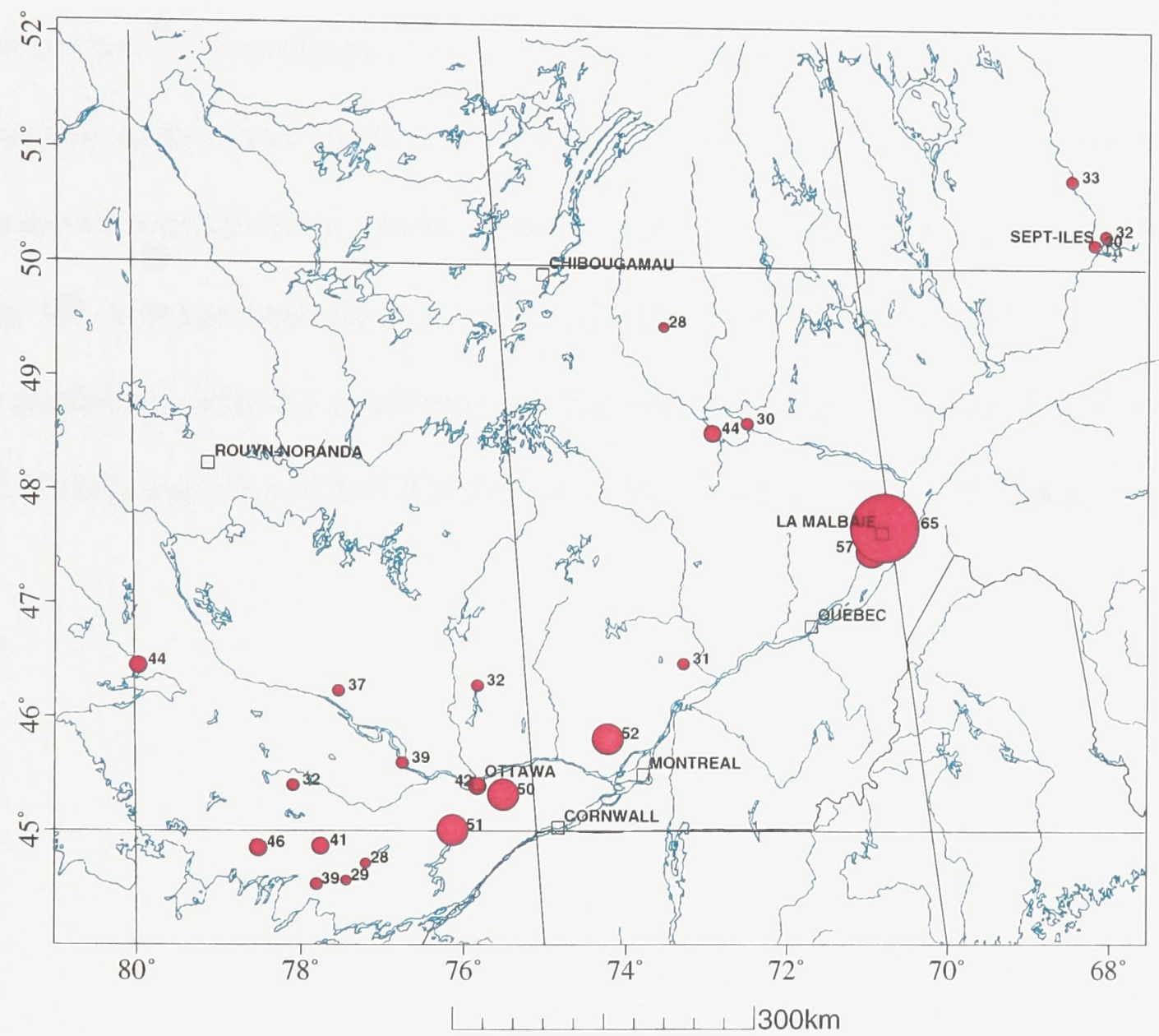

Figure 2.4 Distribution of heat flow measurements in the Grenville Province, with circles proportional to the heat flow values, given in mW/m2 (from Jessop et al., 1984; Drury, 1987; Pinet et al., 1991; GuillouFortier et al., 1995). 
Figure 2.5 Computed geotherms for the Grenville region, (A) using parameters of Table 2.1. Five curves are shown: the absolute Maximum (MAX) and Minimum (MIN) geotherms; the Average (Av) geotherm which represent the average value of all geotherms at a given depth; and the MIN90\% and MAX $90 \%$ which enclose $90 \%$ of all geotherms. Ninety-nine percent of all earthquakes occur above $D_{99 \%}$. (B) Temperature variations due to one parameter while others are kept at their average values of Table 2.1. Surface heat flow is the most important factor, while all others constrain geotherm fluctuations within $50^{\circ} \mathrm{C}$ when the average heat flow is used. (C) Comparisons of MIN90\%, AV, and MAX90\% geotherms with the geotherms of Chapman (1986) for a surface heat flow of $40 \mathrm{~mW} / \mathrm{m}^{2}(\mathrm{Ch} 40)$ and $50 \mathrm{~mW} / \mathrm{m}^{2}(\mathrm{Ch} 50)$. Both fall within the present $90 \%$ confidence margin. 


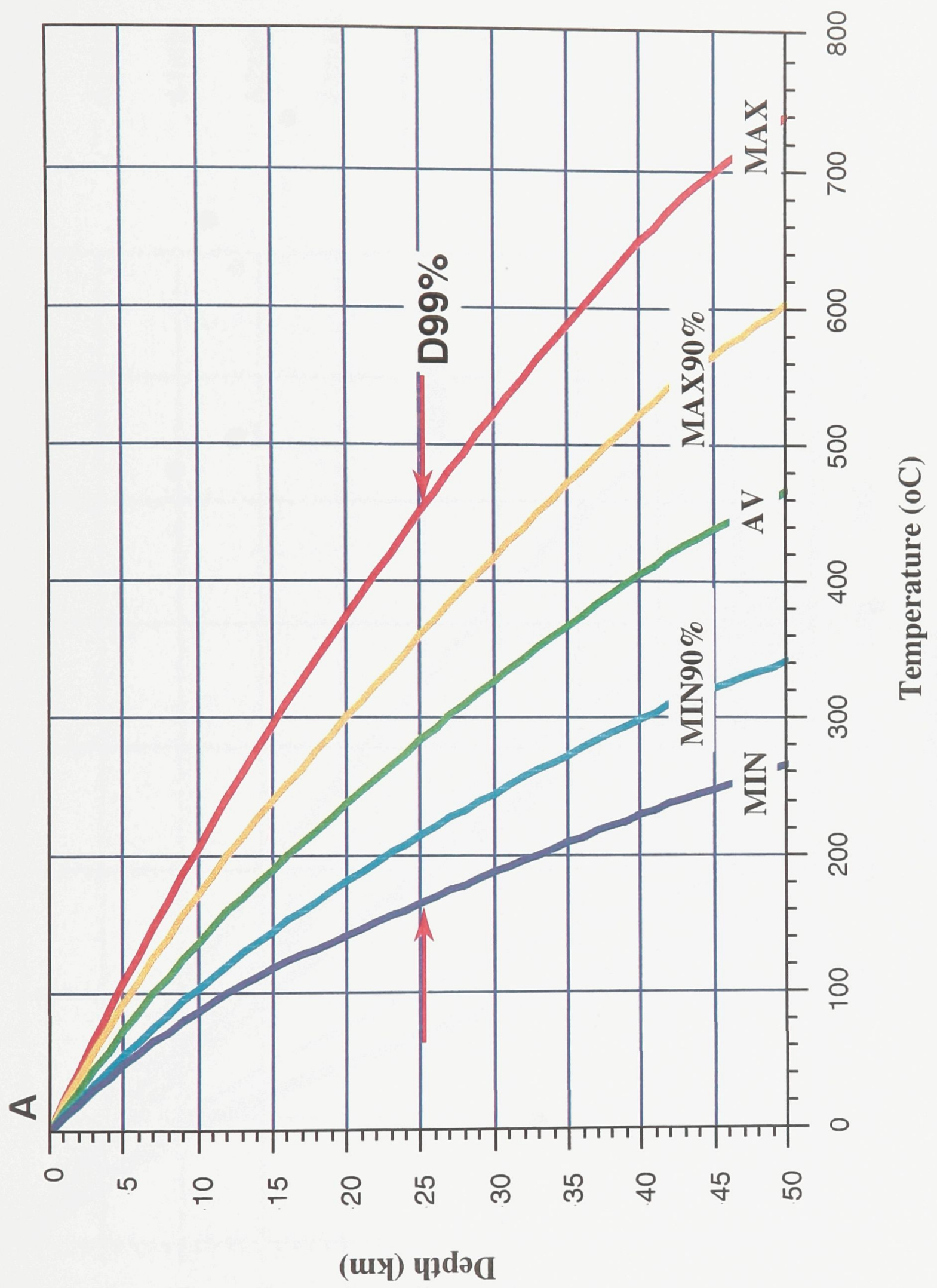




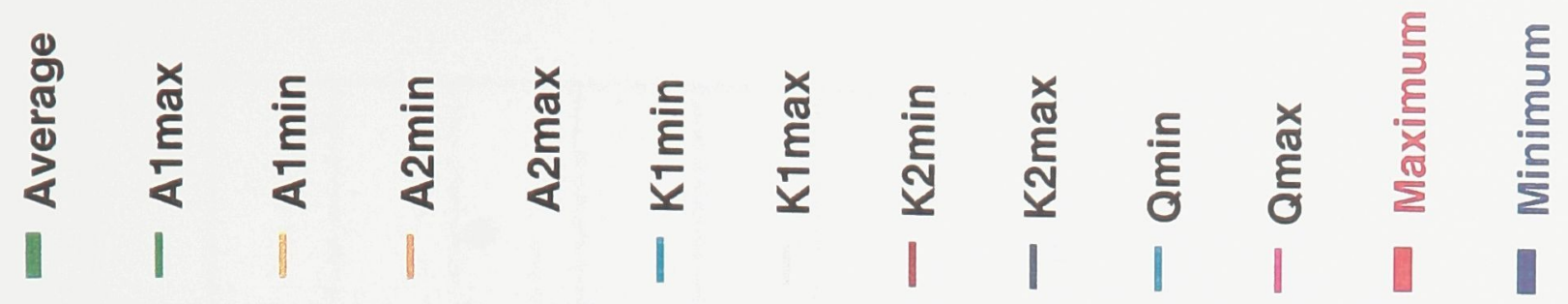

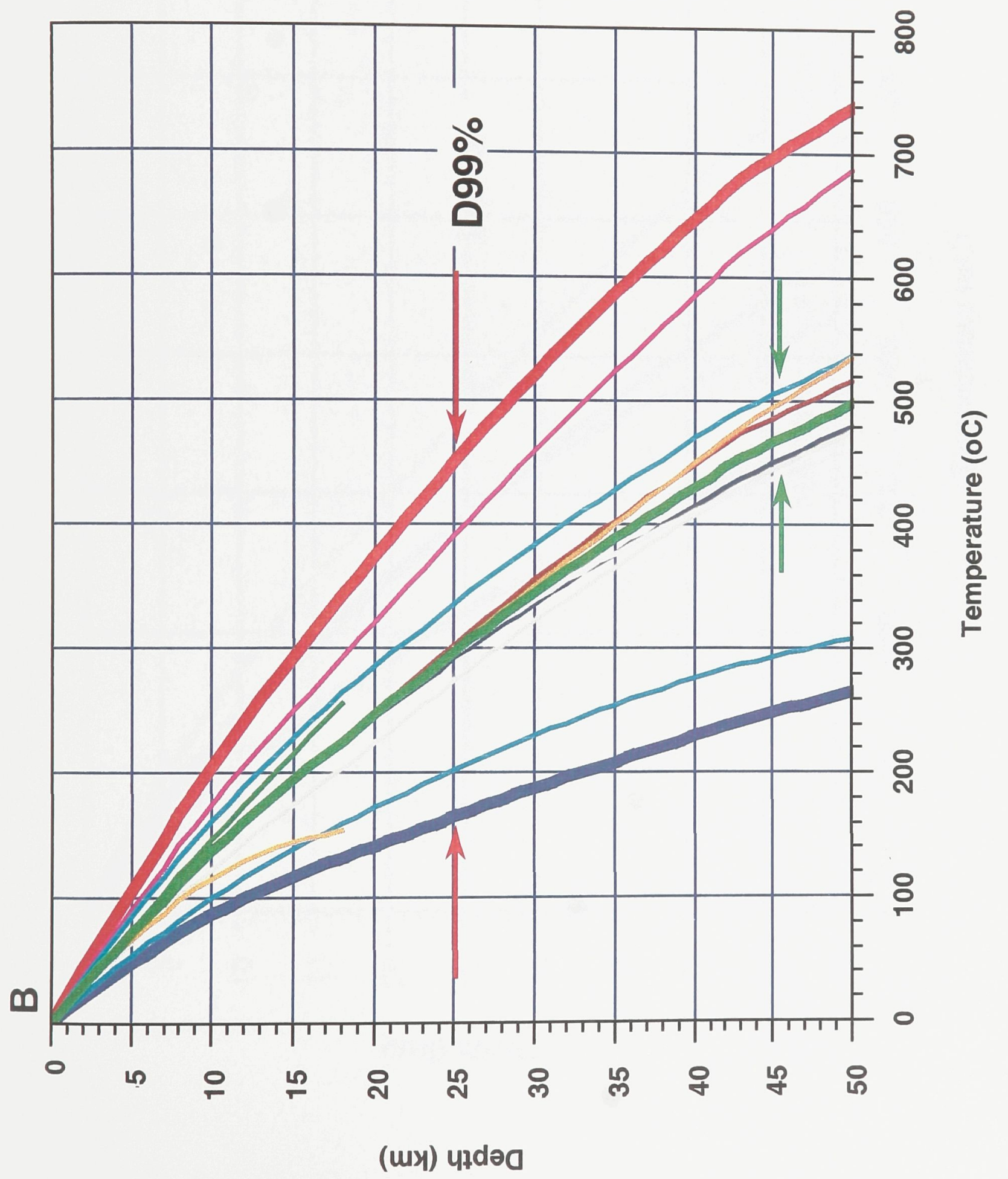




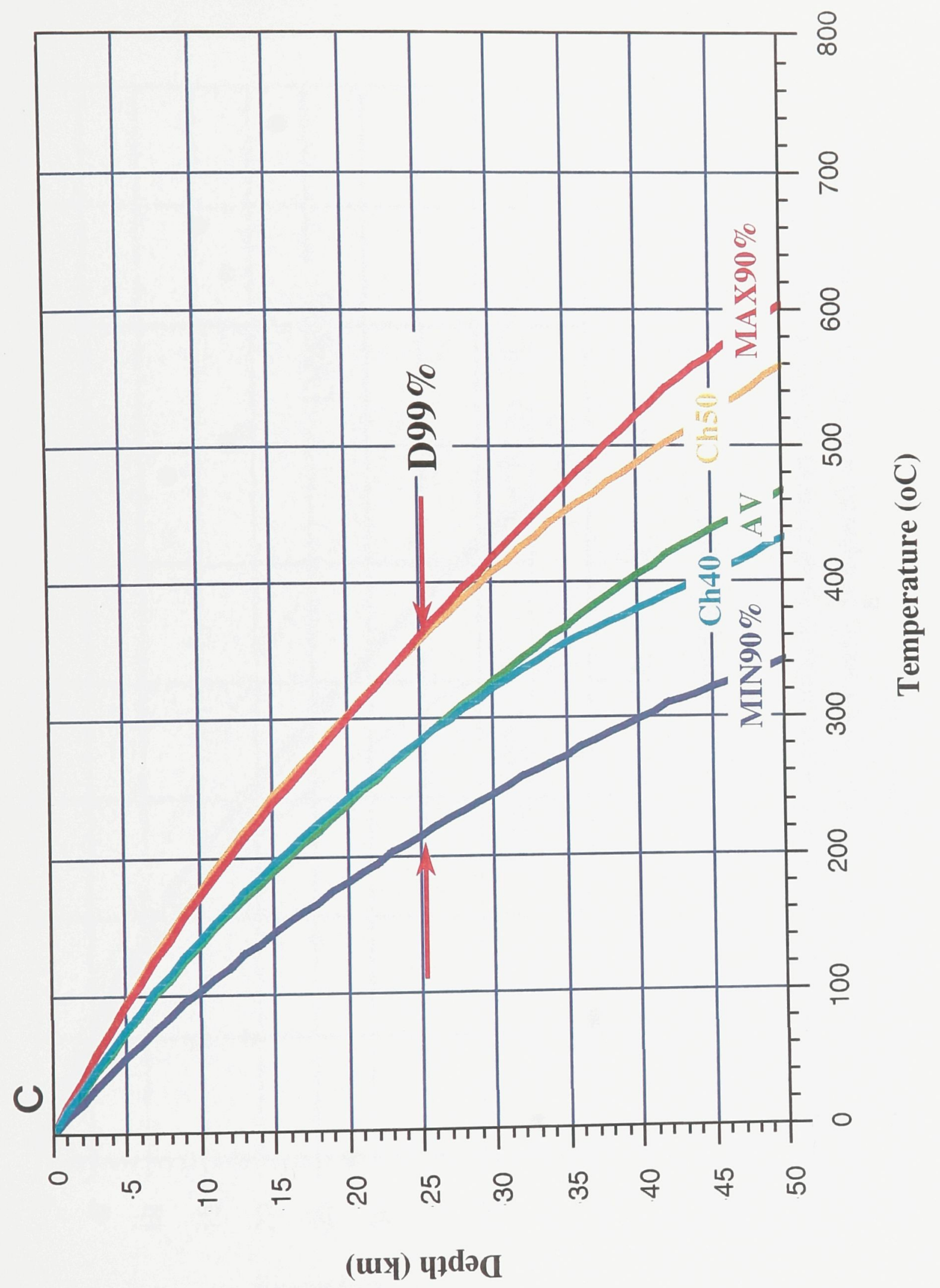




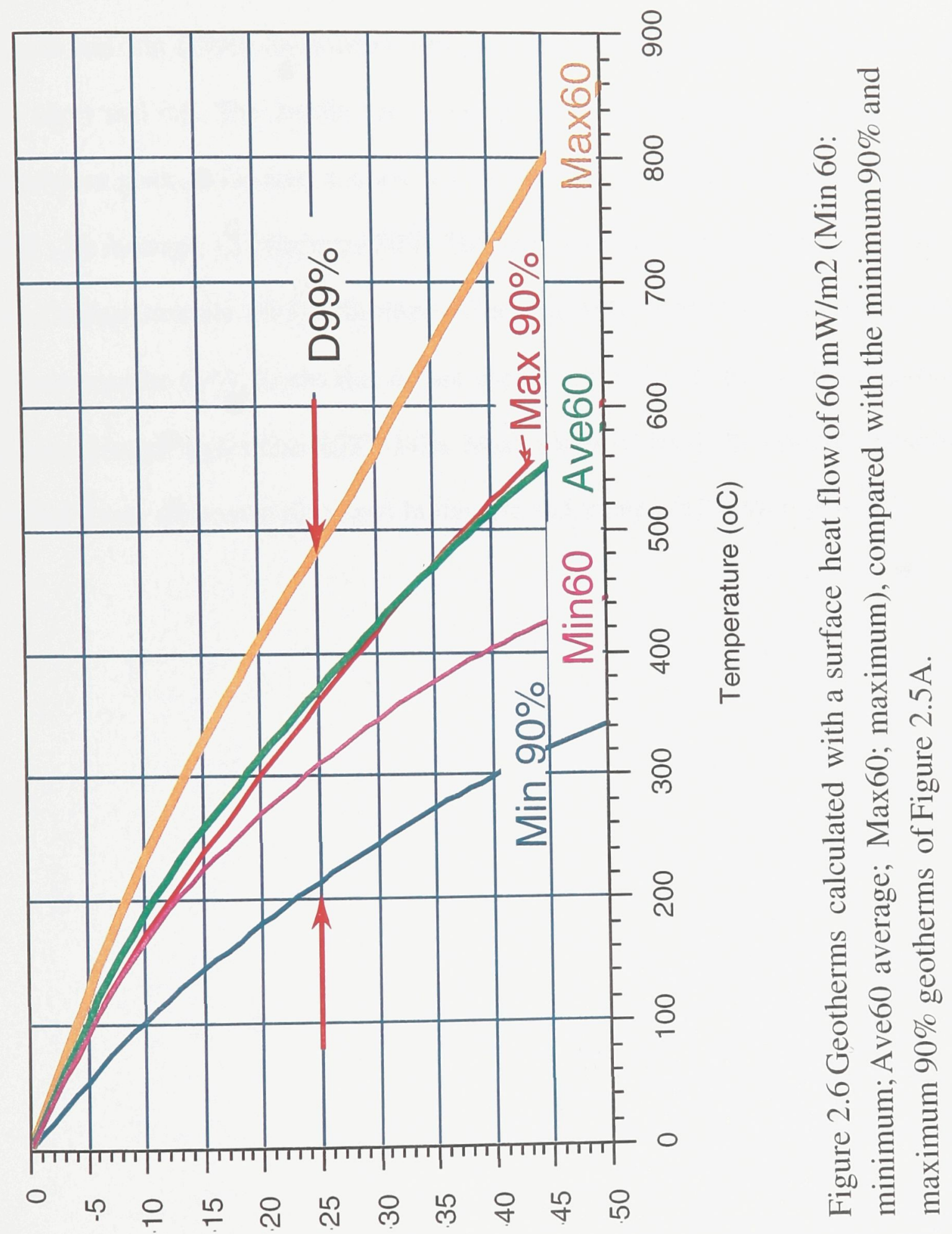

(uy)yاdəa 
Figure 2.7 Crustal strength as a function of depth. The brittle part is computed from the Ranalli and Yin (1990) formulation using $\mu=0.75, \mathrm{~S}_{0}=10 \mathrm{MPa}, \rho=2.6 \mathrm{~g} \cdot \mathrm{cm}^{-3}$ and $\lambda=$ 0.0 (dry) and 0.9 . The ductile part is computed using equation 2.17 , with rheological parameters given in the text, a strain rate of $10^{-16} \mathrm{~s}^{-1}$, and three geotherms: A) Minimum 90\% ; B) Average; C) Maximum 90\%. The rocks used are: Adirondack Granulites (AG); wet Orthopyroxenite (wO); Pikwitonei Granulite (PG); wet Websterite (wW); and wet Clinopyroxenite (wC). Rocks that do not appear in the ductile part of the diagrams have a creep strength higher than $10000 \mathrm{MPa}$. MaxS placed at $200 \mathrm{MPa}$ indicates the maximum crustal stress difference discussed in the text and interpreted from Figure 2.3. 


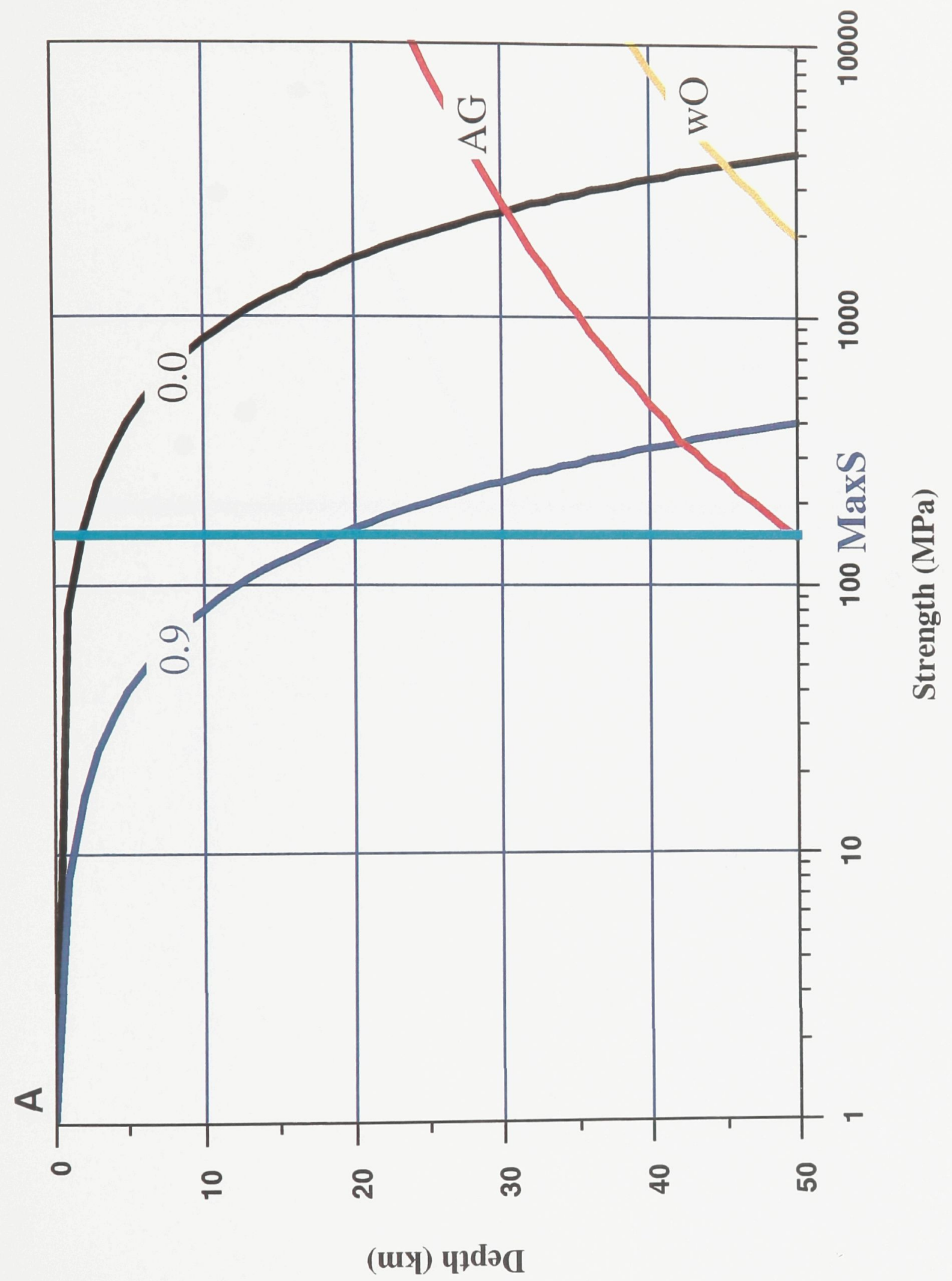




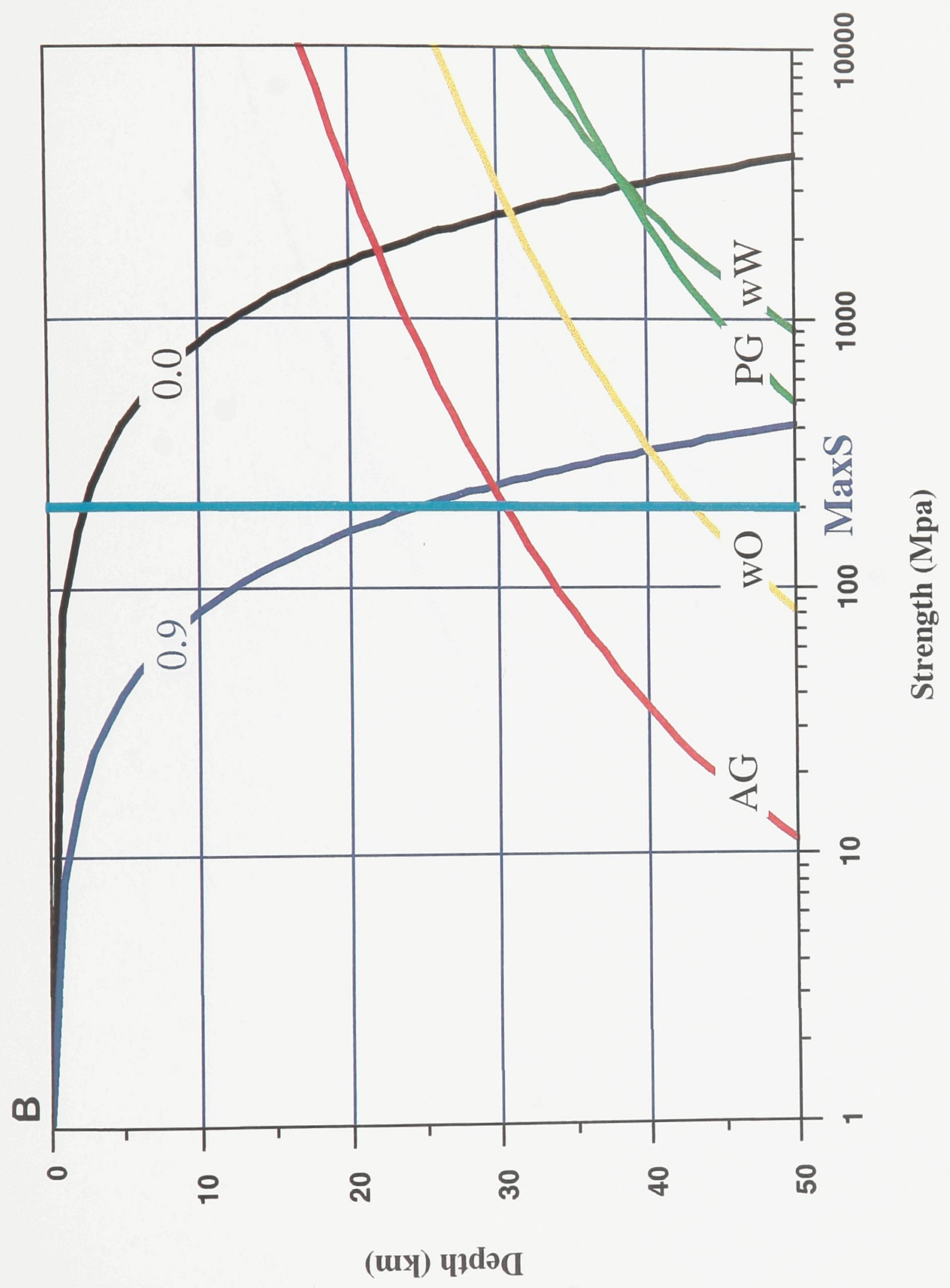




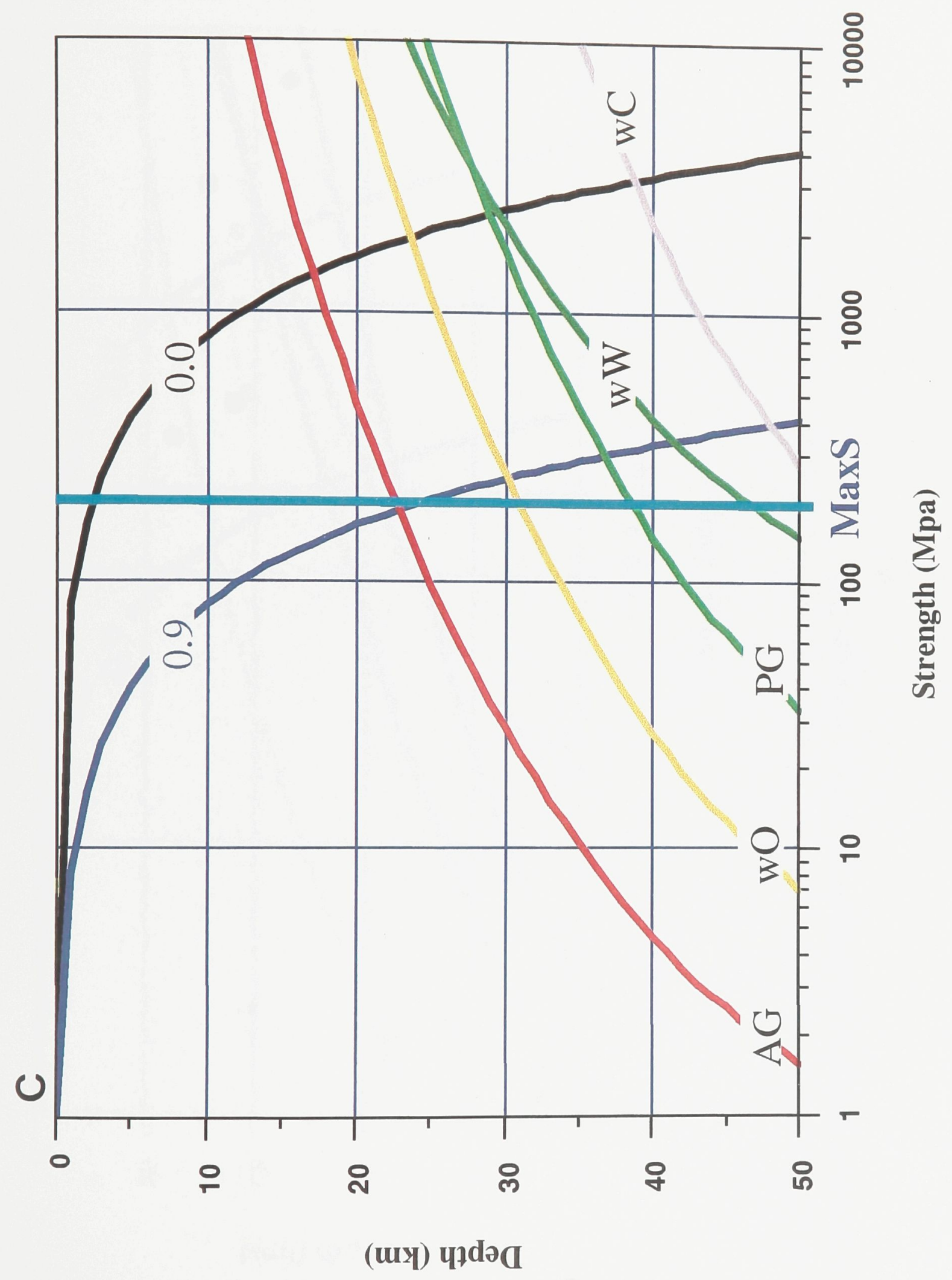



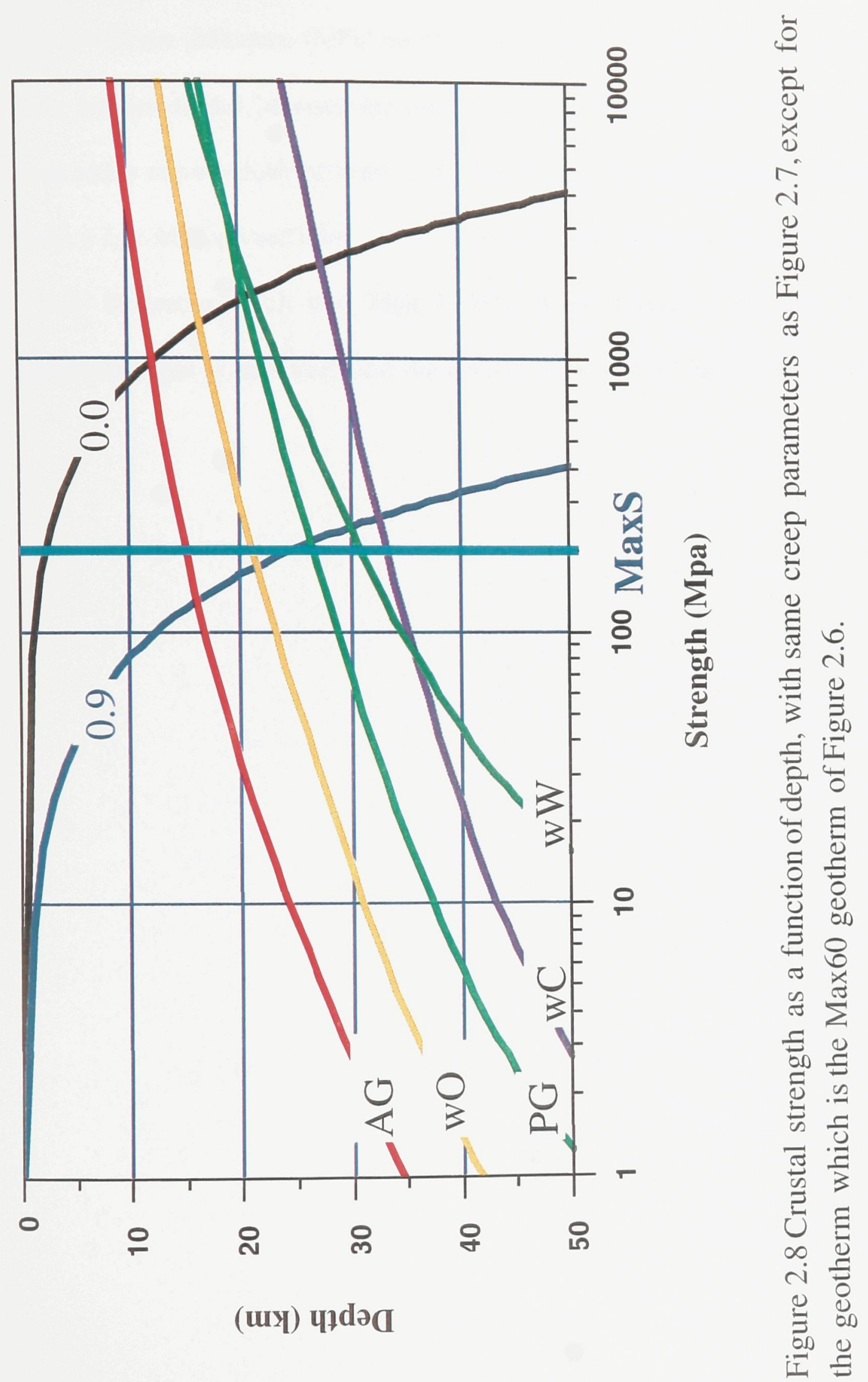
Figure 2.9 Stress difference (MPa) necessary to reactivate a fault located at a depth of 20 $\mathrm{km}$ for various angles between the maximum compressive stress axis and the fault and various ratios of pore fluid pressure $\lambda$ : A) With a friction coefficient $\mu=0.75$ (standard); B) with a low friction coefficient $\mu=0.3$. In A), a maximum stress difference of $200 \mathrm{MPa}$ can only be reached with very high $\lambda$. With a low friction coefficient, the maximum reactivation angle is increased and the necessary pore-fluid pressure is decreased. 


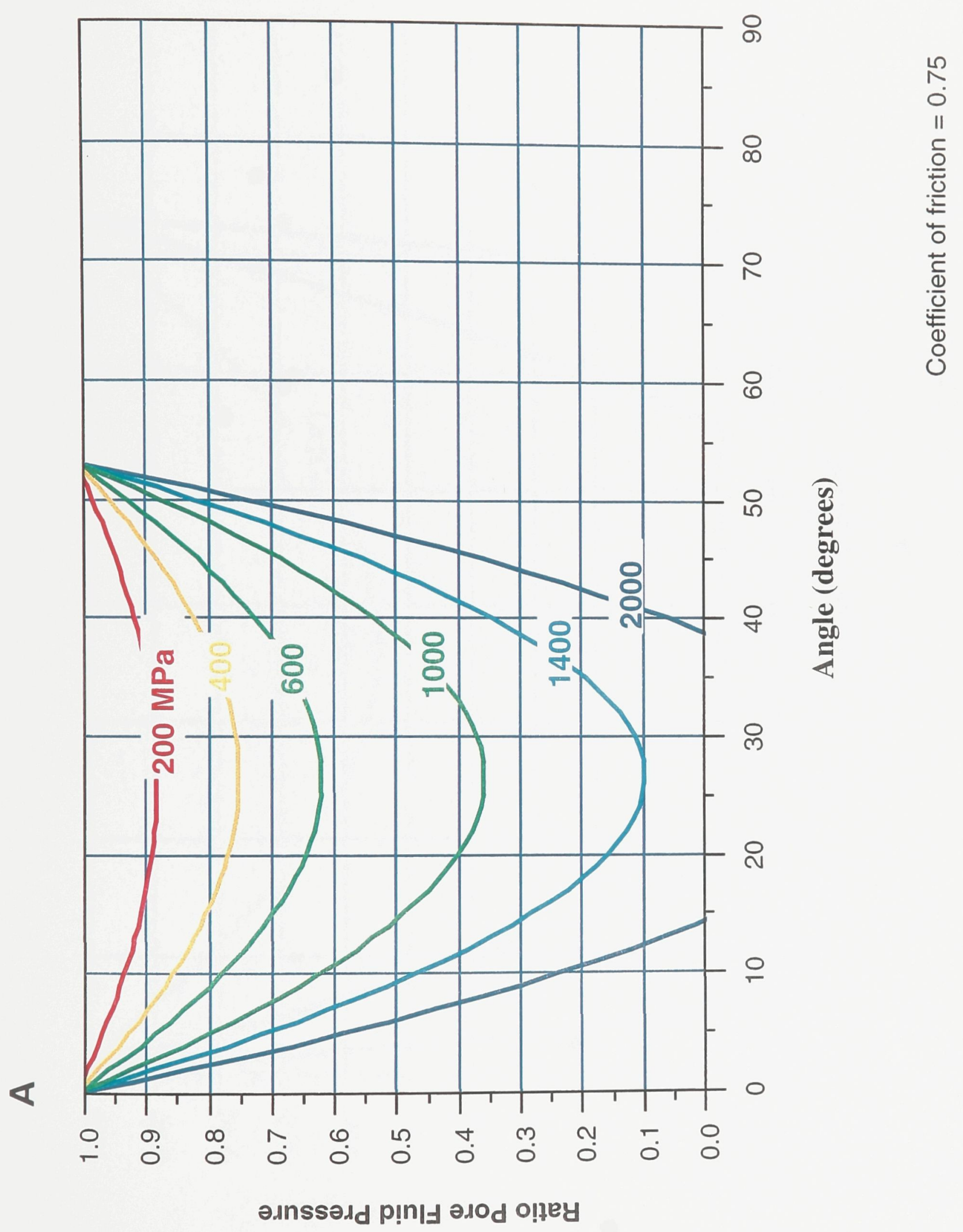




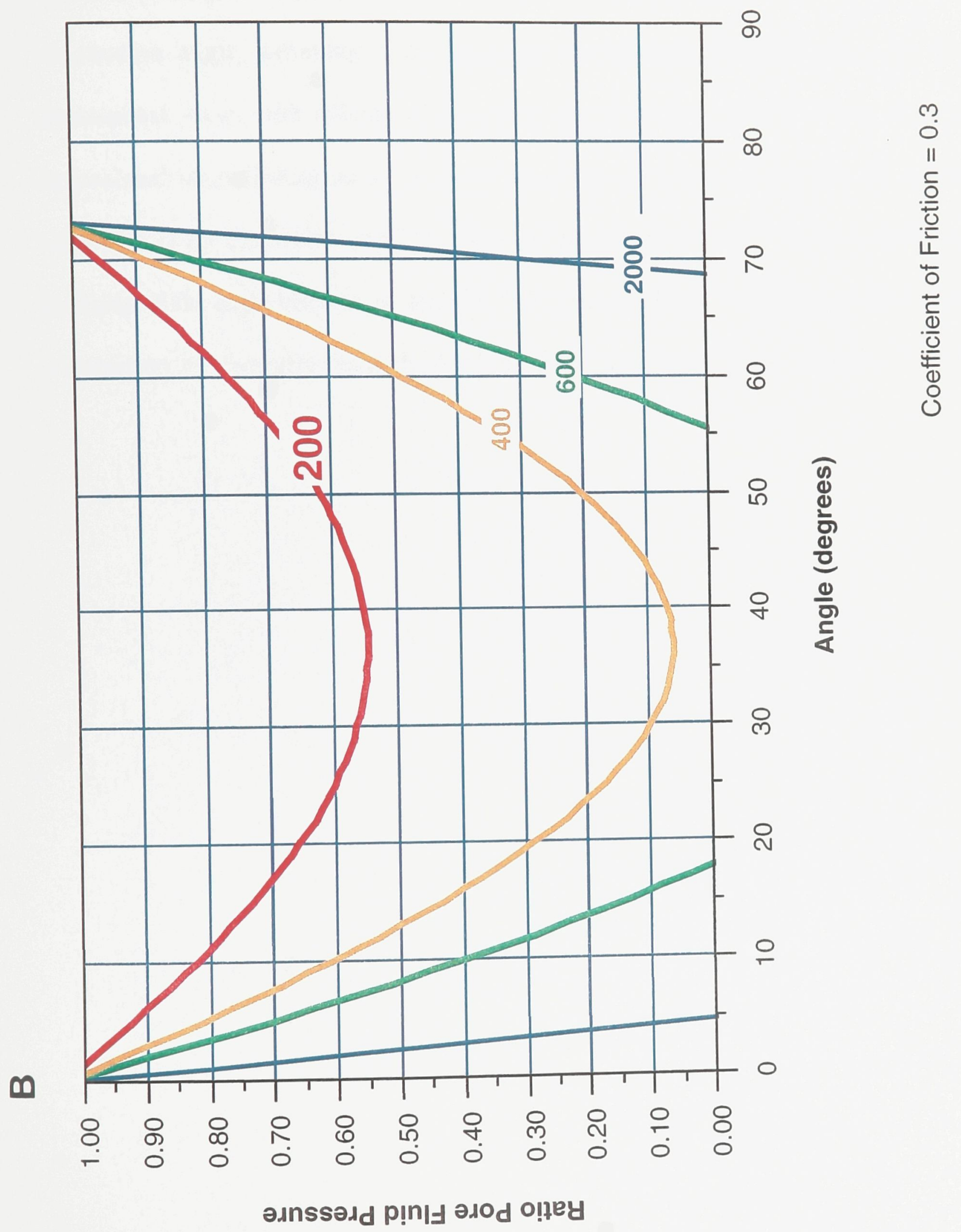


Figure 2.10 Map of the relation between pore-fluid pressure, coefficient of friction and reactivation angle, assuming a maximum stress difference of $200 \mathrm{MPa}$. A) Three dimensional view, with colours representing the pore fluid pressure ratio; B) a two dimensional view. Taking an angle of $30^{\circ}$ as an example, one can see that the assumed value of 0.75 for the friction coefficient requires pore fluid pressures in the $>0.80$ range. Similarly, if the angle between $\sigma_{1}$ and the fault plane is $70^{\circ}, a<0.35$ friction coefficient is necessary to reactivate the fault. Areas in black are outside the range $0.0 \leq \lambda \leq 1.0$. 


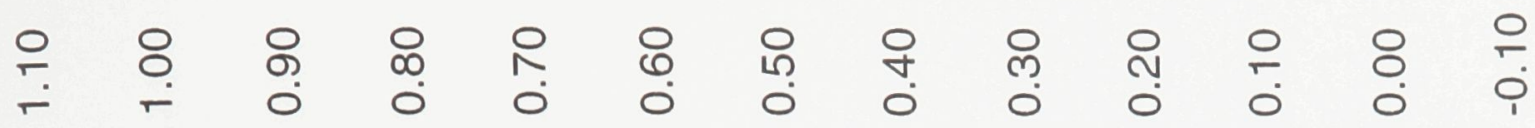
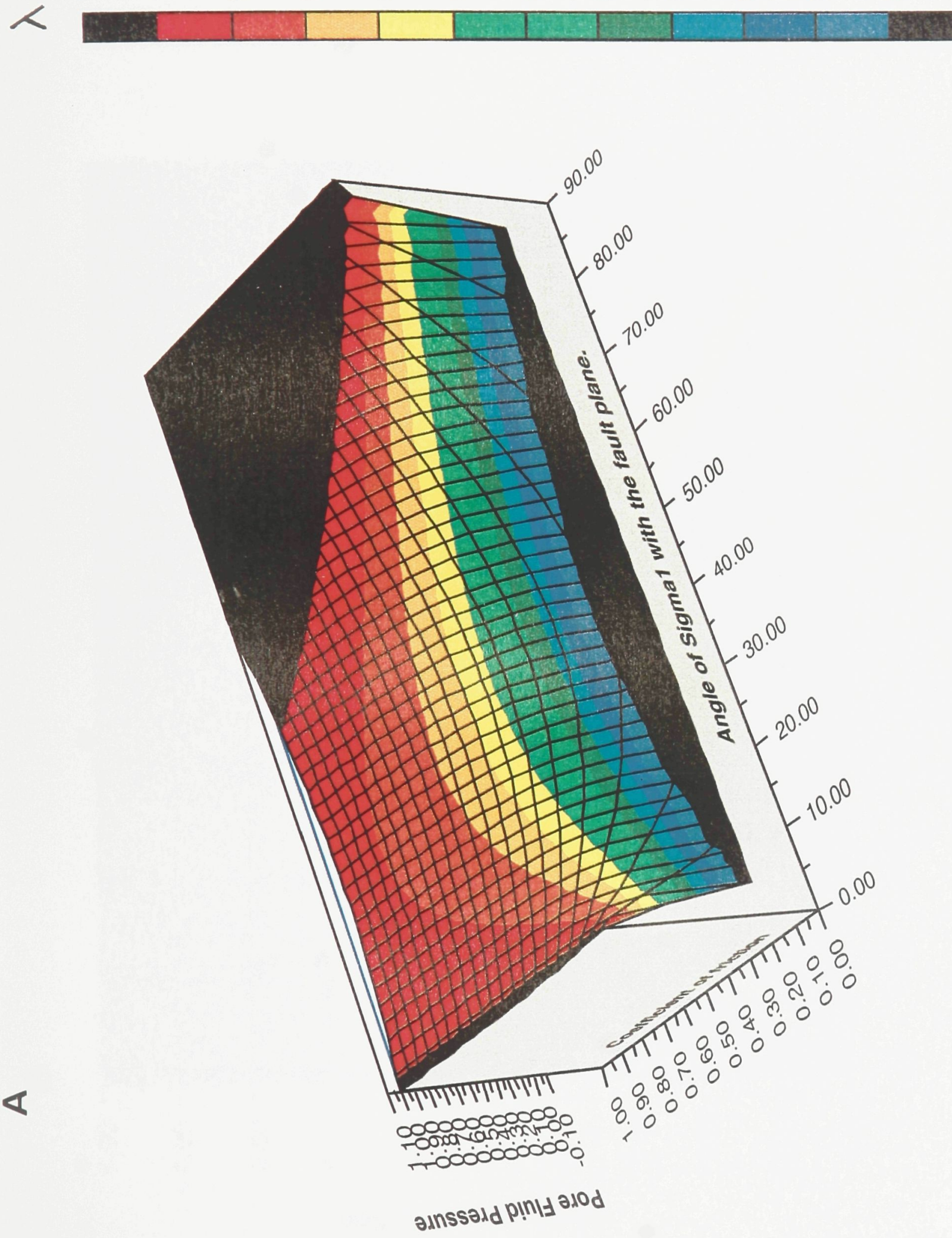


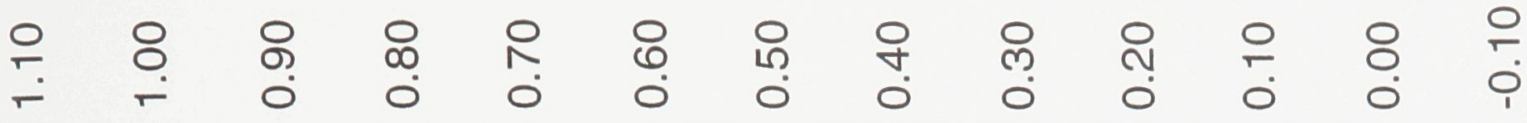
\begin{tabular}{|r|l|l|l|l|l|l|l|}
\hline & & & & & & & \\
\hline
\end{tabular}

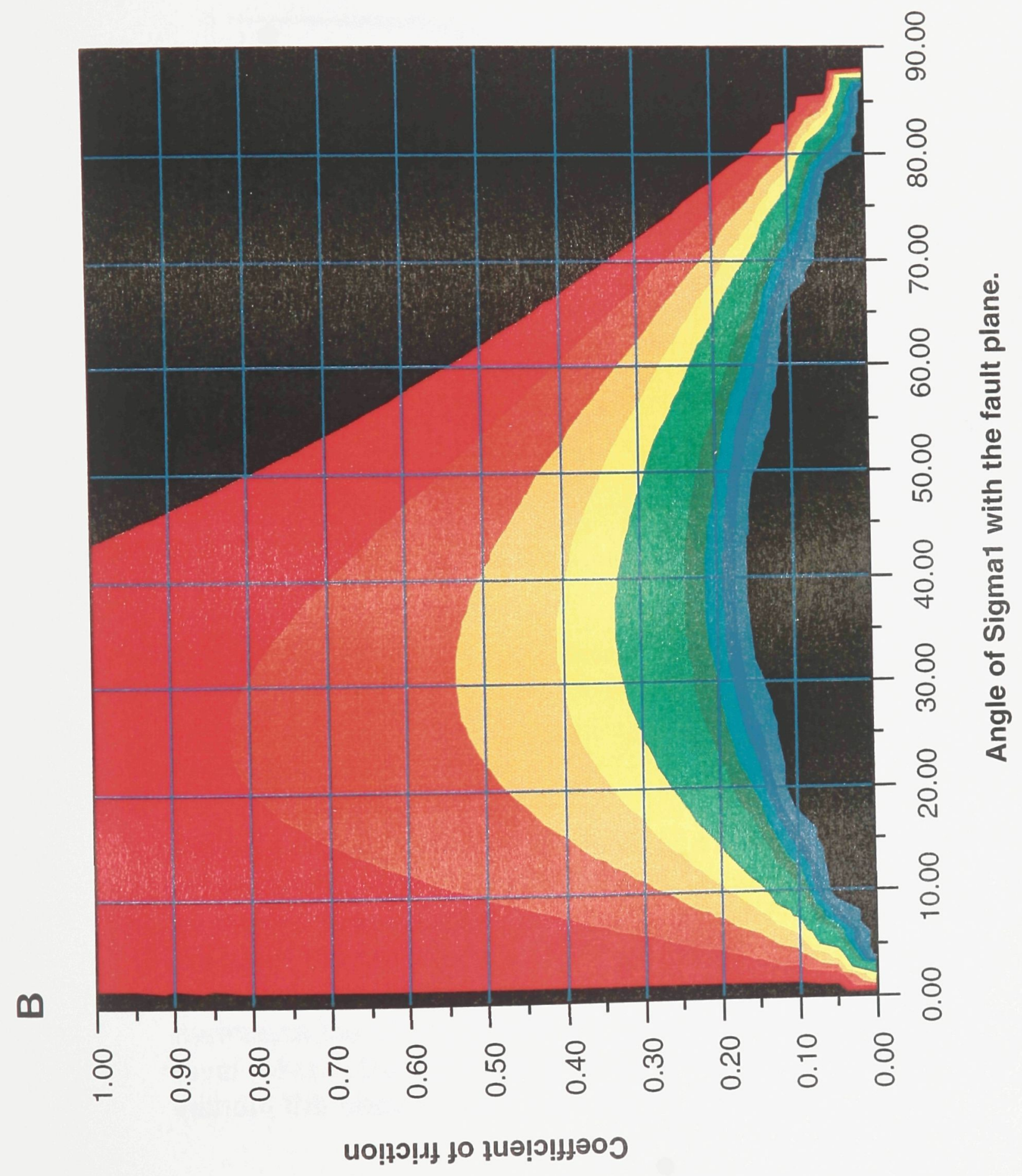




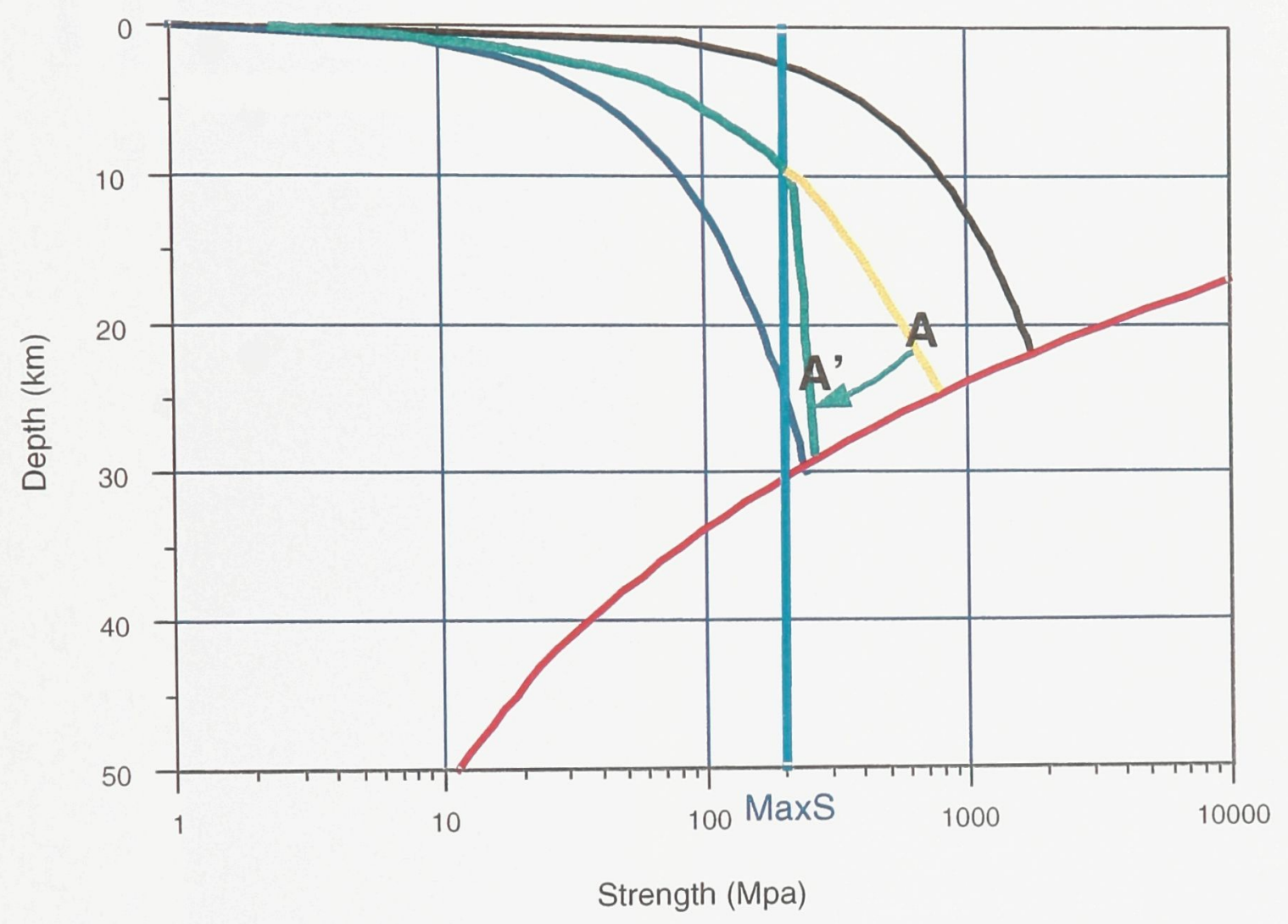

Figure 2.11 Example of the impact of a change in fracture type for the rheological profile. At a given depth $(10 \mathrm{~km}$ in this example), the brittle fracture changes from Byerlee's law (A), between the dry (black) and the wet (blue) curves, to a high pressure type of fracturing $\left(A^{\prime}\right)$. This change in fracture type maintains the strength near the maximum plausible crustal level (MaxS). Earthquakes can occur down to the ductile level without the need for very high stress difference. 

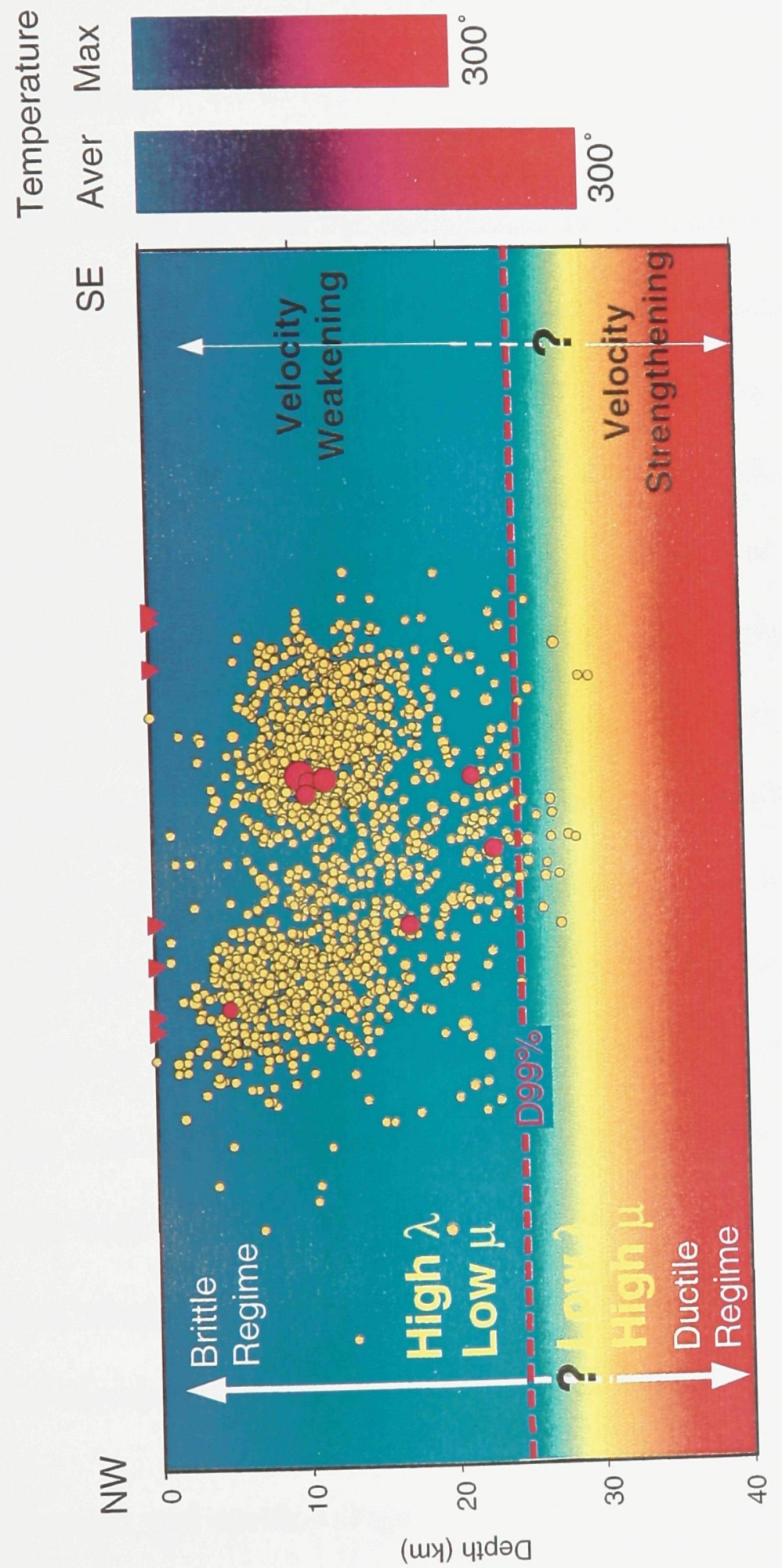

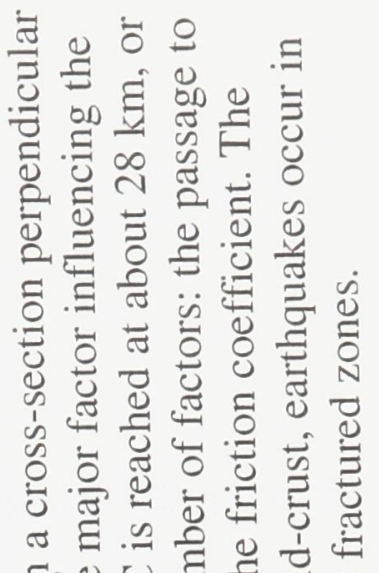

107

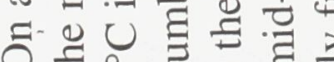
N.F

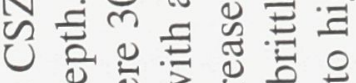
\& ชิ ఏ $\Xi \frac{1}{\square} \Xi \Xi$ ปั ป

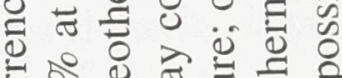

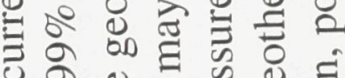
ठู่

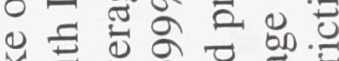

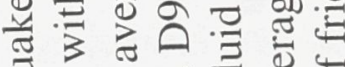

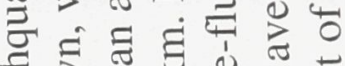

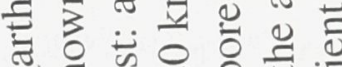
(i) 至 त

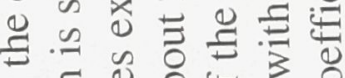

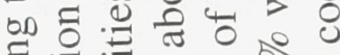

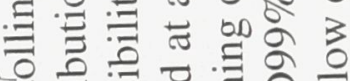

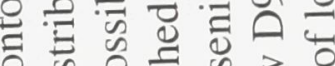

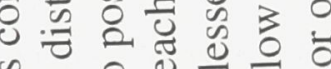
S $000 \%$ 은.

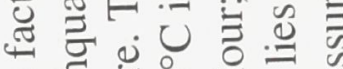
\&

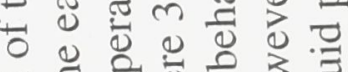

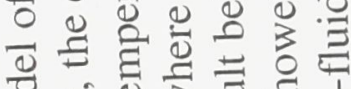
过包主完 घ. ¿ छ 뜨 \&.

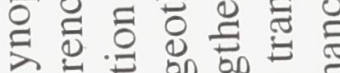

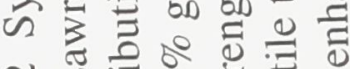
느유유ํ

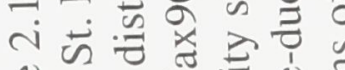

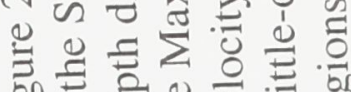
品 0 की 


\section{Chapter 3}

\section{Geological faults in the CSZ and their correlation with earthquakes}

\subsection{Introduction}

The relation between the earthquakes of the Charlevoix Seismic Zone (CSZ) and the St. Lawrence rift faults is a major element in the seismic zoning of Eastern Canada. It is generally assumed that CSZ earthquakes cluster along or between the St. Lawrence paleo-rift faults (also called Iapetan faults; Anglin, 1984; Adams et al., 1995). This relationship is obscured by the incomplete knowledge of geological faults, especially under the St. Lawrence River. In this chapter, the geological faults of the CSZ are described, in some cases for the first time, using geophysical, geological and remote sensing information. This analysis relies on new geoscientific information (gravity, radar images, seismic profiles) and more powerful analysis techniques of the potential fields. Based on this information, the spatial correlations between geological faults and earthquakes are reexamined. The chapter is divided in three parts. First, the geoscientific data sets and the interpretation methods are presented. Second, regional faults are described with newly-acquired remote sensing imagery, potential fields, seismics and geological mapping. Finally, the relationships between the earthquakes and faults of the CSZ are discussed. Figure 3.1 displays the main place names used in text.

\subsection{Data sets and methodology}

Three major types of information are used to refine knowledge of the positions of 
geological faults: remote sensing imagery (airborne and satellite-borne radar); geophysical data sets (seismics, magnetics and gravity); and field mapping of the north shore (Roy, 1978; Rondot, 1979; 1989).

\subsubsection{Remote sensing imagery}

On land, remote sensing imagery, mainly radar, is central to analysis and interpretation. Passive remote sensing systems, such as SPOT or Landsat, record the energy reflected by the Earth's surface at frequencies roughly equivalent to those detected by our eyes. Landsat images of the region were examined but did not yield any structural information not already described by Rondot (1979). Radar sensors, on the other hand, are active systems that send a microwave pulse towards the Earth's surface and measure the amount of energy reflected (Figure 3.2). Unlike passive systems, radar is not affected by atmospheric conditions, such as darkness, clouds, rain, dust, or haze. For geological applications, the incidence angle of the beam enhances terrain topography, often related to structural lineaments.

Over the course of this study, radar coverage of the CSZ became available: Canadian airborne SAR (Synthetic Aperture Radar), the satellite-borne ERS-1 (European Remote Sensing Satellite), JERS-1 (Japanese Earth Resources Satellite) and Radarsat (Canada) (Figure 3.3), each one with its own look directions and incidence angles. Most images were corrected geometrically using ground reference points, an acceptable approximation for the low relief areas near the centre of the impact structure but approximate for the steep elevation gradients of the Laurentians. The Radarsat data were 
ortho-corrected by the Canada Centre for Remote Sensing, resulting in accurate lineament orientations (T. Toutin, pers. comm.). The various radar images partly overlap over the crater.

On the radar images, the most striking regional feature is the impact crater. Inside the crater, the topography is generally subdued, due to the intense fracturing that favoured erosion. In the Laurentians, north-south lineaments are sub-parallel to the main direction of the glacier flow (Roy et al., 1993; De Sève et al., 1994), suggesting preferential glacial erosion along that trend. Other smaller lineaments match the regional lithologies.

\subsubsection{Geophysical data sets}

Geophysical data sets include the magnetic and Bouguer gravity fields and a series of seismic profiles acquired in the early 1970's, under the leadership of the Société Québécoise d'Initiatives Pétrolières (SOQUIP).

\subsubsection{Magnetics}

Regional magnetic maps show the spatial distribution of geological units with different magnetic susceptibilities. Sedimentary rocks have the lowest average susceptibility and basic igneous rocks, the highest (Telford et al., 1976). In the CSZ, these differences in magnetic susceptibilities result in the north shore having a highly variable magnetic field, due to the outcropping Precambrian rocks, and the south shore having a very smooth field due to the deep Precambrian basement under the almost magnetically transparent Appalachian nappes (Figure 3.4). The magnetically contrasting areas 
correspond to variations in Precambrian lithologies and in Precambrian basement depth under the Appalachians. Steps in the Precambrian basement depth can correspond to normal faults. Our depth estimates are not dependent on the magnitude of the anomaly, but rather on the anomaly shape, especially the sharpness. An outcropping Precambrian unit will produce a sharp anomaly, whereas the same body will have a low frequency signature if buried under a few kilometres of Appalachian nappes.

With the Euler deconvolution technique, steep gradients in the potential fields can be interpreted as sources of various shapes and depth (Figure 3.5). Assuming a shape for the source of the magnetic anomaly, the Euler deconvolution provides the depth and the location of the source (Thomson, 1982; Reid et al., 1990). The technique is based on Euler's homogeneity equation

$$
\left(\mathrm{x}-\mathrm{x}_{0}\right) \partial \mathrm{T} / \partial \mathrm{x}+\left(\mathrm{y}-\mathrm{y}_{0}\right) \partial \mathrm{T} / \partial \mathrm{y}+\left(\mathrm{z}-\mathrm{z}_{0}\right) \partial \mathrm{T} / \partial \mathrm{z}=\mathrm{N}(\mathrm{B}-\mathrm{T})
$$

where $\left(\mathrm{x}_{0}, \mathrm{y}_{0}, \mathrm{z}_{0}\right)$ is the source position, whose total field $(T)$ is detected at $(\mathrm{x}, \mathrm{y}, \mathrm{z})$, with a regional field value $(\mathrm{B})$. The factor $(\mathrm{N})$ is the order of homogeneity, also called the structural index. The structural index depends on the geometry of the causative body: for magnetics, a sub-vertical contact corresponds to $\mathrm{N}=0$; for gravity, $\mathrm{N}=1$. Other possible shapes for the magnetics are: sphere $(\mathrm{N}=3)$, vertical pipe $(\mathrm{N}=2)$, and dike $(\mathrm{N}=1)$. The method, explained in more detail in Reid et al. (1990), is as follows. First, the gradients $\partial \mathrm{T} / \partial \mathrm{x}, \partial \mathrm{T} / \partial \mathrm{y}, \partial \mathrm{T} / \partial \mathrm{z}$ are calculated from the gridded data. Second, a square window within the grids of gradient values is determined (10 X 10 for example). Third, for a given structural index, all points in the window are used to solve Euler's equation (3.1) for a 
source position $\left(\mathrm{x}_{0}, \mathrm{y}_{0}, \mathrm{z}_{0}\right)$ and a background value $\mathrm{B}$ using least-squares estimates. The solution is kept if the depth uncertainty is less than a set proportion of the estimated depth. Four, the previous steps are repeated for all possible window positions over the map area. Five, maps of the solutions are produced with a symbol showing the solution's depths.

Euler deconvolution is very sensitive to the gradients of the field and is very useful to identify contacts, or body edges. Reid et al. (1990) provide examples of its use to delimit faults and geological units. With its down-faulted Precambrian basement under the St. Lawrence River, the CSZ geology is ideally suited for this method. The possibilities offered by the Euler solutions were demonstrated with the gravity field (Keating, 1998). Using the CSZ magnetic map, Euler solutions with $\mathrm{N}=0$ provides an estimate of the location and depth of a sub-vertical contact separating lithologies with contrasted magnetic susceptibilities. Hence, where the Precambrian outcrops, Euler solutions should be shallow. Under the St. Lawrence River, along with the Precambrian basement, Euler solutions progressively deepen. Consequently, the Euler solutions provide estimates of the position and depth of the Precambrian contacts.

The Euler solutions for the CSZ are shown in Figure 3.5. As one can see, most of the shallow solutions are found on, or near, the north shore, where the Precambrian either outcrops, or is near the surface. The solutions can be used to map the depth variations of the Precambrian basement. From seismic reflection profiles, no Euler solutions exist where the Precambrian is deeper than about $6 \mathrm{~km}$. 


\subsubsection{Gravity and rock densities}

Bouguer anomaly maps represent the gravity field, which depends mainly on the crustal distribution of rock densities. Until 1994, the CSZ Bouguer anomaly map was based solely on 300 land measurements, leaving out the most seismogenic part of the CSZ, over the St. Lawrence River. Following a request from the Seismicity Section, the GSC gravity group completed the coverage in August 1994. In the CSZ, the St. Lawrence River is too shallow and narrow for a conventional ship gravity survey. Consequently, a LaCoste and Romberg dynamic gravity meter controlled by a portable computer was installed on a small boat (Figure 3.6; Lamontagne et al., 1995). Differential Global Positioning System (GPS) phase measurements were used to compensate uneven boat motions in the strong tidal currents. To minimize the corrections due to the rotation of the Earth, survey lines were mostly oriented north-south and east-west. Upstream from the CSZ, where navigation is constrained by water depth, the north and the south channels were surveyed. With this survey, the offshore coverage is now better than that on land (Figure 3.7A).

To model gravity anomalies, rock densities were measured on 288 samples from the rock collections of the GSC and the Québec Department of Natural Resources, and some hand specimens. Densities were determined using standard techniques for nonporous rocks (weight in air and water). Our results are comparable to other studies (Table 3.1; Figure 3.7C). The densities of the Grenville rocks show considerable scatter, due to the highly variable lithologies. Our mean density value for the Grenville, $2.71 \mathrm{~g} \cdot \mathrm{cm}^{-3}$, is somewhat lower than elsewhere in the Grenville $\left(2.74 \mathrm{~g} \cdot \mathrm{cm}^{-3}\right.$, Keary and Thomas, 1979; 


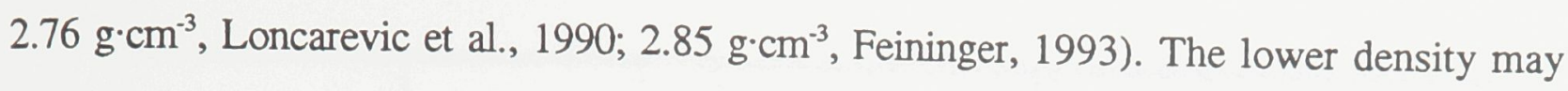
be due to the intense fracturing induced by the impact. The densities of the Ordovician limestones and the Appalachian nappes are clustered around a mean $2.65 \mathrm{~g} \cdot \mathrm{cm}^{-3}$. The density for the hard, compacted and boulder rich Quaternary sequence was established at $2.3 \mathrm{~g}^{\mathrm{cm}} \mathrm{cm}^{-3}$ (B. Long, pers. comm.). For modeling purposes, density contrasts with the Grenville were $-0.15 \mathrm{~g} \cdot \mathrm{cm}^{-3}$ for the Ordovician-Appalachian rocks, and $-0.5 \mathrm{~g} \cdot \mathrm{cm}^{-3}$ for the Quaternary sequence.

\subsubsection{Seismic profiles}

During the early 70's, SOQUIP lead a series of offshore seismic reflection surveys to define the hydrocarbon potential of eastern Québec (Figure 3.8). SOQUIP kindly provided paper copies of the profiles, and later on, the digital data from one seismic line for reprocessing (line 13). The number of folds generally determine the quality of the seismic profiles (Table 3.2). In most profiles, seismic energy trapped in the shallow water of the St. Lawrence River produced multiple reflections that masked deeper reflectors. Most profiles show sub-horizontal reflectors, some in the Quaternary deposits, some in the underlying Precambrian basement and in the Appalachian nappes. The PrecambrianAppalachian interface is generally difficult to identify, probably due to the small acoustic impedance contrast between the indurated Ordovician carbonates and the underlying Precambrian. In the figures and discussions, a seismic P-wave velocity of $6.0 \mathrm{~km} / \mathrm{s}$ is used to convert time to depth (from seismic refraction results; Lyons et al., 1980). This 


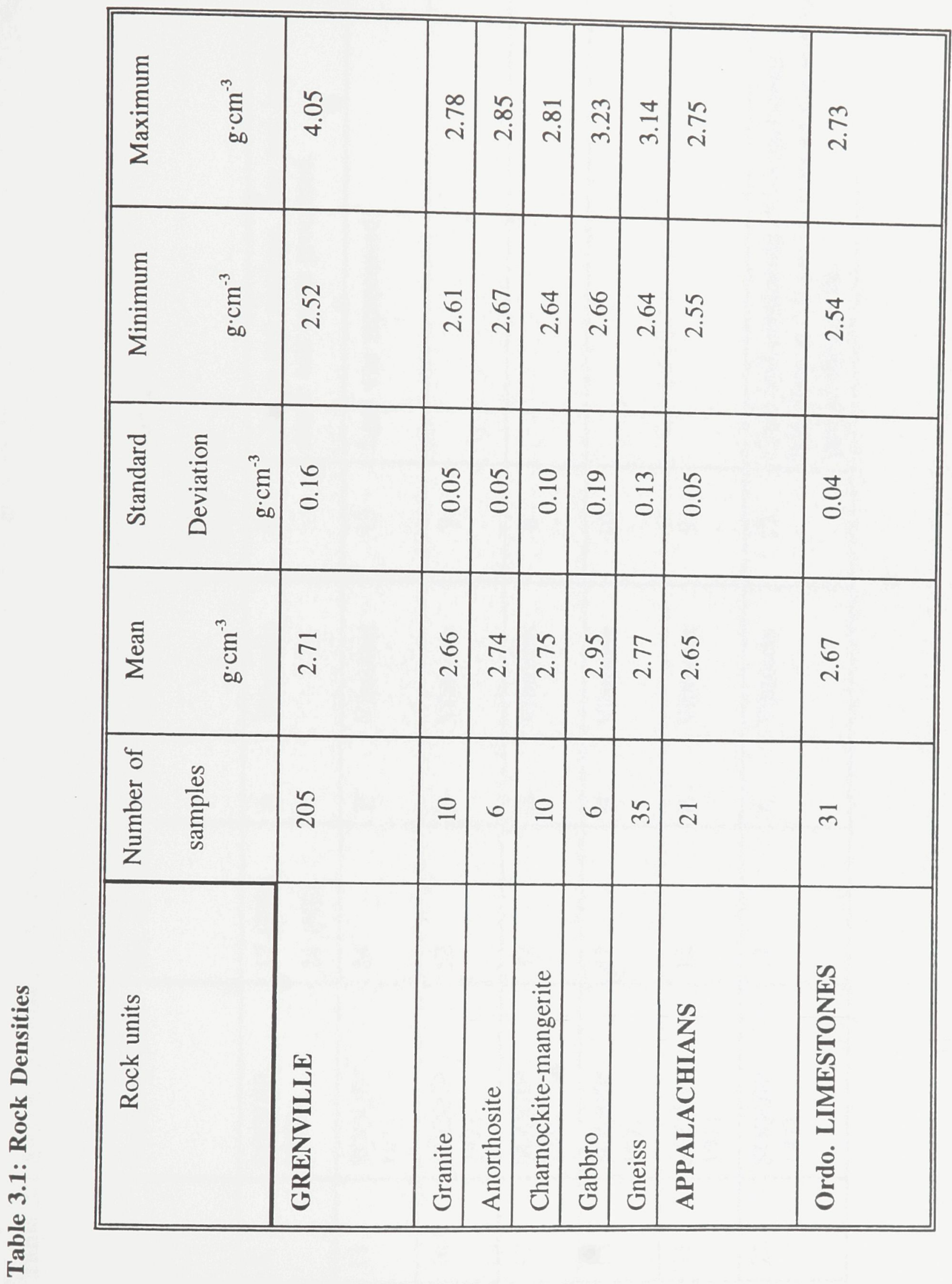




\begin{tabular}{|c|c|c|c|c|c|c|c|}
\hline 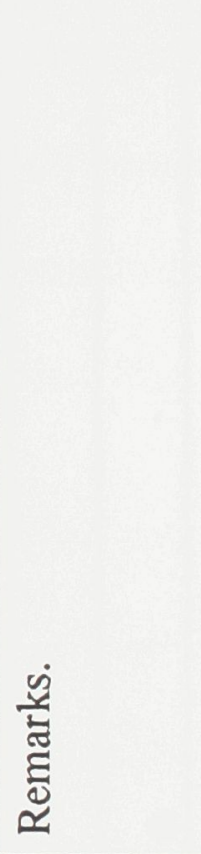 & 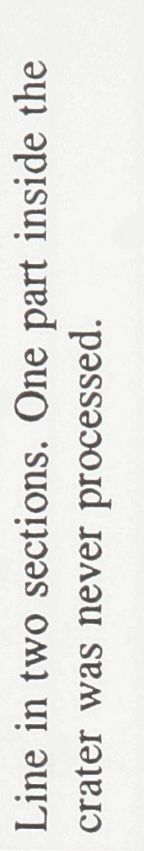 & 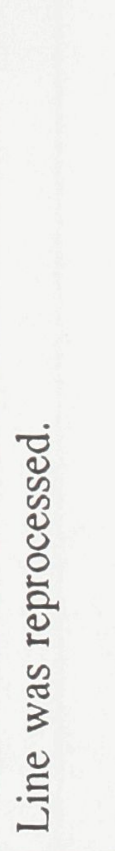 & & & & & 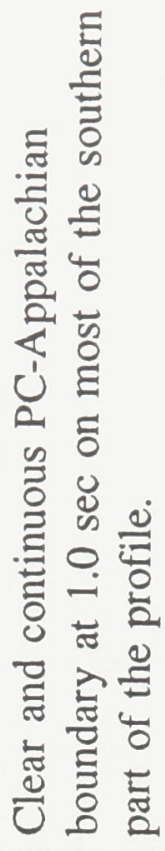 \\
\hline 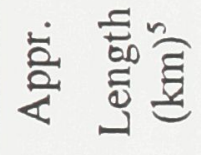 & $\infty$ & 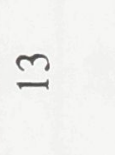 & $a$ & $\infty$ & 으 & $a$ & I \\
\hline 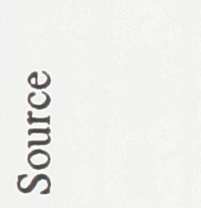 & 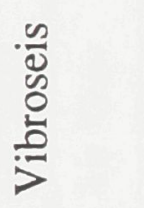 & 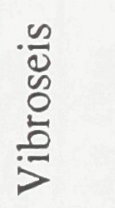 & $\begin{array}{l}\frac{n}{2} \\
0 \\
0 \\
\vdots \\
\frac{5}{7}\end{array}$ & $\begin{array}{l}\frac{n}{D} \\
0 \\
0 \\
0 \\
j\end{array}$ & $\begin{array}{l}\frac{n}{10} \\
0 \\
0 \\
\vdots \\
\vdots \\
0\end{array}$ & $\begin{array}{l}\frac{\infty}{0} \\
0 \\
0 \\
\vdots \\
0 \\
1\end{array}$ & $\begin{array}{l}\infty \\
\mathbb{1} \\
0 \\
0 \\
0 \\
0\end{array}$ \\
\hline 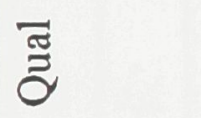 & $<$ & $D$ & 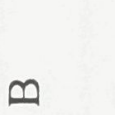 & $D$ & $\infty$ & 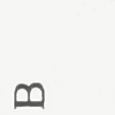 & $\ll$ \\
\hline $\begin{array}{l}\frac{\pi}{0} \\
\frac{1}{4} \\
0 \\
\dot{2}\end{array}$ & 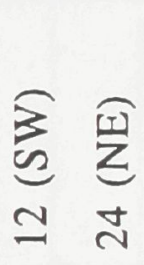 & $\stackrel{ \pm}{\sim}$ & $\simeq$ & $\simeq$ & $\stackrel{\sim}{-}$ & $\simeq$ & 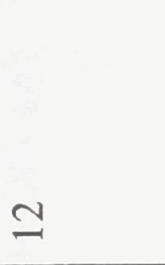 \\
\hline 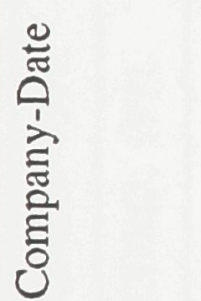 & 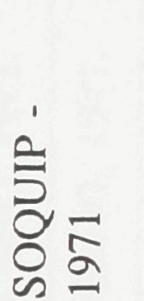 & $\overbrace{0}^{1}=$ & $\overbrace{0}^{1}=$ & 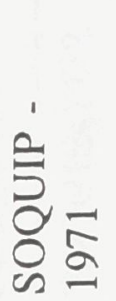 & $\overbrace{\infty}^{\prime} \approx$ & 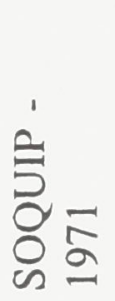 & 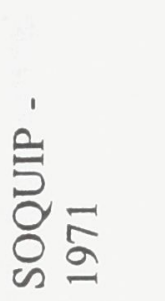 \\
\hline$\stackrel{0}{\Xi}$ & $<$ & 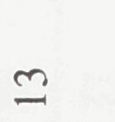 & $\underline{6}$ & $\simeq$ & $\infty$ & $\bar{\sim}$ & N \\
\hline
\end{tabular}




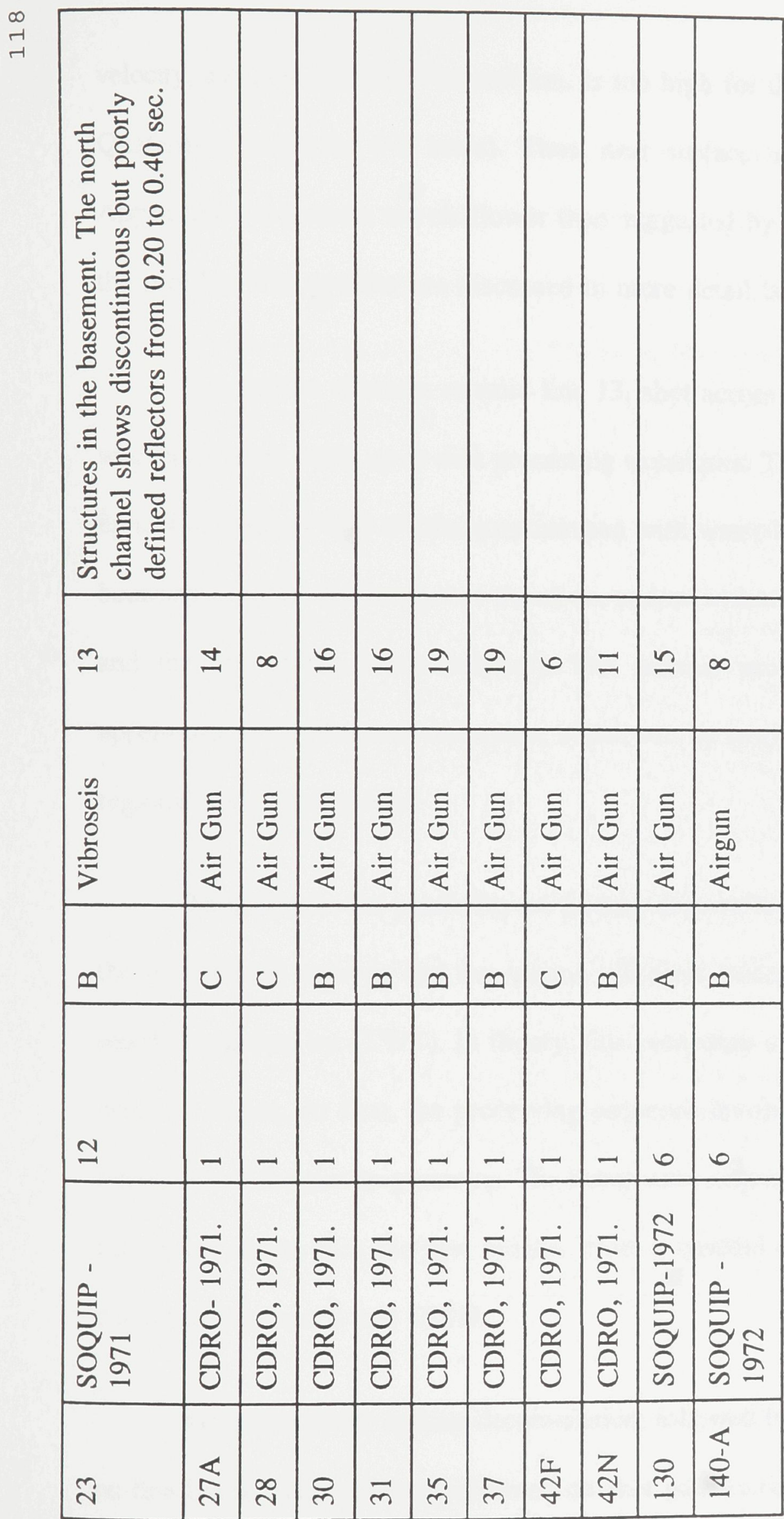

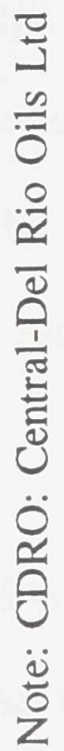


velocity, acceptable for the Precambrian, is too high for the Appalachian $(\approx 5.6 \mathrm{~km} / \mathrm{s})$ and Quaternary sequence $(\approx 2 \mathrm{~km} / \mathrm{s})$. Thus, near surface reflectors in the Quaternary and Appalachian sequences are shallower than suggested by the depth values on the right of the profiles. The profiles are discussed in more detail below.

The marine vibroseis seismic line 13, shot across the St-Lawrence River in 1970, was reprocessed using up-to-date processing techniques. The initial seismic section showed up to 4 seconds (TWT) of data contaminated with water-bottom related multiples (energy bouncing between the bottom of the river, and/or within the sedimentary layers beneath, and the top of the water column). The seismic profile was reprocessed to image upper-crust and mid-crustal reflectors, which can be seismogenic faults, and to refine the regional geological model.

To maximize the possibility of finding deep reflectors, an extended correlation of the raw seismic records and the marine vibroseis sweep was performed, yielding a 13 second long data set (TWT). In theory, this procedure could image reflectors down to a depth of $30 \mathrm{~km}$. At first, the processing sequence involved the extended correlation and integration of the survey geometry. The traces were inspected one by one to discard noisy recordings and to pick the first breaks. From a spectral analysis, most of the signal was contained between 8 and $55 \mathrm{~Hz}$.

Minimum phase spiking deconvolution, followed by predictive deconvolution based on first break energy, were performed on shot gathers to compress the signals, level the spectrum and remove water-bottom related multiples. Velocity analysis turned out to be 
the most important processing step. Semblance and constant velocity analyses were performed. Due to the presence of strong multiples, picks were made on constant velocity stacks. Best seismic velocities vary between $1500 \mathrm{~m} / \mathrm{s}$ in the unconsolidated sediments to more than $5000 \mathrm{~m} / \mathrm{s}$ in the Precambrian shield. The 24-fold data set was stacked and coherency filtering was applied. The resulting section is shown in Figure $3.13 \mathrm{G}$ and $\mathrm{H}$, and discussed in section 3.2.4.

\subsubsection{Testing the methodology on the magnitude $\mathrm{m}_{\mathrm{N}}$ 5.1 Cap-Rouge earthquake}

On November 6, 1997 a magnitude $m_{N} 5.1$ earthquake occurred near Cap-Rouge, in the western suburbs of Quebec City (Nadeau et al., 1998). Since the depth to basement is well-assessed by high quality SOQUIP seismic profiles, this earthquake occurrence provided an opportunity to ground truth the methodology developed for Charlevoix. Geologically, the Quebec City region is very similar to the CSZ; it is an area where the Appalachian nappes were thrust over the rifted Precambrian.

Since the Appalachian nappes are nearly magnetically transparent, the magnetic field partly depends on the depth of the Precambrian Shield. Where the Precambrian Shield outcrops, such as to the North and West of Quebec City, the magnetic field is made up of very high frequency variations in its intensity. Where the Precambrian basement is deeper, such as under the south shore of the St. Lawrence River, the high frequency variations disappear, leaving a smooth field with low frequency variations. This change in wavelength of the magnetic anomalies is due to an abrupt change in the depth of the Precambrian rocks, most likely due to large throw on normal faults. 
The correlation between the magnetic data and the normal faults inferred from the seismic profiles is good. These faults, which have a vertical throw of $2 \mathrm{~km}$ or more, are easily identified in the magnetic data. In general, they correspond to elongated magnetic anomalies whose response is slightly higher on the upthrow side than on the downthrow side. They trend at about $\mathrm{N} 45^{\circ} \mathrm{E}$.

The Cap Rouge epicentre is located on an elongated magnetic anomaly which is a normal fault of the Precambrian basement with vertical slip exceeding $2 \mathrm{~km}$ (Figure 3.9). If the faults dip steeply towards the southeast, as it is generally assumed for the St. Lawrence rift faults, the Neuville fault, located to the NW, may be the reactivated fault, an interpretation supported by the focal mechanism (Nadeau et al., 1998). The mapped Neuville fault is imaged in the magnetics and in the seismics, with a $\approx 2 \mathrm{~km}$ throw. The good correlation between the solutions of the Euler deconvolution and the seismics support the validity of our integrated approach to delineate normal faults in the CSZ, a region where seismic profiles are of lesser quality.

\subsubsection{Profiles across the CSZ}

To define the geological structures along the St. Lawrence River, four profiles were defined in the CSZ, each one with measured and computed Bouguer gravity anomalies, crustal density model, Euler solutions, structural interpretation and one or more nearby seismic profiles (Figure 3.10 to 3.14 ). Gravity modelling has shown that the Quaternary deposits controlled most of the high frequency variations, masking the signal from the Appalachians. The thickness of the Quaternary was resolved using the seismic 
reflection profiles. The longer period variations of the gravity field are related, for the most part, to the depth of the Precambrian-Appalachian interface. Along the north shore of the St. Lawrence River, there appears to be a change in the density of the Precambrian basement, possibly related to the St-Laurent fault. For this reason, the depth of the Precambrian basement there was based on the Euler solutions. The structural interpretations include information from gravity, magnetics, and seismics and display major faults and structures, with approximate fault dips (sub-vertical) and basement depth.

The four models are presented in Figure 3.11-3.14. The Ile-aux-Coudres profile presents many complications, modeling Mle-aux-Coudres being one of them. Near the north shore, there is a sharp gradient in the gravity field, which is interpreted to be due to the combined Quaternary sequence, Ordovician-Appalachian sequence, and possible lower density of the Precambrian basement. Constraints for Ile-aux-Coudres are the depth-tobasement clearly seen on the land profile (Figure $3.11 \mathrm{~F}$ ), and the interpreted step-like structure southeast of the island (Figure $3.11 \mathrm{G}$ and $\mathrm{H}$ ). The island appears to rest on an important normal fault, shown in the Euler solutions. South of the island, the Shield appears to deepen (gravity low with no gradient in the magnetics), while near the south shore, it becomes shallower (Euler solutions and gravity). These suggest the presence of an offshore graben. Under the south shore, there is a large step in the basement, interpreted from the gravity low and the lack of magnetic gradient. The modelled depth of $8 \mathrm{~km}$ is similar to that suggested by seismic refraction and reflection profiles (Lyons et al., 1980).

The crater profile presents characteristics similar to the Ile-aux-Coudres profile, 
i.e., a central portion with no magnetic gradient, and a possible shallower basement towards the south shore. The gravity data suggest variations in the depth of the Precambrian basement under the St. Lawrence River.

The Line 13 profile appears to match a relatively smooth Appalachian-Precambrian interface for the central portion (Figure 3.13 A-D). This interpretation is supported by the reprocessed seismic line (Figure $3.13 \mathrm{H}$ and I). There is a suggestion of a step fault, a few kilometres offshore from the north shore, that brings the Precambrian to a depth of about $2 \mathrm{~km}$. Again, under the south shore, a large normal fault is interpreted from the gravity and the magnetics.

The Me-aux-Lièvres profile is simpler than the previous profiles (Figure 3.14 A-D). A series of three steps in the Precambrian basement fits the gravity field and the magnetic gradient.

\subsection{Geological faults of the CSZ}

Based on the various geoscientific data sets, the main structural aspects of the CSZ can now be outlined. Numerous lineaments exist in the radar images and the geophysical data sets. On land, most faults are described in geological reports (Roy, 1978; Rondot, 1979; 1989), while offshore, most structures are interpreted for the first time. In this section, regional faults are discussed first, followed by the local structures, grouped by sub-areas with similar characteristics: northeast, central and southwest (Figure 3.15). Figure 3.16 shows the adopted fault model for the Precambrian structure of the CSZ. 


\subsubsection{Regional Faults}

The CSZ is cut by the St. Lawrence paleo-rift system, a series of regional normal faults that run parallel to the St. Lawrence River (Kumarapeli, 1978; Rondot, 1979; also called Iapetan normal faults: Wheeler, 1995). Most faults that outcrop on the north shore of the St. Lawrence River, such as the St-Laurent and the Gouffre NW faults are described in geological reports (Rondot, 1979; 1989). Others lie beneath the St. Lawrence River where their existence is revealed by geophysics.

\subsubsection{The St-Laurent fault}

The St-Laurent fault is the most prominent CSZ structure in radar imagery and in the potential field maps. With a length exceeding $150 \mathrm{~km}$ and a vertical throw of $2 \mathrm{~km}$ (Rondot, 1970), it is a major fault of the St. Lawrence paleo-rift system. Created as an Iapetan fault, the St-Laurent fault was reactivated during the Taconian orogeny (Rondot, 1979). The St-Laurent fault is probably made up of multiple fault segments, as suggested by its jagged course between the Ile d'Orléans and the Saguenay River. The gravity and magnetics suggest three main subdivisions of the St-Laurent fault: a southwest and northeast areas separated by a middle portion centred on the impact structure.

In the central uplift of the impact structure, the St-Laurent fault is oriented $N 40^{\circ} \mathrm{E}$ and dips steeply $\left(70^{\circ}\right)$ towards the SE (Rondot, 1979). Here, the St-Laurent fault separates mangerite/charnockite assemblages to the NW from granodioritic to granitic migmatite assemblages to the SE. The lithological change is reflected in the magnetic field, where the generally high values to the NW abruptly change to low values SE of the fault. The 
Bouguer gravity field gradually changes from high values to the NW (-30 mgal or more) to low values to the $\mathrm{SE}$ ( -40 to $-60 \mathrm{mgals})$. On land, the gravimetric low reflects solely the lower density rocks of the Precambrian basement, while offshore, it combines with the low densities of the platform sediments, the Appalachian sequences and the unconsolidated Quaternary sediments. The density change across the fault makes gravity modelling more difficult, as described above for the Ile-aux-Coudres profile.

To the SW of the impact, the St. Laurent fault is parallel to the north shore (oriented $\mathrm{N} 40^{\circ} \mathrm{E}$ ). It may line up with a series of Euler solutions in the magnetics under Ile d'Orléans. There, seismic reflection profiles indicate that, over a $10 \mathrm{~km}$ distance, a series of normal faults oriented north-south brings the depth to Precambrian basement from about $2.1 \mathrm{~km}$ to about $4.7 \mathrm{~km}$ (SOQUIP, pers. comm.).

To the NE of the impact, the St-Laurent fault is not as prominent in the geophysics. The St-Laurent fault never comes ashore there and its position is assumed to follow the north shore from the Gros Cap-à-l'Aigle to Tadoussac (Rondot, 1979). In contrast to the situation within the impact crater, the magnetics do not show any change across the fault. This can be explained by a smaller throw than to the SW or by a much thinner sedimentary cover. The fault may die out NE of the impact. 


\subsubsection{The Gouffre NW fault}

The Gouffre NW fault (sometimes called Gouffre) is named after a small creek that flows into the Gouffre River near Baie-St-Paul. To the SW of the crater, this fault is a prominent lineament on the radar images and in the magnetics (Figures 3.17). Within the impact crater and to the northeast, the fault position is not obvious. Geologically, its position inside the impact is based on stratigraphic evidence that suggests that the fault existed at the time of deposition (Rondot, 1968). To the NE, its extension is based on lineaments with similar trends. Compared with the St-Laurent fault, the Gouffre NW fault appears to have a small throw with little or no geophysical signature inside the CSZ. Its position is approximate within the impact and uncertain to the NE.

\subsubsection{The Charlevoix fault (new feature)}

A few kilometres offshore from lle d'Orléans to Tadoussac, a normal fault parallels the St-Laurent fault. The fault separates a $2-8 \mathrm{~km}$ wide Precambrian basement plateau from a deeper basement to the southeast. In the magnetics, the plateau corresponds to high frequency anomalies, while the deeper basement correspond to low frequency anomalies. The fault's gravity signature is less conspicuous due to the proximity of the St-Laurent fault and to the sediment-filled valleys. In the southwestern portion of the fault, the SE shallow-dipping Precambrian-Appalachian plateau is imaged at $\approx 3.0 \mathrm{~km}$ depth (Figure 3.18). Under De-aux-Coudres, the fault may also correspond to the truncated Precambrian reflector of Figure 3.11E. The position of the Charlevoix fault coincides with the overlying Logan's thrust, suggesting that the footwall may have acted as a buttress, or that 
the fault was reactivated by the weight of the advancing nappes.

\subsubsection{The South Shore fault (new feature)}

Along the south shore of the St. Lawrence River, the gravity and the magnetic fields suggest a large normal fault in the Precambrian basement. On all profiles, gravity modelling suggests that the Precambrian depth drops from about $3-4 \mathrm{~km}$ to $7-8 \mathrm{~km}$. The latter depth value corresponds to the seismic refraction results (Lyons et al., 1980). In the southern part of the fault, slightly outside the CSZ, the Bouguer anomaly low implies an even deeper basement than to the NE. The gravity suggests that this fault may terminate near Ile-aux-Grues.

\subsubsection{Northeast zone}

In the NE section of the CSZ, the NS trend of lineaments seen on land continues under the River. While the St-Laurent fault trends mostly NE, in this northern portion of the "Jacques Cartier block", a large proportion of lineaments trend NNE (Roy et al., 1993). Under the St. Lawrence River, a similar trend is found in the Euler solutions (Figure 3.5C). Most of these lineaments appear to relate to Precambrian lithologies.

South of Ile-aux-Lièvres and oriented parallel to the St. Lawrence River axis, a normal fault is suggested by the gravity and by the Euler solutions (Ile-aux-Lièvres fault). Gravity modelling (Figure 3.14A-D) suggests a 2 to $3 \mathrm{~km}$ throw for this fault, i.e. comparable to the St-Laurent fault. This is supported by the magnetics and the Euler solutions that get progressively deeper southeast of this fault. The fault runs from the 
outer rim of the impact crater, near La Malbaie, and extends beyond the NE boundary of the CSZ.

The Palissades fault (PAL), the southernmost fault of the Saguenay graben, is supposed to correspond to the NE extension of the seismic zone (Anglin, 1984). This structure of regional extent can be seen on ERS-1 imagery to the NW, outside the seismic zone. The Palissades fault my continue offshore, as suggested by the Euler solutions and the gravity.

\subsubsection{The impact structure faults}

The $55 \mathrm{~km}$ diameter Charlevoix astrobleme of Devonian age ( $\approx 350 \mathrm{Ma}$; Rondot, 1979) is a "complex" impact structure characterized by a central uplift surrounded by an annular trough and a peripheral down-faulted structurally complex rim (Grieve, 1993). Across the structure, the nature and the extent of the block movements vary from upward movement in the central uplift to subsidence in the rim. The faults directly created by the impact are found near the central uplift, where the shock has been most intense, and where the vertical movement can reach $9 \mathrm{~km}$ (Robertson, 1975). This area is made up of a series of blocks separated by normal faults (Roy, 1978). In the rim, structures are a series of locally sub-parallel normal faults of about $11 \mathrm{~km}$ depth extent (Rondot, 1994; similar to the Siljan impact structure of Sweden; Juhlin and Pedersen, 1987). Whereas most rim faults are conspicuous in the radar images, inside the Charlevoix impact structure, lineaments are less clear (Figure 3.3D). This is possibly due to the erosion of highly fractured rocks. Beneath the zone affected by the impact, faults without surface 
expressions probably exist.

Beneath the St. Lawrence River, geophysical data suggest structures possibly related to the impact. The impact structure deformation is illustrated by the SW part of seismic Line A (Figure 3.19). Moving towards the impact structure, a series of subhorizontal reflectors is present until the $60 \mathrm{~km}$ radius line is reached. There, a small basin, possibly controlled by shallow faults, is found near the theoretical position of the peripheral graben.

The Mle-aux-Coudres corresponds to an area of elevated basement, an interpretation supported by seismic reflection profiles and by higher magnetic and gravity values (Figure 3.11A-D). East of Île-aux-Coudres in the centre of the crater, the smooth magnetic field and the low gravity values suggest a deep Precambrian basement, which is interpreted as a graben structure on Figures 3.11A-D and 3.12A-D.

\subsubsection{The SW section}

To the southwest of Mle-aux-Coudres, the gravity and the magnetics suggest a deep basin, probably controlled by a series of normal faults. Under Ile-aux-Grues, where a gravimetric low is found, a SOQUIP seismic line suggests a Paleozoic-Precambrian interface at about $5.5 \mathrm{~km}$ depth. This basin is controlled by at least two normal faults, one oriented nearly E-W inferred from the seismics and one parallel to the north shore, inferred from the Euler solutions. 


\subsection{Faults and seismicity of the CSZ}

This section examines the relationships between the geological faults described above and the CSZ earthquakes. Earthquake magnitudes and fault dimensions for intraplate earthquakes may be related through proposed scaling laws (Table 3.3). During the period 1977-1997, only eight earthquakes exceeded magnitude $m_{N} 4.0$. Thus, most CSZ earthquakes reactivated relatively small fault surfaces, that may not have a surface expression. As described below, regional faults bound highly seismically active blocks. Geographically, the level of activity varies: whereas the highly fractured central zone has frequent, but small magnitude, earthquakes, the $S W$ and NE areas, with their long normal faults, produce infrequent, but larger, events.

Table 3.3 Fault dimensions for stable continental earthquakes of various moment magnitudes (M; after Johnston, 1993)

\subsubsection{Faults of regional extent}

\begin{tabular}{|c|c|c|c|}
\hline $\mathbf{M}$ & Length (L) & Width (W) & slip (d) \\
\hline 0.0 & $5.8 \mathrm{~m}$ & $5.8 \mathrm{~m}$ & $1 \mathrm{~mm}$ \\
\hline 1.0 & $18 \mathrm{~m}$ & $18 \mathrm{~m}$ & $3 \mathrm{~mm}$ \\
\hline 2.0 & $58 \mathrm{~m}$ & $58 \mathrm{~m}$ & $9 \mathrm{~mm}$ \\
\hline 3.0 & $183 \mathrm{~m}$ & $183 \mathrm{~m}$ & $2.9 \mathrm{~cm}$ \\
\hline 4.0 & $577 \mathrm{~m}$ & $577 \mathrm{~m}$ & $9.1 \mathrm{~cm}$ \\
\hline 5.0 & $1.8 \mathrm{~km}$ & $1.8 \mathrm{~km}$ & $29 \mathrm{~cm}$ \\
\hline 6.0 & $8.0 \mathrm{~km}$ & $4.1 \mathrm{~km}$ & $91 \mathrm{~cm}$ \\
\hline 6.5 & $15 \mathrm{~km}$ & $7.0 \mathrm{~km}$ & $1.6 \mathrm{~m}$ \\
\hline 7.0 & $30 \mathrm{~km}$ & $11 \mathrm{~km}$ & $2.9 \mathrm{~m}$ \\
\hline
\end{tabular}


The St-Laurent fault (SL) appears to bound the earthquake distribution, especially in the Les Eboulements-Cap-à-l'Aigle section. There, most shallow $(z<10 \mathrm{~km})$ earthquakes locate to the NW of a south-east boundary, which is interpreted to be the subvertical SL (Figure 3.20). Below $13 \mathrm{~km}$ depth, most earthquakes occur SE of the fault in a central corridor bound by two weakly seismic areas. Near Ile-aux-Coudres, earthquakes are generally shallower than $10 \mathrm{~km}$ depth northwest of the fault, whereas to the SE, deeper earthquakes are found (down to $15 \mathrm{~km}$ depth). To the NE of Cap-à-l'Aigle, the St-Laurent fault does not appear to affect the earthquake distribution. There, another rift fault, the Rang-Ste-Mathilde fault, separates shallow activity to the west from deeper activity to the east.

To the NE, the Charlevoix Fault $(\mathrm{CH})$ may be currently reactivated by the earthquake activity. The NE area is one of the two zones where magnitude $\geq 4.0$ earthquakes in the period 1924-1978 occurred, including the M 6.21925 Charlevoix earthquake (Stevens, 1980). Under the river, most earthquakes occur within a river-parallel planar volume which includes most $m_{N} \geq 4.0 \mathrm{CSZ}$ events, including the magnitude 5.0 earthquake of 1979 , and the recent October $28,1997 \mathrm{~m}_{\mathrm{N}}$ 4.7. A cross-section through the 1978-1997 hypocentres shows a remarkable alignment with a dip of about $50^{\circ}$ (Figure 3.21), in agreement with the focal mechanisms and depths $(10 \mathrm{~km})$ of the $1925 \mathbf{M} 6.2$ and the $1979 \mathrm{~m}_{\mathrm{N}} 5.0$ earthquakes (Bent, 1992; Lamontagne, 1997). Inside the impact crater, the Charlevoix Fault may be a boundary to the earthquake activity rather than the active structure. Under Me-aux-Coudres for example, events northwest of the fault are shallower than to the southeast. 
To the SE, and possibly to the NE, regional faults act as boundaries. To the SE, the South Shore fault (SS) delimits the seismicity, without being active itself. To the NW, the Gouffre NW (GNW) fault has been proposed to limit the earthquake activity (Anglin, 1984). This correlation may only be apparent: the position of the Gouffre NW fault is approximate and hypocentres appear independent of a clear and linear NW boundary. Remote sensing images and aeromagnetics also suggest a NE lineament that lines up with a portion of the St-Laurent fault (named Crater Lineament, CRL; Figure 3.17).

\subsubsection{The NE portion of the CSZ}

In the NE, most earthquakes appear to correlate with faults. As described above, offshore hypocentres line up with the Charlevoix fault. In addition, this area also has multiple lineaments oriented NNE. It is possible that some faults with this orientation are reactivated (such as the 1989 doublet of Wetmiller and Adams, 1990). Anglin (1984) noticed that the "B" fault (Figure 1.4) matches numerous surface-projected hypocentres. This fault is one of many faults, parallel to the St. Lawrence River, seen in ERS-1 imagery. One of these lineaments could be the Rang-Ste-Mathilde fault (RSM) of Rondot (1989). Offshore, the Ile-aux-Lièvres fault (L) is not seismically active as it lies to the southeast of the activity previously linked with the Charlevoix fault. The NE extremity of the CSZ contains mainly deep events $(>20 \mathrm{~km})$. The earthquake activity appears to terminate at the offshore extension of the Palissades fault (PAL).

\subsubsection{The impact structure}

The relationship between CSZ earthquakes and the impact structure remains 
unclear. The majority of CSZ earthquakes locate within the volume of the impact structure defined by the $60 \mathrm{~km}$ diameter of the outer rim and the $10 \mathrm{~km}$ depth extent of the faults. Two focal mechanisms correspond to the trend of the rim faults (Lamontagne and Ranalli, 1997). This suggests that some impact-related faults are currently reactivated. One of the faults of the astrobleme ("A" fault; Figure 1.4) was thought to cause an offset to the seismicity (Anglin, 1984). Within the impact structure, clouds of earthquakes without any particular alignment are seen (except near St-Joseph-de-la-Rive, where micro-earthquakes define an alignment, which does not correlate with radar and geophysics lineaments). Under the river as well, the highest concentration of activity of the CSZ corresponds to the highly fractured graben, possibly created by the impact. It is possible that these highly fractured areas give rise to numerous low magnitude events with highly variable focal mechanisms. The central uplift of the astrobleme, where fracturing and faulting have been the most intense, however, is not more particularly active.

\subsubsection{The SW section}

Earthquakes occur very infrequently in this area and their correlation with faults is more difficult to establish. Since the area is outside the seismograph network, hypocentral depths are not as precise as in the rest of the CSZ. The area is important, however, since it is one of the two areas where magnitude $\geq 4.0$ events of the period 1924-1978 have occurred (Stevens, 1980). Iapetan faults are known to exist there, with some possibly at high angle to the river axis. With conditions similar to the rest of the $\mathrm{CSZ}$, the lower rate of earthquake occurrences is enigmatic. The normal fault near Ile-auxGrues, or possibly the impact crater rim, may act as a boundary to the higher level of 
activity to the NE.

\subsection{Discussion}

This analysis has brought to light the main structural patterns of the CSZ. In the NE area, the Precambrian basement is cut by a series of long normal faults parallel and at high angles to the river axis. In the centre, the impact crater controls the faults, at least down to about $10 \mathrm{~km}$ depth. Finally, in the SW zone, the Precambrian basement, deep under the Appalachians, is cut by normal faults parallel and at high angles to the river axis. The CSZ is a transition zone between the SW part, with its steeply-dipping faults with large normal throw, and a NE part, with its en echelon normal faults with progressive deepening of the basement under the Appalachians.

In Anglin (1984), CSZ earthquakes were correlated with five geological faults (Figure 1.4): St-Laurent; Gouffre NW; Palissades and faults "A" and "B". These correlations were established on the basis of projections of the hypocentre distribution to the surface along a trend $\left(\mathrm{N} 52^{\circ} \mathrm{E}\right)$ and a $\operatorname{dip}\left(70^{\circ} \mathrm{SE}\right)$ that provided the tightest cluster of hypocentres. The main assumption was that most earthquakes occur on planar structures that cross the entire seismic zone. After some 20 years of micro-earthquake recording, it is now apparent that earthquakes do not concentrate only on planar structures. Locally, earthquakes define depth-limited volumes of enhanced activity. In this context, most large faults seem to bound these active volumes rather than being active themselves.

Three Iapetan faults bound seismically active sub-zones: the St-Laurent, South Shore and Charlevoix faults. These faults separate blocks possibly with different fracturing 
levels. The foot-wall of the St-Laurent fault, for example, has most of the micro-seismic activity, whereas the hanging-wall has weaker and deeper activity. Conceptually, the footwall may be highly fractured, and/or subject to high pore-fluid pressures. Iapetan faults do not seem particularly active (for micro-earthquake activity): hypocentres do not concentrate along the St-Laurent and the South Shore faults. The best correlation between an Iapetan fault and earthquakes is found in the NE part of the zone. There, hypocentres define a narrow steeply-dipping volume, possibly the Charlevoix fault. Inside this volume, earthquakes may or may not occur directly on the main fault, as shown by the variability in the focal mechanisms.

Contrasting with its conspicuous surface expression, the SE-dipping St-Laurent fault itself is not particularly active. However, it bounds the earthquake activity over part of the CSZ. In the central part, most of the deep (>20 km) events occur to the east of the St. Laurent fault. Our analysis suggests that the St-Laurent fault acts more like a boundary to the activity than as an active structure. Similarly, the South Shore fault bounds the seismicity to the SE. To the NW, a fault-controlled boundary is not as clear.

The relation between the Charlevoix impact structure and the current earthquake activity has been subject to much debate. On the one hand, those who disclaim any relationship observe that earthquakes do not distribute over the whole impact structure, but concentrate in zones parallel to the St. Lawrence paleo-rift faults (Adams and Basham, 1989). In addition, most impact structures are currently aseismic (Salomon and Duxbury, 1987). According to others, however, the structure might contribute to the inherent weakness of the region (Leblanc and Buchbinder, 1977; Lamontagne, 1987; Kumarapeli, 
1987). "Impacting has undoubtedly complicated the pattern of potential failure in the area and consequently may have created an environment for stress concentration in an otherwise throughgoing Iapetan fault system" (Kumarapeli, 1987). At present, it is unclear why earthquakes do not occur over the whole impact structure. Instead, they appear to concentrate in two bands elongated along the St. Lawrence. Some earthquakes, however, appear to occur on faults, possibly created as Iapetan faults, but clearly reactivated by the impact (Lamontagne and Ranalli, 1997). Interestingly, most of the large events tend to concentrate at both ends of the CSZ, outside the impact structure. Within the impact structure, the highly fractured Grenville releases strain energy in small earthquakes only $\left(\mathrm{m}_{\mathrm{bLg}} \leq 3.5\right)$, with highly variable fault plane orientations. 


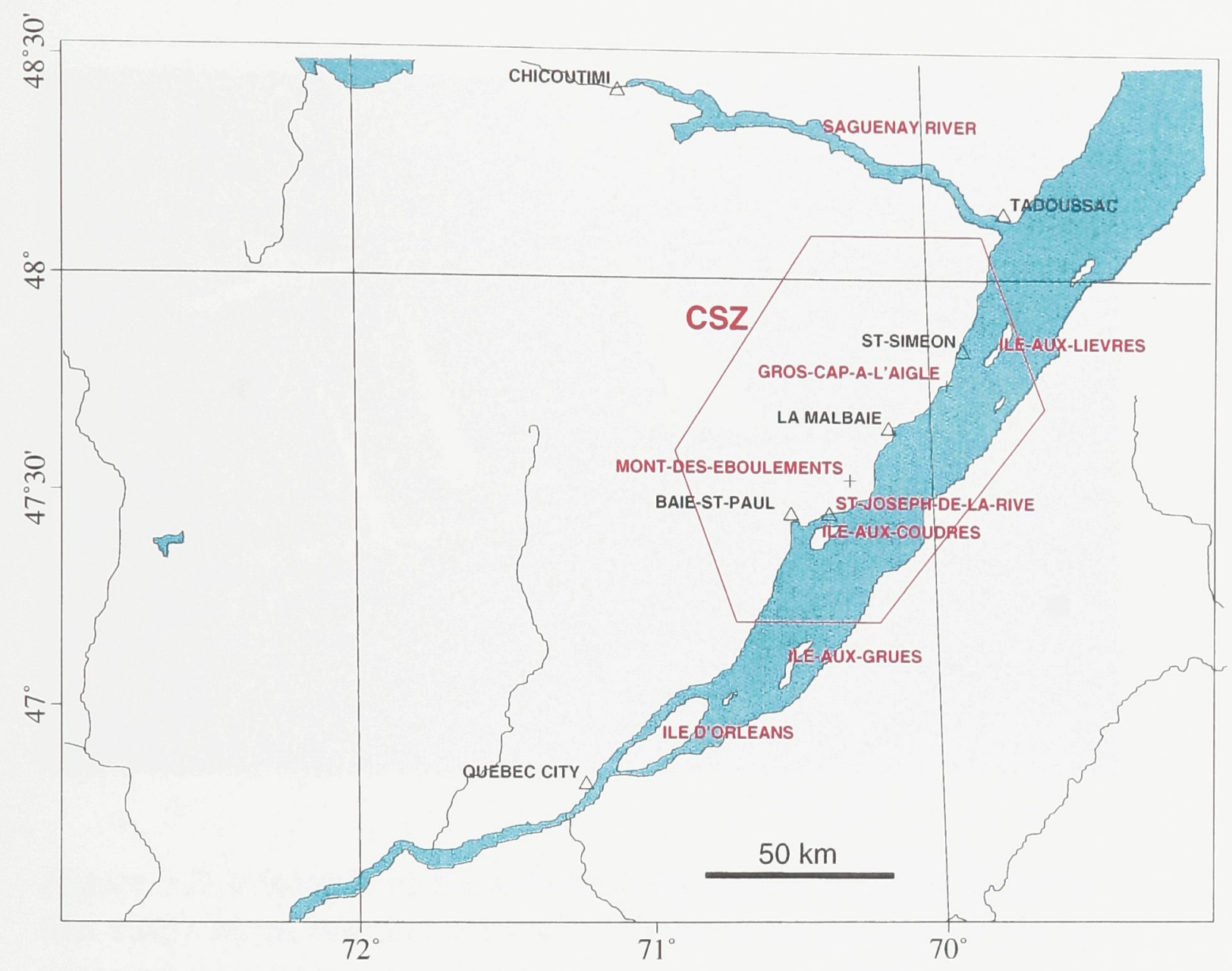

Figure 3.1 Location map of the CSZ surroundings and geographic names mentioned in the text. 


\section{SAR Operating Modes}

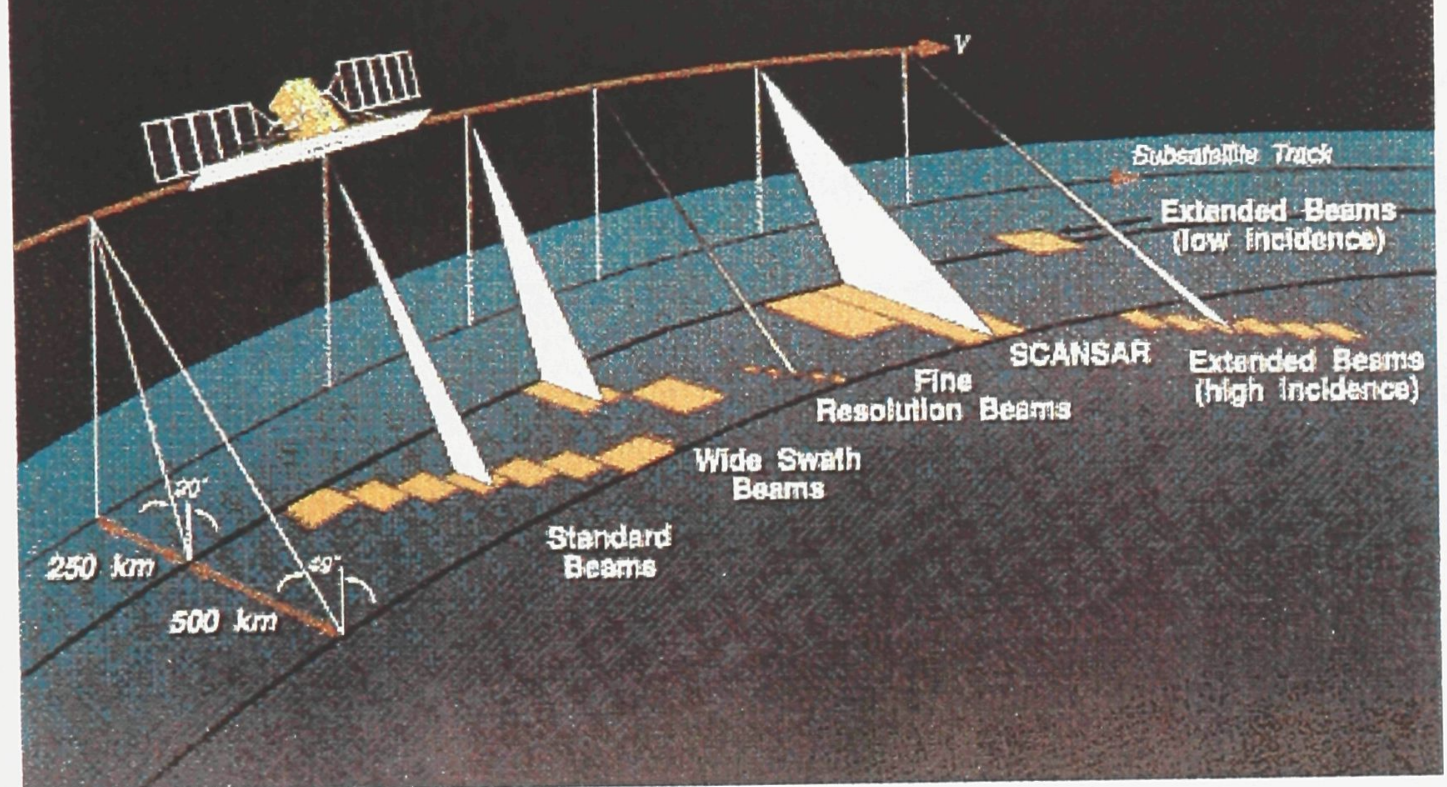

Figure 3.2 Principle of the side-looking radar system (Radarsat in this case). Each beam is defined by the area covered and the level of detail (resolution) available) 
Figure 3.3 Remote sensing radar images of the CSZ. On these various radar images, regional and local lineaments can be recognized: (A) Radarsat image of the St. Lawrence River between Quebec City and Tadoussac that shows the numerous lineaments in the Precambrian Shield, north of the river (courtesy of the Ministère des ressources naturelles du Québec). (B) JERS-1 image of the area to the west of the CSZ; (C) ERS-1 image of the CSZ; (D) Airborne SAR with West-facing direction of the beam; (E) Airborne SAR with South-facing direction of the beam; $(F)$ Enlarged view of $E$ that shows the high resolution of the airborne-radar system. (G) Chromo-stereoscopic image that integrates a Radarsat image (texture) and topographic information (colours). Courtesy of Thierry Toutin, Canada Centre for Remote Sensing. 


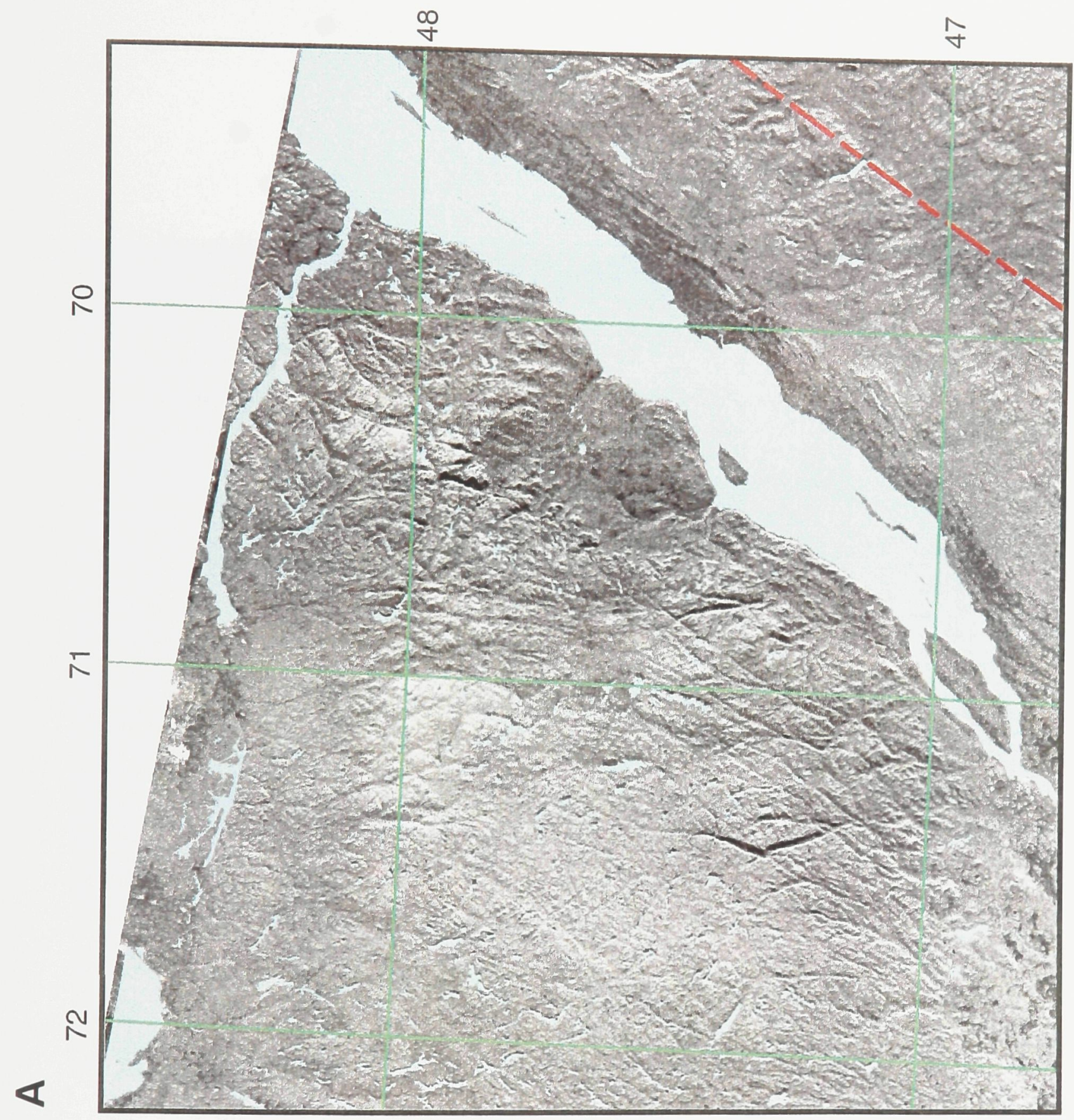




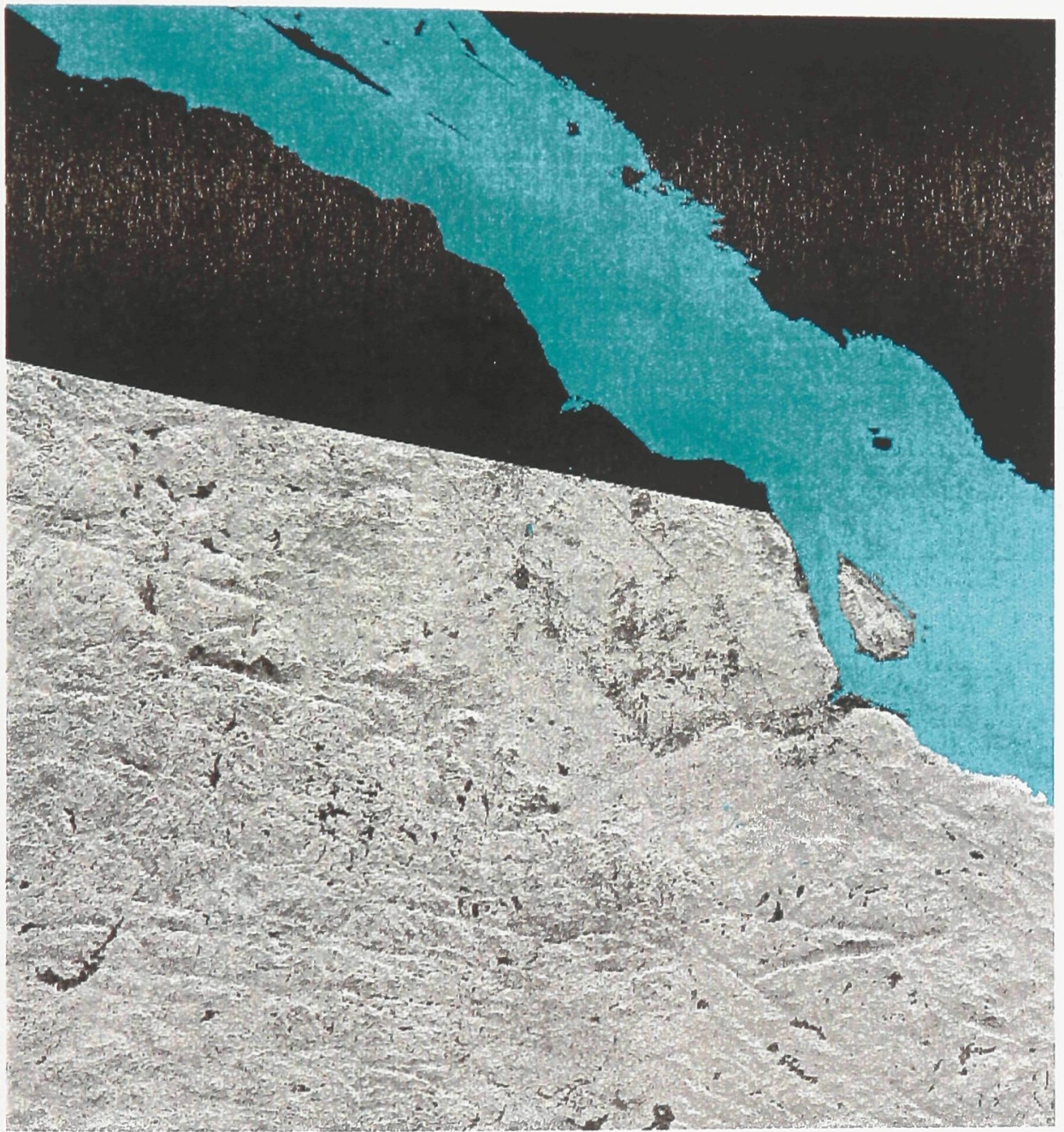




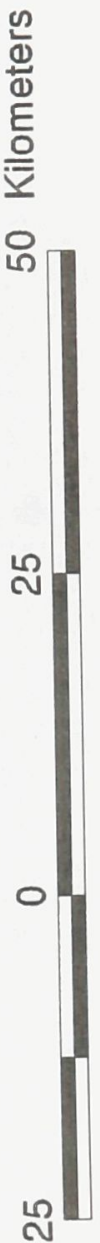

0

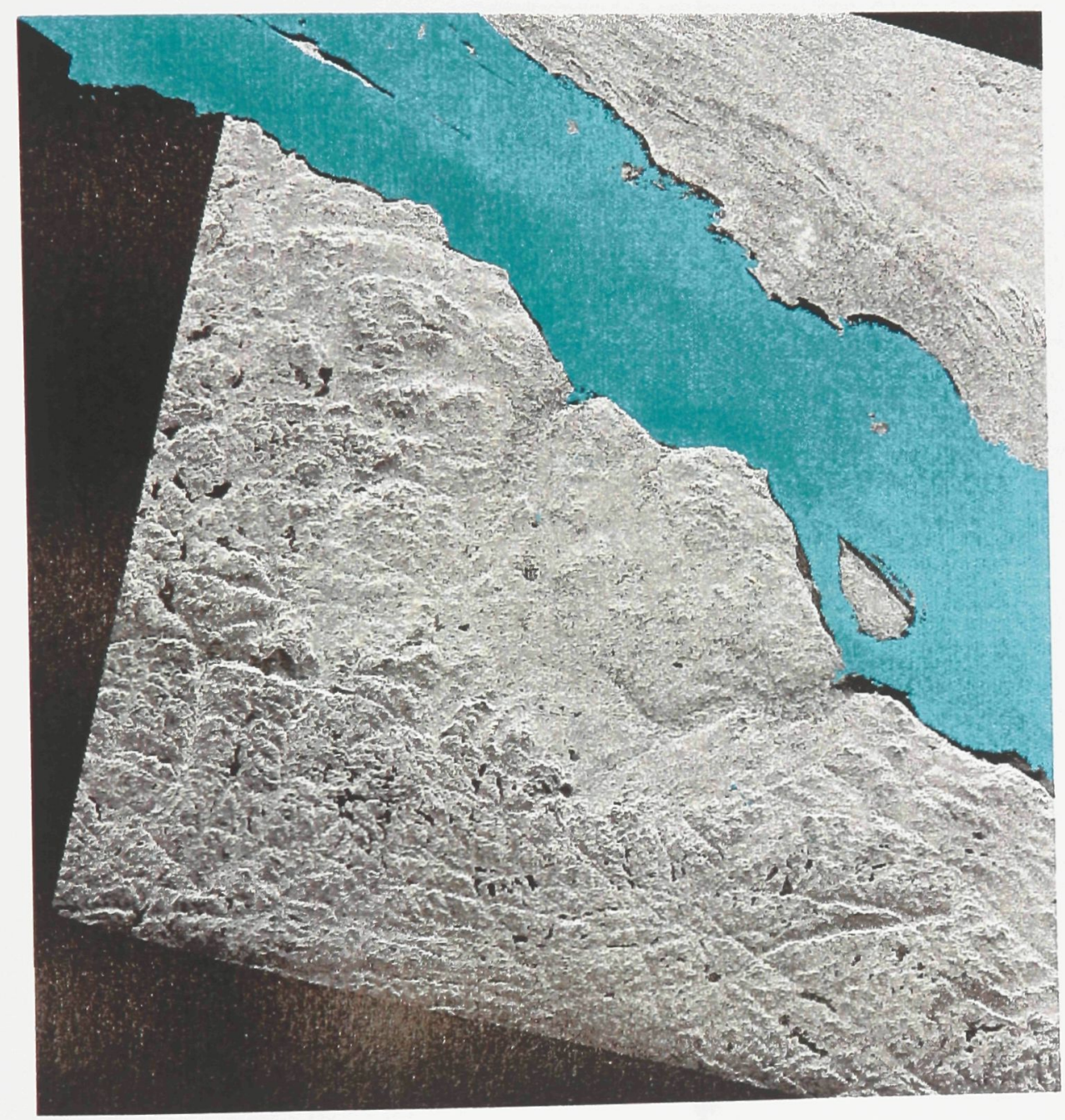




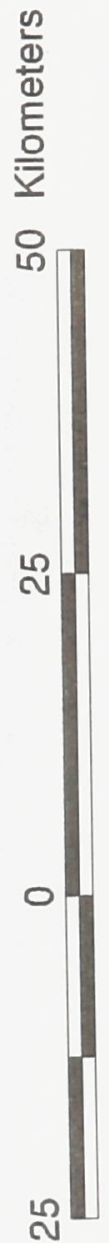




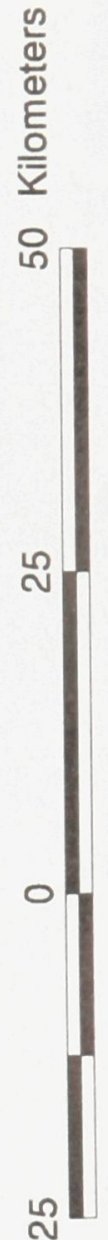

U

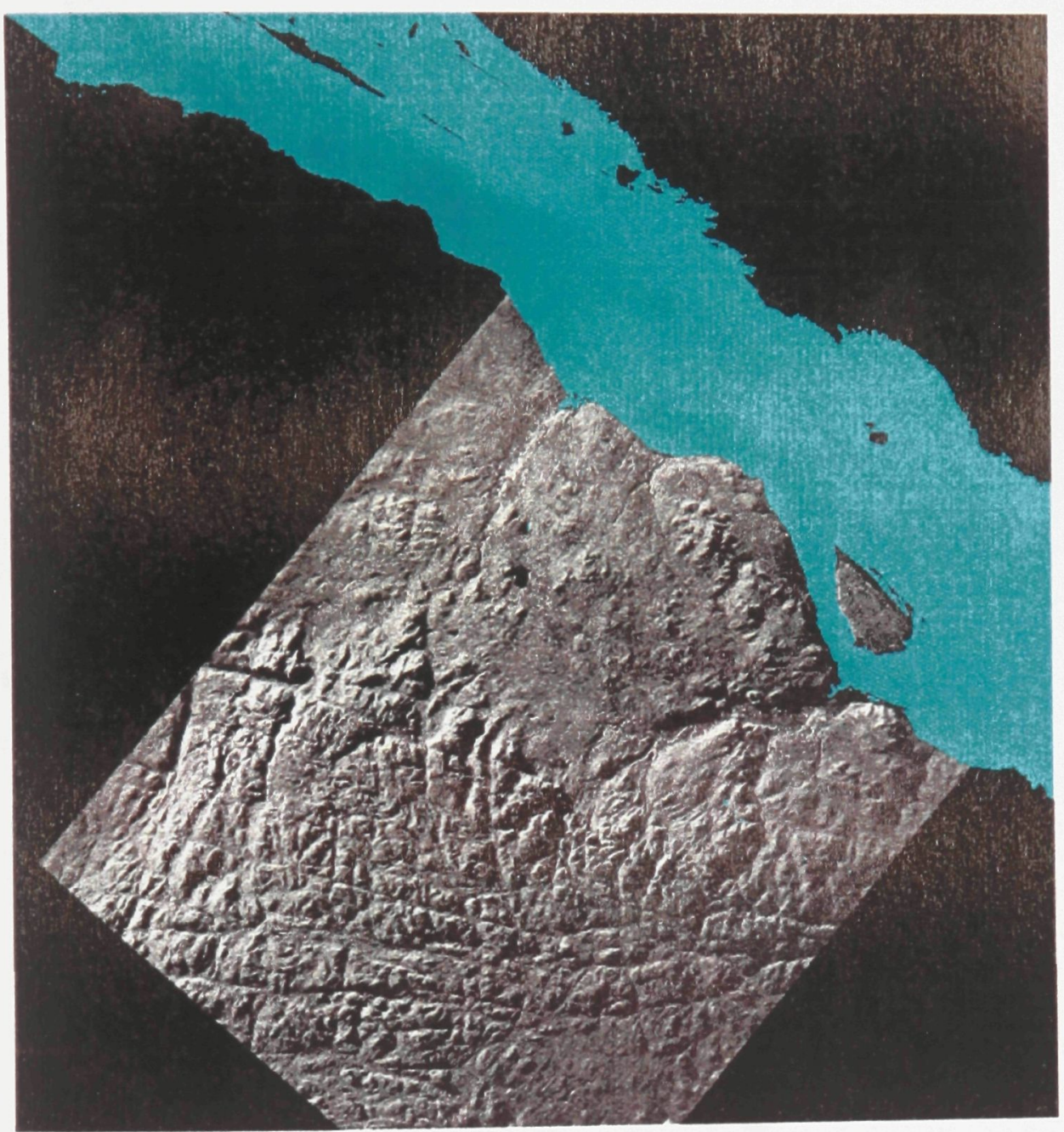



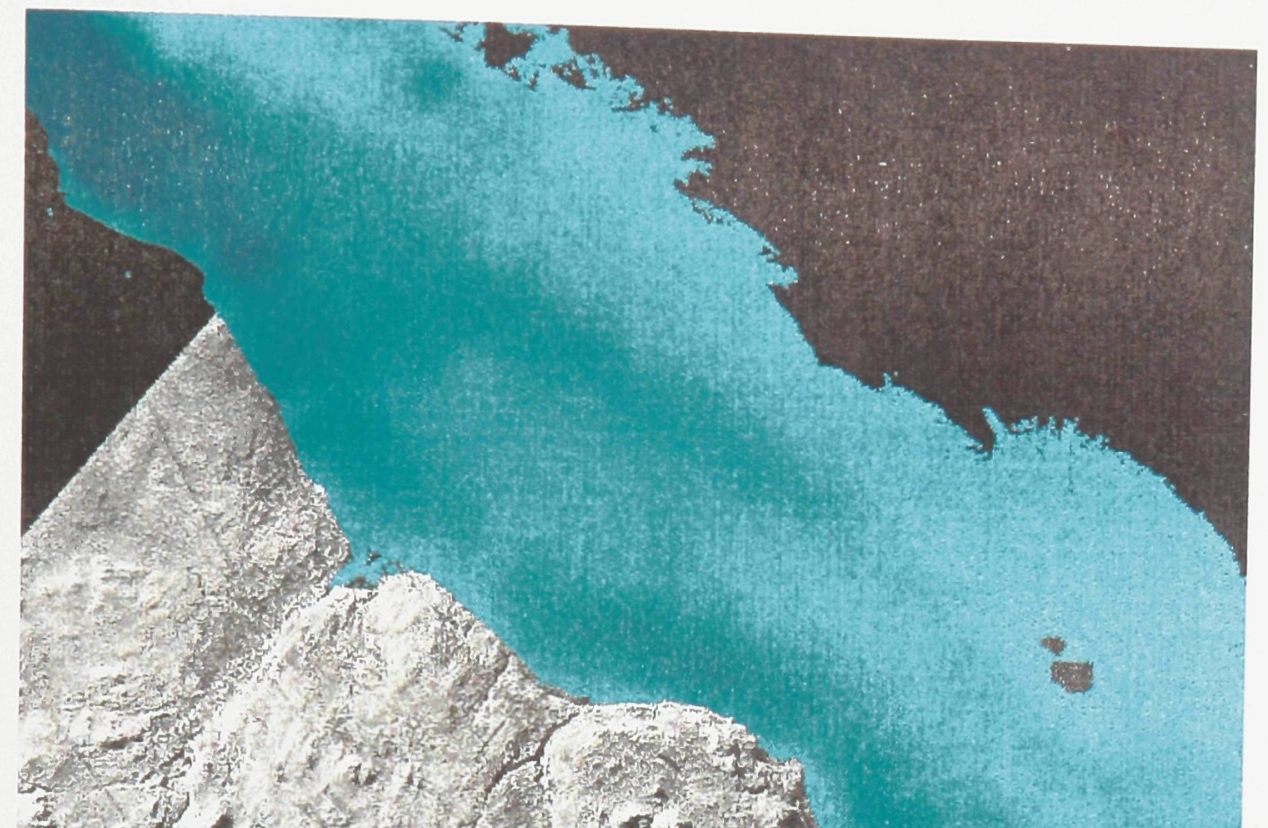

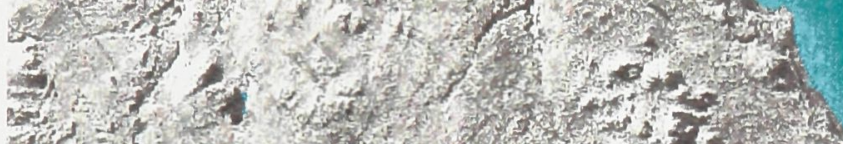

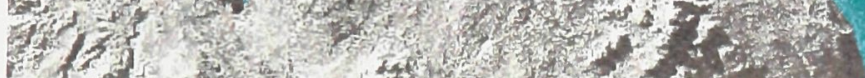
r.t.

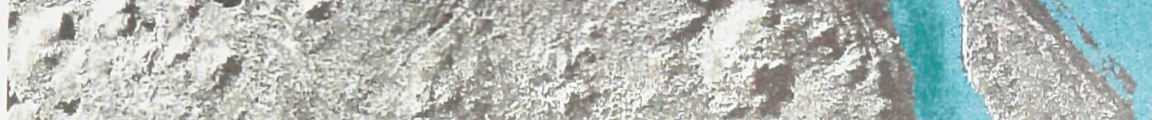

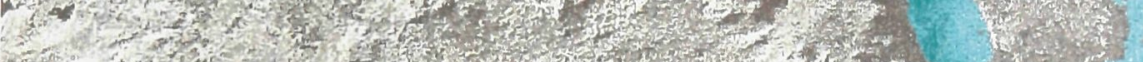

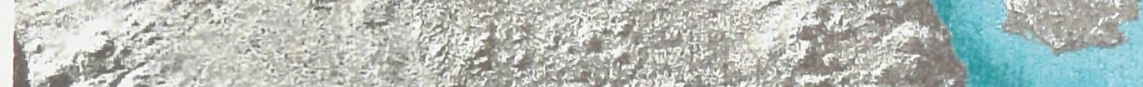

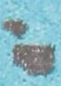

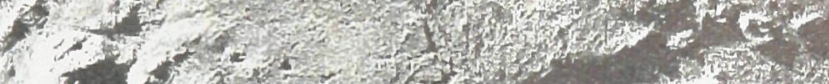

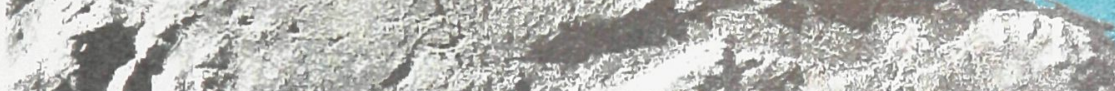
I. 3 (3)

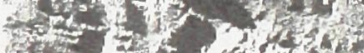

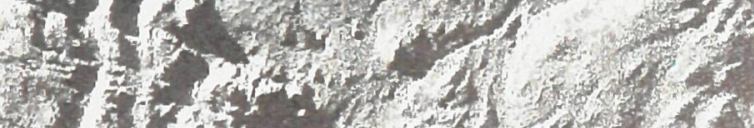

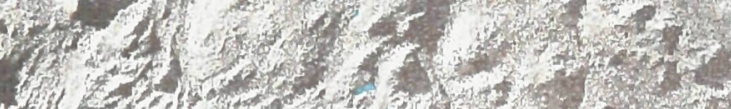

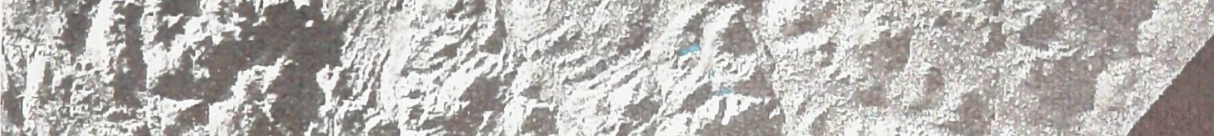

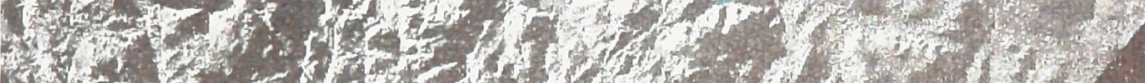

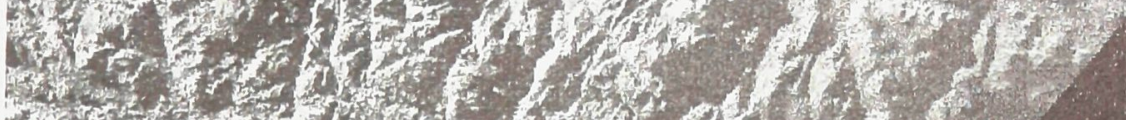

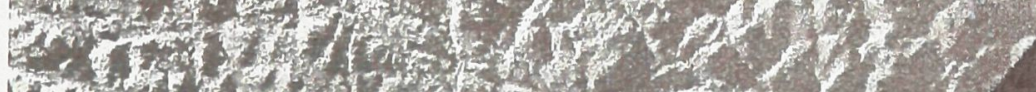

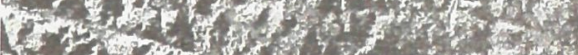

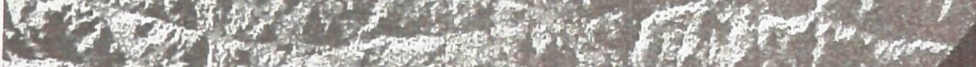

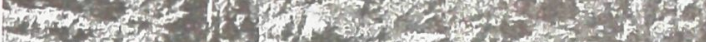

u 


\section{G}

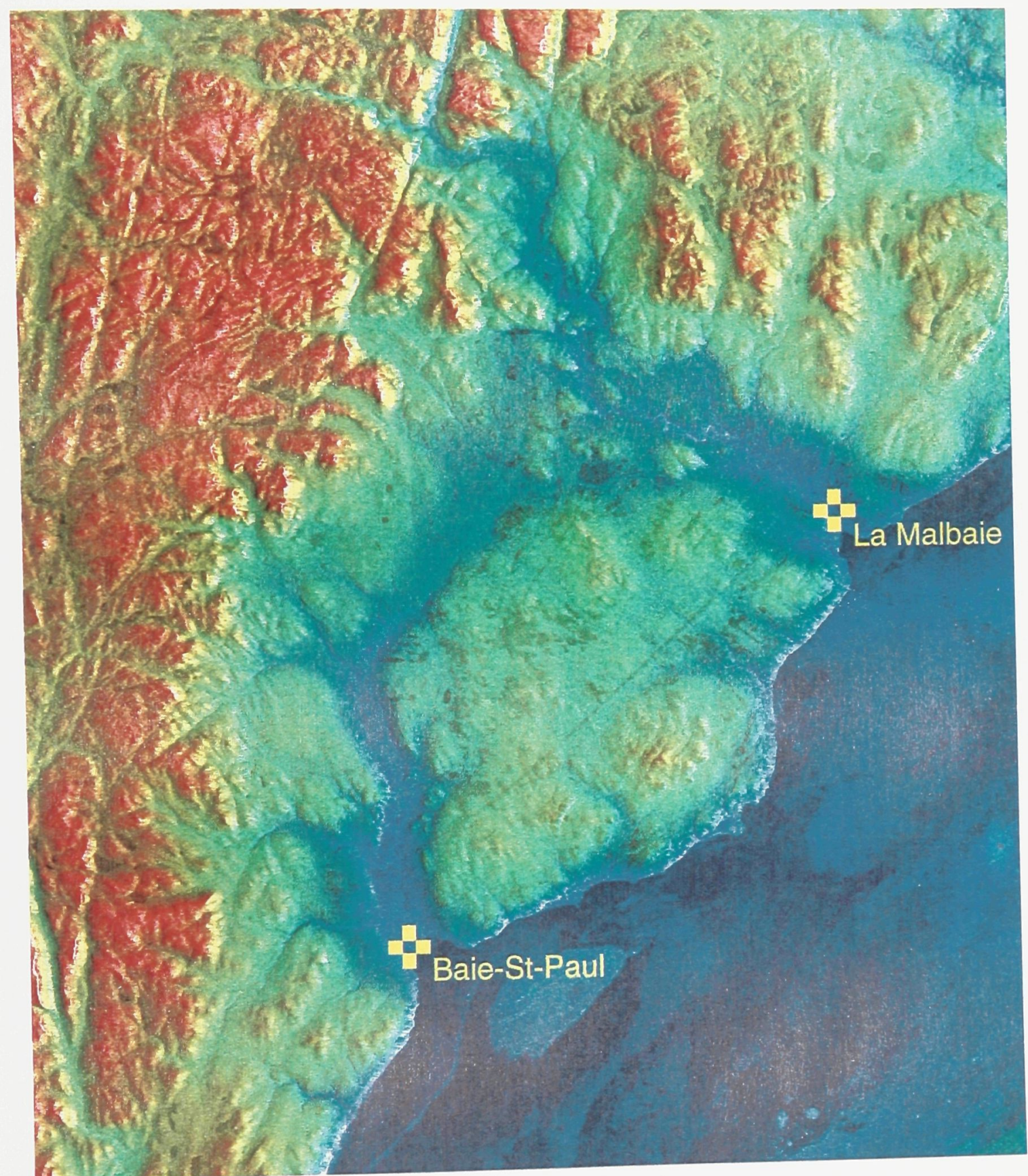




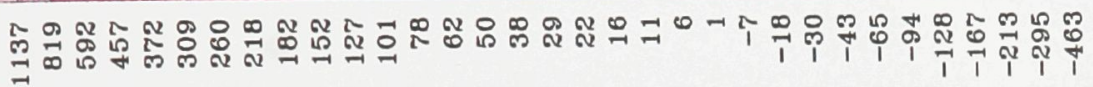

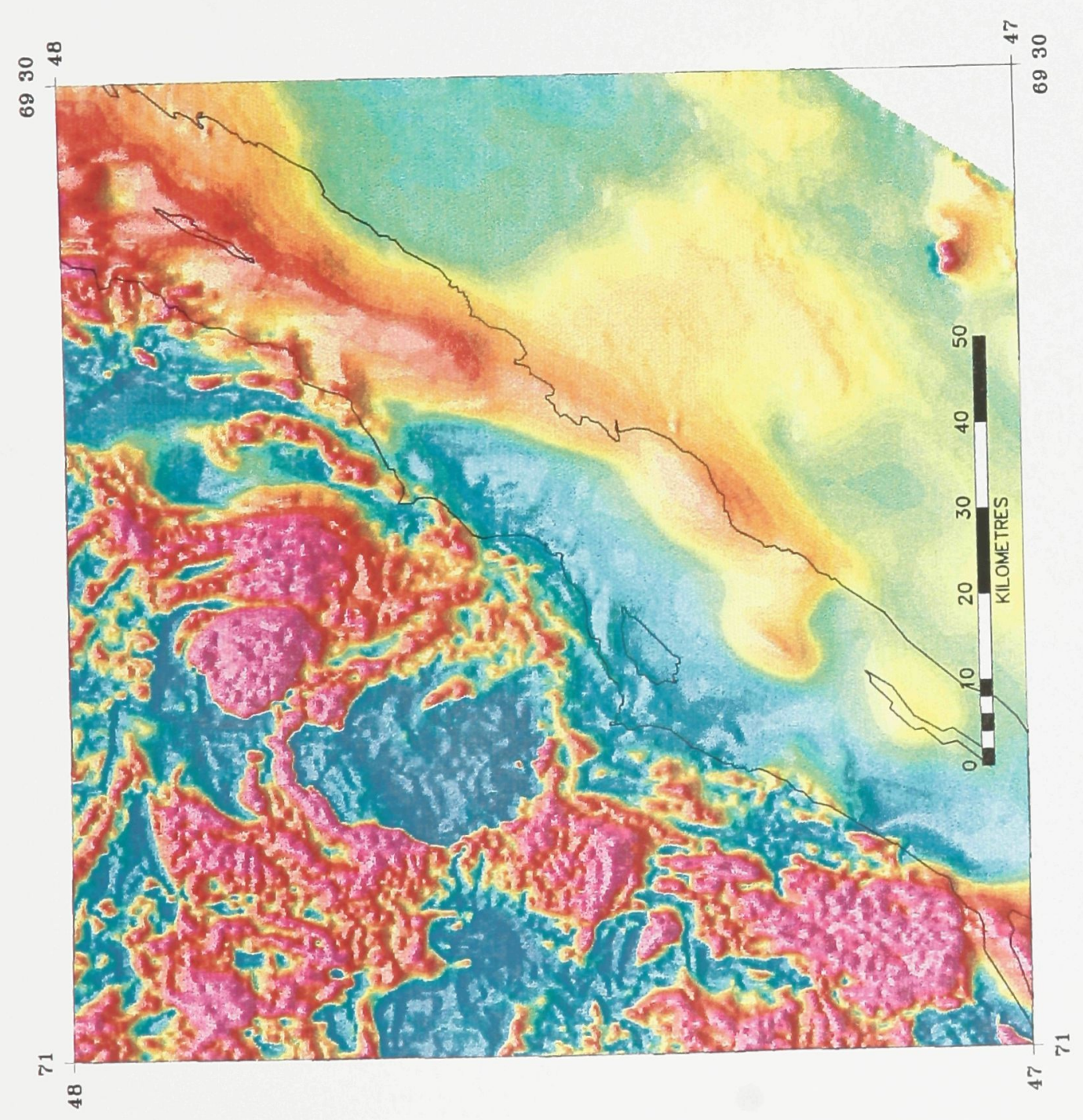




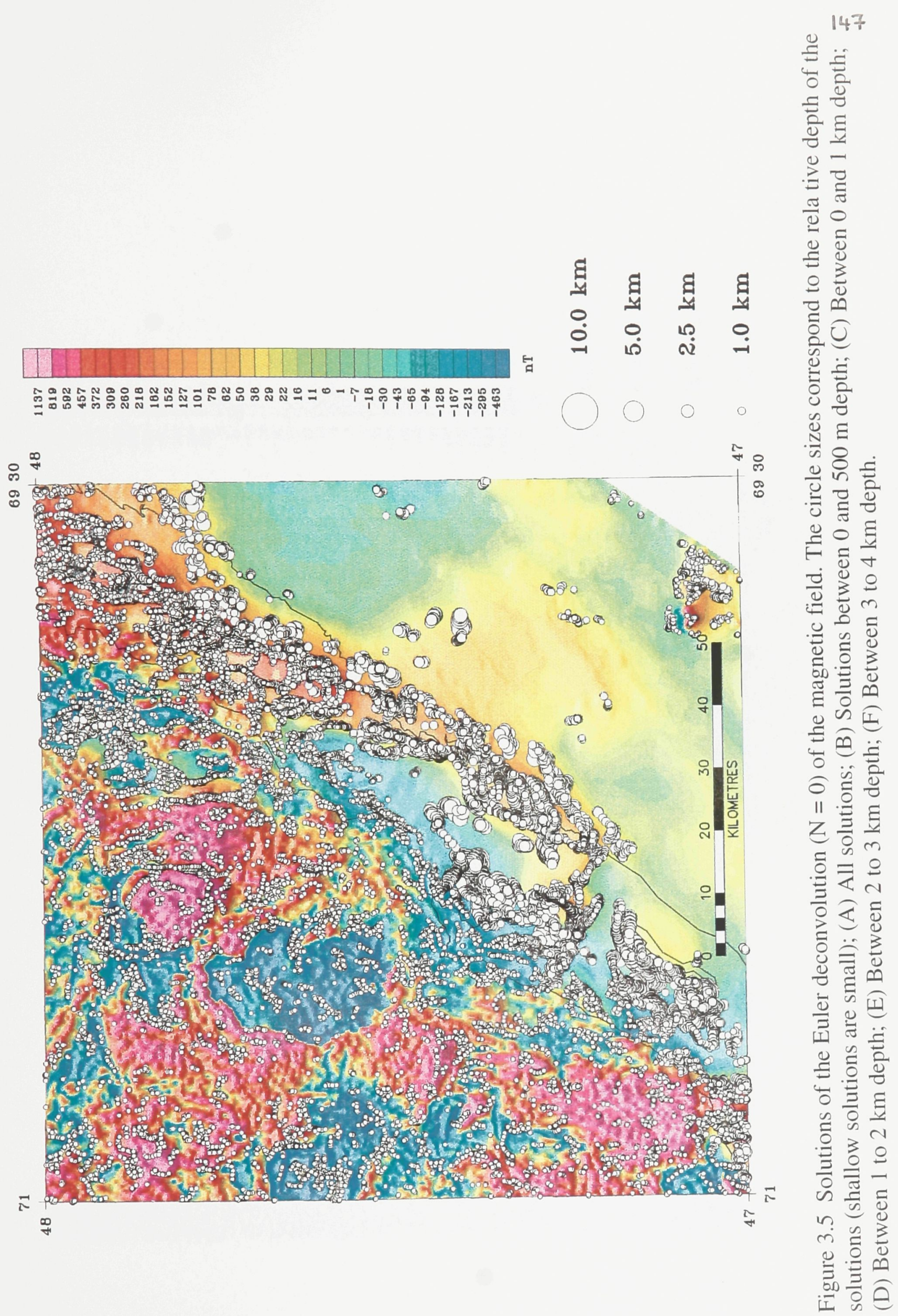




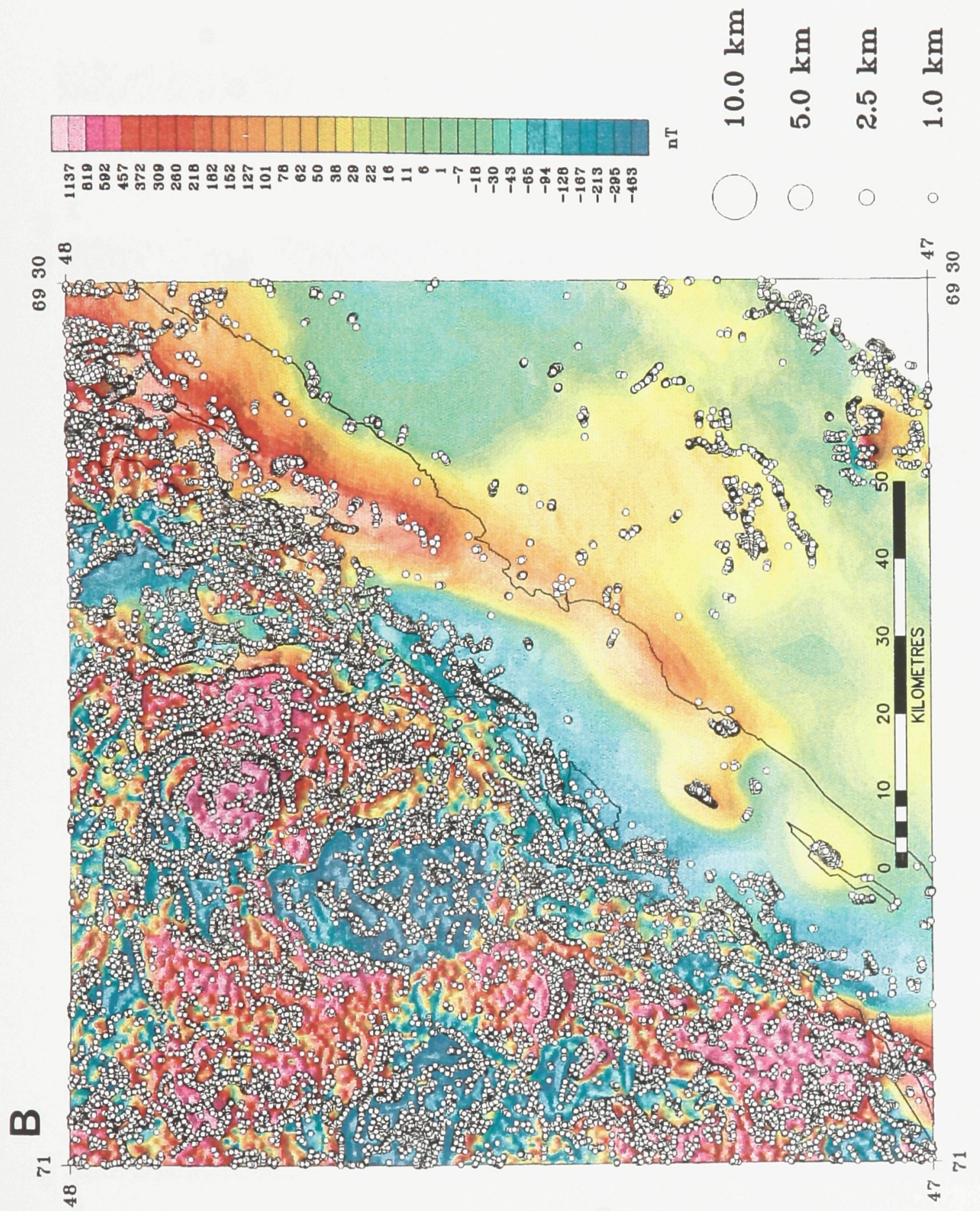



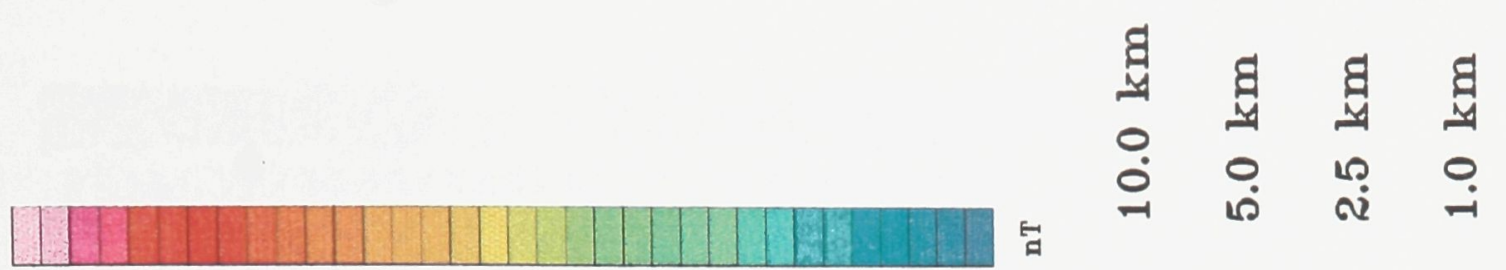

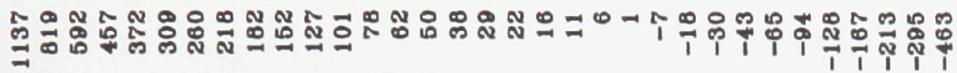

文

:

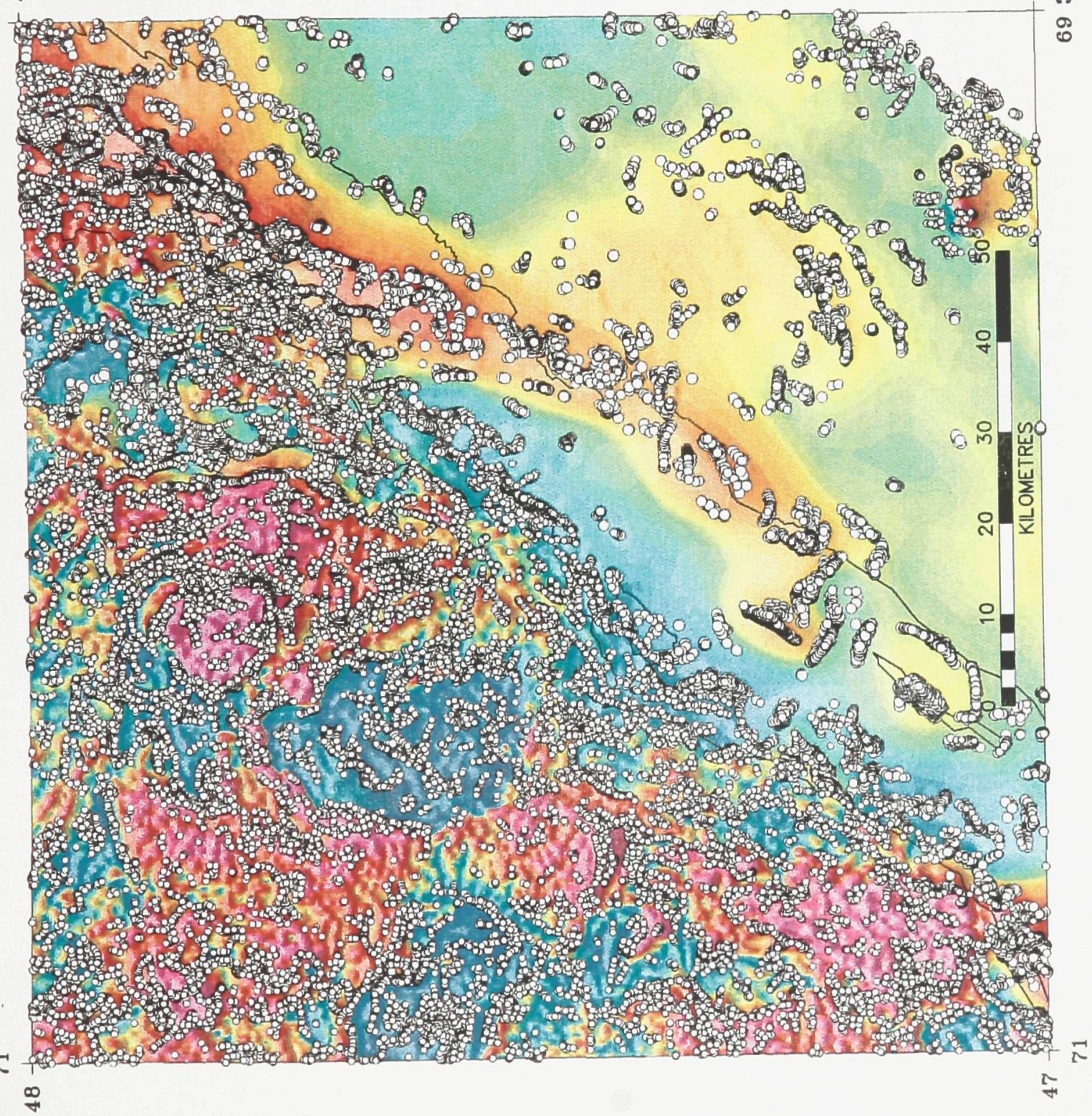

กิ 


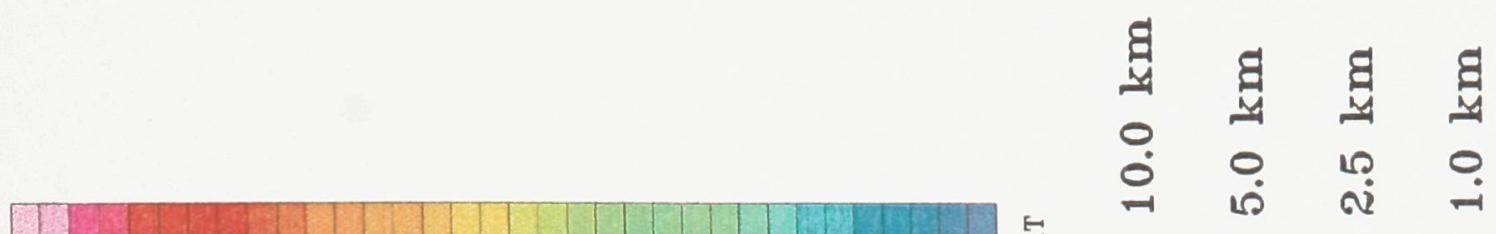

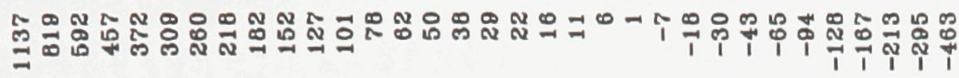

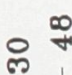

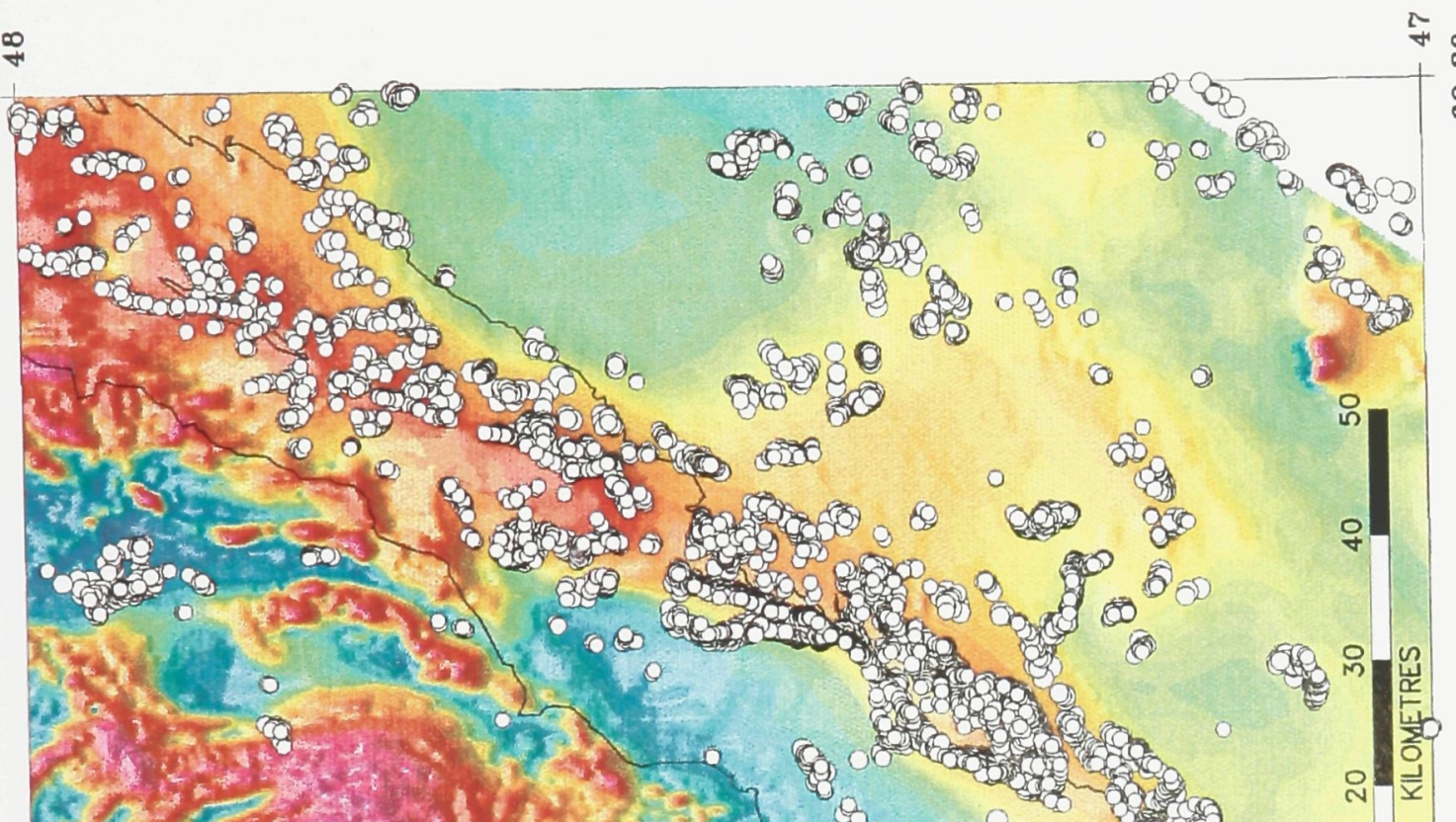

พิ
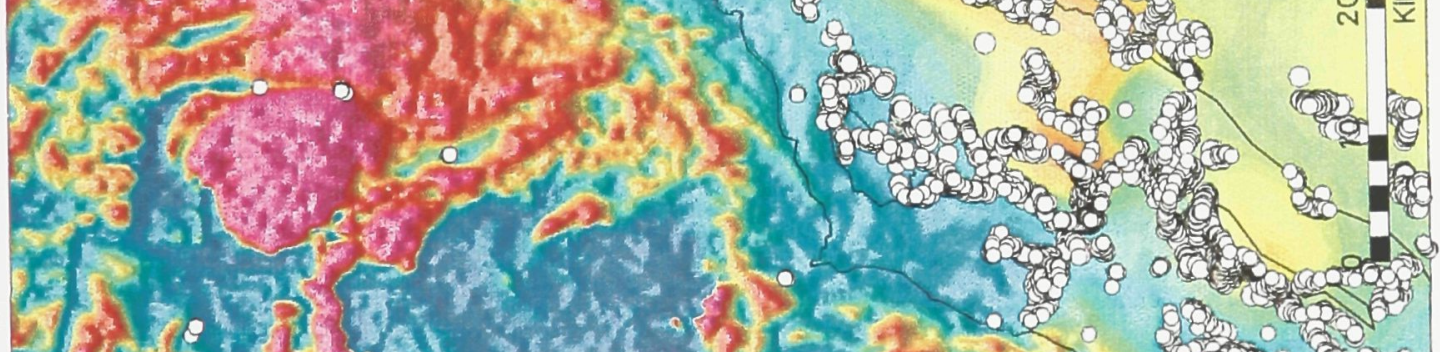

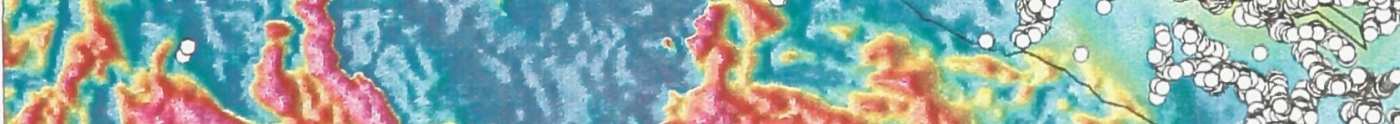

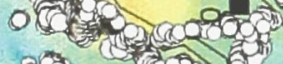

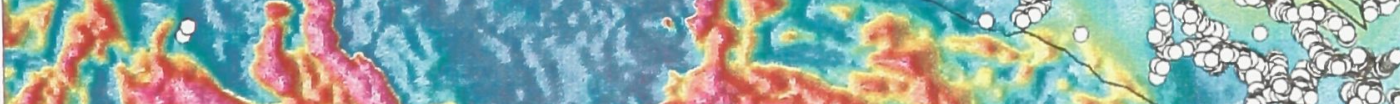

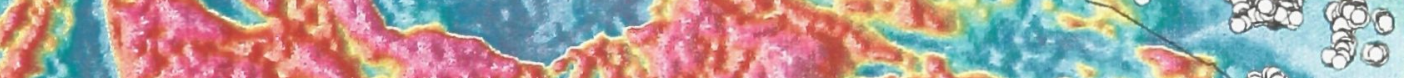

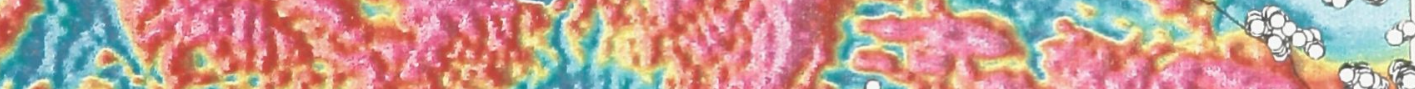
16.7.t.

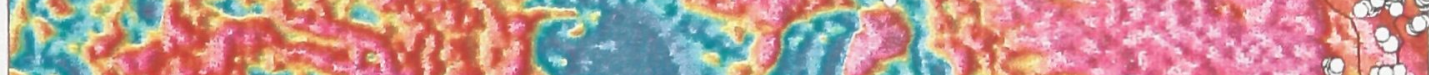

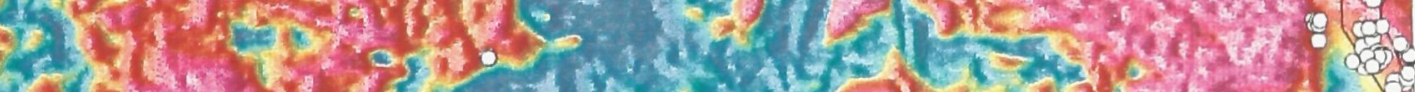

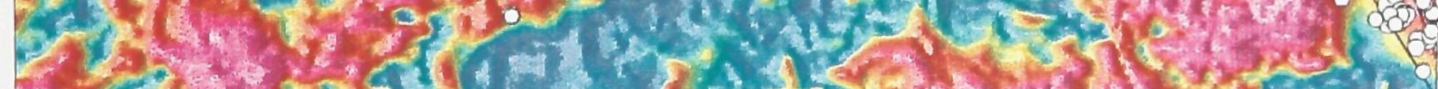

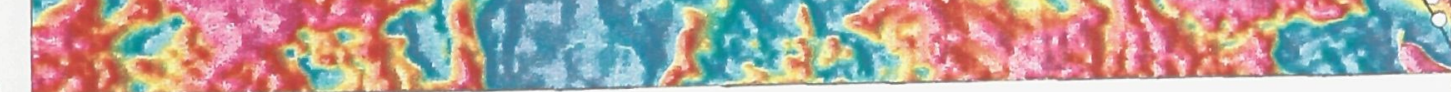
$\pi$ $\stackrel{\infty}{+}$ 

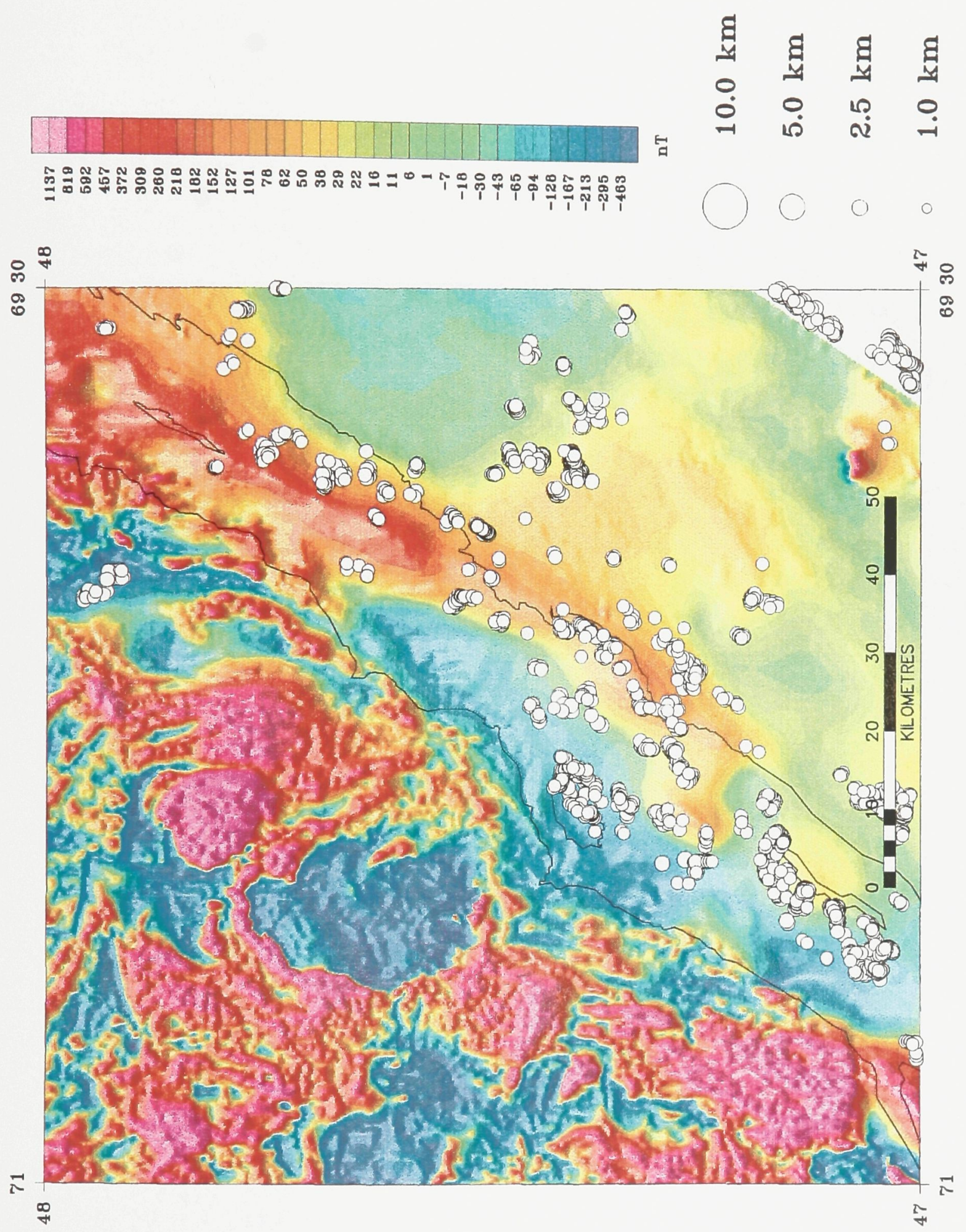


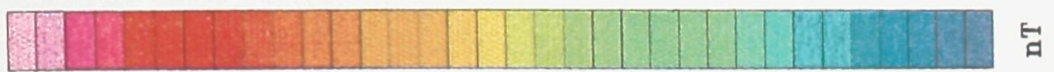

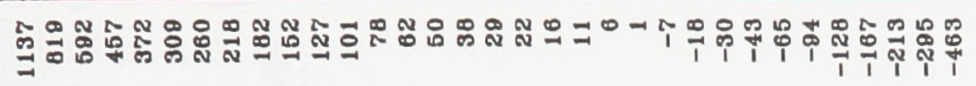

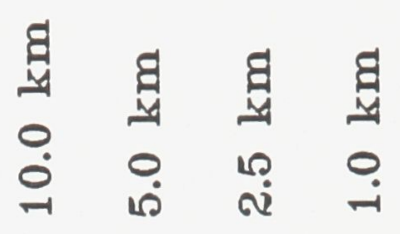

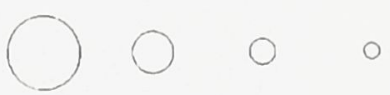

זิ ๑

우

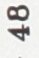

8

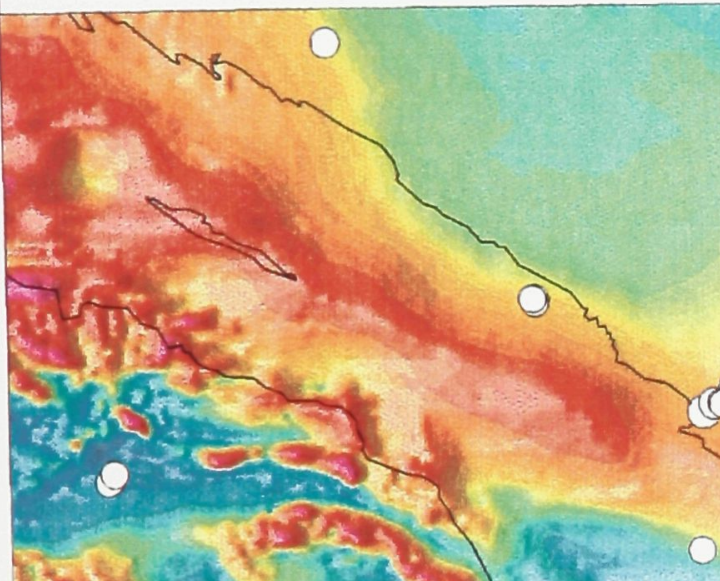

(2)

a 80

(1)

(9)<smiles>O=S1(=O)OCCSO1</smiles>

1.e

Ba.

4

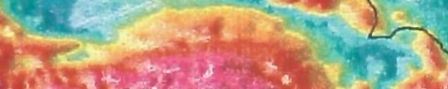

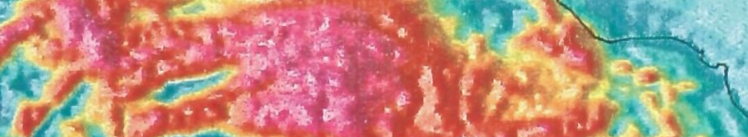

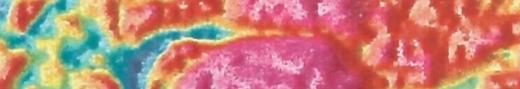

Q.

No

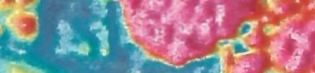

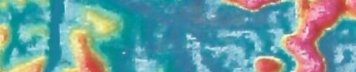

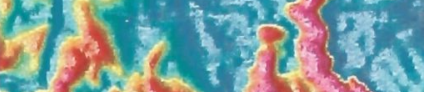

orthe inon

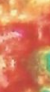

ail

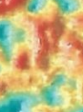

201

का)

(.).

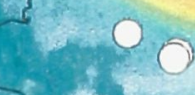

(1)

$10=2 e^{2}$

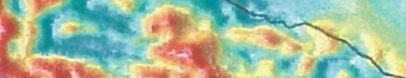

$3.50=1$. res

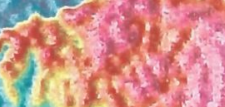

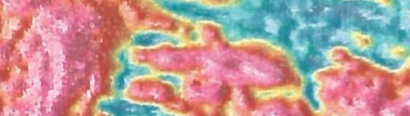

frostring

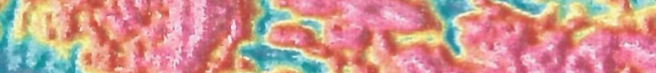

ar

the?

2

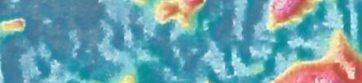

prestwom

$x \rightarrow 203001$.

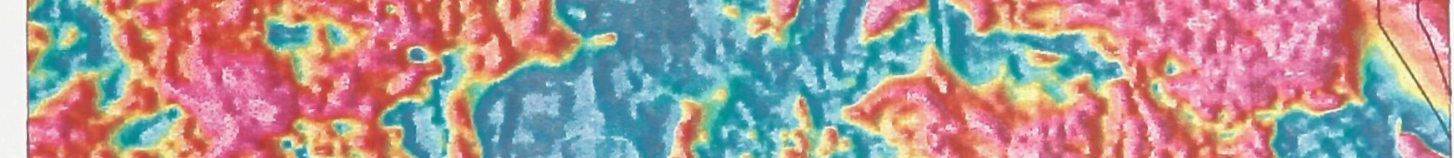

L

$\pi$

$\stackrel{\infty}{*}$ 
Figure 3.6 Photos taken during the August 1994 gravity survey: the LaCoste and Romberg dynamic gravity meter, with the portable computer and the GPS receiver (right), and the launch used on the St. Lawrence River (below)
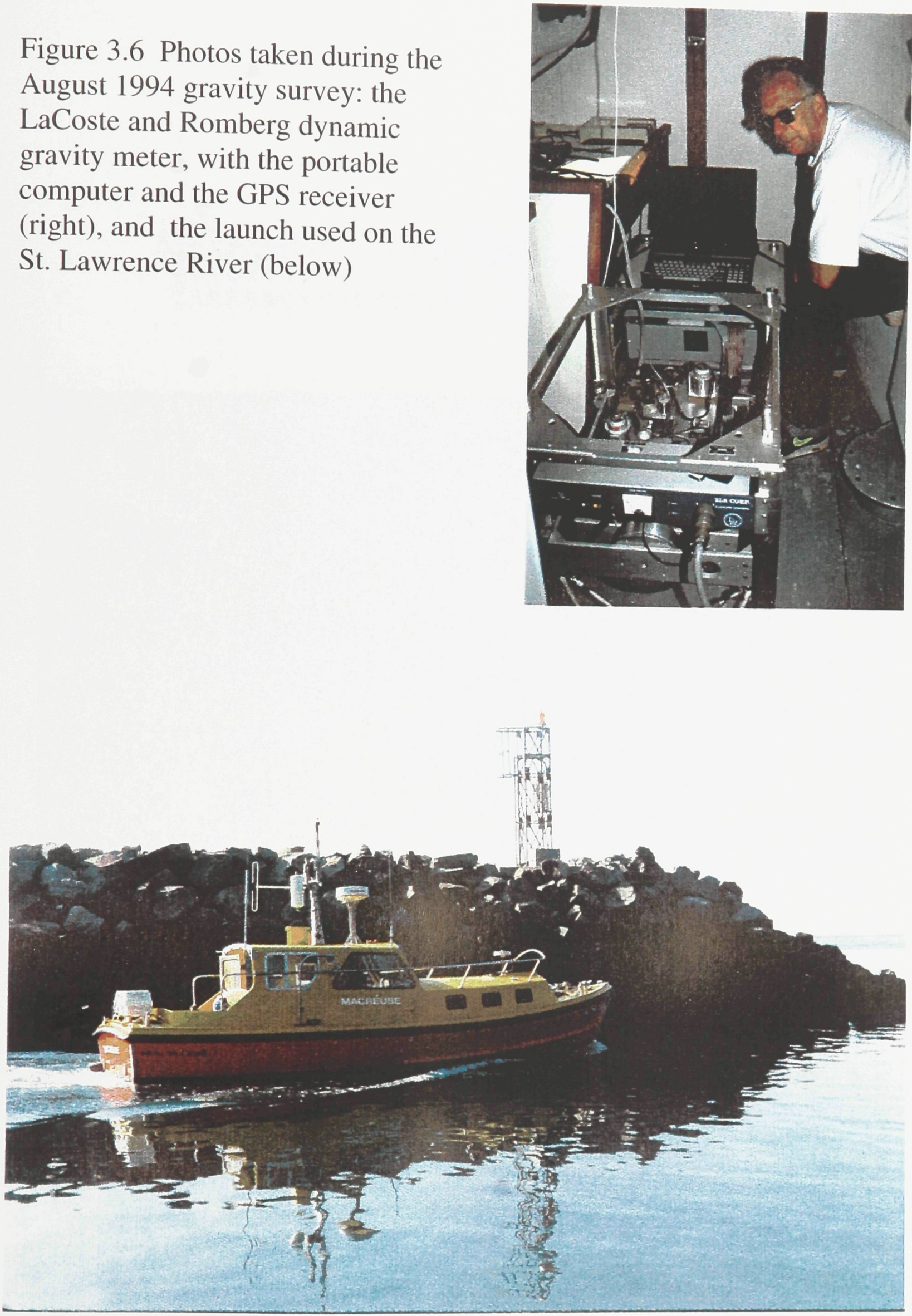


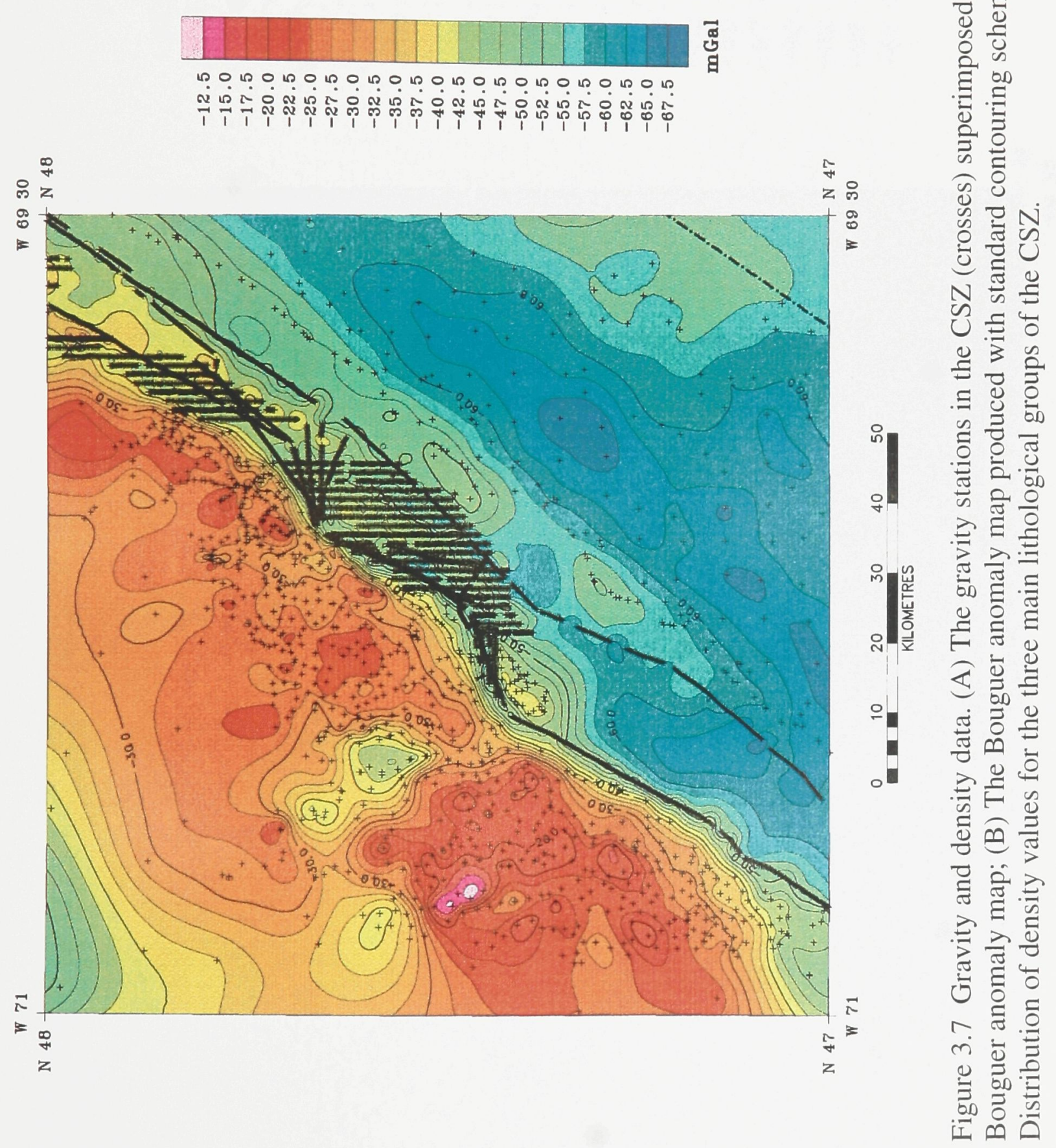




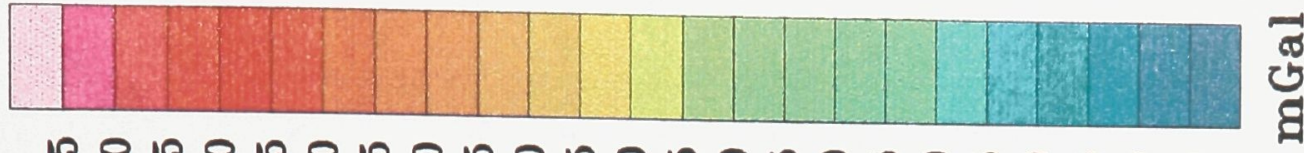

. ㄴ

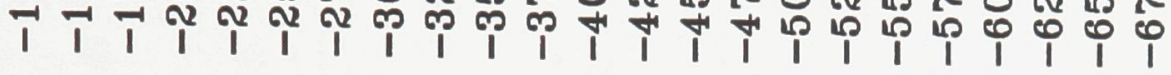

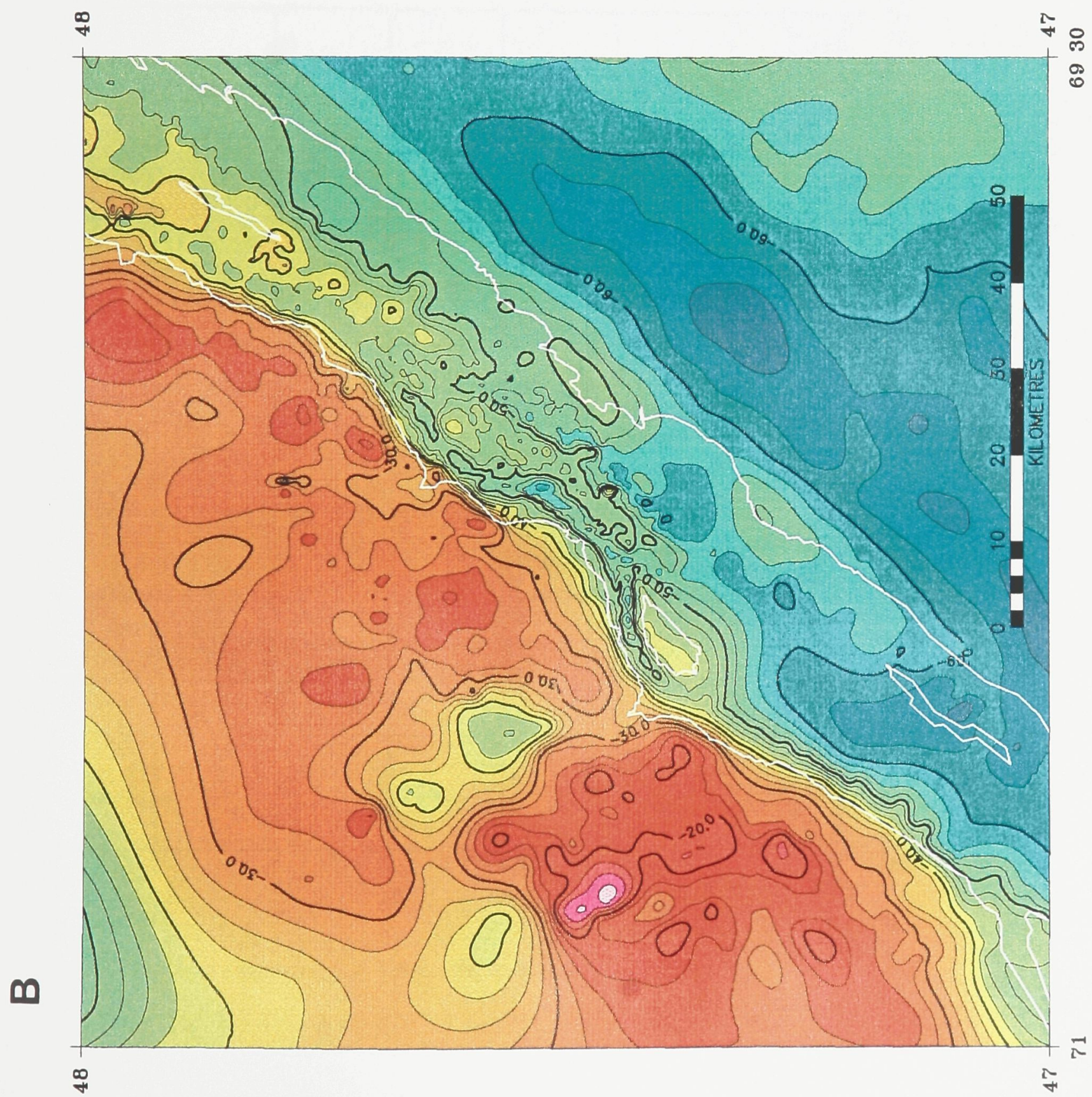



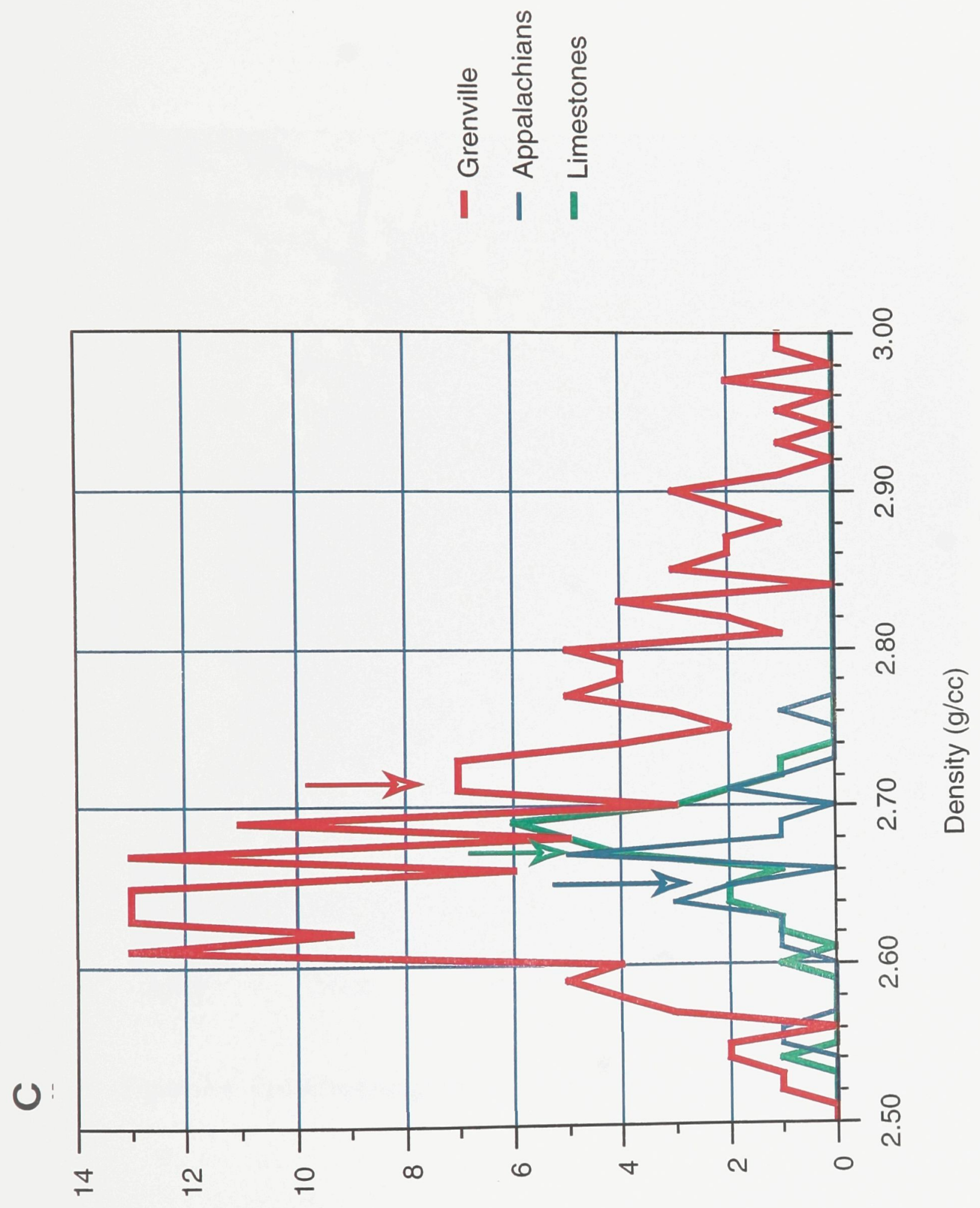

sseן ว /6 L0.0 1әd sәjdures fo ıәqunN 
Elevation

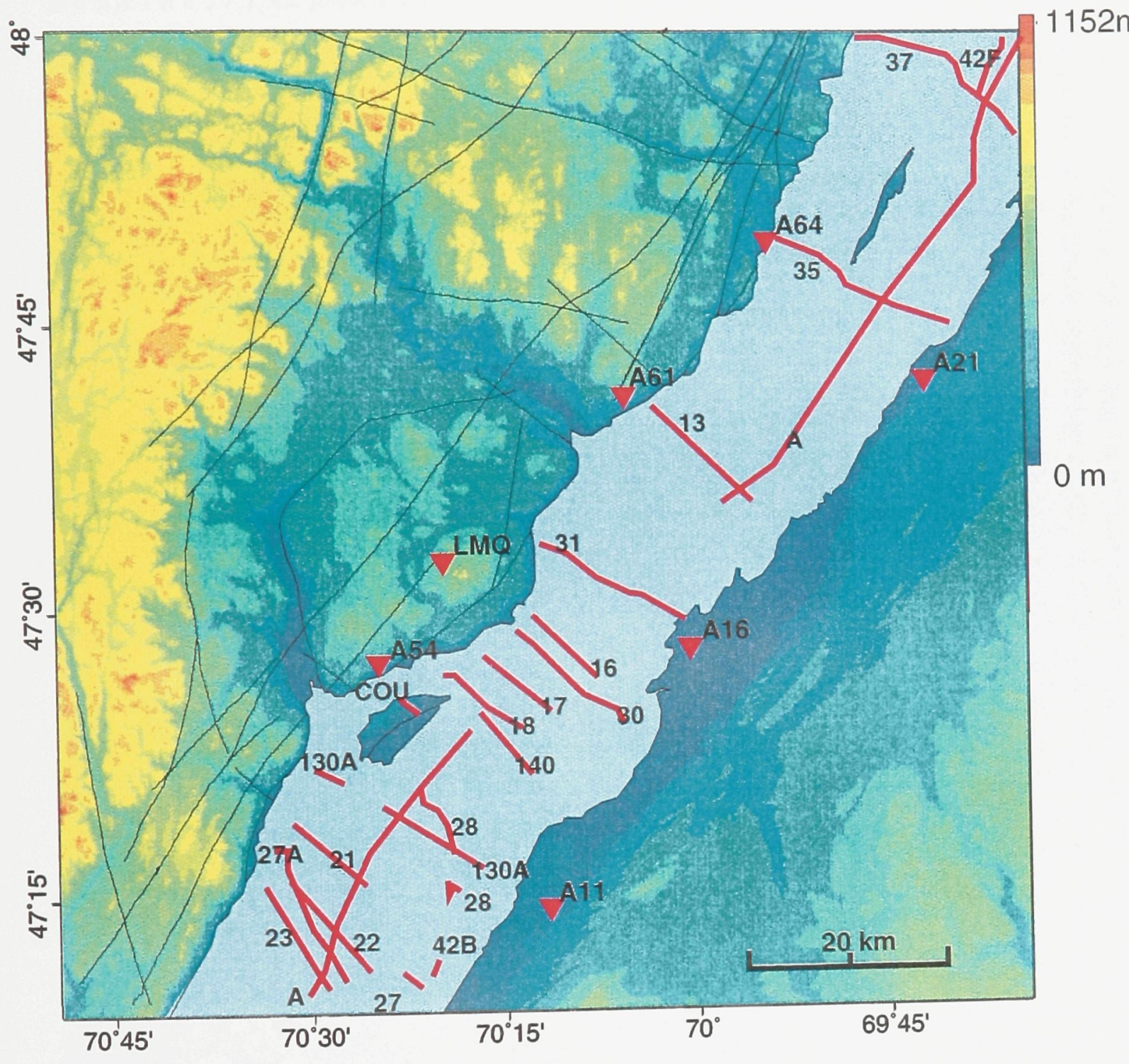

Figure 3.8 Location map of the SOQUIP seismic reflection lines in the CSZ. 


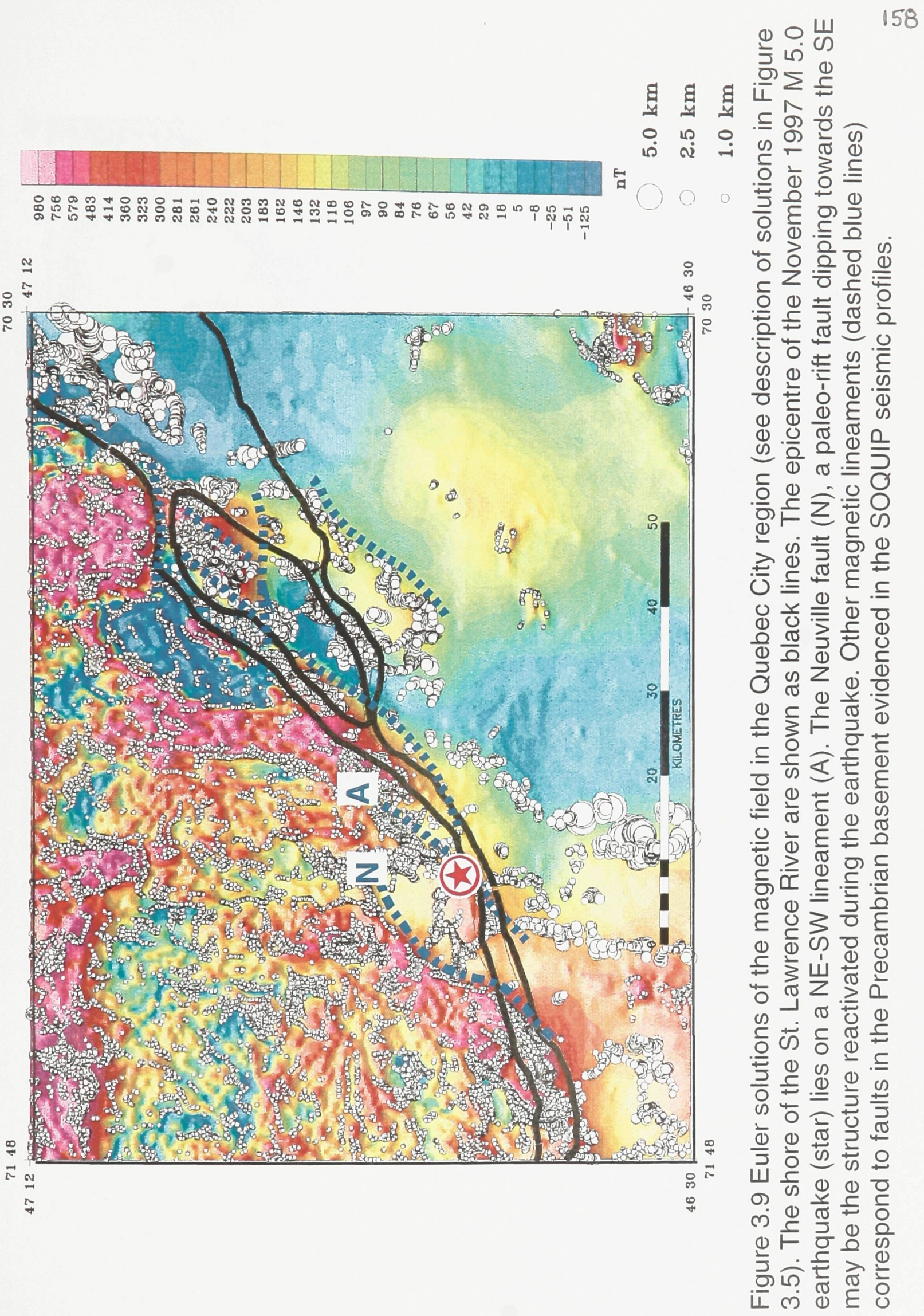


Elevation

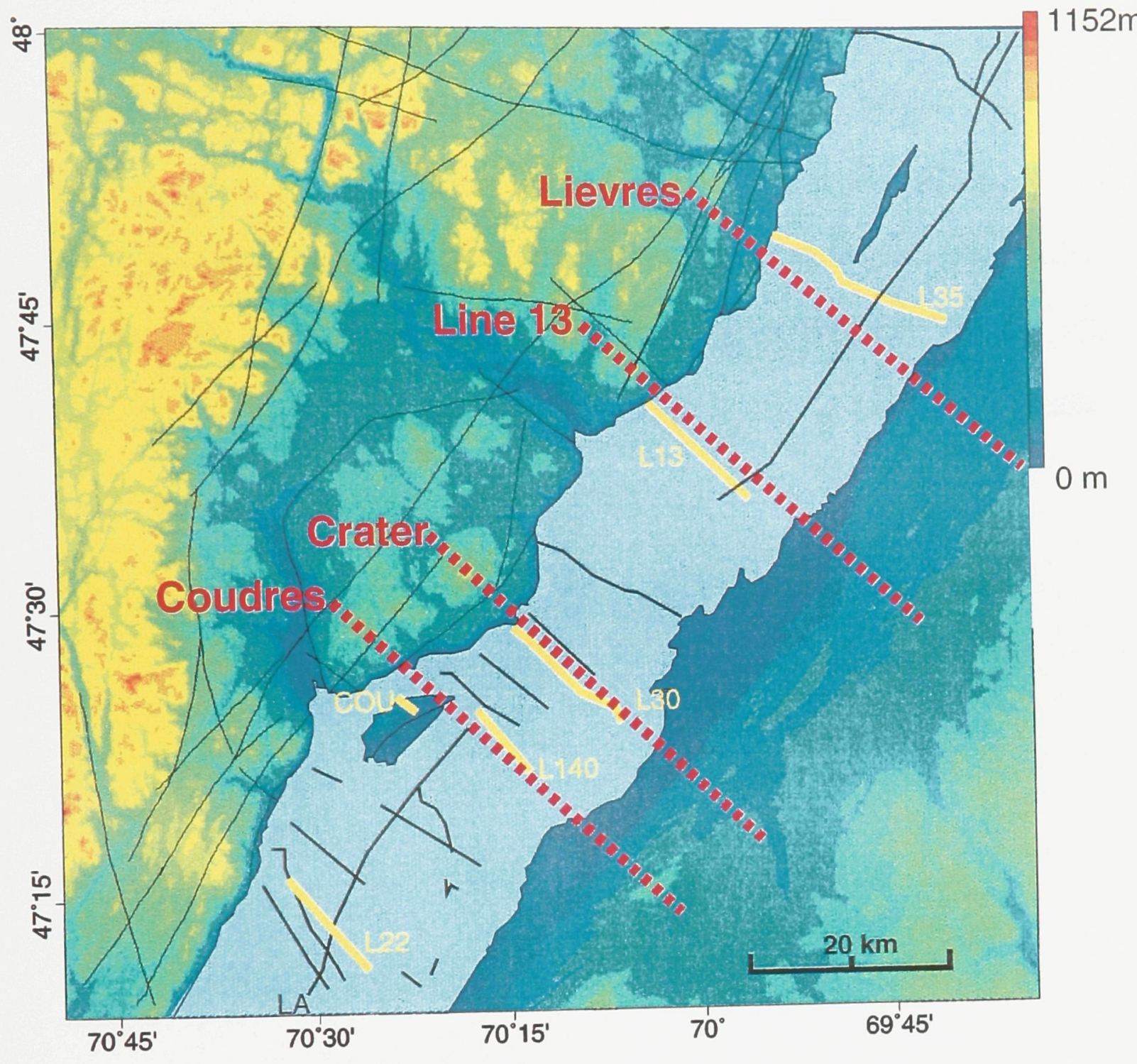

Figure 3.10 Location of the four geophysical profiles discussed in text (red dotted lines) and presented in Figures 3.11 to 3.14. The yellow lines are the SOQUIP seismic profiles shown in the following figures. 
Figure 3.11 Geophysical profile near Ile-aux-Coudres: (A) Bouguer anomaly (circles) and modelled field (red line); (B) Gravity model and density contrasts from the Precambrian; (C) Euler solutions within $5 \mathrm{~km}$ of the profile, plus locations of the seismic lines; (D) Structural model based on geophysical information; (E) Structural model with hypocentres located within $5 \mathrm{~km}$ on both sides of the profile; (F) Seismic profile on Ile-aux-Coudres with the red arrow indicating the surface of the Precambrian (SOQUIP, pers. comm.); (G) Seismic profile 140 on the St. Lawrence River; (H) Interpretation of the seismic profile. 
Ile aux Coudres
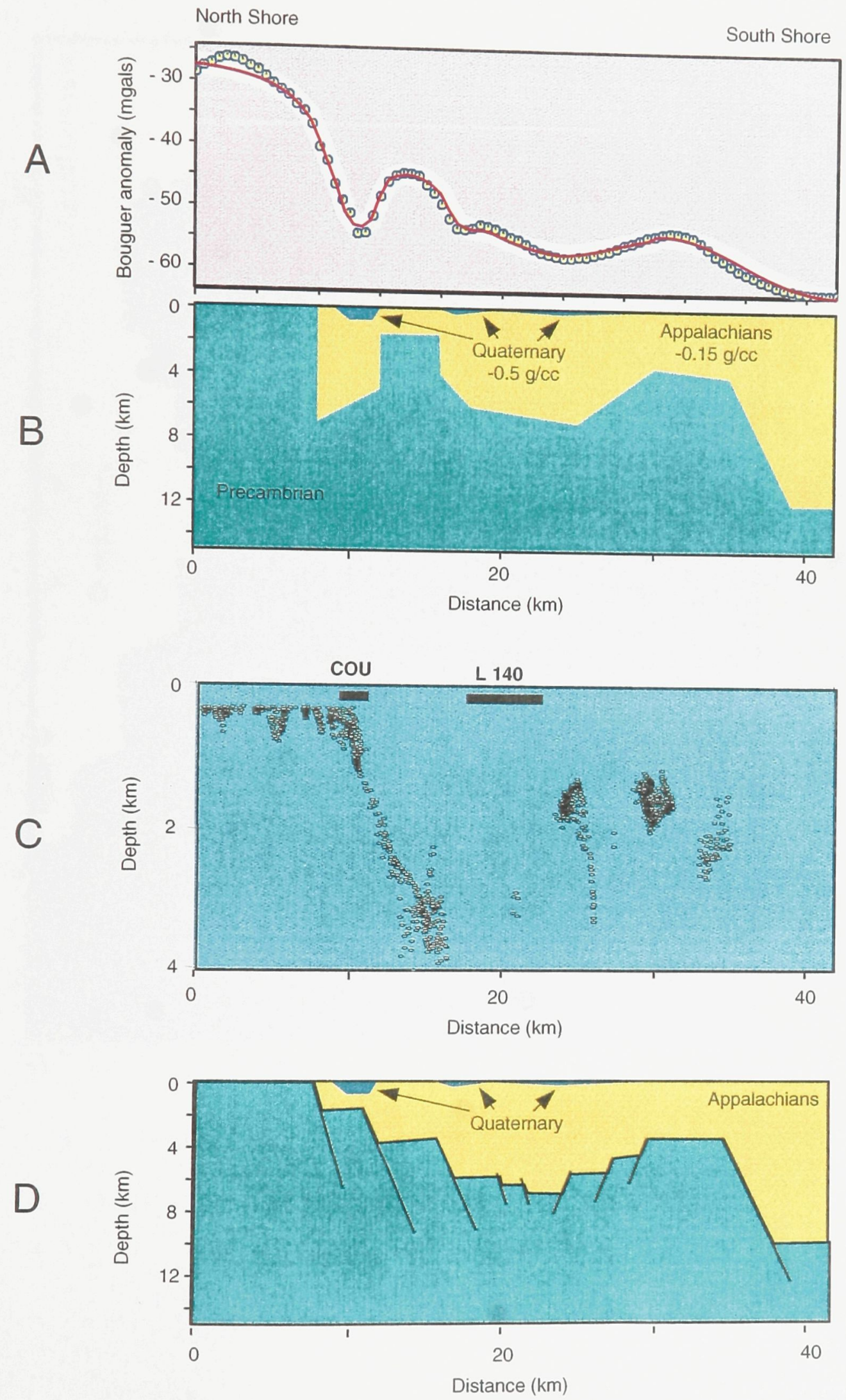
162

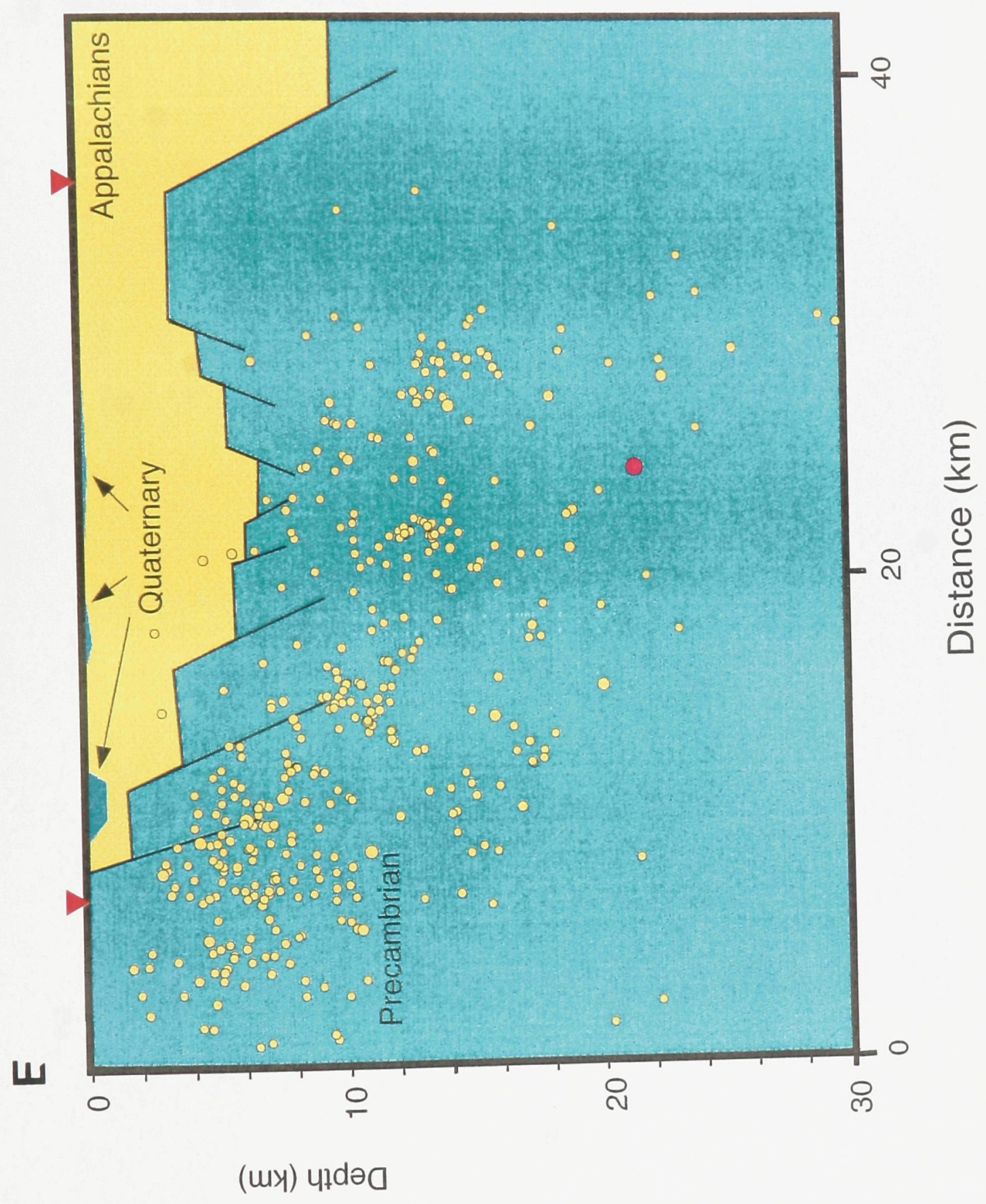




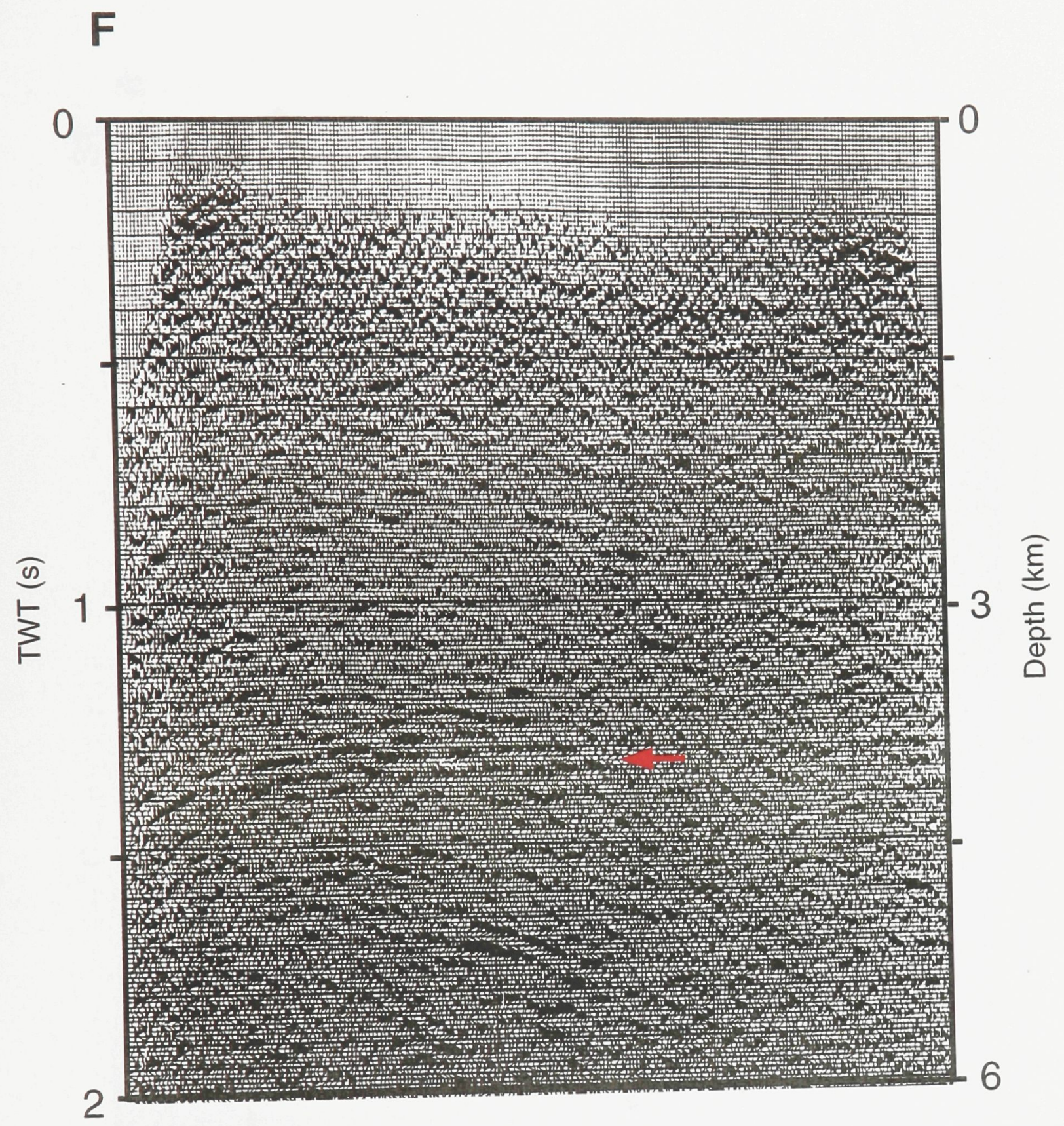




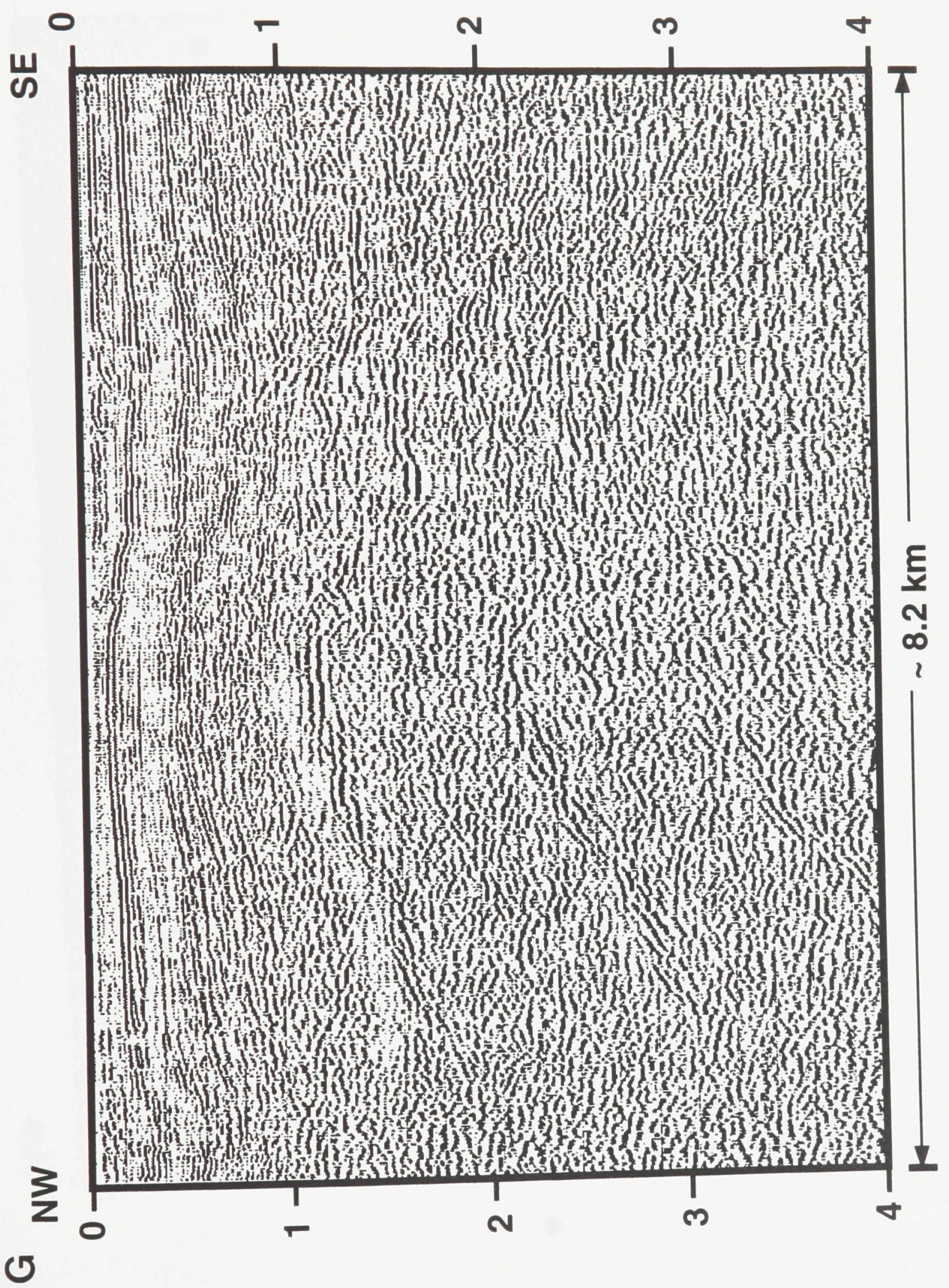

(गə5) $\perp M \perp$ 


\section{(uy) प1dә0}

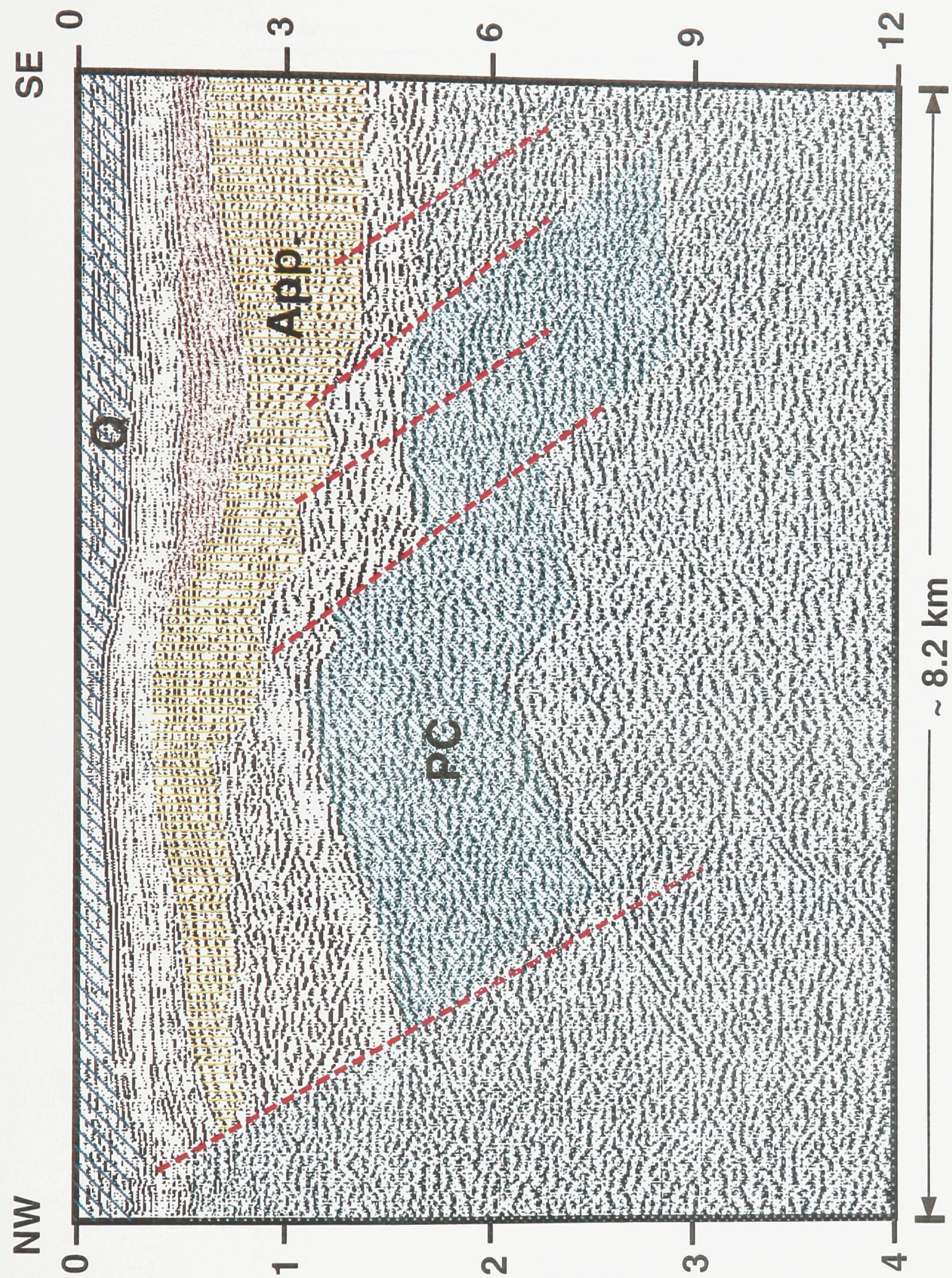

(s) $\perp M \perp$ 

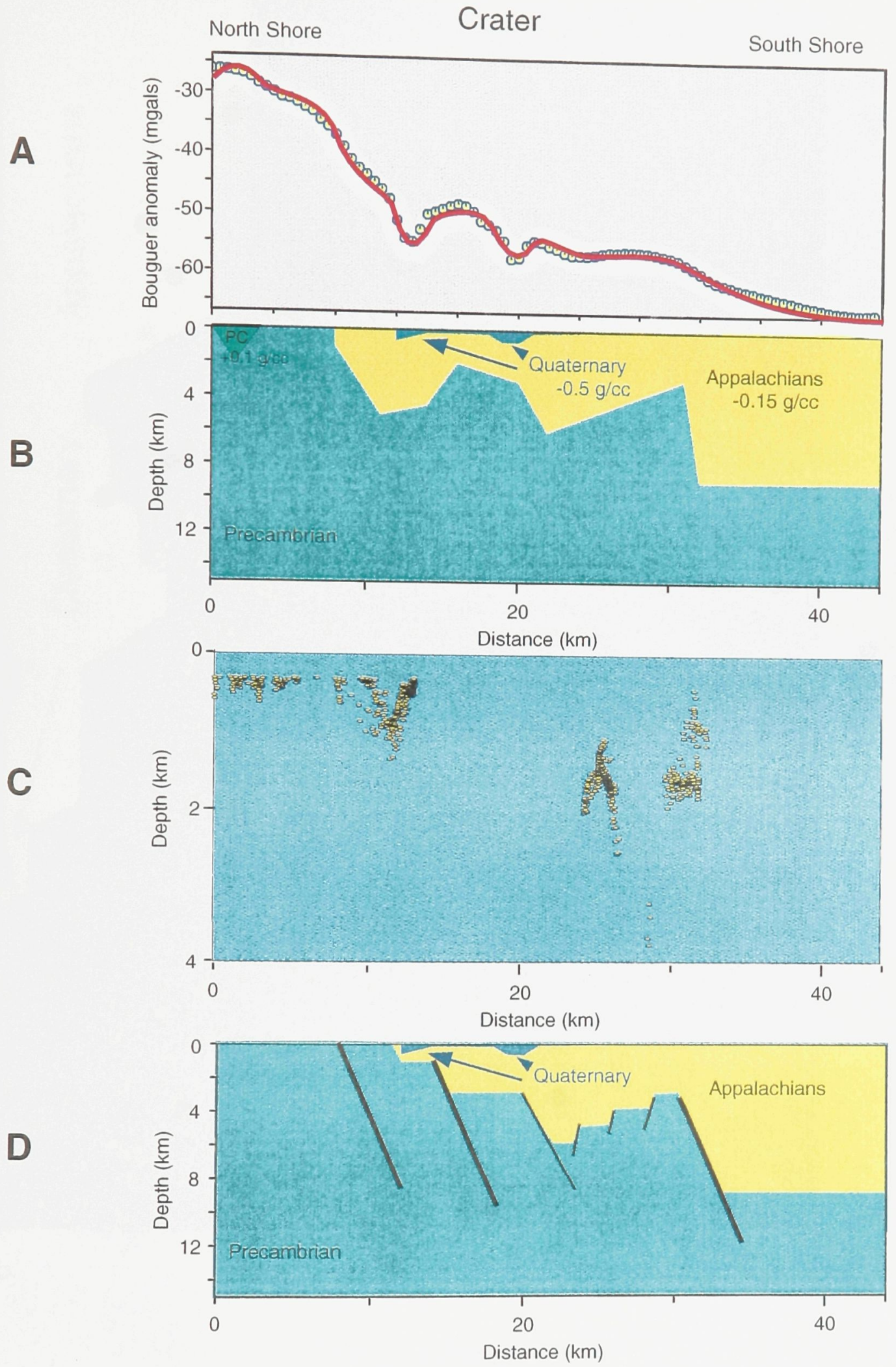

Figure 3.12 Crater profile (A-E), with legend similar to 3.11 A-E; (F) Seismic line 30 over the St. Lawrence River (top) and interpretation (below). The interpreted Quaternary sequence is evident, while deeper reflectors are not continuous. 


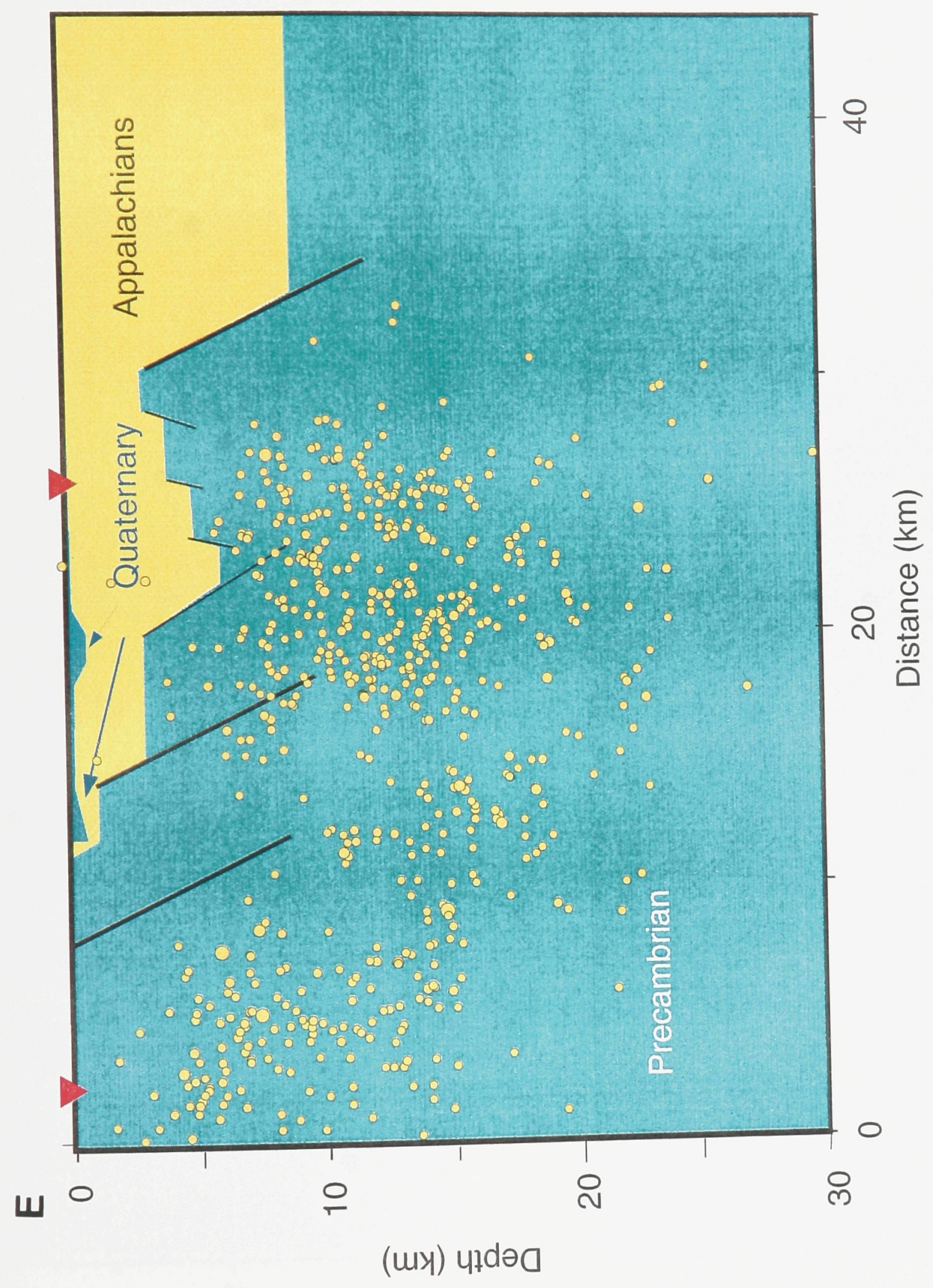




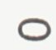

6 
Figure 3.13 Line 13 profile (A-E) with legend similar to 3.11A-E; (F) Original SOQUIP profile with arrows showing interpreted reflectors in the Precambrian shield; $(G)$ Reprocessed Line 13; (H) Interpretation of G. The Appalachian sequence (yellow), possibly cut across by two faults (red) appears to have a sub-horizontal interface with the Precambrian. A number of reflectors can be seen in the Precambrian. The attitude of these reflectors changes with depth. A normal fault may exist to the NE of the line (right side). 
Seismic Line 13

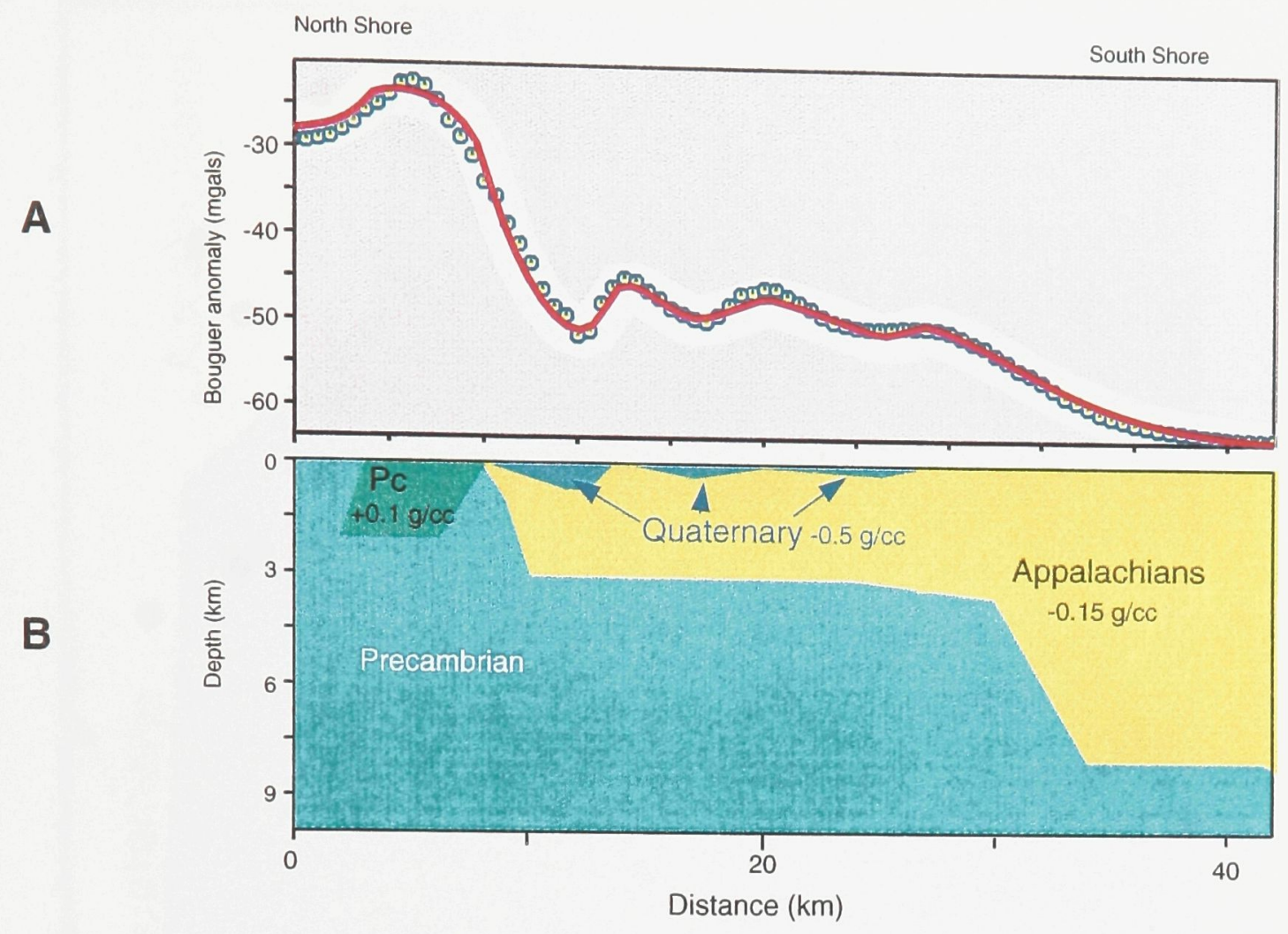

L 13
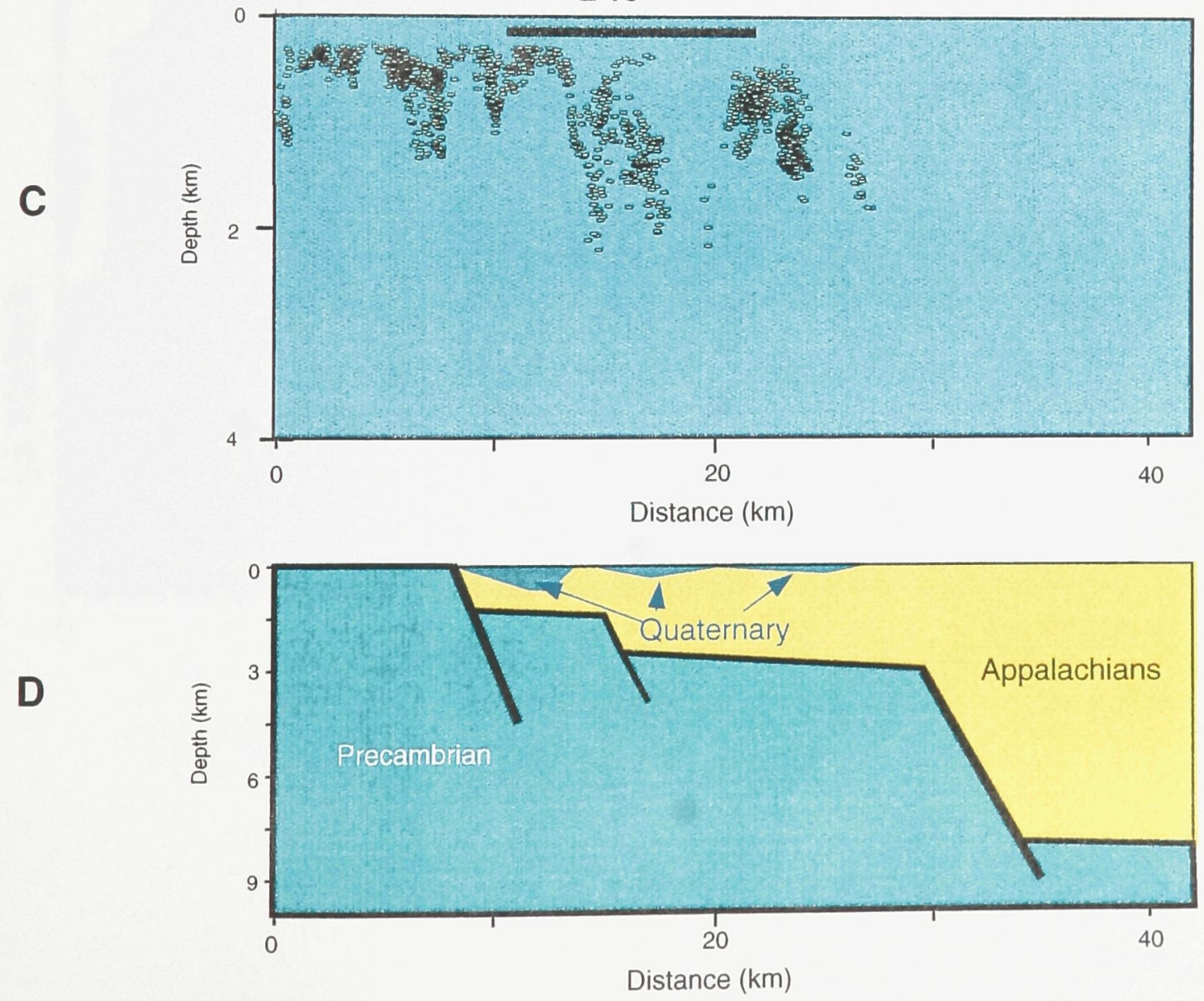


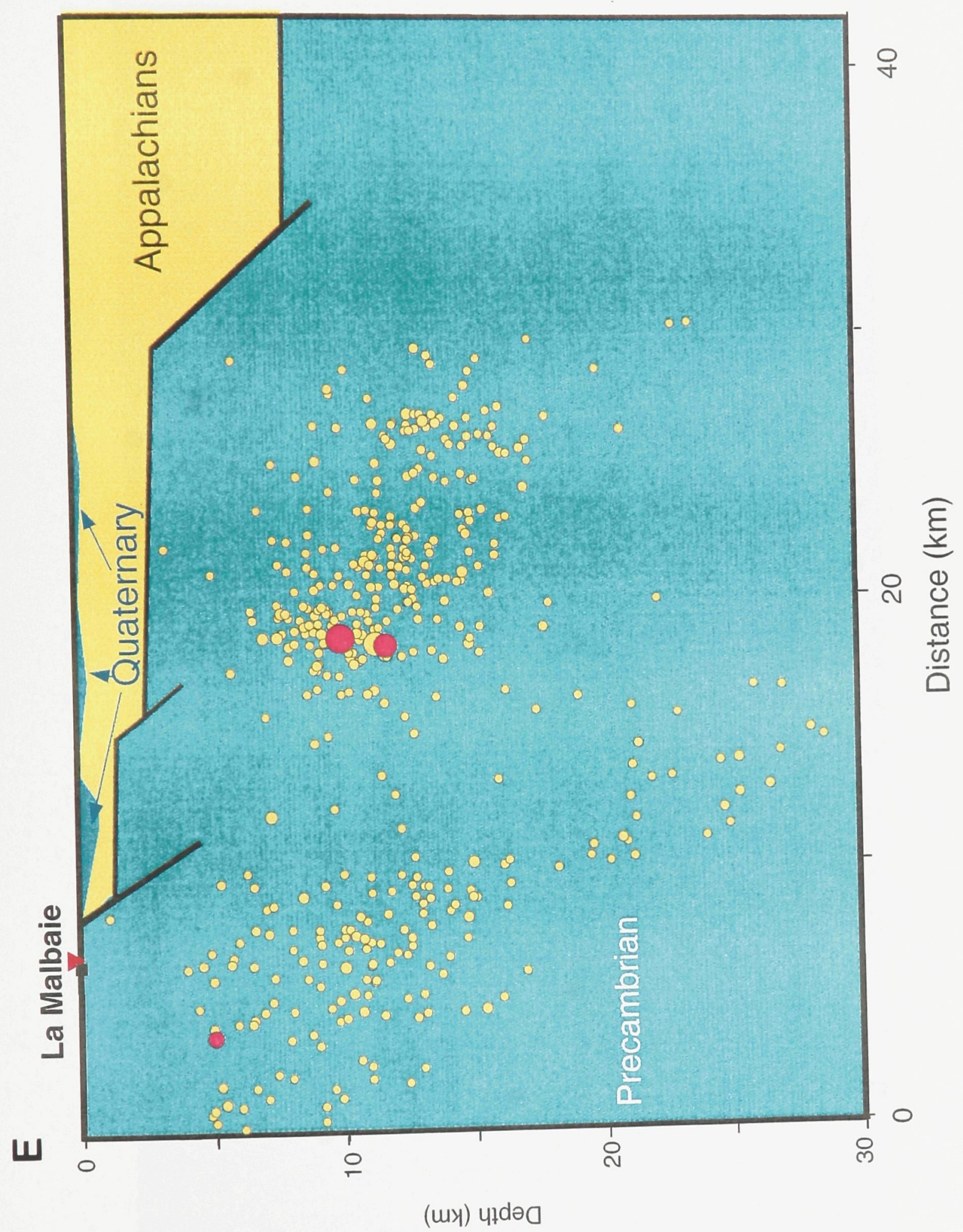


(uy) प1

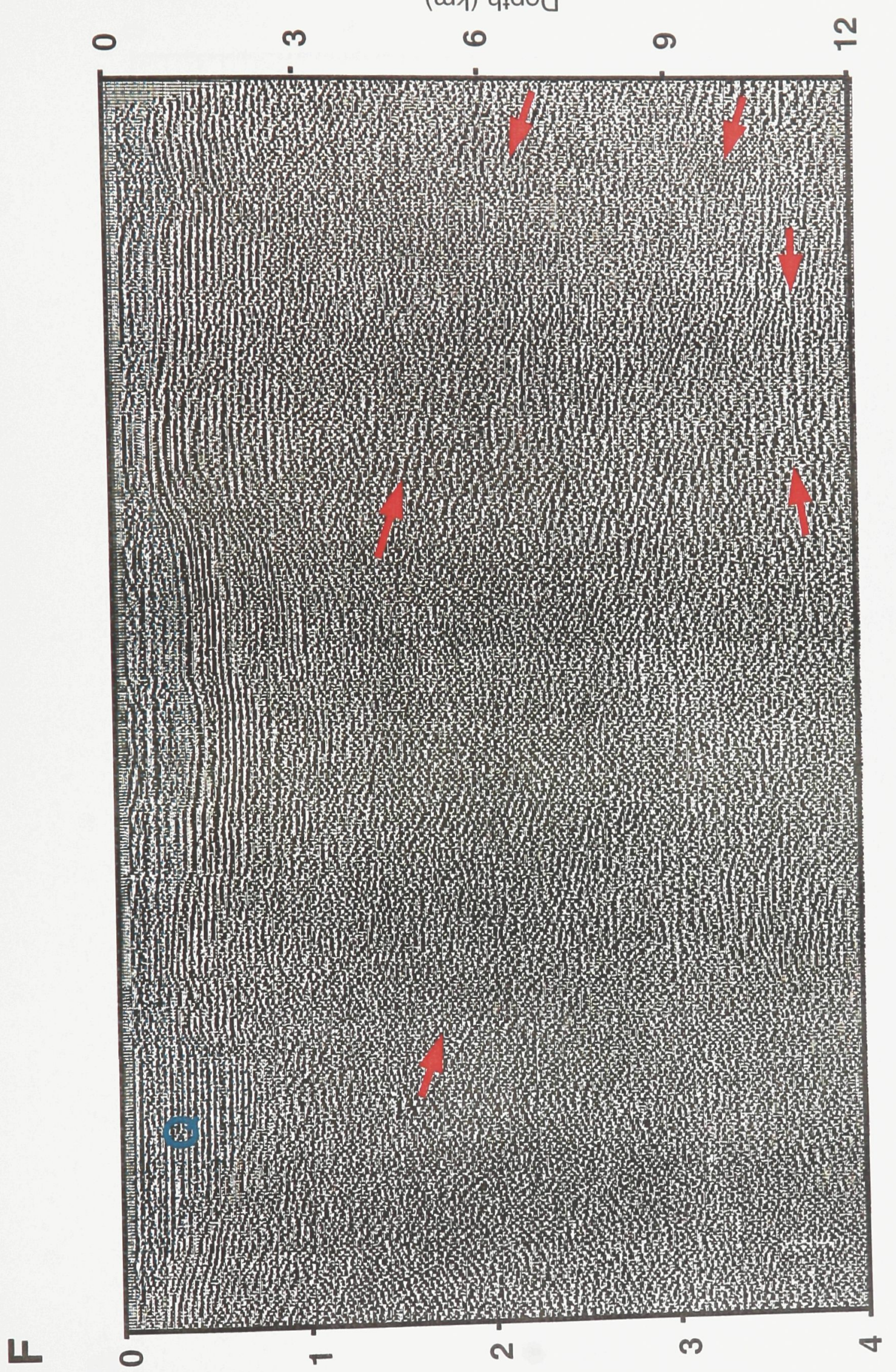

(s) $\perp M \perp$ 


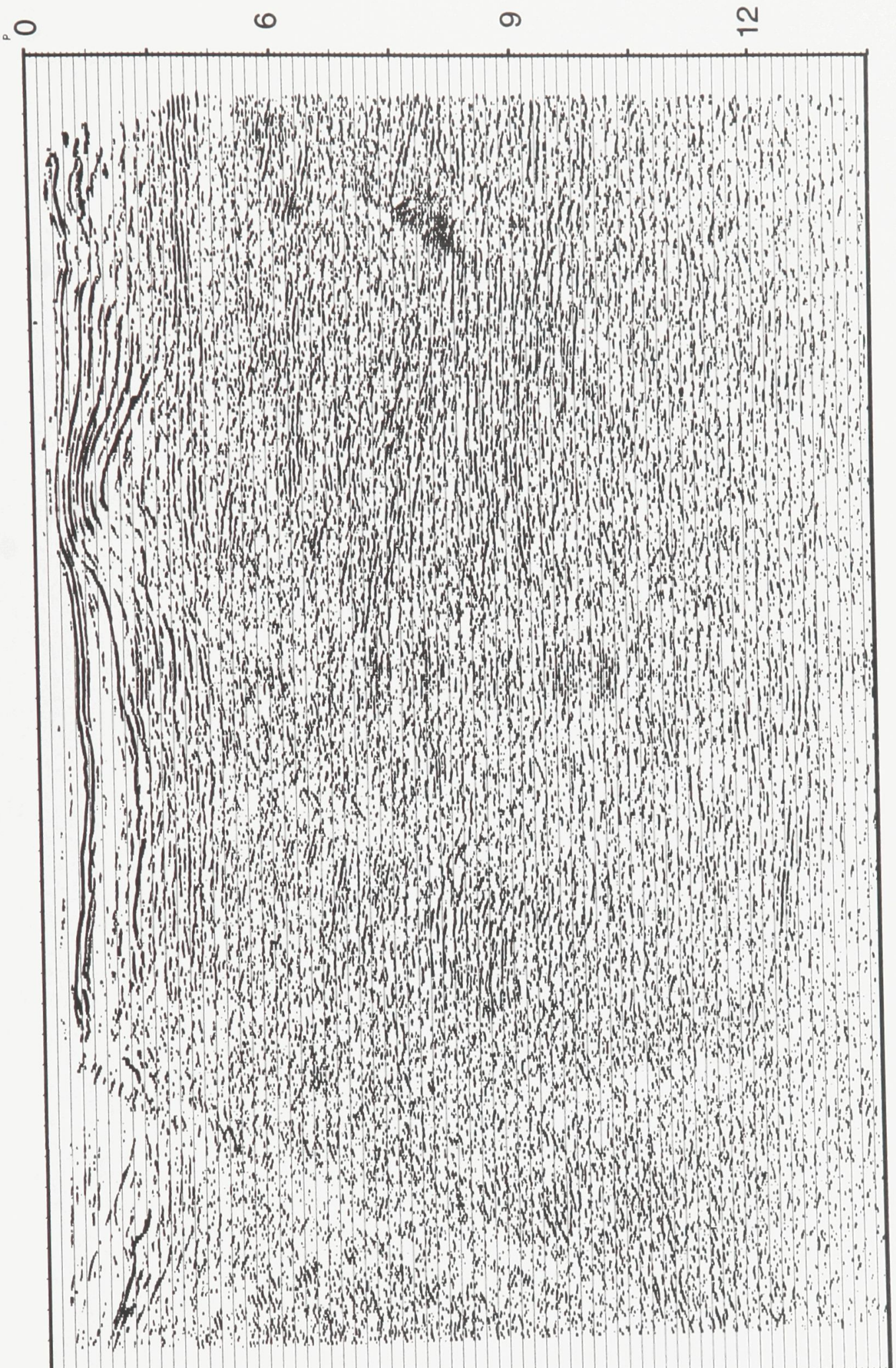

(1)

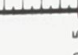

:

?

(oəs) $\perp M \perp$ 


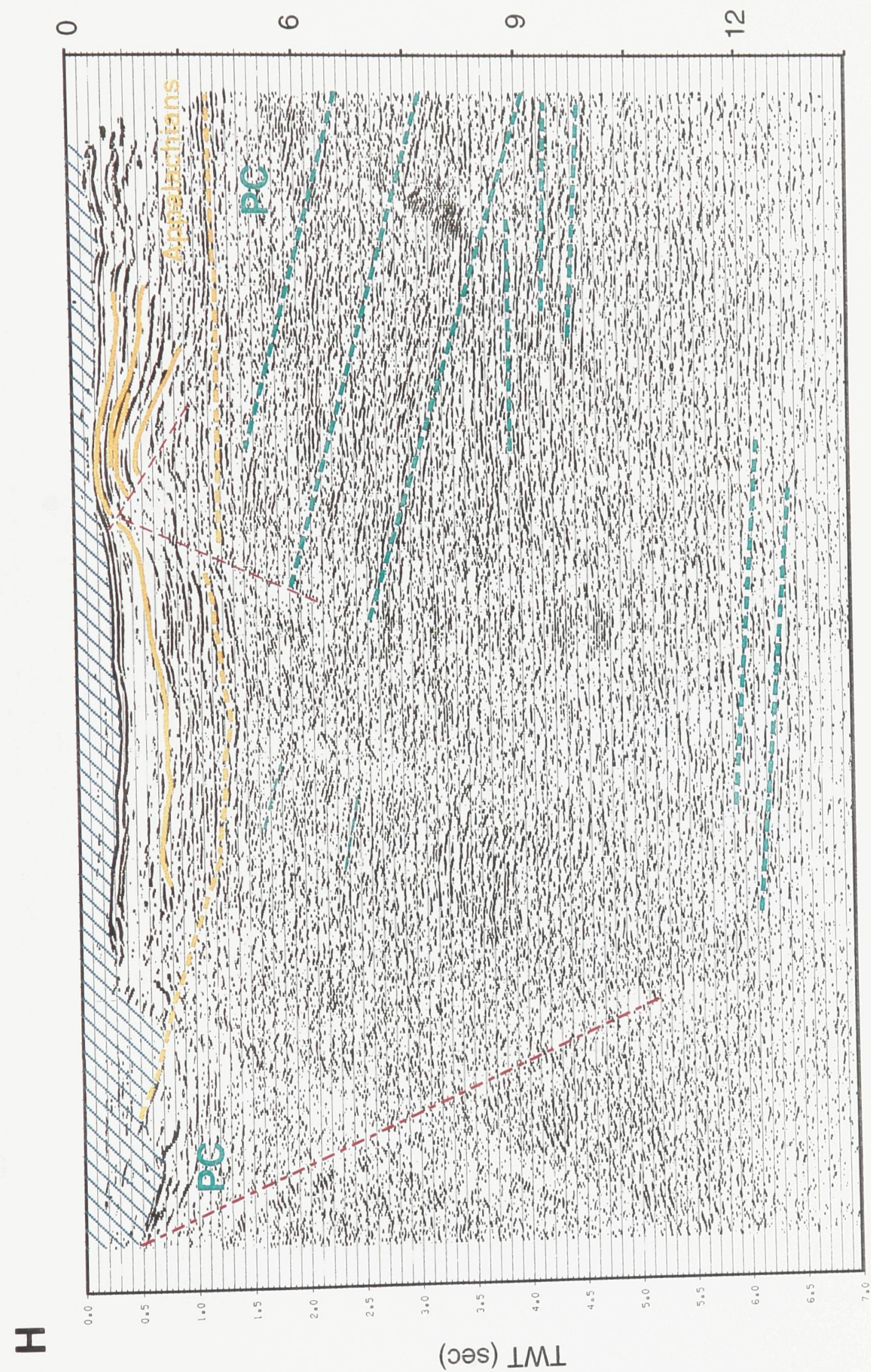


Ile aux Lievres
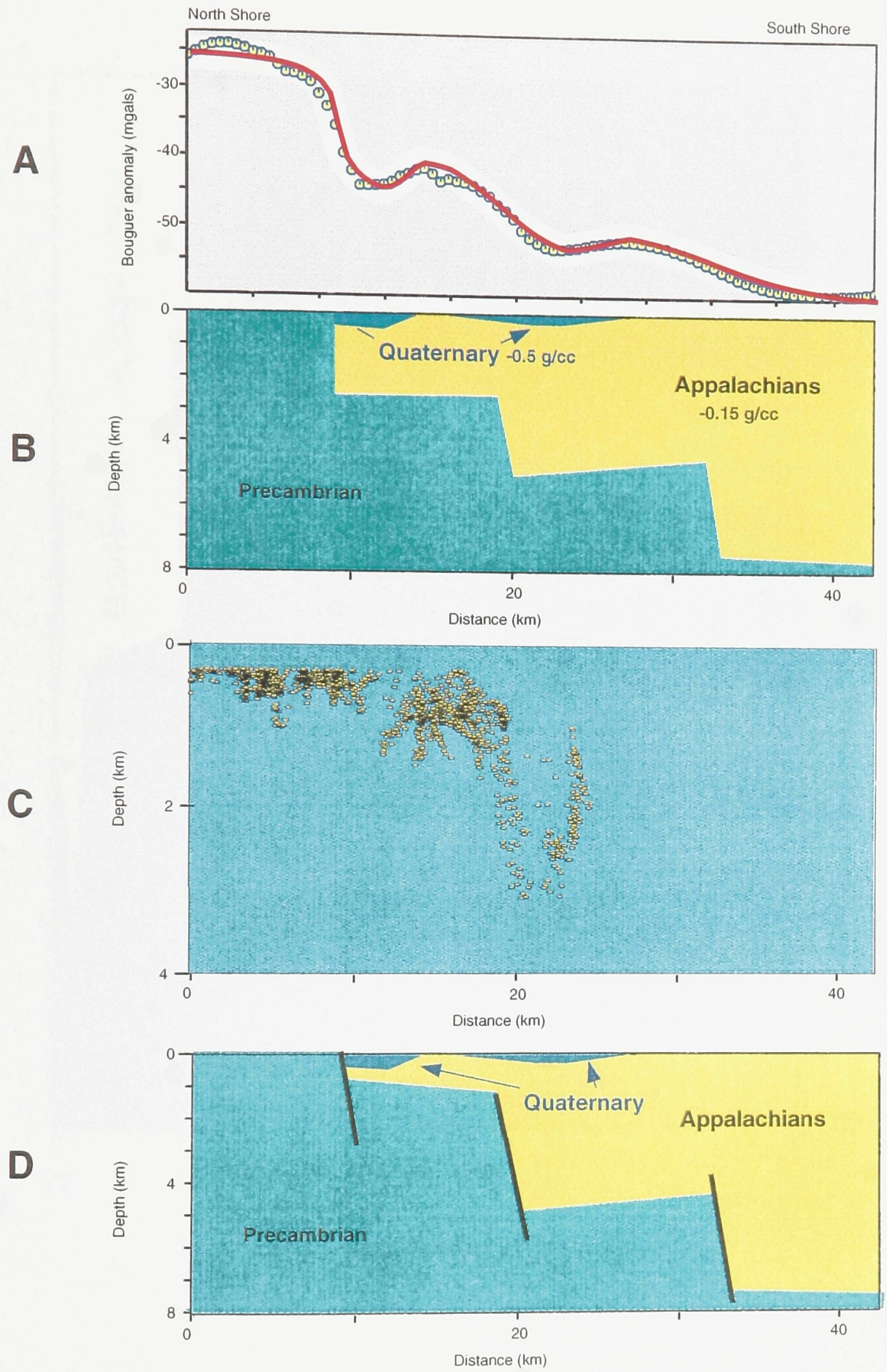

Figure 3.14 Ile-aux-Lievres profile (A-E), with legend similar to $3.11 \mathrm{~A}-\mathrm{E}$; (F) Seismic line 35 (top) with interpretation (below). 


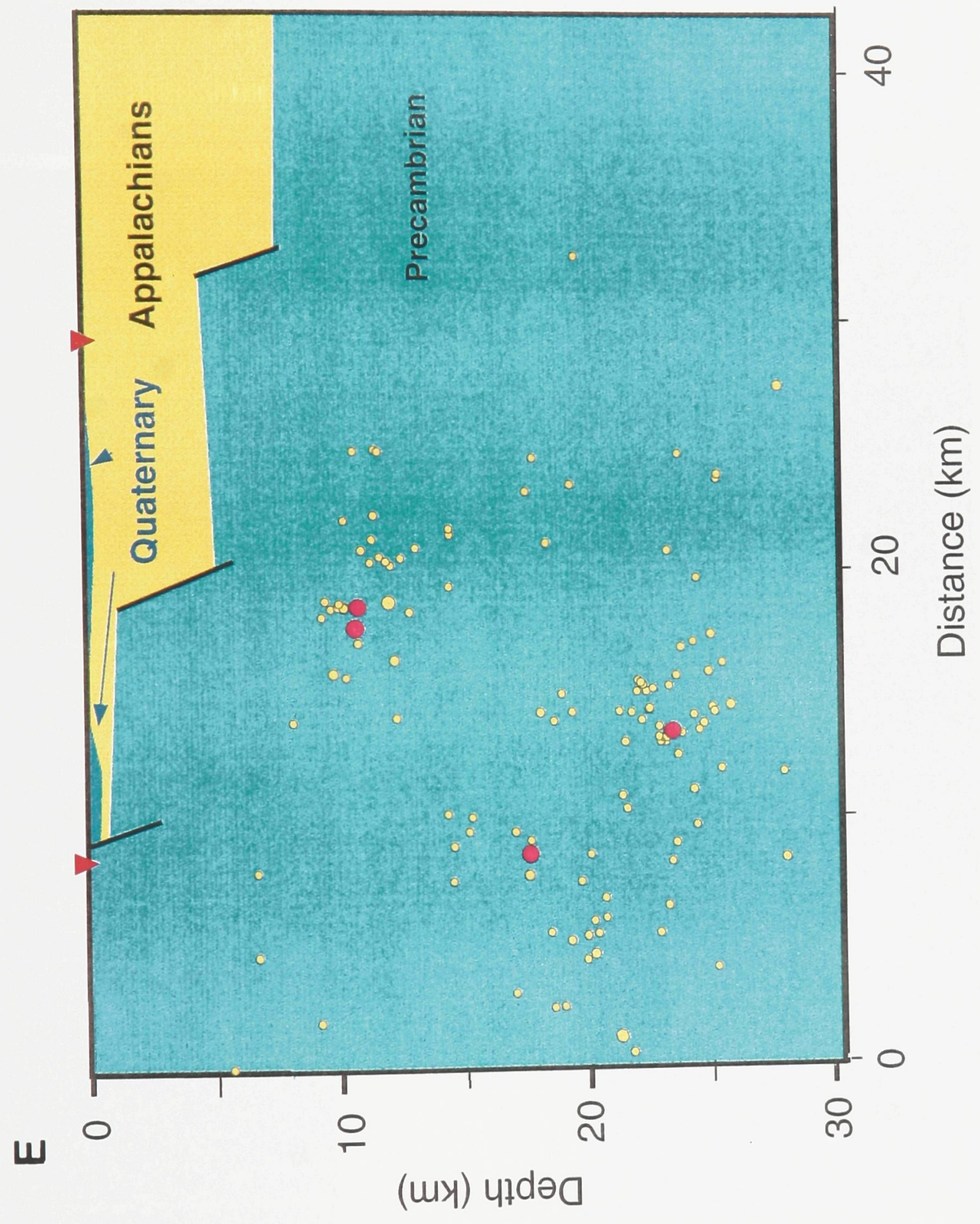


(uxy) 41dә0

$$
\text { o }
$$

ल

0

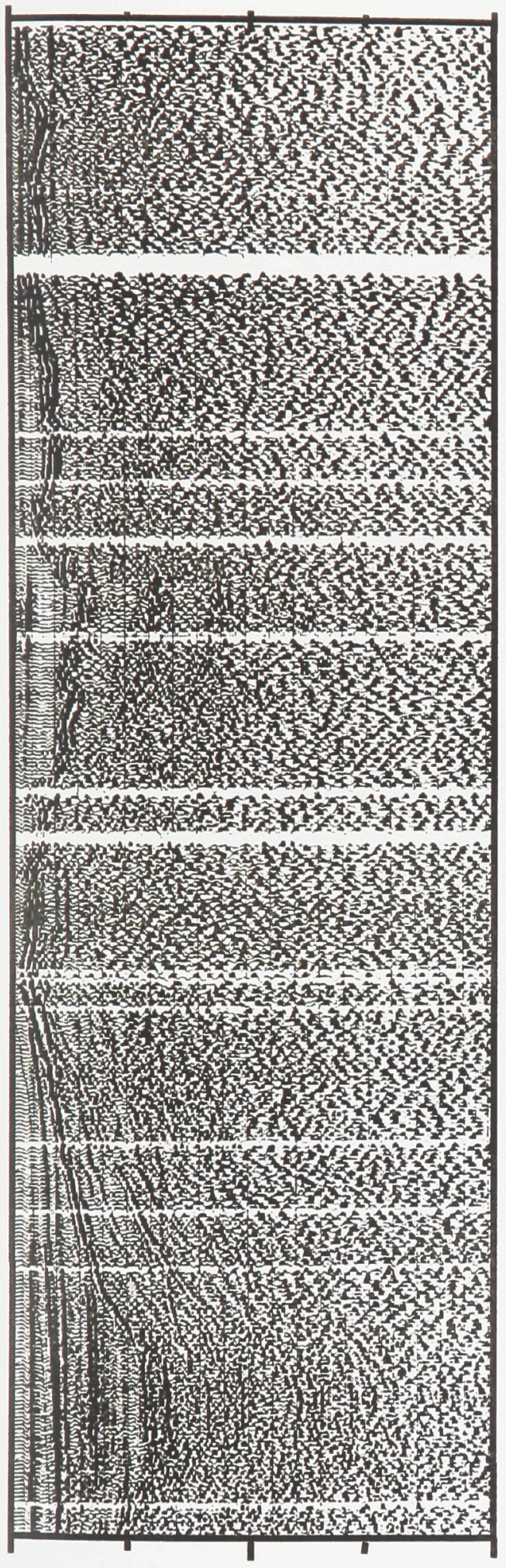

110

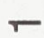

N (wy) प1dә0

$m$

6

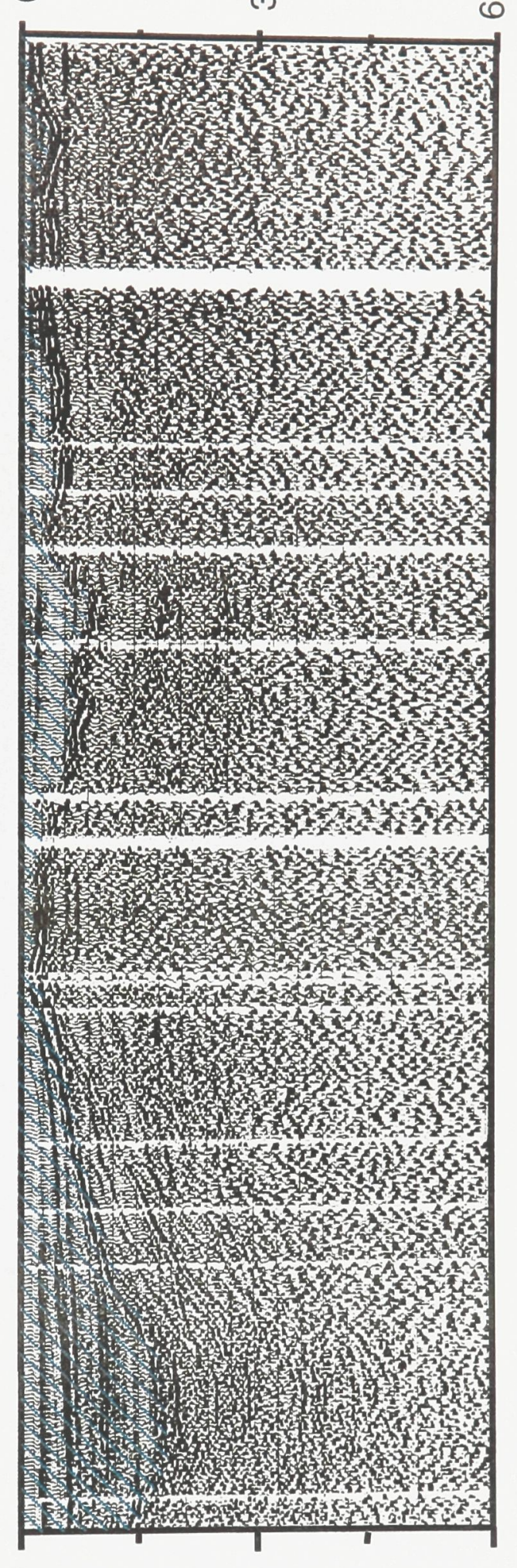

N

(วə) $\perp \perp M \perp$

(วəs) $\perp \perp M \perp$ 


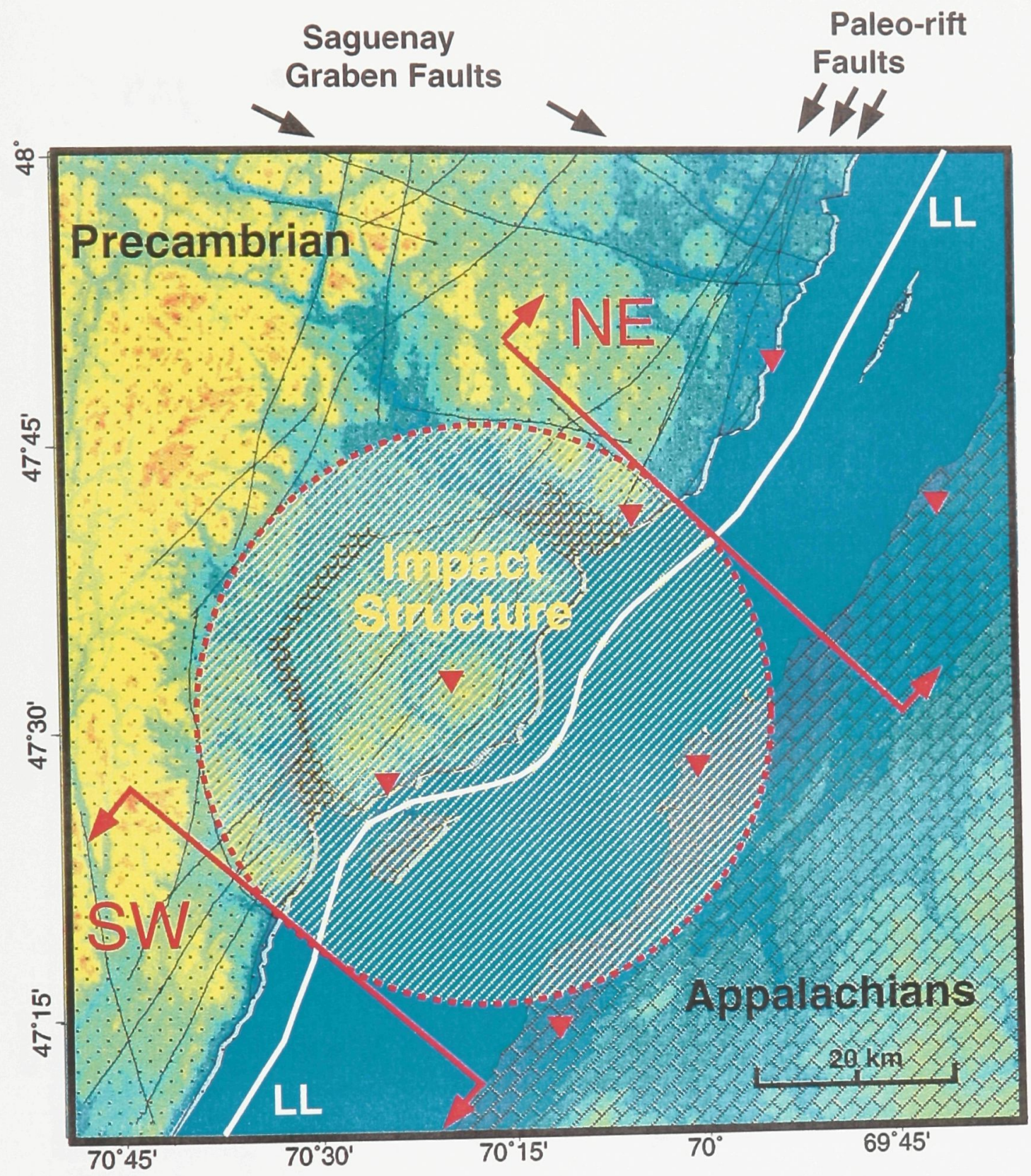

Figure 3.15 The three main sub-regions discussed in text (NE, Impact crater (Central) and SW). Geological features presented in Figure 1.7 are also shown. 


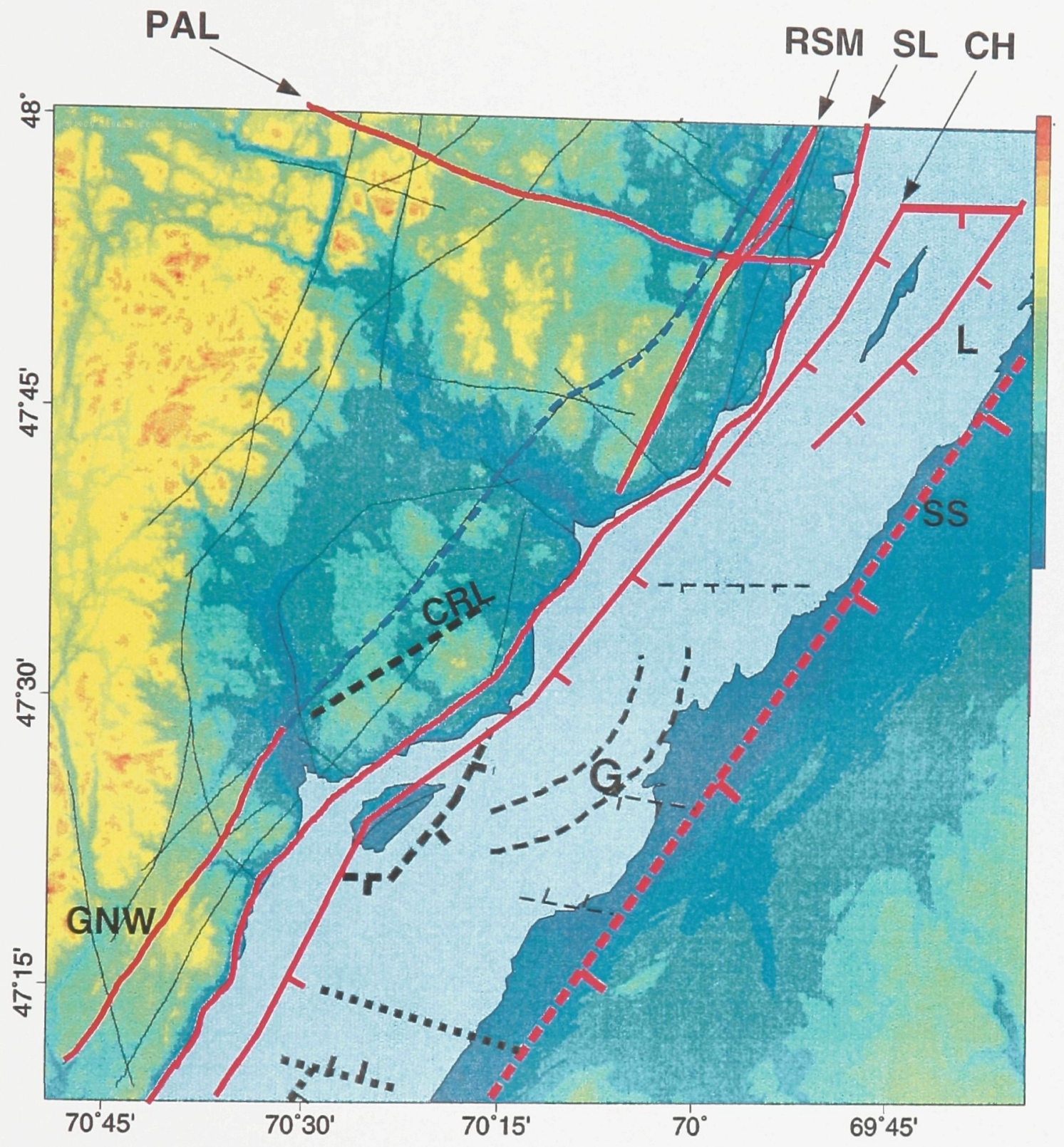

Figure 3.16 Interpreted structures of the CSZ. Acronyms used: PAL: Palissades fault; RSM: Rang Sainte-Mathilde fault; SL: Saint-Laurent fault; CH: Charlevoix fault; L: Lievres fault; SS South shore fault; G: postulated graben under the St. Lawrence River; CRL: crater fault; GNW: Gouffre NW fault. 


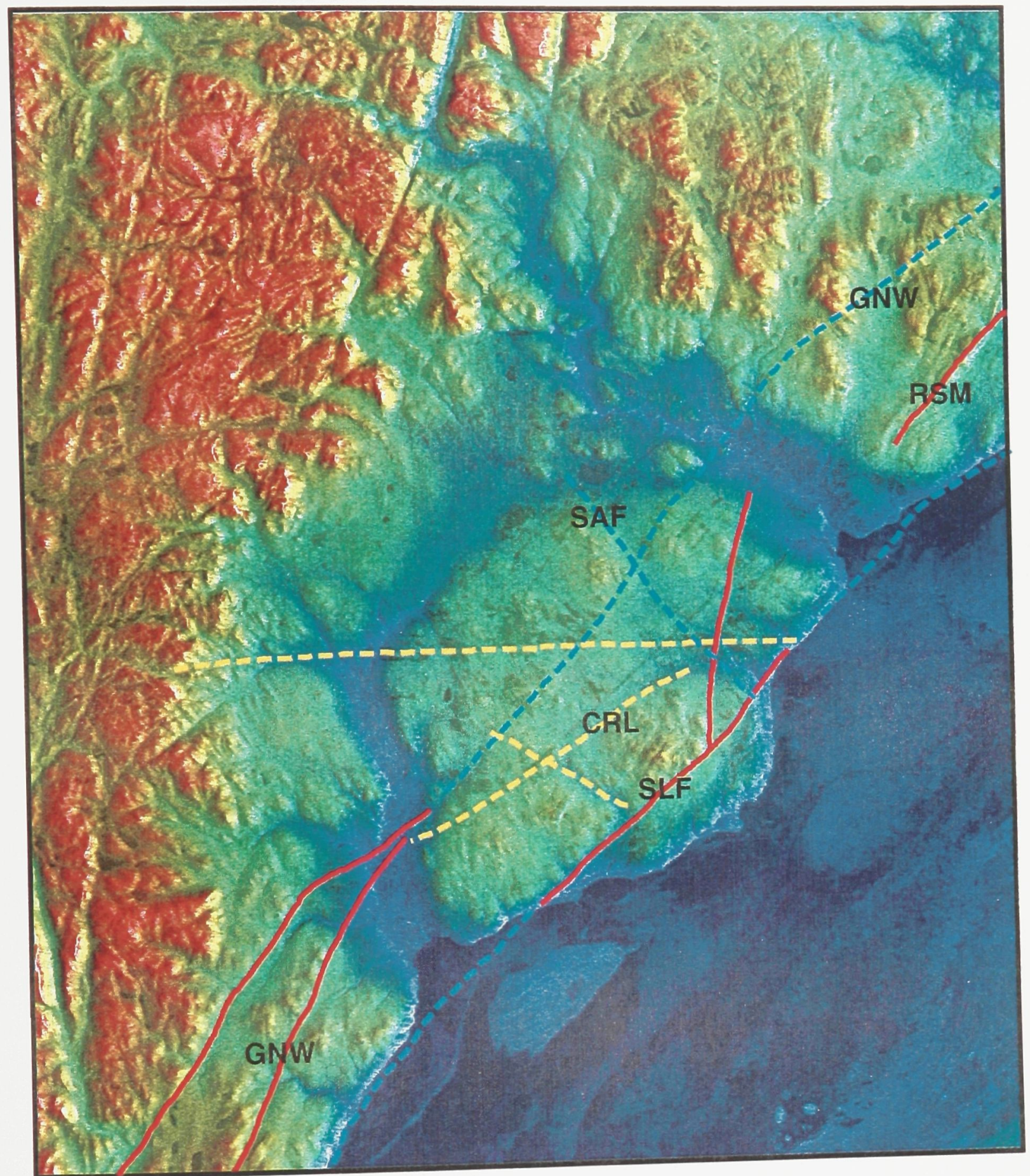

Figure 3.17 Major faults of the CSZ, mapped (red), interpreted (dashed blue), and lineaments (dashed yellow) in the Radar chromo-stereoscopic image (courtesy of T. Toutin, Canada Centre for Remote Sensing). 


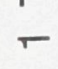

(s) $\perp M \perp$ 
(s) $\perp M \perp$ 


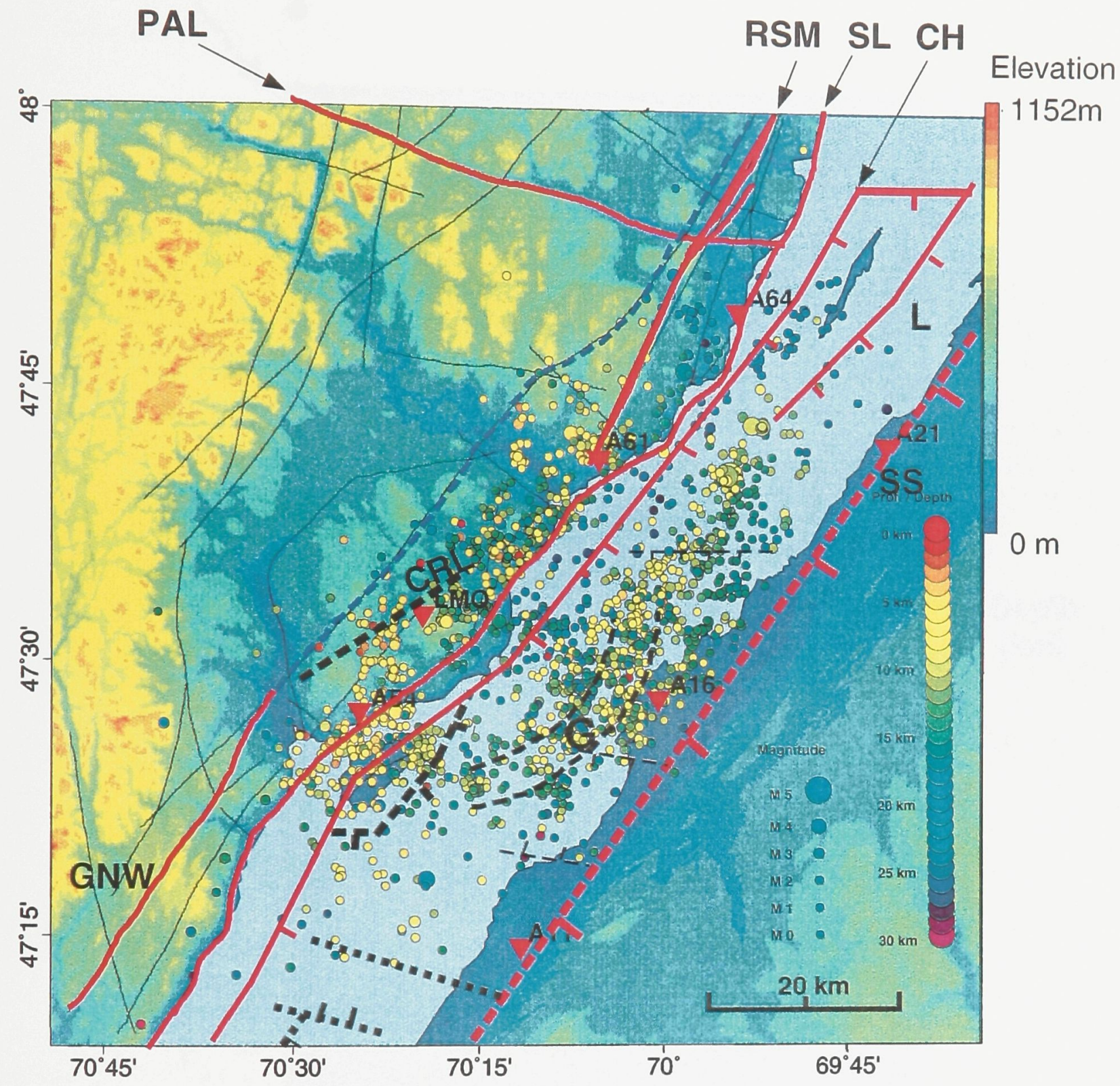

Figure 3.20 Geological faults and CSZ hypocentres for the period October 1977 to December 1997. 


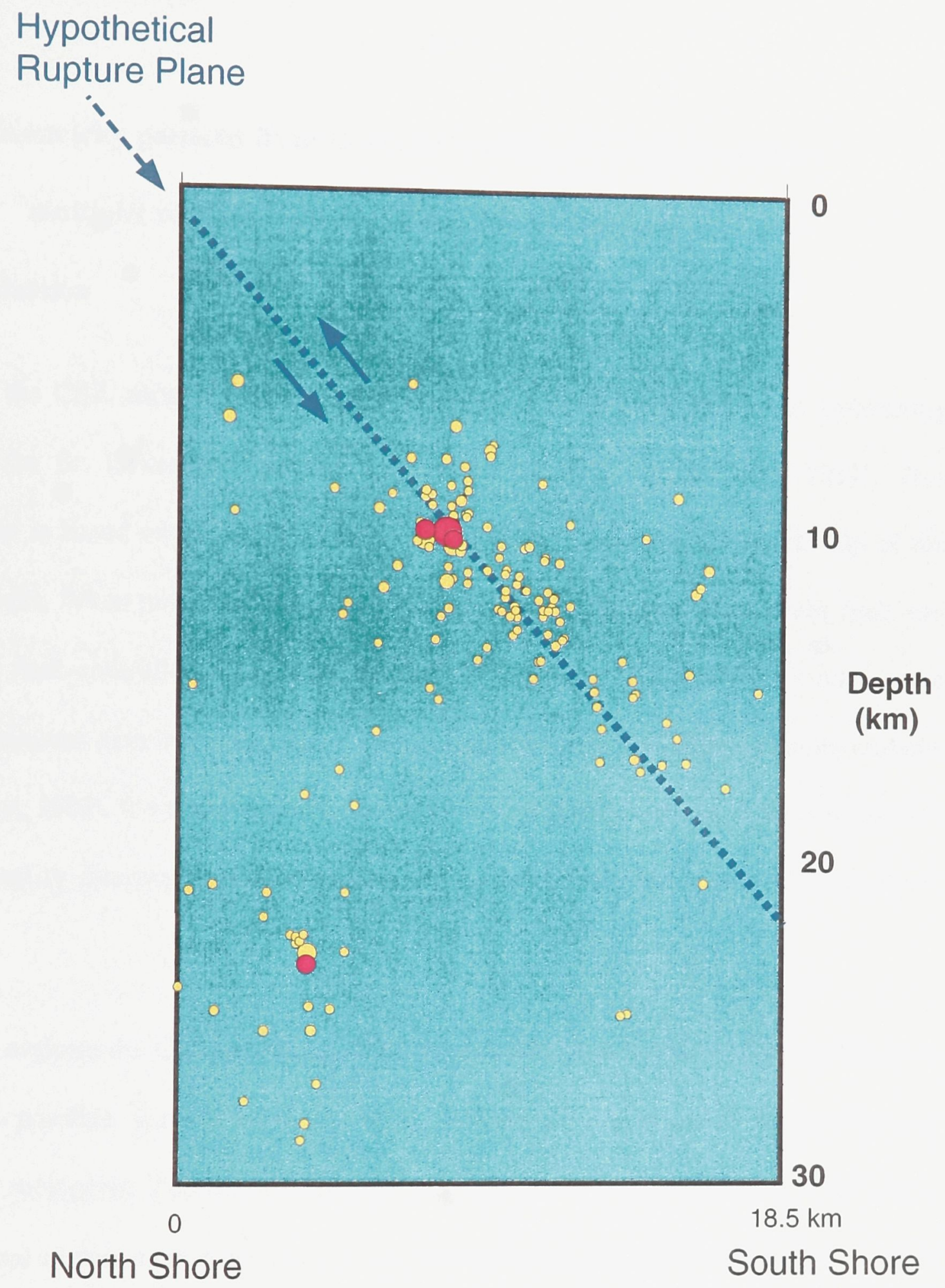

Figure 3.21 Vertical section across the 1979 M5 earthquake zone. Earthquakes are within $10 \mathrm{~km}$ of a line across the trend of the St. Lawrence River, and centred on the M5 event of 1979. Pure reverse-faulting on the best hypocentre alignment is shown. 


\section{NOTE TO USERS}

Page(s) missing in number only. Scanned as received 


\section{Chapter 4}

\section{Seismicity patterns from focal mechanisms, earthquake clusters, multiplet analysis, and the search for surface fault ruptures}

\subsection{Introduction}

In the CSZ, most earthquakes are assumed to be spatially related to preexisting faults of the St. Lawrence Paleozoic rift system (Adams and Basham, 1989). This relationship is based on a projection of the hypocentres to the surface up the dip of the regional faults. When projected, the earthquakes are located between a paleo-rift fault and a possible fault-controlled bathymetric feature. In support of the paleo-rift model, some focal mechanisms have one nodal plane oriented similarly to the paleo-rift faults (Adams and Basham, 1989). It was recognized, however, that the highly variable focal mechanisms are not easy to interpret, possibly due to the complications introduced by the impact structure.

To evaluate the CSZ earthquake-fault connection, four sources of information are examined: possible surface ruptures, focal mechanisms, hypocentre alignments and earthquake multiplets. The best evidence of the earthquake-fault connection would be to find a surface rupture caused by some of the numerous $\mathbf{M}>6 \mathrm{CSZ}$ earthquakes. Section 4.2 describes the search for such a rupture under the St. Lawrence River. Focal mechanisms are a representation of the earthquake rupture process and, as such, constitute an essential source of seismotectonic information (Section 4.3). They provide the strikes 
and dips of two nodal planes (one of which being the rupture plane), the trends and plunges of the $\mathrm{P}, \mathrm{T}$ and $\mathrm{B}$ axes, and the nature of faulting that produced the earthquake. Fault zones can also be located from hypocentre groups and alignments (Section 4.4). Another source of information on fault orientations is provided by earthquake multiplets, which represent earthquakes with similar locations and focal mechanisms (Section 4.5).

In the CSZ, hypocentres are not distributed randomly. There are areas where earthquakes are shallow (<10 km depth), intermediate $(10-15 \mathrm{~km})$, deep $(>15 \mathrm{~km})$, or dispersed. To better define the local factors that determine the hypocentre distribution, earthquakes are divided into a series of sub-zones in Section 4.6. The seismotectonics of these sub-zones are examined using the available focal mechanisms, earthquake groups and multiplets. Based on the findings, regional seismicity aspects of the CSZ are discussed in Section 4.7. Finally, in Section 4.8, recommendations for future work are presented.

\subsection{The search for surface fault ruptures}

The best possible correlation between the CSZ earthquakes and the regional faults would be a surface rupture caused by one or by a series of magnitude $>6$ earthquakes. In the CSZ, at least five earthquakes of this size are known to have occurred since the $\mathrm{XVII}^{\text {th }}$ century, and numerous prehistorical earthquakes are suggested by local landslides and lake disturbances (Filion et al., 1991; Doig, 1986). Despite these large earthquakes, no surface rupture has ever been reported in the geological maps (Rondot, 1979; 1989), in the historical accounts, or in the scientific reports on the 1925 earthquake (Hodgson, 1925 ; 1950). Based on the source parameters for a moment magnitude (M) 6.0 (Table 3.3) 
and the focal depth (10 km; Bent, 1992), the 1925 earthquake is unlikely to have ruptured the surface. However, the recurrence of similar or larger events over thousands of years may have led to a surface rupture.

It can be argued that the likelihood of a surface rupture is greater under the St. Lawrence River where most magnitude $>4$ earthquakes of the $\mathrm{XX}^{\text {th }}$ Century occurred (Stevens, 1980; Chapter 1). Under the river, however, thick sequences of unconsolidated Quaternary deposits cover the basement. These sequences represent multiple glacial and inter-glacial periods covering more than 250,000 years (Occhietti et al., 1997). The seismic lines by the Société Québécoise d'exploration pétrolière (SOQUIP) suggest that some river-parallel valleys include up to $600 \mathrm{~m}$ of sediments. At present, the complete sequence has not been drilled and, consequently, the Quaternary age of the basal units can only be assumed. A model was defined for a surface rupture caused by a thrust earthquake occurring in the Precambrian basement (Figure 4.1). A rupture from the bedrock causes offsets or truncations of the basement-sediment interface, propagates into the sedimentary sequences, giving displaced, or truncated sub-horizontal horizons on seismic sections. A bathymetric feature can be evident in the depth soundings, such as those done during the 1994 gravity survey. To consider this model, a series of factors were defined (Table 4.1).

The SOQUIP seismic profiles, acquired in the early 70's (described in Chapter 3) can be used to infer the position of sub-river ruptures. Most profiles show continuous horizontal reflectors in the Quaternary deposits, in the underlying Precambrian basement and in the Appalachians (Figure 4.2). It is assumed that a vertical throw of $20 \mathrm{~m}(0.02 \mathrm{~s}$ offset) through the sediments would be evident on most SOQUIP lines. This corresponds 
to the accumulated slip of seven shallow $\mathbf{M} \geq 6.0$ earthquakes. In addition, a series of shallow high resolution seismic profiles were acquired jointly by the Université du Québec à Rimouski (UQAR) and the Université du Québec à Montréal (UQAM), with partial financial support by the GSC. More than $200 \mathrm{~km}$ of shallow seismic reflection profiles were acquired on the St. Lawrence and Saguenay rivers during the summers of 1995 to 1998. Up to $800 \mathrm{~ms}$ of analogue data were acquired (corresponding to about $800 \mathrm{~m}$ of penetration with a P-velocity of $2 \mathrm{~km} / \mathrm{s}$ ). The resolution power of the method is very high, and provides images of sedimentary facies within the Quaternary sequences.

Ruptures with meter-size slips should be seen. As of May 1998, the careful examination of the shallow seismic lines is ongoing at the UQAR (B. Long, pers. comm.). One of these lines (line 13) is shown in Figure 4.4B and is discussed below.

On most SOQUIP seismic sections, one or more continuous sub-horizontal reflectors is evident in the Quaternary sequences, in the basement or in the interpreted interface between the two (Figure 4.2). On some profiles of lesser quality, a few small, although ambiguous, offsets were seen southwest of the Ile-aux-Coudres and within the impact structure. Elsewhere, no unambiguous ruptures were found on any profile, and most areas have clear uninterrupted markers (Figure 4.3). The NE end of the CSZ, where most magnitude $>4$ earthquakes concentrate, shows no evidence of a rupture on Lines 13, 35 and 37, including in the thick Quaternary sequence near the north shore (Figure 4.4A). 
욱

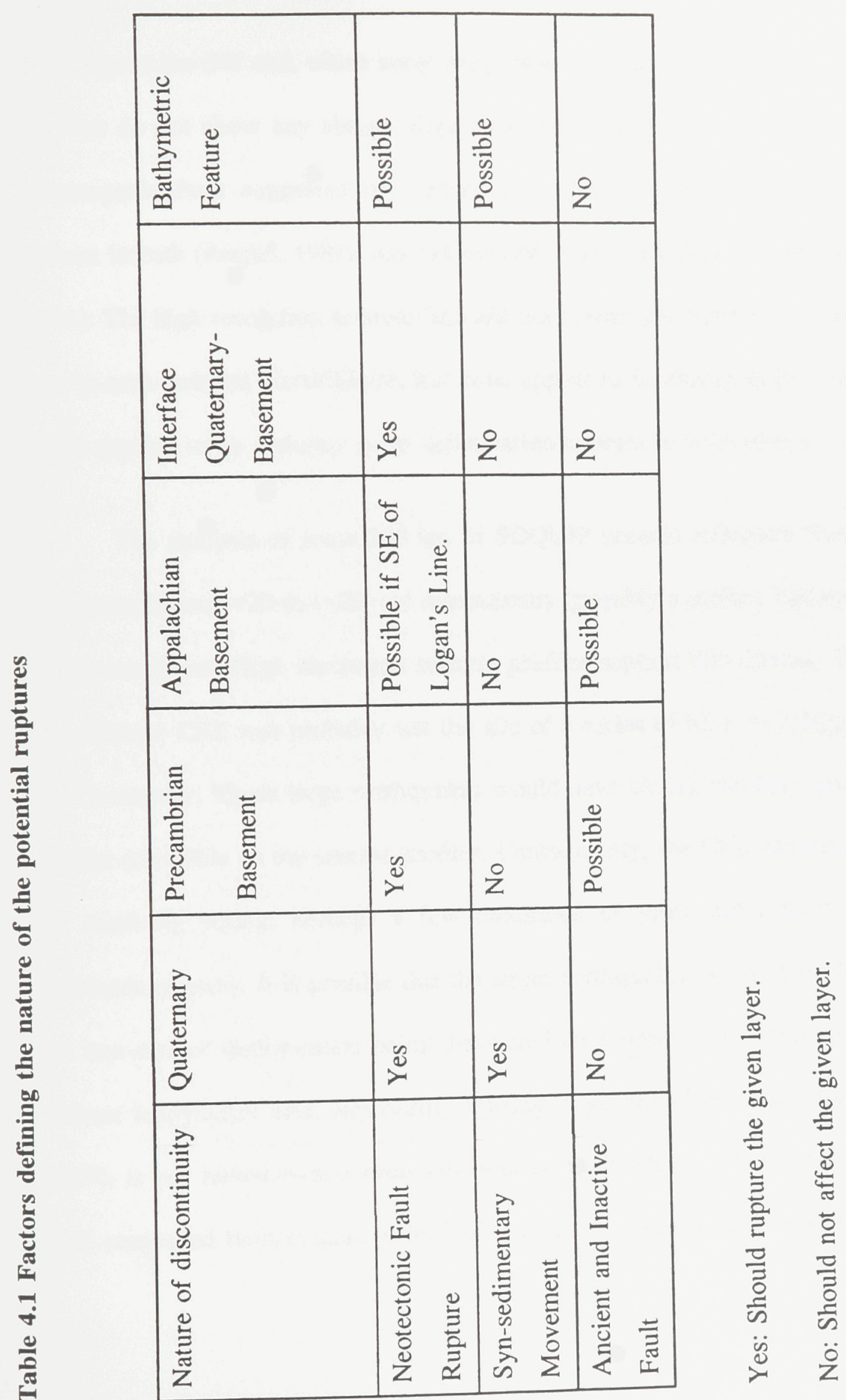


Similarly, at the SW end, where some magnitude $>4$ earthquakes cluster, shallow seismic profiles do not show any abrupt disruptions that could be interpreted as a rupture. The seismogenic fault suggested by correlating surface-projected hypocentres and the six fathom isobath (Anglin, 1984), was not evident on the section that crosses the area (Figure 4.4A). The high resolution seismic line did not reveal any rupture. A series of reflectors can be seen near the North Shore, but none appear to be disrupted by a fault. Except for what appears to be a slump, most deformation appears to be related to compaction.

The analysis of some $200 \mathrm{~km}$ of SOQUIP seismic reflection lines did not reveal any unambiguous $>20 \mathrm{~m}(\approx 20 \mathrm{~ms}$ ) discontinuity (possibly a surface rupture), under the St. Lawrence River. High resolution seismic profiles support this finding. This implies that the offshore CSZ was probably not the site of a series of $\mathbf{M} \geq 6$ shallow earthquakes in the Quaternary. These large earthquakes would have almost certainly produced a surface rupture detectable on the seismic profiles. Consequently, the CSZ earthquake activity may be relatively young, perhaps a few thousands of years old instead of hundreds of thousands of years. It is possible that the larger earthquakes occur at $>10 \mathrm{~km}$ depth, with the near-surface displacement being dissipated on a series of sub-parallel faults. The sixfathom bathymetry line, supposedly making a SE boundary to the seismicity (Anglin, 1984), is not linked with a deep seismogenic fault. Hence, the reference to "a possibly fault controlled fault evidenced in the bathymetry" (Anglin, 1984), should be dropped. 


\subsection{Focal mechanisms of CSZ earthquakes}

\subsubsection{Introduction}

Traditionally, focal mechanisms of micro-earthquakes have been determined with P-wave first motions, due to the availability of the data (most stations are vertical component only) and to the simplicity of the method. Unfortunately for CSZ studies, events below magnitude $m_{N} 4.0$ rarely provide enough P-wave first motions for a wellconstrained mechanism. With the present rate of $m_{N} \geq 4.0$ events (seven during the 19771997 period), decades would be needed to obtain a comprehensive focal mechanism database. To compute focal mechanisms of smaller earthquakes, two approaches are possible: adding $\mathrm{S}$ wave information and/or increasing the number of seismograph stations. Both solutions were attempted in this study. First, the information contained in the $S$ wave was added. $S_{\mathrm{H}}$ first motions were preferred to $\mathrm{S}_{\mathrm{v}} / \mathrm{P}$ ratios, which are usually difficult to assess due to the imprecise onset of the $S$ phases. $S_{H}$ first motions are generally better defined and only require the conversion of the horizontal traces into the transverse component of the $S$ wave. This rotation can be easily applied to the three-component Charlevoix data. Using $\mathrm{P}$ and $\mathrm{S}_{\mathrm{H}}$ first motions, CSZ focal mechanisms can be computed for events larger than $m_{N}$ 3.0. The second approach is to increase the number of seismograph stations, which was done during the 1996 summer field survey (Lamontagne et al., 1997). The following sections review the methodology and the results of these studies. Some re-computed solutions of previously published focal mechanisms are also given. More details on these aspects, including the full descriptions of the mechanisms, can be found in Lamontagne (1998). 


\subsubsection{Input data and methodology}

In the CSZ, a focal mechanism can be determined if the event is sufficiently large (i.e. yields enough first-motion observations) and if three component data are available (i.e. to determine $S_{H}$ first motions). Consequently, only events of magnitude $m_{N} \geq 3.0$ recorded on the three-component CSZ network were selected (between November 1988 and April 1997). Earthquake locations and focal mechanisms were calculated primarily with the data of the CSZ permanent network (LMQ; A11; A16; A21; A54; A61; A64; Figure 1.8). When available, first motions were added from five additional stations located within $150 \mathrm{~km}$ of the active zone (DAQ; SHQ; SLQ; CIQ; QCQ; Figures 1.11). During the period from mid-June to mid-November 1996, smaller events $\left(m_{N} \geq 2.0\right)$ were also considered, with data from up to eight additional analogue and digital field seismographs (Lamontagne et al., 1997; Figure 1.12).

All hypocentre locations of this study were routinely computed with CLTN phases only, except between June to November 1996, when additional phases from field stations were added. Earthquakes were located using the "standard" GSC velocity model, which assumes a $36 \mathrm{~km}$ thick crust with $6.2 \mathrm{~km} / \mathrm{s} \mathrm{Pg}$ velocity and $3.57 \mathrm{~km} / \mathrm{s} \mathrm{Sg}$ velocity. The lateral velocity contrast introduced by the Appalachian nappes does not change significantly the takeoff angles and azimuths for south shore stations (Lamontagne, 1987).

P-first motions on the digital and analogue records were mostly read directly by the author. $S_{\mathrm{H}}$ first motions were read on rotated traces from the three-component stations. In general, $\mathrm{S}_{\mathrm{H}}$ first motions were less consistent than P-first motions. For example, two 
focal mechanisms had sufficient $P$ first motions to give a reliable solution (events 960714 18:46 and $96092423: 41$, both recorded during the 1996 summer field survey). In the first case, three $S_{\mathrm{H}}$ out of seven did not fit the solution, while two out of nine did not fit the second solution. From these results, it was decided that the P first motions were the primary constraints to the focal mechanisms, while $S_{H}$ would further refine the solutions.

The mechanisms were determined with the program FOCMEC of Snoke et al. (1984). The program uses a grid search algorithm that finds all mechanisms that match a given number of $\mathrm{P}$ and $\mathrm{S}_{\mathrm{H}}$ first motion misfits. The program was run interactively, using a one degree B-axis increment. In cases where too many solutions existed, two degree, then, five degree increments were used. The variations in the $\mathrm{P}, \mathrm{T}$ and $\mathrm{B}$ axes were used to quantify the constraints on the nodal planes. The method was inspired by the work of Moustafa (1992). The P, T and B axes were treated as vectors for which average direction, plunge and length were computed. The average length is a measure of the dispersion of the axes, i.e. the best solutions have lengths close to 1. A quality factor was assigned to the solutions using the scheme shown in Table 4.2. The rating scheme agreed with a visual inspection of the focal mechanisms. In a few cases, the $\mathrm{P}, \mathrm{T}$ and $\mathrm{B}$ axes were well constrained but the solutions were rejected (quality " $X$ ") based on the poor distribution of first motions. For every event, the description of the mechanism and three figures were provided: the focal mechanisms, the first motion picks and the epicentral map (Lamontagne, 1998; Appendix 1). 


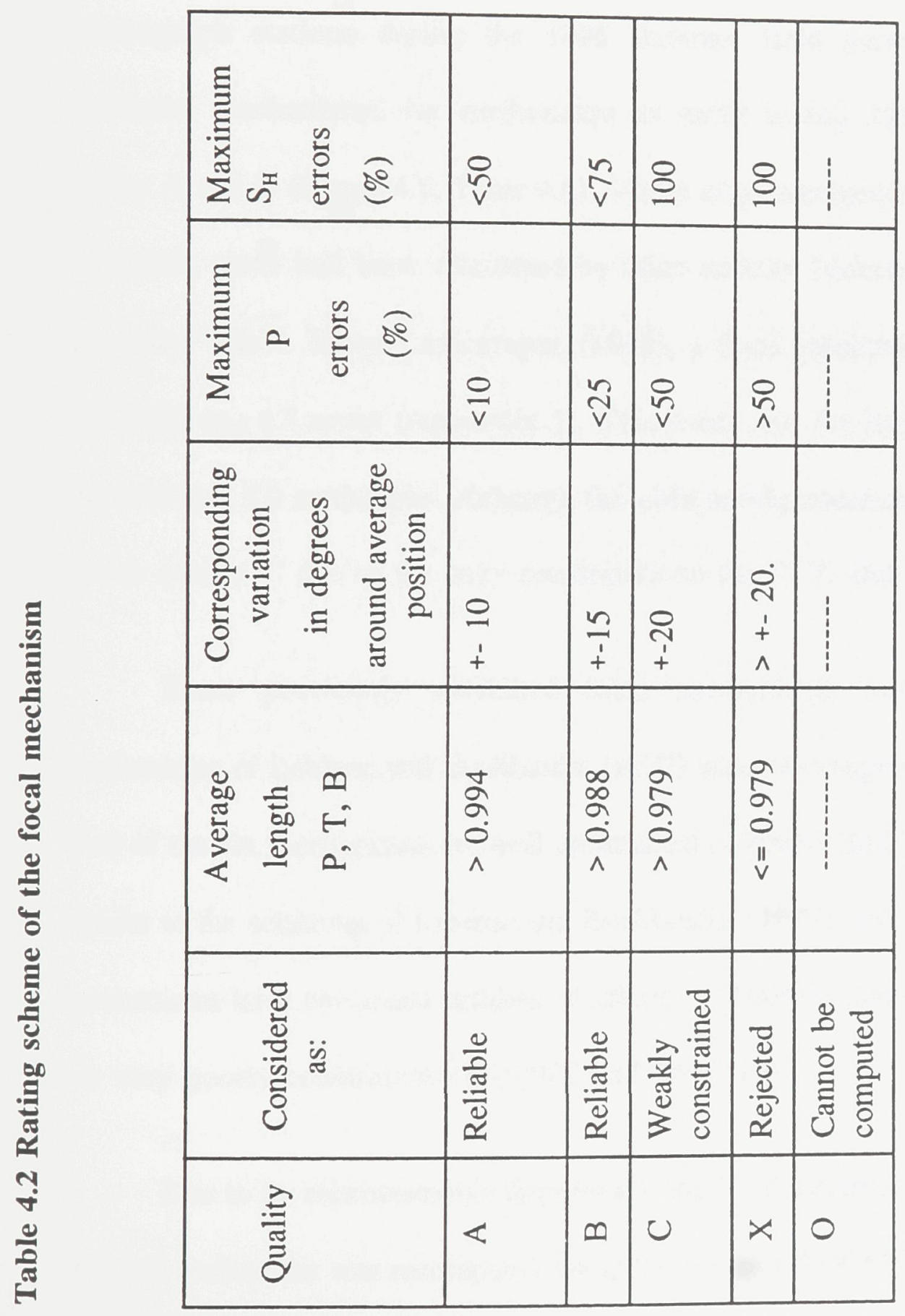




\subsubsection{Results}

Some 20 new focal mechanisms were computed for the period November 1988 to December 1997. Out of the 27 magnitude $\mathrm{m}_{\mathrm{N}} 3.0$ events of that time period, 12 resulted in quality $\mathrm{A}$ and $\mathrm{B}$ mechanisms (Figure 4.5; Table 4.3). The addition of up to eight seismograph stations during the 1996 Summer field survey, provided data for 15 additional mechanisms, for earthquakes as small as $m_{N}$ 2.0. Of these, eight were of quality A and B (Figure 4.6; Table 4.4). While most mechanisms were calculated for the first time, some had been calculated by other authors (referenced in Table 4.5) and are discussed below. Since Lamontagne (1998), a focal mechanism was computed for the $19971028 \mathrm{~m}_{\mathrm{N}} 4.7$ event (Appendix 1). This event was the largest CSZ earthquake since the $1979 \mathrm{~m}_{\mathrm{N}} 5.0$ earthquake. Although the oblique-slip mechanism is fairly well defined, it was quality $\mathrm{C}$ due to the poor constraints on the $\mathrm{P}, \mathrm{T}$, and $\mathrm{B}$ axes.

Some previously published focal mechanisms were re-examined. The six mechanisms of Leblanc and Buchbinder (1977) were re-computed using the original data. Two of the six mechanisms are well constrained (74/06/09 and 74/06/23; Figure 4.7), and similar to the solutions of Leblanc and Buchbinder (1977) and Adams et al. (1989). Two mechanisms have two main families of solutions (74/06/20 and 74/06/30) and the last two are very poorly constrained $(74 / 07 / 02$ and $74 / 07 / 13)$.

Due to its seismotectonic importance, the focal mechanism of the 19 August 1979, $\mathrm{m}_{\mathrm{bLg}} 5.0$ earthquake was recomputed using the program FOCMEC. Since the original data set was lost, first motion data were assembled from GSC analogue and digital playouts, 
Table 4.3: Focal mechanisms of earthquakes of magnitude 3.0 and larger

Q Date Time Latitude Long. Depth Mag Sta/Pha References: yymmdd hhmm ss (oN) (oW) (km)

$\begin{array}{llllllll}\text { A } 890131 & 1439 & 48.20 & 47.4426 & -70.6710 & 19.69 & 3.1 m_{N} & 7 / 012\end{array}$

$\begin{array}{llllllll}X & 890309094132.26 & 47.7171 & -69.8569 & 10.52 & 4.3 m_{N} & 6 / 011 & 123\end{array}$

$\begin{array}{lllllllll}X & 8903110831 & 52.16 & 47.7182 & -69.8699 & 10.41 & 4.4 m_{N} & 7 / 012 & 123\end{array}$

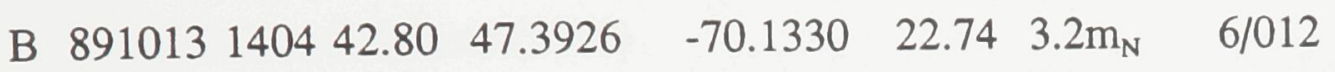

$\begin{array}{lllllll}\text { A } 891122 & 230251.72 & 47.4559 & -70.3420 & 7.39 & 3.4 m_{\mathrm{N}} & 7 / 014\end{array}$

$\begin{array}{llllllll}\text { A } 9003030206 & 03.38 & 47.8559 & -69.9765 & 20.85 & 3.6 \mathrm{~m}_{\mathrm{N}} & 8 / 015 & 4\end{array}$

$\begin{array}{lllllllll}\text { A } 900313191039.34 & 47.5338 & -70.1366 & 15.38 & 3.2 m_{N} & 7 / 014 & 4\end{array}$

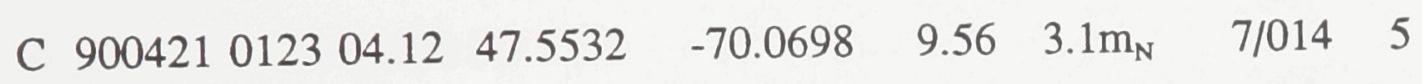

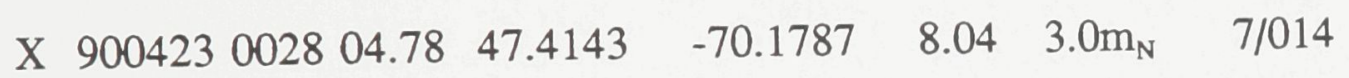

$\begin{array}{lllllllll}\text { A } 901021 & 1338 & 43.20 & 47.3975 & -70.3644 & 15.85 & 3.3 m_{\mathrm{N}} & 7 / 013 & 5\end{array}$

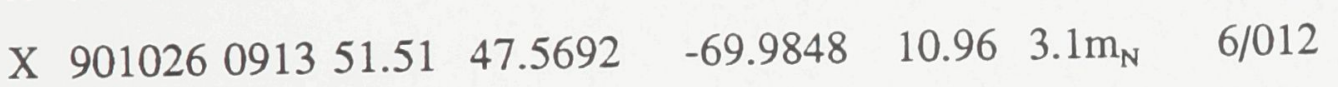

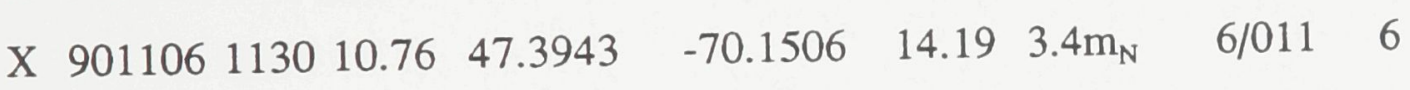

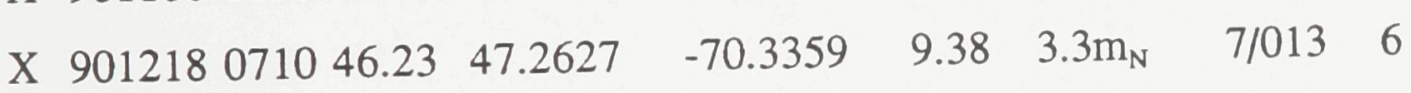

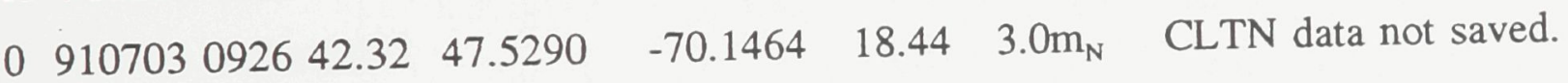

$\begin{array}{llllllll}\text { B } 911208 & 0300 & 30.12 & 47.7792 & -69.8643 & 23.05 & 4.3 m_{N} & 7 / 013\end{array}$

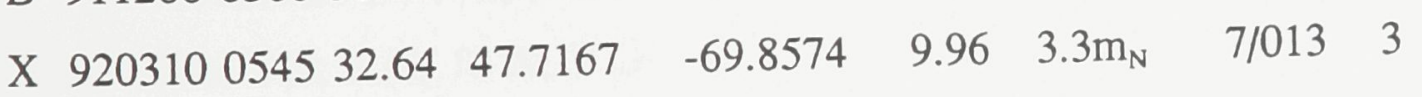

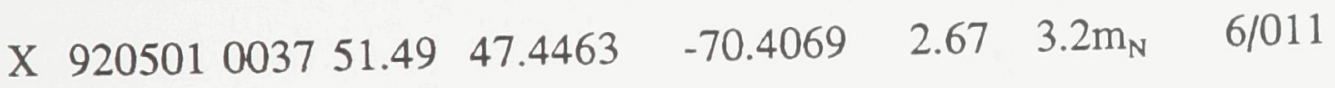

A $930304220221.84 \quad 47.5145 \quad-70.3621 \quad 4.39 \quad 3.1 m_{N} \quad 6 / 011$

$\begin{array}{lllllll}\text { X } 9308072125 & 31.92 & 47.6681 & -69.8893 & 7.75 & 3.1 \mathrm{~m}_{\mathrm{N}} & 7 / 014\end{array}$

$\begin{array}{llllllll}0 & 931201 & 1247 & 15.89 & 47.4671 & -70.1584 & 18.0 \mathrm{~g} & 3.5 \mathrm{~m}_{\mathrm{N}}\end{array} \quad$ No CLTN data.

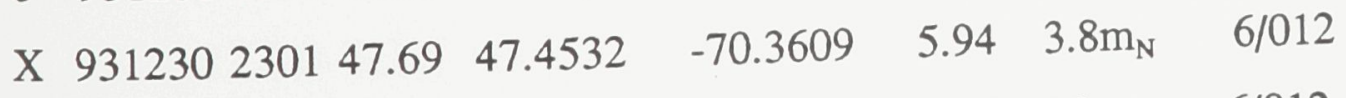

$\begin{array}{lllllll}\text { A } 9409250053 & 29.46 & 47.7518 & -69.9612 & 12.18 & 4.3 m_{N} & 6 / 012\end{array}$

$\begin{array}{llllllll}\text { B } 941201 & 1302 & 47.14 & 47.4374 & -70.3138 & 10.77 & 3.0 m_{\mathrm{N}} & 5 / 009\end{array}$

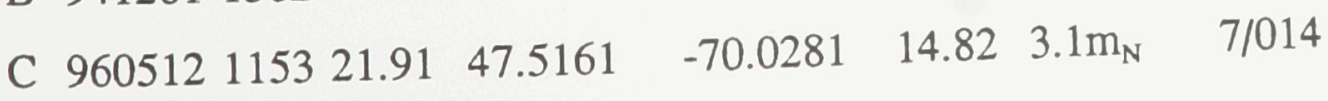


Q Date Time Latitude Long. Depth Mag Sta/Pha References: yymmdd hhmm ss $\quad(\circ \mathrm{N}) \quad(\circ \mathrm{W}) \quad(\mathrm{km})$

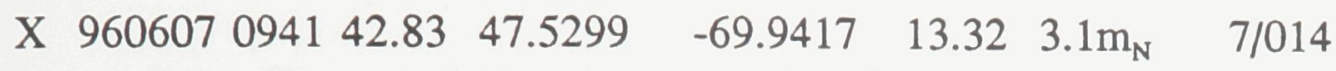

A $970110192727.56 \quad 47.5094 \quad-70.1965 \quad 17.06 \quad 3.2 m_{N} \quad 7 / 014$

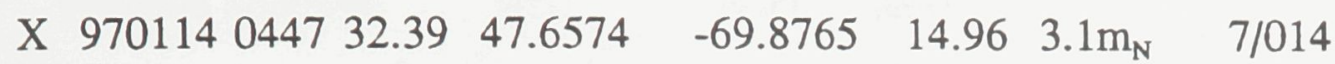

1- Drysdale et al. (1989);

2- Wetmiller and Adams (1990).

3- Li et al. (1995).

4- Drysdale et al. (1990);

5- Drysdale et al. (1991a).

6- Drysdale et al. (1991b).

Q: Quality.
A: Very good
B: Good
C: Fair
X: Rejected
0 : Cannot be computed.

Total: 8 A; 2 B; 3 C; 12 X; 2 O 
Table 4.4: Focal mechanisms of earthquakes recorded during the 1996 summer field survey

Q Date Time Latitude Longitude Depth Mag Sta/Pha yymmdd hhmm ss $\quad(\circ \mathrm{N}) \quad(\circ \mathrm{W}) \quad(\mathrm{km})$

$\begin{array}{lllllll}\text { A } 960617111830.66 & 47.5328 & -70.1463 & 14.11 & 1.9 m_{N} & 8 / 016\end{array}$

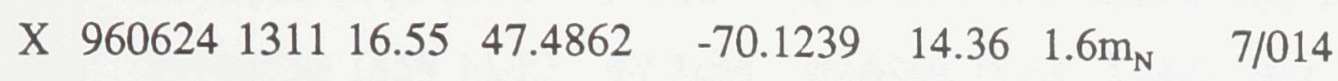

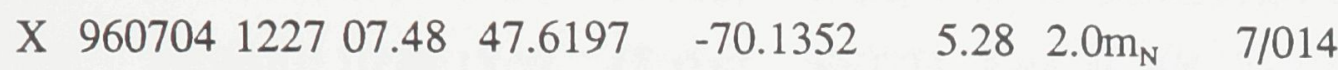
$\begin{array}{lllllll}\text { A } 960714071502.89 & 47.4829 & -70.0503 & 13.71 & 2.2 m_{N} & 7 / 014\end{array}$ $\begin{array}{llllll}\text { A } 960714184649.22 & 47.6938 & -69.9927 & 7.26 & 3.3 m_{N} & 7 / 013\end{array}$

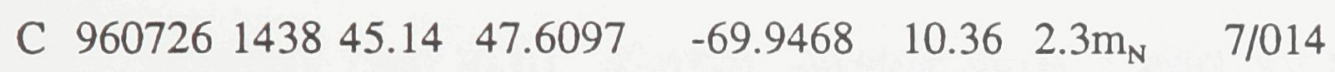

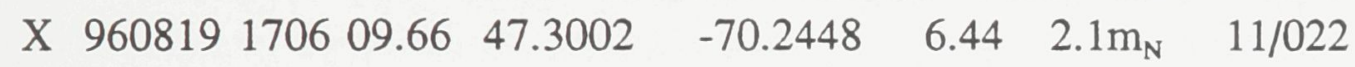
$\begin{array}{lllllll}\text { C } 9609132355 & 35.92 & 47.5008 & -70.2134 & 12.09 & 2.2 \mathrm{~m}_{\mathrm{N}} & 11 / 022\end{array}$

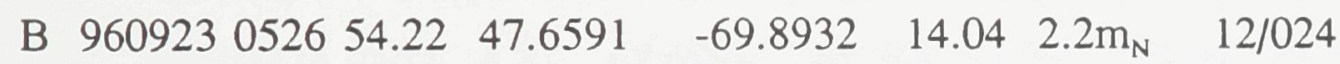
$\begin{array}{lllllll}\text { A } 9609240644 & 45.55 & 47.5875 & -70.1451 & 21.40 & 2.0 m_{\mathrm{N}} & 12 / 024\end{array}$ $\begin{array}{lllllll}\text { A } 9609242341 & 02.88 & 47.5475 & -70.2417 & 12.83 & 3.1 m_{\mathrm{N}} & 11 / 021\end{array}$

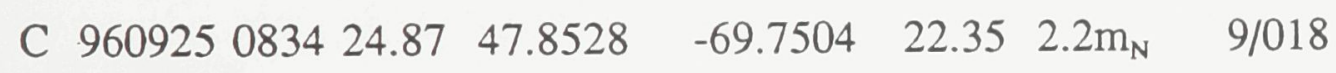

$\begin{array}{lllllll}\text { C } 9610110228 & 50.34 & 47.4761 & -70.0551 & 15.56 & 1.9 m_{\mathrm{N}} & 11 / 022\end{array}$

$\begin{array}{lllllll}\text { A } 961025094724.43 & 47.4281 & -70.3887 & 4.06 & 2.2 m_{N} & 13 / 025\end{array}$

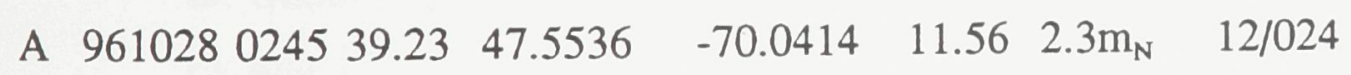

Q: Quality.
A: Very good
B: Good
C: Fair
X: Rejected / 0: Cannot be computed.

Total: $7 \mathrm{~A}$; $1 \mathrm{~B}$; $4 \mathrm{C}$; $3 \mathrm{X}$. 
Table 4.5 Other mechanisms. (1974; 1979 + events near La Malbaie)

Q Date Time Latitude Longitude Depth Mag Sta/Pha yymmdd hhmm ss $\quad(\circ \mathrm{N}) \quad(\circ \mathrm{W}) \quad(\mathrm{km})$

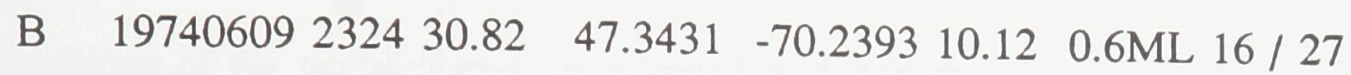

X $\quad 19740620183657.48 \quad 47.4041 \quad-70.1802 \quad 17.30 \quad 1.5 \mathrm{ML} 18 / 22$

A $19740623140657.40 \quad 47.5127 \quad-70.2144 \quad 14.95 \quad 0.4 M L \quad 16 / 28$

$\begin{array}{llllllll}X & 19740630 & 1655 & 11.21 & 47.7155 & -69.8409 & 15.54 & 2.0 M L ~ 20 / 27\end{array}$

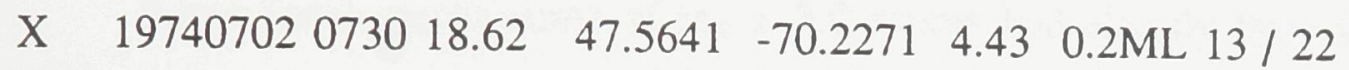

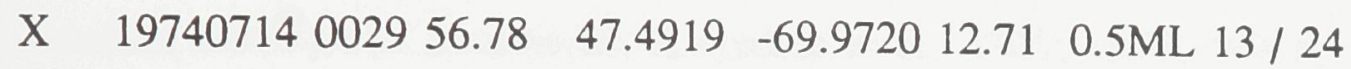

B $\quad 19790819224930.60 \quad 47.6720 \quad-69.9010 \quad 10.00 \quad 5.0 \mathrm{MN} \quad 8 / 13$

X $\quad 19891208172034.44 \quad 47.7009 \quad-70.0644 \quad 10.37 \quad 2.6 \mathrm{MN} \quad 6 / 12$

$\begin{array}{lllllllll}\text { C } & 199107230103 & 14.31 & 47.6869 & -70.1031 & 11.31 & 1.9 \mathrm{MN} & 7 / 12\end{array}$

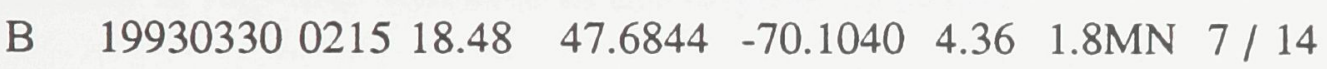

Q: Quality.
A: Very good
B: Good
C: Fair
X: Rejected
0: Cannot be computed. 
from paper playouts of Lamont-Doherty and Weston Observatory and from the ISC Bulletin for regional and teleseismic phases. A total of 45 P-first motions was gathered, slightly more than the 39 used in Hasegawa and Wetmiller (1980). Although both the original and the new solution show predominantly reverse faulting (Figure 4.8), the positions of the nodal planes are somewhat different. The new solution shows one plane steeply dipping to the west and one plane more shallowly dipping towards the southeast.

Some focal mechanisms of $m_{N} \geq 3.0$ events had already been published in the Canadian Earthquake Summaries (Drysdale et al., 1989; 1990; 1991a; 1991b). Four of the new mechanisms are similar to those previously calculated $(890309 ; 890311 ; 900311$; 900313) while four others are significantly different. The original solutions relied on $\mathrm{P}$ first motions and on Sv/P ratios. The differences arose due to the use of emergent P first motions at regional distances in the original solutions.

The four mechanisms of $\mathrm{Li}$ et al. (1995) were re-computed using $\mathrm{P}$ and $\mathrm{S}_{\mathrm{H}}$ first motions. In Li et al. (1995), the plotting of the first motions for stations within $150 \mathrm{~km}$ was wrong. For direct $\mathrm{P}$ and $\mathrm{S}$ phases, the azimuths were not reversed, which imply that the mechanisms are questionable especially for the 901021 and 920310 solutions that depend heavily on the CLTN data. Three of the four mechanisms calculated by Li et al. (1995) did not meet our quality criteria and were rejected. Differences were mainly due to our conservative picking of the $S_{H}$ first motions. Our quality " $\mathrm{A}$ " mechanism is sensibly different due to the differences in plotting the CLTN data.

For a sub-zone near station A61, Lamontagne and Ranalli (1997) published three 
focal mechanisms for three small events (magnitude $m_{N}$ 2.6: 891208; $m_{N}$ 1.9: 910703 and $m_{N}$ 2.6: 930330). While the general tectonic style is well defined for the three mechanisms, only the 930330 event is rated B.

\subsubsection{Discussion of the focal mechanisms}

With the current CSZ seismograph network, earthquake focal mechanisms can be computed for events as small as magnitude $m_{N} 3.0$, when additional $S_{H}$ constraints are added. Approximately $50 \%$ of the mechanisms in that magnitude range can be considered reliable. The eight additional seismograph stations of the 1996 summer field survey added much needed $\mathrm{P}$ and $\mathrm{S}_{\mathrm{H}}$ first motions. They allowed the calculation of focal mechanisms for events as small as magnitude $\mathrm{m}_{\mathrm{N}}$ 2.0. Some published mechanisms were found to be poorly defined and should be discarded (Figure 4.9). More important, a total of 25 well-defined mechanisms is now available for the CSZ (Figure 4.10).

The faulting style that emerges from the focal mechanism study is mainly thrust to oblique-thrust faulting on fault planes with highly variable orientations. Out of 22 mechanisms of quality " $A$ " and " $B$ ", none was of a pure normal-faulting type. The nodal planes do not have any specific trend, only a weak concentration in the NE quadrant (Figure 4.11A). The stress system appears to consist of a shallow-dipping P axis with heterogeneous orientation (Figure 4.11B). 


\subsection{Hypocentre groups and alignments}

\subsubsection{Hypocentre groups}

A series of earthquakes can reactivate various portions of a given fault. If sufficiently numerous, well-located hypocentres of these earthquakes can define the strike and the dip of the reactivated fault. Various methods have been proposed to compare hypocentre alignments with faults (e.g., Rieken and Thiessen, 1992; Jones and Stewart, 1997; Chapman et al., 1998). For this study, a simple method to define hypocentre alignments was developed. Given a group of hypocentres, each event is associated with its neighbour, located within a given distance. These associated hypocentres are grouped into strings of events (Figure 4.12). A string can be defined as a volume within which each event has at least one neighbour within the given radius. The analysis can define earthquake clusters, alignments, and concentration of activity.

As a first step, areas that include most CSZ events were defined. A data set that insures location completeness was used, i.e. events with $\mathrm{M}_{\mathrm{L}} \geq 0.2$ and $\mathrm{m}_{\mathrm{N}} \geq 1.5$ (as discussed in Section 1.7). The data set included some 1205 hypocentres of the period October 1977 to December 1997. To examine associations between events, a maximum inter-event distance of $2 \mathrm{~km}$ was selected, slightly larger than the uncertainty in relative hypocentre positions. Some 918 events (76\%) have at least one neighbour within $2 \mathrm{~km}$ hypocentre distance, while $287(24 \%)$ occurred as "isolated" events. Eleven groups include ten events or more, representing $54 \%$ of all CSZ events (Figure 4.13). Out of the eight magnitude $\geq 4.0$ events of the $1977-1997$ period, two occurred in the most active 
string of events, one was within a 15 -event string; three had between two and six events; and one was isolated. Except for the region surrounding the $m_{N} 5.0$ hypocentre, most magnitude $\geq 4.0$ events occur in weakly active areas. About $30 \%$ of all CSZ events regroup into one group of hypocentres (Figure 4.14). This group of events defines a faulted volume under the St. Lawrence River with a length of about $40 \mathrm{~km}$, a width that varies between 2 and $11 \mathrm{~km}$, at depth between 6 and $18 \mathrm{~km}$. Variations in strike and dip occur along the length of the fault zone: whereas it is well defined near the magnitude 5.0 earthquake (steeply dipping towards the SE; Figure 4.14D), it becomes progressively shallowly dipping (Figure 4.14C), and diffuse in the middle of the impact crater (Figure 4.14 A-B). Inside the group, various smaller alignments appear to exist. Other groups of events define a series of alignments either at an angle with the strike of the St. Lawrence River or as isolated clusters.

In order to delineate more detailed hypocentre concentration, a similar test was conducted for all CSZ hypocentres of the period 1977-1997, recorded on 5 stations with 8 phases, with a shorter inter-event distance $(1.5 \mathrm{~km})$. Out of some 1643 events, 517 (31\%) had no associated neighbours. About 38\% occurred in groups of 10 events or more. Compared with the $2 \mathrm{~km}$ groups, smaller groups become evident and display a variety of orientations.

\subsubsection{Discussion}

Over a 20 year period, approximately one-fourth of the CSZ events with $\mathrm{m}_{\mathrm{N}} \geq$ 1.5 occurred as isolated events, i.e., without neighbouring events within a $2 \mathrm{~km}$ radius. 
We can infer that stresses take a long time to rebuild along some faults and fractures. On the other hand, under the St. Lawrence River, one-third of all CSZ events, including some magnitude $\geq 4.0$ events, occurred within a faulted volume of $50 \mathrm{~km}$ length, $10 \mathrm{~km}$ width, located between 5 and $20 \mathrm{~km}$ depth. Although the faulted zone is parallel to the St. Lawrence River, earthquakes define multiple orientations, especially towards the centre of the CSZ. Earthquakes surrounding the magnitude 5.0 event are discussed in detail in Section 4.6.3.

Grouped hypocentres can define a volume, which may be a fault or a weak zone where failure conditions exist. The orientation of these volumes can be compared with the focal mechanisms. Focal mechanisms of events within groups of 2 or more events are shown in Figure 4.15 (groups defined with a $1.5 \mathrm{~km}$ minimum inter-event distance). For most focal mechanisms, it is difficult to pick the best nodal plane by looking at the groups of events, either due to their clustered nature, to the small number of events or to the similar orientation of the two nodal planes of any given mechanism. In a few cases, the orientation of the group reflects one of the two nodal planes, providing a way to infer the actual fault trend. In other cases, however, the orientation of the whole group does not correspond to one fault plane, implying that the group defines a weak volume.

\subsection{Earthquake multiplets}

\subsubsection{Introduction}

In many seismic areas of the world, earthquakes occur in spatial clusters. Events 
within these clusters (also called families or multiplets) display highly-correlated seismic traces, caused by repeated slip on the same fault planes. The identification of such clusters represents a real advance in seismology: what appeared as clouds of events can become hypocentres a few hundreds of meters apart (see, among many others, Deichmann and Garcia-Fernandez, 1992; Nadeau et al., 1994 and, for some Charlevoix multiplets, Li et al., 1995). Due to their spatial closeness, the hypocentres of a multiplet can be used to derive the source parametres of the main shock (the effects of the path, site and instrument response being removed; see e.g. Li et al., 1995) and to infer the orientation of the reactivated fault via precise hypocentre locations and possible comparisons with the nodal planes.

Earthquake multiplets were sought among the 915 hypocentres recorded with at least 8 phases from 5 seismograph stations between November 1988 and August 1997 (the data format prior to November 1988 is not currently readable). All existing time series were extracted from the archives of the GSC (a few files were missing before the beginning of continuous archiving, in August 1994). All time series files, originally in GSC MKII or SEED formats, were reformatted in SAC format. The original time series files and the SAC files now exist on one 1.2 Gbyte optical disk.

All available seismic traces were systematically cross-correlated to find earthquake multiplets. The procedure consisted of cross-correlating each of the three-component seismic traces for two events and calculating the normalized correlation coefficient. Two highly similar traces would yield a coefficient approaching one and 
inversely, two dissimilar traces would give a coefficient approaching 0 (generally below 0.7). A time window was defined to include $0.5 \mathrm{~s}$ before the $\mathrm{P}$ onset and $0.5 \mathrm{~s}$ after the $\mathrm{S}$ onset. In most cases, the total trace duration varied between 2.5 and $6.5 \mathrm{~s}$, depending on the hypocentral distance. Stations A61 and A54 were generally chosen due to their lower background noise levels. Figure 4.16 displays a series of traces for events that define a 9-event multiplet.

\subsubsection{Results}

Out of the $915 \mathrm{CSZ}$ events tested, 170 (19\%) turned out to have at least one associated event. These events constitute 67 multiplets, of which 51 are doublets, and five are five-tuplets or more (see Appendix 2 for complete list). During the time period considered, the majority of CSZ earthquakes (81\%) occurred as isolated (i.e. nonmultiplet) events. For events of the multiplets, the inter-event time varied between seconds and years, with 25 to $30 \%$ within the first 0.1 year (Figure 4.17). Spatially, about $90 \%$ of the events are within $2 \mathrm{~km}$ distance of the first hypocentre (Figure 4.17). Since two events of a multiplet must lie within a few hundred metres of each other (to have similar waveforms), the inter-event distance found is related to the precision of the routine hypocentre locations. When relocated with carefully re-picked phases, most events cluster within $1 \mathrm{~km}$ hypocentral distance. It was found that multiplets are more common in some areas than in others. The area near the 1979 magnitude 5.0 earthquake has the highest percentage with $38 \%$ of events that had at least one associated event (15 events out of 39). The most active areas of the CSZ, such as the Central and the Ile-aux- 
Coudres sub-zones, do not have higher proportions of multiplets. This seems to imply that most events, even if spatially associated, are not related to the same fault plane, and consequently, reinforces the conclusion that seismicity occurs in highly fractured volumes.

Unlike grouped events which are only spatially associated, multiplets are events that occurred on the same fault plane or on nearby sub-parallel fault planes. If a focal mechanism exists, this fault plane is one of the two nodal planes. With high precision hypocentres, one can define which nodal plane is the actual fault plane. Ideally, one would have liked to find numerous multiplets with focal mechanisms, but only five multiplets included a quality A or B focal mechanism (Figure 4.18). Of these, only one had more than two associated events (911208 03:00 U.T $\left.m_{N} 4.3\right)$. This event is discussed in more detail in Section 4.6.3.2.

\subsection{Integration of focal mechanisms, earthquake groups and multiplets}

The previous four sections have provided the basis of a search for a correlation between earthquakes and faults in the CSZ. Without a surface rupture to directly correlate earthquakes and faults, 25 focal mechanisms can be compared with earthquake groups and multiplets. A similar approach was used in the eastern Tennessee seismic zone by Chapman et al. (1997).

To examine the local variations in CSZ seismotectonics, 19 sub-zones were defined on the basis of epicentral clustering and on common depth distribution (Figure 

of the median of their respective focal depth (Table 4.6): shallow $(z<10 \mathrm{~km}$; Section 4.6.1; Figure 4.20A); intermediate ( $10 \leq z<15 \mathrm{~km}$; Section 4.6.2; Figure 4.20B); and deep ( $z \geq 15 \mathrm{~km}$; Section 4.6.3; Figure 4.20C). The weakly seismic sub-zones are examined separately (Section 4.6.4).

\subsubsection{Sub-zones with shallow activity (A61, COU, EBO)}

\subsubsection{Earthquakes of the A61 sub-zone}

A sub-zone near seismograph station A61 (thereafter named sub-zone A61) was defined for a pilot-test of our study of other sub-zones. The A61 sub-zone is a cluster of events within a few kilometres of station A61. The boundaries correspond to a change in focal depths to the southeast and to a decrease of earthquake activity elsewhere. The following section updates the description of the sub-zone given in detail in Lamontagne and Ranalli (1997).

The sub-zone presents many favourable characteristics for a detailed seismotectonic study: (1) good constraints on relative focal depths (probably better than $\pm 1 \mathrm{~km}$ due to the proximity of station A61); (2) a large proportion of shallow hypocentres ( $90 \%$ at less than $12 \mathrm{~km}$ depth) located onshore providing the potential for stronger correlations with remote sensing lineaments than in most of the CSZ; (3) location within the sub-zone of an onshore earthquake of magnitude $m_{N} \geq 4.0$ (most others $m_{N} \geq 4.0$ have occurred under the St. Lawrence River in areas known for their 


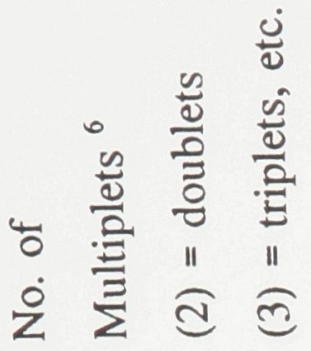

$\dot{0} \stackrel{+}{\Sigma}$

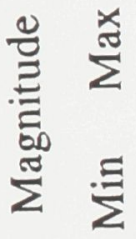

$\frac{\text { J }}{\sum^{0}}$

き

बิ

苂

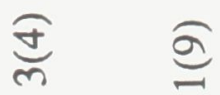

㐱

茯产

$\infty-00$ t 000

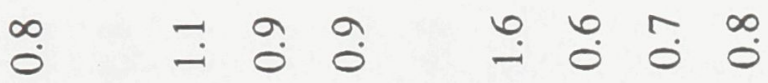

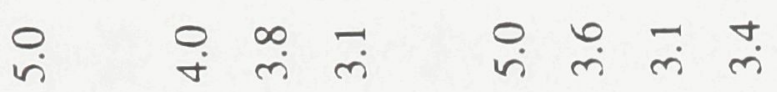

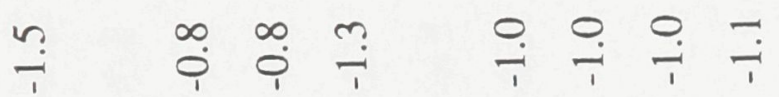

苞

$\stackrel{n}{=} \stackrel{m}{\infty}, \frac{m}{0}$

$\stackrel{0}{\varrho} \stackrel{\sim}{=} \stackrel{\sim}{=}$

言高

$\equiv$

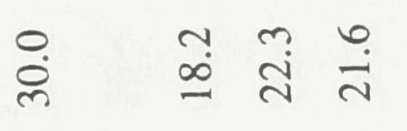

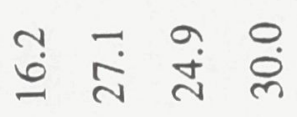

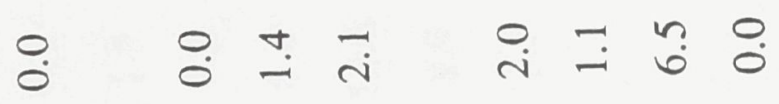

๖

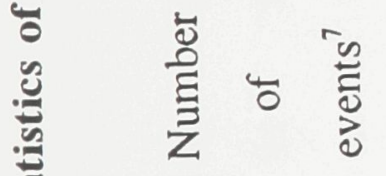

$\stackrel{+}{+}$

ฝั

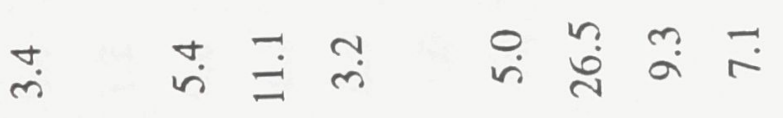

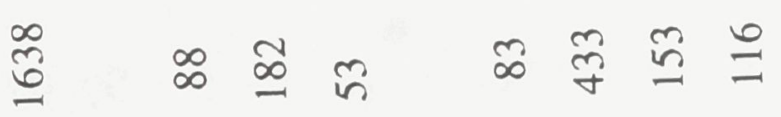

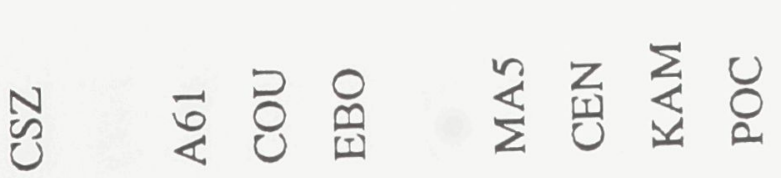

恶

产

$\stackrel{0}{2}$

ธิ

รั

हूँ

ฐั

合

苋

ญे

苞

营

웅

-

aे

品

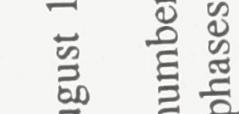

\.

$\infty$ :

$\stackrel{0}{\circ}$

है

品

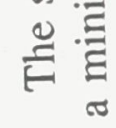




$$
\begin{aligned}
& \underbrace{\mathrm{j}} \quad \underline{6} \\
& \stackrel{\ddot{n}}{\ddot{\sigma}}
\end{aligned}
$$

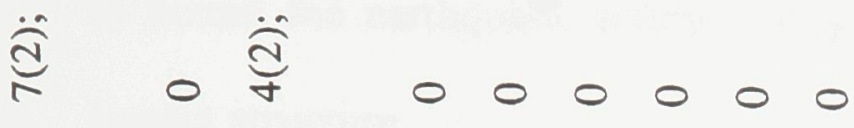

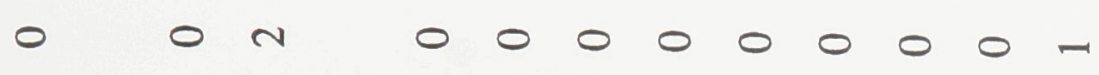

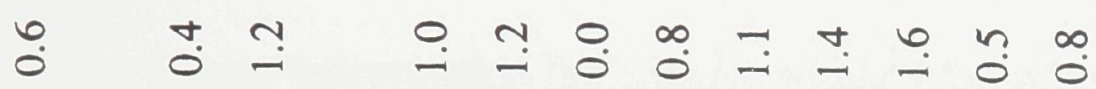

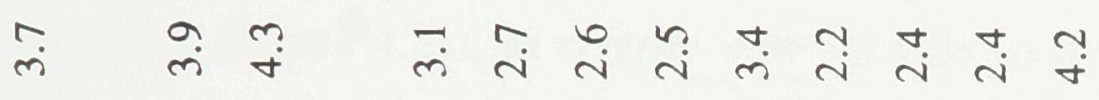

そ

$\because$ ๓

ホ⿱艹

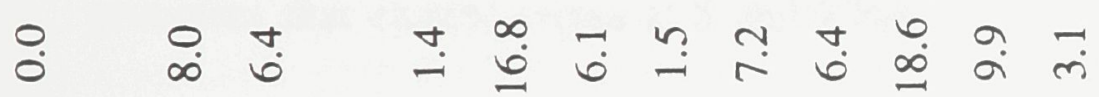

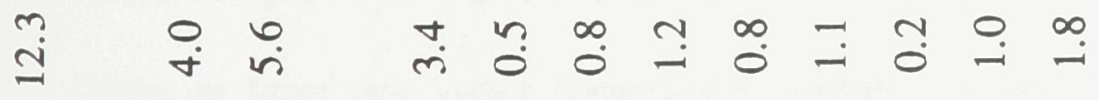

유

采 宸省 䎡 
concentration of larger events); (4) two focal mechanisms available; (5) occurrence of faults related to both major structural systems, i.e. paleo-rift faults which are assumed to bound the earthquake activity (Anglin, 1984) and faults of the Devonian meteor impact structure.

A total of 88 seismic events were located in the A61 sub-zone, or about $5 \%$ of some $1644 \mathrm{CSZ}$ hypocentres. In the sub-zone, earthquake epicentres can be divided into an eastern concentration (all located within $5 \mathrm{~km}$ of station A61), and a diffuse western group (Figure 4.21). In contrast with the CSZ as a whole, which shows a continuous increase of activity between 0 and $9 \mathrm{~km}$ depth, focal depths in the A61 sub-zone show a bimodal distribution which peaks at about 5 and $9 \mathrm{~km}$ (Figure 4.22). Compared with the activity of the CSZ, the $5 \mathrm{~km}$ group can be considered shallow, while the $9 \mathrm{~km}$ group is average. It is not known if this bimodal distribution is due to the short period of observation (i.e. the $8 \mathrm{~km}$ low might disappear over a longer time period) or to physical processes that cluster events at 5 and $9 \mathrm{~km}$.

As a first step to evaluate clustering, routinely-determined hypocentre locations were compared to evaluate their spatial proximity. It was found that about $45 \%$ of events have at least one other hypocentre within $1.5 \mathrm{~km}$. The rest, about $28 \%$, occurred as isolated events. Ten clusters of two events or more are found, with one group of 31 events and one of nine. Surprisingly, the largest earthquake $\left(m_{N} 4.0\right)$ has no event within $1.5 \mathrm{~km}$ of its focus, which implies that it was not preceded by foreshocks or followed by aftershocks. 
Three multiplets were found in the sub-zone. In general, the normalized coefficients were lower for the vertical component than for the horizontal components, suggesting scattering of the incident Pg wave. The small magnitude of these events makes P arrivals emergent on most other stations. One quadruplet (891208; 891221; 940614; 960215 with a focal depth of $10 \mathrm{~km}$ ) includes an event with a computed focal mechanism (event 891208). Routinely-computed hypocentres are very similar for these events. While most traces are consistent for the three events, some are different implying variations in source mechanisms. Although it can be assumed that most of these variations are due to variable focal mechanisms, the similarity of traces on some stations and differences on others suggests that velocity complexities near the hypocentres also play a role. Hence, for some azimuths, small changes in hypocentral locations can produce travel path changes. This quadruplet may have occurred near a lithological complexity, such as a geological contact or a wide fault zone. Traces are extremely similar for events of the triplet (dates of events: 930706; 950303 and 950820 with a focal depth of $9 \mathrm{~km}$ ). Routine hypocentre locations also show that they are within $1 \mathrm{~km}$ of each other. One doublet was also found.

The multiplets represent a total of 9 events out of 47 events tested (or about 19\% of the total). Thus, over the seven year period, only a minority of events occurred as consistent reactivations of the same fracture planes. In the A61 sub-zone, very few events could have occurred on the same fractures with similar focal mechanisms. A number of isolated events was found. The time intervals of up to 4.5 years between events of multiplets may indicate a slow strain build-up on a given fracture. 
An interesting offshoot of the method described above is the discrimination between seismic events and quarry blasts, as previously applied in Mount St. Helens (Frémont and Malone, 1987). Three quarry blasts were detected by their highly similar waveforms (average normalized correlation coefficients greater than 0.9; Figure 4.23).

In the area surrounding the A61 sub-zone, a very dense system of faults of various orientations and nature exists (Figure 4.24), most of them corresponding to faults either mapped in the field or photo-interpreted by Rondot (1989). In the A61 sub-zone, the focal mechanisms of the two largest earthquakes (11 January $1986, \mathrm{~m}_{\mathrm{N}} 4.0$ and 18 March 1987, $\mathrm{m}_{\mathrm{N}}$ 3.3) show mostly reverse faulting in agreement with most other solutions of the CSZ. In both cases, a nodal plane is sub-parallel to the conspicuous WNW-ESE set of lineaments (Figure 4.24). Thus, it is plausible that these earthquakes represent reactivations of this series of faults especially when one considers the shallow focal depths of these two events (in the $4-5 \mathrm{~km}$ range) and the well-constrained nodal planes based on first motions.

Three additional focal mechanisms have been computed for small magnitude events based on first motions and $S_{H}$ polarities. These focal mechanisms are relatively well constrained and show strike-slip-reverse, reverse, and normal faulting respectively. While the reverse faulting type agrees with most mechanisms of the CSZ, dominant strike-slip components and normal faulting are less common. First motions on A61 indicate that the strike-slip component and/or normal faulting types are not unusual: many events had dilatational first motions on station A61. Dilatational first motions in 
the centre of the focal sphere are inconsistent with pure reverse faulting mechanisms. In addition, a composite mechanism of all earthquakes of the sub-zone shows a large scatter in first motions incompatible with a unique focal mechanism for all events (78 out of 264 or $30 \%$ of all readings are misfits to the best solution). Faulting complexity appears to be present everywhere in the sub-zone; events located within a few kilometres of each other are found to have very different first motions and transverse $S_{H}$ on A61.

For the period 1978-1982, hypocentres along the north shore of the St. Lawrence define steeply-dipping volumes bound by paleo-rift faults (Anglin, 1984). The present study suggests that within the A61 sub-zone, numerous preexisting fractures are being reactivated by local stress and/or strength variations. This WNW-ESE fault system is older than the paleo-rift faults (Rondot, 1979), but was reactivated by the post-impact readjustment as were many faults of the CSZ (Roy, 1978). These peripheral impact structure faults are part of an inward-dipping system of normal faults. In the A61 subzone, the south-dipping nodal planes should be the fault planes. Hence, it appears that some impact structure faults may be reactivated in the A61 sub-zone.

When earthquake concentrations are seen in a data set, the hypocentre precision is always questioned. The earthquake concentrations of this study are not an artifact of location uncertainty. In the A61 sub-zone, highly-correlated traces were found only for events that had routinely-determined hypocentres within $1 \mathrm{~km}$. Thus, these hypocentres appear reliable, probably enough to examine possible correlations between earthquake alignments and lineaments. 
Unlike in most of eastern Canada, focal mechanisms of the A61 sub-zone are not pure reverse faulting. While focal mechanisms of two earthquakes with magnitude larger than 3 show reverse faulting, smaller magnitude earthquakes indicate variations in the faulting style, evidenced by the mechanisms of some events (some strike-slip component and normal faulting), and by the rather inconsistent first motion distribution on A61 for the composite mechanism.

\subsubsection{Ile-aux-Coudres sub-zone (COU)}

The hypocentres of the Ile-aux-Coudres sub-zone occur from $2 \mathrm{~km}$ down to 22 $\mathrm{km}$ depth, with peaks at 5-7 $\mathrm{km}$ and at $10 \mathrm{~km}$ depth (Figure $4.20 \mathrm{~A}$ ). The four focal mechanisms display a mixture of pure reverse faulting on NE planes to strike slip mechanism (Figure 4.10). The area appears to be heterogeneous in terms of stress and reactivated fault planes. No nodal planes are oriented parallel to the NE trending paleorift faults with their steep dip to the SE. The deepening of the SE activity in respect to the NW may correspond to the Charlevoix fault, described in Chapter 3.

\subsubsection{Les Eboulements sub-zone (EBO)}

The Les Eboulements sub-zone is only midly active (3\% of CSZ) and is the shallowest sub-zone. The sub-zone includes one of the best epicentre alignment of the CSZ. Most events occur within a $4 \mathrm{~km}$ wide $\mathrm{N}-\mathrm{S}$ corridor which does not correlate with any lineament in the Radar imagery. It is possible, however, that the earthquakes occur within a highly fractured layer, sub-paralell to the N-S magnetic lineaments to the North 
of the sub-zone. The only focal mechanism has one nodal plane oriented N-S and steeply dipping to the west, consistent with a group of 10 earthquakes located within $1.5 \mathrm{~km}$ of each other. Hence, in this sub-zone, most earthquakes occur within a N-S volume, possibly lithologically controlled, which includes a fault with similar orientation. Earthquake groups suggest that this zone may continue under Ile-aux-Coudres.

\subsubsection{Intermediate depth sub-zones (MA5, POC, IRE, CEN, KAM)}

\subsubsection{The Magnitude 5 sub-zone (MA5)}

The Magnitude 5 sub-zone was named after the largest earthquake of the 19771997 period, the August 19, $1979 \mathrm{~m}_{\mathrm{N}} 5.0$ earthquake. The sub-zone is bound to the South by a cluster of earthquakes and by deeper activity elsewhere. With only $5 \%$ of the CSZ activity, the sub-zone is not the most active, but four of the eight $m_{N} \geq 4.0$ earthquakes of the 1977-1997 period occurred there. In addition, an anomalously high proportion of multiplets were found: 15 events out of 37 (40\%). Four mechanisms are available, all for magnitude $>4.0$; the $m_{N} 5.0$ event with its pure reverse faulting mechanism; a strike-slip solution for the $19971028 \mathrm{~m}_{\mathrm{N}} 4.7$ event; and two reverse faulting solutions for the $\mathrm{m}_{\mathrm{N}}$ 4.3 and 4.4 doublet of March 1989. On a cross-section perpendicular to the River, the hypocentres define a steeply-dipping plane (Figure 4.14A).

Based on available information, it is likely that the 1925 M 6.2 earthquake occurred in this sub-zone. It is known that the earthquake occurred within the NE portion of the CSZ at a $10 \mathrm{~km}$ focal depth, that its magnitude defines fault dimensions of about 
8 length by $4 \mathrm{~km}$ width, and that it was a pure-reverse faulting event on a plane oriented NNE to NE. The M5 sub-zone matches all these parameters: it lies within the epicentral zone of the 1925 earthquake, earthquakes concentrate at $10 \mathrm{~km}$ depth, and hypocentres define a plane with a trend and dimensions that match what is expected of the 1925 event. In addition, the sub-zone is subject to some of the largest earthquakes of the CSZ, and three out of four mechanisms have more-or-less the same reverse faulting mechanism as the 1925 event.

On October 28, 1997, a $\mathrm{m}_{\mathrm{N}} 4.7$ event occurred, the largest CSZ earthquake since the 19 October $1979 \mathrm{~m}_{\mathrm{N}} 5.0$ earthquake. The main shock was followed by a series of ten aftershocks (as of May $1^{\text {st }} 1998$; Table 4.7), all within $3 \mathrm{~km}$ epicentral distance of the main shock. Within the aftershock sequence, a doublet and a triplet were found. The largest aftershock of the sequence (magnitude $\mathrm{m}_{\mathrm{N}} 3.2$ ) occurred 90 seconds after the main shock. Its exact location in respect to the main shock is uncertain due to overlapping traces. Most of the other events were well recorded by the four nearest stations (A16, A21, A61 and A64), and were carefully picked to relocate the main shock and aftershocks (Figure 4.25). The aftershocks are all 0.9 to $3.4 \mathrm{~km}$ shallower than the main shock, and are well outside the dimensions of the rupture for an event of this size (in the $600 \mathrm{~m}$ range; Table 3.3). Interestingly, aftershocks of the nearby $1979 \mathrm{~m}_{\mathrm{N}} 5.0$ event were also shallower than the main shock, and also outside the immediate rupture area (Hasegawa and Wetmiller, 1980). A possible upward migration of fluids to trigger events outside the rupture zone, and possibly on other fault planes can be envisaged, especially if the surrounding volume is highly fractured. 
Table 4.7 Aftershocks of the 19971028 event

Date Time Lat Long Depth Mag
(UT)

$97 / 10 / 28 \quad 11: 44: 18 \quad 47.67 \mathrm{~N} \quad 69.91 \mathrm{~W} \quad 11.3 \quad 4.7 \mathrm{~m}_{\mathrm{N}}$ 97/10/28 $11: 45: 48 \quad 47.67 \mathrm{~N} \quad 69.91 \mathrm{~W} ? ? ? \quad 3.2 \mathrm{~m}_{\mathrm{N}}$ $97 / 10 / 28 \quad 15: 14: 10 \quad 47.67 \mathrm{~N} \quad 69.91 \mathrm{~W} \quad 9.4 \quad 1.5 \mathrm{~m}_{\mathrm{N}}$ $97 / 10 / 28 \quad 16: 54: 03 \quad 47.68 \mathrm{~N} \quad 69.91 \mathrm{~W} \quad 10.5 \quad 2.5 \mathrm{~m}_{\mathrm{N}}$ $97 / 10 / 29 \quad 13: 25: 15 \quad 47.67 \mathrm{~N} \quad 69.91 \mathrm{~W} \quad 8.2 \quad 1.3 \mathrm{~m}_{\mathrm{N}}$ $97 / 10 / 31 \quad 10: 19: 18 \quad 47.67 \mathrm{~N} \quad 69.91 \mathrm{~W} \quad 8.6-1.0 \mathrm{M}_{\mathrm{L}}$ 97/11/02 00:00:30 $\quad 47.66 \mathrm{~N} \quad 69.92 \mathrm{~W} \quad 9.2 \quad 1.8 \mathrm{~m}_{\mathrm{N}}$ $97 / 11 / 28 \quad 10: 56: 35 \quad 47.68 \mathrm{~N} \quad 69.91 \mathrm{~W} \quad 9.1 \quad 2.4 \mathrm{~m}_{\mathrm{N}}$ $98 / 01 / 12 \quad 02: 49: 25 \quad 47.66 \mathrm{~N} \quad 69.90 \mathrm{~W} \quad 7.9 \quad 1.3 \mathrm{~m}_{\mathrm{N}}$ $98 / 03 / 10 \quad 13: 28: 43 \quad 47.68 \mathrm{~N} \quad 69.91 \mathrm{~W} \quad 10.4 \quad 1.0 \mathrm{~m}_{\mathrm{N}}$ $98 / 03 / 18 \quad 18: 21: 06 \quad 47.67 \mathrm{~N} \quad 69.92 \mathrm{~W} \quad 8.3 \quad 1.2 \mathrm{~m}_{\mathrm{N}}$ 


\subsubsection{The St-Irénée sub-zone (IRE)}

The St-Irénée sub-zone is fairly active with $12 \%$ of the CSZ earthquakes. The earthquakes, however, are of low magnitude with only two events exceeding magnitude $m_{N}$ 3.0. The area is bound to the SE by the St-Laurent fault. Only one focal mechanism exists for the sub-zone, displaying pure-reverse faulting on planes oriented ENE. About $20 \%$ of events (20 out of 98 ) were multiplets. The low magnitude of the events suggests a highly fractured area, possibly related to the meteor impact.

\subsubsection{The Central (CEN) and Kamouraska (KAM) sub-zones}

The CEN and KAM sub-zones group approximately $35 \%$ of all CSZ activity, with $25 \%$ only for CEN. Contrasting with this high level of earthquake occurrence, both areas did not witness any magnitude $>4.0$ for the period 1924-1997. The CEN sub-zone is an area of diffuse activity, where earthquakes concentrate but do not define planar features (Figure 4.14 A-B). The KAM sub-zone, on the other hand, was defined primarily on the more homogeneous and slightly deeper depth distribution than the one of the CEN. The hypocentres of this sub-zone define a SE dipping plane, very similar to one of the nodal planes of the 1925 earthquake (Figure 4.14 C-D).

\subsubsection{The La Pocatière (POC) sub-zone}

The POC sub-zone, an area of mild activity, is made up of two main clusters of events. As opposed to the CEN sub-zone, it does not show one large hypocentre volume. It appears to mark a transition between the highly active central zone to a less active area 
to the SW. A total of 17 events out of 66 were part of multiplets (26\%), including a nine-event multiplet (the largest earthquake swarm found), and a six event multiplet. All events of these two multiplets were of small magnitude $\left(m_{N} \leq 2.2\right)$, hence none has a focal mechanism.

\subsubsection{Deep activity sub-zones (OIE, DNE)}

\subsubsection{The Cap-aux-Oies sub-zone (OIE)}

The Cap-aux-Oies sub-zone lies along the trend of the midly active corridor that parallels most of the north shore of the St. Lawrence (see Section 4.6.4). The sub-zone has a radial trend from the central peak of the impact crater. The hypocentre groups suggest that the NE planes may be the reactivated structures. Four focal mechanisms exist for this sub-zone with two showing a reverse-oblique-slip mechanism on NE to SW oriented planes. No multiplets were found in this sub-zone.

\subsubsection{The Deep Northeast sub-zone (DNE)}

The Deep Northeast sub-zone includes a series of deep earthquakes located at the northeast extremity of the CSZ (Figure 4.26). The earthquakes are markedly deeper than in any other sub-zone of the CSZ. The depth of these earthquakes is not due to its location in respect to the seismograph network: the emergence angles on station A64 agree with deep focii. On land, the shallow depths to the West correspond to the SteMathilde fault of Rondot (1989). Although most events occur as isolated earthquakes spread out over the whole sub-zone, there are a few clusters of activity, including some 
multiplets that represent $25 \%$ of the events. The largest cluster started with the 19911208 $\mathrm{m}_{\mathrm{N}} 4.1$ earthquake, with an unusual strike-slip mechanism. It was followed by a series of aftershocks, including two within the first 6 hours, that constitutes a seven event multiplet. The Pg and Sg arrival times at four stations were carefully re-picked and the events were relocated using time corrections defined by the residuals of the main shock (as in Deichmann and Garcia-Fernandez, 1992). The hypocentres suggest that the NNESSW plane is the actual rupture. Two other mechanisms show pure-reverse faulting on NE oriented planes. These fault trends correspond to the numerous lineaments of the north shore.

4.6.4 Weakly seismic sub-zones (SHI, SGA, CGA, AIG, NGA, UPS, DOW, SOS, LOU)

A number of weakly active sub-zones exists in the CSZ, especially in a riverparallel corridor (SGA, CGA, AIG, NGA) or in the periphery of the more active zone (UPS, DOW, SOS, SHI). All together, only $11 \%$ of all CSZ earthquakes occur there, with most events representing isolated occurrences (no multiplets were found). Three focal mechanisms exist, showing mostly pure or oblique reverse faulting. At present, there is no evidence for a lithological control of the river-parallel corridor, but the NE boundaries of the SGA, CGA, AIG and NGA sub-zones correspond to changes in hypocentre density and depth, coincident with the position of the St-Laurent fault. The relative quiescence of this strong region may be due to an undetected time dependence of micro-earthquake activity (Wetmiller and Adams, 1990). More simply, the seismic 
quiescence may be due to the absence of high pore fluid pressure or of gouge material with low coefficient of friction.

\subsection{Discussion}

In this chapter, four sources of information were examined to bring to light the relationships between CSZ earthquakes and faults. No surface rupture was found at the bottom of the St. Lawrence on the seismic profiles. Future work with high resolution profiles will bring a more definite answer on this. An absence of surface rupture implies a lower rate of activity during the past few thousands of years, or that earthquakes were too small and/or too deep.

For larger events of the CSZ, such as the $1925 \mathbf{M ~} 6.2$ and the $1979 \mathrm{~m}_{\mathrm{N}} 5.0$ earthquakes, focal mechanisms suggest that $\mathrm{N}$ to $\mathrm{NE}$ trending paleo-rift faults are reactivated in response to regional stresses. On the basis of earthquake depth, focal mechanisms, and hypocentre alignments, the area surrounding the $1979 \mathrm{~m}_{\mathrm{N}} 5$ earthquake may represent the source region of the 1925 event. This area has been subject to repeated $\mathrm{M}>4$ events and is a likely candidate of future large CSZ earthquakes. Although this area is the most likely to have a surface rupture, none was found on the seismic lines that cross it.

Concerning the possible correlations between seismic events and structural trends, some earthquakes do spatially relate to remotely-sensed and/or potential field lineaments, but not exclusively to paleo-rift faults. Although the A61 sub-zone is intersected by a 
regional rift fault (the Rang-Ste-Mathilde fault of Rondot, 1989; Figure 4.24), nodal planes of the two largest earthquakes are not parallel to it. For lower magnitude earthquakes, smaller fractures with various orientations might be reactivated by local stresses, as shown by the variety of focal mechanisms and the scatter in $\mathrm{P}$ and $\mathrm{T}$ axes. In the A61 sub-zone, two of these events have clear orientations parallel to a WNW-ESE series of lineaments possibly reactivated by the Devonian meteor impact. Since not all CSZ impact structure faults are currently being reactivated, it is possibly the combination paleo-rift--impact faults that gives rise to the seismicity. The St-Laurent fault, evident in the remote sensing as well as in the Bouguer gravity anomaly, is a clear boundary to the seismicity of the sub-zones IRE and A61. Southeast of the fault, earthquakes are more dispersed. In general, earthquakes do not concentrate on this paleo-rift feature.

For small magnitude events, the varied faulting styles imply that local stress and/or strength variations control earthquake occurrence. This contradicts the general assumption that background seismicity corresponds to regional stress systems. In our opinion, earthquakes controlled by local conditions are more likely where resistance to sliding is low, for instance as a consequence of high background pore-fluid pressures or low friction coefficient. Interestingly, a high electrical conductivity zone has been detected by a magnetotelluric survey close to the eastern concentration of hypocentres of sub-zone A61 (Chouteau, 1985). This anomaly has been explained by the presence of water or solutions in a zone of high porosity at depth deeper than $1400 \mathrm{~m}$. In the CSZ, two aftershock sequences may be explained by the migration of fluids away from the immediate rupture of the main shocks. 
The complexity of CSZ seismicity can tentatively be explained by a combination of factors. In the A61 sub-zone, evidence of lithological complexity near faults is accompanied with variations in fault plane trends and faulting styles. This suggests that CSZ fault zones are irregular surfaces, surrounded by highly fractured rocks. These highly fractured zones respond primarily to regional stresses; however, for some smaller events, they may respond to local changes in stress and/or strength. The whole process can be enhanced, especially for deeper events, by high pore-fluid pressures as discussed in Chapter 2 and in Lamontagne and Ranalli (1996). The concentration of CSZ events near $10 \mathrm{~km}$ depth (Figure 4.20B) may indicate a highly stressed level or a frictionally weak level, possibly due to high pore-fluid pressures or to highly fractured rocks.

The small proportion of multiplets found in the CSZ (19\%) contrasts, for example, with the Parkfield area of California where most earthquakes occur as clusters (63\% for the period 1987-1992; Nadeau et al., 1995). This shows that stress takes a long time to replenish along most faults of the CSZ and that most sub-zones of the CSZ are intensely fractured. 
North Shore

South Shore

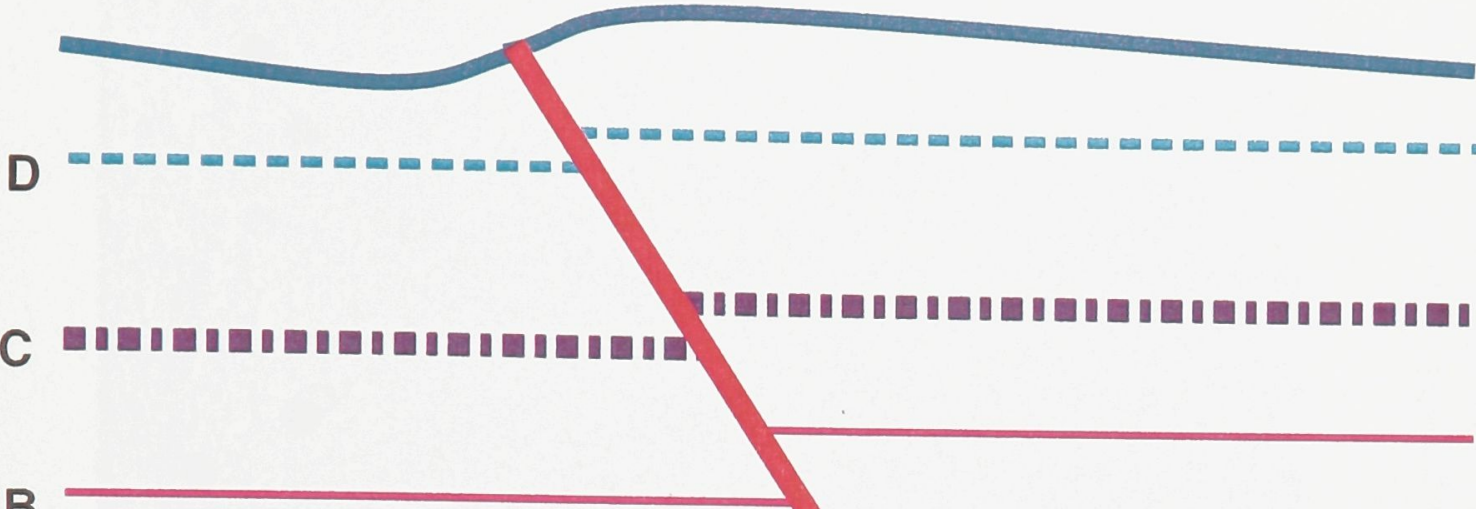

B

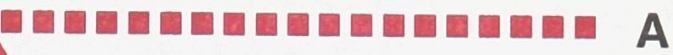

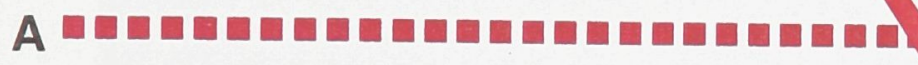

PC or Appalachians

Figure 4.1 Schematic cross-section of the type of rupture expected in the CSZ. Layers A, B, C, D represent sediments accumulated during and between glacial episodes. The rupture due to multiple reverse faulting events originating in the Precambrian basement propagates to the surface (possibly through the Appalachian sequence). The rupture reaches the thick sequence of sedimentary layers. Since more earthquakes ruptured the basal layers (A for example), the amount of slip is larger there than for the top layers. The rupture may reach the bottom of the St. Lawrence River, causing a bathymetric feature. 
(wy) प1dә

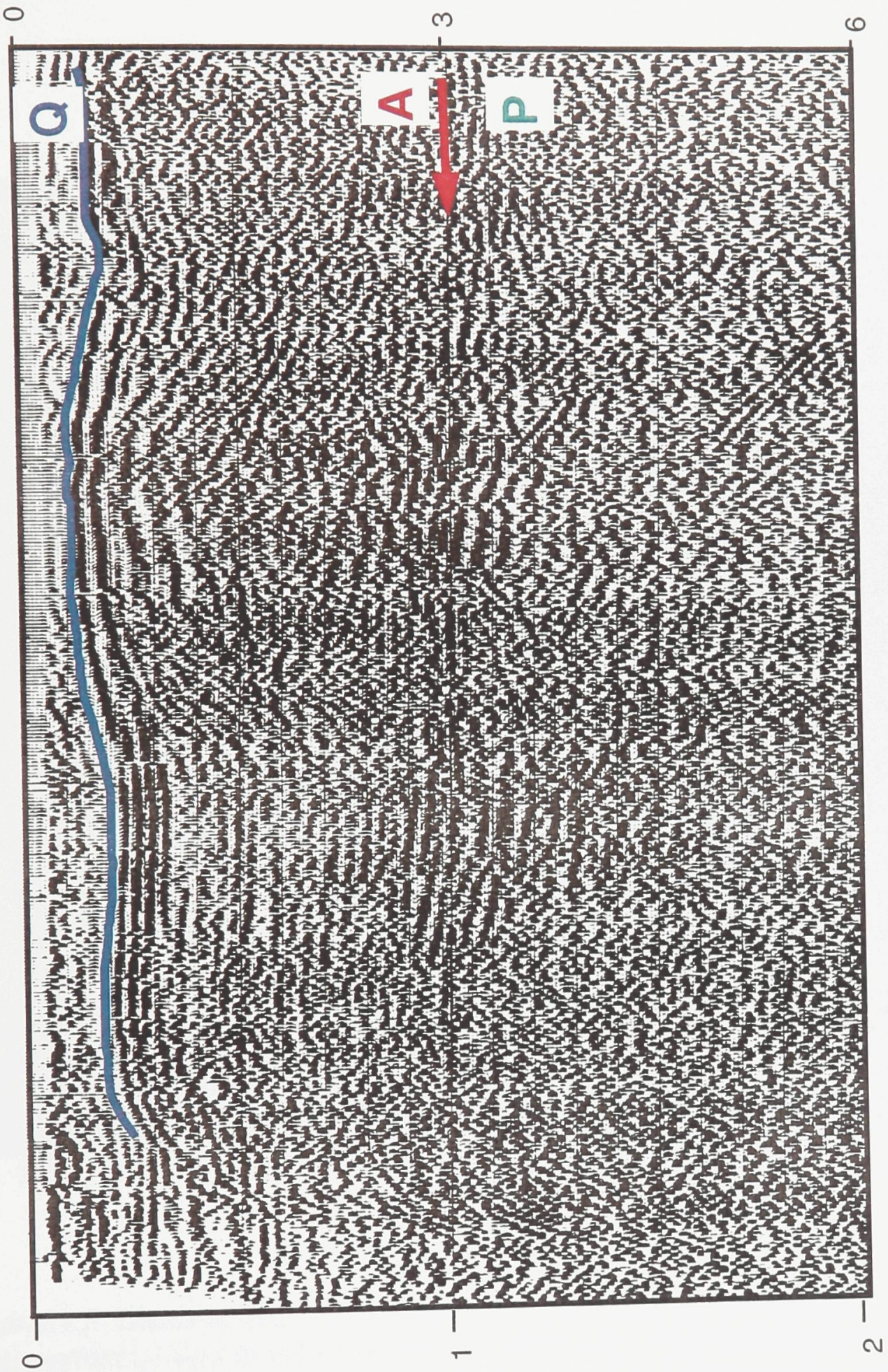

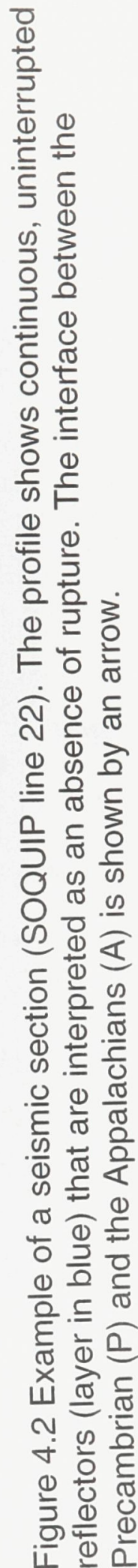

(s) $\perp M \perp$ 
Elevation

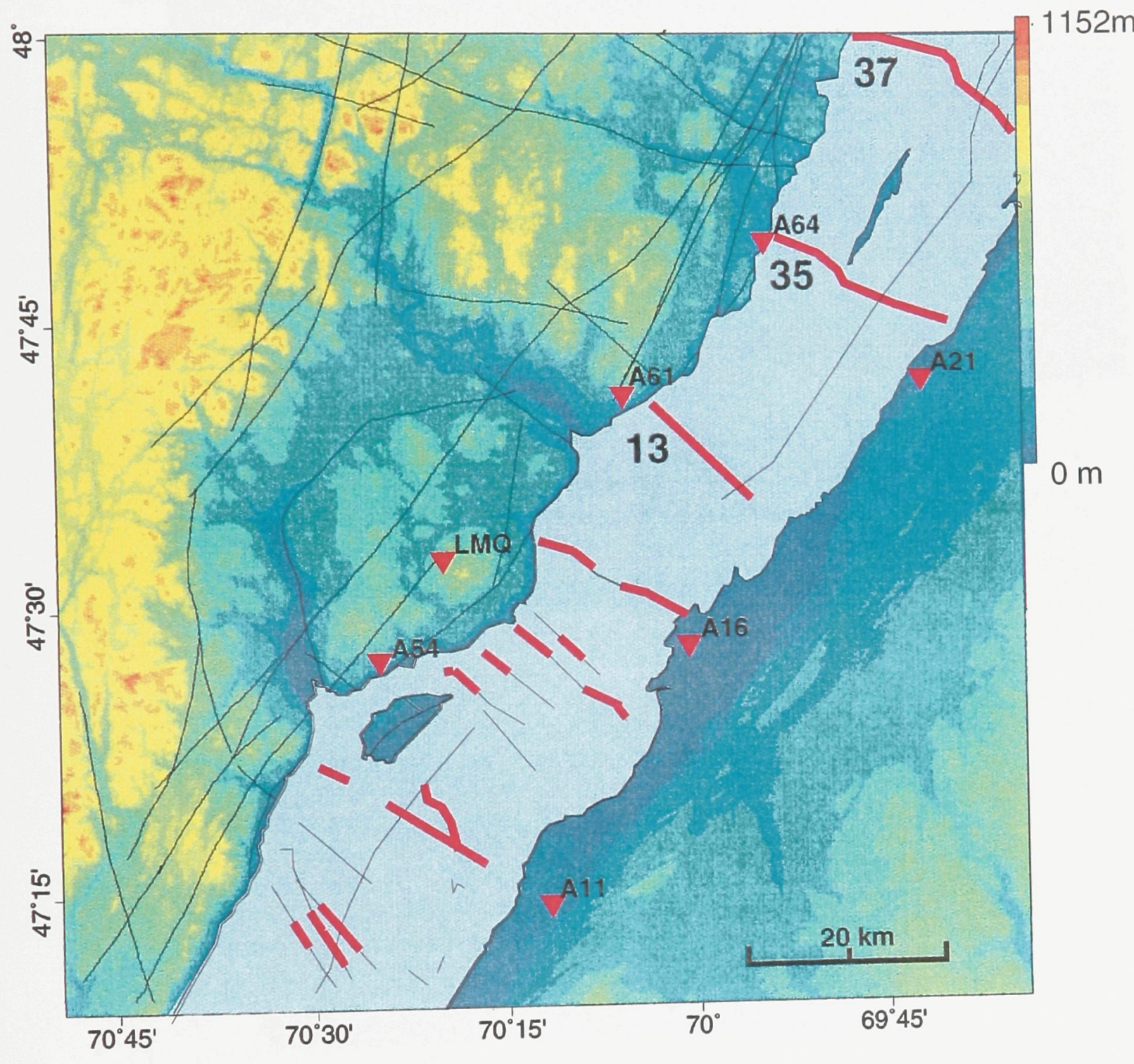

Figure 4.3 Location map of the seismic lines acquired by SOQUIP and their partners. Lines in red show portions of profiles where sub-horizontal markers can be seen. These areas are interpreted to be free of $>20$ m ruptures. 

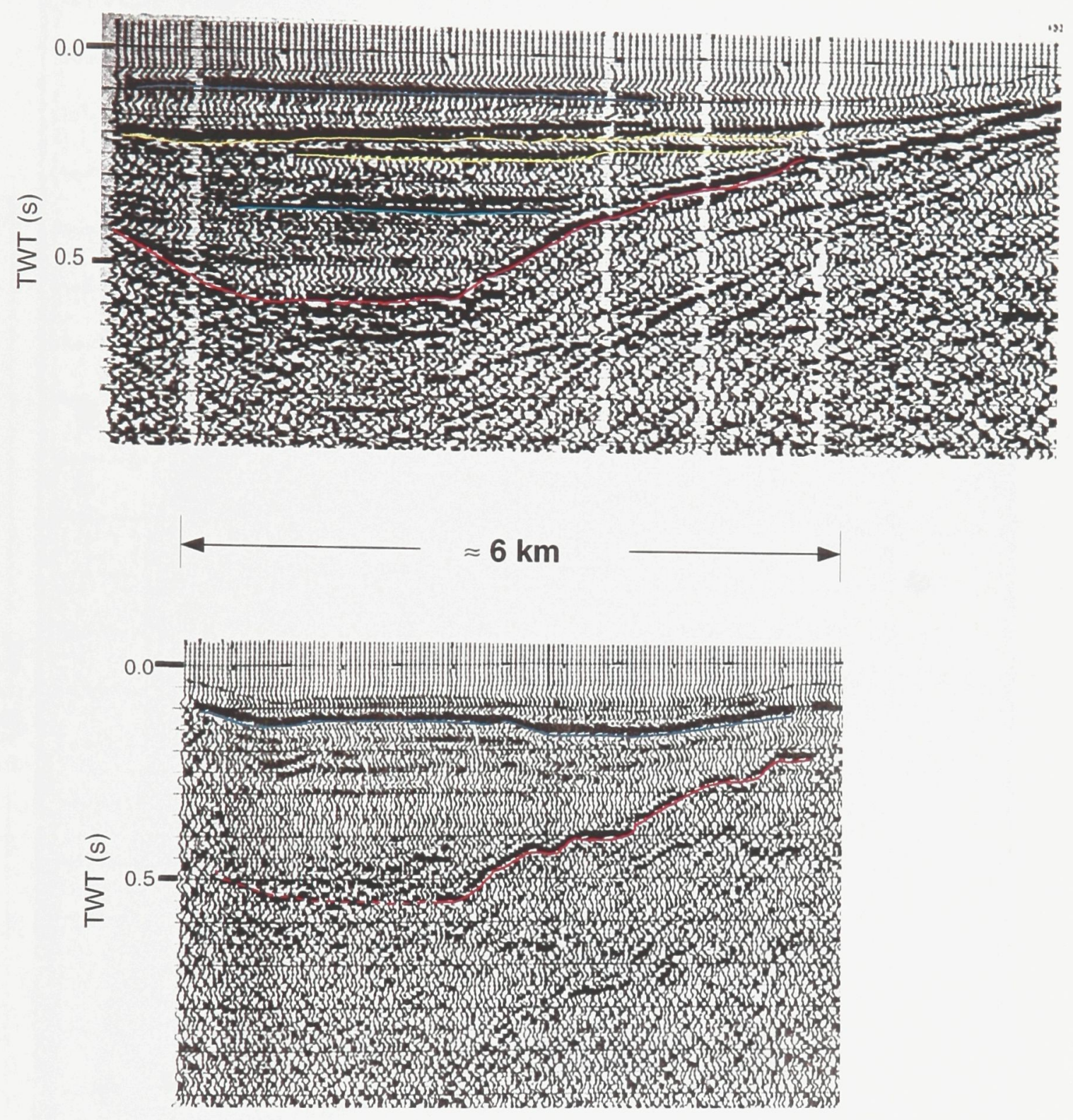

Figure 4.4 Seismic profiles that show the interpreted Quaternary sequence: (A) Enlarged view of the SOQUIP seismic lines near the North shore: Line 35 (top) and 37 (bottom). These two profiles cross the region with most $M>4$ events. The sediment-filled valleys and their sub-horizontal reflectors can be seen. (B) The high resolution profile acquired along SOQUIP line 13. The reflector in red represents the bedrock. Reflectors in colour represent interpreted Quaternary layers that can be distinguished in the numerous multiples. The blue rectangle represents the area where the 6 fathom line lies. The line was proposed to represent a deep seismogenic fault (Anglin, 1984). No rupture can be seen within the rectangle. 


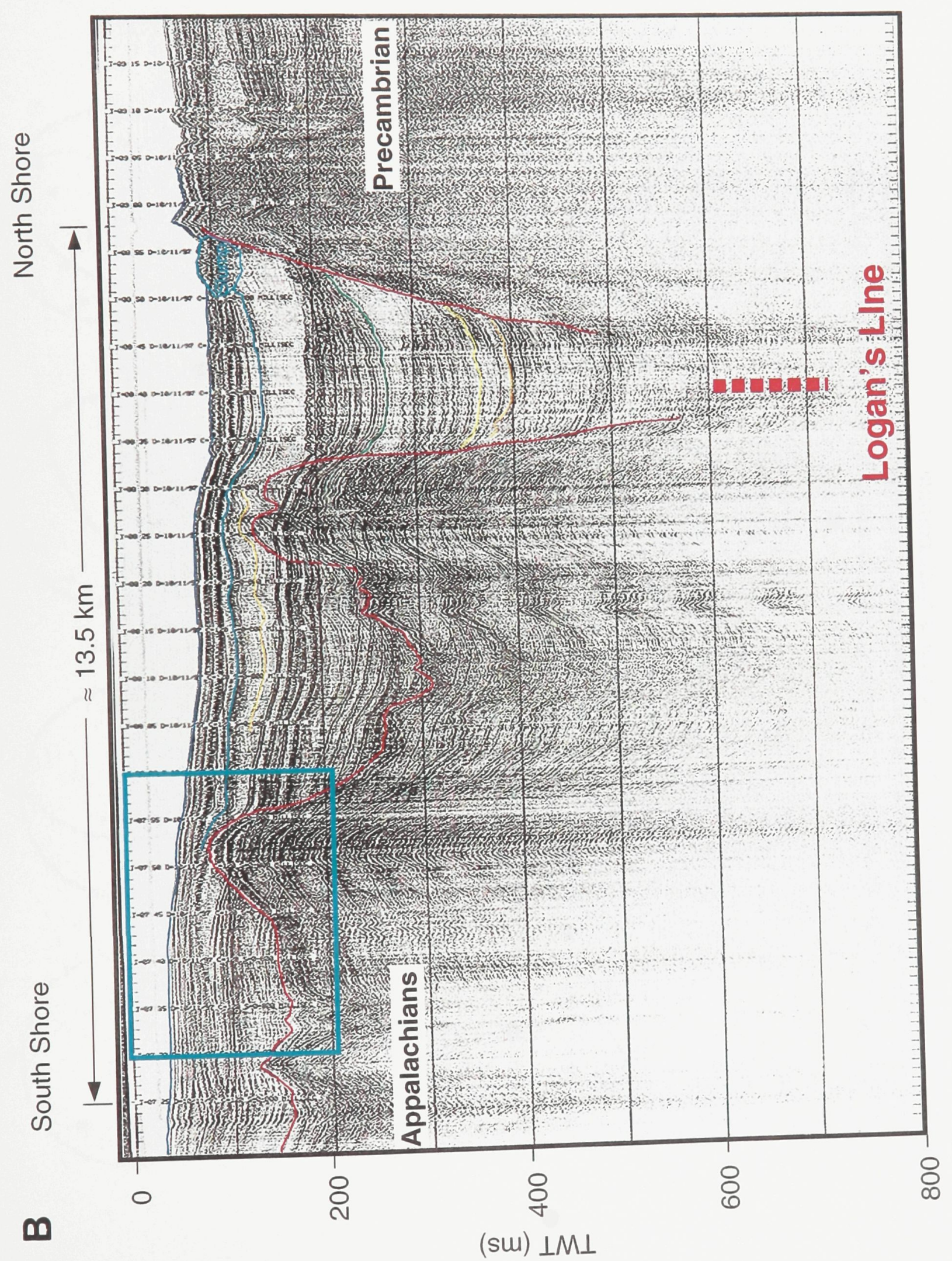




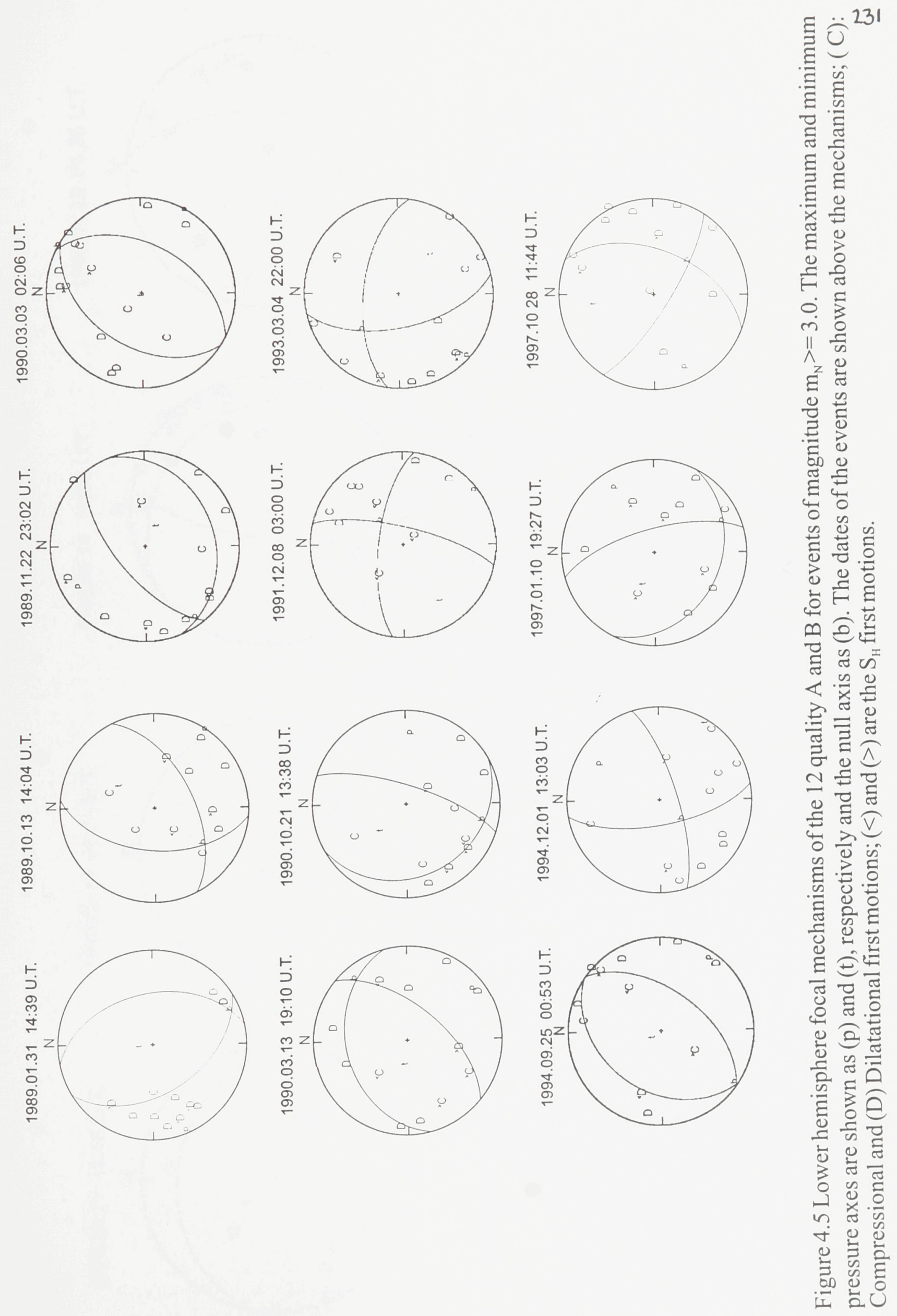



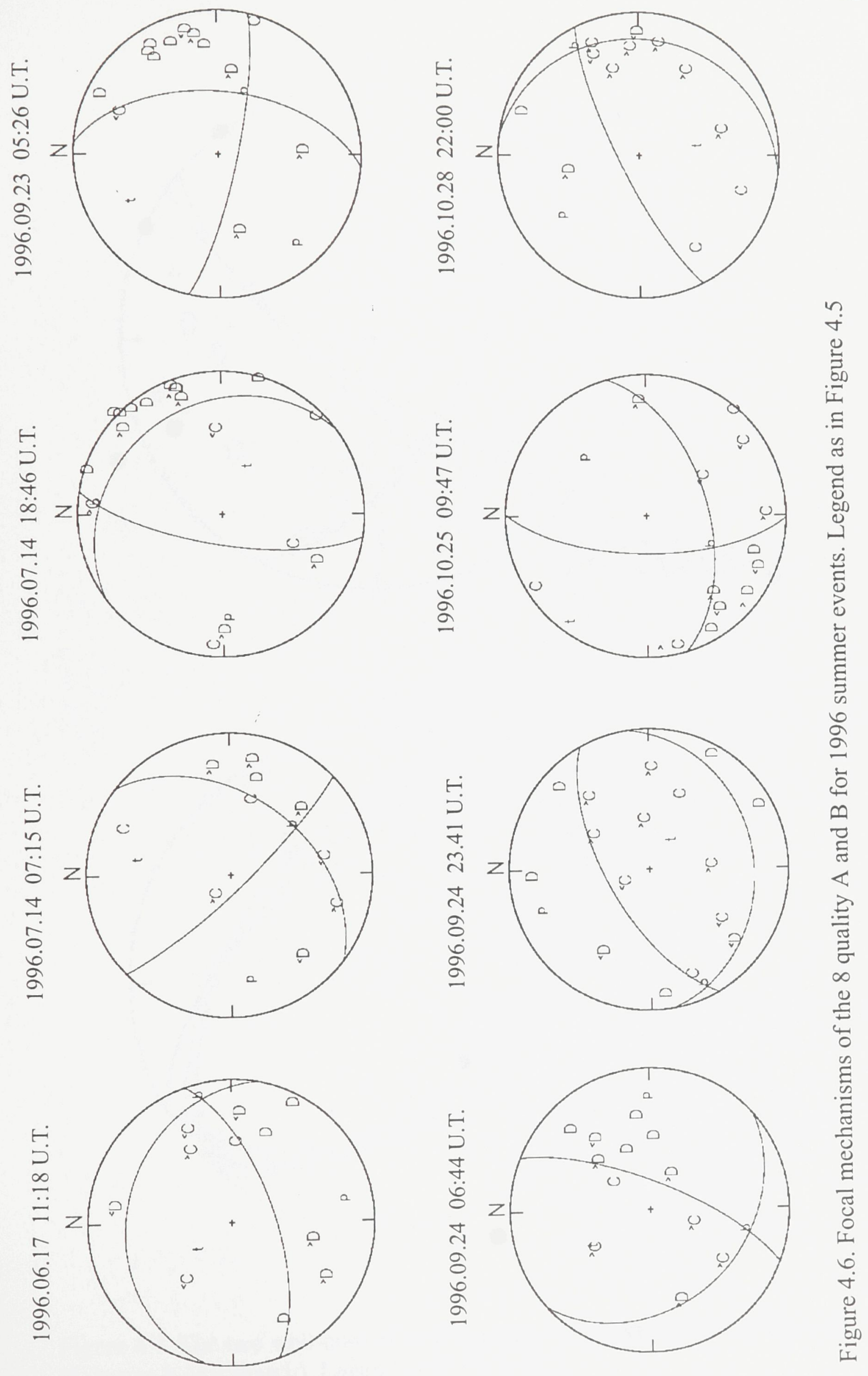

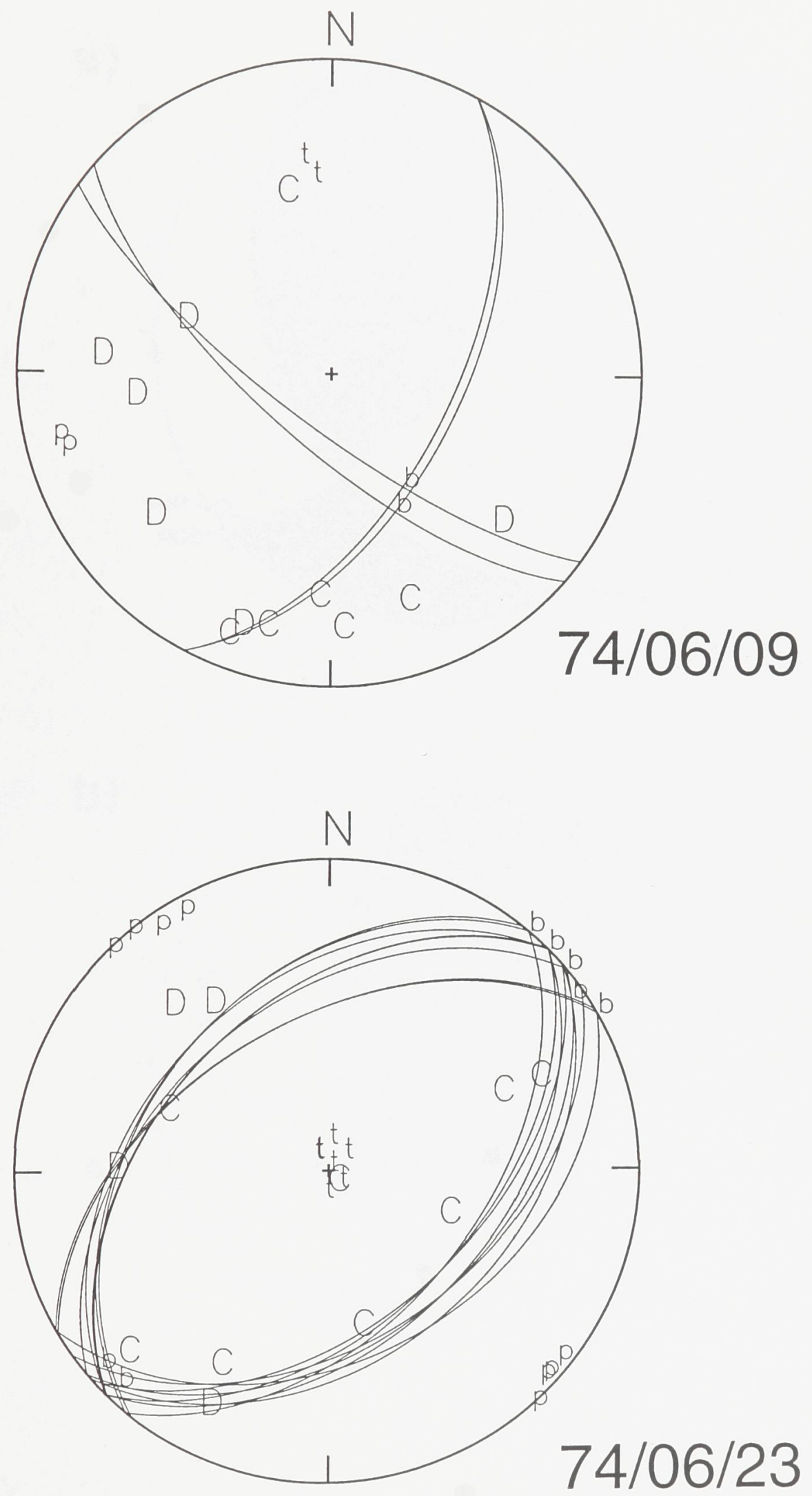

Figure 4.7 The two well-constrained focal mechanisms for the 1974 field survey (5 degree b-axis search). Legend as in Figure 4.5. 

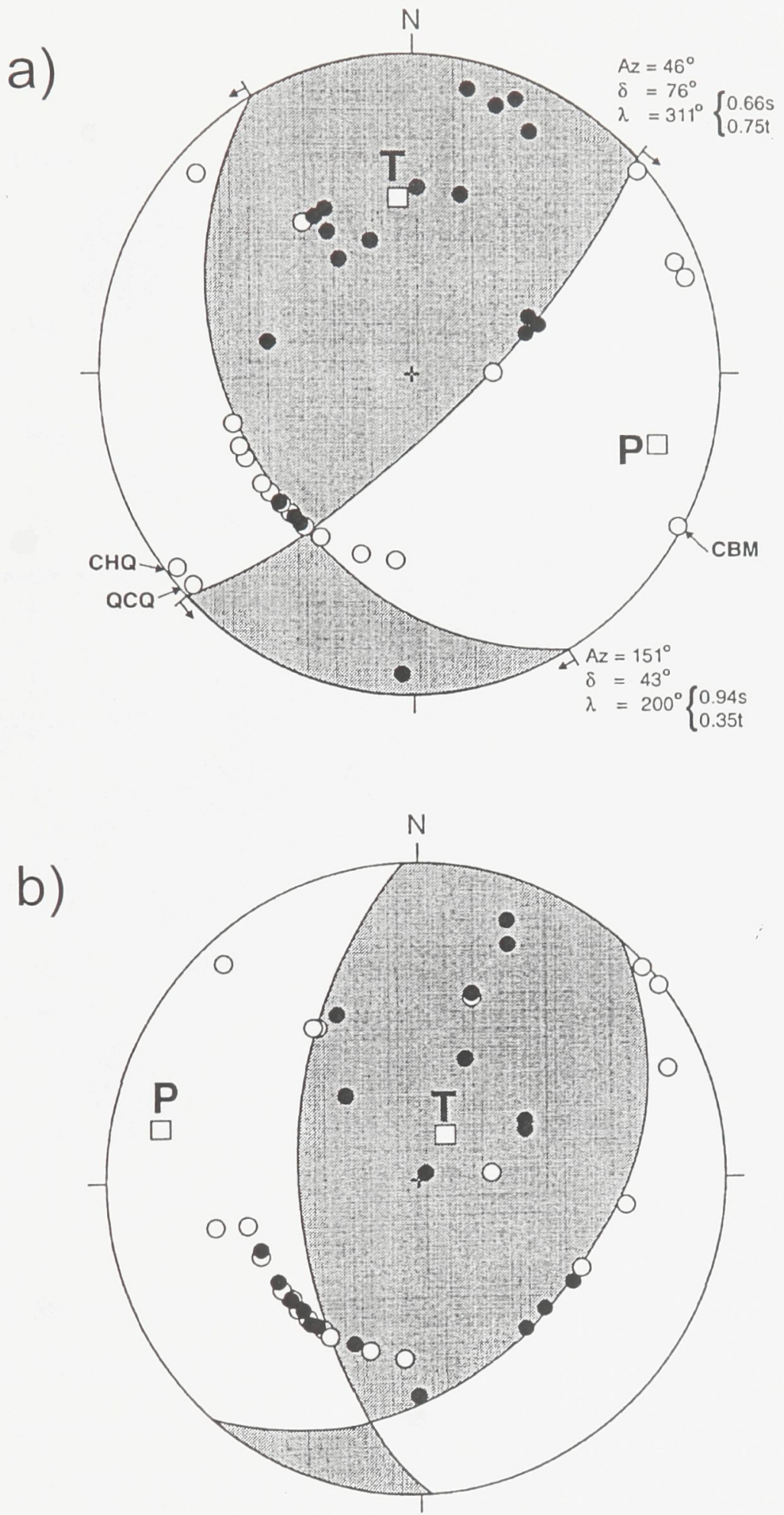

Figure 4.8 Focal mechanisms of the $1979, \mathrm{mN} 5.0$ earthquake: (A) as published in Hasegawa and Wetmiller (1980); (B) The revised version of Lamontagne (1998). 


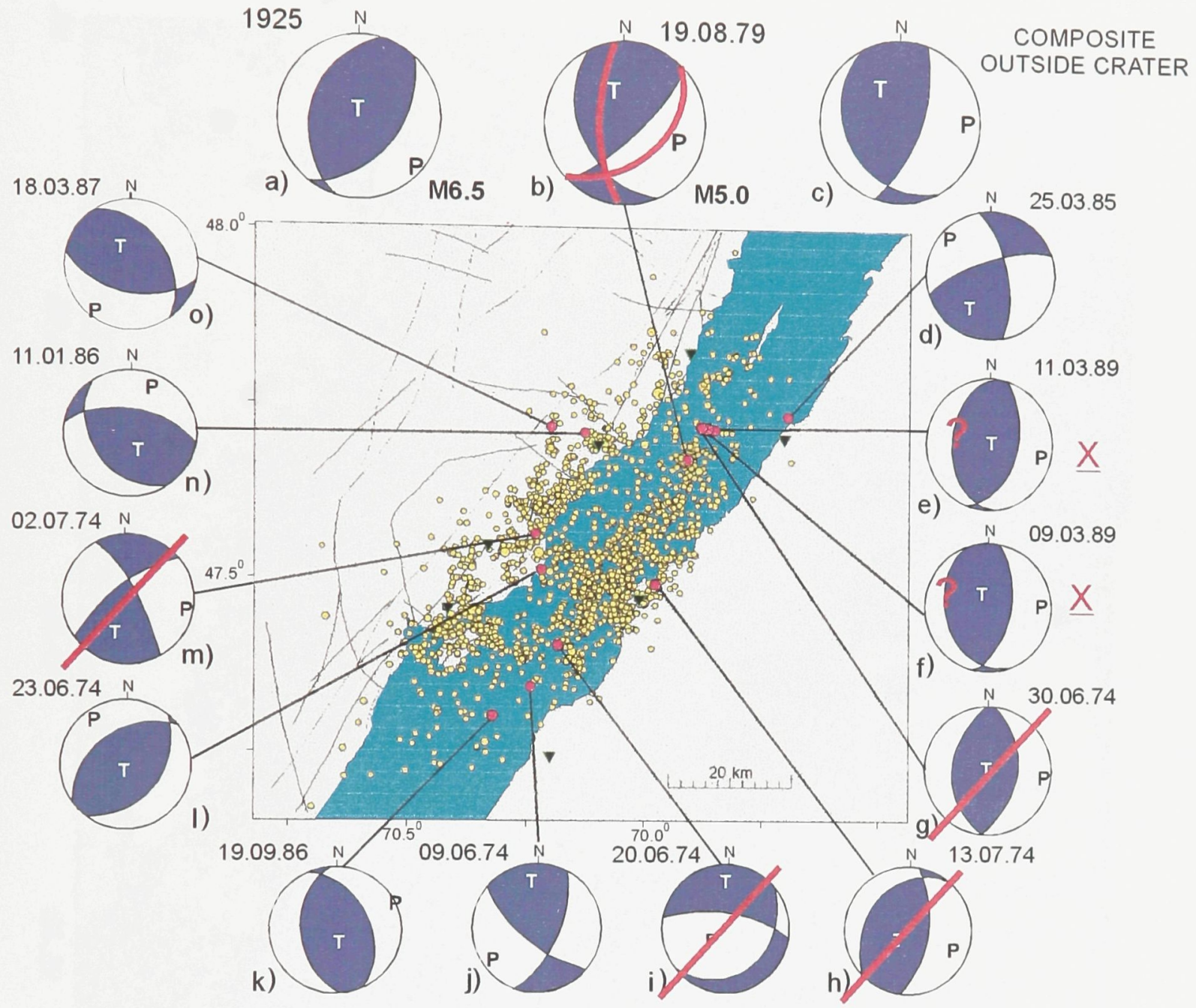

Figure 4.9 Revised focal mechanisms of Figure 1.26. Poorly constrained mechanisms of 1974 are crossed while the two acceptable ones are checked. Events 890309 and 890311 were found to have one poorly constrained nodal plane (shown as ?) and were rated " $\mathrm{X}$ ". For the $1979 \mathrm{mN} 5.0$ event, the two nodal planes found in this study are shown on the previous solution. The other mechanisms were not reexamined. 


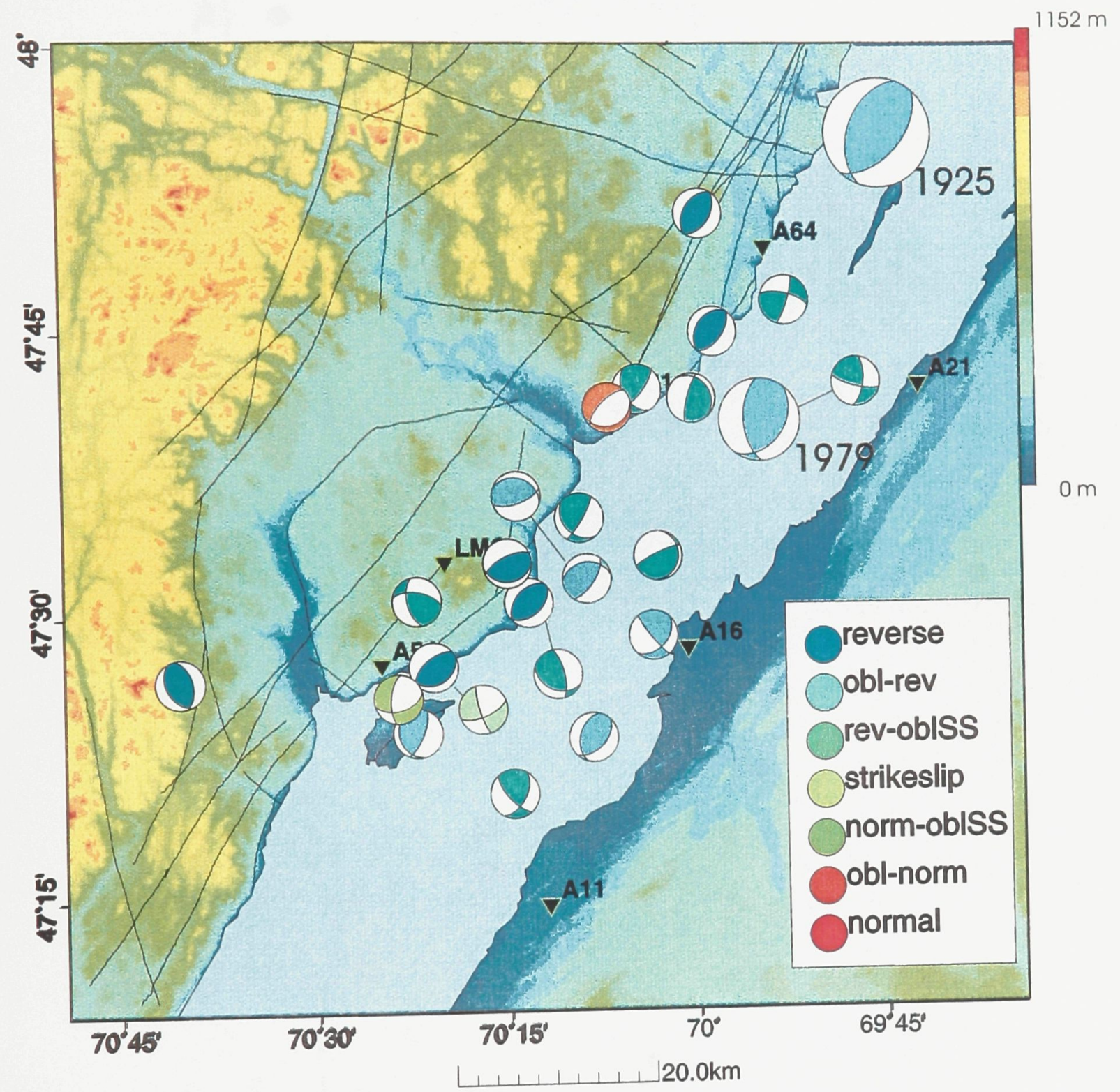

Figure 4.10 Focal mechanisms of quality "A" and "B", including the mechanisms of the $1979 \mathrm{mN} 5.0$ event, the two 1974 events, and the event near La Malbaie. In addition, the 1925 focal mechanism (Bent, 1992) is shown in the upper right corner, in the general area where its epicentre was located by Stevens (1980). An arrow shows the location of a few mechanisms. 
A)

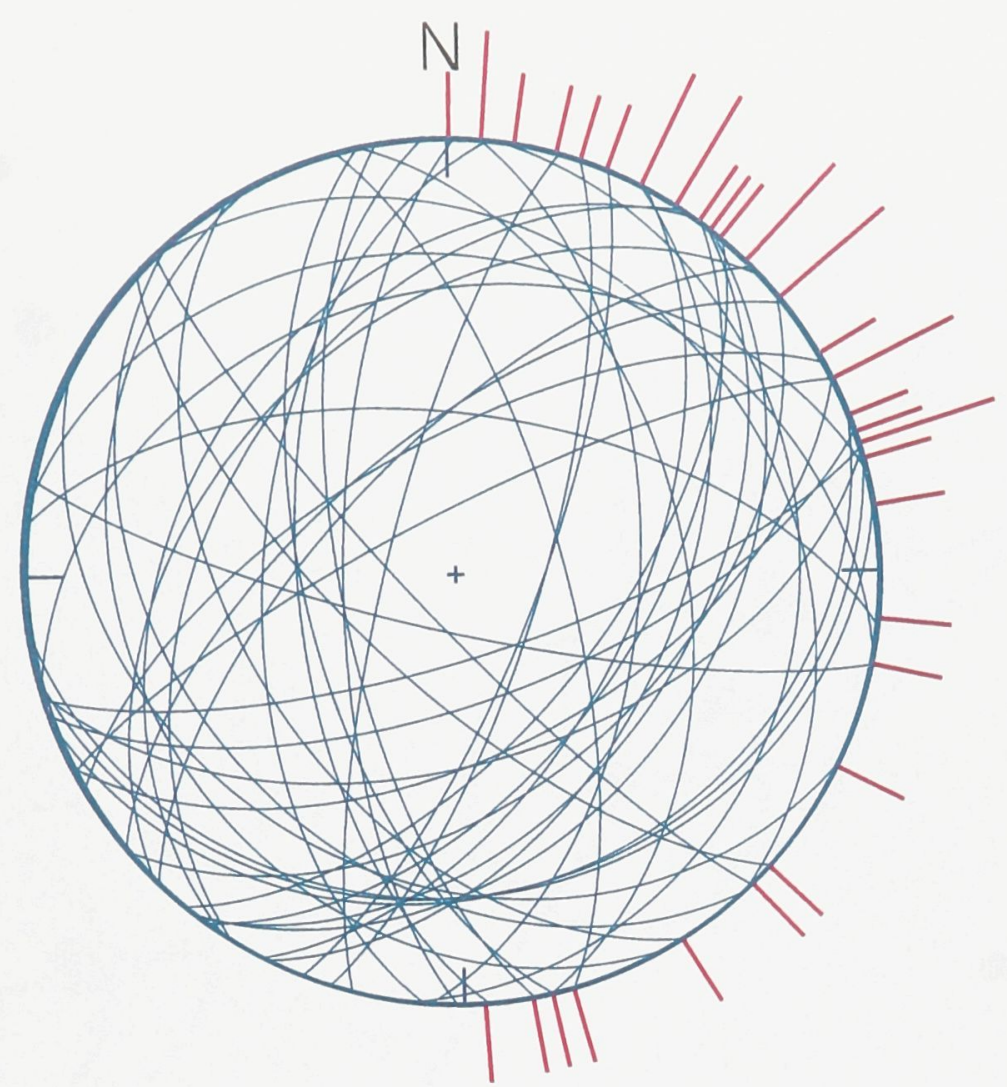

B)

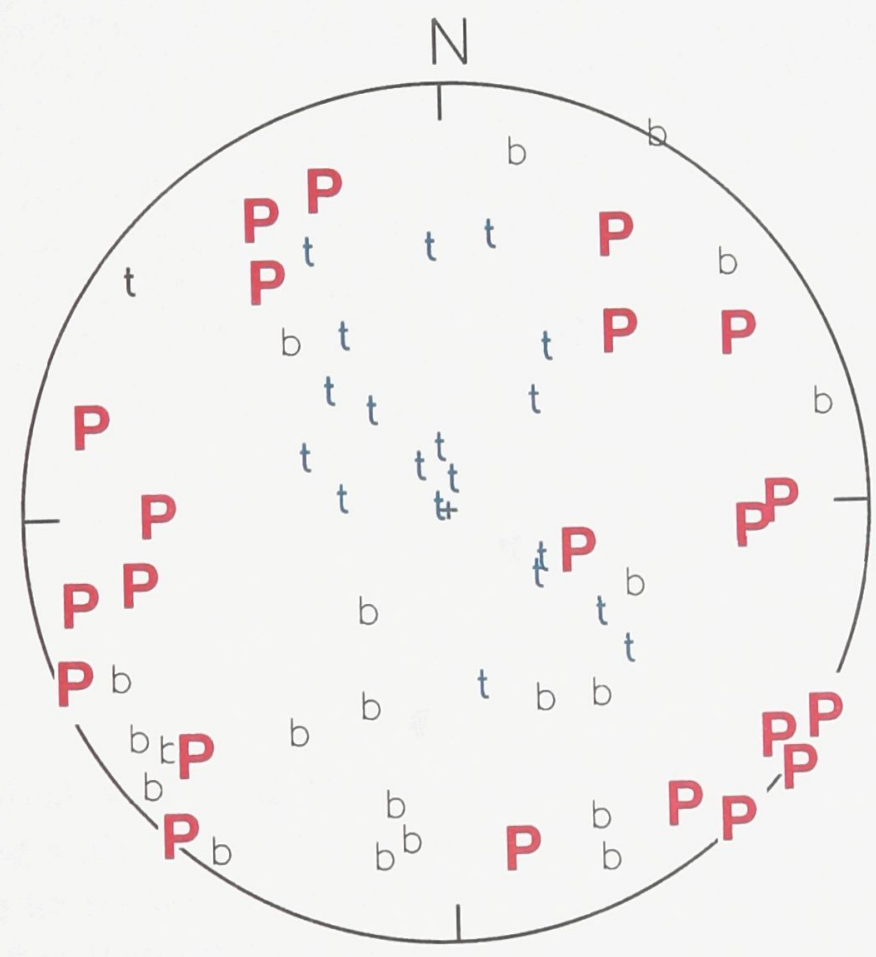

Figure 4.11 Results from the quality "A" and "B" events of Figure 4.8: (A) Nodal planes; (B) P, T, and B axes. 

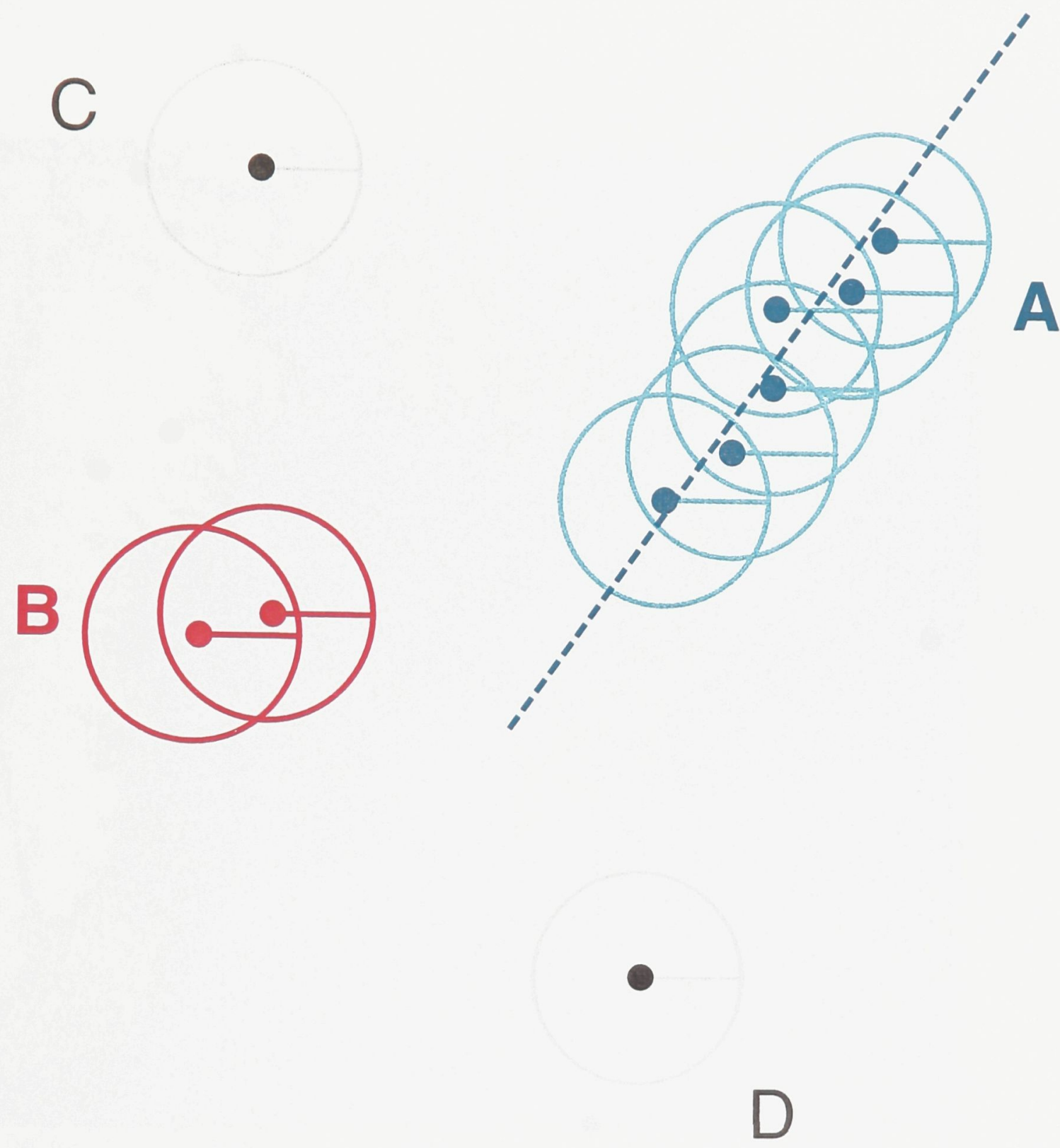

Figure 4.12 Method of defining earthquake groups. Hypocentres (dots) are grouped if located within a given distance (horizontal line) from each other. Although this figure shows epicentres for simplicity, the association is made according to the hypocentral distance. (A) and (B) are groups of events, whereas (C) and (D) are isolated events. The hypocentres of group (A) define a preferential orientation shown by the dotted line. This trend can be compared with the available focal mechanism of group (A). 


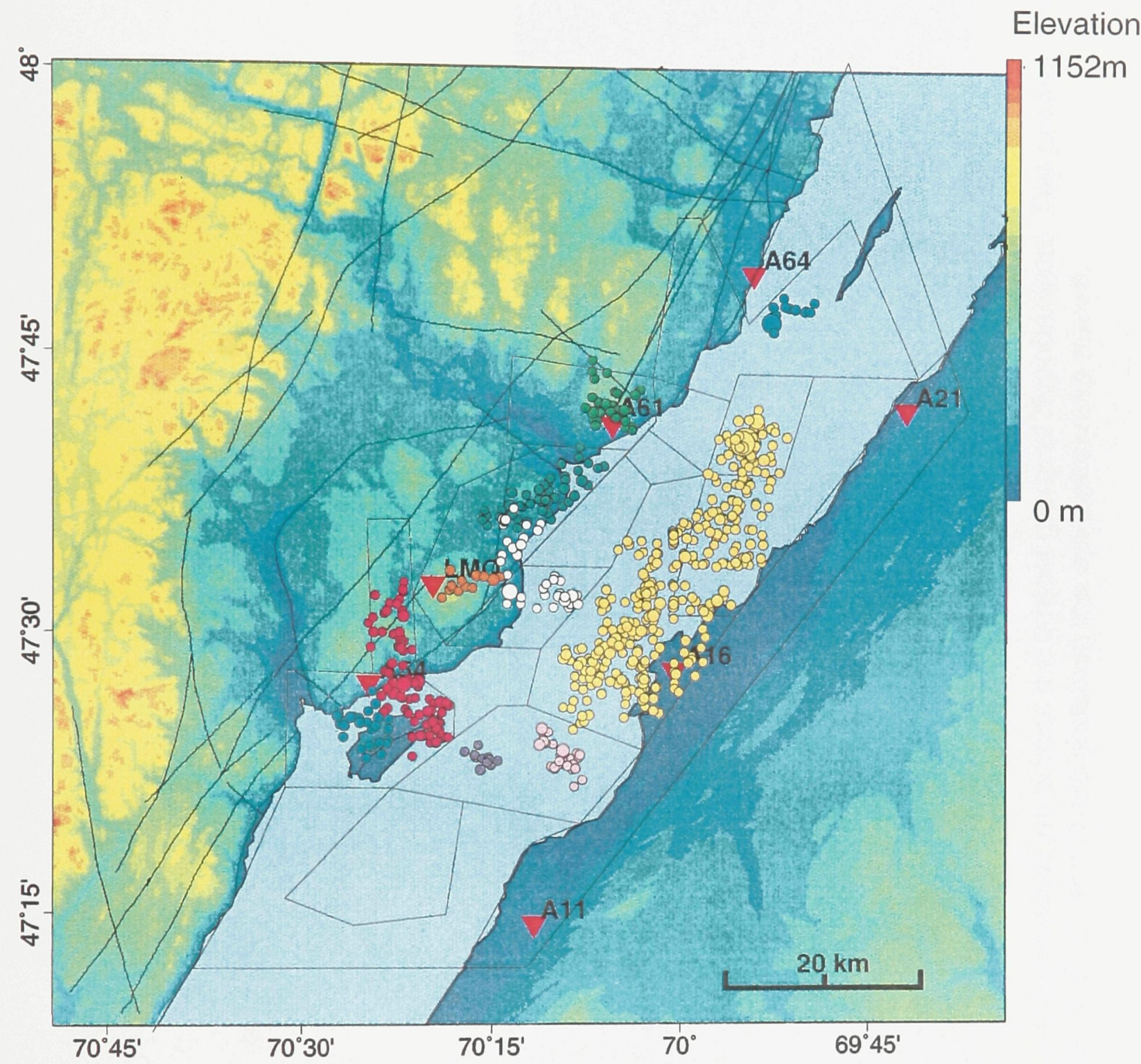

Figure 4.13 Hypocentre groups with 10 events or more created with an interevent distance of $2 \mathrm{~km}$. 


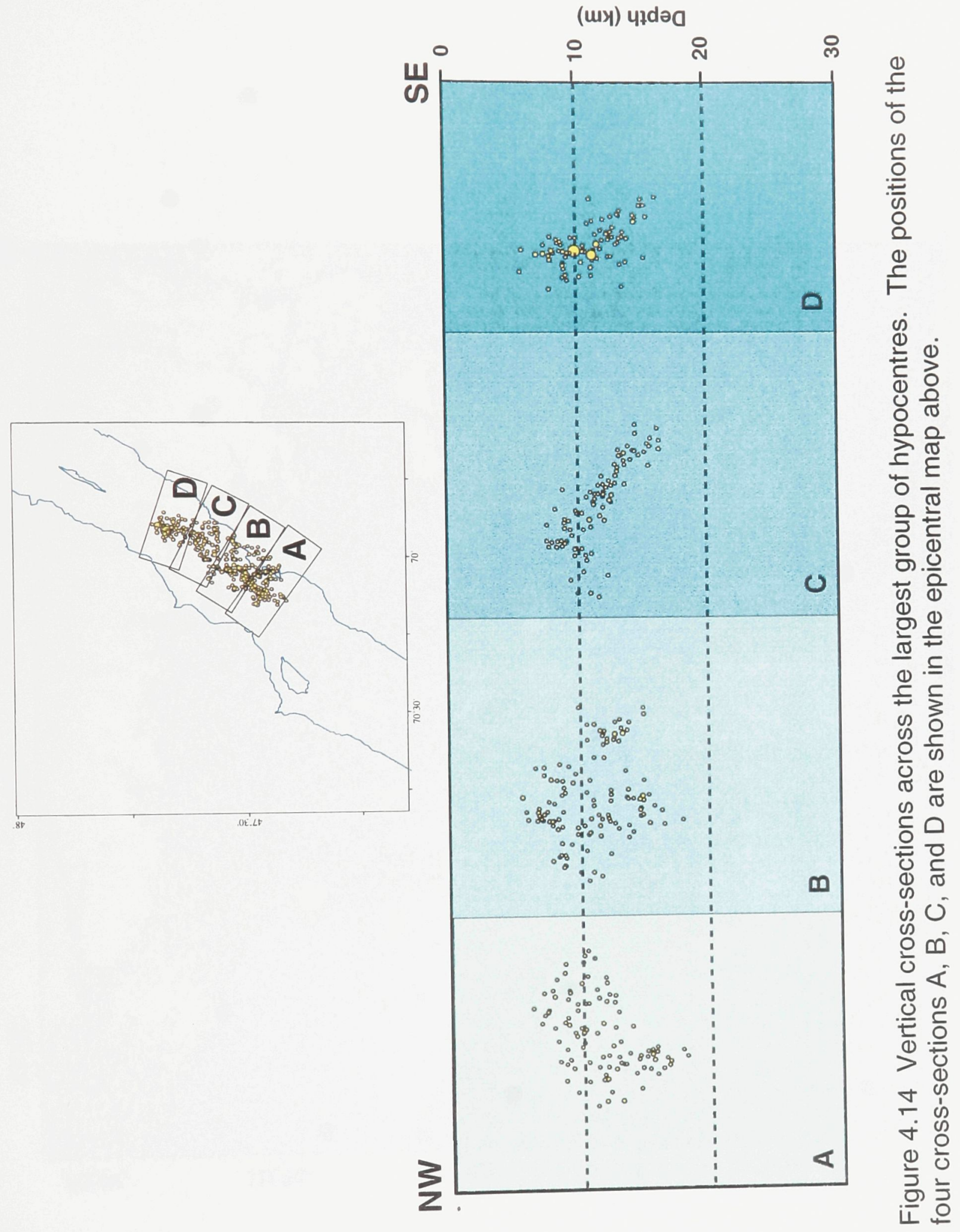




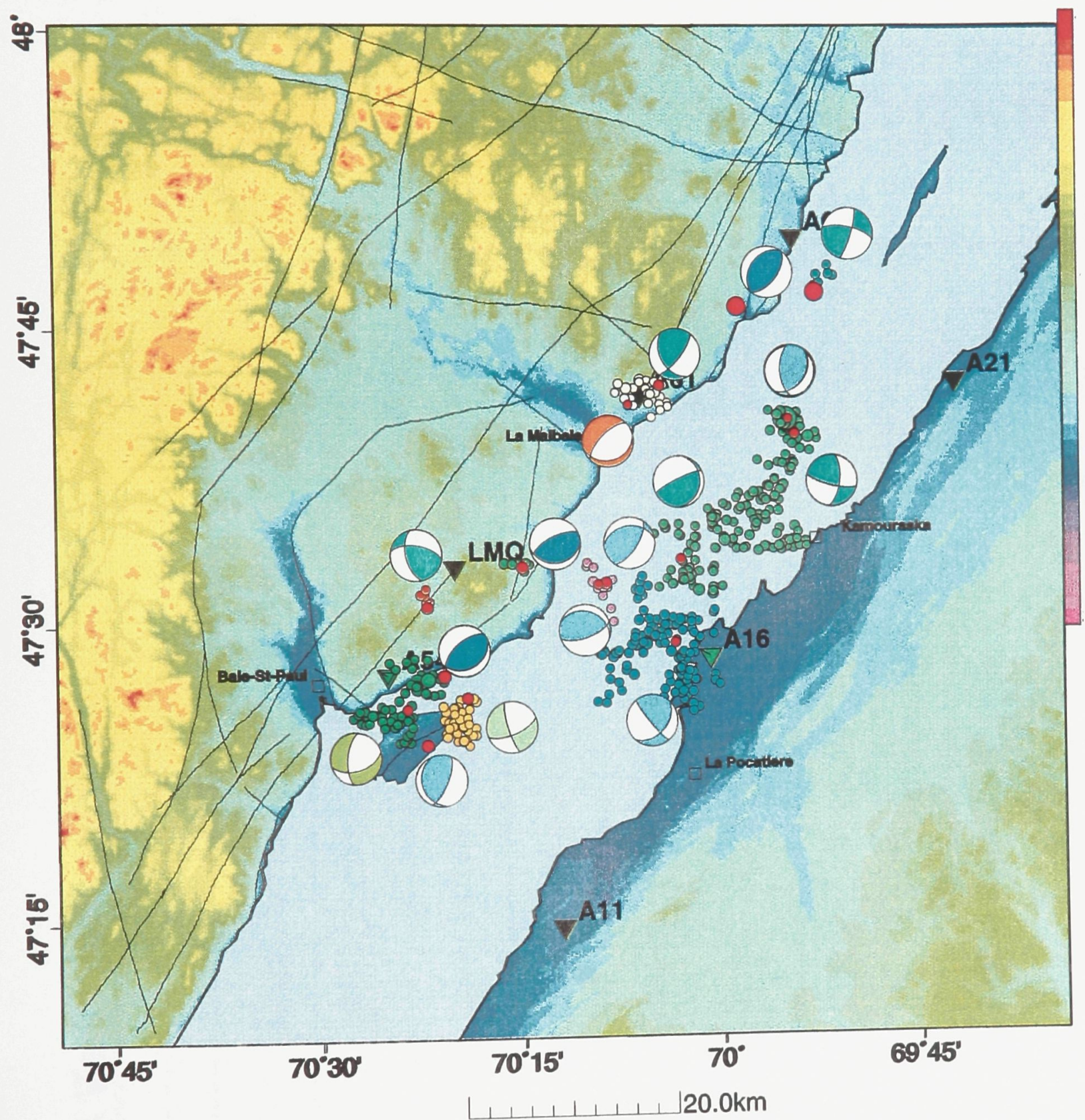

Figure 4.15 Earthquake groups ( $1.5 \mathrm{~km}$ distance) with a focal mechanism (red dot). When possible, the mechanism is located as to line up one of the nodal planes with the orientation suggested by the group. 


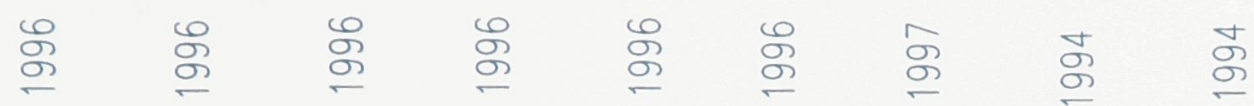

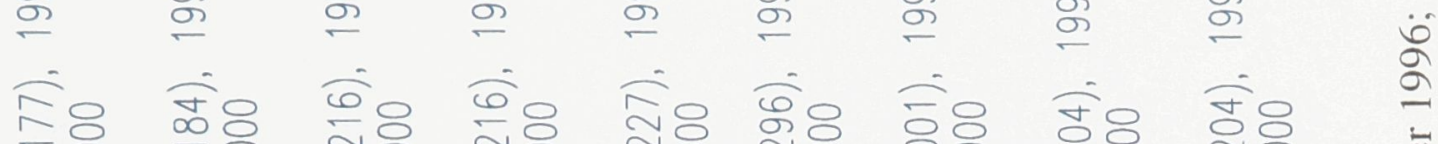

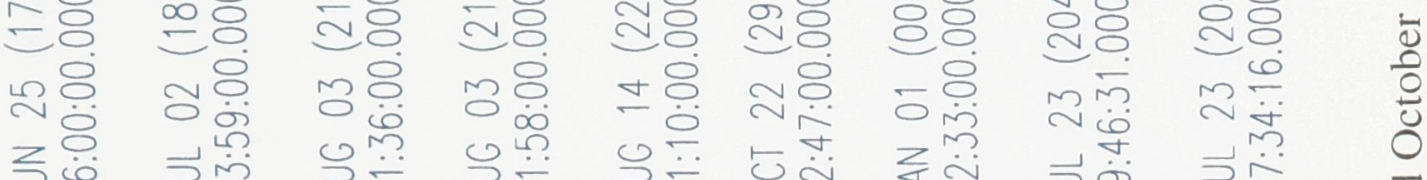

引 $引$ 引

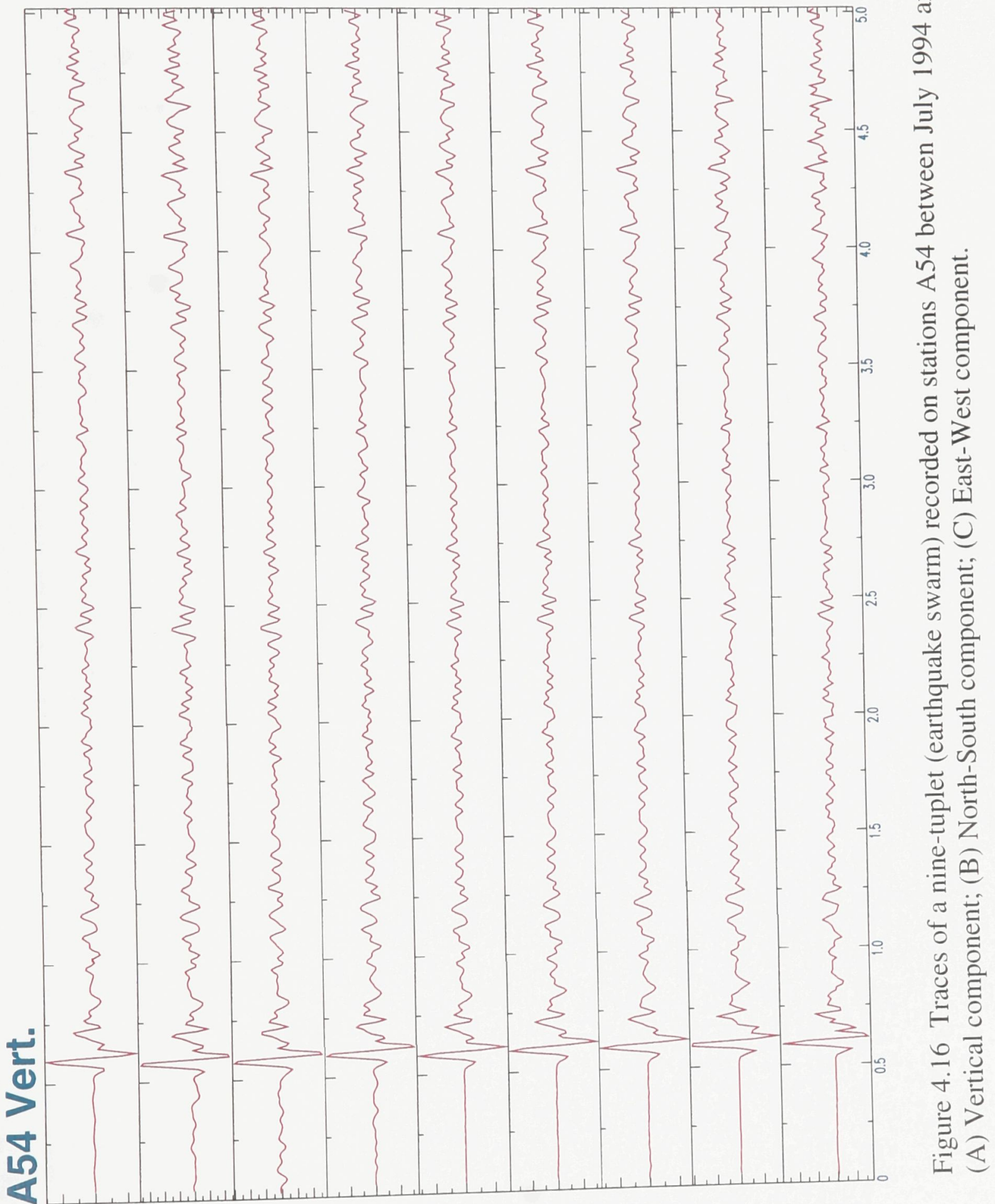


ஜ

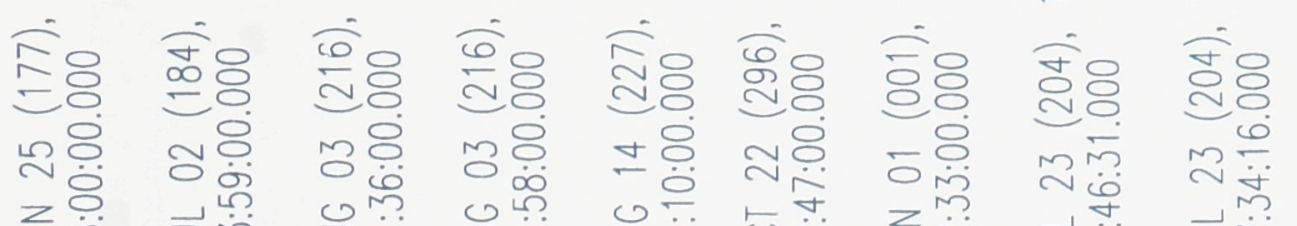

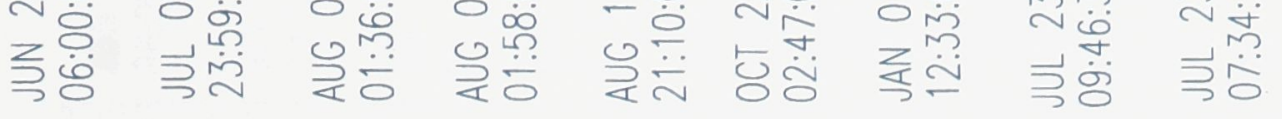

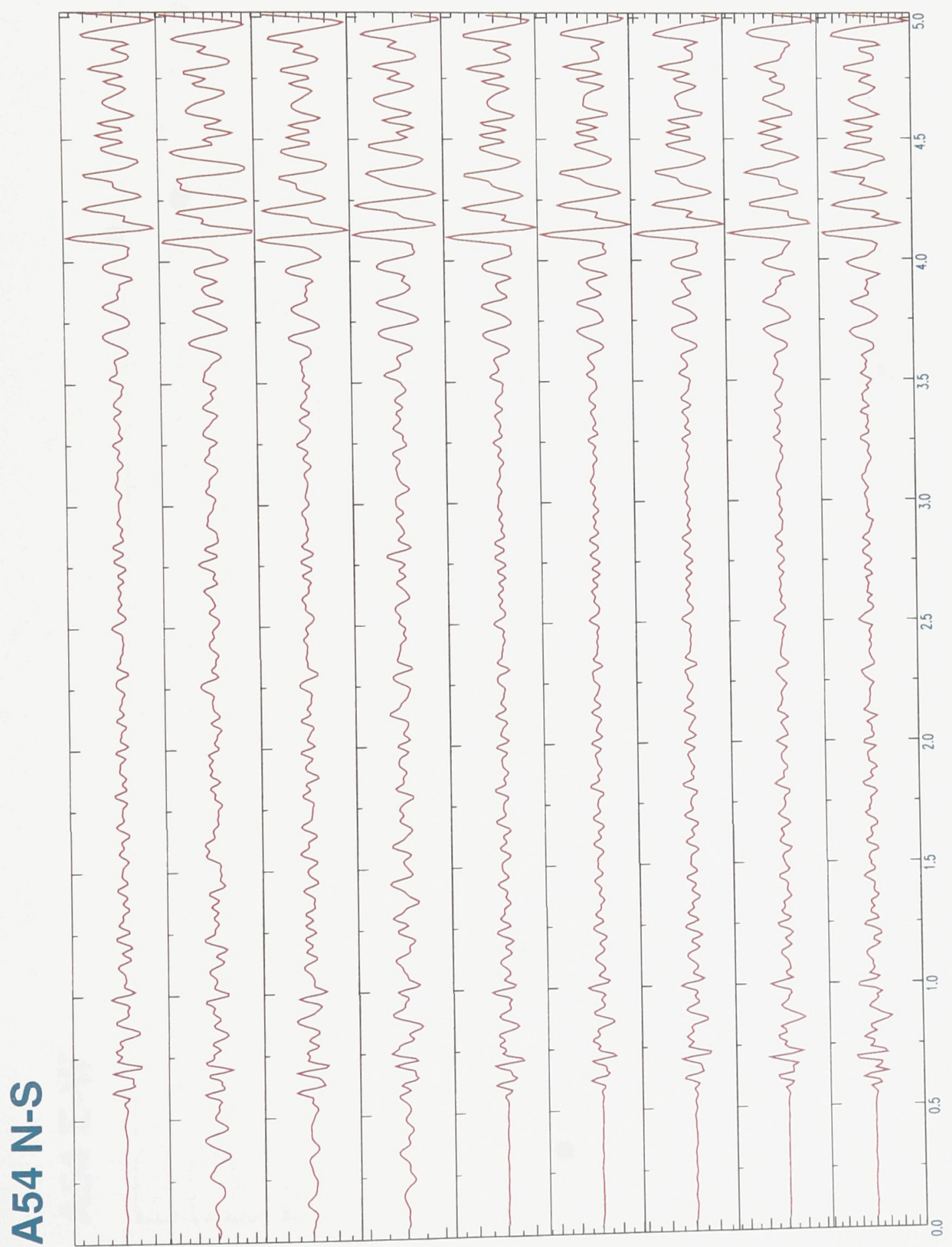


\%

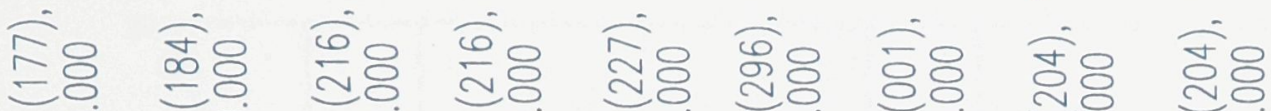

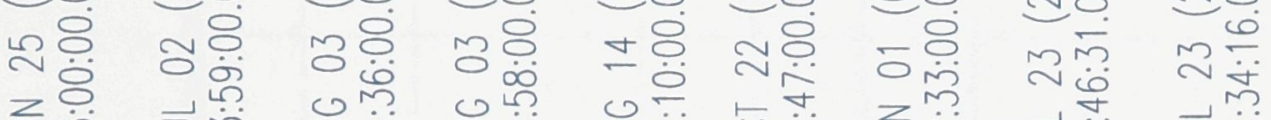

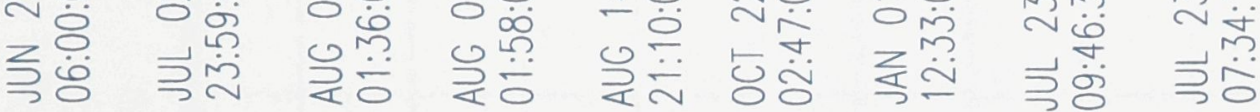

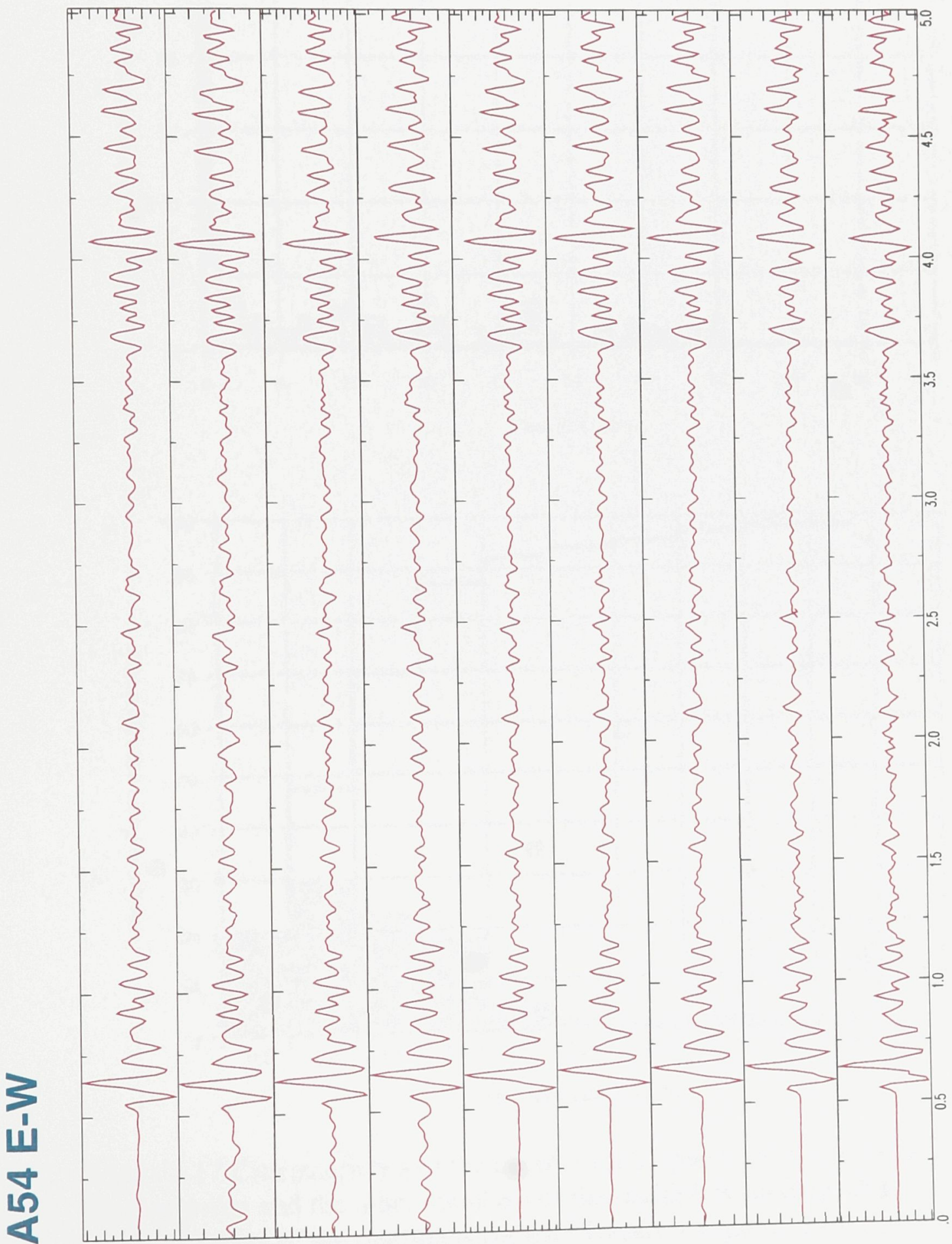



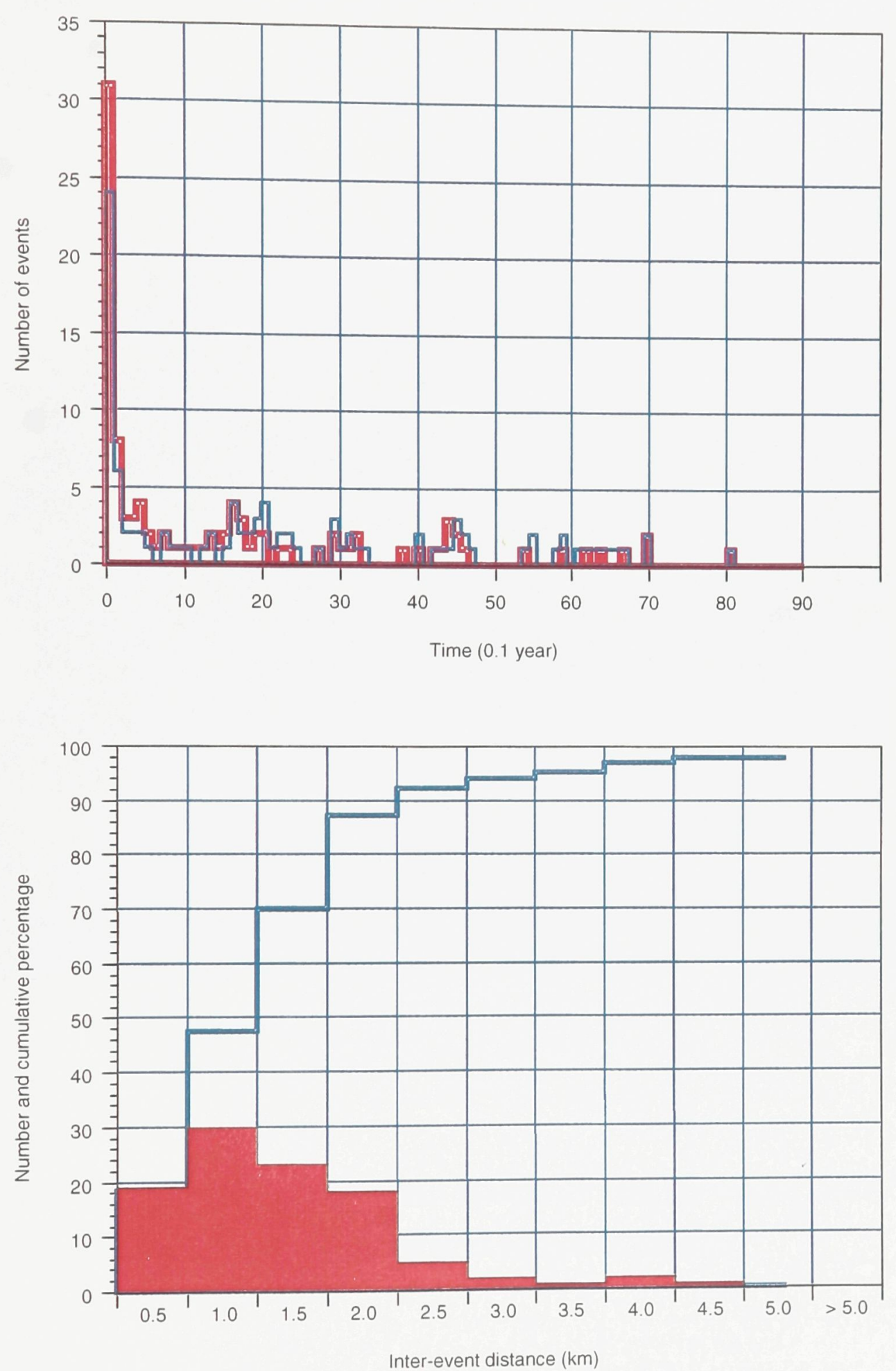

Figure 4.17 Characteristics of the events of multiplets. (A) Time between the first event and the other members of the multiplets (in blue) and between events of the multiplets (in red). Events are grouped in 0.1 year time intervals. (B) Hypocentral distance between the first event and the other members of the multiplet. Events are grouped by $0.5 \mathrm{~km}$ distance, absolute distance in red; cumulative percentage in blue. 


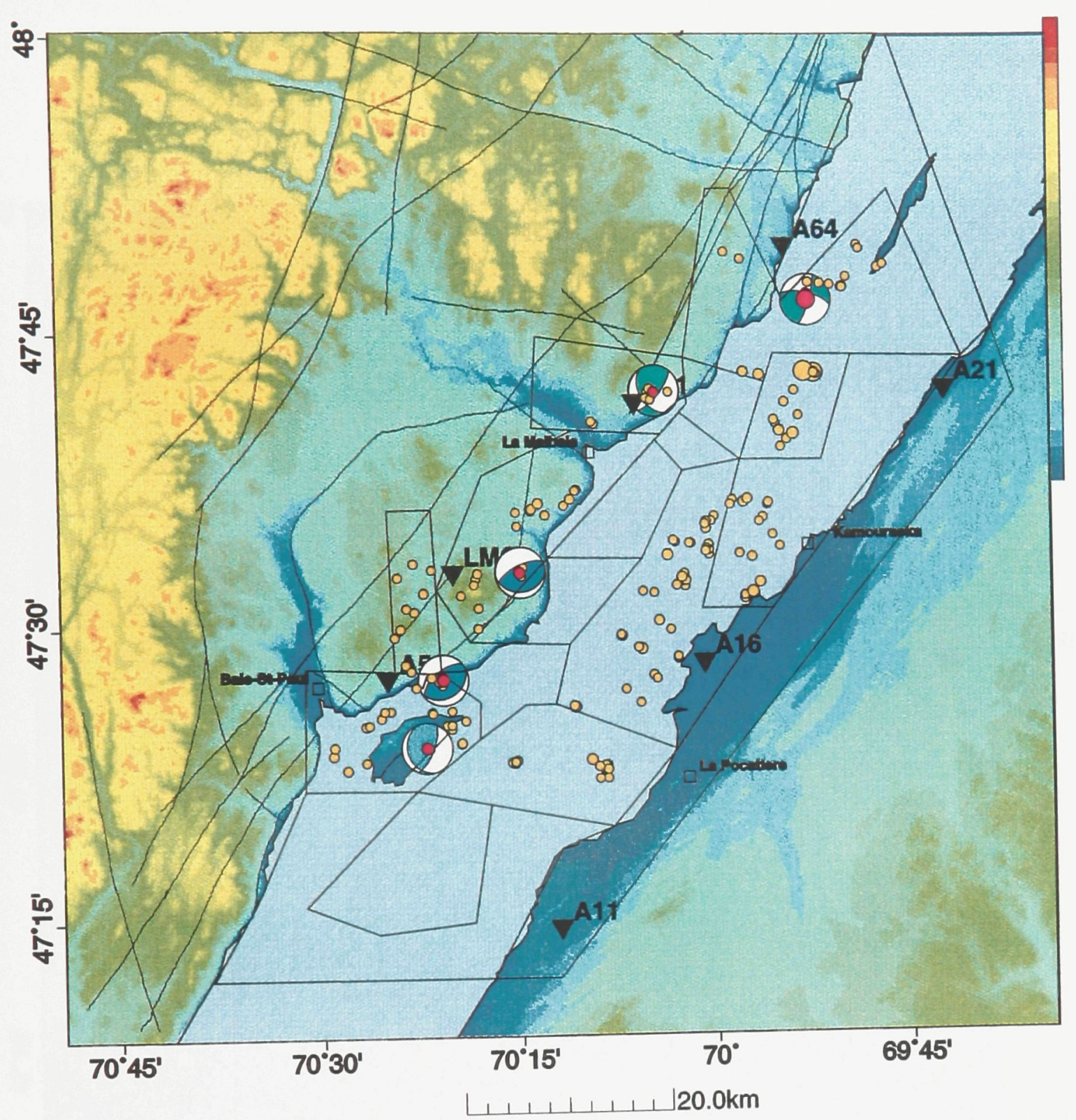

Figure 4.18 CSZ Multiplets of the period November 1988 to August 1997 (yellow); focal mechanism are centered on the event epicentre (red). 
Elevation

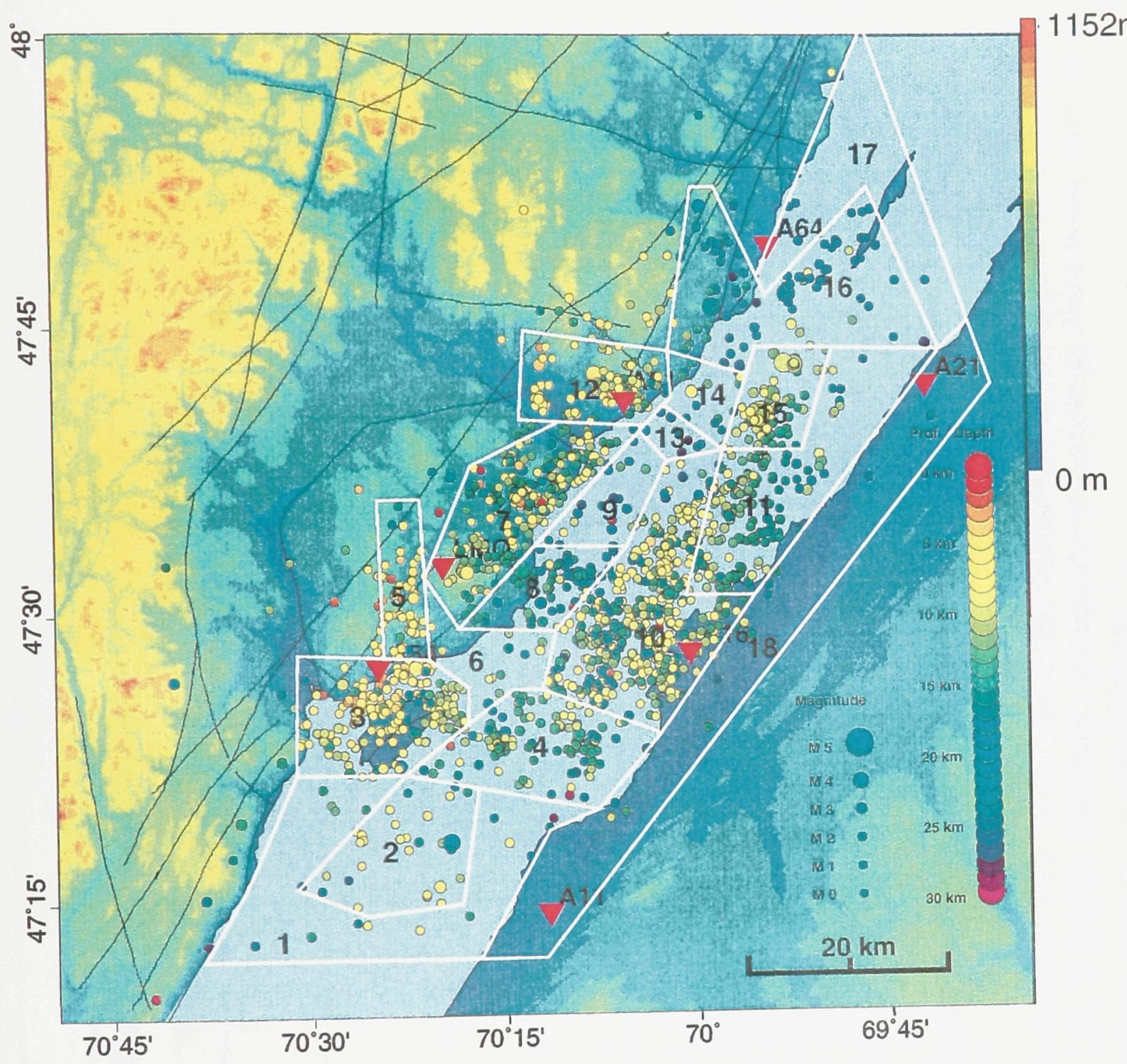

$\begin{array}{llll}\text { 1- UPS } & \text { 6- SGA } & \text { 10- CEN } & \text { 16- DNE } \\ \text { 2- LOU } & \text { 7- IRE } & \text { 11- KAM } & \text { 17- DOW } \\ \text { 3- COU } & \text { 8- OIE } & 12-\text { A61 } & \text { 18- SOS } \\ \text { 4- POC } & \text { 9- CGA } & \text { 13-AIG } & \\ \text { 5- EBO } & \text { 10- CEN } & \text { 14- NGA } & \\ & & 15-\text { MA5 }\end{array}$

Figure 4.19 Earthquake hypocentres and sub-zones. The sub-zone numbers refer to the acronyms listed below. Table 4.7 lists the earthquake statistics of the sub-zones. 


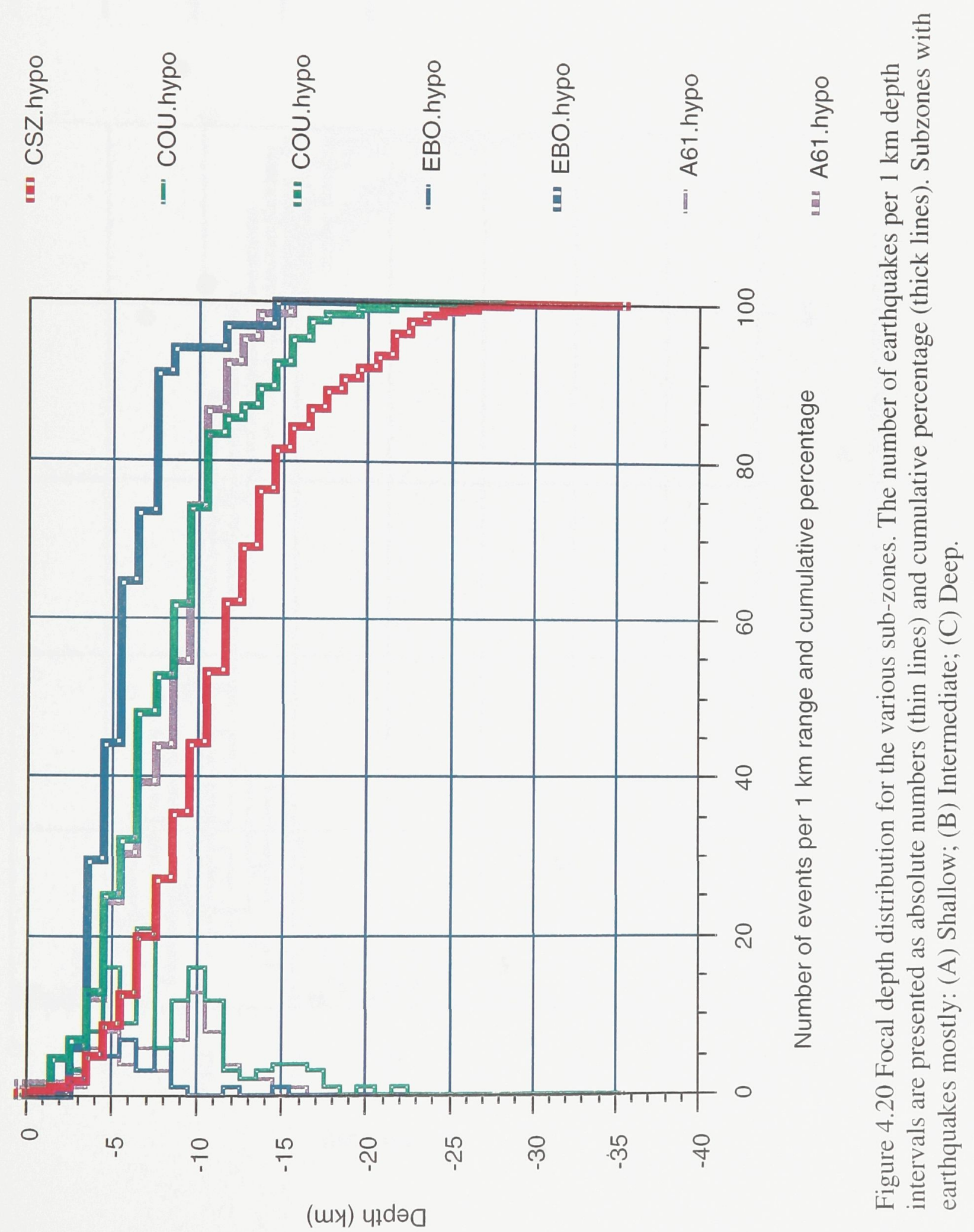




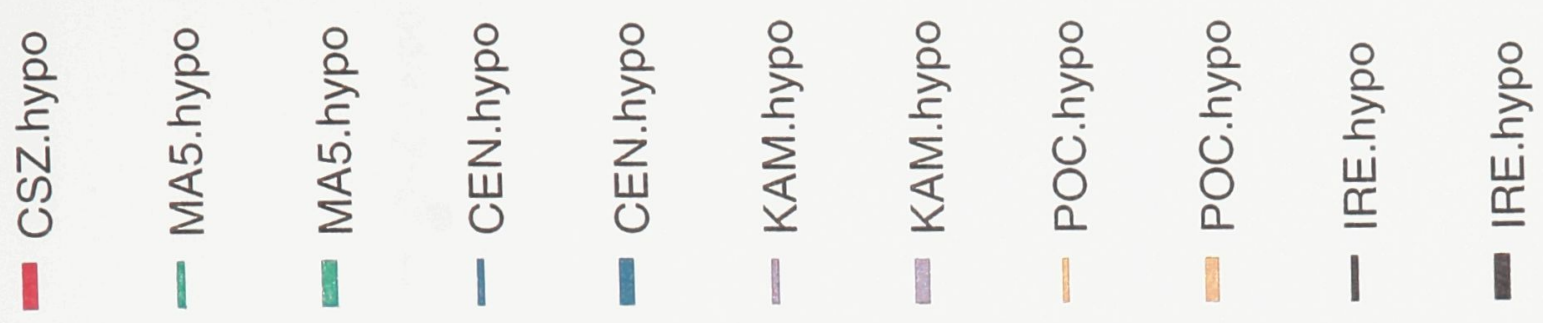

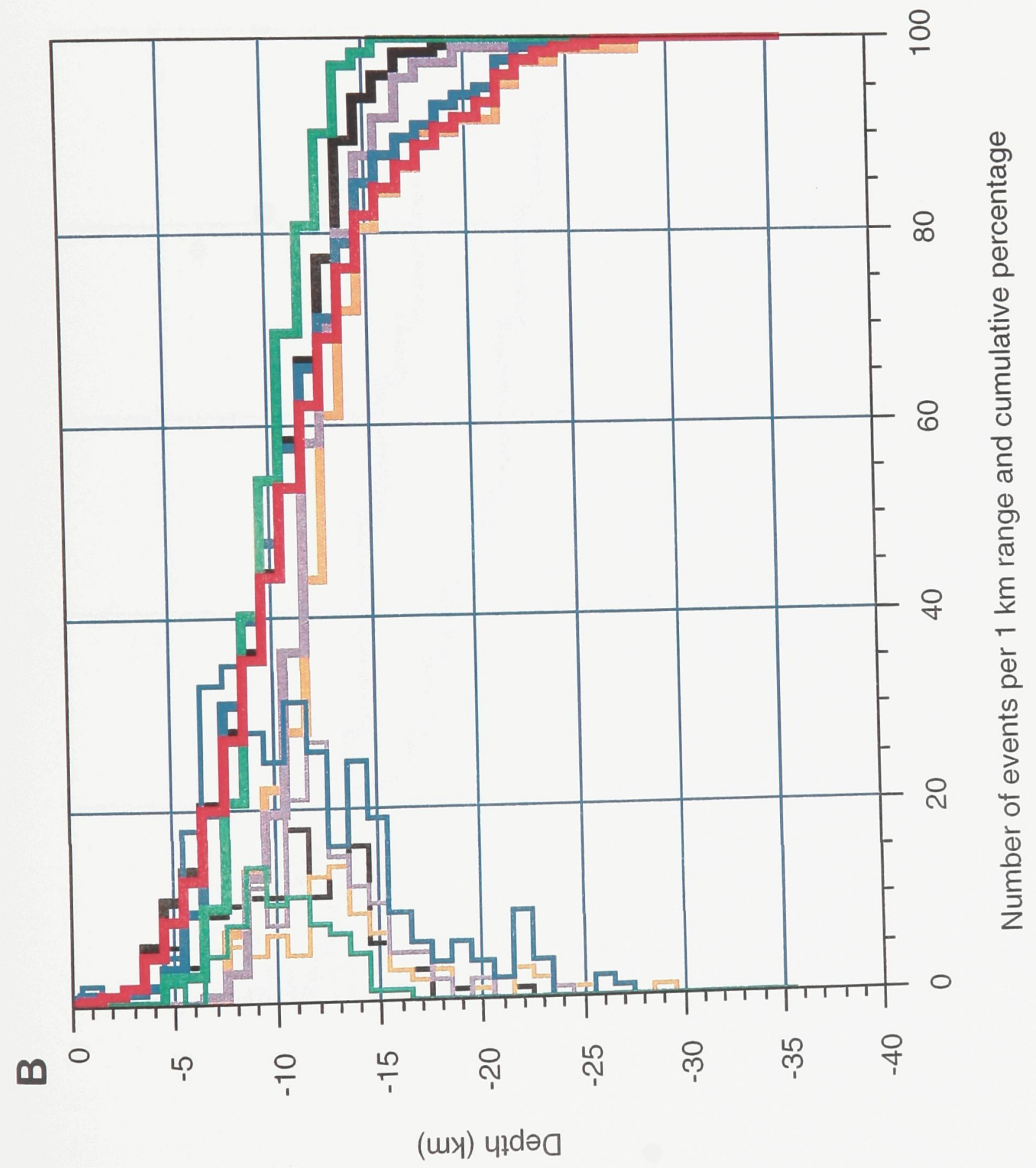



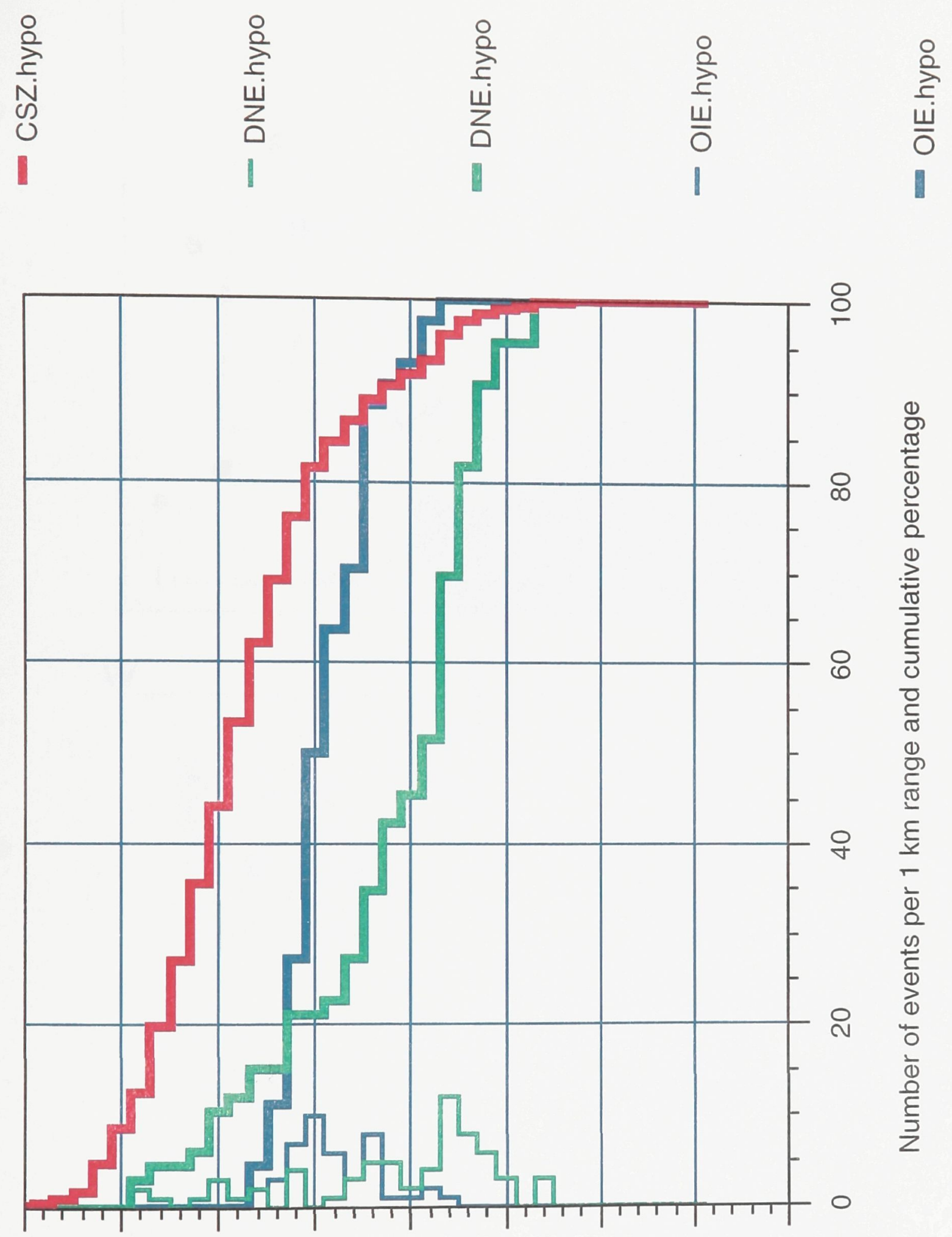
0
0
$10 \frac{0}{1}$
$\frac{1}{1}$ ก
กิ
?
กิ ษ
(uy) 4łdəa 

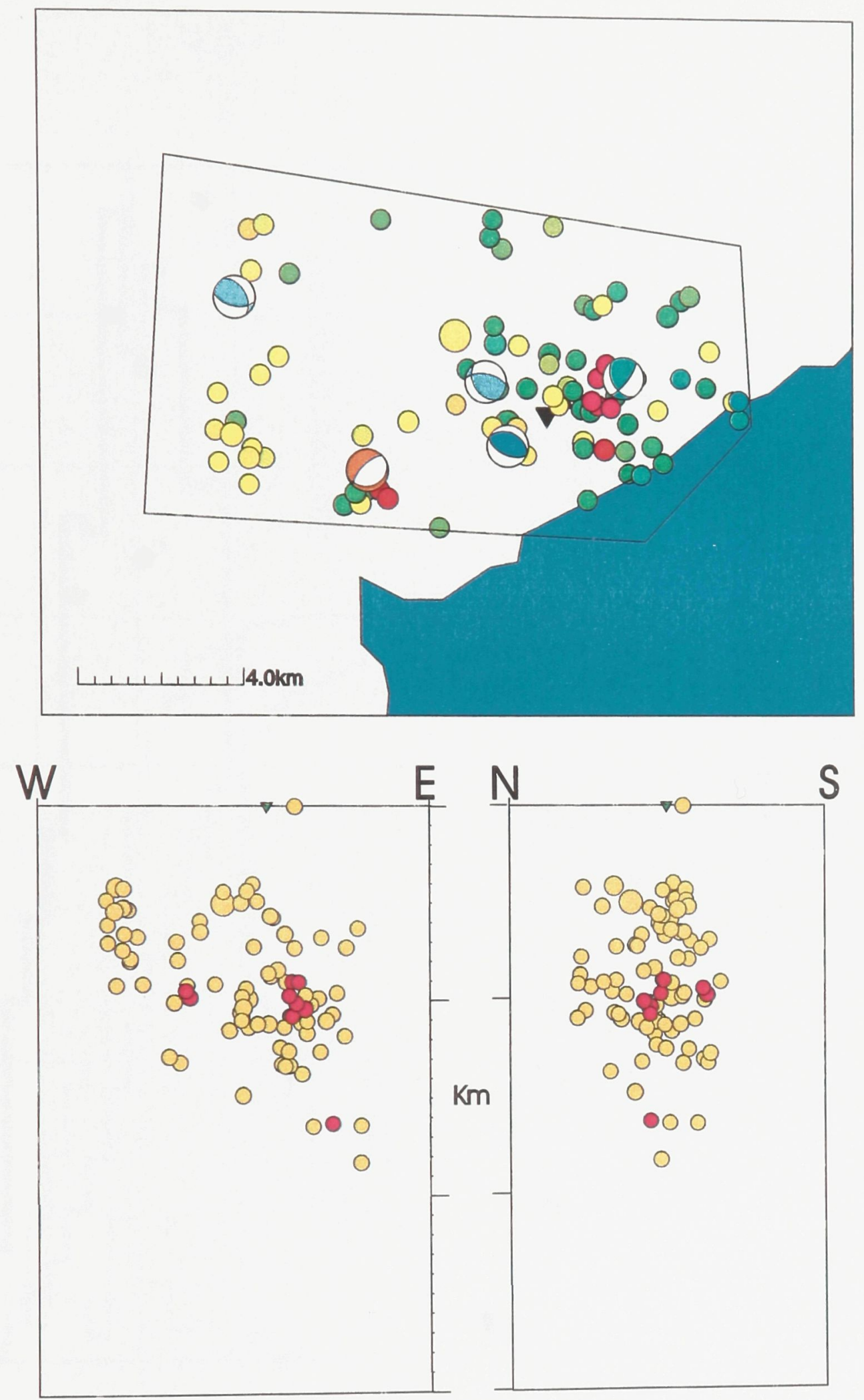

Figure 4.21 Hypocentres of the A61 sub-zone in map view (top), W-E (below left) and N$\mathrm{S}$ (below right) cross-sections. The map view presents focal mechanisms hypocentres with depth colour scheme similar to Figure 4.19. Red dots indicate the positions of events belonging to earthquake multiplets. 


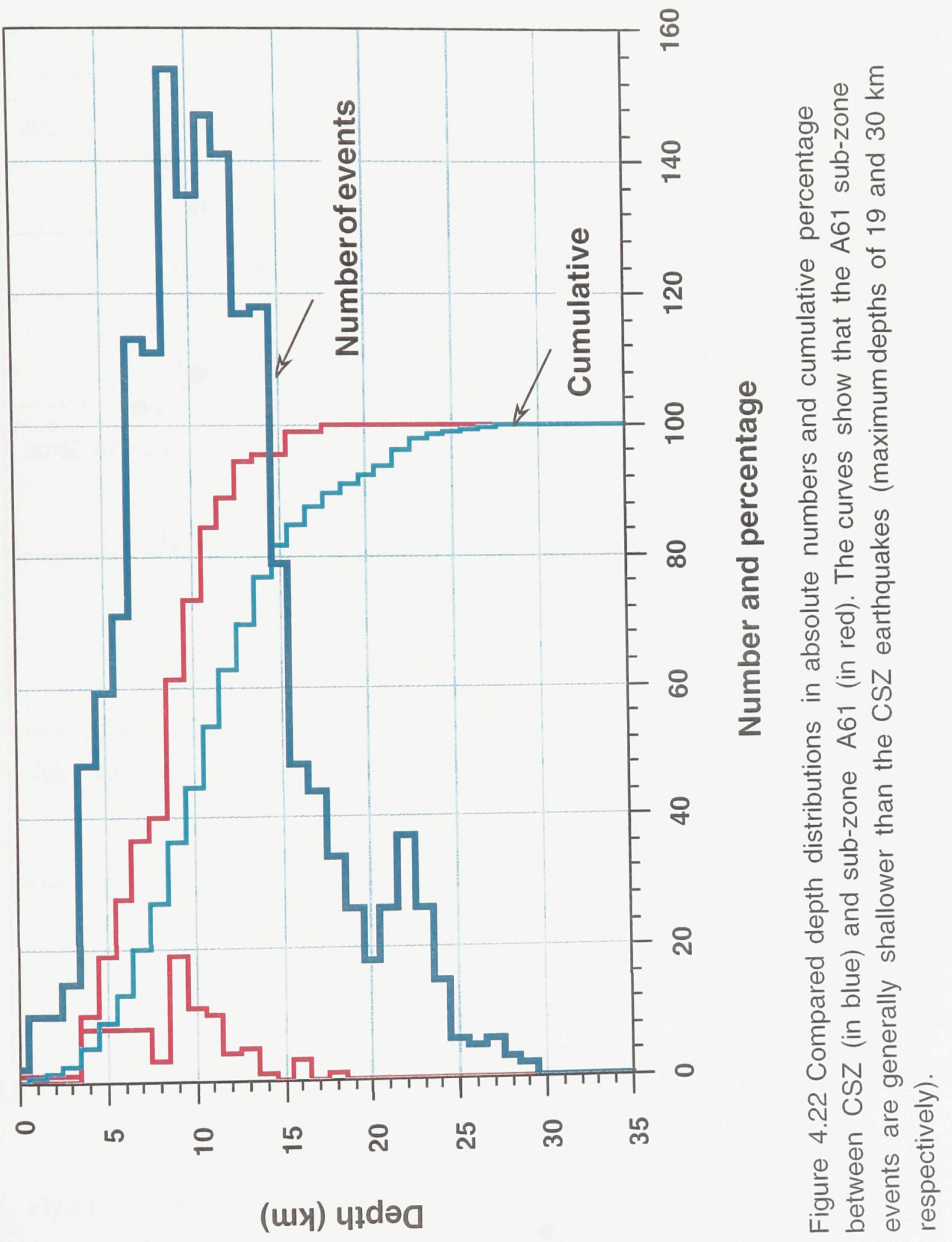




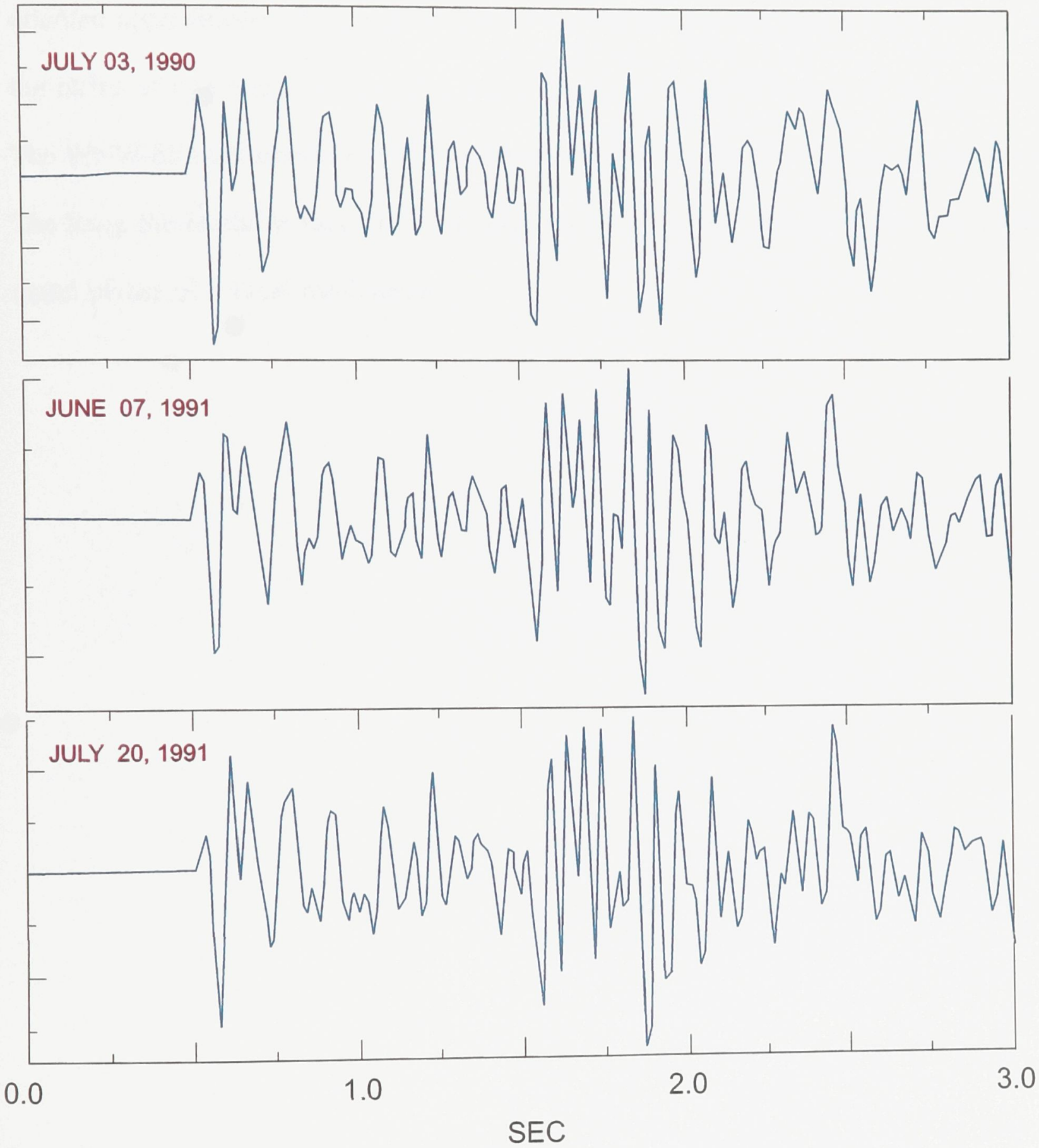

Figure 4.23 Vertical seismic traces of three quarry blasts recorded on station A61 and recognized by their highly similar traces. 
Figure 4.24 Airborne Synthetic Aperture Radar (SAR) image of the A61 Sub-zone (green polygon) with earthquake epicentres of the period 1978-1995 (red dots). Lineaments oriented approximately E-W (shown by the dashed lines to the left) are sub-parallel to the strike of two nodal planes (blue lines) for the two largest events of the sub-zone. The WNW-ESE lineaments and their convergence towards the sub-zone are clearly seen. The Rang Ste-Mathilde fault (Rondot, 1979) is shown and is sub-parallel to one of the nodal planes of a focal mechanism. 


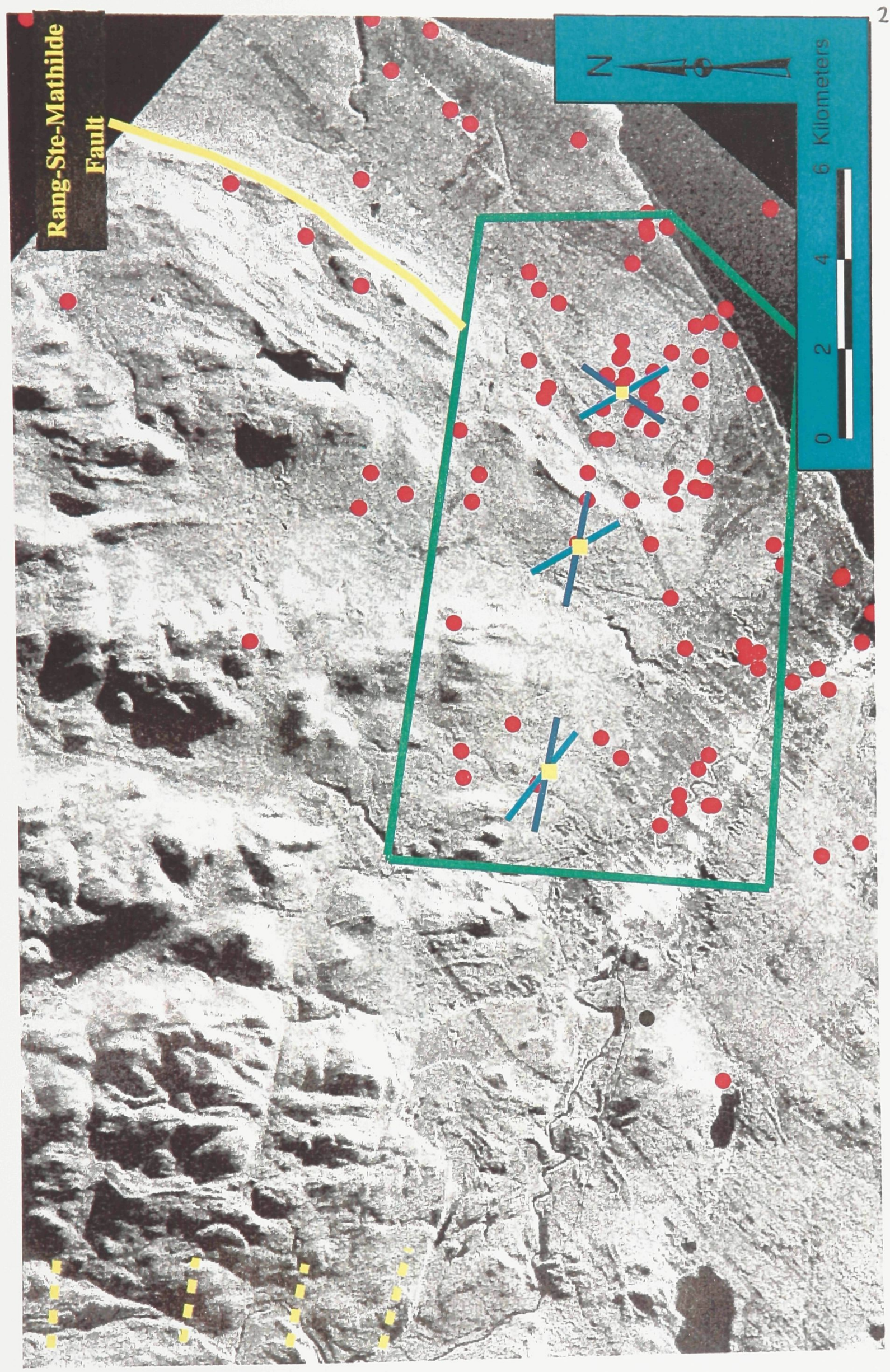




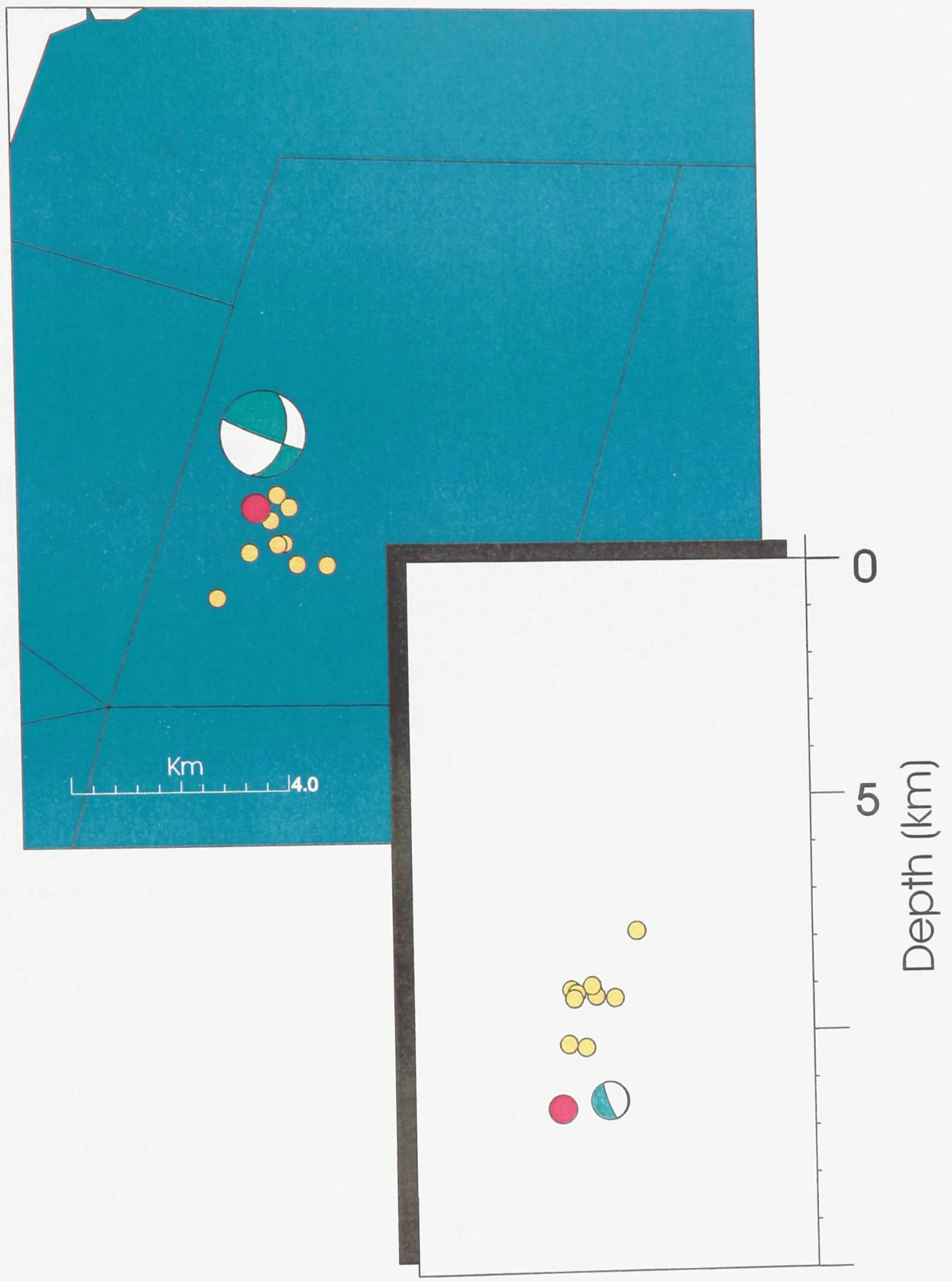

Figure 4.25 The 19971028 aftershock sequence. Map view (above): epicentres of the 19971028 event (red dot), of its aftershocks and focal mechanism of the main shock. (Below): Cross-section perpendicular to one of the nodal planes that shows the shallower locations of the aftershocks. 

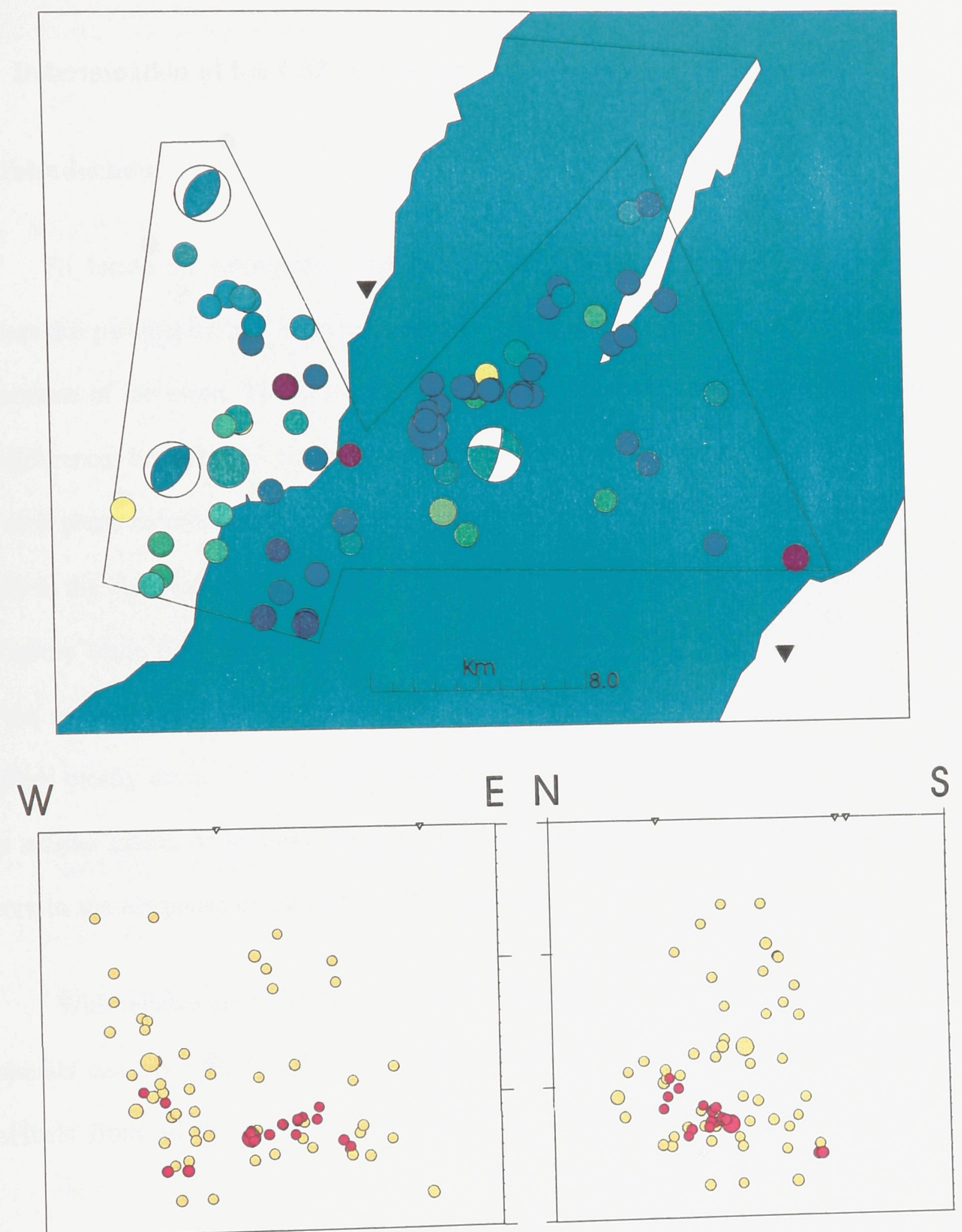

Figure 4.26 Hypocentres of the DNE sub-zone. (Above) Epicentral map of the DNE subzone with focal mechanisms. (Below left) West-East cross-section; (Below right) NorthSouth cross-section. Earthquake multiplets are shown in red on the cross-sections. 


\section{Chapter 5}

\section{Determination of the CSZ velocity structure from local earthquake data}

\subsection{Introduction}

To locate an earthquake, one has to determine the optimum values of four earthquake parameters: the latitude, longitude, depth of the hypocentre, and the time of occurrence of the event. The best estimates of these parameters are those that minimize the differences between the observed and the calculated arrival times (i.e., the residuals) for each phase recorded at seismograph stations (Kissling, 1988). Residuals exist due to errors in the observed and the calculated (theoretical) arrival times. For the observed data, the errors come from the inaccuracy of the picked arrival times and of the time control of the recording system. The accuracy of calculated arrival times, on the other hand, depends mostly on how closely the velocity model resembles that of the real Earth, and to a smaller extent, on location errors of recorders, near-surface velocity perturbations and errors in the estimates of the hypocentral parameters.

With reliable observed data and good control on the sources of uncertainties, the residuals can be used to infer the velocity structure of the Earth. For an event, the residuals from all stations can be expressed in a RMS (Root Mean Square) sense as

$$
R M S=\left(\frac{\left(\sum_{I}(\text { residua })^{2} X(\text { weight })^{2}\right)}{N P}\right)^{\frac{1}{2}}
$$

$$
\text { for } \mathrm{I}=1, \mathrm{NS}
$$


where the residual is the difference between the observed and the calculated arrival times, the weight is a quality factor assigned to a picked arrival time, NS is the number of stations, and NP is the number of phases used in the solution. The optimum velocity model minimizes the RMS of a series of events.

Extracting velocity information from microearthquakes is called simultaneous inversion of local earthquakes or local earthquake tomography (Thurber, 1993). In contrast with the tomographic inversion of controlled sources and teleseisms, the simultaneous inversion of local earthquakes determines the location and origin time of events, along with the velocity of the material between the source and the recording stations. With sufficient data, the inversion can define a local or a regional velocity model, either one-dimensional (1-D; homogeneous or layered) or three-dimensional (3-D; Kissling, 1988; Kissling et al., 1994).

In order to clarify seismotectonic properties, the main objective of this chapter is to infer the optimum CSZ velocity model contained in the local earthquake data of the period 1977-1997. The chapter is divided into ten sections. In Section 5.2, the previous studies of CSZ velocities are presented, along with the routine procedure for locating earthquakes. Section 5.3 discusses two possible sources of errors of the observed phase data, namely the time control of the seismograph network and the picking precision of Charlevoix phase data. The selected data used in the inversion are presented in Section 5.4. With this data set, optimum velocity models of the CSZ are presented: the average $\mathrm{Vp} /$ Vs ratio (Section 5.5); the homogeneous velocity model (Section 5.6); and two layered models (one for the north shore and one for lower velocity Appalachian sediments of the 
south shore; Section 5.7). The impact of the velocity models on the earthquake locations is discussed in Section 5.8. An inversion of the Laurentides Park velocity model is presented in Section 5.9. Finally, the velocity information is discussed in Section 5.10.

\subsection{Previous studies of the regional velocity structure and routine analysis of the} CSZ data

Crustal velocity models of the Charlevoix-Saguenay area are shown in Figure 5.1. To the west of the CSZ, across the Grenville Front, P-wave upper crustal velocities in the $6.3-6.5 \mathrm{~km} / \mathrm{s}$ range were determined, with mid to lower crustal values of about $6.55 \mathrm{~km} / \mathrm{s}$ (Mereu and Jobidon, 1971; Berry and Fuchs, 1973). Later, these velocities were used to model the strong motion records of the $1988 \mathrm{~m}_{\mathrm{bLg}} 6.5$ Saguenay earthquake (Somerville et al., 1990). In the CSZ itself, a seismic refraction-reflection survey showed that the velocity structure differed between the two shores of the St. Lawrence River (Lyons et al., 1980). Logan's Line was modeled as a $20^{\circ} \mathrm{SE}$ dipping interface separating the Appalachian nappes and the Grenvillian rocks with respective P-velocities of 5.5 and 6.1 $\mathrm{km} / \mathrm{s}$. Under the north shore, velocities increase linearly from the surface to $18 \mathrm{~km}$ depth, where they jump from 6.6 to $6.8 \mathrm{~km} / \mathrm{s}$. Near surface velocities are lower inside the Charlevoix impact crater $(6.08 \pm 0.04 \mathrm{~km} / \mathrm{s})$ than in the north shore $(6.27 \pm 0.11 \mathrm{~km} / \mathrm{s})$, a fact possibly related to the intense fracturing. To the northeast of the crater, velocities progressively move towards the average value of $6.2 \mathrm{~km} / \mathrm{s}$. To the west of the crater, in the Laurentians, a higher apparent velocity of $6.48 \mathrm{~km} / \mathrm{s}$ was found for one station.

The 35 microearthquakes recorded during the 1974 Charlevoix experiment were 
inverted to obtain a crustal velocity model (Leblanc and Buchbinder, 1977). Within the P-velocity range of 5.6 to $6.6 \mathrm{~km} / \mathrm{s}$, the $6.2 \mathrm{~km} / \mathrm{s}$ Pg gave the smallest RMS (with a 3.57 $\mathrm{km} / \mathrm{s} \mathrm{Sg}$ velocity). These velocities were later adopted for Charlevoix routine locations. During the same field survey, surface blasts of the north shore were best located with near surface P-velocities of $6.0 \mathrm{~km} / \mathrm{s}$.

In addition to the work of Lyons et al. (1980), the strong velocity contrast between the Grenville rocks and the overlying Appalachian sequence was also modelled with other data sets. Using locally recorded teleseisms, Hearty et al. (1977) modelled the interface as a $19^{\circ} \mathrm{SE}$ dipping plane separating the $6.1 \mathrm{~km} / \mathrm{s}$ Grenville from the $5.4 \mathrm{~km} / \mathrm{s}$ Appalachians. Using some local CSZ earthquakes, Lamontagne (1985) found that a $15^{\circ}$ SE dipping boundary between the $6.2 \mathrm{~km} / \mathrm{s}$ Grenville and the $5.5 \mathrm{~km} / \mathrm{s}$ Appalachian rocks minimized the RMS. Although these experiments showed that this strong velocity contrast should be considered in CSZ locations, the homogeneous "standard" velocity model continued to be used for routine locations. It was assumed that the shift due to the Appalachian rocks would be approximately the same for all CSZ events, i.e., a few kilometres to the SE (Anglin and Buchbinder, 1980; Lamontagne, 1985).

Over the years, the Geological Survey of Canada (GSC) has used two programs to locate CSZ earthquakes. Between 1978 and 1993, the location program "LOC" (also named "CANCESS") was used. "LOC" uses a nonlinear regression technique, similar to the HYPO-series of programs (Drysdale et al., 1990). Since 1993, Charlevoix earthquakes are routinely located with the GSC program "GRL" which uses a grid search algorithm. The program calculates the RMS for a series of equally-spaced grid points in the origin 
time, latitude, longitude and depth space. The grid is re-centred on the parameters with the minimum RMS, and the RMS are recomputed using a finer mesh. The grid search stops when the mesh is smaller than a predetermined precision for the origin time, latitude, longitude and depth. The program "GRL" currently accepts a homogeneous or a layered velocity model, with direct or refracted phases. In this thesis, the adopted approach combines the respective advantages of the two location programs. The program "GRL" is less susceptible to local minima due to its grid search approach. "LOC", on the other hand, converges faster to the hypocentre than "GRL" (with a layered velocity model, it could be as much as 30 times faster). Although both "GRL" and "LOC" use layered velocity models, "LOC" can accept two layered velocity models to compute hypocentres. Thus, with "LOC", a velocity structure can be associated with a group of stations. As described in Section 5.7, this property is central to the calculation of the north shore-south shore velocity contrast.

\subsection{Sources of uncertainties in the observations}

The timing accuracy of the Charlevoix Local Telemetered Network (CLTN) was briefly discussed in Section 1.4. For the period October 1977 to August 1994, time series data for all CLTN stations were time tagged at the concentrator site, providing uniform time across the network. During the period October 1977 to November 1988, two analogue (LMQ and POC) and one digital (LPQ) vertical sensors were in operation at various periods (Figure 1.7). As these stations were vertical component only, their lower precision data were not used to invert the velocity model. 
For the post-August 1994 period, Global Positioning System (GPS) timing has been tagged along with the data at each site. This scheme ensures accurate timing at each site, completely independent of the transmission time to the central site. The only possible source of error is the drift of the internal clock that occurs when the signal from a GPS satellite is lost. This, fortunately, rarely occurs and is generally of very short duration (K. Beverly, GSC, pers. comm.). In January 1994, the station LMQ became a digital threecomponent broadband station, part of the Canadian National Seismograph Network. Accurate timing was provided by a GPS clock, which makes data from this station compatible with the CSZ local network. For station LMQ, however, the $40 \mathrm{~Hz}$ sampling rate $(0.025 \mathrm{~s} / \mathrm{sample})$ makes the phase readings less precise than the $100 \mathrm{~Hz}(0.01$ s/sample) for the local CSZ network.

In terms of station location accuracy, all CSZ stations, including those of the 1996 summer experiment, were located with GPS, accurate to within $25 \mathrm{~m}$ for latitude and longitude (G. Girouard, GSC, pers. comm.; Lamontagne et al., 1997). To be consistent with other locations of the network, elevations were scaled on 1/50,000 topographic maps.

In a simultaneous inversion study, the precision of the observed data also depends on the picking of the $\mathrm{P}$ and $\mathrm{S}$ phases. The picking precision can be evaluated by comparing the picks made by two analysts. To evaluate this precision, phase data from 21 events of the period 1988-1994, originally read by F. Anglin of the GSC, were compared with picks made by the author. The original data were read with the GSC analysis package "SAM" which offers a rotated trace option to ease Sg picking (F. Anglin, pers. comm.). The package "DAN" (Nanometrics Inc) was used for the re-reading. 
This package is better at enlarging portions of a given trace. The two packages round off the time picks to the nearest hundred of second, implying that the measured time differences between the two picks are given in hundreds of seconds and not in number of samples (0.0125 s/sample for the 1988-1994 CLTN). In general, most phases are impulsive in nature, especially for sites at short epicentral distance or located on the north shore. There were, however, instances where background noise hampered precise phase picking.

The absolute values of the time differences are shown in Figure 5.2. In general, the two sets of P arrivals are more consistent than S arrivals; approximately $80 \%$ of phase readings for $\mathrm{Pg}$ are within 0.02 seconds whereas about $80 \%$ are within $0.05 \mathrm{~s}$ for $\mathrm{Sg}$. The larger scatter of Sg picks may be partly due to shear wave splitting which creates smaller amplitude signals prior to the real S arrival (Buchbinder, 1985). Furthermore, the S phase can be emergent rather than impulsive, especially for smaller magnitude events, for larger epicentral distance, and for stations on the south shore which have a higher background noise. In addition, the $\mathrm{S}$ onset can be picked as a sharp increase in amplitude or as a weak emergence a few samples before. Compared with three component data, vertical traces do not allow the same precision level, especially for $\mathrm{Sg}$ arrivals at larger epicentral distances.

For the post-August 1994 period, the raw data were filtered with a Finite Impulse Response ("FIR") filter which gives rise to unwanted precursory effects prior to the $\mathrm{P}$ and $S$ arrivals. In order to eliminate these artifacts, the time series data are routinely band-pass filtered (5-15 $\mathrm{Hz}$ pass band) at the analysis stage. This filtering removes the unwanted 
ringing, while preserving the micro-earthquake signal. With this band-pass filter, the CLTN picks are within $0.01 \mathrm{~s}$ of those obtained with the "un-FIR filter" (M. Andrew, GSC, pers. comm.).

\subsection{Selection of the earthquake data}

The most reliable and consistent hypocentral data for the CSZ were recorded after the local network became a three-component array in November 1988. CSZ events with a minimum magnitude of $m_{N} 1.5$ were selected to insure conspicuous $P$ and $S$ arrivals on all CSZ stations. To obtain reliable depth control, selected events had to be located within the CLTN 6-station network, and recorded on at least 6 stations with a minimum of 12 seismic phases (P and S). Finally, only events with focal depth of $6 \mathrm{~km}$ and deeper were selected, to avoid the poorly converging solutions of some shallow events.

For the period November 1988 to December 1997, 171 events met the selection criteria (Figure 5.3A). Their depth distribution is very similar to that of all CSZ events recorded between 1978 and 1993 (Figure 5.3B). In order to account for the lower precision of S phase picks, P phases were weighted 4 (Quality "A" of the GSC scheme) whereas $S$ phases were weighted 1 (Quality "B"). In the few cases where the residuals were higher than $0.4 \mathrm{~s}$, a weight of 0.25 (Quality "C") was assigned to the Sg pick. With this weighting scheme, the average RMS is $0.084 \mathrm{~s}$, with $90 \%$ of RMS less than $0.12 \mathrm{~s}$ (Figure 5.3C). 


\subsection{Vp/Vs Ratio for the CSZ}

The traditional method of computing the ratio of $\mathrm{P}$ to $\mathrm{S}$ wave velocities (Vp/Vs ratio) is the so-called Wadati plot (Wadati, 1933). On this type of graph, where the Sg-Pg travel time is plotted against the $\mathrm{Pg}$ travel time, the $\mathrm{Vp} / \mathrm{Vs}$ ratio is simply equal to the slope of the best fitting line plus one. In the CSZ case, for given hypocentre and station, the Pg travel time is obtained by subtracting the origin time calculated with the "standard" GSC velocity model from the Pg arrival time. The S-P time is computed for each station by subtracting the Pg time from the Sg time. The best fitting line is obtained with a "robust" linear regression method (Huber, 1981). Based on some $1267 \mathrm{P}$ and S phase picks from the data set discussed in Section 5.4, a Vp/Vs ratio of 1.74 is found (Figure 5.4), very close to the assumed value of the GSC "standard" velocity model (1.73, assuming a Poisson's ratio of 0.25 ). Since the Pg travel time depends on the origin time computed using $\mathrm{P}$ and $\mathrm{S}$ phases, Wadati plots have some dependence on the $\mathrm{S}$ velocity used to derive the hypocentres. In the CSZ, this dependence is small, however, mainly due to the smaller weight assigned to $S$ phases.

\subsection{Homogeneous velocity model}

The current "standard" homogeneous velocity model was established by Leblanc and Buchbinder (1977) using 35 micro-earthquakes. To test this model with a more complete data set, RMS values were computed for a series of Pg and Sg velocities. Vp was varied between 5.80 and 6.60 by $0.05 \mathrm{~km} / \mathrm{s}$ increments, while $S g$ was computed from Vp using a Vp/Vs ratio of between 1.65 and 1.80 by $0.03 \mathrm{~km} / \mathrm{s}$ increments. Velocities of 
$6.20 \pm 0.10 \mathrm{~km} / \mathrm{s}$ for $\mathrm{Pg}$ and $3.58 \pm 0.06 \mathrm{~km} / \mathrm{s}$ for $\mathrm{Sg}$ velocities gave the minimum RMS (Figure 5.5). These velocities correspond to the "standard" GSC velocity model, determined by Leblanc and Buchbinder (1977). The Vp/Vs ratio (1.73) is similar to the one determined with the Wadati plot of the previous section.

Although the homogenous velocity model is an acceptable representation, the $0.08 \mathrm{~s}$ RMS is still higher that the picking precision of $\mathrm{P}$ and $\mathrm{S}$ phases. For the permanent stations, the Pg residuals, obtained with the "standard" velocity model, show a systematic bias (Figure 5.6). Whereas LMQ, A16 and A11 are more or less centred on $0.00 \mathrm{~s}$, a bias can be observed for the stations A64 ( $\sim-0.10 \mathrm{~s}), \mathrm{A} 61(\approx+0.05 \mathrm{~s}), \mathrm{A} 54(\approx+0.05 \mathrm{~s})$ and A21 ( $\approx+0.21$ s). Thus, the average velocity to station A64 should be higher than the "standard" velocity model, whereas it should be lower for the three other stations. These results are in line with the seismic refraction results of Lyons et al. (1978), which showed a lower velocity for the south shore (A11 and A21) and for the crater (A54), and higher velocities for the NE portion of the CSZ, outside the crater (A64). To test these regional variations, the data set was subdivided into two groups: one for the southwesternmost stations (the "crater": A11-A16-A61-A54) and one for the northeasternmost stations ("outside the crater": A16-A21-A64-A61). Earthquakes in these two groups were relocated using only the phases from the four stations that defined the polygon, while only the residuals were computed for the two other stations. With this smaller number of stations, the RMS for the two groups were smaller for the "standard" model: $0.046 \mathrm{~s}$ for both groups (Figures 5.7). While the "standard" velocity model appears appropriate inside the crater, outside the crater slightly higher velocities provide the lowest RMS (about 6.3 
$\mathrm{km} / \mathrm{s}$ for $\mathrm{Pg}$ and $3.64 \mathrm{~km} / \mathrm{s}$ for $\mathrm{Sg}$ ). Higher velocities outside the crater were also suggested by Lyons et al. (1980). The Pg residuals for the two groups of stations also reveal a systematic bias: the velocity between the crater events and station A64 should be higher than $6.2 \mathrm{~km} / \mathrm{s}$ (negative residuals), while velocities to stations A21, A11 and A54, should be somewhat lower (positive residuals; Figure 5.8). To consider this bias, station corrections were defined for the Pg and Sg phases (Table 5.1), bringing the RMS from 0.0838 down to $0.0719 \mathrm{~s}$.

\subsection{Calculation of layered velocity models for the north and the south shores}

As the minimum RMS with a homogeneous velocity model remains higher than the reading uncertainties, layered velocity models were tested to further reduce the RMS. Since it is known that the largest velocity perturbations arise from the Appalachian rocks of the south shore, it was decided to use two velocity models for the CSZ, one for the north shore stations and one for the south shore stations. To test the validity of this approach, the velocity models of Lyons et al. (1980) were used as a first approximation to calculate travel times to the north shore and south shores (Figure 5.1; Table 5.2). With these models, the RMS was $0.071 \mathrm{~s}$, similar to the best homogeneous model plus the station corrections. On the basis of these positive results, it was decided to further refine these models with the hypocentral data. 
Table 5.1: Station corrections to be used with the standard velocity model

\begin{tabular}{|c|c|c|}
\hline & Pg & Sg \\
\hline Station & Station Correction & Station Correction \\
& $(\mathrm{s})$ & $(\mathrm{s})$ \\
\hline A11 & 0.00 & -0.15 \\
\hline A16 & 0.00 & 0.05 \\
\hline A21 & -0.10 & -0.15 \\
\hline A54 & -0.05 & 0.00 \\
\hline A61 & -0.05 & 0.00 \\
\hline A64 & 0.10 & 0.10 \\
\hline LMQ & -0.05 & -0.05 \\
\hline
\end{tabular}


Table 5.2 Velocities used to model the north and the south shore (based on Lyons et al., 1980)

\begin{tabular}{|c|c|c|}
\hline $\begin{array}{l}\text { Depth to top } \\
(\mathrm{km})\end{array}$ & $\begin{array}{c}\text { Vp } \\
\text { North Shore }\end{array}$ & $\begin{array}{c}\text { Vp } \\
\text { South Shore }\end{array}$ \\
\hline 0 & \multirow[t]{2}{*}{6.4} & 5.5 \\
\hline 6 & & \multirow[t]{2}{*}{6.5} \\
\hline 8 & \multirow[t]{2}{*}{6.5} & \\
\hline 14 & & \multirow[t]{2}{*}{6.6} \\
\hline 18 & \multirow[t]{2}{*}{6.8} & \\
\hline 22 & & \multirow[t]{2}{*}{7.0} \\
\hline 29 & \multirow[t]{2}{*}{6.9} & \\
\hline 37 & & 7.1 \\
\hline
\end{tabular}

The best layered velocity models were sought by systematically computing the RMS for a suite of layered velocity models for the north and the south shores. A major constraint of the LOC program is the maximum number of layers (9). In order to prioritize the upper crustal velocity structure, the Appalachian sequence was defined as four $2 \mathrm{~km}$ thick layers, while the north shore had only one $8 \mathrm{~km}$ thick layer. The north shore and south shore models are the same below $8 \mathrm{~km}$ depth. Ranges of velocities and increments were defined for the eight layers of both models (Table 5.3), with the aim of defining the minimum RMS between areas of higher RMS. No velocity reversals with depth are allowed by the program LOC. This restriction is reasonable as a velocity increase with 
Table 5.3 Range of $\mathrm{P}$-wave velocities used in the 2-D velocity analysis

\begin{tabular}{|c|c|c|c|c|}
\hline & \multicolumn{2}{|c|}{ North Shore } & \multicolumn{2}{|l|}{ South Shore } \\
\hline Depth to top & Min $\mathrm{Vp}$ & $\operatorname{Max} V p$ & $\operatorname{Min} V p$ & $\operatorname{Max} V p$ \\
\hline$(\mathrm{km})$ & $(\mathrm{km} / \mathrm{s})$ & $(\mathrm{km} / \mathrm{s})$ & $(\mathrm{km} / \mathrm{s})$ & $(\mathrm{km} / \mathrm{s})$ \\
\hline 0 & \multirow[t]{4}{*}{6.1} & \multirow[t]{4}{*}{6.4} & 5.5 & 5.9 \\
\hline 2 & & & 5.6 & 5.9 \\
\hline 4 & & & 5.6 & 6.0 \\
\hline 6 & & & 6.0 & 6.4 \\
\hline 8 & 6.1 & 6.4 & \multirow[t]{4}{*}{ Same as } & \multirow[t]{4}{*}{ North Shore } \\
\hline 10 & 6.2 & 6.7 & & \\
\hline 12 & 6.2 & 6.7 & & \\
\hline 14 & 6.2 & 6.7 & & \\
\hline
\end{tabular}

depth is generally assumed for the crust. For a given layer, the $S$ velocity was computed from the P velocity using a Vp/Vs ratio of 1.74 , as suggested by the Wadati plot (Section 5.5). The RMS calculations were performed on nearly 28000 models which took 18 days to compute on an Axil 320 Sun workstation. Although this systematic search method is more computer intensive than an iterative method that converges to a minimum RMS, it tests all plausible velocity models.

The resulting velocity models for the north and the south shores are presented in Figure 5.9. The figures present the minimum RMS that can be obtained with a velocity 
value at a given depth, providing a view of the velocity resolution. Using Figure 5.9B as an example, at $1 \mathrm{~km}$ depth, the best RMS that can be expected for a $5.9 \mathrm{~km} / \mathrm{s}$ P-velocity is in the range between $0.061 \mathrm{~s}$ and $0.062 \mathrm{~s}$, well above the best RMS value in the $0.059 \mathrm{~s}$ range. Hence, for the 0 to 2 kilometer layer, the 5.5 to $5.8 \mathrm{~km} / \mathrm{s}$ values are more likely. The velocity models that minimize the RMS to $0.0594 \mathrm{~s}$ are given in Table 5.4. With these velocity models, the $\mathrm{P}$ and $\mathrm{S}$ residuals become more tightly clustered at around 0.00 s (Figure 5.10). The P residuals are clustered near $0.00 \mathrm{~s}$, which implies that most of the homogeneous model P-velocity biases (Figure 5.6), are resolved with the layered velocity models. The $S$ residuals are more dispersed, a combined consequence of their lower weight in the solutions, the lower precision of the observed data, and possibly, variations in the $\mathrm{Vp} / \mathrm{Vs}$ ratio.

To a certain extent, the details of the resulting velocity models depend on the assumptions made to derive them. The two most important assumptions are the 0-8 $\mathrm{km}$ homogeneous velocity layer for the north shore, and the 1-D model under $8 \mathrm{~km}$. Independent models for the north and the south shores could possibly define a layered structure for the north shore. Similarly, below $8 \mathrm{~km}$, there could be lateral variations between the north and the south shore. These questions could be answered with future 3D inversion.

Considering the picking precision of the $\mathrm{S}$ data, resolving the $\mathrm{Vp} / \mathrm{Vs}$ ratio for each layer is not feasible. An attempt was made, however, to resolve the $\mathrm{Vp} / \mathrm{Vs}$ ratio for the Appalachian and the Grenvillian sequences taken as two blocks. Using the minimum 
Table 5.4 Velocity model that minimizes the RMS

\begin{tabular}{|c|c|c|}
\hline $\begin{array}{l}\text { Depth to } \\
\text { top (km) }\end{array}$ & $\begin{array}{c}\text { Vp North Shore } \\
(\mathrm{km} / \mathrm{s})\end{array}$ & $\begin{array}{c}\text { Vp South Shore } \\
\qquad(\mathrm{km} / \mathrm{s})\end{array}$ \\
\hline 0 & \multirow[t]{4}{*}{6.1} & 5.5 \\
\hline 2 & & 5.6 \\
\hline 4 & & 5.6 \\
\hline 6 & & 6.1 \\
\hline 8 & \multicolumn{2}{|l|}{6.4} \\
\hline 10 & \multicolumn{2}{|l|}{6.4} \\
\hline 12 & \multicolumn{2}{|l|}{6.6} \\
\hline 14 & \multicolumn{2}{|l|}{6.6} \\
\hline 40 & \multicolumn{2}{|l|}{8.0} \\
\hline
\end{tabular}

RMS model of Table 5.4, Vp/Vs ratios for the two blocks were systematically tested between 1.70 to 1.85 by 0.01 increments; one block for the first four layers ( 0 to $8 \mathrm{~km}$ ) of the south shore and one block for the remaining layers of both shores. The best Vp/Vs ratios were 1.72 for the 0 to $8 \mathrm{~km}$ south shore model, and 1.73 for the north shore model. With these slightly different $\mathrm{Vp} / \mathrm{Vs}$ ratios, the RMS was lowered to $0.05844 \mathrm{~s}$ (from the original $0.05938 \mathrm{~s}$ ). Hence, the average CSZ Vp/Vs ratio is close to the "standard" value of 1.73 . 


\subsection{Impact on CSZ earthquake locations}

Figures 5.11 and 5.12 compare the earthquake locations inferred here with the homogeneous "standard" velocity model. As expected, most earthquakes relocate to the SE due to the lower velocity Appalachian nappes. The average shift is about $1.5 \mathrm{~km}$ along an azimuth of $135^{\circ}$. About two thirds of the events are shallower than the original locations, but the average shift for the whole data set is close to $0 \mathrm{~km}$. The epicentral shifts are relatively small (Figure 5.12). The general pattern of the CSZ earthquakes does not change with the improved velocity model.

\subsection{Velocity model between the CSZ and station DAQ}

One interesting question is how different the CSZ velocity structure is compared with the mostly aseismic Grenville Province. The seismograph station Lac Daran, Québec (DAQ), located some $100 \mathrm{~km}$ west of the CSZ (Figure 1.11), has recorded numerous CSZ events, as small as $m_{\mathrm{N}}$ 1.0. These phase data can be used to infer a 1-D velocity structure between the CSZ and station DAQ (thereafter named the Laurentides Park region). In addition to providing comparisons with the CSZ, the regional crustal velocity model could be used in future studies of the Saguenay earthquake zone.

A total of 96 events with $m_{N} \geq 2.0$ were chosen from the data set used in the CSZ inversion (Figure 5.13A). The hypocentral information (latitude, longitude, depth, origin time) was pegged at the values computed with the CSZ stations and the "standard" homogeneous velocity model. This data set has a RMS of $0.7883 \mathrm{~s}$, due to rather high residuals for $\mathrm{Pg}$ (centred near $-0.7 \mathrm{~s}$ ) and $\mathrm{Sg}$ (centred near $-0.3 \mathrm{~s}$ ), which indicate higher 
velocities than the "standard" velocity model (Figure 5.13B). DAQ phase readings are used to compute the RMS of the events, with a weighting scheme of 4,1 and 0.25 for $\mathrm{P}$, $\mathrm{S}$ and the absolute value of the residuals $\geq 1.0 \mathrm{~s}$ respectively. The Wadati plot indicates a $\mathrm{Vp} / \mathrm{Vs}$ ratio of 1.786 , with some scatter in the phase information (Figure 5.14). The best homogeneous velocity model gives a minimum RMS of 0.439 , with $\mathrm{Pg}$ and $\mathrm{Sg}$ velocities of 6.45 and $3.69 \mathrm{~km} / \mathrm{s}$ respectively (Vp/Vs ratio of 1.75 ; Figure 5.15). The best layered model gives a minimum RMS of $0.430 \mathrm{~s}$, assuming a Vp/Vs ratio of 1.786 (Figure 5.16; Table 5.5). With this velocity model, $\mathrm{Pg}$ and $\mathrm{Sg}$ residuals are closer to $0.0 \mathrm{~s}$, with some remaining events with residuals exceeding $\pm 0.5 \mathrm{~s}$ (Figure 5.17). Some events have anomalous $\mathrm{P}$ and $\mathrm{S}$ residuals, due possibly to differences in timing between the CLTN network (prior to August 1994) and station DAQ of the ECTN network. Two events, recognized as earthquake multiplets, had very different relative arrival times on DAQ. The timing difference between the CLTN and the ECTN cannot be measured directly.

To clarify whether the high $\mathrm{P}$ and $\mathrm{S}$ residuals could be due to timing, the layered velocity model was recomputed with events recorded after November 1995, i.e., after both the CLTN and station DAQ relied on GPS clocks. Events were selected with the same criteria as before, with additional events recorded between January and March 1998. The 44 event data set had a RMS of 0.644 s, with a large scatter of P and S residuals (Figure 5.18). The Wadati plot is less scattered and gives a $\mathrm{Vp} / \mathrm{Vs}$ ratio of 1.89 (Figure 5.19). The homogeneous velocity model minimizes the RMS (0.239) with Pg and Sg velocities of $6.45 \mathrm{~km} / \mathrm{s}$ and $3.57 \mathrm{~km} / \mathrm{s}$ respectively (Vp/Vs ratio of 1.81 ; Figure 5.20 ). The best layered model has P-velocity of $6.0 \mathrm{~km} / \mathrm{s}$ down to $6 \mathrm{~km}$, and $6.6 \mathrm{~km} / \mathrm{s}$ beneath $6 \mathrm{~km}$ (assuming 
Table 5.5 Velocity model for the Laurentides Park region

\begin{tabular}{|c|c|c|c|}
\hline \multirow{2}{*}{$\begin{array}{c}\text { Depth to } \\
\text { top of layer }\end{array}$} & \multicolumn{2}{|l|}{ Range of } & $\begin{array}{c}\text { Optimum } \\
\text { value }\end{array}$ \\
& \multicolumn{2}{|l|}{ Vp values } & \multirow{2}{*}{$(\mathrm{km} / \mathrm{s})$} \\
& \multicolumn{2}{|c|}{$(\mathrm{km} / \mathrm{s})$} & \\
\cline { 2 - 4 } & Minimum & Maximum & \\
\hline 0 & 6.0 & 6.6 & 5.9 \\
\hline 2 & 6.0 & 6.6 & 6.1 \\
\hline 4 & 6.0 & 6.6 & 6.2 \\
\hline 6 & 6.2 & 6.7 & 6.3 \\
\hline 8 & 6.2 & 6.7 & 6.4 \\
\hline 10 & 6.3 & 6.7 & 6.7 \\
\hline 14 & 6.3 & 6.7 & 6.7 \\
\hline 18 & 6.3 & 6.8 & 6.7 \\
\hline 40 & 8 & & \\
\hline
\end{tabular}

$\mathrm{Vp} / \mathrm{Vs}$ of 1.81; Figure 5.21). The RMS is reduced to $0.238 \mathrm{~s}$, slightly less than the homogeneous model. Although most of the $\mathrm{P}$ and $\mathrm{S}$ residuals are recentred near $0.00 \mathrm{~s}$ (Figure 5.22), high anomalous residuals remain, especially for the $\mathrm{S}$ phase. Except for one cluster of five events with high $\mathrm{S}$ residuals, most events with high $\mathrm{P}$ and/or $\mathrm{S}$ residuals are not clustered in one specific part of the CSZ. Since the timing uncertainty is not the source of the problem, variations in the Vp/Vs ratio must exist in the Laurentides Park 
region. The positive $S$ residuals suggest a lower-than-average $S$ velocity, implying a $\mathrm{Vp} / \mathrm{Vs}$ ratio $>1.81$

The anomalous S residuals imply that the misfits of the 1988-1997 data set were not entirely due to bad time control of the ECTN and the CLTN. One reason for these anomalies can be that the geology between the CSZ and station DAQ is not homogeneous, but made up of various lithologies. For a given ray path, $\mathrm{S}$ residuals will vary according to the $\mathrm{Vp} / \mathrm{Vs}$ ratio of the geological unit. Another possibility is that the $\mathrm{P}$ and the $\mathrm{S}$ phases are using different ray paths, possibly not the direct ones, due to the complex geology of the area. This could lead to anomalous $\mathrm{S}$ residuals.

\subsection{Impact of the velocity models on the understanding of the CSZ}

From the local hypocentre data, it has been possible to infer velocity information for the CSZ and the Laurentides Park region and to reduce significantly the RMS of the earthquake solutions. The current CSZ network is sufficient to invert a "pseudo-2-D" Pvelocity model, i.e., two 1-D velocity models, one for the Appalachian sequence under the south shore, and one for the Grenville. For the south shore model, the $6 \mathrm{~km}$ thick Appalachian rocks have P-velocities in the $5.5-5.6 \mathrm{~km} / \mathrm{s}$ range. For the Grenville, transitions in the P-wave velocities occur at 8 and 12 kilometres, with a passage from an average $6.2 \mathrm{~km} / \mathrm{s}$ upper crustal to $>6.5 \mathrm{~km} / \mathrm{s}$ mid-crustal velocities. Interestingly, this velocity transition also corresponds to the peak in the earthquake occurrence distribution, possibly related to a lithological change. In general, the velocity results are similar to those obtained in seismic refraction surveys (Figure 5.23). The layered velocity models 
could be used as the starting model in future 3-D hypocentre-velocity inversion. Appendix 3 discusses how the current CSZ network could be upgraded to allow 3-D velocity determination.

Using the best layered velocity model, earthquake locations shift by an average $1.5 \mathrm{~km}$ to the southeast, with most hypocentral depths remaining within $2 \mathrm{~km}$ of the original positions. Although individual hypocentres may shift with the new velocity model, the hypocentre distribution at a whole may not be very different. The uncertainty in absolute hypocentre positions must be kept in mind while correlating earthquakes with lineaments or structures at depth.

In the Laurentides Park region, the P-velocity structure differs from the CSZ, especially in terms of the $\mathrm{Vp} / \mathrm{Vs}$ ratio (1.81 and 1.73 , respectively). Variations in $\mathrm{Vp} / \mathrm{Vs}$ ratios are related to difference in pore fluid pressure, fabric and composition (Musacchio et al., 1997). High Vp/Vs ratios can correspond to high pore pressure, foliation parallel to the ray path or low quartz content. With high pore-fluid pressure, it is a decrease in $\mathrm{S}$ velocity, rather than an increase in $\mathrm{P}$ velocity, that increases the $\mathrm{Vp} / \mathrm{Vs}$ ratio. Based on the homogeneous model for the Laurentides Park (Figure 5.20) however, we know that $\mathrm{Vp}$ is higher and Vs is similar to the CSZ. The second possible explanation, the parallel foliation, is also unlikely: constant foliation attitude is not realistic over some $100 \mathrm{~km}$ distance in the very geologically complex Laurentides Park region. The probable explanation lies in a difference in the mid crustal lithology. The Laurentides Park contains typical Grenvillian rocks, such as mangerite, charnockite and garnet gneiss. Similar high $\mathrm{Vp} /$ Vs ratios and high $\mathrm{P}$-wave velocities are found in Grenvillian crust further south, in 
the Southern Ontario-Northern New York region (Musacchio et al., 1997). Consequently, the Laurentides Park region appears to be a "standard" Grenvillian crust, with some spatial Vp/Vs variations as suggested by the misfit $\mathrm{S}$ residuals.

The CSZ, on the other hand, appears to differ from the Grenvillian crust found in the Southern Ontario-Northern New York region (average crustal Vp/Vs ratios: 1.73 for the Appalachians; 1.81 for the Grenville; Musacchio et al., 1997). While the CSZ Appalachian ratio is similar (1.72), the CSZ Grenville ratio is much lower than elsewhere (1.73). The reason for the CSZ average $\mathrm{Vp} / \mathrm{Vs}$ ratio is not obvious. High pore fluid pressure can explain fault reactivation (Chapter 2), but its relationship with low Vp/Vs in unclear. High pore fluid pressure can be highly localized along fault zones. The Vp/Vs ratio, on the other hand, results from averaging over a whole region, including some inactive, and possibly dry, blocks. Unless pore fluids are pervasive, their presence may not be revealed by the current data. In some experiments with high pore pressure, the reduced effective pressure brings about an increase in the $\mathrm{Vp} / \mathrm{Vs}$ ratio (increase in Poisson's ratio; Spencer and Nur, 1976). The interrelations between Vp/Vs, lithology, pore geometry and pressure are not sufficiently well understood to be definite (Wenzel and Sandmeier, 1992). Lithologically, an average Vp/Vs ratio corresponds to granite at midcrustal depth (Musacchio et al., 1997). This is incompatible with the outcropping CSZ lithologies (mangerites, charnockites and garnet gneisses) that have $\mathrm{Vp} / \mathrm{Vs}$ ratios in the 1.78 to 1.81 range. The most likely explanation is that, with the CSZ data set, the more felsic upper crust $(\mathrm{Vp} / \mathrm{Vs} \approx 1.73)$ is better sampled than the more basic lower crust. According to Figure 5.9A, velocities in the $6.5-6.6 \mathrm{~km} / \mathrm{s}$ range, generally associated with 
more basic rocks, are found below $12 \mathrm{~km}$ depth. Hence, most of the travel path, on which $\mathrm{Vp} / \mathrm{Vs}$ is based, goes through more felsic rocks. In the Laurentides Park case, on the other hand, the basic rocks are shallower (below $6 \mathrm{~km}$ depth), and most of the travel paths take place within them. In the future, independent calculations of Vp and Vs at depth may validate this interpretation. 

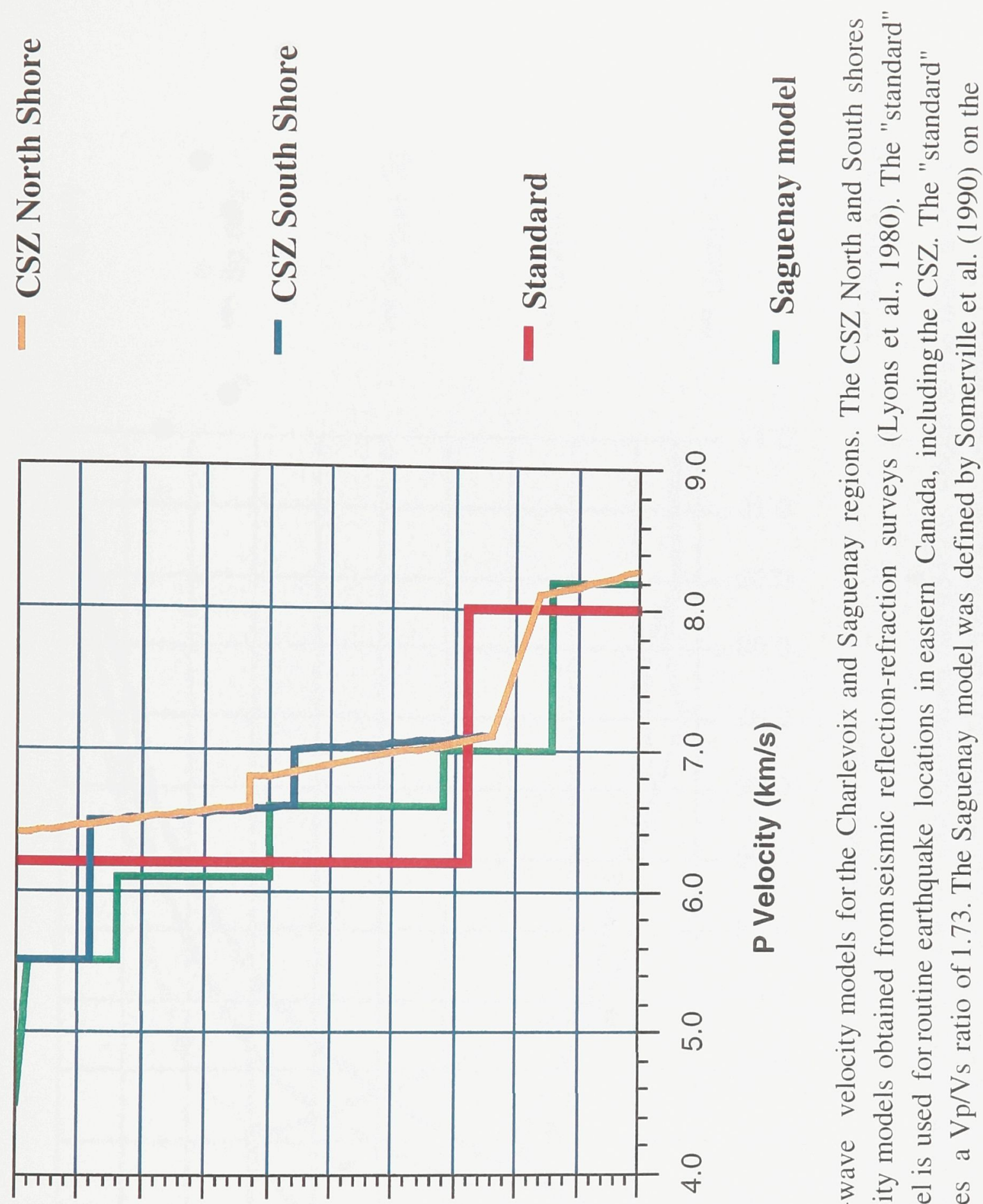

है $\cong$

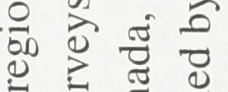

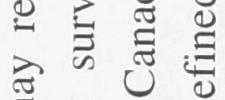

ฮี

荡造

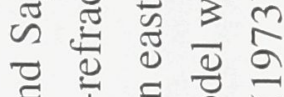

ส

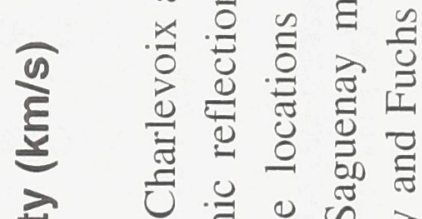

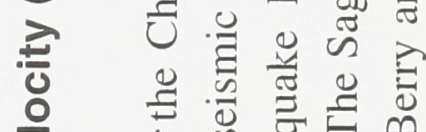

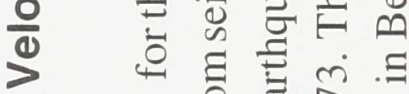

ฉ $)$

ठ

ヨ.

需

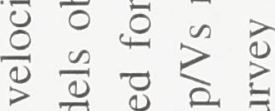

- $\stackrel{\exists}{0}>$ क

ส $\approx$ ๙

उ.

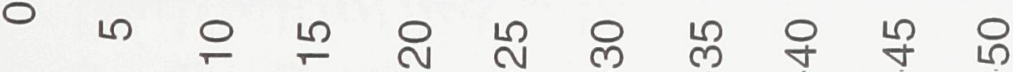

(шя) प1dəa

穴

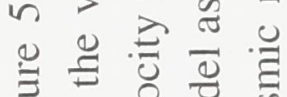

茫 


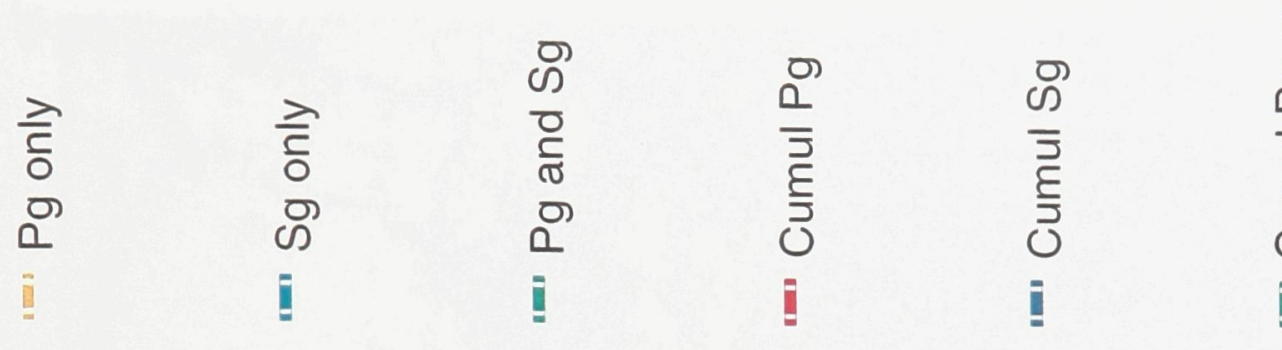

ঠ
ত্

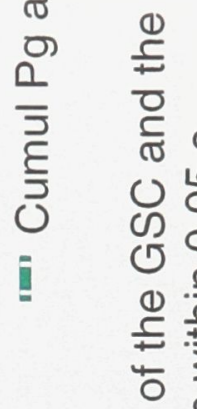

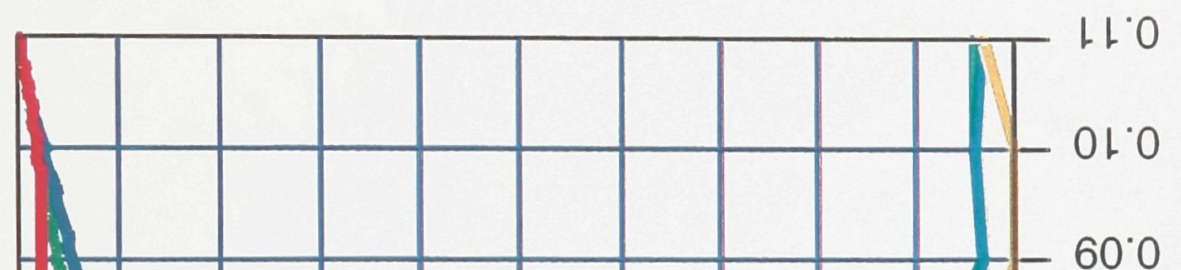

당

ठำ 을

एँ 츠음 ठ 过 $80^{\circ} 0$ $\angle 0^{\circ} 0$

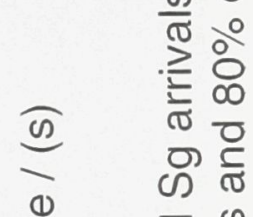
ป ब1 ब

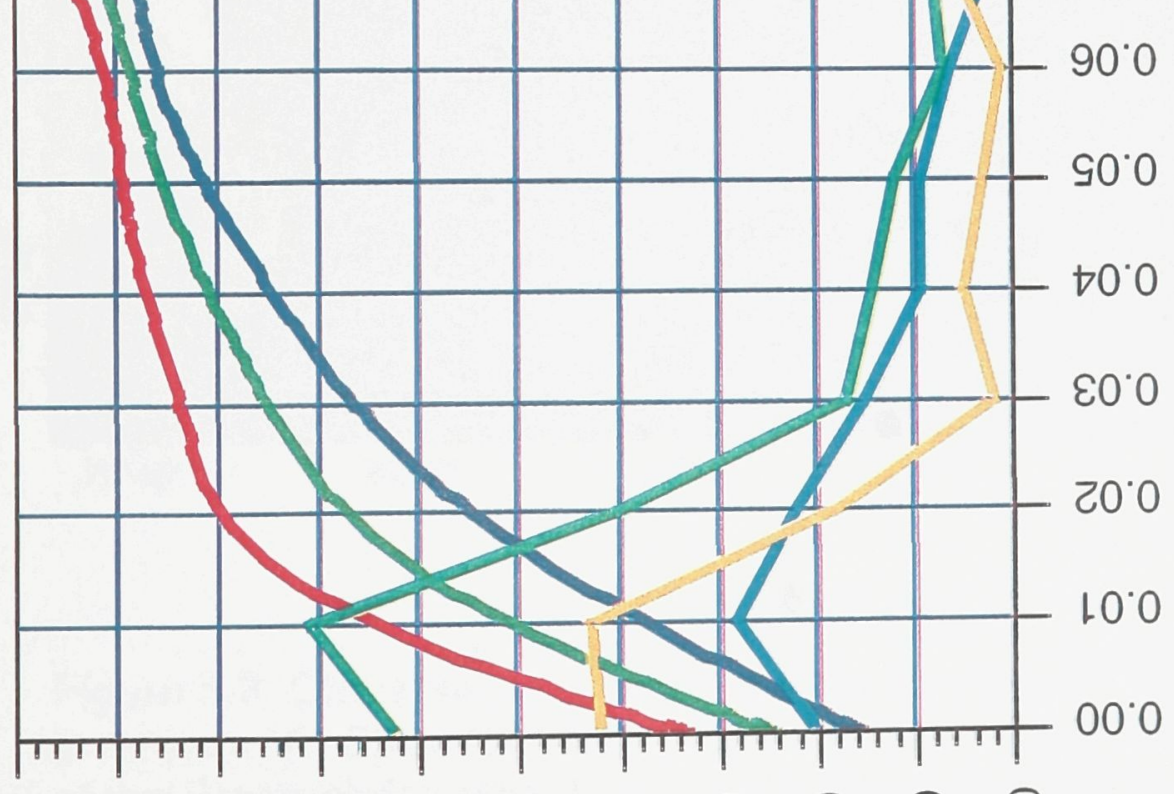
900

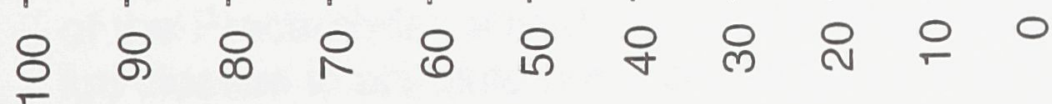

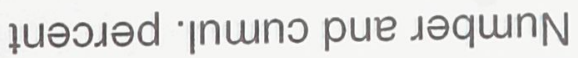

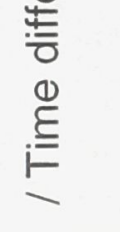
$\triangle 0$ (1) $\sum_{0}^{\infty} \frac{1}{5}$ ำ ஸ 으 บั ब1 造完

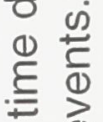
(1) 产 号 는 ํㅡㄴ 흔 
Elevation

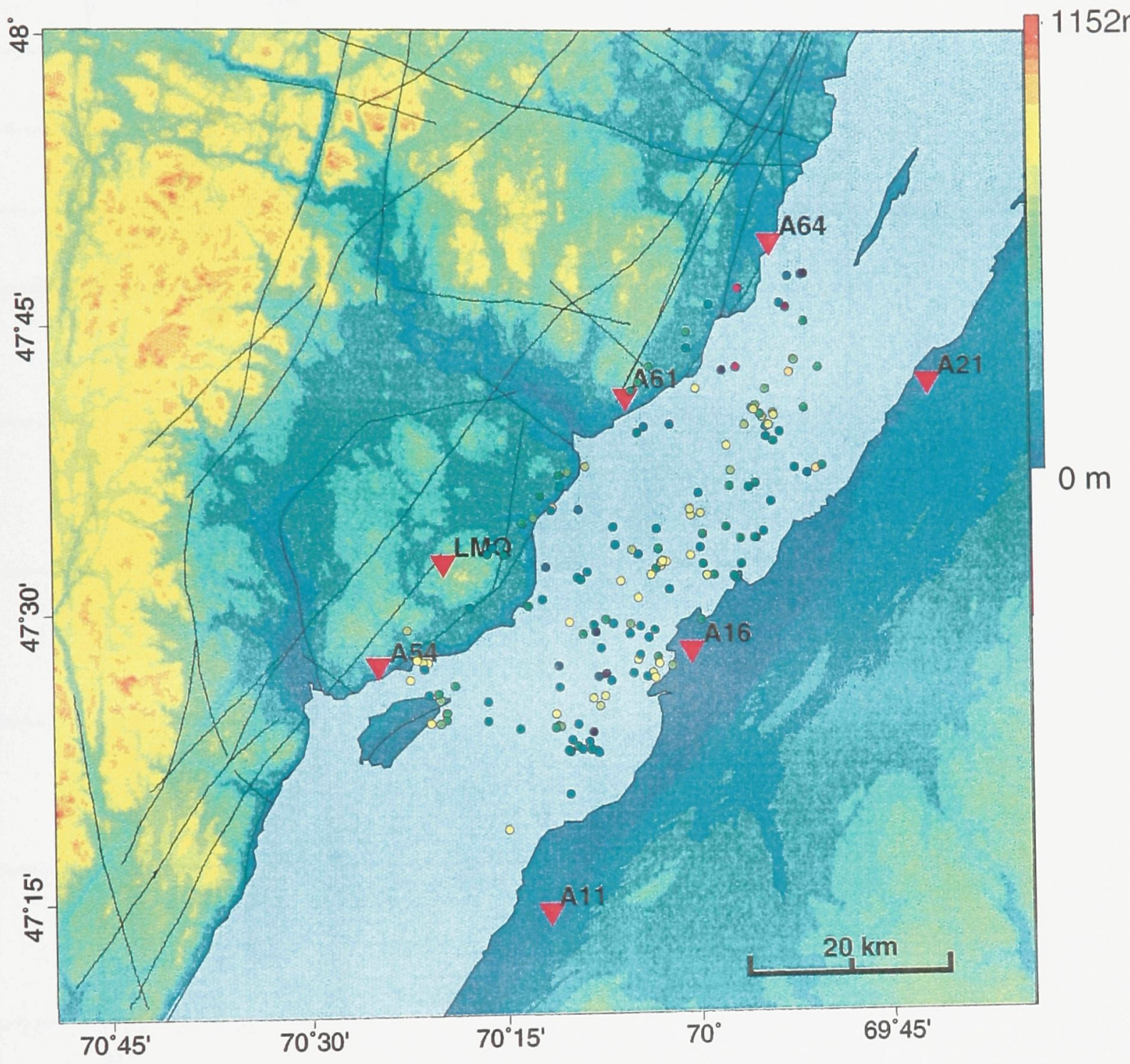

Figure 5.3 Characteristics of the events selected for the velocity inversion: (A) Epicentral map with black lines representing the faults of the Precambrian shield; (B) Depth distribution of the events by 1 $\mathrm{km}$ classes in absolute numbers (left) and in cumulative numbers (right). (C) RMS distribution of the selected events, calculated with the "standard" velocity model. 

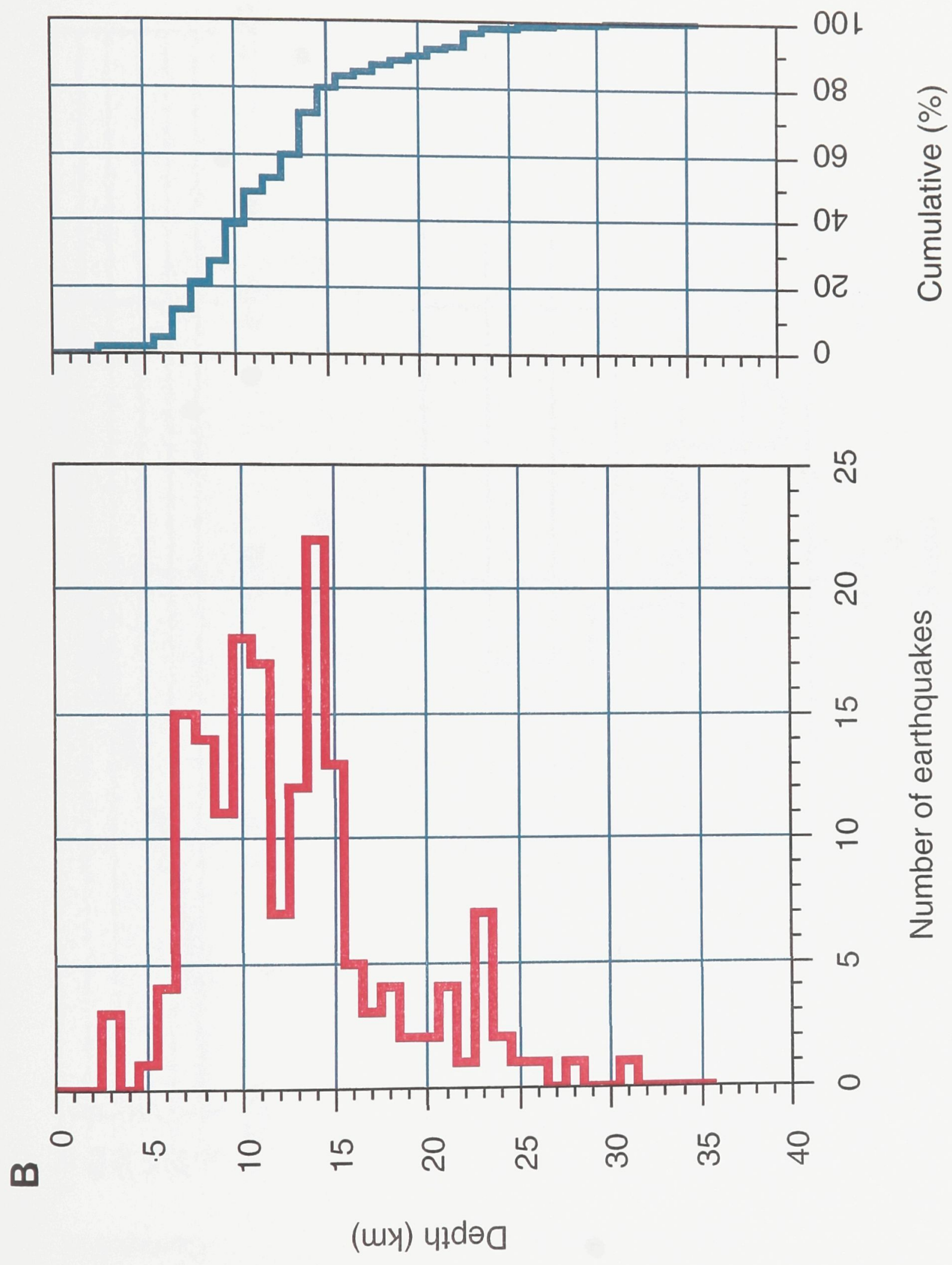

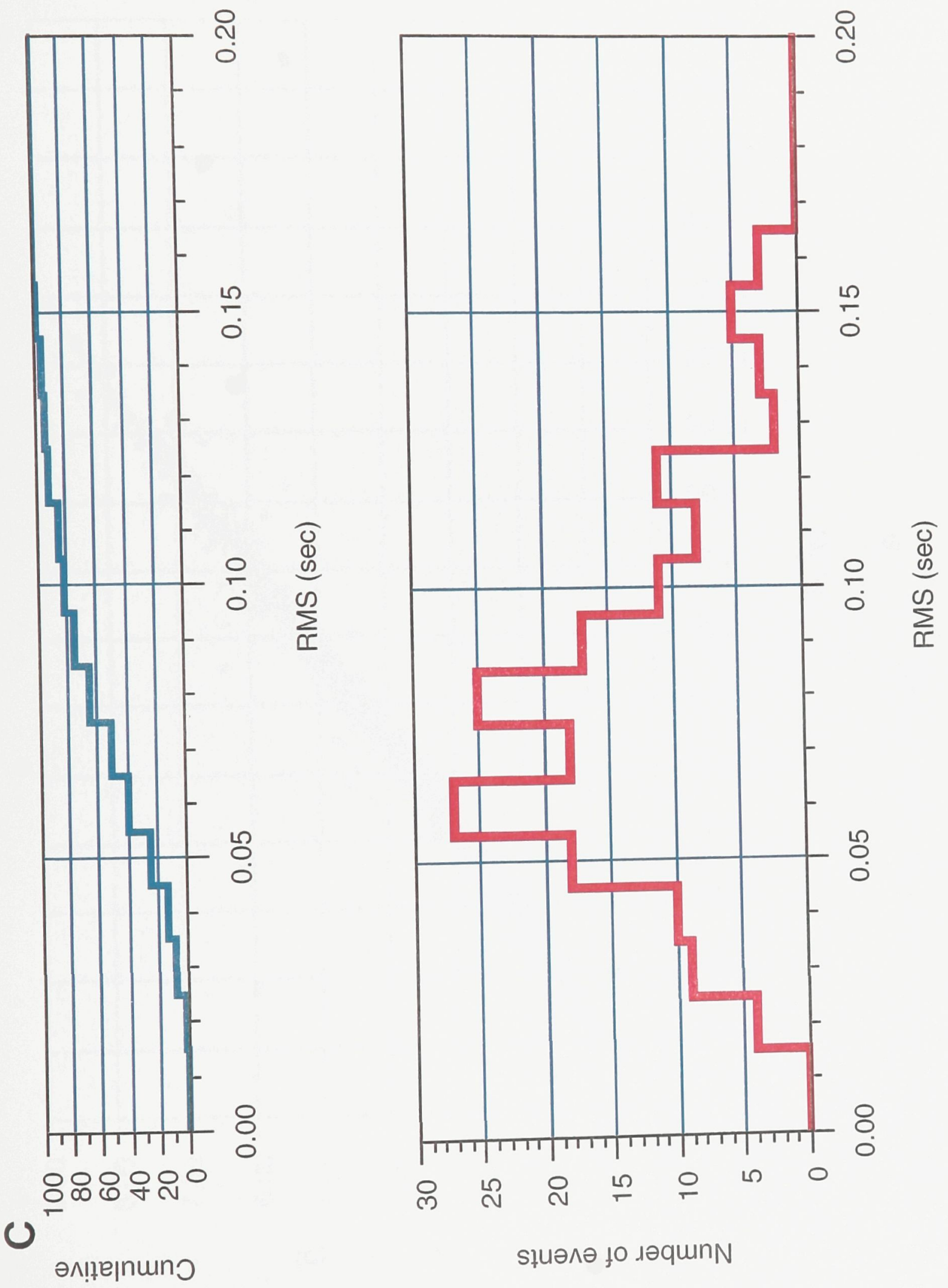


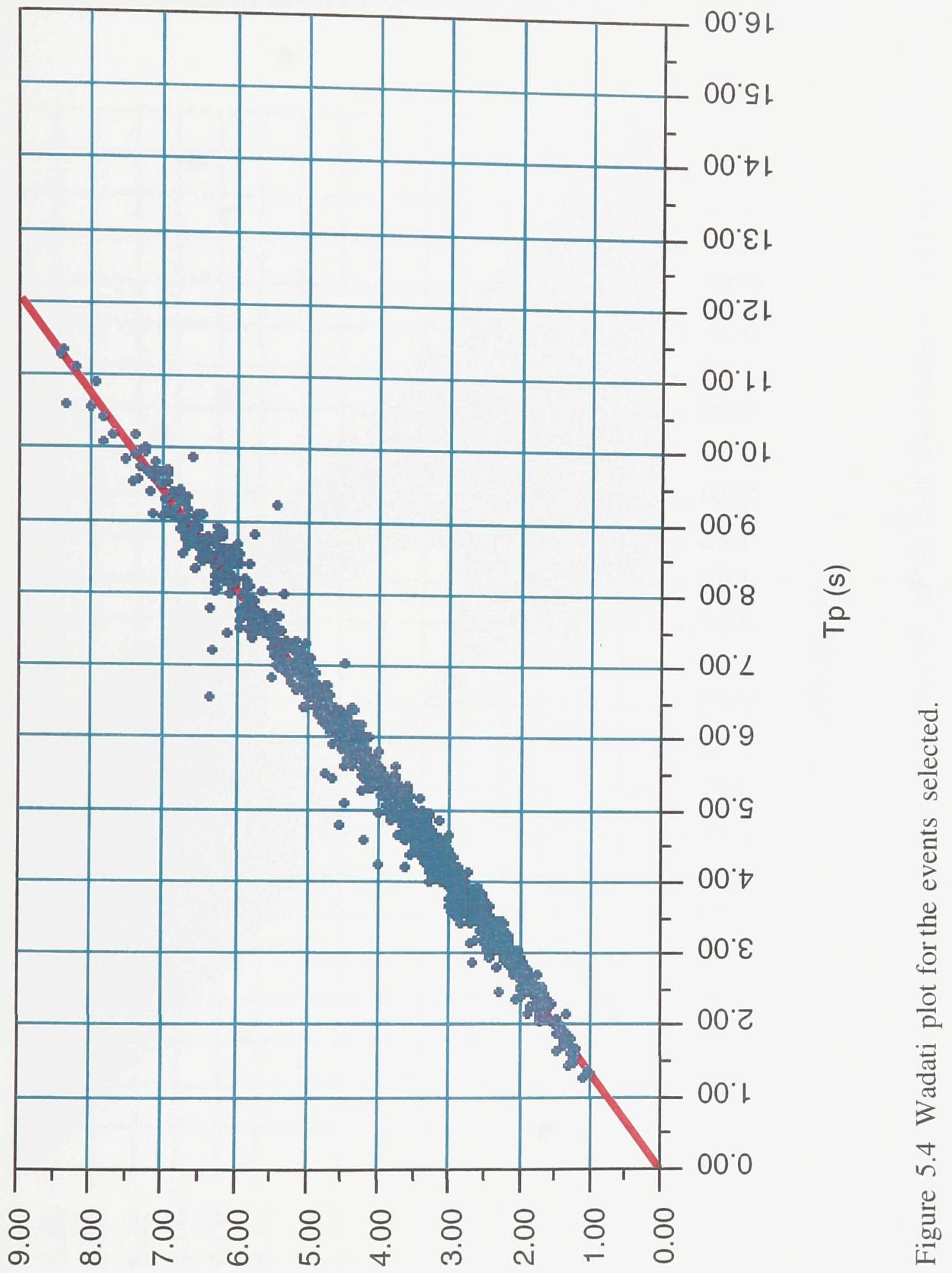

(s) $d_{\perp}-s_{\perp}$ 


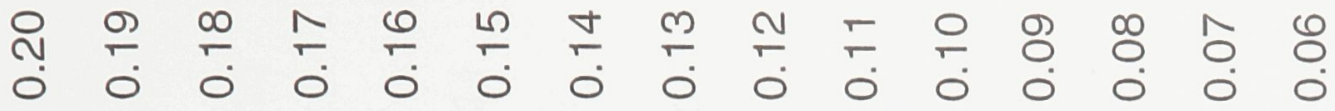
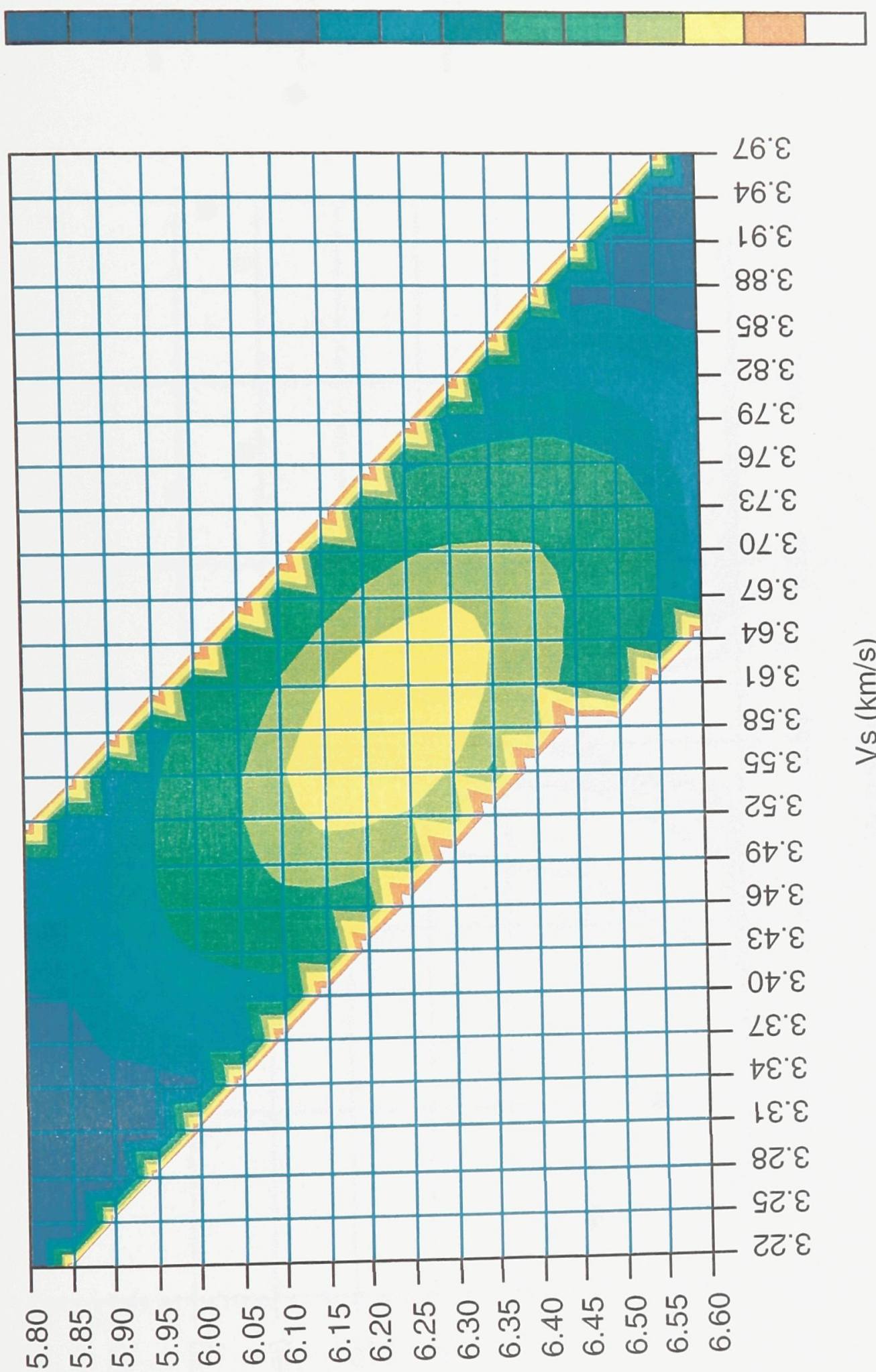

뭄 용 d (1) 0

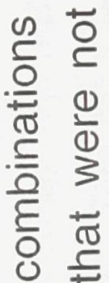

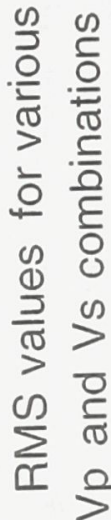
เก (1) 흐 은 은

$(s / u y) d \wedge$ 


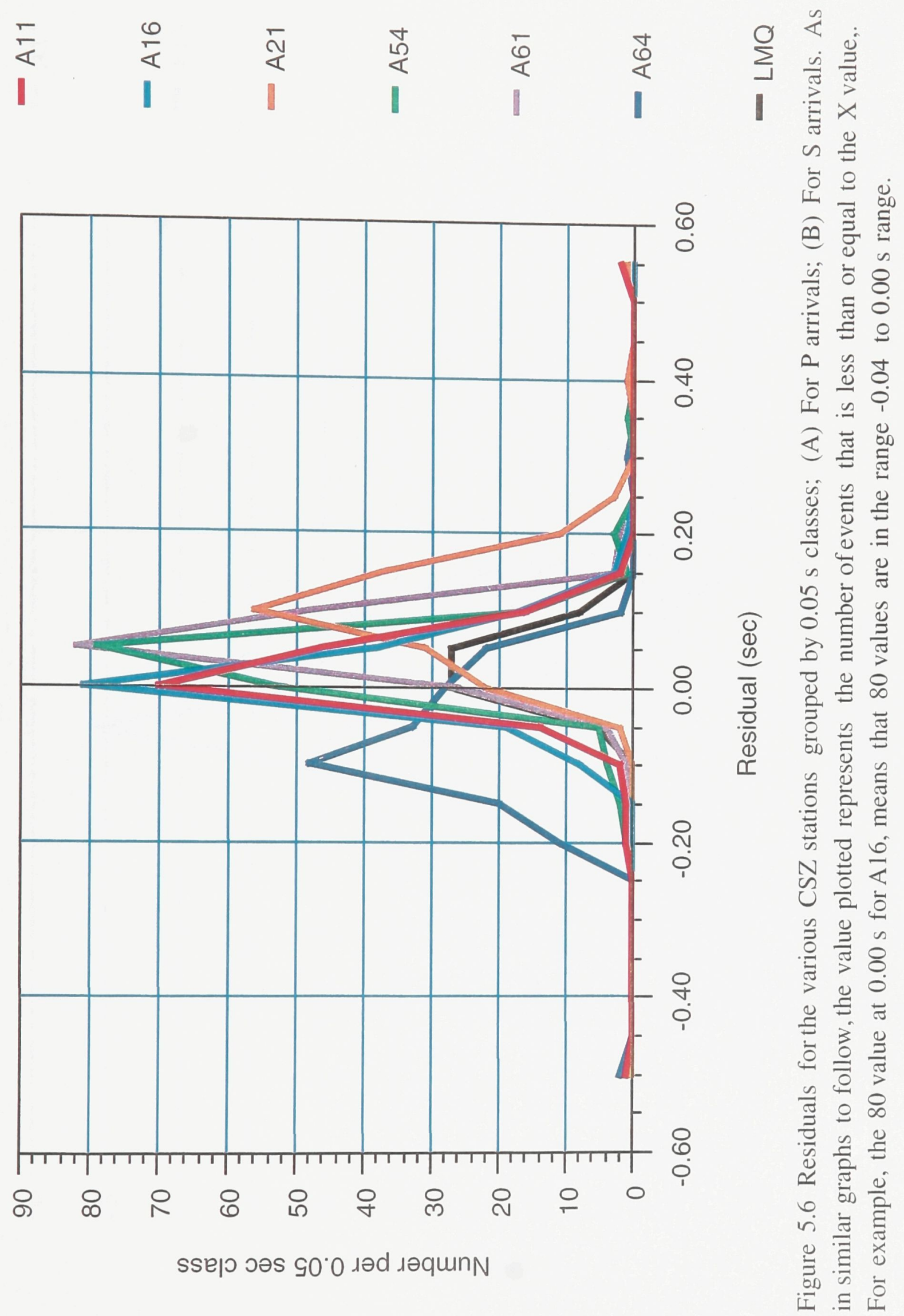



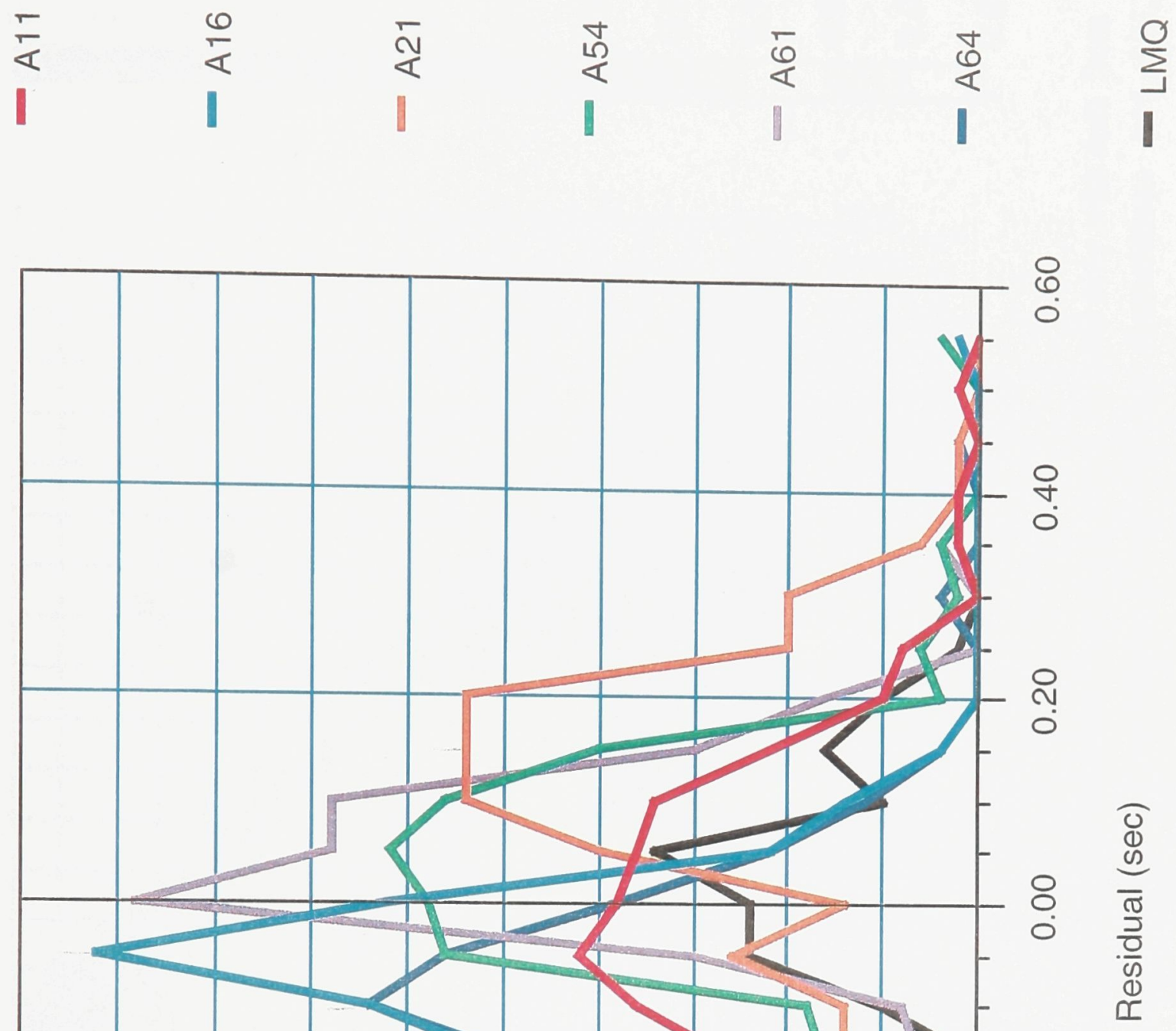

๓

(1)

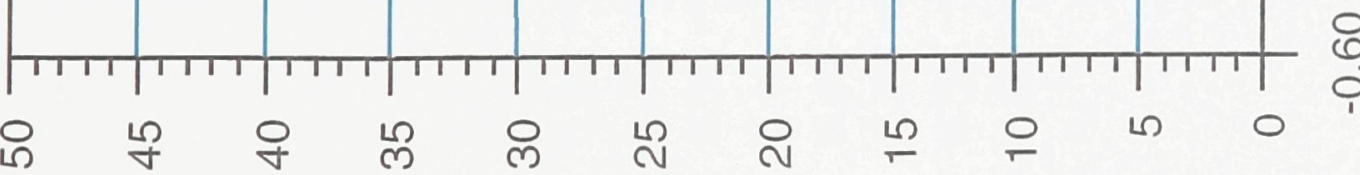

ssejo गәs s0.0 1әd 1әqunN 


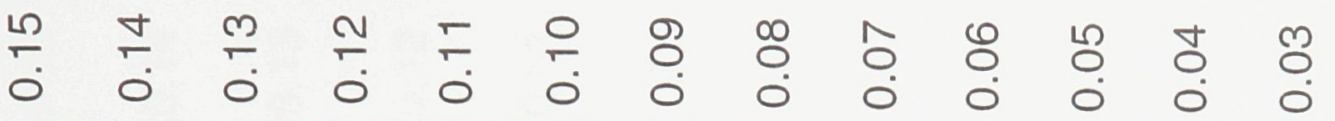

ำ

葲 $\frac{0}{4}$

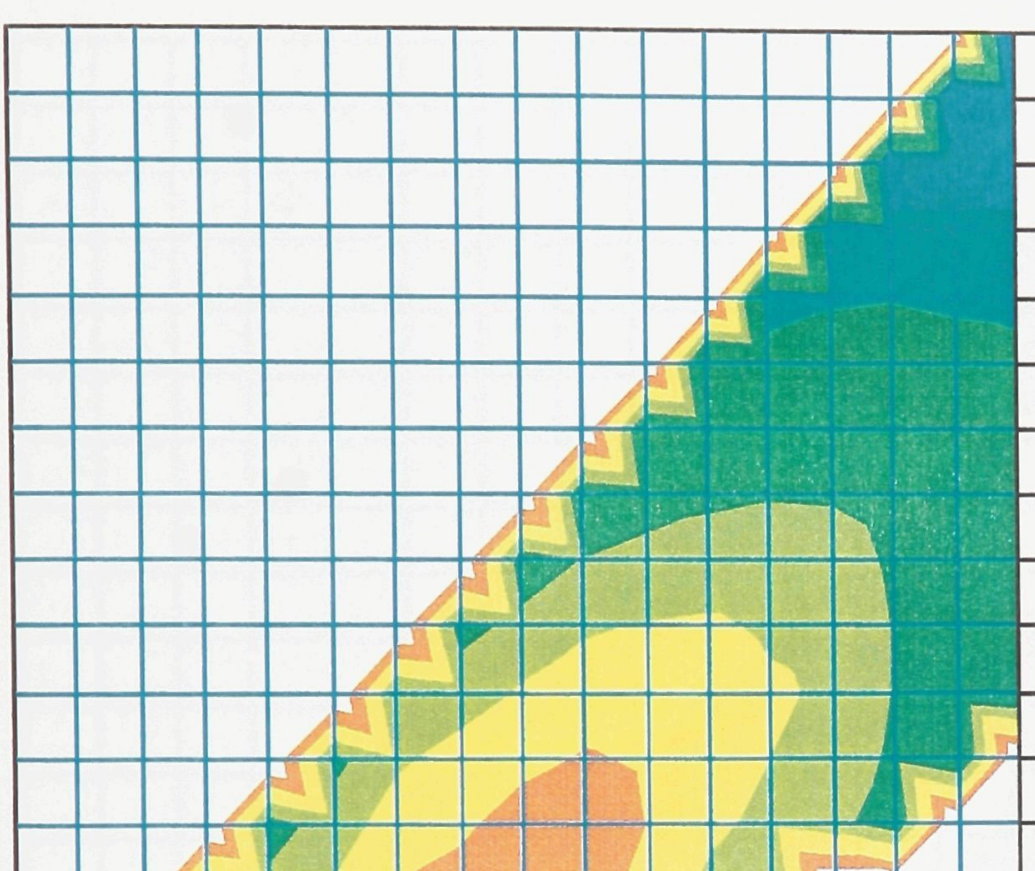

$\angle 6^{\circ} \mathcal{E}$

节

츰

○ิ

ฮู

洁

t)

츰

엉

$\varepsilon L \cdot \varepsilon$

$0 \angle{ }^{\circ} \varepsilon$

ฮ

$\angle 9^{\circ} \varepsilon$

$\nabla 9^{\circ} \varepsilon$

$19^{\circ} \varepsilon$

$89^{\circ} \varepsilon$

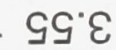

乙S' $\varepsilon$

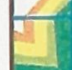

$6 \nabla^{\circ} \varepsilon$

$9 \nabla^{\prime} \varepsilon$

$\varepsilon \nabla^{\circ} \varepsilon$

O $0 \nabla^{\circ} \varepsilon$

$\angle \varepsilon^{\circ} \varepsilon$

$\nabla \varepsilon \cdot \varepsilon$

เย' $\varepsilon$

$8 \tau^{\circ} \varepsilon$

५ट $\varepsilon$

टટ'

○

$\frac{a}{\frac{n}{5}}$

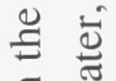

$\Xi$ ठ

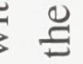

节兽

ये

$\stackrel{\infty}{\Xi} \cong$

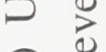

\&

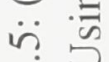

0 ิิ

$\exists$

임 $\ddot{\forall}$

$\Xi \ll$

$\approx \tilde{\Xi}$

के

त

$>0$

$\sum \ll$

$\approx=6$

r. $\ll$

i $)$ Ð

(s/uy) d^

竞. 兽 


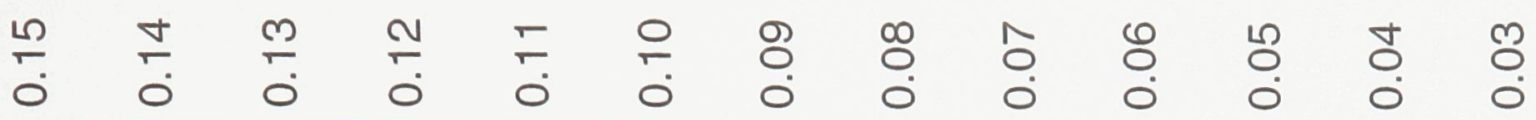
\begin{tabular}{|l|l|l|l|l|l|l|l|l|}
\hline & & & & & & & \\
\hline
\end{tabular}

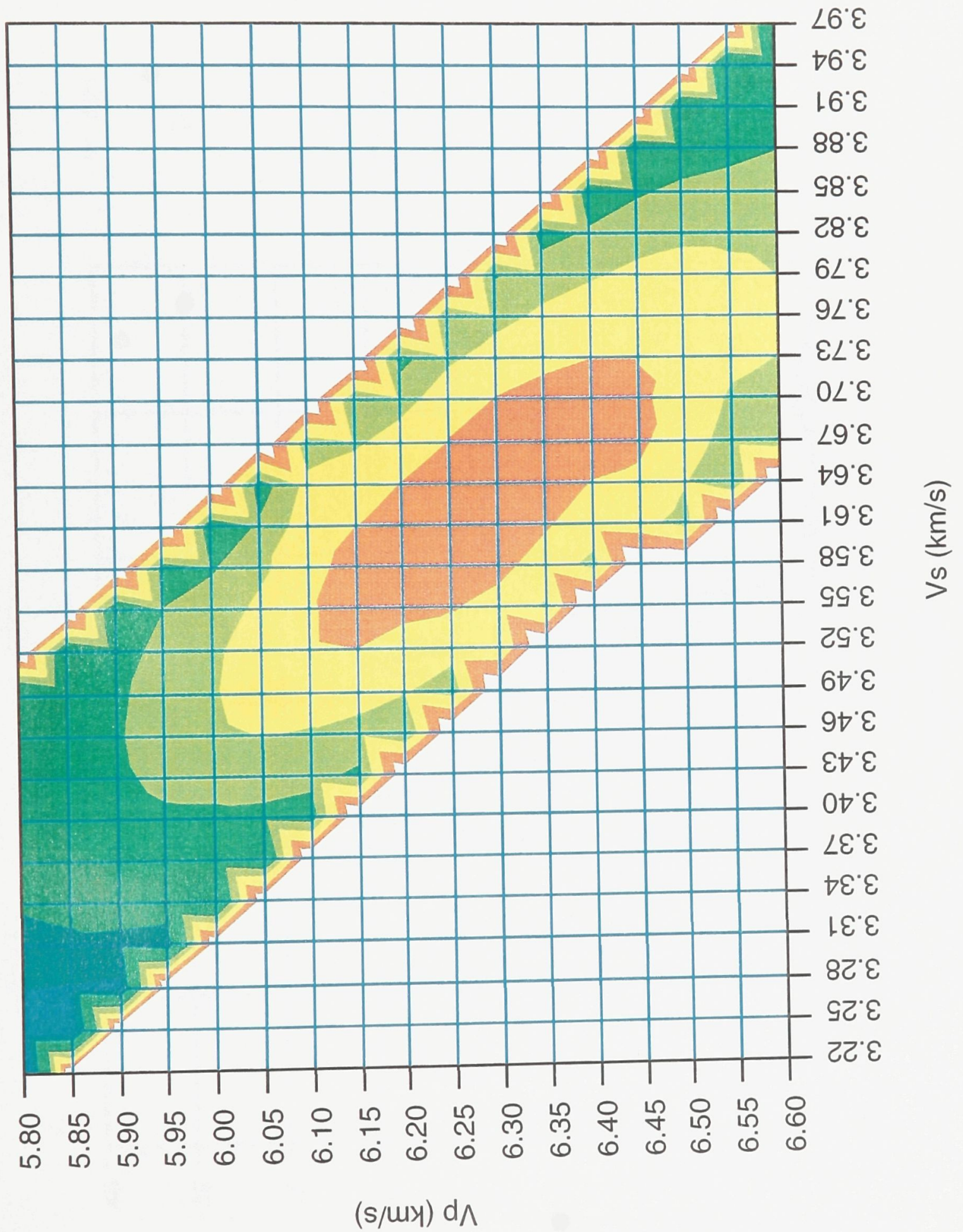




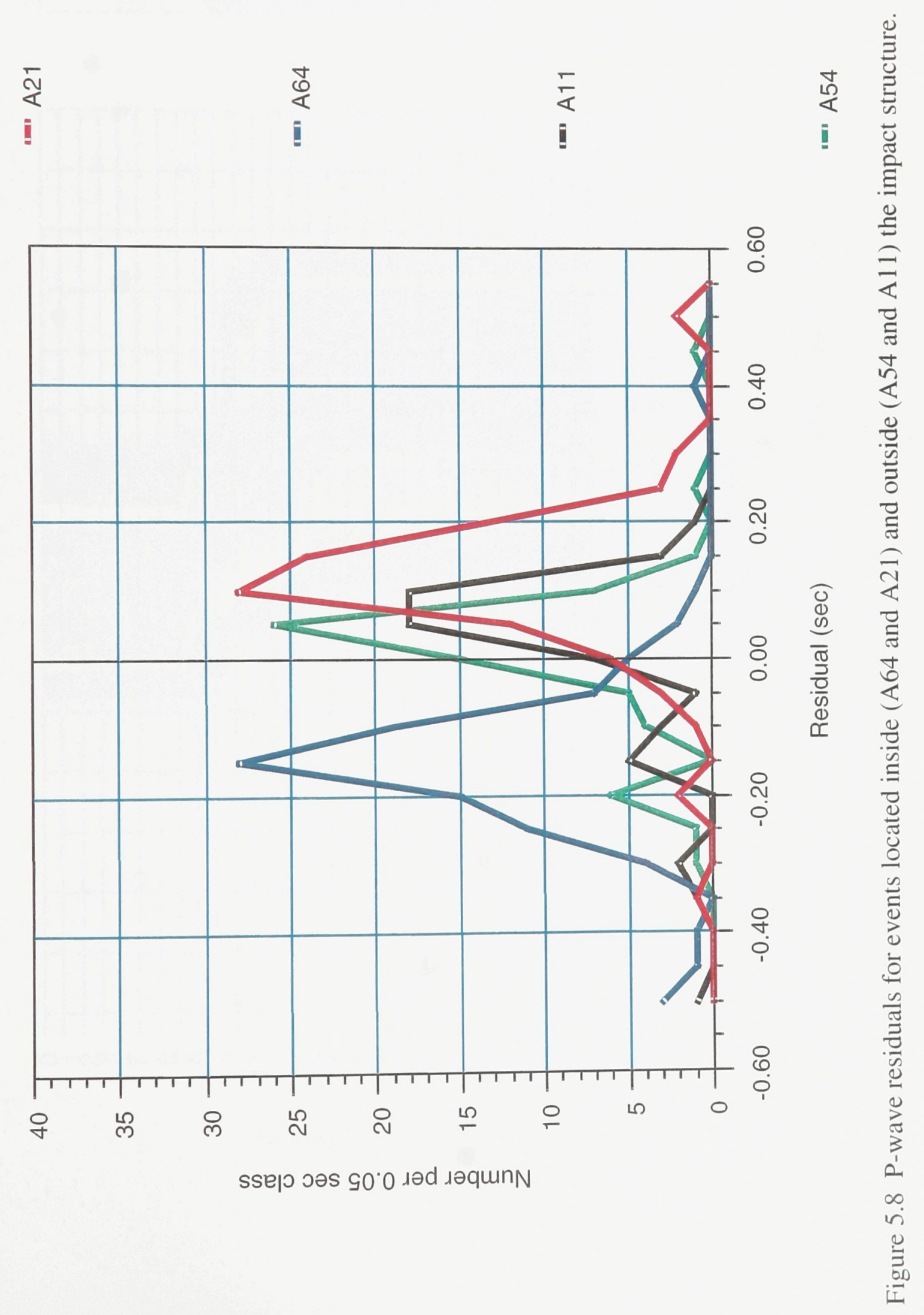




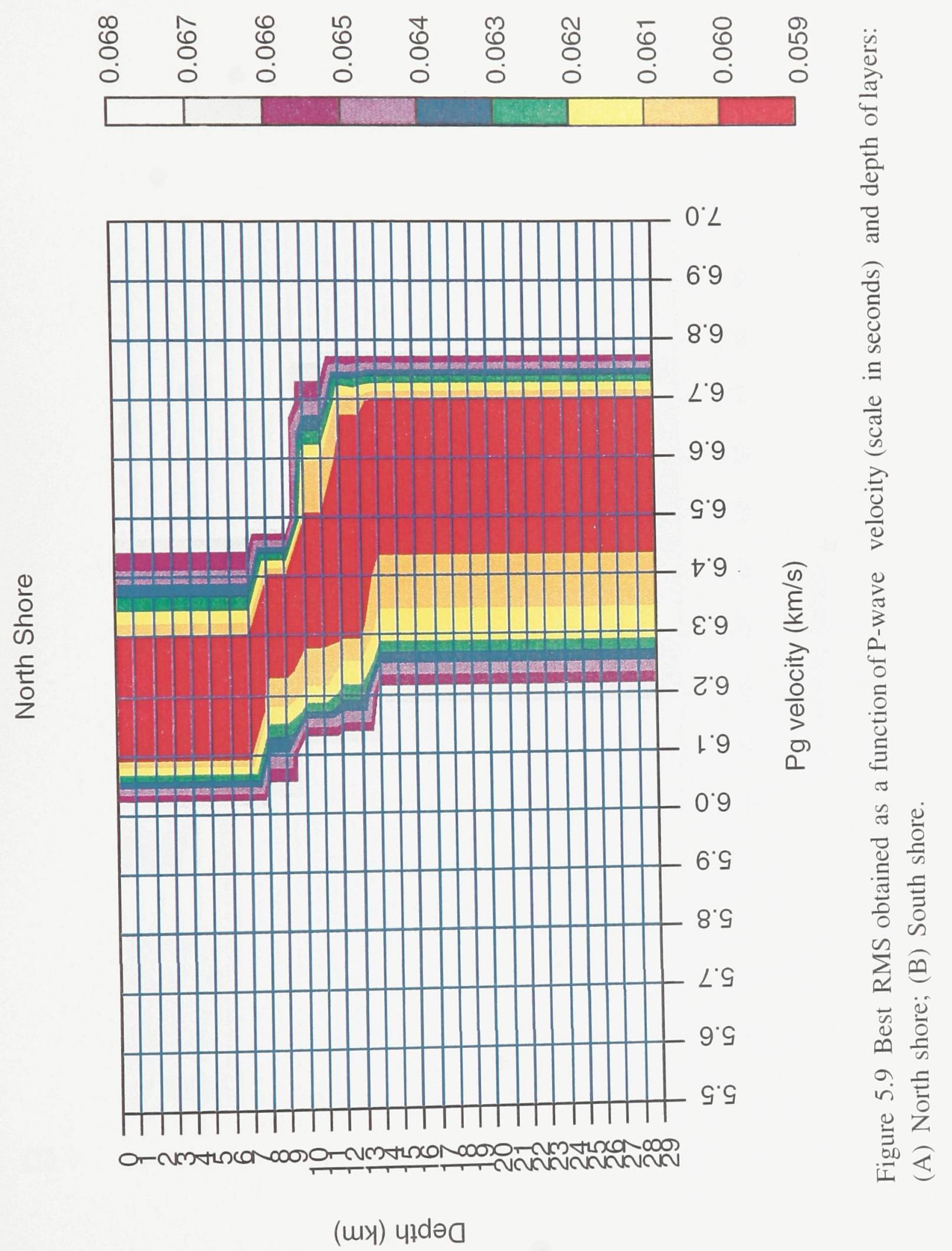




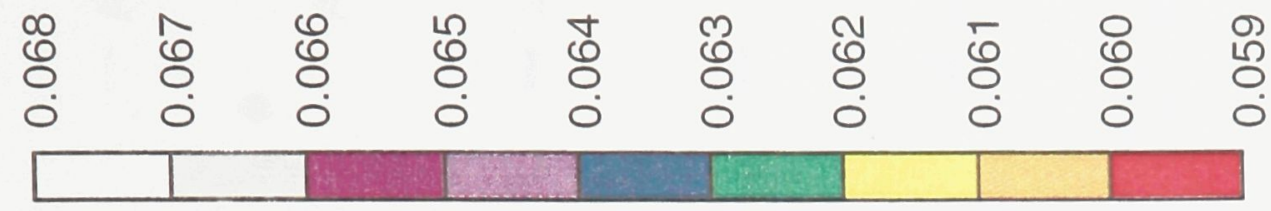

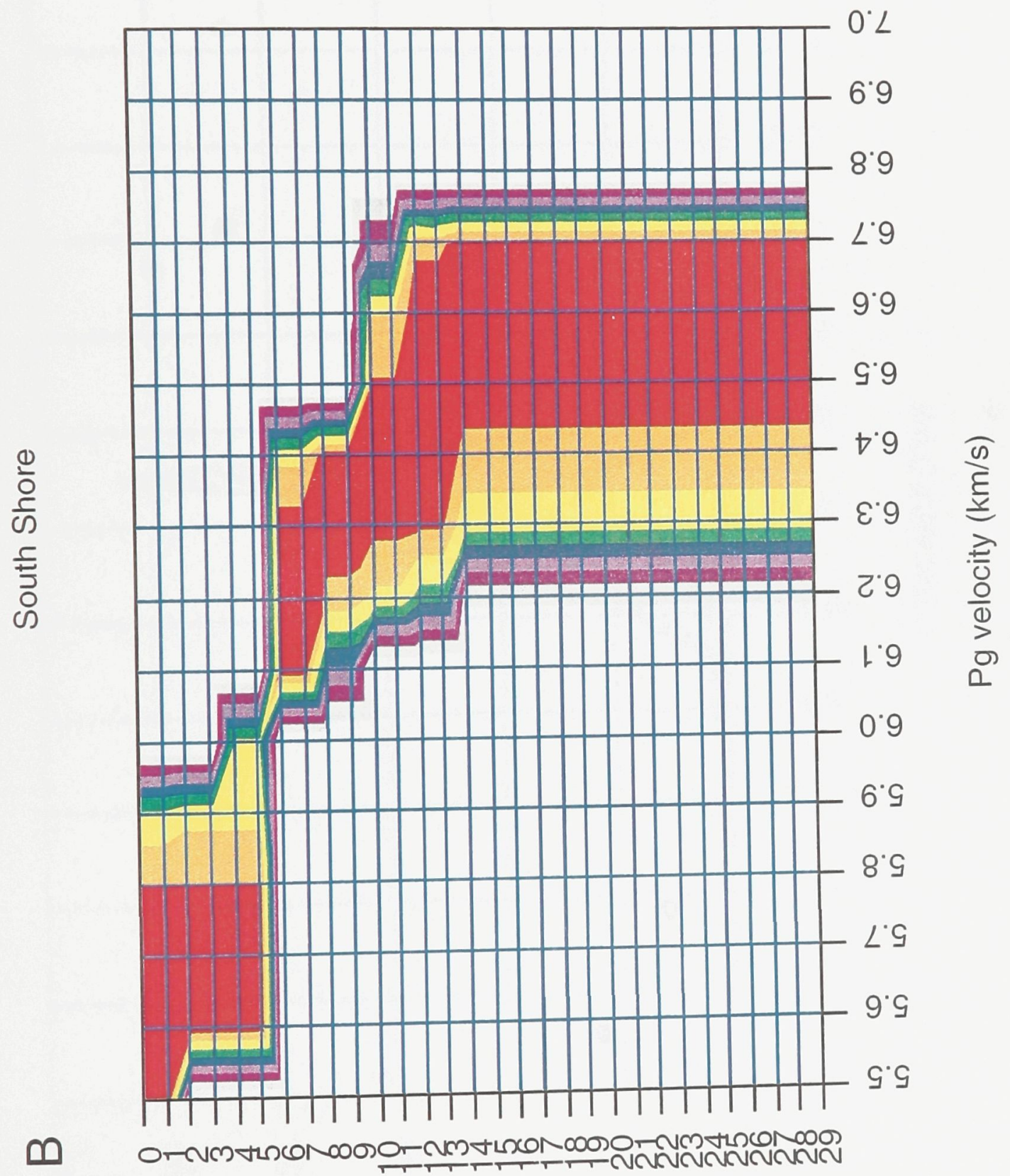

(wY) प1 


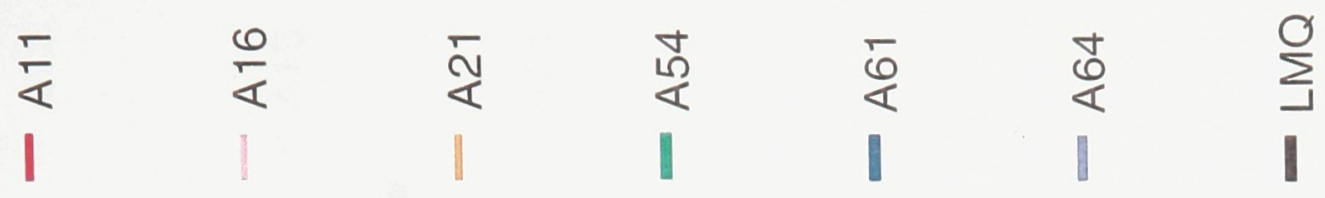

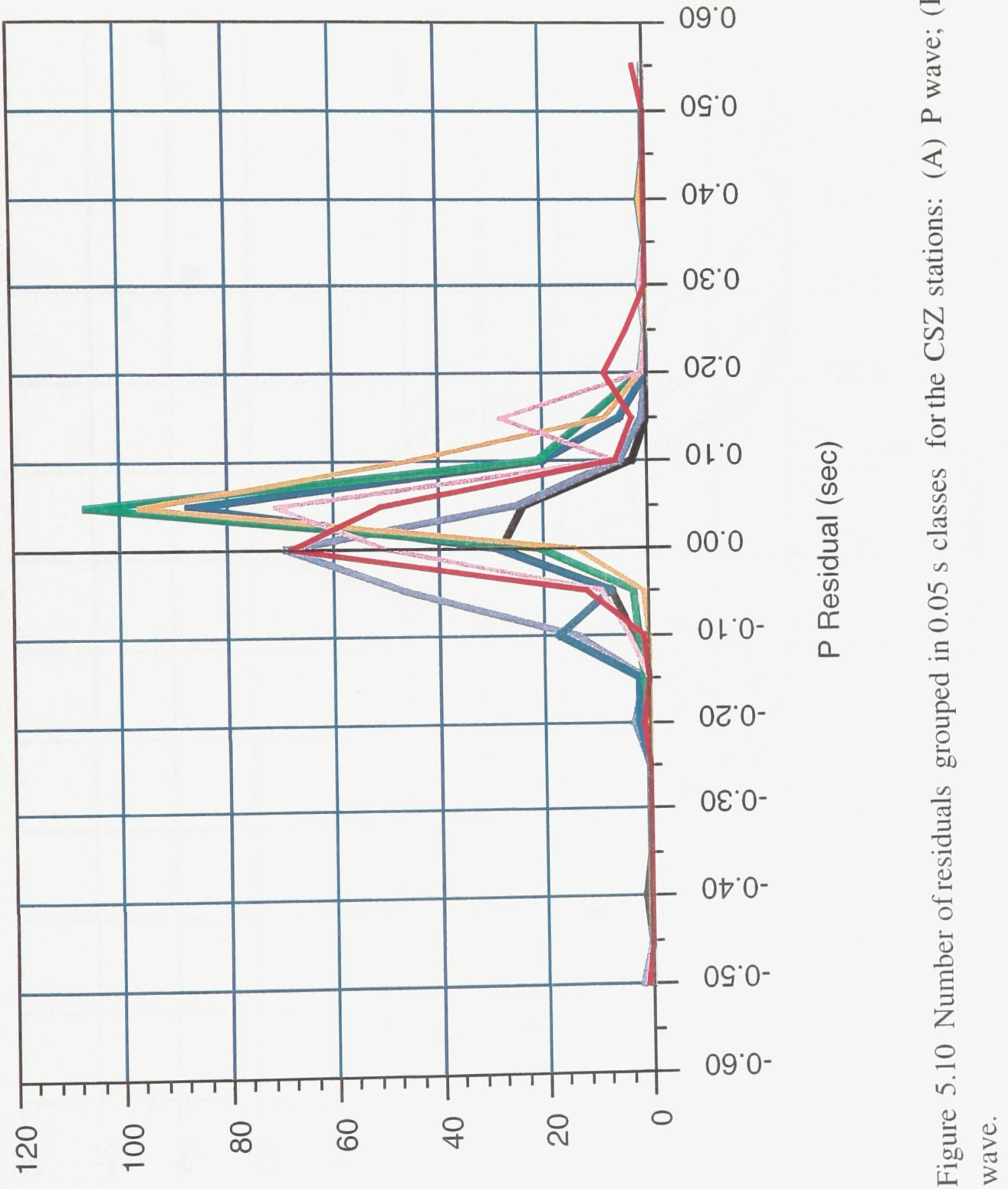

ssejo oəs $90^{\circ} 0$ ləd ləqunN 


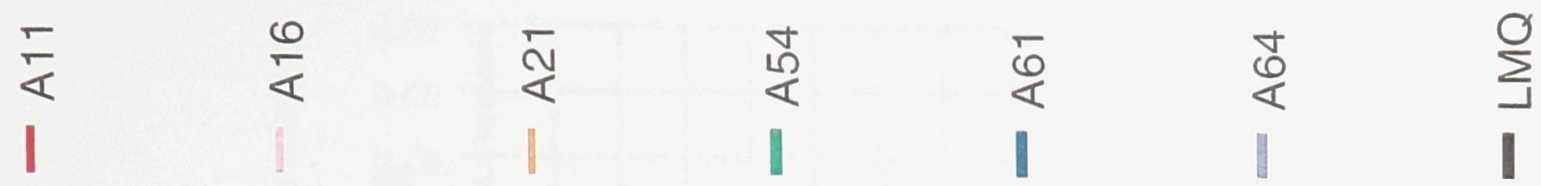

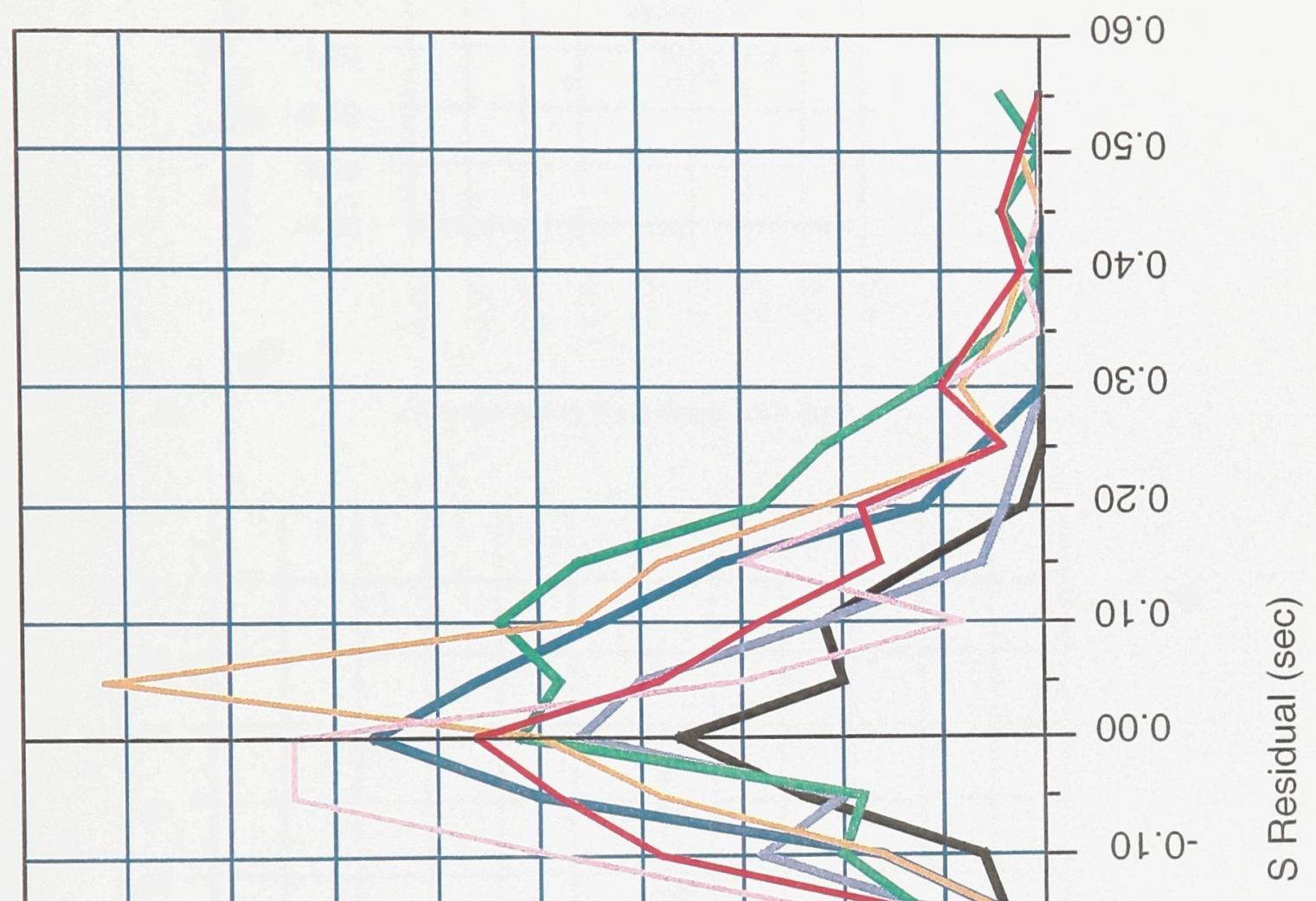




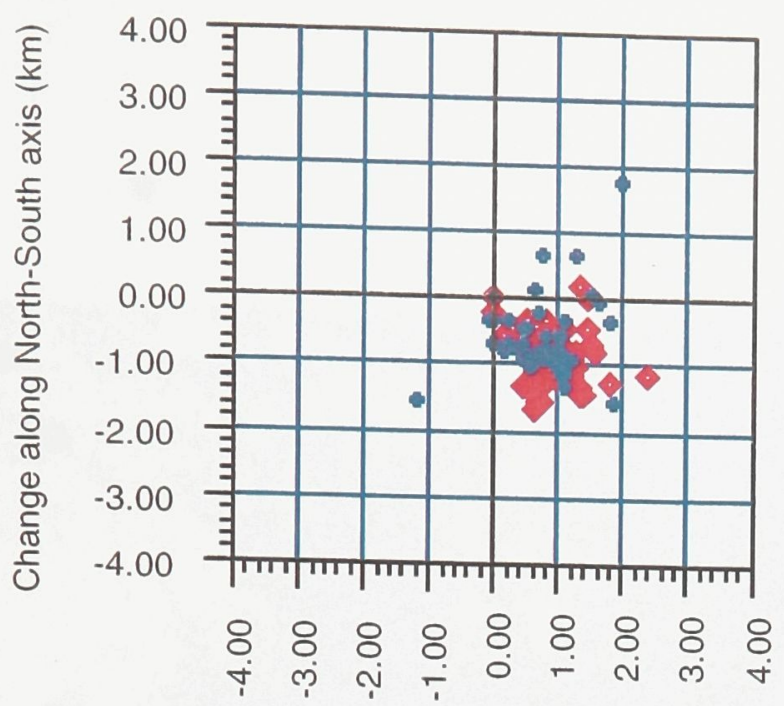

Change along East-West axis $(\mathrm{km})$

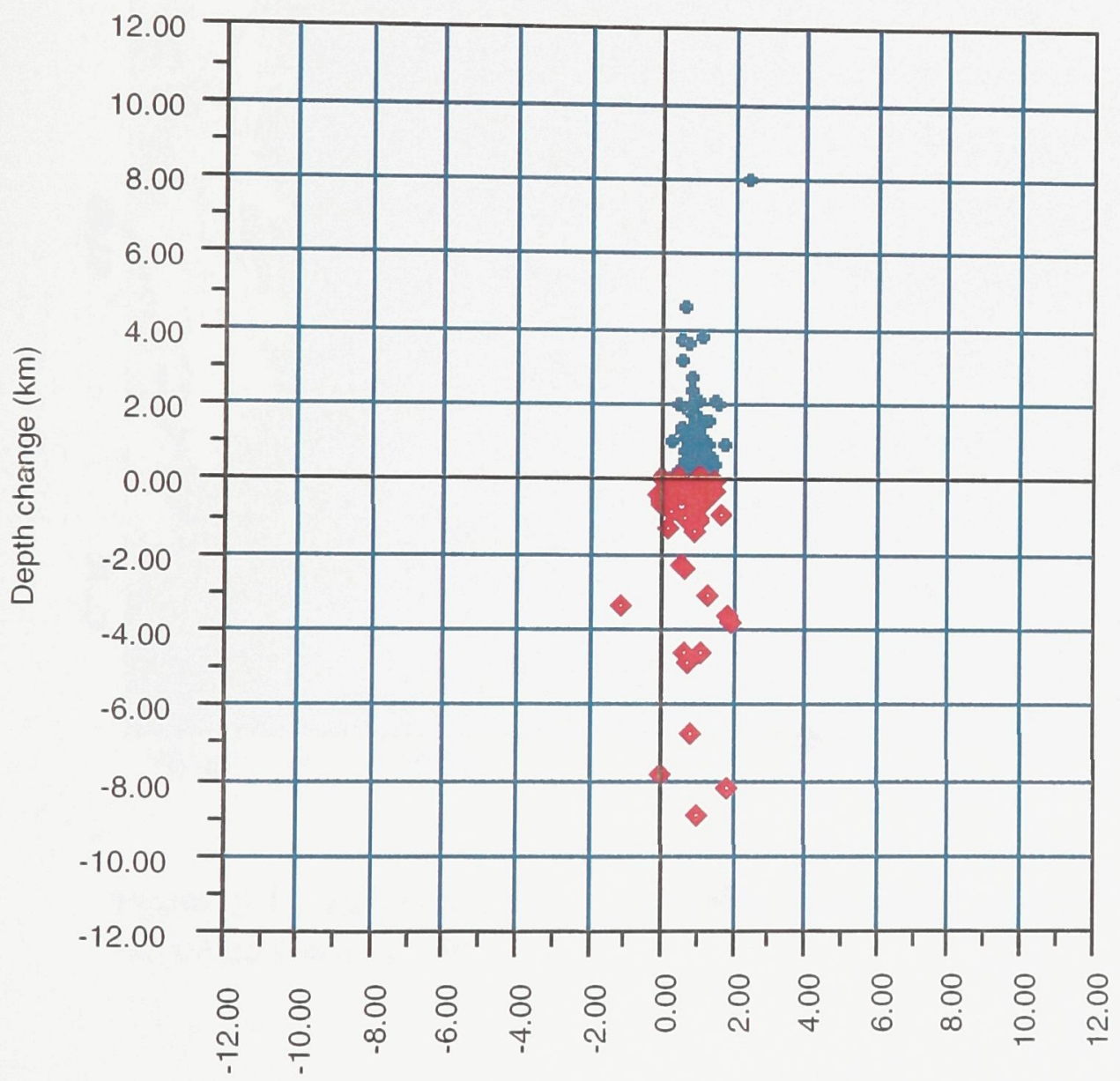

Change along East-West axis $(\mathrm{km})$

Figure 5.11 Shifts between original event locations ( $\mathrm{X}=\mathrm{Y}=0$ ) and locations computed with the best layered model: (A) Epiecntres; (B) Hypocentres along E-W vertical section. Blue crosses are shallower relocated hypocentres andred diamonds deeper ones. 
Elevation

$\stackrel{\infty}{+}$

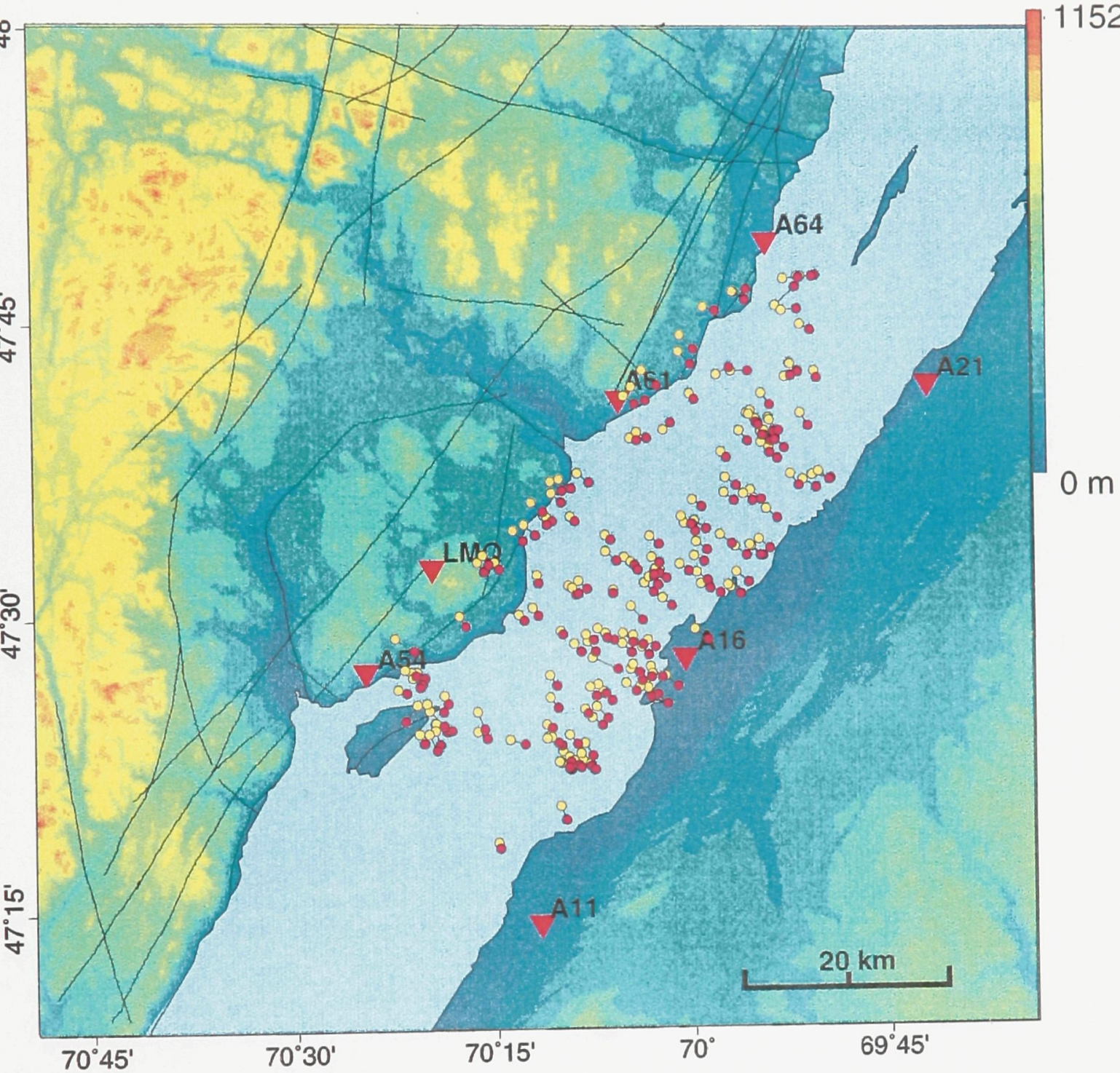

Figure 5.12 Epicentral map showing shifts between original (yellow) and relocated (red) epicentres. 
Elevation

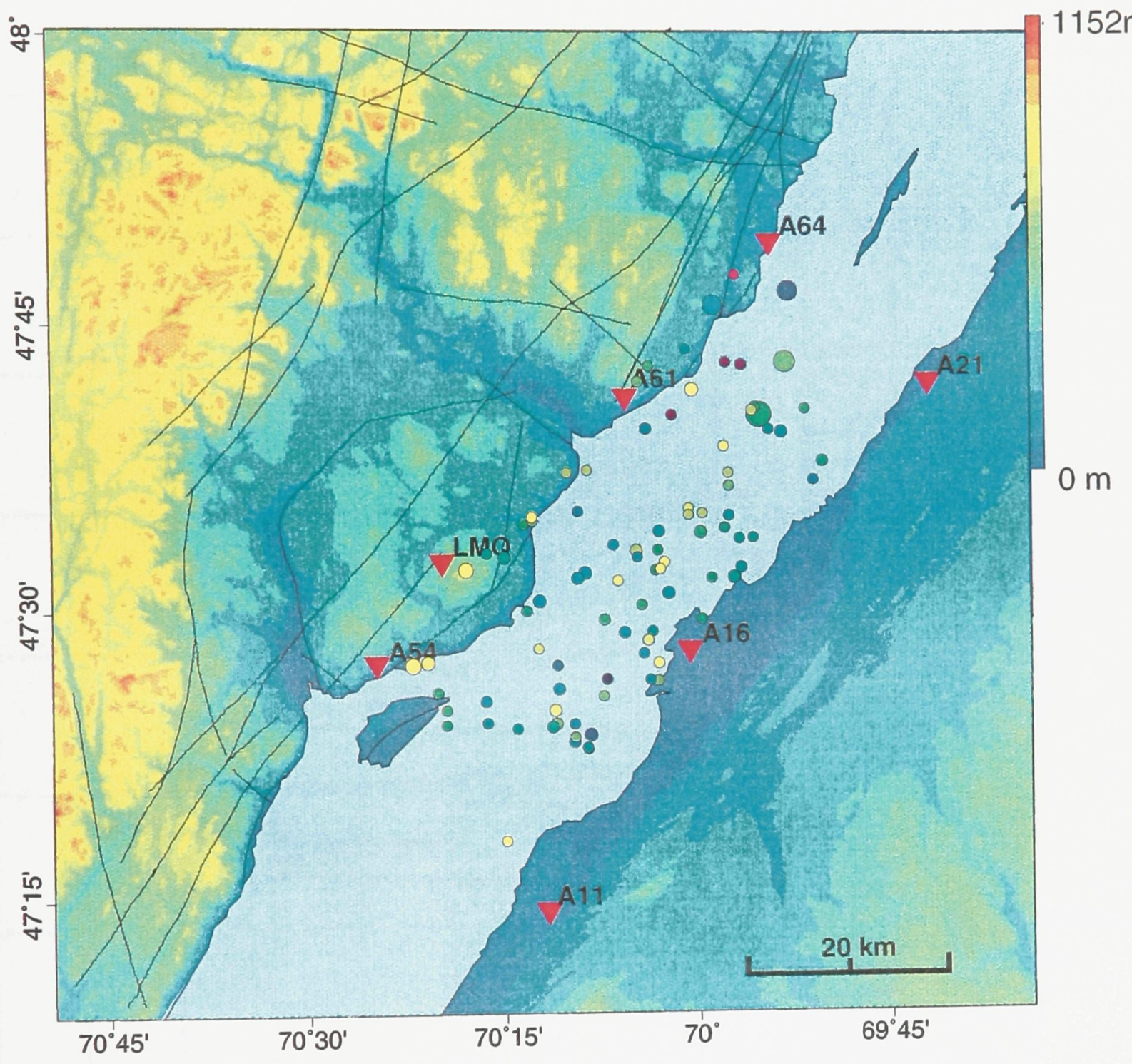

Figure 5.13 CSZ events recorded at station DAQ; (A) Hypocentres; (B) Distribution of $\mathrm{P}$ and $\mathrm{S}$ residuals. 
$\begin{array}{ll}0 & 0 \\ 1 & 1\end{array}$

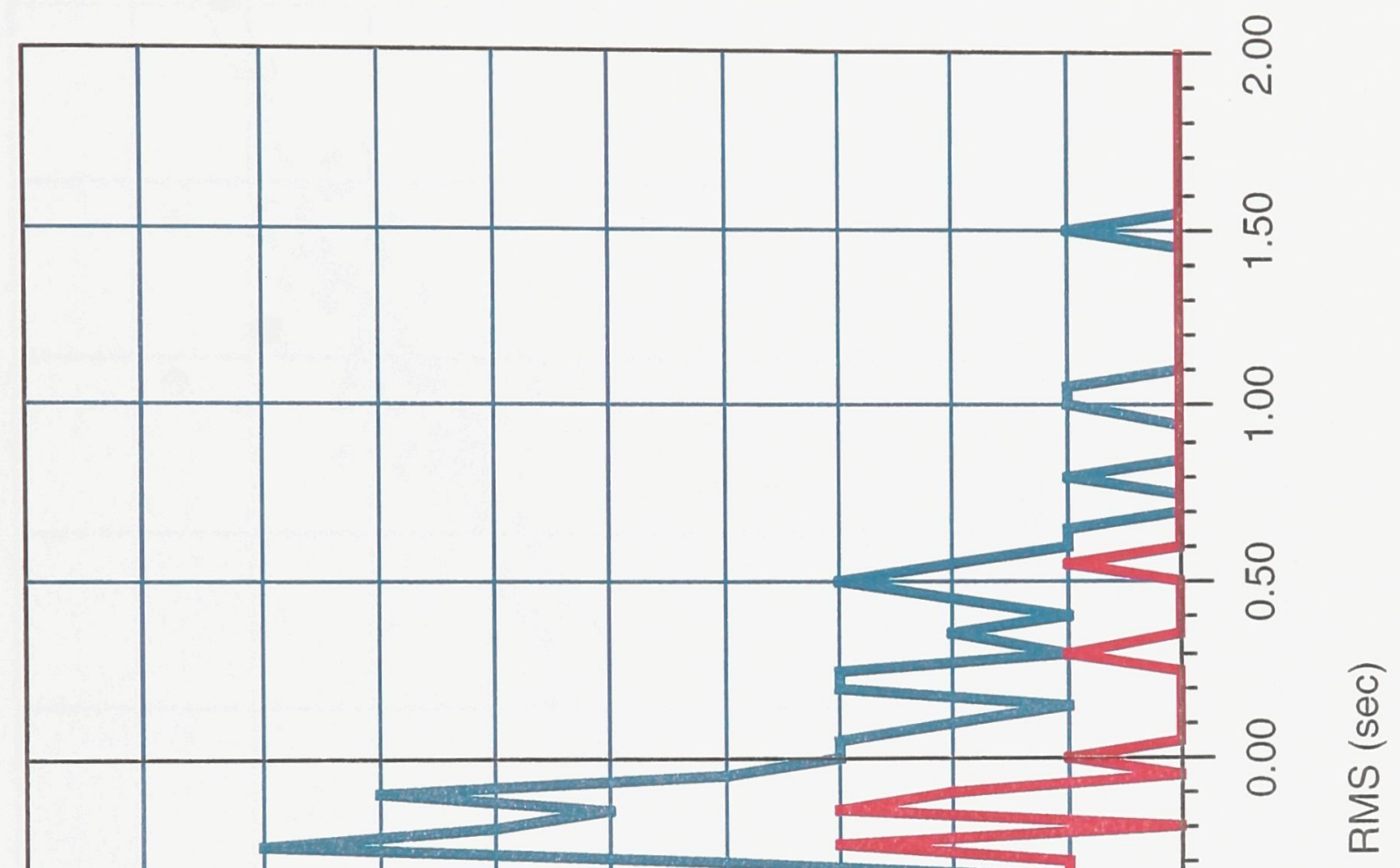

$\infty$ 우
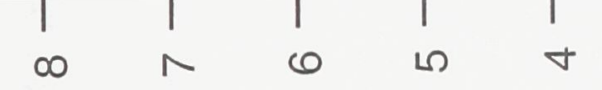

ssejo oəs 90.0 ləd ləqunN 


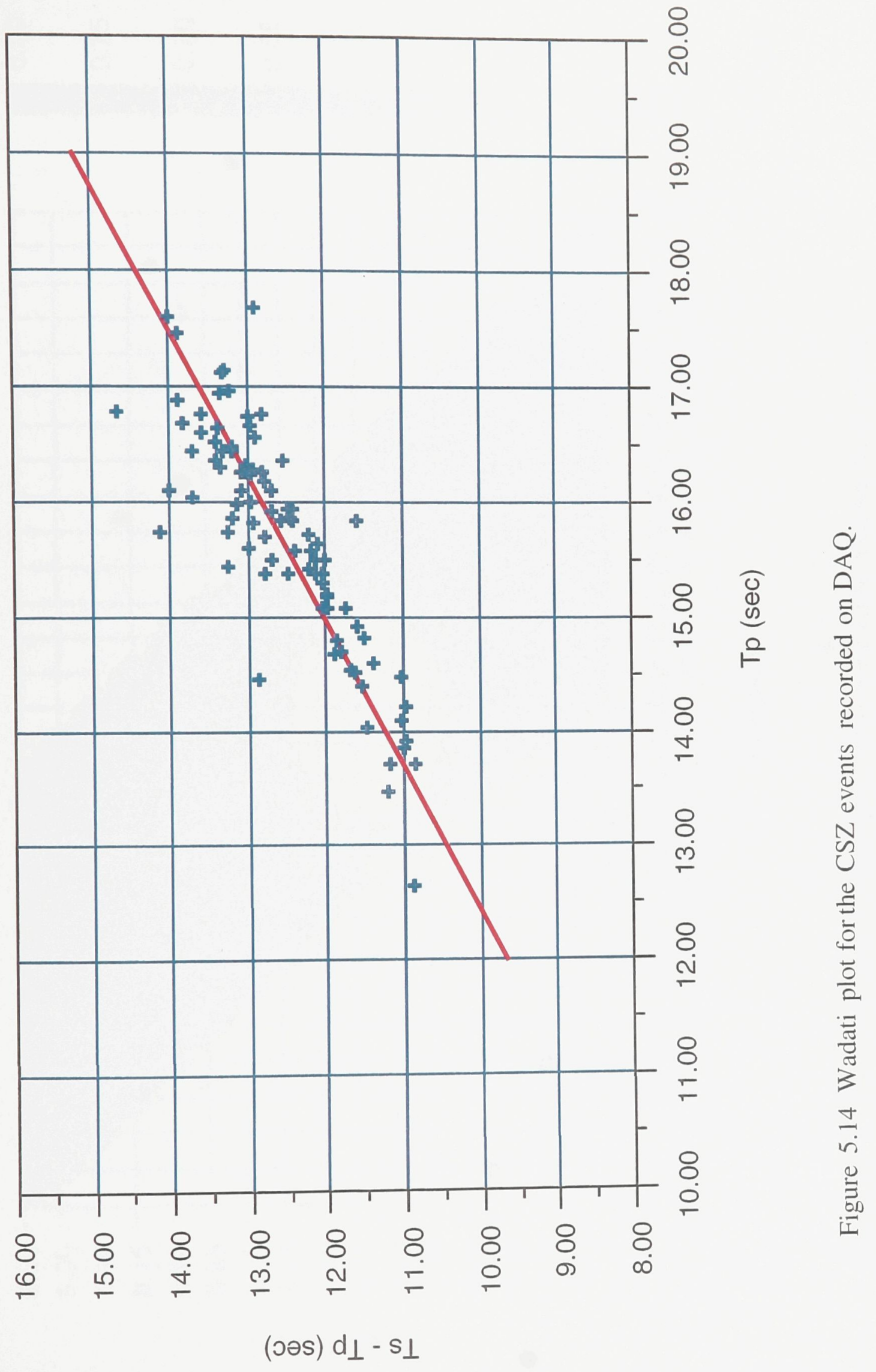




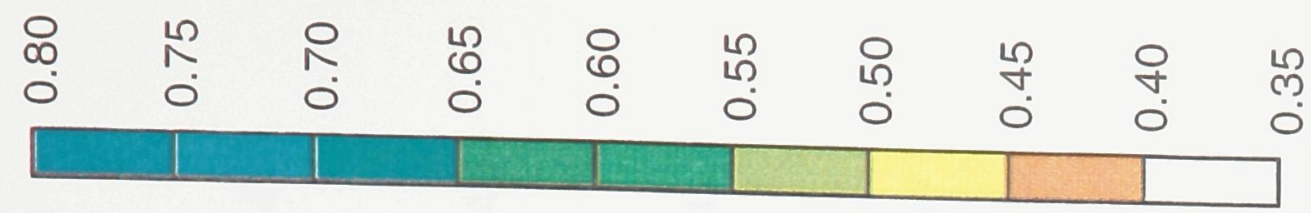

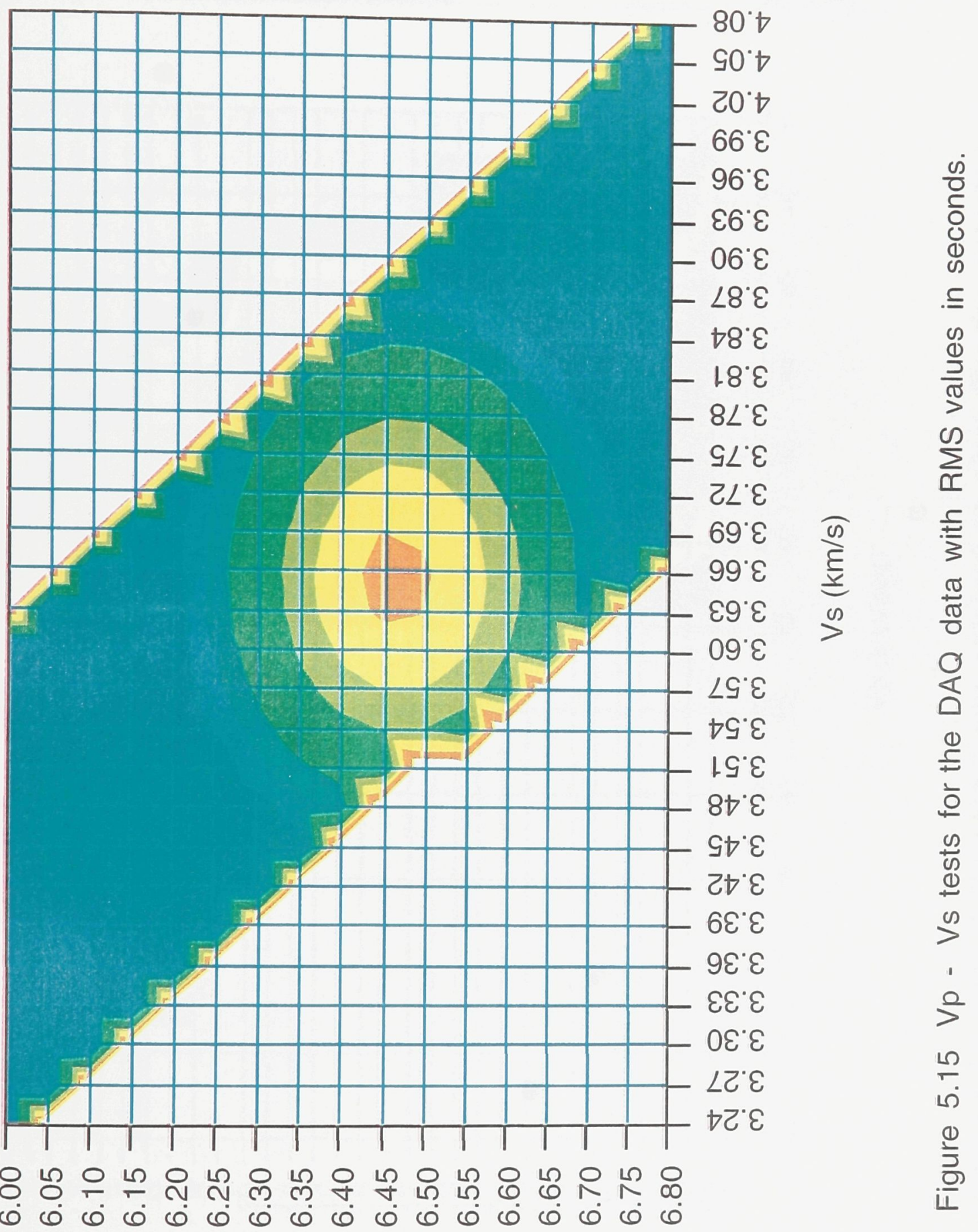

$(s / u y) d \wedge$ 

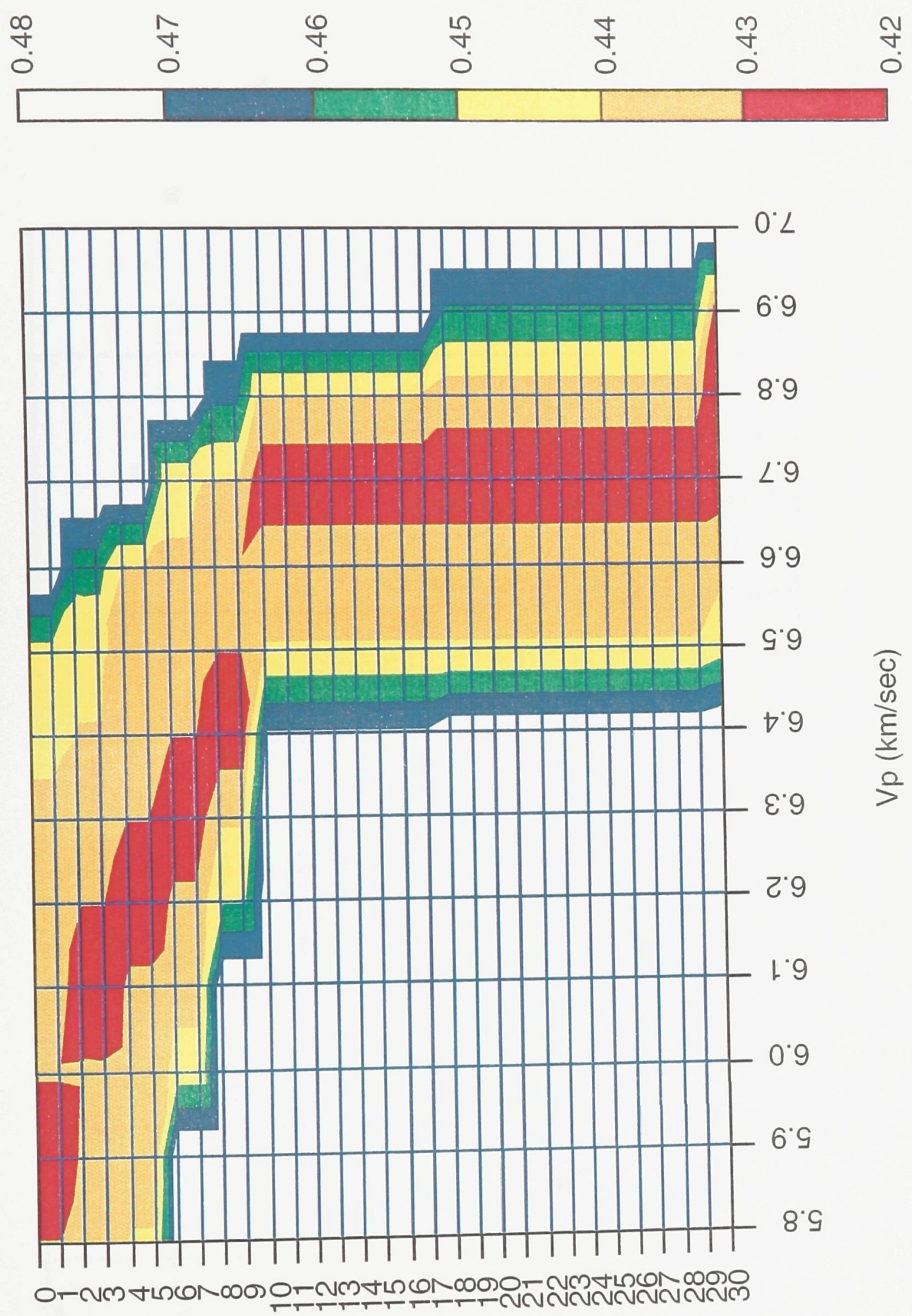

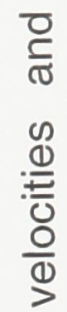

0
$\frac{1}{3}$
$\frac{1}{0}$
$\frac{1}{0}$
$\frac{1}{0}$
$\frac{1}{0}$
$\frac{1}{0}$
$\frac{0}{0}$
$\frac{0}{0}$
$\frac{0}{0}$
$\frac{0}{0}$

$\frac{1}{0}$

京

$\sum_{\square 1}^{\infty}$

馬

๓)

0 을

เ

产

(uy) 4ұdəa 
$\begin{array}{ll}\circ & 8 \\ 1 & 1\end{array}$

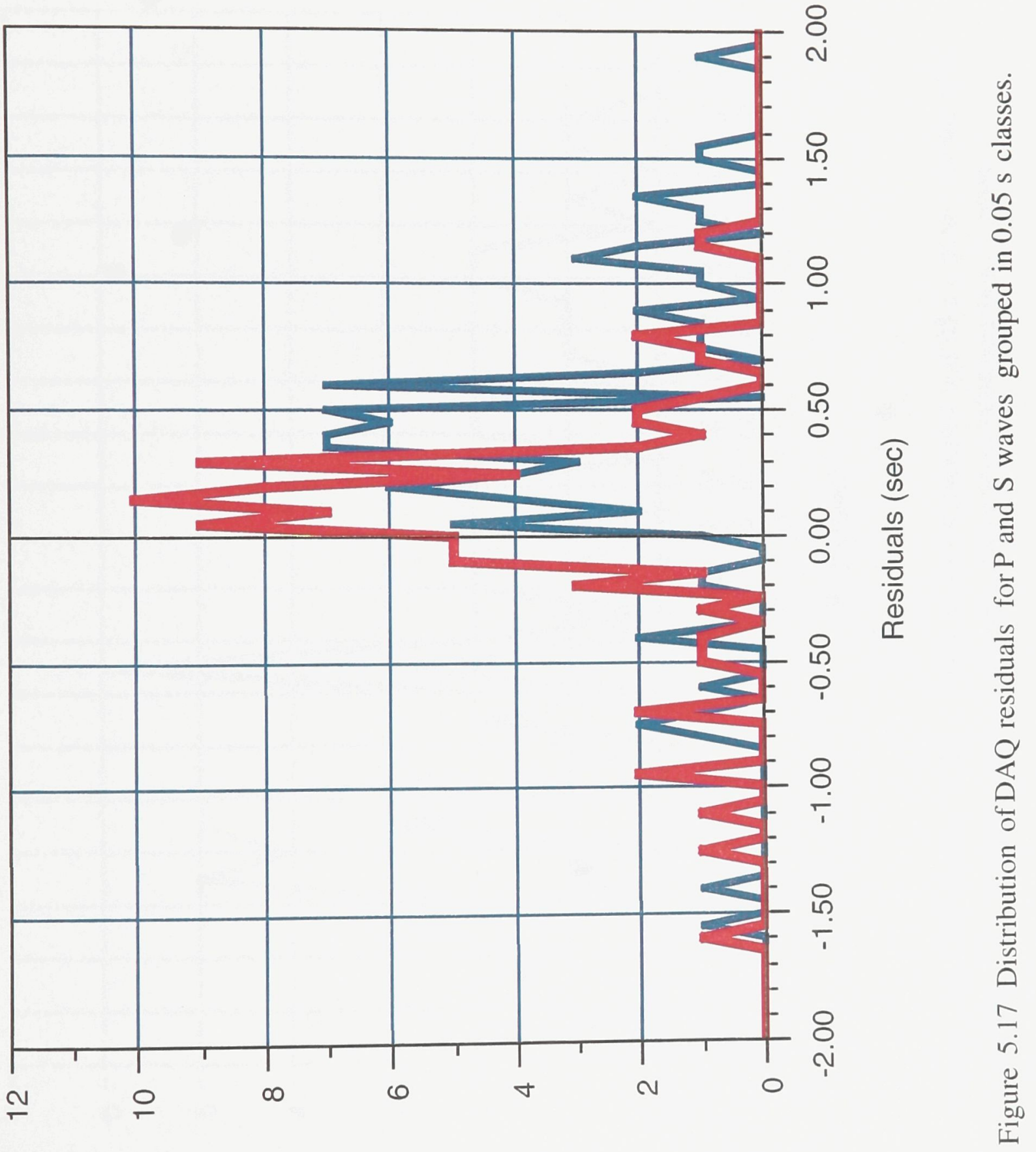

ssejo s0.0 

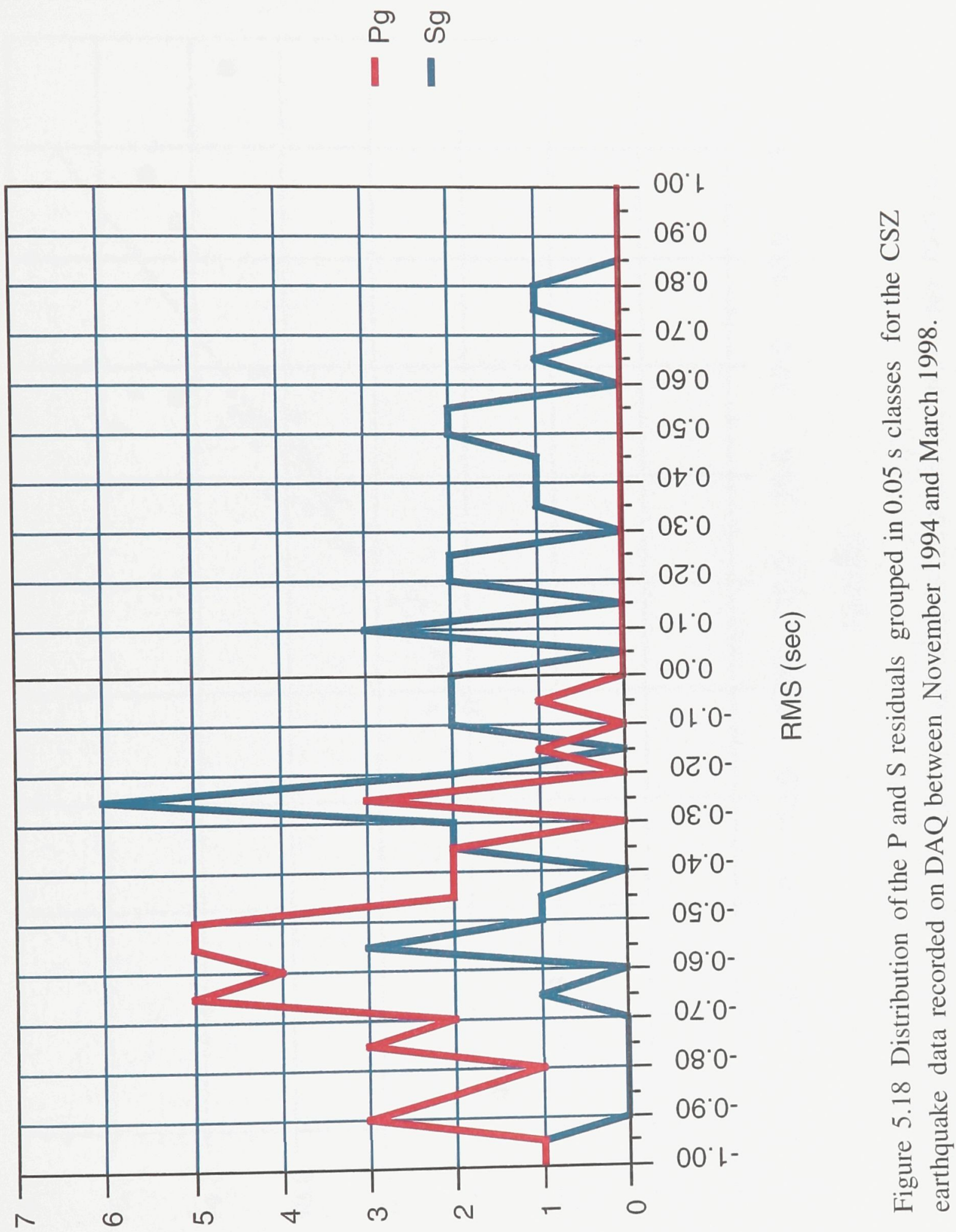

ssejo jəs $90^{\circ} 0$ ləd ıəqunN 


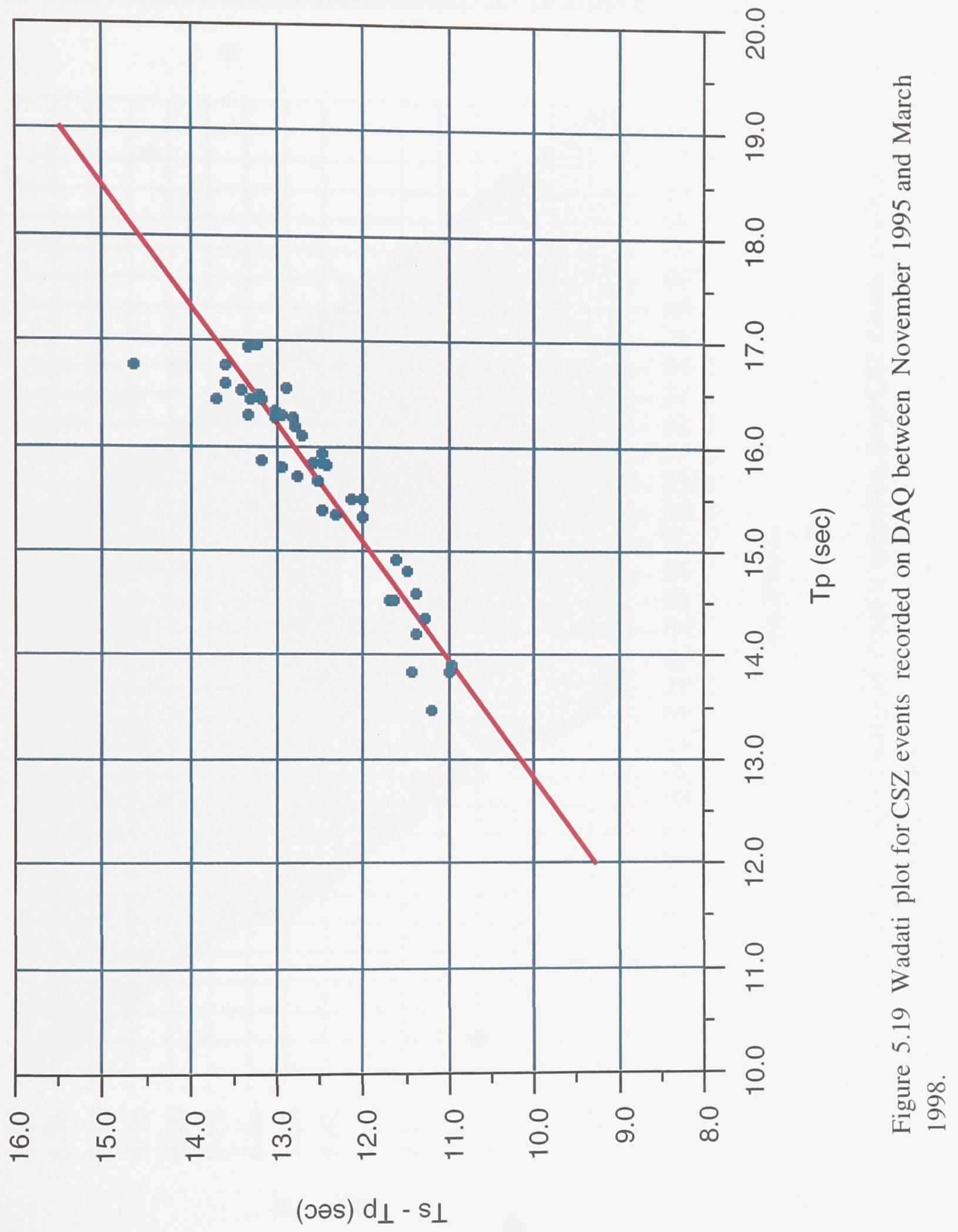




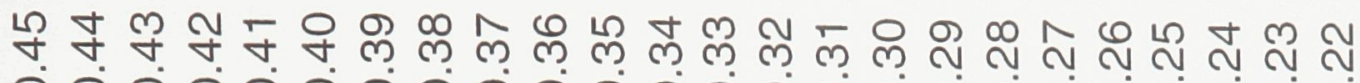

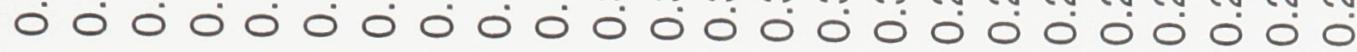

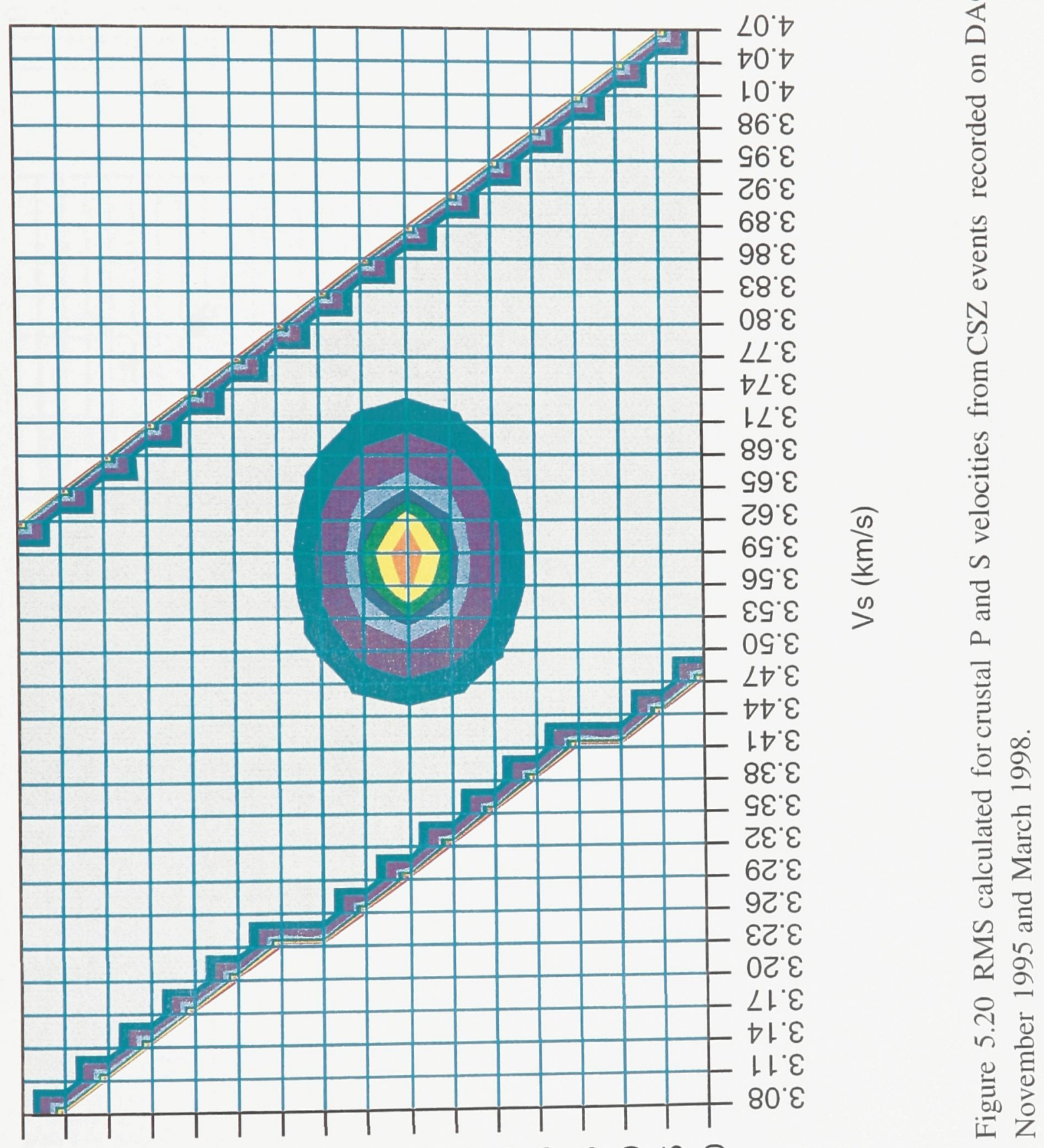

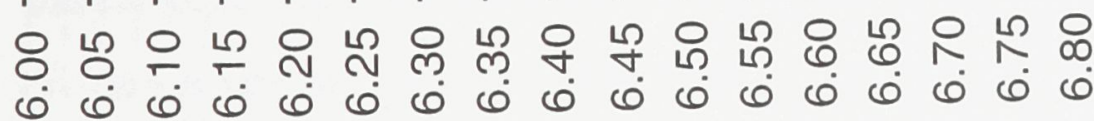

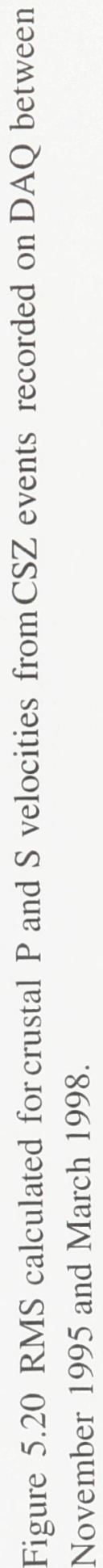

$(s /$ w) $d \wedge$ 


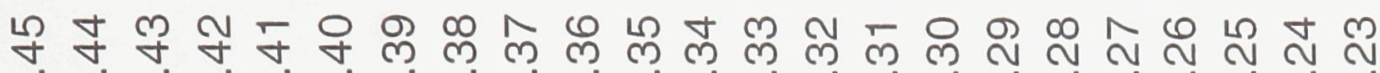

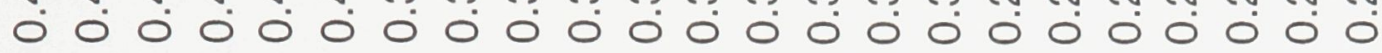

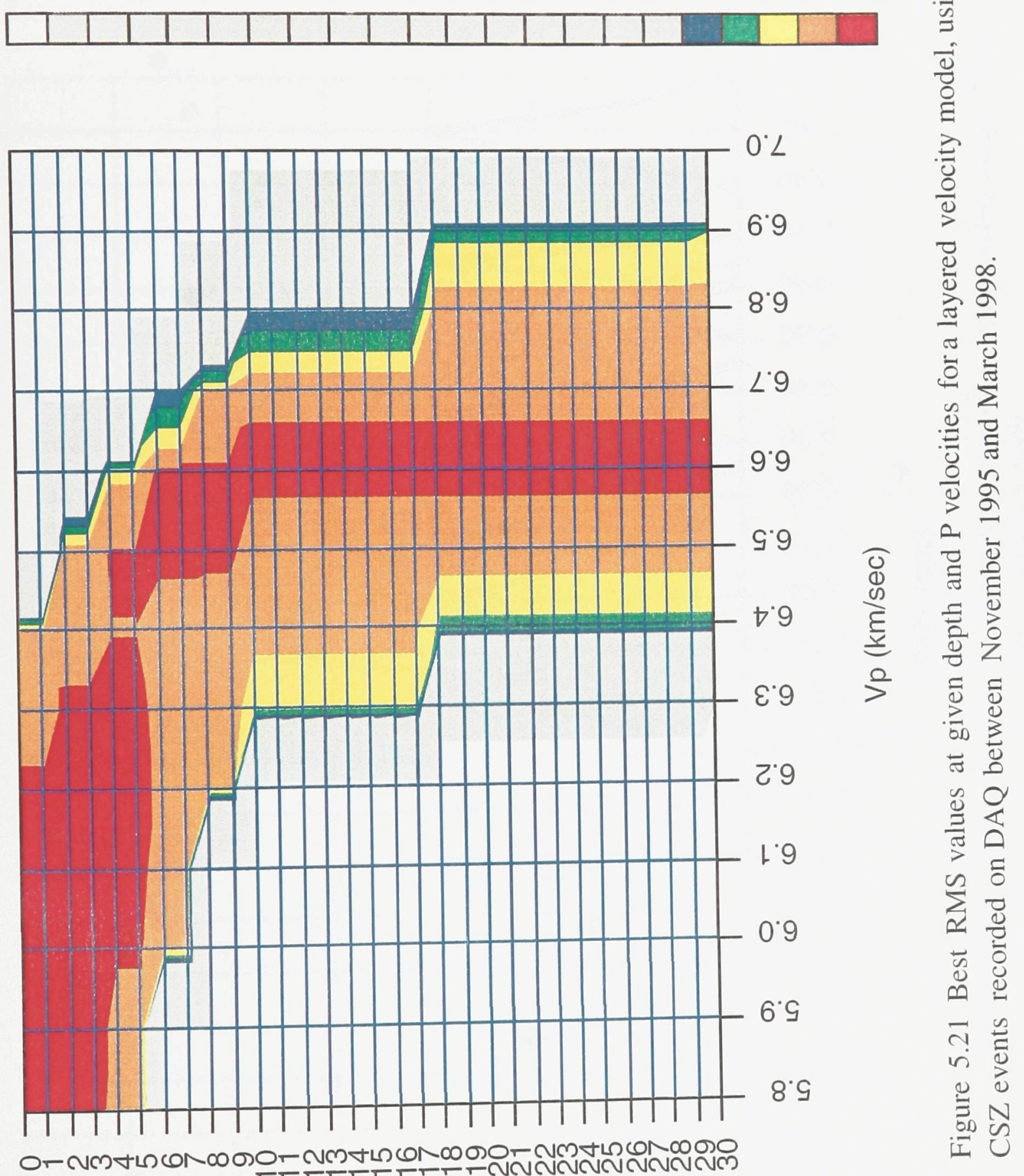

(uy) प1dә0 


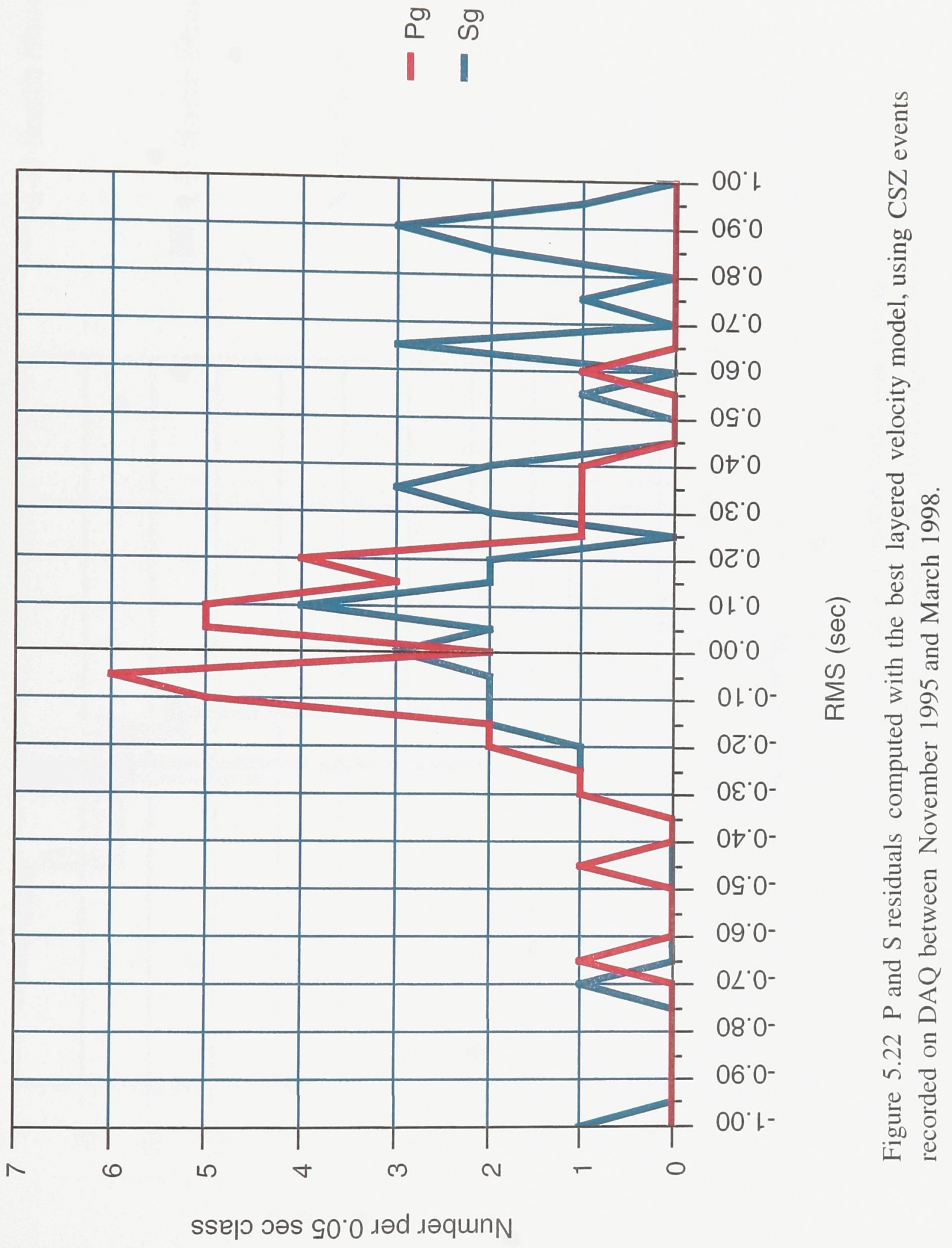



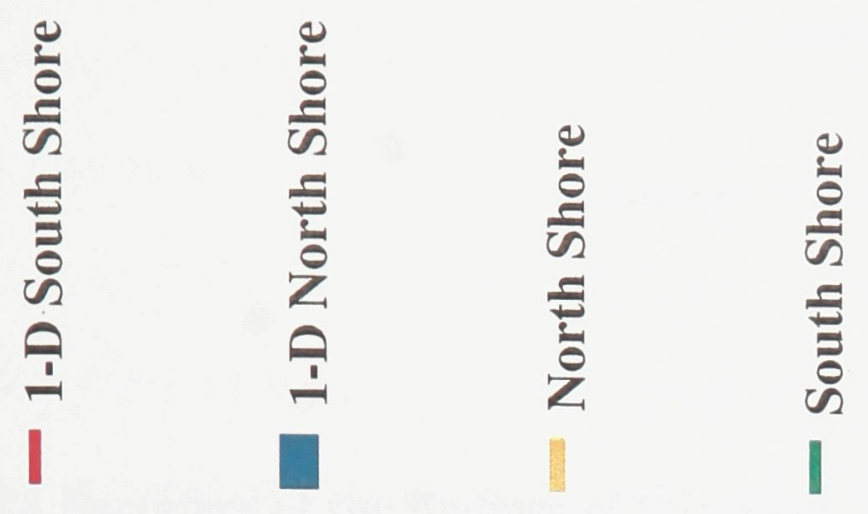

Ð

है

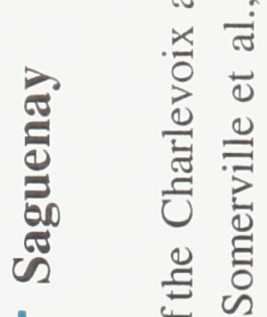

I

莒

象

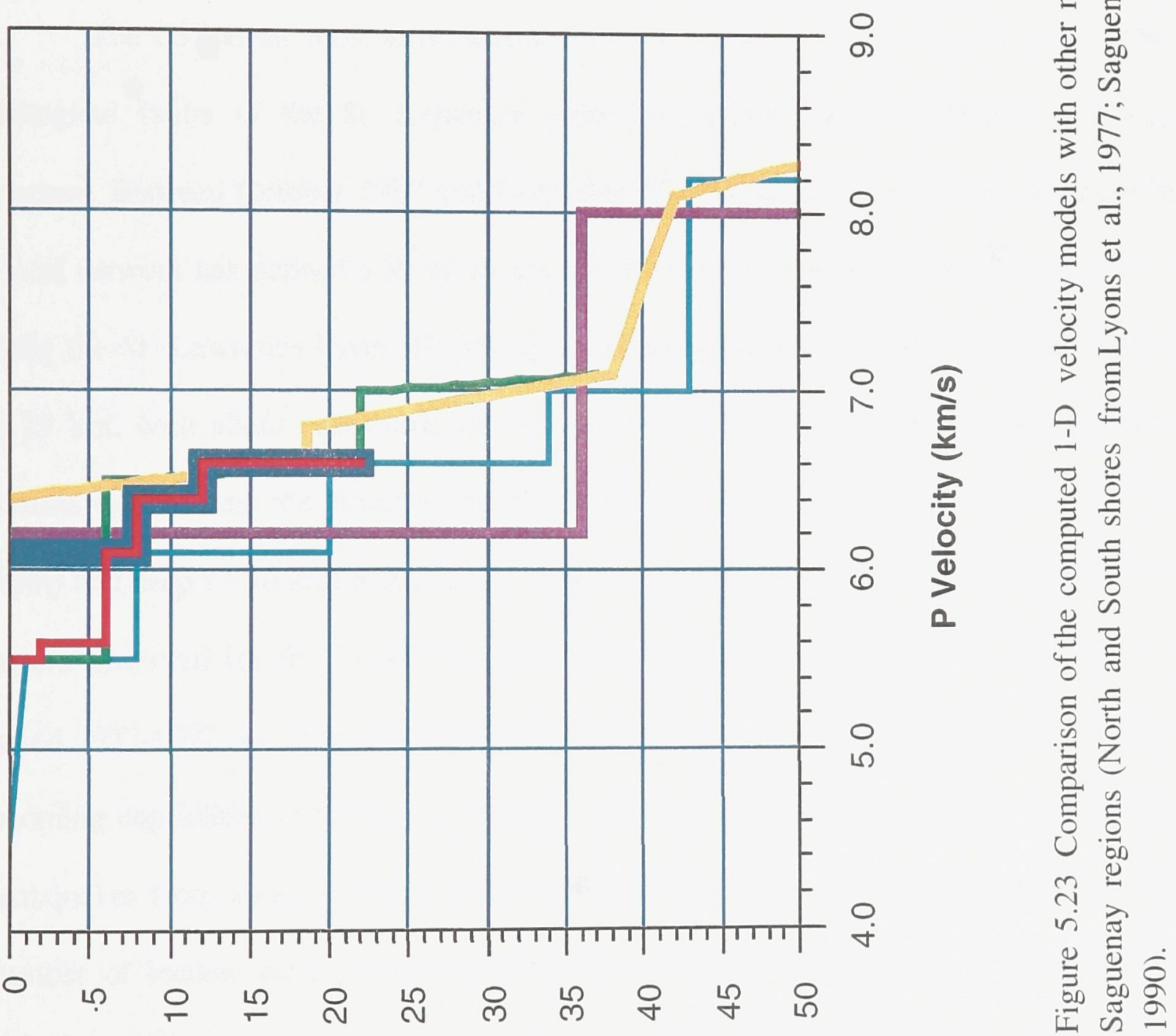

(шу) पұdəa 


\section{Chapter 6}

\section{Summary and discussion}

\subsection{Summary of the findings of this thesis}

The CSZ is the most active seismic zone of eastern Canada. The region contains geological faults of the St. Lawrence paleo-rift system and of a Devonian impact structure. Between October 1977 and December 1997, monitoring of the earthquakes by a local network has defined a 30 by $85 \mathrm{~km}$ active zone of elliptical shape with major axis along the St. Lawrence River. Hypocentral depths are distributed from near the surface to $29 \mathrm{~km}$, with about two thirds between 5 and $16 \mathrm{~km}$. A prominent weakly seismic volume exists along the North Shore of the St. Lawrence River. Most shallow $(<5 \mathrm{~km}$ depth) and deep (> $20 \mathrm{~km}$ ) events occur in specific subareas of the CSZ. Similarly to the pattern observed for the 1924-1978 period, 6 out of the 7 magnitude $>4$ events in the period 1977-1997 occurred in the SW and NE ends of the CSZ. The improvement in the recording capabilities of the local seismograph network has brought the number of located earthquakes from about 100/year in the late 70 's to more than 200/year since 1995 . The number of located earthquakes varies between 0 and 30 per month, with no obvious correlation with magnitude $>4$ occurrences, at either the regional or local level. Using microearthquakes recorded both on regional and local stations, an empirical relation 
between the Nuttli magnitude $\left(m_{N}\right)$ and the Richter magnitude $\left(M_{L}\right.$, used for events only recorded locally) was defined: $\mathrm{m}_{\mathrm{N}}=0.63 \mathrm{M}_{\mathrm{L}}+1.41$ (Section 1.4.3). With a unified magnitude scale, the CSZ magnitude-recurrence curve was extended down to magnitude $\mathrm{m}_{\mathrm{N}} 1.5$, which is the estimated magnitude for completeness of reporting for the 1977-1997 period. On a magnitude recurrence curve, the rate of magnitude $>4$ earthquakes exceeds the level suggested by the lower magnitude events recorded between 1977 and 1997. This may suggest that the magnitude $>4$ events have overestimated magnitudes, or that there is a real change in occurrence rates at higher magnitudes.

On the basis of the heat conduction equation and Grenvillian surface heat flow, the temperature at the cutoff depth of CSZ earthquakes $\left(D_{99 \%}=25 \mathrm{~km}\right)$, has been estimated to be between 215 and $355^{\circ} \mathrm{C}$ (Chapter 2). These temperatures and the inferred mafic mid- and lower-crustal compositions imply a brittle-ductile transition deeper than $25 \mathrm{~km}$. The transition could occur at $25 \mathrm{~km}$ only for surface heat flow higher than the average Grenville value (in the $50 \mathrm{~mW} \mathrm{m^{-2 }}$ range). Currently, two low quality measurements suggest such a high value. With the assumed absence of quartz at mid- and lower crustal depths, the earthquake cutoff depth may correspond to the passage from velocity strengthening to velocity weakening if the onset of flow of hydrated feldspars occurs at temperatures in the $300-350^{\circ} \mathrm{C}$ range. With an assumed maximum crustal stress difference of about $200 \mathrm{MPa}$, fault reactivation at mid-crustal depth can occur with a low friction coefficient and/or with a high pore fluid pressure, or with a change to a highpressure type of fracturing (see also discussion in Section 6.2 in this chapter).

A series of normal faults associated with the St. Lawrence paleo-rift system breaks 
the CSZ crust. On land, most of these faults correspond to lineaments in the remote sensing imagery. Some of these faults, but not all, have geophysical expressions in the magnetic and gravity fields (see discussion in Chapter 3). Offshore and under the Appalachian sequence, some regional-scale normal faults are revealed in the Precambrian basement, using magnetic, gravimetric and seismic reflection data. The structure of the CSZ was studied along four profiles perpendicular to the St. Lawrence River, revealing regional as well as local characteristics. Long normal faults, such as the St. Lawrence faults, and the newly-revealed Charlevoix and South Shore faults, cut across the whole CSZ. The Charlevoix fault is a few kilometres offshore and parallels the north shore. It may represent the structure reactivated by some of the largest CSZ earthquakes, including the 1925 M 6.2 earthquake. The South Shore fault appears to bound the seismic activity to the SE. The attitude of the Precambrian-Appalachian interface changes along the strike of the St. Lawrence River. The NE part of the CSZ, where most magnitude $>4$ events occur, is an area with linear normal faults defining a series of steps in the Precambrian basement. The impact crater, on the other hand, coincides with an interpreted graben under the river, possibly created by the impact readjustment. The SW part, which is weakly seismic, is cut by numerous normal faults parallel and perpendicular to the river's trend. It is suggested that the Charlevoix fault could be one major reactivated fault, while the St-Laurent and South Shore faults bound highly fractured blocks. Reprocessing of a seismic line revealed deep reflectors in the Precambrian basement.

Although the CSZ has been subject to at least five earthquakes of magnitude 6 or greater, no surface rupture was found under the St. Lawrence River (see Chapter 4). A 
systematic search for surface faulting was done on seismic reflection lines for oil exploration and for Quaternary mapping. Some $20 \mathrm{CSZ}$ focal mechanisms for magnitude $>2$ events show mostly reverse to reverse-oblique faulting in the CSZ, with no preferential orientation of the P-axis, but with a higher number of nodal planes in the NE quadrant. Local variations in the stress system appear to occur across the CSZ. Most earthquakes occur in clusters of two events or more, that may or may not have preferred orientation. One of these groups, located under the St. Lawrence, contains about one third of CSZ events, including the $1979 \mathrm{~m}_{\mathrm{N}} 5$ event. It defines one of the best alignments of hypocentres, possibly related to the newly-defined Charlevoix fault. Comparison of these groups with focal mechanisms suggest multiple orientations for the reactivated faults. For the period November 1988 to August 1997, cross-correlation of seismic traces has revealed that less than $15 \%$ of CSZ events are multiplets. Most of these events occurred within a few days of each other. Comparing earthquakes groups and multiplets with focal mechanisms has revealed some fault planes. Reactivated structures can be of local or regional importance, with orientations not necessarily sub-parallel to the Iapetan rift faults. Since most earthquakes are small, the actual dimension of the fracture, or reactivated fault surface, is small (generally in the tens of meters in radius). This aspect, together with the varied orientations of the fault planes, suggest that most earthquakes occur in highly fractured volumes. Study of the various sub-zones of the CSZ also suggest that faults with varied orientations can be reactivated, including some related to the impact crater.

The microearthquake data of the local Charlevoix network was used in an inversion procedure to determine the local velocity structure (Chapter 5). Using some 171 
events recorded between November 1988 and December 1997, the best 1-D crustal model for the CSZ is very close to the "standard" GSC model, i.e., $6.2 \mathrm{~km} / \mathrm{s}$ and $3.57 \mathrm{~km} / \mathrm{s} \mathrm{P}$ and S-wave velocities. Station corrections, defined for the local network, imply lower velocities inside the impact crater. The data were also used to obtain a pseudo 2-D velocity model, i.e. two velocity models corresponding to the north and the south shores respectively. The model resolves the Appalachian sequence of the south shore (6 $\mathrm{km}$ thick sequence with velocities in the 5.6 to $5.8 \mathrm{~km} / \mathrm{s}$ ) and the Precambrian basement (increase in velocity between 8 to $14 \mathrm{~km}$ depth from 6.2 to $6.6 \mathrm{~km} / \mathrm{s}$ ). The best 2-D velocity model reduces significantly the RMS of the solutions. With the improved velocity model, locations of most CSZ events move towards the SE by about $1.5 \mathrm{~km}$. Using CSZ events recorded on the regional station DAQ, a 1-D velocity model was defined for the Laurentides Park region, to the West of the CSZ. The model shows a gradual P-velocity increase from the surface to $10 \mathrm{~km}$ from about 5.9 to $6.7 \mathrm{~km} / \mathrm{s}$. The CSZ velocity structure is different from that of the Laurentides Park. While the Vp/Vs ratio is 1.73 for the CSZ, the $\mathrm{Vp} / \mathrm{Vs}$ is higher $(\approx 1.81)$ in the Laurentides Park. Lithology and possibly the degree of fracturing appear to be the main factor controlling these variations.

\subsection{Why do earthquakes occur in the CSZ?}

Over the last 30 years, a number of studies have proposed factors that may lead to CSZ earthquakes. The proposed causative factors can be grouped in four classes. First, some studies refer to the inherent geological weakness of the CSZ, either primarily due to the rift faults (Adams and Basham, 1991) or to the combined meteor impact-rift faults (Roy and Du Berger, 1983; Anglin, 1984; Lamontagne, 1987). A second group refers to 
the combination of high stress difference and crustal weakness: either postglacial reboundimpact crater (Leblanc et al., 1973; Leblanc and Buchbinder, 1977; Anglin and Buchbinder, 1981); mafic intrusion-impact crater (Stevens, 1980); or stress concentrationimpact crater (Lyons et al., 1980; Hasegawa and Wetmiller, 1980). A third group invokes mainly the effect of stress modifiers: postglacial rebound stress (that can favour thrust earthquakes in the CSZ: James and Bent, 1994; Wu and Hasegawa, 1996); crustal subsidence in the Laurentides Park (which is anomalous compared with the postglacial uplift witnessed in eastern Canada: Frost and Lilly, $1966^{8}$ ); or the effect of past major earthquakes (Bent, 1992; Ebel, 1998). Finally, some refer to possible anomalies in the rock properties such as high pore-fluid pressures at depth (Hasegawa, 1986; Sibson, 1989; Zoback, 1991; Lambert et al., in prep.) and/or low coefficient of friction (Lamontagne and Ranalli, 1996).

The Mohr diagram can be used as a graphic illustration of the factors leading to shear failure (Figure 6.1). Sliding occurs when the Mohr circle is tangent to the Coulomb envelope, i.e. when the shear stress exceeds the strength along the plane of failure. This instability can occur by changing the ambient stress field and/or the stability conditions of the pre-existing fracture. First, the Mohr circle (i.e. the stress conditions) can be brought closer to the failure envelope by modifying either its radius (i.e. the stress difference) or its position. The stress difference can be increased with a larger principal

However, a recent re-evaluation of this subsidence has shown that it is within the error margins of measurements, and consequently of doubtful significance ( $T$. Lambert, pers. comm.). 
compressive stress $\left(\sigma_{1}\right)$, or inversely, by a decrease in the least compressive stress $\left(\sigma_{3}\right)$. The Mohr circle can approach failure (i.e. a shift to the left) with higher pore-fluid pressures, a process responsible for reservoir-induced seismicity. Secondly, fault reactivation can occur if failure conditions are modified. The failure envelope can be brought closer to the Mohr circle, by lowering the cohesion (S) of the pre-existing fractures, or by lowering the coefficient of friction $(\mu)$. In the following sections, I discuss separately the factors affecting the stress system, and those affecting the failure strength of rocks in the CSZ. A summary is given in Figure 6.2.

\subsubsection{The stress system in the CSZ}

In Eastern North America, the inferred maximum horizontal compressive stress axis correlates well with plate tectonics interpretations (Zoback and Zoback, 1991). Over most of the so-called mid-plate stress province, plate driving and resisting forces are primarily responsible for the predominantly ENE orientation of the maximum compressive stress axis. The reorientation in the CSZ may be due to glacioisostatic effects (Wu, 1998). The tectonic stresses can be amplified in the brittle upper crust leading to absolute levels in the $100 \mathrm{MPa}$ range (Hasegawa et al., 1985). Thus, over most of eastern North America, the fundamental situation could be described by the Mohr diagram (Figure 6.1). The situation is stable with stress differences arising from the plate-wide forces which are generally too small to cause reactivation. Unstable situations, such as the one existing in the CSZ, can come about by adding local sources of stress to the ambient stress field (such as flexural stresses and lateral density contrasts/buoyancy forces) and/or by concentrating existing stresses. 
Flexural stresses are caused by changes in the loads on or within the lithosphere (erosion, sedimentation, postglacial readjustment). Of these three, only postglacial rebound is significant in continental Eastern Canada. In areas formerly covered by continental glaciers, glacial rebound stresses can perturb the ambient stress field for thousands of years after glaciers have retreated. Interestingly, the change in the faulting style from reverse faulting in Eastern Canada to strike-slip faulting in the eastern United States occurs approximately at the limit of the former glacial maximum (Zoback, 1992; James and Bent, 1994). Consequently, it is evident that postglacial rebound stresses are perturbing the eastern Canadian stress field. The level of induced stresses, however, is low: the deviatoric stress field is increased only by about 5 to $10 \mathrm{MPa}$ (Wu and Hasegawa, 1996). In the CSZ, the radial component of the postglacial stress field is compressive, oriented NW-SE and larger than the transverse component (James and Bent, 1994). Due to their orientation and small magnitude, postglacial stresses may contribute to thrust faulting in the St. Lawrence Valley (Hasegawa et al., 1985; Wu and Hasegawa, 1996; James and Bent, 1994). In other words, they can favour reverse faulting earthquakes, without constituting the primary cause.

Lateral mass anomalies within or just beneath the lithosphere are additional sources of stress. In the CSZ, upper crustal density variations exist between the Canadian Shield and the Appalachians (evident in Bouguer anomaly maps, e.g. Figure 3.7B). Two approaches have been used to model their impact on the local stresses. In the first one, an elastic model suggested near vertical maximum compressive stress corresponding to the negative gravity anomaly (which in the CSZ case, is approximately the St. Lawrence 
River; Goodacre and Hasegawa, $1980^{\circ}$ ). In the second approach, an elastic multi-layer FE model was used to compute stresses induced by lateral density variations (Assameur and Mareschal, 1995). At $10 \mathrm{~km}$ depth, average stress difference can reach about $27 \mathrm{MPa}$ in regions with the highest density contrasts (east of the Grenville Front, Thetford Mines and the lower St. Lawrence). Of these three areas, only the lower St. Lawrence is seismically active. In the CSZ, induced stress differences are about $10 \mathrm{MPa}$ at $10 \mathrm{~km}$ depth. Assuming a $20 \mathrm{MPa}$ horizontal compression oriented $\mathrm{N} 60^{\circ} \mathrm{E}$, the ambient stress difference increases to $24 \mathrm{MPa}$ when the orientation of the local stress field is considered (Assameur and Mareschal, 1995). Other sources, such as crustal thinning and lithosphere thickening, should not apply to the relatively constant crustal thickness in the CSZ (as inferred from seismic refraction; Lyons et al., 1980). The fact that regions with the highest induced stress differences are mostly aseismic suggests that mass anomalies cannot be the main factor of the CSZ seismicity.

At least two factors can increase the crustal stress difference: inclusions of materials with elastic parameters different from the surroundings, and fault intersections. Stresses can concentrate around a weak inclusion in a rigid and brittle material. Weak hydrated materials such as serpentinized gabbros at mid-crustal depth are particularly good stress concentrators due to the high rigidity contrast they provide with the surrounding rocks (Campbell, 1978). Appropriate orientation of the long axis of the

7 In a thrust environment, additional vertical stress translates into more stable faults. In most papers, paired gravity low and high are usually referred to as a perturbing addition to the stress field, without mentioning the additional stability obtained in a reverse faulting environment. Consequently, the Canadian Shield-Appalachians boundary should not enhance earthquake probability in the CSZ. 
intrusive with respect to the stress field and large size of the intrusive also enhance the effect. In Eastern Canada, it has been noticed that large intrusions such as the Morin anorthosite in the Western Quebec Seismic Zone and the Sept-Iles layered mafic intrusion in the Lower St. Lawrence Seismic Zone, are apparently aseismic areas in epicentral maps (Lamontagne et al., 1989; Lamontagne et al., 1994). In the CSZ, the massive St-Urbain anorthosite body does not seem to act as a stress concentrator; it is not seismic and it is not surrounded by earthquake activity. However, it is possible that a highly fractured volume (i.e. the volume beneath and around the impact crater) may have average elastic parameters lower than the surrounding, less fractured, rock. The analysis by Campbell (1978) shows that, if the body is elliptical in plan view with long axis perpendicular to the direction of maximum compressive stress, the largest stress differences occur just outside the ellipse along the prolongation of its long axis. This situation shows some similarity with the one in the CSZ, where the largest earthquakes occur at the two extremities of the area. The possible effect of contrast in elastic moduli cannot therefore be excluded.

Upper crustal stress concentration of 10 to $100 \%$ can arise due to the strength decrease of a localized area of the lower crust subject to ductile creep (Long and Zelt, 1991). This idea is somewhat different than the model of Hasegawa et al. (1985) which showed upper crustal stress amplification for plate-wide motions. In Chapter 2, the strength of a ductile layer was shown to vary with the lithology, the fluid content and the heat flow. In the CSZ, while lateral heat flow variations are unlikely, lateral changes of ductility in the lower crust cannot be excluded. 
Stresses can also concentrate around intersecting faults (Talwani, 1988). In a rock subject to stress difference, stresses build up in fracture tips. Stress concentration is highest at the locked portions of intersecting faults, reaching eight times the ambient stress level (Talwani, 1988). The intersecting fault model could explain the high earthquake activity in the highly fractured zone within the impact structure. The intersection of these fractures could lead to enhanced stress levels, favouring ruptures, whereas areas with healed fractures would not give rise to the stress build-up necessary to cause an earthquake.

\subsubsection{Physical conditions of the faults}

On the whole, local sources of stress are relatively modest contributors $\left(\sigma_{1}-\sigma_{3}\right.$ $\leq 10-30 \mathrm{MPa}$ ) to the CSZ stress field. Since these contributions are about the same everywhere in Eastern Canada, the CSZ faults must be inherently weak compared to aseismic faults elsewhere. This could be accomplished by either a decrease in friction, an increase in pore-fluid pressure, or a combination of both.

\subsubsection{Coefficient of friction}

From a fault mechanics point of view, a low friction coefficient decreases the fault strength, making it susceptible to reactivation at plausible stress difference values ( $\leq 200$ $\mathrm{MPa}$ ). As shown in Figure 2.9B, without near-lithostatic pore-fluid pressures, a fault with a coefficient of friction $\mu=0.75$ is too strong to be reactivated in the current stress field. A low coefficient of friction (for instance, $\mu=0.3$ ) makes the faults weaker, i.e. more susceptible to reactivation, and allows the reactivation of steeply-dipping faults $\left(\approx 70^{\circ}\right.$, 
as in the CSZ). Although the coefficient of friction is assumed to be decreasing with increasing depth as illustrated by the shallower slope of the Mohr envelope with increasing pressure (Figure 6.1), values of $\mu$ of less than 0.3 cannot be reached without a fault gouge consisting of hydrated clay minerals (Lockner, 1995).

Fault gouges are documented along regional faults of the CSZ. On the St-Laurent paleo-rift fault, for example, a fault gouge exists and was probably created in the normal faulting regime that prevailed in mid- to upper-Ordovician times (Rondot, 1979). The fault is a highly fractured zone, tens of meters wide, and includes breccias and diabase veins (Brassard, 1990). Down to at least $400 \mathrm{~m}$ (maximum depth of the well), the fractures are interconnected and linked to the surface, implying relative permeability. Alteration (silicification, chloritization and carbonatization) is present. In the Quebec City region, St. Lawrence rift faults show hydraulic breccias created during the opening of the Iapetus Ocean when relatively impermeable rocks of the Precambrian basement were shattered by the fluid pressure exceeding the rock strength (Lachapelle, 1993).

Although fault breccias are found along the St. Lawrence paleo-rift faults, the coefficient of friction on these faults is probably not sufficiently small as to bring the crustal strength in the $200 \mathrm{MPa}$ range. A coefficient of friction of 0.3 corresponds to clays and other sheet silicates inter-layered with water, minerals that dehydrate and lose their lubricating properties at mid-crustal depth (Lockner, 1995; Scholz, 1990). Although the weakness of CSZ faults cannot be entirely due to the breccias, CSZ earthquake epicentres correspond to the locations of these breccias on the St. Lawrence rift system (Lachapelle, 1993). This may be a partial explanation of the confinement of CSZ earthquake clusters 
along the St. Lawrence River, and not further inland in the Precambrian Shield. The fault gouge, mapped on numerous rift faults, may sufficiently lower the coefficient of friction to favour reactivation. It could, for example, lower it from high values found with rock on rock friction $(\mu \approx 0.85)$ to lower values associated with smoother surfaces ( $\mu \approx 0.5$ $0.6)$.

\subsubsection{Pore-fluid pressure}

As discussed in Chapter 2, high pore-fluid pressures (near lithostatic level) can bring the crustal strength to within plausible levels ( $\leq 200 \mathrm{MPa})$, even with an average value for the coefficient of friction ( $\mu \approx 0.75$; Figure $2.9 \mathrm{~B}$ ). Worldwide, high pore-fluid pressures appear to explain the relative crustal weakness of seismically active zones, the San Andreas fault being the most prominent example (Rice, 1992).

In the CSZ, evidences for crustal fluids exist ${ }^{10}$. In the late 70's, fluid flow along fault zones was suggested as an explanation for the temporal disappearance of a microgravity anomaly and a change in P-wave velocities (Buchbinder et al., 1988). The anisotropy of travel-time changes in the CSZ observed between 1979 and 1980 was explained by the closing of saturated cracks (Kirsch et al., 1987). Finally, near La Malbaie, magneto-telluric anomalies deeper than $1400 \mathrm{~m}$ can be explained by water or

8 Fluctuations of the water table creating hydraulic pulses were proposed as a means to trigger earthquakes in a prestressed environment at the limit of failure (Tsoflias et al., 1995). Since water levels were measured near Montreal, one may wonder if these measurements apply to the CSZ, some $300 \mathrm{~km}$ downstream, where the St. Lawrence River is $20 \mathrm{~km}$ wide. The diffusion of the water pressure fluctuations to mid-crustal depths implies an unlikely interconnection of the pores from the surface down to $20-25 \mathrm{~km}$. In any case, the pore-fluid pressures could only be hydrostatic in such a model. 
solutions in a zone of high porosity (Chouteau, 1985).

In intraplate environments, such as the CSZ, the sources of these near-lithostatic pore-fluid pressures at mid-crustal depths are subject to debate. In the upper crust, the recognized sources of high pore-fluid pressures are compaction of saturated sediments overlain by low-permeability rocks, and dehydration reactions in metamorphism (Scholz, 1990). These two mechanisms can hardly apply to mid-crustal depth in the CSZ: no sediments are present there and the absence of local tectonic activity does not support active metamorphism. According to some petrological arguments, lower crustal rocks are essentially dry due to hydration reactions that occur at temperatures above $250^{\circ} \mathrm{C}$ (Frost and Bucher, 1994). This opinion, however, is not shared by all (Hyndman and Shearer, 1989). We can speculate that fluids exist along fault zones, from evidence such as along the San Andreas fault (Sibson et al., 1988). Within the fault zone, high pore-fluid pressures exist, as opposed to the surrounding dry rocks. The source for these fluids could be the ductile roots of faults (Rice, 1992) or the lower crust (Sibson, 1992). For the CSZ mid-crust, two possibilities exist: fluids may be trapped by ancient tectonic processes (but the trapping of these fluids for millions of years remain enigmatic); or fluids may originate from below, possibly within the ductile layers of the lower crust (Rice, 1992) or the mantle (Sibson, 1989). Evidence for the deep origins of these fluids includes the distribution of $\mathrm{CO}_{2}$-rich springs in present-day seismic belts (Irwin and Barnes, 1980) and the anomalously high proportion of gases associated with deep origin (such as helium). These anomalies are interpreted as chemicals from the mantle that percolate to the surface through the region's rift faults (from a yearly report of activities by the GHK Group, 
1988).

Once present in the middle crust, fluid pressures must build up to reach nearlithostatic values to cause fault reactivation. This can be achieved in permeable volumes capped by impermeable material. The motion on the fault breaks the seal and allows fluids to migrate upwards, in a fault-valve fashion (Sibson, 1990). One can speculate that the paleo-rift faults of the St. Lawrence rift system represent the conduits to these fluids. As shown by the mapped hydraulic breccias, the Precambrian Shield (outside the meteor impact) is relatively impermeable and restricts fluid flow to these fault zones. In addition to increasing the pore pressure, the fluids can weaken fault zones by chemically corroding gouge material, lowering the coefficient of friction.

\subsection{Discussion}

The deviatoric stress field in the CSZ does not appear anomalously high compared to that of eastern North America. As elsewhere, the CSZ is subject to the mid-plate ambient stress field that provides a large proportion of the deviatoric stress. The CSZ stress difference may be marginally higher than elsewhere due to postglacial rebound, a factor contributing to reverse faulting (James and Bent, 1994). Mass anomalies and stress concentration factors (inclusions with different moduli and fault intersections) can modestly contribute to the stress field. Since most of these conditions exist throughout the Grenville Province, their impact in the CSZ can only be related to the inherent weakness of the mid- to upper crust.

Since the CSZ stress field is comparable to surrounding areas, the Charlevoix 
earthquake activity is likely due to a local crustal weakness, caused by a low coefficient of friction and/or high pore-fluid pressures. A friction coefficient in the 0.2 to 0.3 range, necessary to bring the fault strength to plausible levels, is improbable due to the dehydration of gouge clay minerals at mid-crustal depths. The presence of a fault gouge may, however, bring the coefficient of friction towards the low end of the measured values $(\mu \approx 0.5-0.6$ ). High pore-fluid pressures appears as a likely explanation to many characteristics of the CSZ, such as the low crustal strength (Chapter 2), the sub-zones of enhanced activity (Chapter 4), the tendency of aftershocks to be shallow and outside the immediate rupture of the main shocks (Section 4.6.2.1), the variations in the stress field and in the reactivated fault orientations at the sub-zone level (Section 4.6), and the mismatch of the orientations of reactivated faults with respect to the mid-plate stress field (Zoback, 1992).

In order to take into account the seismic characteristics of the CSZ, any seismotectonic model must be centred on crustal weakness, created in all likelihood by high pore-fluid pressures. Such a model is proposed in Figure 6.3. First, fluids are assumed to exist along some of the major rift faults. The exact source of these fluids is uncertain but they could ascend from the mantle or possibly from the ductile lower crust (Chapter 2). One may speculate that the approximate linear zone defined by the $20 \mathrm{~km}$ depth earthquakes (Figure 1.21E) represents the mid-crustal conduit where fluids ascend to the surface. These fluids migrate to mid-crustal levels, where locally-sealed zones cause local over-pressures (Sibson et al., 1988). The over-pressures, mainly found near the major faults, can reach near-lithostatic levels, inducing fault weakening and favouring 
reactivation. When an earthquake is triggered, the motion on the fault breaks the seal, allowing fluids to migrate upwards, in a fault-valve fashion (Sibson, 1990). If the shock is sufficiently large, aftershocks can be induced where the migrating fluids create instability conditions. Where the surrounding rocks are impermeable, due to fault healing for example, the fluids concentrate, and remain, along the rift faults. This situation appears to be found outside the impact crater, where hypocentres define a clear alignment, and where most magnitude $>4$ earthquakes occur. Where highly fractured zones exist, fluids diffuse in all directions, locally increasing the pore-fluid pressure and eventually creating numerous but small earthquakes. This situation is found within the highly fractured zone inside the crater where hypocentre groups are diffuse, and active faults extremely variable in orientations (as shown by focal mechanisms, earthquake groups and multiplet analysis). Near the central peak of the impact crater, the dense network of intersecting faults can also amplify the local stress level favouring earthquake occurrences.

Outside the CSZ, the lack of seismicity could be due to a combination of factors such as the absence of fluids or of a conduit if fractures are sealed or without fault breccias. The absence of breccias can possibly explain the boundaries of the CSZ. To the NW of the CSZ, the stable craton was never reactivated after the Grenvillian orogeny, whereas the CSZ crust was reactivated in the Paleozoic. According to Wheeler (1996), the SE boundary of the seismicity corresponds to the transition from relatively intact Precambrian rocks to the NW to a zone with thinner Precambrian crust to the SE where faults have been healed. Outside the CSZ, but still along Iapetan rift faults, a much slower 
rate of pore-fluid pressure build-up (and possibly a lower level of fracturing) could explain the rarity of earthquake occurrences. Using the CSZ model, fluid flow from the lower crust can explain the occurrence of two deep earthquakes: the 1988 Saguenay earthquake (29 km depth) and the 1997 Cap-Rouge earthquake (22 km depth).

The absence of any apparent CSZ surface rupture suggests that the current rates of seismic strain release are geologically recent. Had these rates existed over millions of years, evidence of this activity would have been mapped in the field and seen in the seismic reflection profiles. The earthquake activity likely started some thousands of years ago, possibly right after the last glaciation, when conditions were most favourable for reverse faulting in the CSZ (Wu and Hasegawa, 1996). In all likelihood, the current conditions that create CSZ earthquakes may persist for thousands of years in the future. The current stress field depends mainly on factors that change on geological time scales, such as plate motions, and to a lesser extent, postglacial rebound and other stress contributors that will continue to play a role for thousands of years to come. 


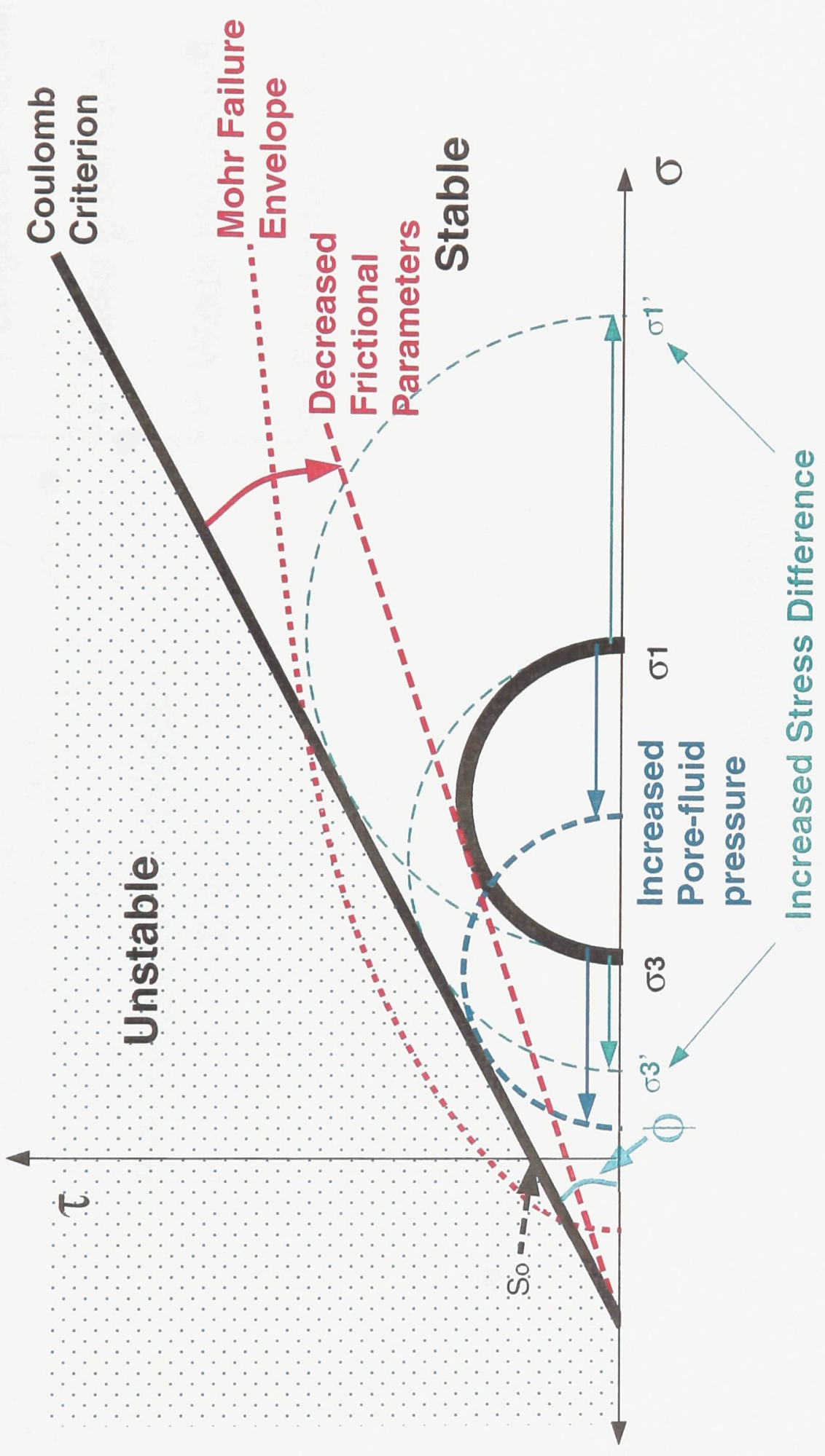

ฮี

E $\dot{\vec{z}} \vec{\theta} \overrightarrow{0}$ 递总 记

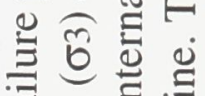
त.$\Xi$ 营苛宁 을

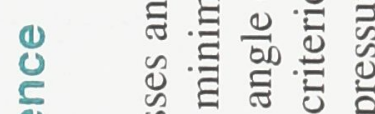

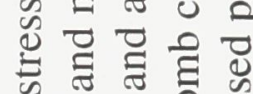

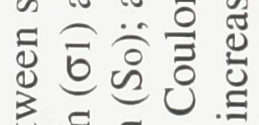
蛋国

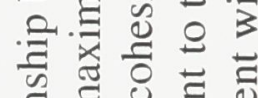

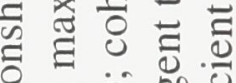
言它交焉焉 品: 巳 कo क के

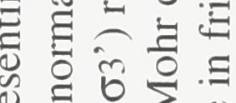

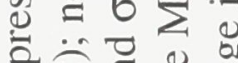
言它㖉 छิ क्ष 0 क $\frac{\pi}{3}$

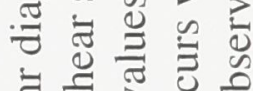
言 战

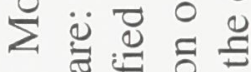
ঢ. 켸 江苛苛 

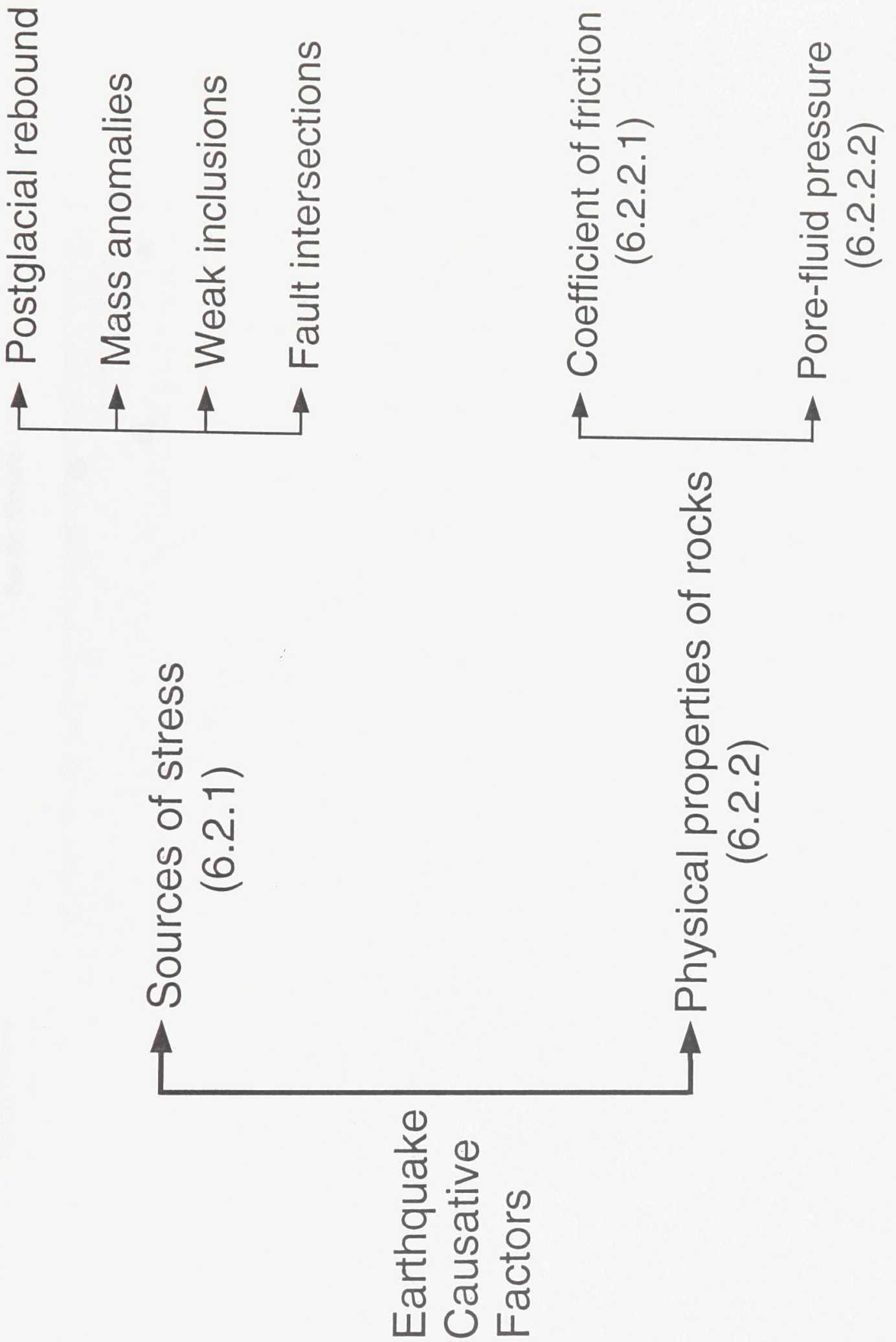


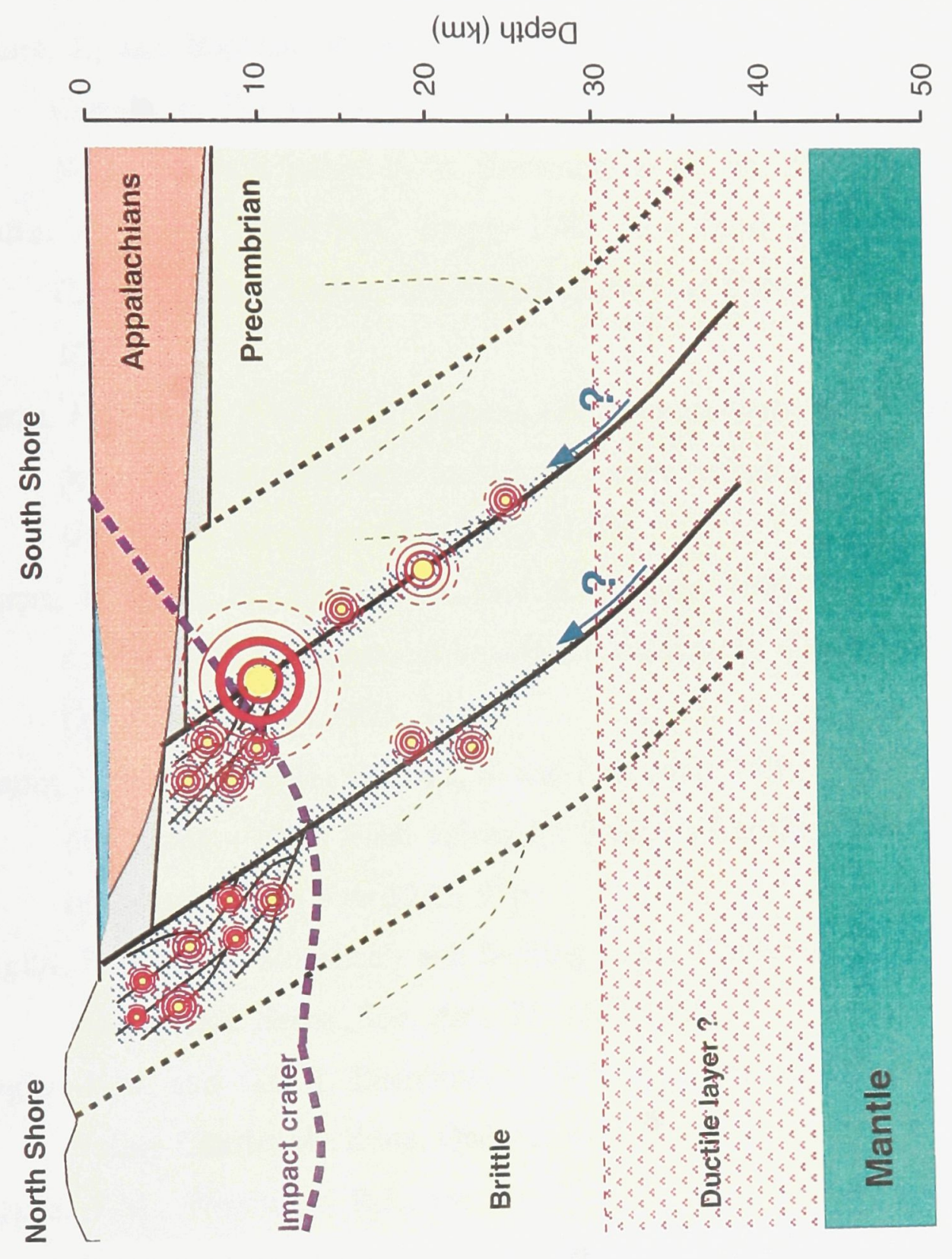

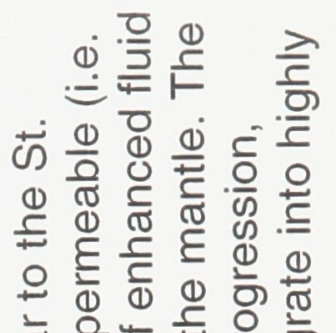

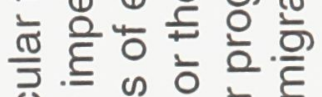

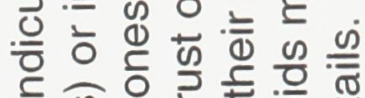
बิ 는 0

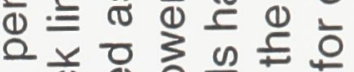

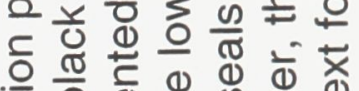
은 $\frac{\pi}{0}$

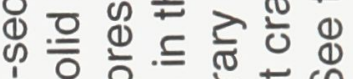

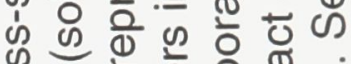
( ) 잉 क्ष ช

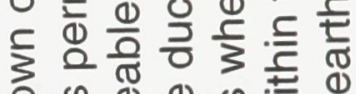
ช क व 以 ब

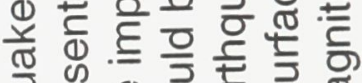

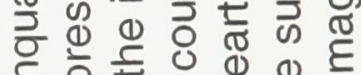

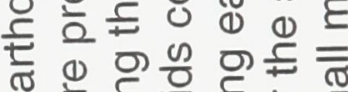

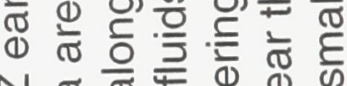
N

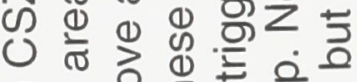
(1) 을 둔

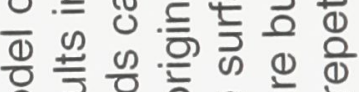

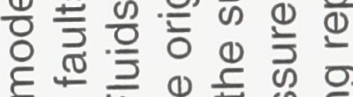

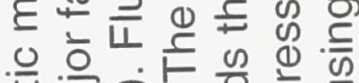

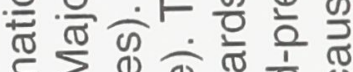

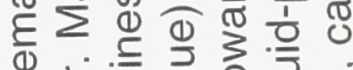
Ф

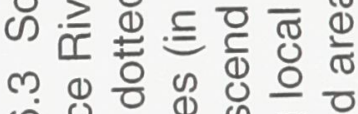
0 웡 凹

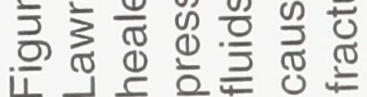




\section{References}

Adams, J., and P.W. Basham, 1989. The seismicity and seismotectonics of Canada East of the Cordillera, Geoscience Canada, 16, 3-16.

Adams, J., and Basham, P. W., 1991. The seismicity and seismotectonics of eastern Canada. in The geology of North America, Decade Map vol. 1, Neotectonics of North America, edited by B. Slemmons et al., pp. 261-275, Boulder, Colo.

Adams, J., Sharp, J. and M.C. Stagg. 1988. New focal mechanisms for southeastern Canadian earthquakes, Geological Survey of Canada Open File Report 1992, 109p.

Adams, J., Basham, P.W. and S. Halchuk,1995. Northeastern North American earthquake potential - new challenges for seismic hazard mapping. Current Research 1995-D; Geological Survey of Canada, p. 91-99.

Adams, J., Vonk, A., Pittman, D., and H. Vatcher, 1989. New focal mechanisms for southeastern Canadian earthquakes - Volume II, Geological Survey of Canada Open File Report 1995, 97 p.

Adams, J., Weichert, D.H., Halchuk, S. and P. Basham 1996. Trial Seismic Hazard Maps of Canada - 1995: Final values for Selected Canadian Cities. Geological Survey of Canada Open File 3283, 97p.

Anglin, F.M. 1984. Seismicity and faulting in the Charlevoix zone of the St. Lawrence valley, Bull. Seism. Soc. Am., 71, 1553-1560.

Anglin, F.M. and G.G.R. Buchbinder, 1981. Microseismicity in the mid-St. Lawrence Valley Charlevoix Zone, Québec, Bull. Seism. Soc. Am.., 71, 1553-1560.

Anglin, F.M., Wetmiller, R.J., Horner, R.B., Rogers, G.C., and J.A. Drysdale, 1990. Seismicity map of Canada, Geological Survey of Canada. Canadian Geophysical Atlas, Map 15, scale 1:10 000000.

Ashwal, L.D., Morgan, P., Kelly, S.A., and J.A. Percival, 1987. Heat production in an Archean crustal profile and implications for heat flow and mobilization of heat-producing elements, Earth and Planet. Sci. Lett., 85, 439-450.

Assameur, D.M and J.C. Mareschal, 1995. Stress induced by topography and crustal 
density heterogeneities: implication for the seismicity of southeastern Canada. Tectonophysics, 241, 179-192.

Atkinson, G.M. and D.M. Boore, 1998. Evaluation of models for earthquake source spectra in eastern North America. Bull. Seism. Soc. Am., 88, 917-934.

Avé Lallemant, H.G., 1978. Experimental deformation of diopside and websterite, Tectonophysics, 48, 1-27.

Banda, E. and S. Cloetingh, 1992. Europe's lithosphere - Physical properties. in: A continent revealed - The European geotraverse, Blundell, D., Freeman, R. and S. Mueller eds., Cambridge University Press, Cambridge, U.K., pp. 71-91.

Basham, P. W., Weichert, D.H., Anglin, F.M., and M.J. Berry, 1982. New probabilistic strong ground motion maps of Canada: a compilation of earthquake source zones, methods and results. Publications of the Earth Physics Branch, Open File 82-33, 202p. (Energy, Mines and Resources, Canada).

Bent, A.L. 1992. A re-examination of the 1925 Charlevoix, Quebec, earthquake, Bull. Seism. Soc. Am., 82, 2097-2113.

Berry, M.J., and K. Fuchs, 1973. Crustal structure of the Superior and Grenville Provinces of the northeastern Canadian Shield, Bull. Seis. Soc. Am., 63, 1393-1432.

Blanpied, M.L., Locker, D.A., and J.D. Byerlee, 1991. Fault stability inferred from granite sliding experiments at hydrothermal conditions, Geophys. Res. Lett., 18, 609-612.

Boland, J.N., and T.E. Tullis, 1986. Deformation behavior of wet and dry pyroxenite in the brittle to ductile transition region. In: B.E. Hobbs and H.C. Heard (Editors), Mineral and rock deformation: laboratory studies. The Paterson Volume. Am. Geophys. Union, Monogr., 36, 35-50.

Brassard, B. 1990. Rapport de fin de forage du puits GHK, Les Eboulements no. 1 (90FE011). Travaux Statutaires GHK, Ministère des Ressources Naturelles du Québec, 12p.

Buchbinder, G.G.R. 1985. Shear-wave splitting and anisotropy in the Charlevoix Seismic Zone, Quebec, Geophys. Res. Letters, 12, 425-428. 
Buchbinder, G.G.R., 1989. Shear-wave splitting and anisotropy in the Charlevoix seismic zone, Quebec, in 1985, Can J. of Earth Sci., 26, 2691-2696.

Buchbinder, G.G.R., Lambert, A., Kurtz, R.D., Bower, D.R., Anglin, F.M., and J. Peters. 1988. Twelve years of geophysical research in the Charlevoix seismic zone, Tectonophysics, 156, 193-224.

Byerlee, J. 1978. Friction of rocks, Pure and Applied Geophysics, 116, 615-626.

Campbell, D.L., 1978. Investigation of the stress concentration mechanism for intraplate earthquakes, Geophys. Res. Lett., 5, 477,479.

Carter, N.L., and M.C. Tsenn, 1987. Flow properties of continental lithosphere. Tectonophysics, 136, 27-63.

Chapman, D.S., 1986. Thermal gradients in the continental crust. In: The Nature of the Lower Continental Crust, Dawson, Carswell, Hall, Wedepohl eds., Geological Society Special Publication No. 24, pp. 63-70.

Chapman, M.C., Powell, C.A., Vlahovic, G., and M.S. Sibol, 1997. A statistical analysis of earthquake focal mechanisms and epicenter locations in the eastern Tennessee seismic zone, Bull. Seism. Soc. Am., 87, 1522-1536.

Chen, W.-P., and P. Molnar, 1983. Focal depths of intracontinental and intraplate earthquakes and their implications for the thermal and mechanical properties of the lithosphere. J. Geophys. Res., 88, 4183-4214.

Chen, W.-P., 1988. A brief update on the focal depths of intracontinental earthquakes and their correlations with heat flow and tectonic age, Seism. Res. Lett., 59, 263-272. Chouteau, M., 1985. Magnetotelluric measurements in La Malbaie area (Quebec): the anomalous vertical magnetic field, Can. J. Earth Sci., 22, 1530-1536.

Du Berger, R., D.W. Roy, M. Lamontagne, G. Woussen, R.G. North and R.J. Wetmiller. 1991. The Saguenay (Québec) earthquake of November 25, 1988: Seismological data and geological setting, Tectonophysics, 186, 59-74.

Christie, J.M. and A. Ord, 1980. Flow stress from microstructures of mylonites: example and current assessment, J. Geophys. Res., 85, 6253-6262.

De Sève, D., Desjardins, R., andT. Toutin, 1994. Contribution des données Radar D'ERS-1 dans l'appréhension de l'organisation des linéaments: Le cas de 
l'astroblème de Charlevoix. Can. J. of Remote Sensing, 20, 233-244.

Deichmann, N., and L. Rybach, 1989. Earthquakes and temperatures in the lower crust below the northern alpine foreland of Switzerland. In: Properties and processes of the Earth's lower crust, R.F. Mereu, S. Mueller, and D.M. Fountain (eds.), American Geophysical Union, Geophysical Monograph 51, IUGG Volume 6, pp. 197-213.

Deichmann, N. and M. Garcia-Fernandez, 1992. Rupture geometry from high-precision relative hypocentre locations of micro-earthquake clusters., Geophys. J. Int., 110, 501-517.

Doig, R. 1986. A method for determining the frequency of large-magnitude earthquakes using lake sediments, Can. Journ. Earth Sci., 23, 930-937.

Doser, D.I. and H. Kanamori, 1986. Depth of seismicity in the Imperial Valley region, 1977-1983 and its relationship to heat flow, crustal structure, and the October 15, 1979, earthquake, J. Geophys. Res., 91, 675-688.

Drury, M.J., 1989. The heat flow-heat generation relationship: Implications for the nature of continental crust, Tectonophysics, 164, 93-106.

Drury, M.J., 1987. Heat flow provinces reconsidered, Phys. Earth and Planet. Int., 49, 78-89.

Drysdale, J.A., Horner, R.B., Kolinsky, R. and M. Lamontagne,. 1990. Canadian Earthquakes--National Summary - January-March 1990. Energy, Mines and Resources Canada. (Mechanisms by W. McNeil and J. Adams).

Drysdale, J.A., Horner, R.B., Kolinsky, R. and M. Lamontagne, 1991. Canadian Earthquakes--National Summary - October-December 1990. Energy, Mines and Resources Canada. (Mechanisms by W. McNeil).

Drysdale, J.A., Horner, R.B., Kolinsky, R. and M. Lamontagne, 1989. Canadian Earthquakes--National Summary - January-March 1989. Energy, Mines and Resources Canada. (mechanisms by J. Adams).

Ebel, J. 1998. Paleoseismicity evidence for past large earthquakes. Abstract in Seism. Res. Letters, 69, p. 78.

Emslie, R.F. and P.A. Hunt, 1990. Ages and petrogenetic significance of igneous 
mangerite charnockite suites associated with massif anorthosites, Grenville Province, Journal of geology, 98, 213-231.

Etheridge, M.A., 1983. Differential stress magnitudes during regional deformation and metamorphism: Upper bound imposed by tensile fracturing, Geology, 11, 231-234. Fadaie, K., and G. Ranalli, 1990. Rheology of the lithosphere in the East African Rift System, Geophysical Journal International, 102, 445-453.

Feininger, T., 1993. Geology and geophysics of the "type" anorthosite, Château-Richer, Quebec, The Canadian Mineralogist, 31, 849-859.

Filion, L., Quinty, F., and C. Bégin. 1991. A chronology of landslide activity in the valley of Rivière du Gouffre, Charlevoix, Québec, Can. J. Earth. Sci., 28, 250-256.

Frémont, M.J. and S.D. Malone 1987. High precision relative locations of earthquakes at Mount St. Helens, Washington, J. Geoph. Res., 92, B10, 10223-10236.

Frohlich, C. 1996. Cliff's nodes concerning plotting Nodal Lines for P, Sh and Sv. Seismological Research Letters, 67, 16-24.

Frost, B.R., and K. Bucher, 1994. Is water responsible for geophysical anomalies in the deep continental crust? A petrological perspective. Tectonophysics, 231: 293-309.

Frost, N.H., and Lilly, J.E., 1966. Crustal movements in the Lake St. John area, Quebec. Can. Surveyor, 20, 292-299.

GHK, 1988. Second year exploration summary, Charlevoix Impact structure, The Province of Quebec, Canada. Report on statutory work, Ministère des ressources naturelles du Québec, 3 p.

Goodacre, A.K., and H.S. Hasegawa, 1980. Gravitationally induced stresses at structural boundaries, Can. J. of Earth Sciences, 17, 1286-1291.

Grieve, R.A.F., 1993. Impact craters: Lessons from and for the Earth. Vistas in Astronomy, 36, 203-230.

Guillou, L., Mareschal, J.-C., Jaupart, C., Gariépy, C., Bienfait, G., and R. Lapointe, 1994. Heat flow, gravity and structure of the Abitibi belt, Superior Province, Canada: Implications for mantle heat flow, Earth. Planet. Sci. Letters, 122, 103123. 
Guillou-Frottier, L., Mareschal, J.-C., Jaupart, C., Gariépy, C., Lapointe, R. and G. Bienfait, 1995. Heat flow variations in the Grenville Province, Canada. Earth. Planet. Sci. Letters, 136, 447-460.

Gutenberg, B., and C.F. Richter, 1956. Magnitude and energy of earthquakes, Ann. Geofis., 9, 1-15.

Hasegawa, H.S., 1986. Seismotectonics in eastern Canada: an overview with emphasis on the Charlevoix and Miramichi region, Earthquake Notes, 57, 83-94.

Hasegawa, H.S., and R.J. Wetmiller, 1980. The Charlevoix earthquake of 19 August 1979 and its seismo-tectonic environment, Earthquake Notes, 51, no.4, 23-37.

Hasegawa, H.S., Adams, J., and K. Yamazaki, 1985. Upper crustal stresses and vertical stress migration in eastern Canada, J. Geophys. Res., 90, 3637-3648.

Hearty, D.J., Mereu, R.F. and C. Wright, 1977. Lateral variations in upper crustal structure below La Malbaie area from slowness, azimuth, and travel time measurements of teleseisms, Can. J. Earth Sci, 14, 2284-2293.

Hodgson, E.A. 1925. The St. Lawrence earthquake, February 28, 1925, Bull. Seis. Soc. Am., 25, no. 2, 84--105.

Hodgson, E.A. 1950. The St. Lawrence earthquake, March 1, 1925. Publications of the Dominion Observatory, Ottawa, 7 (10), 361-436.

Huber, P.J., 1981. Robust statistics, John Wiley, New York, 308 p.

Hyndman, R.D., and P.M. Shearer, 1989. Water in the lower continental crust: modelling magnetotelluric and seismic reflection results, Geophys. Journ. Intern., 98, 343365.

Irwin, W. P., and I. Barnes, 1980. Tectonic relations of carbon dioxide discharges and earthquakes, J. Geophys. Res., 85, 3115-3121.

Jaeger J.C. and N.G.W. Cook, 1979. Fundamentals of rock mechanics, 3rd edition, Chapman and Hall, London.

James, T.S. and A.L. Bent, 1994. A comparison of eastern North American seismic strain-rates to glacial rebound strain-rates, Geophys. Res. Letters, 21, 2127-2130. Jaupart, C., Mareschal, J.C., and L. Guillou-Frottier, 1998. Heat flow and thickness of the 
lithosphere in the Canadian Shield, J. Geophys. Res., 103, 15,263-15,286.

Jessop, A.M., Lewis, T.J., Judge, A.S., Taylor, A.E., and M.J. Drury, 1984. Terrestrial heat flow in Canada, Tectonophysics, 103, 239-2619.

Johnston, A.C., 1993. Average stable continental earthquake source parameters based on constant stress drop scaling. Abstract, $65^{\text {th }}$ Annual Meeting of the E.S.S.S.A., Seism. Res. Lett., 64, 261.

Jones, R.H., and R.C. Stewart, 1997. A method for determining significant structures in a cloud of earthquakes, J. Geophys. Res., 102, 8245-8254.

Juhlin, C. and L.B. Pedersen, 1987. Reflection seismic investigations of the Siljan impact structure, Sweden, J. Geophys. Res., 92, 14,113-14122.

Keary, P., and M.D. Thomas, 1979. Interpretation of the gravity field of the Lac Fournier and Romaine River anorthosite massifs, eastern Grenville Province: significance on the origin of anorthosite, J. Geol. London, 136, 725-736.

Kumarapeli, P.S. 1978. The St. Lawrence paleo-rift system: a comparative study. I.B. Remberg and E.-R. Neumann (eds.), Tectonics and geophysics of continental rifts, 367-384.

Keating, P., 1998. Weighted Euler deconvolution of gravity data, Geophysics, 63, 15951603.

Kirby, S.H., 1983. Rheology of the lithosphere. Rev. of Geophys. Space Physics, 21 1458-1487.

Kirby, S.H. and A.K. Kronenberg, 1984. Deformation of clinopyroxenite: evidence for a transition in flow mechanisms and semibrittle behavior., J. Geophys. Res, 89, 3177-3192.

Kirby, S.H., and A.K. Kronenberg, 1987, Rheology of the lithosphere: selected topics, Rev. Geophys., 25, 1219-1244.

Kirsch, R., Lambert, A., and G.G.R. Buchbinder 1987. The seismic travel-time drop in the Charlevoix region from 1979 to 1980: evidence for aligned saturated cracks in the crust, Tectonophysics, $140,145-154$.

Kissling, E. 1988. Geotomography with local earthquake data, Rev. of Geoph., 26, 659-698. 
Kissling, E., Ellsworth, W.L., Eberhart-Phillips, D., and U. Kradolpher, 1994. Initial reference models in earthquake tomography, J. Geophys. Res., 99, 19,635-19,646. Kohlstedt, D.L, and M.S. Weathers, 1980. Deformation-induced microstructures, paleopiezometers, and differential stresses in deeply eroded fault zones, $J$. Geophys. Res., 85, 6269-6285.

Kumarapeli, P.S., 1987. Seismic zones, ancient fault systems and post-glacial faulting in Eastern Canada: Geological Survey of Canada, Open File 1617, 51 p.

Kusznir, N.J., and M.H.P . Bott, 1977. Stress concentration in the upper lithosphere caused by underlying visco-elastic creep, Tectonophysics, 43, 247-256.

Kusznir, N.J., and R.G. Park, 1984. Intraplate lithosphere deformation and the strength of the lithosphere, Geophys. J. Royal Astron. Soc., 79, 513-538.

Lachapelle, R., 1993. La limite sud du bouclier canadien dans la région de Québec: un phénomène de fragmentation continentale reliée à l'ouverture de l'océan Iapetus, M.Sc. Thesis, Université du Québec à Montréal, $100 \mathrm{p}$.

Lambert, A., James, T.S., Liu, J., Stephenson, D.G., Mainville, and M.K. Paul, 1998. Vertical crustal movements in the vicinity of the Charlevoix earthquake Zone revisited. (In prep.)

Lachenbruch, A.H., and J.H. Sass, 1980. Heat flow and energetics of the San Andreas fault zone, J. Geophys. Res., 85, 6269-6222.

Lamontagne, M. 1985. Composite P-nodal solution analysis of earthquakes from the Charlevoix Seismic Zone. M. Sc. Thesis, University of Western Ontario, London, Ont., 135 p.

Lamontagne, M., 1987. Seismic activity and structural features in the Charlevoix region, Quebec, Can. J. Earth Sci., 24, 2118-2129.

Lamontagne, M. 1998. "New and Revised Earthquake Focal Mechanisms of the Charlevoix Seismic Zone, Canada", GSC Open File Report 3556, 302 p.

Lamontagne, M. and G. Ranalli, 1996. Thermal and rheological constraints on the earthquake depth distribution in the Charlevoix, Canada, intraplate seismic zone. Tectonophysics, 257, 55-69.

Lamontagne, M. and G. Ranalli, 1997. Faults and spatial clustering of earthquakes near 
La Malbaie, Charlevoix Seismic Zone, Canada. Seismological Research Letters, $68,337-352$.

Lamontagne, M., Wetmiller, R.J., I. Asudeh, 1997. The 1996 summer field experiment, Geological Survey of Canada Open File Report no. 3453, 104p.

Lamontagne, M., Cooper, R.V., Halpenny, J. and G. Ranalli, 1995. Understanding the Charlevoix Seismic Zone: help given by new gravity data, Canadian Geophysical Union, Program and Abstracts, p. 78.

Lamontagne, M., Adams, J.E., Feininger, T., Loncarevic, and D.B.,Lefebvre. 1989. Seismicity and geophysical characteristics of the Lower St. Lawrence region. Current activities forum; program with abstracts. Geological Survey of Canada, Ottawa, ON, Canada.

Lamontagne, M., Hasegawa, H.S., Forsyth, D.A., Buchbinder, G.G.R., and M. Cajka. 1994. The Mont-Laurier, Québec, earthquake of 19 October 1990 and its seismotectonic environment, Bull. Seism. Soc. Am., 84, 1505-1522.

Laznicka, P. 1988. Breccias and coarse fragmentize: petrology environments, associations, ores, Developments in Economic Geology, 25, Elsevier eds., Amsterdam, 832p.

Leblanc, G. and G.G.R. Buchbinder. 1977. Second micro-earthquake survey of the St. Lawrence Valley near La Malbaie, Quebec, Can. J. Earth Sci., 14, 2778-2789.

Leblanc, G., Stevens, A.E., Wetmiller, R.J. and R. Du Berger. 1973. A micro-earthquake survey of the St. Lawrence Valley near La Malbaie, Quebec, Can. J. Earth Sci., 10, 42- 53.

Li, Y., Doll, C. and M.N. Toksoz 1995. Source characterization and fault plane determinations for $\mathrm{MbLg}=1.2$ to 4.4 earthquakes in the Charlevoix seismic zone, Quebec, Canada, Bull. Seism. Soc. Am. 85, pp 1604-1621.

Locker, D.A. 1995. Rock failure. in Rock physics and phase relations; A handbook of physical constants, AGU reference Shelf 3, 127-147.

Loncarevic, B.D., Feininger, T. and D. Lefebvre, 1990. The Sept- Iles layered mafic intrusion: geophysical expression, Can. J. Earth Sci., 27, 501-512.

Long L.T., and K.-H. Zelt, 1991. A local weakening of the brittle-ductile transition can 
explain some intraplate seismic zones, Tectonophysics, 186, 175-192.

Lyons, J.A., Forsyth, D.A., and J.A. Mair, 1980. Crustal studies in the La Malbaie Region, Quebec, Can. J. of Earth Sci., 17, 478-490.

Mareschal, J.-C., 1991. Downward continuation of heat flow density data and thermal regime in eastern Canada, Tectonophysics, 194, 356-364.

McGarr, A., and N.C. Gay, 1978. State of stress in the earth's crust, Ann. Rev. of Earth and Planet. Sci., 6, 405-436.

Meissner, R. and J. Strehlau, 1982. Limits of stresses in continental crusts and their relation to the depth-frequency distribution of shallow earthquakes, Tectonics, 1 , 73-89.

Meissner, R., and Th. Wever, 1992. The possible role of fluids for the structuring of the continental crust, Earth-Sci. Rev., 32, 19-32.

Mereu, R.F., and G. Jobidon, 1971. A seismic investigation of the crust and Moho on a line perpendicular to the Grenville Front, Can. J. Earth. Sci., 8, 1553-1583.

Molnar, P. and H. Lyon-Caen, 1988. Some simple physical aspects of the support, structure, and evolution of mountain belts, In: Geological Society of America, Special Paper 218, pp. 179-207.

Moustafa, A.R. 1992. A new technique for the analysis of directional and orientational data, Computers and Geosciences, 18, 1107-1119.

Musacchio, G., Mooney, W.D., and J.H. Luetgert, 1997. Composition of the crust in the Grenville and Appalachian Provinces of North America inferred from Vp/Vs ratios, J. Geophys. Res., 102, 15,225-15,241.

Nadeau, L., Lamontagne, M., Wetmiller, R.J., Brouillette, P., Bent, A.B., and P. Keating, 1998. The November 5, 1998 Cap-Rouge, Quebec earthquake, GSC Current Research, (in press).

Nadeau, R., Antolik, M. Johnson, P.A., Foxall, W. and T.V. McEvilly (1994). Seismological studies at Parkfield III: Micro-earthquake clusters in the study of fault-zone dynamics, Bull. Seism. Soc. Am., 84, 247-263.

North, R.G., Wetmiller, R.J., Adams, J., Anglin, F.M., Hasegawa, H.S., Lamontagne, M., Du Berger, R., Seeber, L. and J. Armbruster., 1989. Preliminary results from the 
November 1988, Saguenay, (Quebec) earthquake, Seism. Res. Lett., 60, 89-93.

Nuttli, O.W. 1973. Seismic wave attenuation and magnitude relations for eastern North America, J. Geophys. Res., 78, 876-885.

Occhietti, S., Clet, M., Ghaleb, B., Karrow, P., Lamothe, M, Long, B., andP.J.H. Richard, 1997. Dépôts pre-Illinoiens dans l'estuaire moyen du St-Laurent, sous les systèmes glaciaires de l'Illinoien et de la première phase glaciaire généralisée du Pléistocène supérieur. Communication CANQUA, Rimouski, Quebec.

Pinet, C., Jaupart, P., Mareschal, J.-C., Gariepy, C., Bienfait, C. and R. Lapointe, 1991. Heat flow and structure of the lithosphere in the eastern Canadian Shield. $J$. Geophys. Res., 96, 19,941-19,963.

Ranalli, G., 1991. Regional variations in lithosphere rheology from heat flow observations, in Terrestrial Heat Flow and the lithosphere structure edited by V. Cermak and L. Rybach, Berlin; New York, Springer-Verlag, 507p.

Ranalli, G., 1995. Rheology of the Earth, Chapman and Hall. eds., London, U.K., 413 p. Ranalli, G., and D.C. Murphy, 1987. Rheological stratification of the lithosphere. Tectonophysics, 132, 281-295.

Ranalli, G., and Yin, Z.-M., 1990. Critical stress difference and orientation of faults in rocks with strength anisotropies: the two-dimensional case, J. Struct. Geol., 12 1067-1071.

Reid, A.B., Allsop, J.M., Granser, H., Millest, A.J., and I.W. Somerton, 1990. Magnetic interpretation in three dimensions using Euler deconvolution, Geophysics, 55, 8091.

Rice, J.R. 1992. Fault stress states, pore pressure distributions, and the weakness of the San Andreas fault, in Fault mechanics and transport properties of rocks, edited by B. Evans and T.-F. Wong, 475-503, Academic Press, London,

Richter, C.F., 1958. Elementary Seismology, W.H. Freeman and Co. Inc., San Francisco, California, 768p.

Rieken, E., and R.L. Thiessen, 1992. Three-dimensional model of the Cascadia subduction zone using earthquake hypocenters, Western Washington, Bull. Seism. Soc. Am., 82, 2533-2548. 
Robertson, P.B., 1975. Zones of shock metamorphism at the Charlevoix impact structure, Quebec, Geol. Soc. of America Bull., 86, 1630-1638.

Rondot, J. 1968. Nouvel impact météoritique fossile? La structure semi-circulaire de Charlevoix, Can J. Earth Sci., 5, 1305-1317.

Rondot, J. 1970. La structure de Charlevoix comparée à d'autres impacts météoritiques. Can. J. Earth Sci., 7, 291-292.

Rondot, J. 1979. Reconnaissances géologiques dans Charlevoix-Saguenay. Rapport DPV-682, Ministère des richesses naturelles du Québec, 46 pp.

Rondot, J. 1989. Géologie de Charlevoix. Série des manuscrits bruts, Ministère de l'Énergie et des Ressources du Québec, Rapport MB 89-21.

Rondot, J. 1994. Recognition of eroded astroblemes, Earth-Science Reviews, 35, 331-365.

Ross, J.V., and K.C. Nielsen, 1978. High temperature flow of wet polycristalline enstatite. Tectonophysics, 44, 233-261.

Roy, D.W. 1978. Origin and evolution of the Charlevoix cryptoexplosion structure, $P h D$ Dissertation, Princeton University, pp. 190.

Roy, D.W. and R. Du Berger, 1983. Relations possibles entre la séismicité et l'astroblème de Charlevoix, Can. J. Earth Sci., 20, 1613-1618.

Roy, D.W., Schmitt, L., Woussen, G. and R. Du Berger. 1993. Lineaments from airborne SAR images and the 1988 Saguenay earthquake, Québec, Canada, Photogrammetric Engineering and Remote Sensing, 59, pp. 1299-1305.

Rutter, E.H., and K.H. Brodie, 1992. Rheology of the lower crust. In: Continental lower crust, D. Fountain, R. Arculus, and R.W. Kay eds., Amsterdam, Elsevier, 485p.

Scholz, C.H., 1990. The mechanics of earthquakes and faulting, Cambridge University Press, Cambridge, U.K., 439 pp.

Scholz, C.H., 1988. The brittle-plastic transition and the depth of seismic faulting, Geolo. Rund., 77, 319-328.

Scholz, C.H., 1992. Paradigms or small change in Earthquake mechanics. In Fault mechanics and transport properties of rocks, Academic Press Ltd., 509-517.

Scholz, C.H., J. Beavan and T.C. Hanks, 1979. Frictional metamorphism, argon depletion, and tectonic stress on the Alpine fault, New Zealand. J. Geophys. Res., 84, 
6770-6782.

Shimada, M., 1993. Lithosphere strength inferred from fracture strength of rocks at high confining pressures and temperatures, Tectonophysics, 217, 55-64.

Sibson, R., 1974. Frictional constraints on thrust, wrench and normal faults. Nature, 249, 542-544.

Sibson, R., 1982. Fault zone models, heat flow, and the depth distribution of earthquakes in the continental crust of the United States, Bull. Seism. Soc. Am., 72, 451-463.

Sibson, R., 1984. Roughness at the base of the seismogenic zone: contributing factors. Journ. Geophys. Res., 89, 5791-5799.

Sibson, R.H., 1989. High-angle reverse faulting in northern New Brunswick, Canada, and its implications for fluid pressure levels, J. of Struct. Geol., 11, 873-877.

Sibson, R.H. 1990. Conditions for fault-valve behavior. In Knipe, R.J. and Ruter, E.H. (Eds), Deformation Mechanisms, rheology and tectonics, Geological Society Special Publication No. 54, 15-28.

Sibson, R.H. 1992. Fault-valve behavior and the hydrostatic-lithostatic fluid pressure interface, Earth-Science Reviews, 32, 141-144.

Sibson, R.H., 1992. Implications of fault-valve behavior for rupture nucleation and recurrence, Tectonophysics, 211, 283-293.

Sibson, R.H., Robert, F.R., and K.H. Poulsen, 1988. High-angle reverse faults, fluid pressure cycling, and mesothermal gold-quartz deposits, Geology, 16, 551-555.

Smith, R.B. and R.L. Bruhn, 1984. Intraplate extensional tectonics of the Eastern Basin-Range: inferences on structural style from seismic reflection data, regional tectonics, and thermal-mechanical models of the brittle-ductile deformation. $J$. Geophys. Res., 89, 5733-5762.

Snoke, J.A., Munsey, J.W., Teague, A.G., and G.A. Bollinger, 1984. A program for focal mechanism by combined use of polarity and SV-P amplitude ratio data. Earthquake Notes, 55, no. 3, p. 15.

Solomon, S.C. and E.D. Duxbury, 1987. A test of the longetivity of impact-induced faults as preferred sites for later tectonic activity. Proceedings of the seventeenth lunar and planetary science Conference, part 2, J. Geophys. Res., 92, E759-E768. 
Somerville, P.G., McLaren, J.P., Saikia, C.K., and D.V. Helmberger, 1990. The November 1988 Saguenay, Quebec, earthquake: source parameters and the attenuation of strong ground motion, Bull. Seism. Soc. Am.., 80, 1118-1143.

Spencer , J.W. and A.M. Nur, 1976. The effects of temperature, and pore water on velocities in Westerly granite, J. Geophys. Res., 81, 899-904.

Stevens, A.E., 1980. Reexamination of some larger La Malbaie, Québec earthquakes (1924-1978), Bull. Seism. Soc. Am., 70, 529-557.

Stevens, A.E. 1980. Reexamination of some larger La Malbaie, Québec earthquakes (1924-1978), Bull. Seism. Soc. Am. 70, 529-557.

Talwani, P., 1988. The intersection model for intraplate earthquakes, Seism. Res. Lett., 59, 305-310.

Tapley, W.C. and J.E. Tull, 1990. Guide to the UNIX version of SAC, Lawrence Livermore National Laboratory, Livermore, California.

Telford, W.M., Geldart, L.P., Sheriff, R.E., and D.A. Keys, 1976. Applied Geophysics, Cambridge Univ. Press, Cambridge, U.K., 860 p.

Thomson, D.T., 1982. EULDPH- A technique for making computer-assisted depth estimates from magnetic data, Geophysics, 47, 31-37.

Thurber, C.H., 1993. Local earthquake tomography: velocities and Vp/Vs - theory. In Seismic Tomography: theory and practice, Chapman and Hall, London.

Toutin, T., and B. Rivard, 1997. Value added Radarsat products for geoscientific applications, Can. J. Remote Sensing, 23, 63-70.

Tse, S.T., and J.R. Rice, 1986. Crustal earthquake instability in relation to the depth variation of frictional slip properties, J. Geophys. Res., 91, 9452-9472.

Tsoflias, G.P., Bollinger G.A., and J.K. Costain, 1995. Common cyclities in the seismicity and water level fluctuations at the Charlevoix Seismic Zone on the St. Lawrence River, Quebec, Canada, J. Geodynamics, 19, 117-139.

Tullis, T.E., 1980. The use of mechanism twinning in minerals as a measure of shear stress magnitudes, J. Geophys. Res., 85, 6263-6268.

Tullis, J., and R.A. Yund, 1980. Hydrolytic weakening of experimentally deformed 
Westerly granite and Hale albite rock, J. Struct. Geology, 2, 439-451.

Vlahovic, G., Powell, C., Chapman, M.C., and M.S. Sibol. 1998. Joint hypocentervelocity inversion for the eastern Tennessee seismic zone, J. Geophys. Res., 103, 4879-4896.

Wadati, K. 1933. On the travel time of seismic waves. Geophysical Magazine, 7, 87-153.

Wenzel, F., and K.-J. Sandmeir, 1992. Geophysical evidence for fluids in the crust beneath the Black Forest, SW Germany, Earth-Science reviews, 32, 61-75.

Wetmiller, R.J., and J. Adams, 1990. An earthquake doublet in the Charlevoix seismic zone, Quebec. in Current Research, Part B, Geological Survey of Canada, Paper 90-1, p. 105-113.

Wheeler, R.L., 1995. Earthquakes and the cratonward limit of Iapetan faulting in eastern North America, Geology, 23, 105-108.

Wheeler, R.L., 1996. Earthquakes and the southeastern boundary of the intact Iapetan margin in Eastern North America, Seism. Res. Letters, 67, no. 5, 77-83.

Wilks, K.R., and N.L. Carter, 1990. Rheology of some continental lower crustal rocks. Tectonophysics, 182, 57-77.

Wu, P. 1998. Intra-plate earthquakes and postglacial rebound in Eastern Canada and Northern Europe, in Dynamics of the Ice Age Earth: a modern perpective, Enfield Publishing, 603-628.

Wu, P. and H.S. Hasegawa, 1996. Induced stresses and fault potential in eastern Canada due to a realistic load: a preliminary analysis, Geophys. J. Int., 127, 215-229.

Yin, Z.-M., 1993. A study of the mechanics of faulting and earthquakes, Ph.D. Dissertation, Carleton University, 213p.

Yin, Z.-M., and G. Ranalli, 1992. Critical stress difference, fault orientation and slip direction in anisotropic rock under non-Andersonian stress systems, J. Struct. Geol, 14, 237-244.

Zoback, M.D. and M.L. Zoback, 1991. Tectonic stress field of North America and relative plate motions. In Slemmons, D.B., Engdahl, E.R., Zoback, M.D., and Rockwell, eds., Neotectonics of North America, Boulder, Colorado, Geological Society of America, Decade Map Volume 1. 
Zoback, M.D., Apel, R., Baumgärtner, J., Brudy, M., Emmermann, R., Engeser, B., Fuchs, K., Kessels, W., Richmüller, H., Rummel, F., and L. Vernik, 1993, Uppercrustal strength inferred from stress measurements to $6 \mathrm{~km}$ depth in the KTB borehole, Nature, 365, 633-635.

Zoback, M.L., 1992a. First- and second-order patterns of stress in the lithosphere: the world stress map project, J. Geophys. Res., 97, 11,703-11,728.

Zoback, M.L., 1992b. Stress field constraints on intraplate seismicity in eastern North America, J. Geophys. Res., 97, 11,761-11,782.

Zoback, M.L., and M. Magee, 1991. Stress magnitudes in the crust: constraints from stress orientation and relative magnitude data, Phil. Trans. R. Soc. London, 337, 181-194. 


\section{Appendix 1 \\ Example of a focal mechanism calculation and plots}

Example of the output provided for each focal mechanism in Lamontagne (1998). The 971028 11:44 U.T. event is used: 1) Text; A) The FOCMEC results in five focal spheres (Figure 12A). Starting in the upper left and going clockwise, the first sphere shows the series of solutions obtained with $\mathrm{P}$ and $\mathrm{S}_{\mathrm{H}}$ first motions (entitled "P, $\mathrm{S}_{\mathrm{H}}$ and P-Nodal"). The second shows the solutions obtained using the P first motions only (entitled "Solution with P FM only"). Unless well constrained with $\mathrm{P}$ first motions only (rather rare), the increment for the $\mathrm{b}$ axis is $5^{\circ}$. The lower right sphere shows the $\mathrm{S}_{\mathrm{H}}$ first motions and the $\mathrm{S}_{\mathrm{H}}$ "nodal" lines computed with the $\mathrm{P}$ and $\mathrm{S}_{\mathrm{H}}$ solutions (entitled " $\mathrm{S}_{\mathrm{H}}$ motions and Lines"). The lower left one shows all first motions (entitled "First Motions Only"). Finally, the central mechanism is the average solution using the $\mathrm{P}$ and $\mathrm{S}_{\mathrm{H}}$ families of solutions (entitled "Best Solution"). One should also note that the exact position of the first motion on the focal sphere is not in the centre but in the lower left portion of the $\mathrm{C}$ and $\mathrm{D}$ first motion symbols; B) First motion picks; C) Location map of the earthquake (focal sphere) and background seismicity. 
1- Earthquake information and list of first motions.

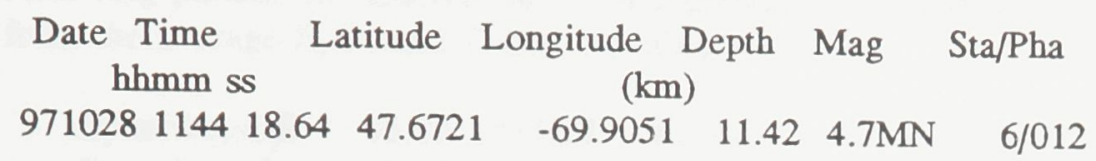

\section{COMMENTS:}

CHARLEVOIX SEISMIC ZONE, QUE. Felt.

Felt in Charlevoix, Riviere-du-Loup, and in the

Quebec City, Saguenay and Lac St-Jean regions.

$18 \mathrm{~km}$ E from LA MALBAIE, QUE.

\$ LMQ; SLQ; QCQ down.

$\$$ CIQ FM from R. Du Berger.

\$ A11 starts with weak C, which is followed by an impulsive D.

$\$$ Isoseismals to come.

\$: REV is F. Revetta, Potsdam, N.Y.

\$ESDC SZ P XB1152 49.700 L

\$ARCE SZ P XB1152 58.300 L

\$LPAZ SZ P XB1154 51.300 L

\$DBIC SZ P XB1155 $21.000 \quad$ L

\$ZAL SZ P XB1156 9.800 L

$\$$ The $\mathrm{Sg}$ lines of some stations include the SH FM.

$\$$ The convention used is the Virginia Tech convention used in FOCMEC:

$\$<$ : SH first motion to left (back to event) impulsive

$\$>$ : SH first motion to right (back to event) impulsive

$\$$ Preliminary Focmec computed by ML.

$\$$ Note: most CLTN Sg FM are unclear.

\begin{tabular}{lccccc} 
Sta & Pha Dist & Azim & Take-off & FM \\
\multicolumn{7}{c}{$(\mathrm{km})$} & \multicolumn{3}{c}{ Angle } \\
A61 & PG & 14 & 280 & -51 & D \\
A61 & SG & 14 & 280 & -51 & $>$ \\
A21 & PG & 17 & 78 & -55 & D \\
A64 & PG & 17 & 3 & -56 & D \\
A16 & PG & 24 & 199 & -64 & C \\
A16 & SG & 24 & 199 & -64 & $>$ \\
SHQ & PG & 38 & 259 & -73 & D \\
A54 & PG & 45 & 238 & -76 & D \\
A11 & PG & 53 & 205 & -78 & C \\
CIQ & PG & 94 & 316 & -83 & C \\
DAQ & PG & 105 & 288 & -84 & D \\
JOQ & PG & 129 & 310 & 0 & C \\
DPQ & PG & 244 & 244 & -87 & D
\end{tabular}

Number of $P$ first motions: 11

Number of SH first motions: 2 
2- Most Representative Solution.

A total of 247 solutions were found using a b axis increment of 3 degree. The following parameters describe the most representative solution, which was derived from the average $B, P$, and $T$ axes listed below.

$\begin{array}{lrrrrrr}\text { dip,strike,rake } & 85.99 & 111.73 & 41.84 & & & \\ \text { dip,strike,rake } & 48.28 & 18.15 & 174.62 & \text { :auxiliary plane } & \\ \text { lower hem. trend, plunge of a,n } & 288.15 & 41.72 & 21.73 & 4.01 \\ \text { lower hem. trend \& plunge of b } & 116.20 & 48.00 & & \\ \text { lower hem. trend, plunge of p,t } & 237.24 & 24.90 & 343.65 & 31.33\end{array}$

Average $B, P$, and $T$ axes:

B $\quad P \quad T$

\begin{tabular}{|c|c|c|c|}
\hline Mean trend: & N 137 & N 246 & N 348 \\
\hline Mean Plunge: & 49 & 16 & 37 \\
\hline Vector Magnitude: & 242 & 244 & 245 \\
\hline Mean length of resulting vecto & or: 0.981 & 0.987 & 0.991 \\
\hline
\end{tabular}

3- Misfits.

All $11 \mathrm{P}$ first motions agreed with the solution.

Out of 2 SH first motions, a total of 1 did not fit the solutions (50/100).

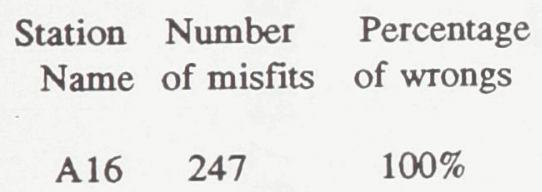

4- Rating of the focal mechanism.

The solution has a $\mathrm{C}$ rating based on the poor constraints on the $\mathrm{P}, \mathrm{T}$ and $B$ axes (value of 0.986).

Appendix 1 

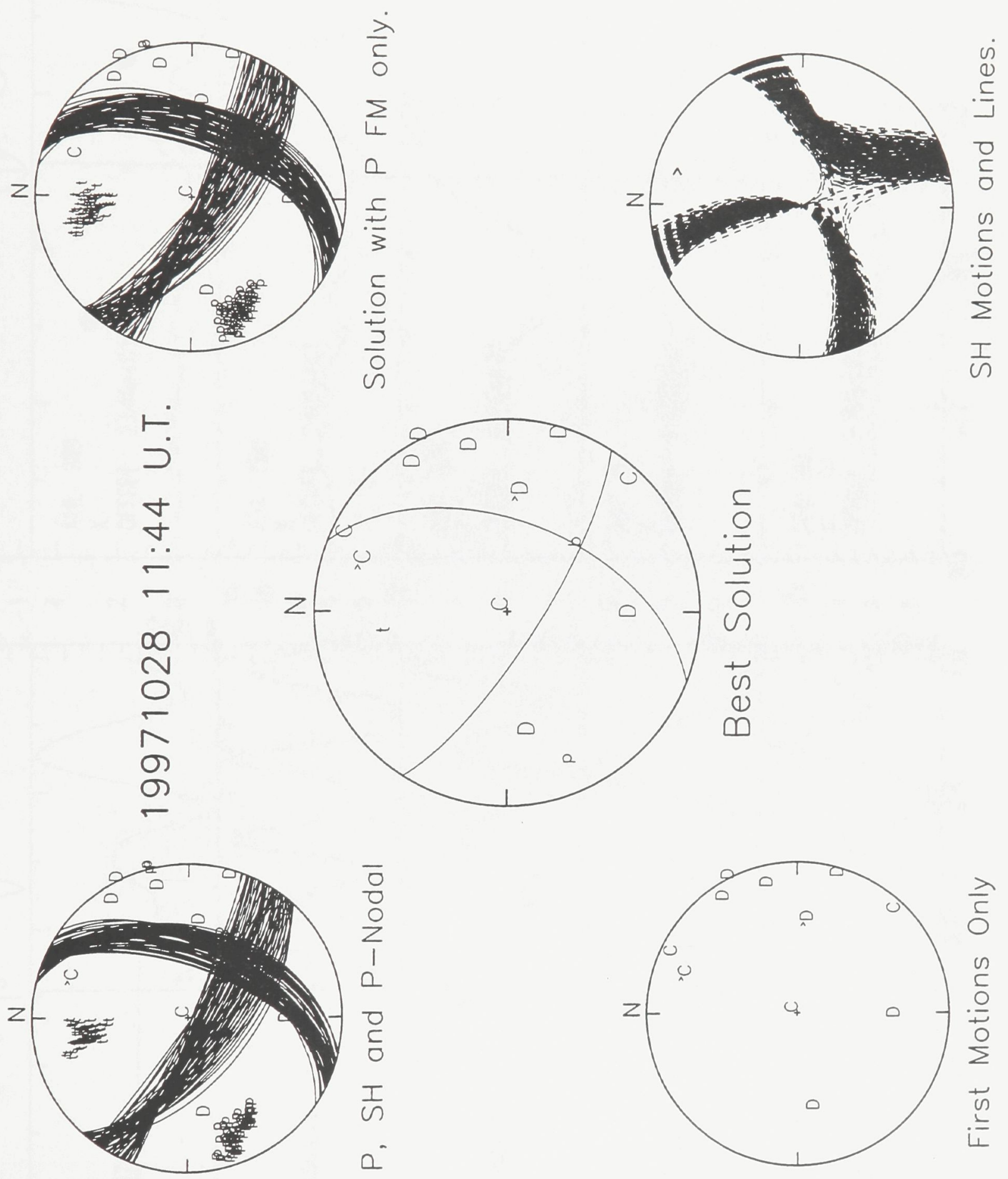


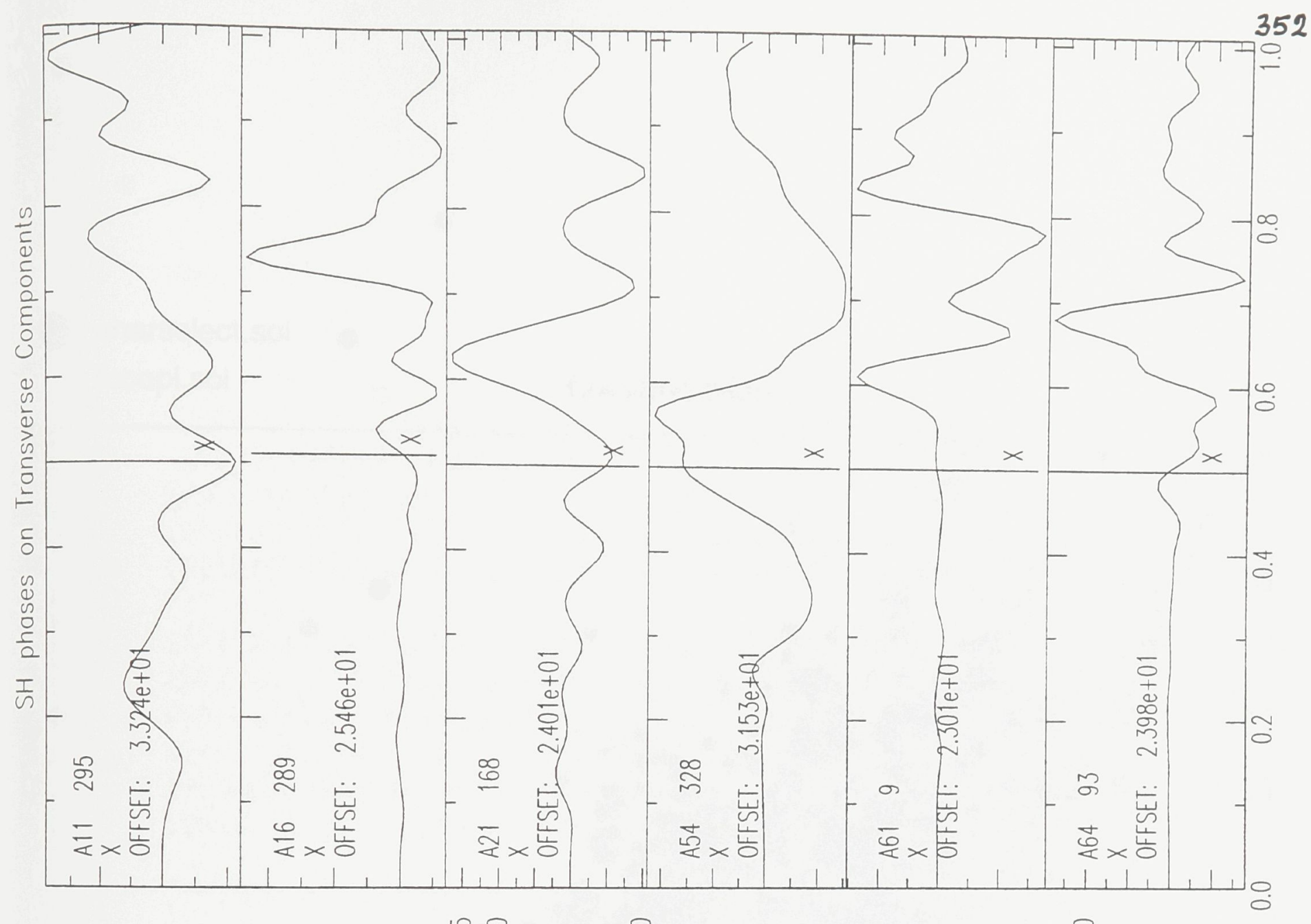

-

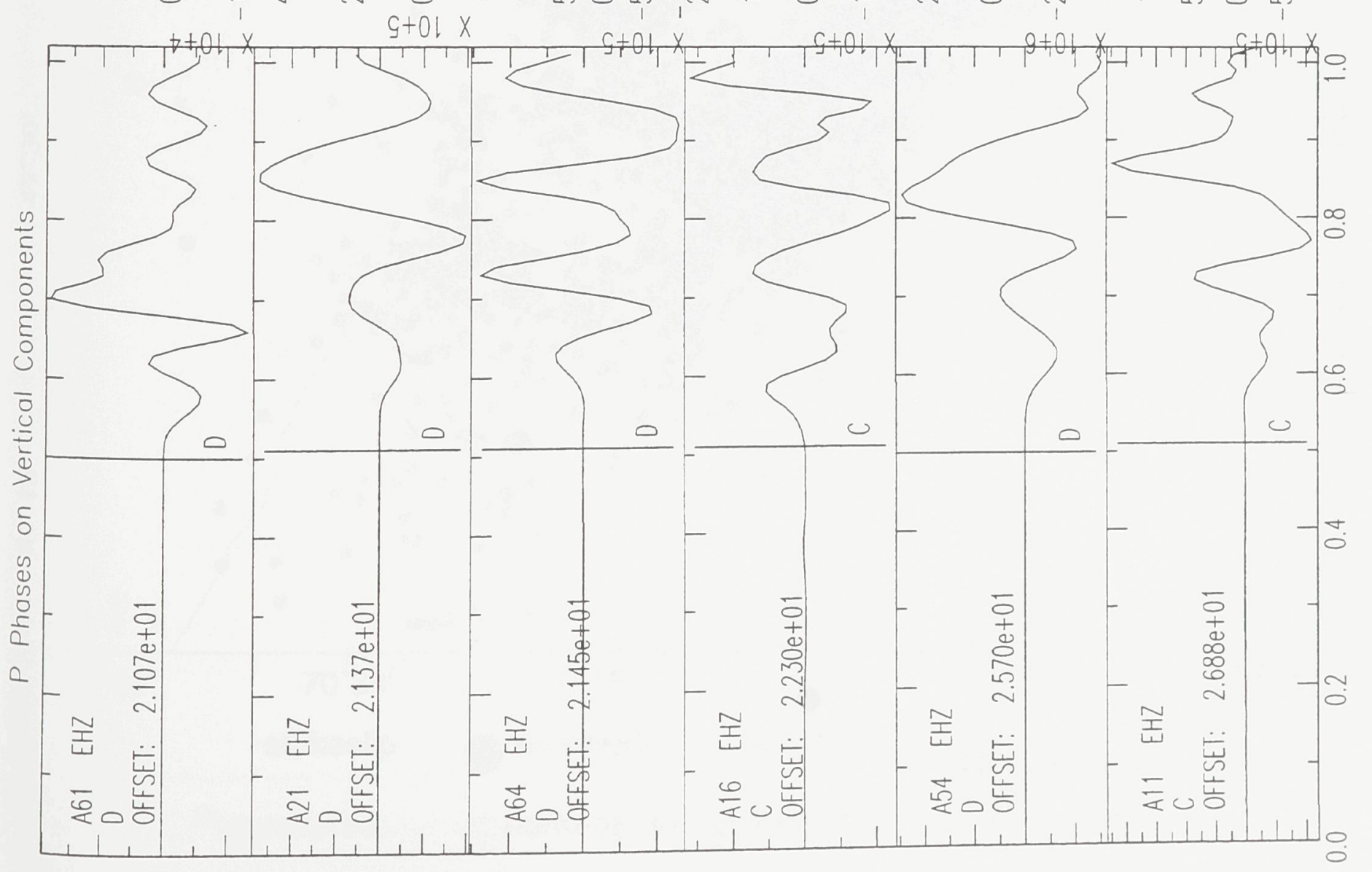

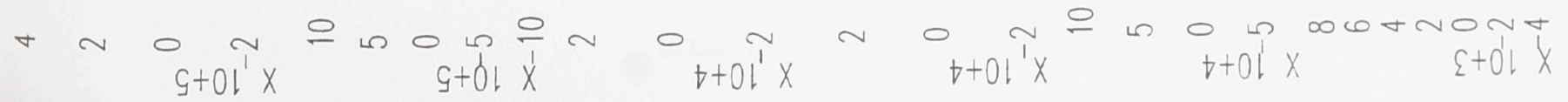


charselect.sol focepi.sol

Location Map

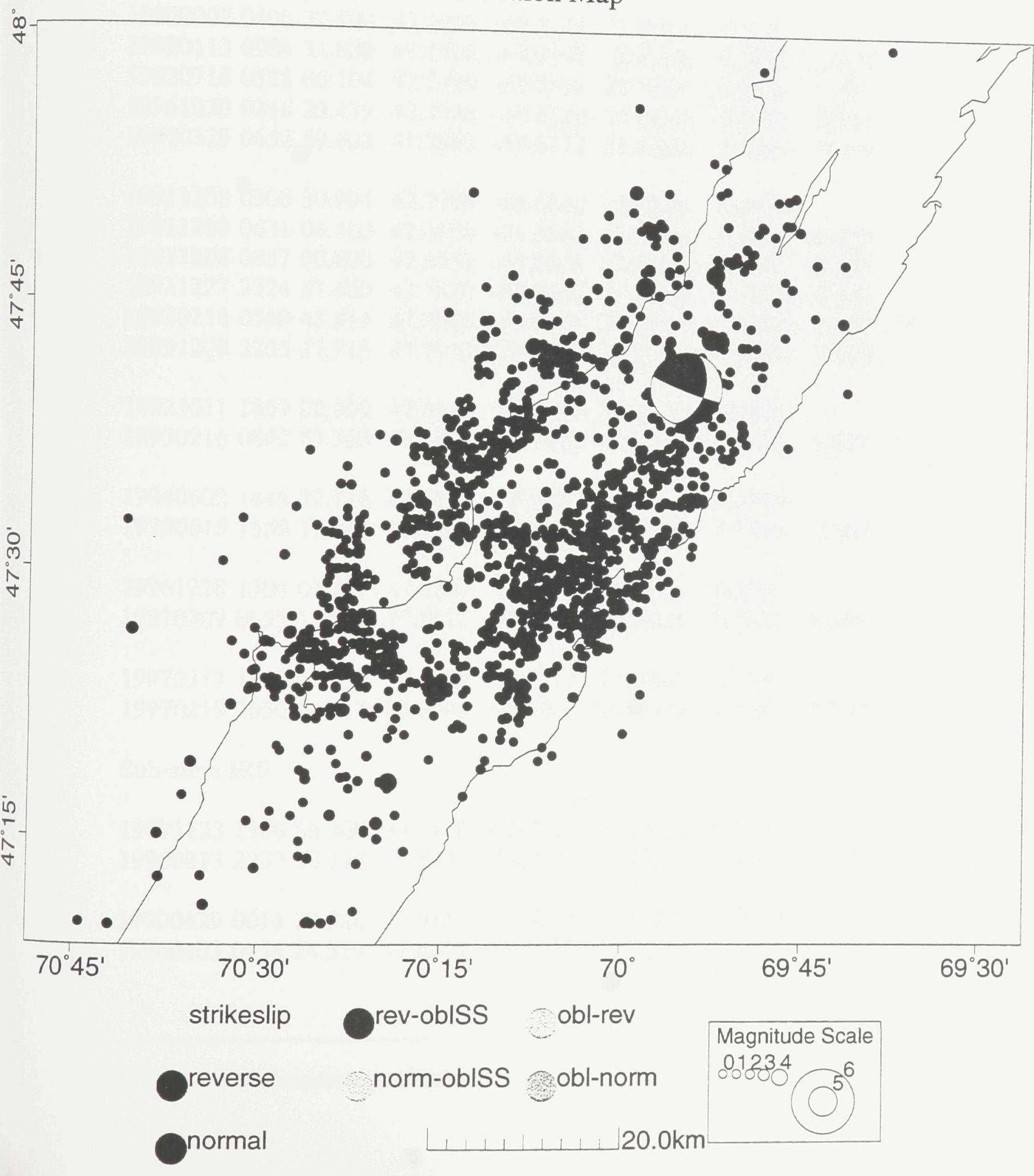


Appendix $2^{11}$

List of earthquake multiplets by sub-zone

yyyymmdd hhmm ss.ddd Lat Lon Depth Mag Distance (km)

Sub-zone DNE

$\begin{array}{llllllll}19900907 & 0406 & 32.800 & 47.7910 & -69.8170 & 21.87 \mathrm{~km} & 0.6 \mathrm{ML} & \\ 19920113 & 0904 & 11.800 & 47.7900 & -69.8190 & 22.91 \mathrm{~km} & 0.4 \mathrm{ML} & 1.057 \\ 19920716 & 0328 & 06.100 & 47.7920 & -69.8330 & 22.10 \mathrm{~km} & 0.8 \mathrm{ML} & 1.225 \\ 19961230 & 0246 & 23.479 & 47.7985 & -69.8120 & 21.62 \mathrm{~km} & -0.2 \mathrm{ML} & 0.947 \\ 19970329 & 0653 & 59.603 & 47.7897 & -69.8172 & 21.78 \mathrm{~km} & 1.2 \mathrm{MN} & 0.171 \\ & & & & & & \\ 19911208 & 0300 & 30.994 & 47.7796 & -69.8640 & 23.20 \mathrm{~km} & 4.3 \mathrm{MN} & \\ 19911208 & 0631 & 04.400 & 47.7850 & -69.8640 & 22.77 \mathrm{~km} & 0.9 \mathrm{ML} & 0.738 \\ 19911208 & 0857 & 00.800 & 47.7850 & -69.8640 & 22.56 \mathrm{~km} & 0.7 \mathrm{ML} & 0.877 \\ 19911227 & 2324 & 37.400 & 47.7820 & -69.8650 & 22.70 \mathrm{~km} & 1.3 \mathrm{MN} & 0.572 \\ 19920218 & 0149 & 45.811 & 47.7946 & -69.8454 & 23.34 \mathrm{~km} & 1.7 \mathrm{MN} & 2.177 \\ 19951209 & 2205 & 37.713 & 47.7940 & -69.8614 & 23.26 \mathrm{~km} & 1.6 \mathrm{MN} & 1.613 \\ & & & & & & \\ 19921011 & 1859 & 02.900 & 47.8140 & -69.9480 & 20.30 \mathrm{~km} & 0.2 \mathrm{ML} & \\ 19930216 & 0842 & 57.300 & 47.8200 & -69.9690 & 19.52 \mathrm{~km} & 0.2 \mathrm{ML} & 1.877 \\ & & & & & & \\ 19940602 & 1445 & 37.118 & 47.7178 & -69.9481 & 25.44 \mathrm{~km} & 2.4 \mathrm{MN} & \\ 19950615 & 1559 & 17.215 & 47.7155 & -69.9275 & 25.39 \mathrm{~km} & 2.7 \mathrm{MN} & 1.567 \\ 19961228 & 1704 & 01.809 & 47.8257 & -69.7970 & 21.81 \mathrm{~km} & -0.2 \mathrm{ML} & \\ 19970309 & 0655 & 11.523 & 47.8227 & -69.7947 & 20.90 \mathrm{~km} & -0.7 \mathrm{ML} & 0.984 \\ 19970217 & 1947 & 43.077 & 47.8069 & -69.7711 & 23.40 \mathrm{~km} & 1.7 \mathrm{MN} & \\ 19970219 & 2056 & 24.113 & 47.8094 & -69.7641 & 23.89 \mathrm{~km} & -1.0 \mathrm{ML} & 0.769\end{array}$

Sub-zone IRE

$\begin{array}{lllllll}19891123 & 1308 & 56.900 & 47.5420 & -70.2980 & 11.34 \mathrm{~km} & 0.4 \mathrm{ML}\end{array}$

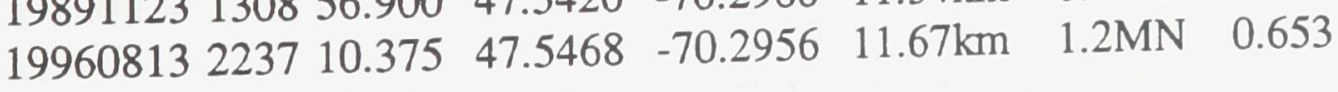

$19900429001429.320 \quad 47.6185 \quad-70.1676 \quad 11.80 \mathrm{~km} \quad 1.7 \mathrm{MN}$

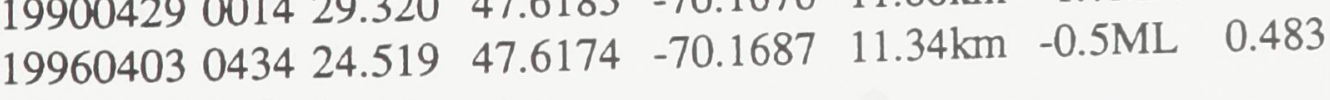

11 Blank lines separate multiplets. 


$\begin{array}{llllllll}19950311 & 1119 & 04.600 & 47.5280 & -70.3170 & 9.43 \mathrm{~km} & 0.5 \mathrm{MN} & \\ 19951228 & 2139 & 01.771 & 47.5372 & -70.3003 & 9.41 \mathrm{~km} & -0.3 \mathrm{ML} & 1.621 \\ 19950820 & 0416 & 10.309 & 47.4998 & -70.2956 & 14.09 \mathrm{~km} & 0.8 \mathrm{MN} & \\ 19951117 & 0757 & 08.213 & 47.5173 & -70.2949 & 15.33 \mathrm{~km} & 1.2 \mathrm{MN} & 2.307 \\ & & & & & & \\ 19960105 & 0425 & 57.522 & 47.6003 & -70.2264 & 6.88 \mathrm{~km} & 1.5 \mathrm{MN} & \\ 19960105 & 0440 & 30.215 & 47.6017 & -70.2251 & 5.85 \mathrm{~km} & 2.0 \mathrm{MN} & 1.046 \\ & & & & & & \\ 19961004 & 2216 & 37.536 & 47.5965 & -70.2076 & 14.41 \mathrm{~km} & 1.3 \mathrm{MN} & \\ 19970422 & 1100 & 45.076 & 47.6065 & -70.2164 & 15.14 \mathrm{~km} & 2.4 \mathrm{MN} & 1.485 \\ & & & & & & \\ 19900618 & 0700 & 16.600 & 47.5870 & -70.2440 & 12.69 \mathrm{~km} & -0.2 \mathrm{ML} & \\ 19961115 & 2329 & 01.620 & 47.5989 & -70.2453 & 12.28 \mathrm{~km} & -0.3 \mathrm{ML} & 1.388 \\ & & & & & & & \\ 19921203 & 1002 & 07.911 & 47.6099 & -70.1753 & 11.84 \mathrm{~km} & 2.0 \mathrm{MN} & \\ 19951108 & 1646 & 05.796 & 47.6045 & -70.1832 & 10.65 \mathrm{~km} & -0.4 \mathrm{ML} & 1.459 \\ 19960403 & 0434 & 24.519 & 47.6174 & -70.1687 & 11.34 \mathrm{~km} & -0.5 \mathrm{ML} & 1.091 \\ & & & & & & & \\ 19960924 & 2341 & 02.882 & 47.5475 & -70.2417 & 12.83 \mathrm{~km} & 3.1 \mathrm{MN} & \\ 19961003 & 1024 & 46.893 & 47.5515 & -70.2373 & 12.83 \mathrm{~km} & 1.3 \mathrm{MN} & 0.554 \\ 19961003 & 1032 & 24.470 & 47.5442 & -70.2396 & 13.14 \mathrm{~km} & 1.3 \mathrm{MN} & 0.506\end{array}$

Sub-zone M5

$19890309094132.262 \quad 47.7170 \quad-69.8568 \quad 10.51 \mathrm{~km} \quad 4.3 \mathrm{MN}$

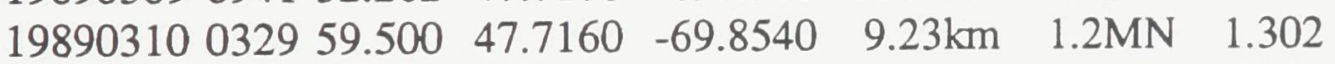

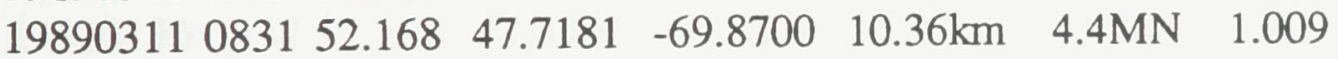

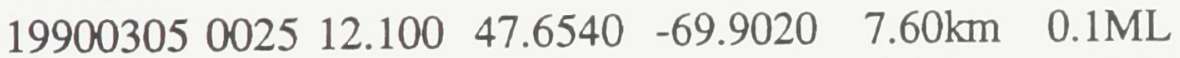

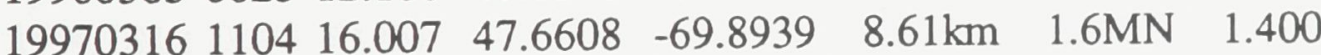

$\begin{array}{lllllll}19910221 & 1702 & 48.400 & 47.7020 & -69.8830 & 9.09 \mathrm{~km} & 0.9 \mathrm{ML}\end{array}$

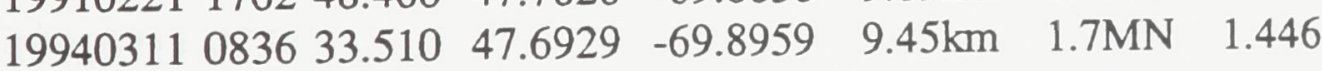

$\begin{array}{llllll}199203110120 & 57.600 & 47.7180 & -69.8570 & 9.45 \mathrm{~km} & 0.2 \mathrm{ML}\end{array}$

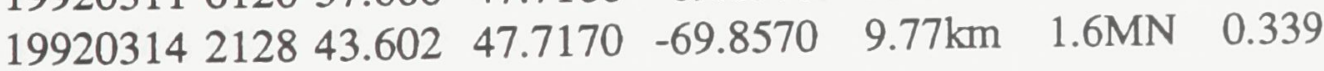

$19930330123528.300 \quad 47.6740 \quad-69.9080 \quad 10.31 \mathrm{~km} \quad 0.0 \mathrm{ML}$ $\begin{array}{llllllll}19930407 & 1402 & 29.500 & 47.6770 & -69.9100 & 10.70 \mathrm{~km} & 1.3 \mathrm{MN} & 0.535\end{array}$

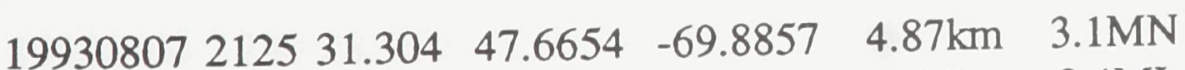

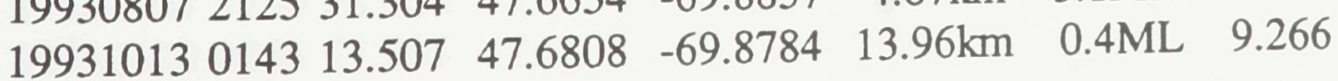
$19950812174255.813 \quad 47.6680 \quad-69.9035 \quad 10.83 \mathrm{~km} \quad 2.5 \mathrm{MN}$ 


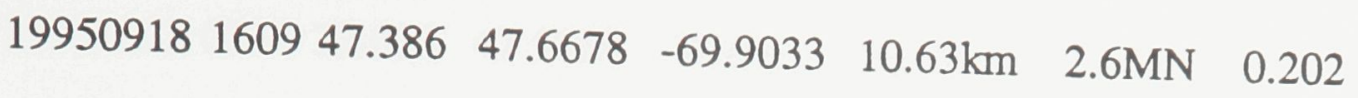

Sub-zone A61

$\begin{array}{llllllll}19891208 & 1720 & 34.446 & 47.7009 & -70.0644 & 10.37 \mathrm{~km} & 2.6 \mathrm{MN} & \\ 19891221 & 1211 & 28.000 & 47.7010 & -70.0730 & 10.79 \mathrm{~km} & 0.2 \mathrm{ML} & 0.770 \\ 19940614 & 2339 & 58.000 & 47.7040 & -70.0700 & 10.12 \mathrm{~km} & 1.4 \mathrm{MN} & 0.598 \\ 19960215 & 0005 & 39.828 & 47.7011 & -70.0454 & 16.27 \mathrm{~km} & 0.0 \mathrm{ML} & 6.070 \\ & & & & & & \\ 19930706 & 0633 & 33.200 & 47.6950 & -70.0730 & 9.02 \mathrm{~km} & 0.6 \mathrm{ML} & \\ 19950303 & 2334 & 37.800 & 47.6960 & -70.0750 & 9.73 \mathrm{~km} & -0.4 \mathrm{ML} & 0.734 \\ 19950820 & 0241 & 42.030 & 47.6946 & -70.0687 & 9.03 \mathrm{~km} & 0.1 \mathrm{ML} & 0.326 \\ 19960803 & 1827 & 03.119 & 47.6744 & -70.1431 & 9.79 \mathrm{~km} & 1.9 \mathrm{MN} & \\ 19960804 & 0918 & 55.206 & 47.6763 & -70.1457 & 9.45 \mathrm{~km} & 0.9 \mathrm{MN} & 0.445\end{array}$

Sub-zone CEN

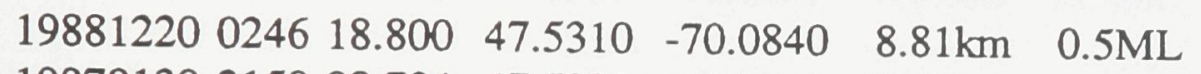

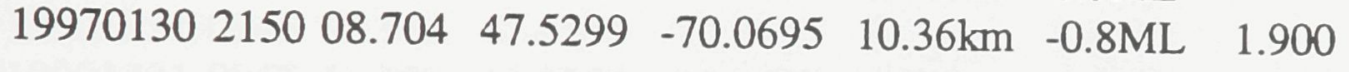

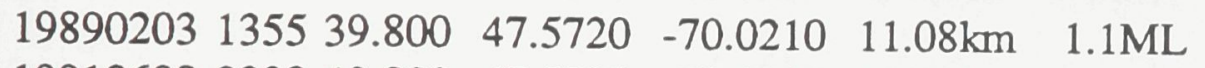

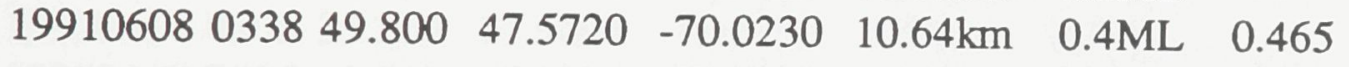

$\begin{array}{llllllll}19900522 & 1221 & 09.700 & 47.5350 & -70.0290 & 7.45 \mathrm{~km} & 0.5 \mathrm{ML} & \\ 19920130 & 1042 & 33.400 & 47.5389 & -70.0349 & 5.99 \mathrm{~km} & 2.0 \mathrm{MN} & 1.586 \\ 19920130 & 1352 & 11.615 & 47.5403 & -70.0277 & 7.20 \mathrm{~km} & 1.9 \mathrm{MN} & 0.647 \\ 19930801 & 1935 & 29.717 & 47.5355 & -70.0390 & 6.69 \mathrm{~km} & 1.7 \mathrm{MN} & 1.071\end{array}$

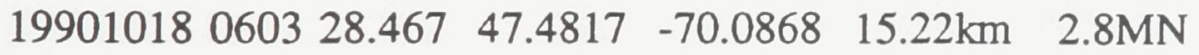

$\begin{array}{llllllll}19920817 & 1255 & 26.600 & 47.4830 & -70.0910 & 14.19 \mathrm{~km} & 0.4 \mathrm{ML} & 1.087\end{array}$

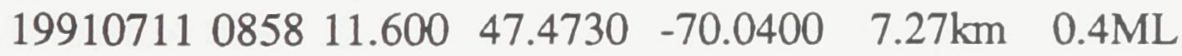

$\begin{array}{llllllll}19910711 & 1451 & 05.600 & 47.4750 & -70.0400 & 7.20 \mathrm{~km} & 0.3 \mathrm{ML} & 0.233\end{array}$

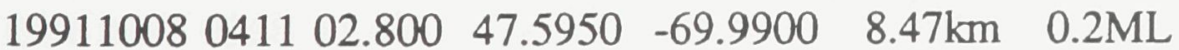

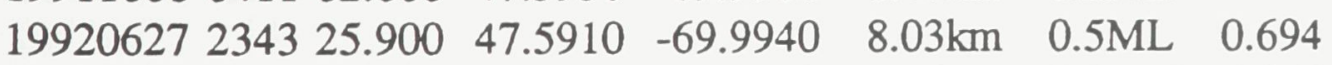

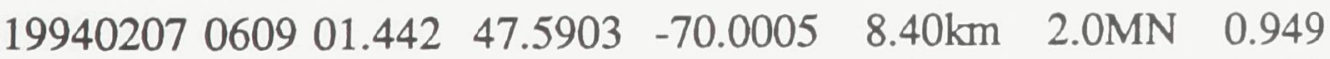

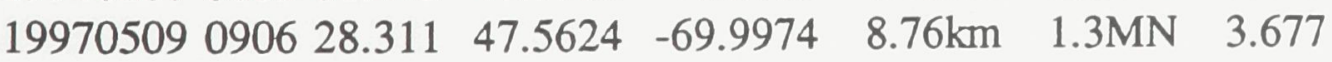

$\begin{array}{llllllll}19920404 & 1230 & 28.560 & 47.4325 & -70.1733 & 18.92 \mathrm{~km} & 2.9 \mathrm{MN} & \\ 19920420 & 0855 & 27.505 & 47.4333 & -70.1748 & 18.90 \mathrm{~km} & 1.9 \mathrm{MN} & 0.145\end{array}$

$19920430040141.000 \quad 47.4980 \quad-70.0490 \quad 11.01 \mathrm{~km} \quad 0.3 \mathrm{ML}$ 


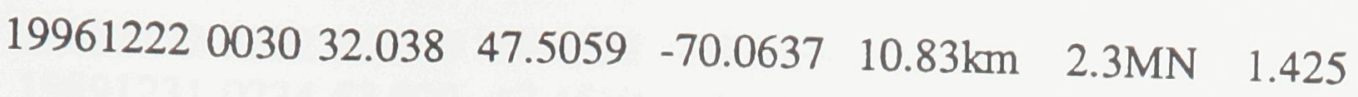

$\begin{array}{llllllll}19920816 & 1851 & 25.300 & 47.5730 & -70.0410 & 10.48 \mathrm{~km} & 0.4 \mathrm{ML} & \\ 19960901 & 0517 & 18.200 & 47.5745 & -70.0434 & 10.84 \mathrm{~km} & 1.4 \mathrm{MN} & 0.436 \\ & & & & & & \\ 19930605 & 0449 & 40.991 & 47.4931 & -70.1126 & 11.03 \mathrm{~km} & 2.6 \mathrm{MN} & \\ 19930606 & 0152 & 11.800 & 47.4940 & -70.1130 & 10.41 \mathrm{~km} & -0.1 \mathrm{ML} & 0.629 \\ & & & & & & \\ 19950718 & 1306 & 38.413 & 47.5706 & -69.9979 & 6.62 \mathrm{~km} & 1.9 \mathrm{MN} & \\ 19950724 & 0328 & 01.314 & 47.5662 & -69.9969 & 5.09 \mathrm{~km} & -0.3 \mathrm{ML} & 1.608 \\ 19951019 & 0316 & 07.603 & 47.5844 & -70.0009 & 9.04 \mathrm{~km} & 2.1 \mathrm{MN} & 2.874 \\ 19970319 & 0953 & 12.399 & 47.5885 & -70.0023 & 7.77 \mathrm{~km} & 1.5 \mathrm{MN} & 2.322 \\ & & & & & & \\ 19950719 & 0953 & 01.613 & 47.5675 & -70.0007 & 13.66 \mathrm{~km} & -0.2 \mathrm{ML} & \\ 19970401 & 1203 & 12.904 & 47.5652 & -70.0017 & 13.81 \mathrm{~km} & 1.6 \mathrm{MN} & 0.306 \\ & & & & & & \\ 19950918 & 1322 & 03.731 & 47.4471 & -70.1084 & 1.90 \mathrm{~km} & 0.6 \mathrm{ML} & \\ 19970112 & 0523 & 24.741 & 47.4357 & -70.0907 & 5.76 \mathrm{~km} & -0.7 \mathrm{ML} & 4.276 \\ 19901221 & 0940 & 32.115 & 47.4583 & -70.0715 & 8.52 \mathrm{~km} & 1.9 \mathrm{MN} & \\ 19901221 & 0957 & 51.500 & 47.4560 & -70.0680 & 8.75 \mathrm{~km} & 0.3 \mathrm{ML} & 0.433 \\ 19910414 & 0508 & 35.300 & 47.5460 & -70.0300 & 7.94 \mathrm{~km} & 0.1 \mathrm{ML} & \\ 199305180017 & 41.713 & 47.5432 & -70.0329 & 7.60 \mathrm{~km} & 2.4 \mathrm{MN} & 0.510 \\ 199407110935 & 41.143 & 47.5620 & -70.0513 & 4.91 \mathrm{~km} & 2.8 \mathrm{MN} & 3.862\end{array}$

Sub-zone COU

$\begin{array}{lllllll}19920914 & 2038 & 14.800 & 47.4230 & -70.4210 & 5.97 \mathrm{~km} & 0.8 \mathrm{ML}\end{array}$

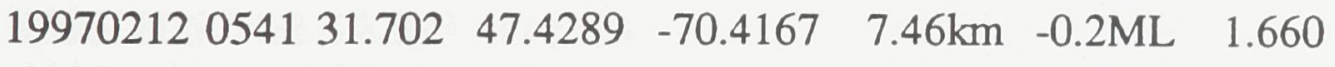

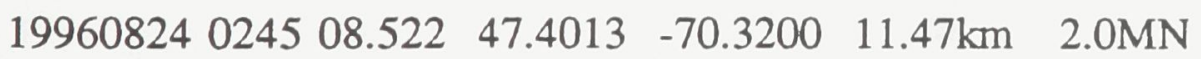

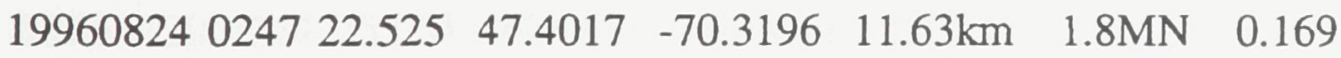

$19961001004903.173 \quad 47.4136 \quad-70.3322 \quad 11.66 \mathrm{~km} \quad-0.6 \mathrm{ML}$

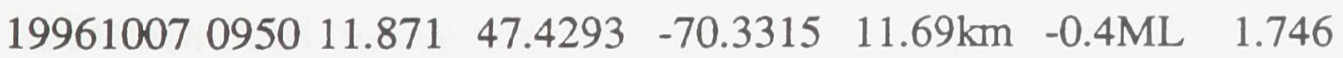

$19930814075520.100 \quad 47.4170 \quad-70.3380 \quad 10.29 \mathrm{~km} \quad-0.3 \mathrm{ML}$

$\begin{array}{llllllll}19930814 & 1456 & 13.700 & 47.4170 & -70.3320 & 9.28 \mathrm{~km} & 0.1 \mathrm{ML} & 1.107\end{array}$

$\begin{array}{llllllll}19960518 & 0816 & 32.273 & 47.4208 & -70.3143 & 9.84 \mathrm{~km} & 0.7 \mathrm{MN} & 1.891\end{array}$

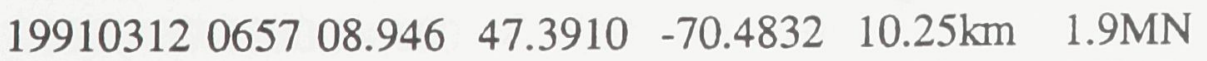

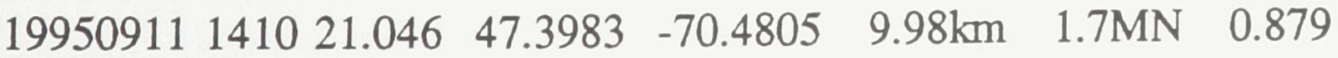


$\begin{array}{lllll}19891122 & 2302 & 51.700 & 47.4558 & -70.3430\end{array}$

$7.61 \mathrm{~km}$

3.4MN

$\begin{array}{lllll}19891231 & 0234 & 53.900 & 47.4510 & -70.3430\end{array}$

$7.63 \mathrm{~km}$

$\begin{array}{ll}0.1 \mathrm{ML} & 0.534\end{array}$

$\begin{array}{lllll}19900111 & 0715 & 12.208 & 47.4544 & -70.3480\end{array}$

$8.36 \mathrm{~km}$

$1.8 \mathrm{MN} \quad 0.854$

$\begin{array}{lllll}19901026 & 1755 & 58.000 & 47.4290 & -70.4090\end{array}$

$6.86 \mathrm{~km} \quad 0.2 \mathrm{ML}$

$\begin{array}{lllll}19970212 & 0541 & 31.702 & 47.4289 & -70.4167\end{array}$

$7.46 \mathrm{~km} \quad-0.2 \mathrm{ML} \quad 0.835$

$\begin{array}{llllll}19901021 & 1338 & 43.209 & 47.3975 & -70.3640 & 15.82 \mathrm{~km}\end{array}$

$3.3 \mathrm{MN}$

$\begin{array}{lllll}19901102 & 0427 & 50.100 & 47.3970 & -70.3610\end{array}$

$14.93 \mathrm{~km}$

$0.5 \mathrm{ML} \quad 0.920$

$19960113073250.103 \quad 47.4160 \quad-70.4406$

$4.81 \mathrm{~km} \quad 1.9 \mathrm{MN}$

$\begin{array}{llllll}19960618 & 0144 & 24.387 & 47.4169 & -70.4364\end{array}$

$4.59 \mathrm{~km}$

$0.8 \mathrm{MN} \quad 0.399$

$19920311130550.015 \quad 47.4578 \quad-70.3570$

$7.03 \mathrm{~km} \quad 1.9 \mathrm{MN}$

$\begin{array}{llllll}19950502 & 1954 & 28.823 & 47.4493 & -70.3766\end{array}$

$7.72 \mathrm{~km} \quad 0.9 \mathrm{ML} \quad 1.885$

$\begin{array}{llllll}19920222 & 2155 & 32.800 & 47.4280 & -70.3570\end{array}$

$7.95 \mathrm{~km}$

$0.3 \mathrm{ML}$

$\begin{array}{lllll}19920816 & 210658.000 & 47.4270 & -70.3560\end{array}$

$7.61 \mathrm{~km}$

$0.2 \mathrm{ML} \quad 0.366$

$\begin{array}{lllll}19911102 & 0254 & 28.800 & 47.3850 & -70.4410\end{array}$

$9.24 \mathrm{~km} \quad 0.4 \mathrm{ML}$ $199704090244 \quad 17.495 \quad 47.3785 \quad-70.4647 \quad 11.35 \mathrm{~km}$

$2.1 \mathrm{MN} \quad 2.859$

Sub-zone EBO

$19900506020443.500 \quad 47.5140 \quad-70.3770$ $19940901044443.300 \quad 47.5170 \quad-70.3870$

$3.21 \mathrm{~km}$

$0.9 \mathrm{MN}$

$4.95 \mathrm{~km}$

$0.5 \mathrm{ML} \quad 1.925$

$19930417053542.519 \quad 47.5293 \quad-70.3672$

$7.55 \mathrm{~km} \quad 1.8 \mathrm{MN}$

$\begin{array}{lllll}19950401 & 0210 & 06.539 & 47.5435 & -70.3978\end{array}$

$6.33 \mathrm{~km}$

$0.7 \mathrm{MN} \quad 3.047$

$\begin{array}{lllll}19950806 & 0436 & 28.823 & 47.5554 & -70.3777\end{array}$

$9.44 \mathrm{~km} \quad 0.8 \mathrm{MN}$

$19961027064737.598 \quad 47.5501 \quad-70.3548$

$9.94 \mathrm{~km}-1.0 \mathrm{ML} \quad 1.889$

$19951120211125.907 \quad 47.4922 \quad-70.4024$

$5.37 \mathrm{~km} \quad 1.0 \mathrm{MN}$

$19960403012352.212 \quad 47.4994 \quad-70.3948$

$\begin{array}{lll}5.35 \mathrm{~km} & 1.4 \mathrm{MN} & 0.984\end{array}$

$19960518050519.606 \quad 47.4687 \quad-70.3891$

$5.82 \mathrm{~km} \quad 1.2 \mathrm{MN}$

$19960530083658.713 \quad 47.4632 \quad-70.3824$

$\begin{array}{lll}5.54 \mathrm{~km} & 0.5 \mathrm{ML} & 0.841\end{array}$

\section{Sub-zone KAM}

19900728143710.000

$47.6090-69.9660 \quad 10.48 \mathrm{~km}$

$0.4 \mathrm{ML}$

19920417133024.600

$47.6050-69.9690$

$9.45 \mathrm{~km}$

$0.6 \mathrm{ML}$

1.144

$19900916211325.300 \quad 47.5630 \quad-69.9580 \quad 11.04 \mathrm{~km} \quad 0.7 \mathrm{ML}$ 


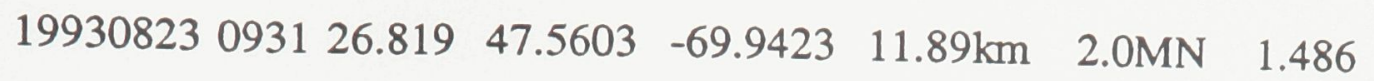

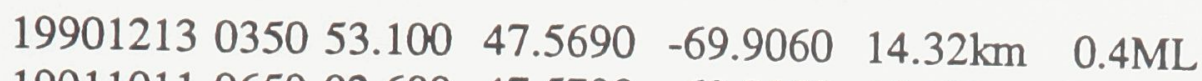

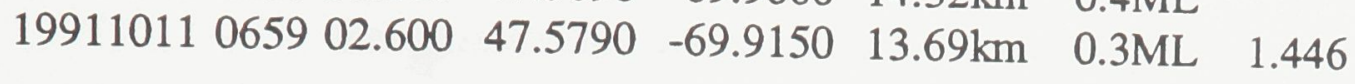

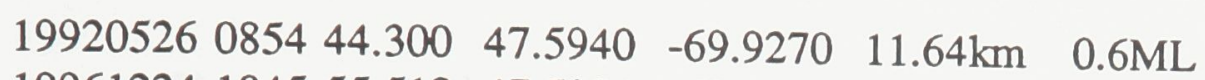

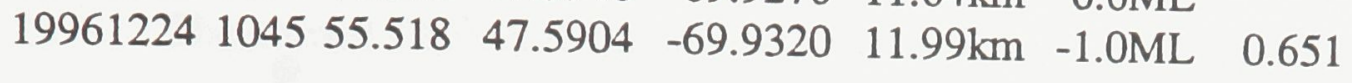

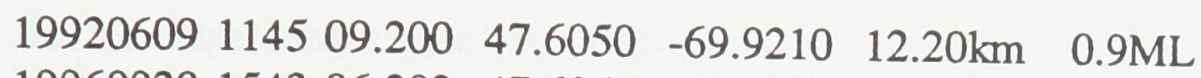

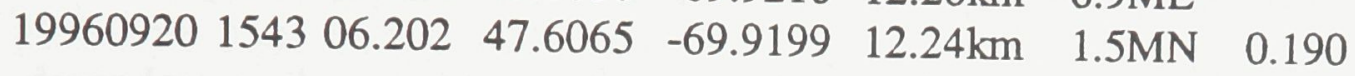

$19910919110653.170 \quad 47.5384 \quad-69.9324 \quad 13.64 \mathrm{~km} \quad 2.6 \mathrm{MN}$ $\begin{array}{llllllll}19920903 & 0704 & 54.400 & 47.5240 & -69.9520 & 12.67 \mathrm{~km} & 0.5 \mathrm{ML} & 2.383\end{array}$ $\begin{array}{llllllll}19940910 & 2342 & 03.500 & 47.5270 & -69.9520 & 12.60 \mathrm{~km} & 0.7 \mathrm{ML} & 2.205\end{array}$ $\begin{array}{llllllll}19960523 & 0939 & 27.217 & 47.5283 & -69.9395 & 13.66 \mathrm{~km} & 1.7 \mathrm{MN} & 1.243\end{array}$

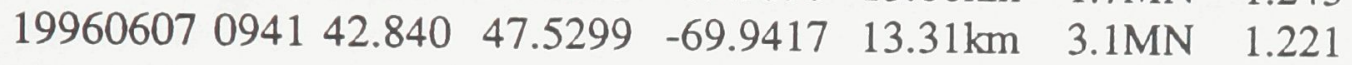

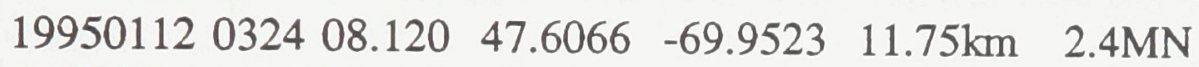
$\begin{array}{lllllll}19960726 & 1438 & 45.149 & 47.6097 & -69.9468 & 10.36 \mathrm{~km} & 2.3 \mathrm{MN}\end{array}$

1.491

Sub-zone POC

$\begin{array}{llllllll}19900731 & 1510 & 35.938 & 47.3866 & -70.2493 & 11.99 \mathrm{~km} & 0.6 \mathrm{ML} & \\ 19921109 & 1757 & 13.600 & 47.3860 & -70.2490 & 12.13 \mathrm{~km} & 0.1 \mathrm{ML} & 0.157 \\ 19960205 & 0810 & 27.122 & 47.3849 & -70.2561 & 13.47 \mathrm{~km} & 1.4 \mathrm{MN} & 1.578 \\ 19960601 & 0201 & 42.306 & 47.3844 & -70.2564 & 12.18 \mathrm{~km} & -0.1 \mathrm{ML} & 0.619 \\ 19960720 & 1649 & 21.345 & 47.3835 & -70.2521 & 13.87 \mathrm{~km} & 0.2 \mathrm{ML} & 1.923 \\ 19970315 & 1303 & 00.310 & 47.3853 & -70.2520 & 12.38 \mathrm{~km} & 0.7 \mathrm{MN} & 0.463 \\ & & & & & & & \\ 19940723 & 0734 & 25.500 & 47.3820 & -70.1350 & 13.66 \mathrm{~km} & 1.4 \mathrm{MN} & \\ 19940723 & 0946 & 41.208 & 47.3804 & -70.1365 & 15.16 \mathrm{~km} & 2.0 \mathrm{MN} & 1.515 \\ 19960625 & 0600 & 12.684 & 47.3778 & -70.1384 & 14.57 \mathrm{~km} & 1.6 \mathrm{MN} & 1.054 \\ 19960702 & 2359 & 31.804 & 47.3792 & -70.1397 & 13.02 \mathrm{~km} & 1.0 \mathrm{MN} & 0.795 \\ 19960803 & 0136 & 34.329 & 47.3812 & -70.1387 & 12.94 \mathrm{~km} & 1.4 \mathrm{MN} & 0.777 \\ 19960803 & 0159 & 20.822 & 47.3707 & -70.1343 & 13.22 \mathrm{~km} & 0.9 \mathrm{MN} & 1.332 \\ 19960814 & 2110 & 54.634 & 47.3816 & -70.1371 & 13.90 \mathrm{~km} & 2.2 \mathrm{MN} & 0.291 \\ 19961022 & 0247 & 22.775 & 47.3808 & -70.1450 & 13.33 \mathrm{~km} & 1.7 \mathrm{MN} & 0.835 \\ 19970101 & 1233 & 06.148 & 47.3783 & -70.1342 & 15.55 \mathrm{~km} & 1.6 \mathrm{MN} & 1.935\end{array}$

$\begin{array}{lllllll}19891218 & 1455 & 35.616 & 47.3866 & -70.1543 & 18.20 \mathrm{~km} & 2.8 \mathrm{MN}\end{array}$

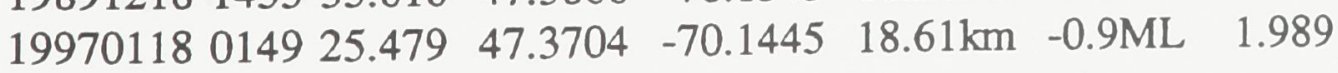




\section{Appendix 3}

\section{Recommendations for future monitoring of the CSZ}

The current CSZ seismograph network can be used to compute focal mechanisms for earthquakes as small as magnitude $m_{N} 3.0$. These solutions, however, are strongly dependent on the correctness of every first motion reading. In order to make the solutions more robust, the number of stations within $100 \mathrm{~km}$ of the seismic zone should be increased especially in the NE and SW quadrants. The 1996 summer field survey showed that with about six additional stations, focal mechanisms can be computed for events as small as magnitude 2.0. Clearly, additional CSZ stations are needed to derive well defined focal mechanisms from which seismo-tectonic conclusions can be drawn. The calculations of focal mechanisms with Sv/P ratios should be examined carefully to test its reliability. One could test how consistent the Sv/P ratios are in focal mechanisms well constrained with $\mathrm{P}$ first motions. For events below magnitude 4.0, P first motions are emergent on stations at regional distances and the velocity model between the CSZ and these stations is at best approximate. This causes problems in using Pn first motions to constrain CSZ mechanisms.

It is possible to resolve more accurately the relative arrival times at a station using the cross-correlation technique (Deichmann and Garcia-Fernandez, 1994; Li et al., 1995). The relative arrival times can be resolved at the sub-sample rate level. In the CSZ case, this method can only be applied to the data recorded between November 1988 and August 1994 , i.e. when the three-component data was time-tagged at a central site. The current 
scheme of GPS time tagging at the various CSZ sites does not provide the consistency required for such an analysis. In the future, the time series files for multiplets recorded between 1988 and 1994 could be correlated.

The data from the current seven local stations do not permit resolution of a 3-D velocity model, which could yield important seismotectonic information, such as lateral velocity contrast across geological faults. An estimate of the network requirements needed to infer a 3-D velocity model for the CSZ follows. The CSZ is a zone $40 \mathrm{~km}$ wide, 70 $\mathrm{km}$ long and $25 \mathrm{~km}$ deep. A velocity model with $2.5 \mathrm{~km}$-sided blocks implies the determination of some 4480 blocks for $\mathrm{P}$ and for $\mathrm{S}$ velocities. The number of unknowns can be divided in half by assuming a Vp/Vs ratio. For each earthquake, four additional unknowns have to be defined: latitude, longitude, depth and origin time. The observed data, on the other hand, are the total number of stations, times the number of phases used ( $\mathrm{P}$ and $\mathrm{S}$ ) times the number of events. The minimum number of stations and events to solve a CSZ 3-D model can be approximated as follows

Number of observed data $=$ number of unknowns

$$
\mathrm{Sta} * \mathrm{Pha} * \mathrm{Ev}=\mathrm{NB}+4 \mathrm{Ev}
$$

Where Sta: Number of Stations; Pha: Number of Phases; Ev: Number of Events; and NB: Number of blocks.

Assuming Sta $=12 ; \mathrm{Pha}=2 ;$ and $\mathrm{NB}=4680$, the minimum number of events is 224. If one assumes an annual rate of 75 events with magnitude $m_{N} \geq 1.5$ (the minimum level for events to be recorded across the CSZ), then one would have to run the 12 station 
network for a minimum of about 3 years. Naturally, additional stations mean a shorter time period to reach the objective, while providing a better sampling of the near surface layers. A better network also means more focal mechanisms and better hypocentre locations.

Therefore, the inversion of a local 3-D velocity model for the CSZ requires an expansion of the CSZ seismograph network from the current 7 stations, to 12 or more. During the 1996 summer experiment, up to 8 seismograph stations were operated simultaneously during a 6 month period (Lamontagne et al., 1997). A total of 142 events was recorded, of which 40 met the $m_{N} \geq 1.5$ selection criteria. The biggest drawback of the portable seismographs was the drift of the internal clocks between the weekly servicing. The drift was generally less than $\pm 0.05 \mathrm{~s}$, which is still too high for local velocity inversion purposes. The expansion of the CSZ network should make use of portable seismographs with accurate timing. Fortunately, the next generation of portable seismographs will use continuous GPS timing. The joint inversion of the hypocentrevelocity structure is imperative to infer velocity variations and therefore imaging zones of possibly enhanced earthquake activity. 